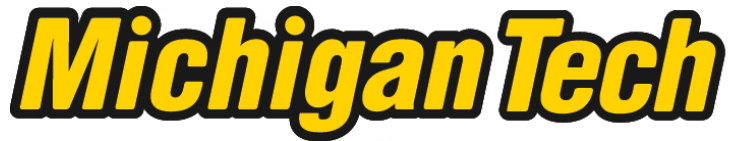 \\ Michigan Technological University Create the Future Digital Commons @ Michigan Tech
}

Dissertations, Master's Theses and Master's Reports - Open

Dissertations, Master's Theses and Master's

Reports

2005

Study of particle movement in the nearshore region of Lake Superior with radioisotope tracers

Yingtao Chai

Michigan Technological University

Follow this and additional works at: https://digitalcommons.mtu.edu/etds

Part of the Civil and Environmental Engineering Commons

Copyright 2005 Yingtao Chai

\section{Recommended Citation}

Chai, Yingtao, "Study of particle movement in the nearshore region of Lake Superior with radioisotope tracers", Dissertation, Michigan Technological University, 2005.

https://doi.org/10.37099/mtu.dc.etds/723

Follow this and additional works at: https://digitalcommons.mtu.edu/etds

3 Part of the Civil and Environmental Engineering Commons 


\title{
STUDY OF PARTICLE MOVEMENT IN THE NEARSHORE REGION OF LAKE SUPERIOR WITH RADIOISOTOPE TRACERS
}

\author{
By \\ YINGTAO CHAI
}

\author{
A DISSERTATION \\ Submitted in partial fulfillment of the requirements \\ for the degree of \\ DOCTOR OF PHILOSOPHY \\ (Engineering: Environmental) \\ MICHIGAN TECHNOLOGICAL UNIVERSITY \\ 2005
}

Copyright (C) Yingtao Chai 2005 
This dissertation, "Study of Particle Movement in the Nearshore Region of Lake Superior with Radioisotope Tracers", is hereby approved in partial fulfillment of the requirements for the degree of DOCTOR OF PHILOSOPHY in the field of Engineering: Environmental.

\section{DEPARTMENT or PROGRAM:}

Ph.D. in Engineering: Environmental

Signatures:

Dissertation Advisor

Noel R. Urban

Department Chair

(Program Director)

Neil J. Hutzler

Date 


\section{ABSTRACT}

Biogeochemical processes in the coastal region, including the coastal area of the Great Lakes, are of great importance due to the complex physical, chemical and biological characteristics that differ from those on either the adjoining land or open water systems. Particle-reactive radioisotopes, both naturally occurring $\left({ }^{210} \mathrm{~Pb},{ }^{210} \mathrm{Po}\right.$ and $\left.{ }^{7} \mathrm{Be}\right)$ and man-made $\left({ }^{137} \mathrm{Cs}\right)$, have proven to be useful tracers for these processes in many systems. However, a systematic isotope study on the northwest coast of the Keweenaw Peninsula in Lake Superior has not yet been performed.

In this dissertation research, field sampling, laboratory measurements and numerical modeling were conducted to understand the biogeochemistry of the radioisotope tracers and some particulate-related coastal processes. In the first part of the dissertation, radioisotope activities of ${ }^{210} \mathrm{Po}$ and ${ }^{210} \mathrm{~Pb}$ in a variability of samples (dissolved, suspended particle, sediment trap materials, surficial sediment) were measured. A completed picture of the distribution and disequilibrium of this pair of isotopes was drawn. The application of a simple box model utilizing these field observations reveals short isotope residence times in the water column and a significant contribution of sediment resuspension (for both particles and isotopes). The results imply a highly dynamic coastal region.

In the second part of this dissertation, this conclusion is examined further. Based on intensive sediment coring, the spatial distribution of isotope inventories (mainly ${ }^{210} \mathrm{~Pb}$, ${ }^{137} \mathrm{Cs}$ and ${ }^{7} \mathrm{Be}$ ) in the nearshore region was determined. Isotope-based focusing factors categorized most of the sampling sites as non- or temporary depositional zones. A twodimensional steady-state box-in-series model was developed and applied to individual 
transects with the ${ }^{210} \mathrm{~Pb}$ inventories as model input. The modeling framework included both water column and upper sediments down to the depth of unsupported ${ }^{210} \mathrm{~Pb}$ penetration. The model was used to predict isotope residence times and cross-margin fluxes of sediments and isotopes at different locations along each transect. The time scale for sediment focusing from the nearshore to offshore regions of the transect was on the order of 10 years. The possibility of sediment longshore movement was indicated by high inventory ratios of ${ }^{137} \mathrm{Cs}:{ }^{210} \mathrm{~Pb}$. Local deposition of fine particles, including fresh organic carbon, may explain the observed distribution of benthic organisms such as Diporeia.

In the last part of this dissertation, isotope tracers, ${ }^{210} \mathrm{~Pb}$ and ${ }^{210} \mathrm{Po}$, were coupled into a hydrodynamic model for Lake Superior. The model was modified from an existing 2-D finite difference physical-biological model which has previously been successfully applied on Lake Superior. Using the field results from part one of this dissertation as initial conditions, the model was used to predict the isotope distribution in the water column; reasonable results were achieved. The modeling experiments demonstrated the potential for using a hydrodynamic model to study radioisotope biogeochemistry in the lake, although further refinements are necessary. 


\section{ACKNOWLEDGEMENTS}

I will never REALLY know what a Ph.D. is all about only after I get this step writing my acknowledgment and looking back the past five and half years. It is a wonderful journey and once-in-a-lifetime opportunity for me. But it would not become a reality without the help, encouragement and assistance from so many people.

First of all, I am grateful to have Dr. Noel Urban, a dedicated scientist, as my doctoral advisor. According to an ancient Chinese definition of teacher, a (good) teacher is supposed to transmit wisdom, teach subject and clarify (students') confusion (师者, 所以传道授业解惑也。( 韩愈, ( 768- 824)) ). To my luck, Dr. Urban is such a teacher. Not only he led me into the field of biogeochemistry, he also taught me how to be a good scientist and to enjoy the fun of revealing the mystery of the nature. Without his mentorship and encouragement, this dissertation would be in nowhere. His view even changed my vision of my future career; I would like to become a teacher like him eventually.

I would also like to take this chance to thank Dr. Martin Auer, Dr. Richard Honrath and Dr. Sarah Green for sitting on my committee. Their valuable comments and input are essential for the completion of this dissertation. A special thanks also goes to Dr. Henry J. Niebauer for kindly providing the computer model used in the Chapter four.

I want to express sincerely appreciation to the members of Urban research group, Dr. Jaebong Jeon, Xuefei Lu and Pei-Fun Siew, for their help during my study at Michigan Tech. Other graduate students and undergraduate students in the CEE department, Edward Verhamme and David Tobias, Heather Kleimola, Taher Chowdhury (Adil), Tiffany Torrance and especially terrific Cory Larson, are also highly appreciated for their help on this research. It is impossible to complete all the field sampling and laboratory analysis without their assistant.

As an international student, I got numerous helps from so many peoples from the 
department and the school. I am grateful to the CEE department, to the CIE (Center for International Education) and Grad School at MTU to make my Ph.D. study a smooth journey. I would like to take this chance to express my sincerely appreciation to some individuals including Corrine Leppen, Shelle Sandell, David Perram and Kenneth Palosaari from the CEE department, Nancy Byers-Sprague of the Grad School and Mary Ann Brunner from the CIE.

I am very regretful that my mother, who passed away during the course of my Ph.D. study, can not wait to see the day when I become a doctor. Being the first to go to college and to get a Ph.D. in my family, I have always been the hope and the pride of hers. She was and will always be my inspiration of working out my best.

However, I do feel the spirit kept in my family from the eyes of my beloved son, Steven, whose birthday is just one day after his grandmother's. I enjoy the happiness he has brought to my life. In his small mind, I am the greatest knowing-why-andhow-of-everything dad, but I know it is him who changes my life forever and teaches me the real meaning of the word responsibility.

Last but not least, I appreciate my wonderful wife, Yanyan Lu, for the countless love and support for not only the six years since we landed on this land, but for the eleven years we have been knowing each other, learning from each other and loving each other. It is not ambitious to say that there will not be today's myself without her, not to mention a Ph.D. degree. Thank you, Yanyan, my love of the life! 


\section{INDEX}

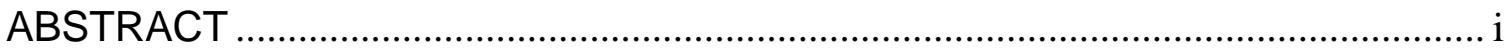

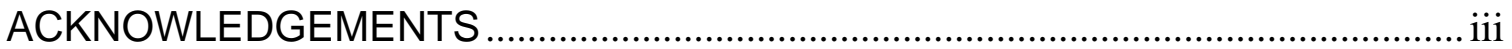

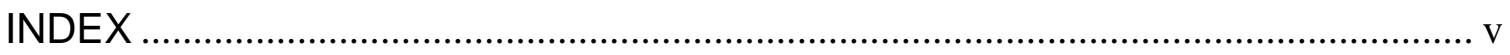

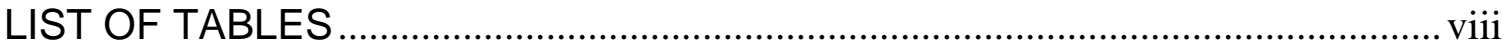

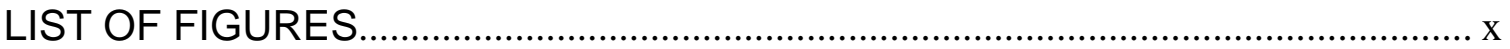

Chapter One - Introduction to the Dissertation ........................................... 1

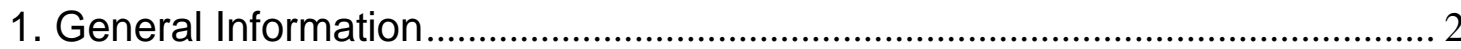

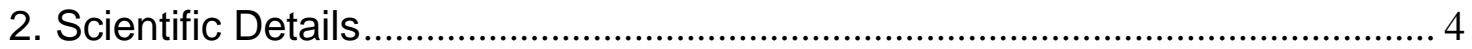

2.1. Bckground knowledge ............................................................................... 4

2.2. Focal questions of this dissertation ................................................................ 6

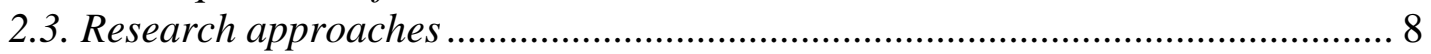

2.4. Questions remaining ................................................................................... 11

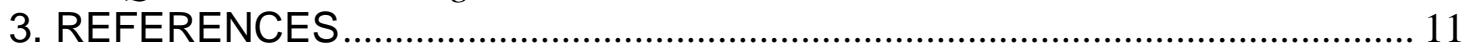

Chapter Two $-{ }^{210} \mathrm{Po}$ and ${ }^{210} \mathrm{~Pb}$ Distributions and Residence Times in the Near-Shore Region of Lake Superior ………………………………..... 16

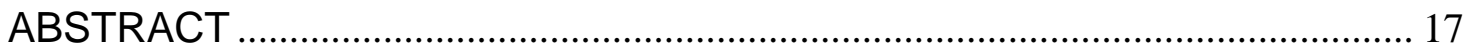

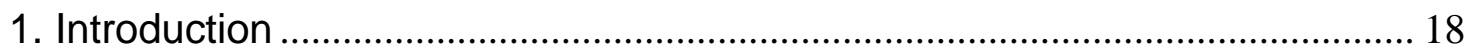

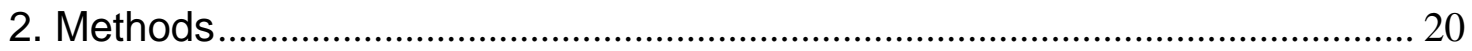

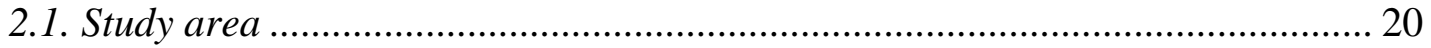

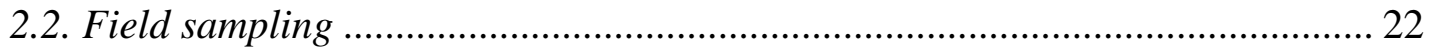

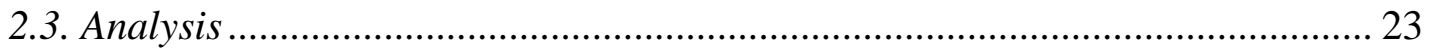

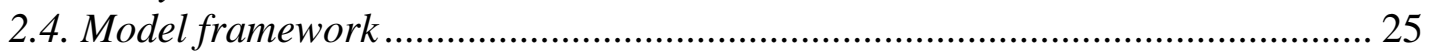

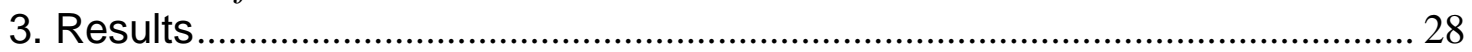

3.1. System characteristics.................................................................................. 28

3.2. Partitioning of isotope between water and particulate matter ........................... 29

3.3. Isotope activities on the TSP samples ............................................................... 31

3.4. Isotope activity and fluxes in sediment traps .................................................. 38

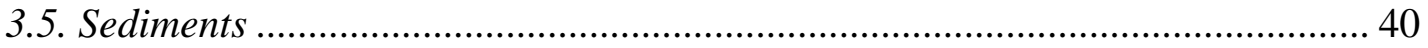

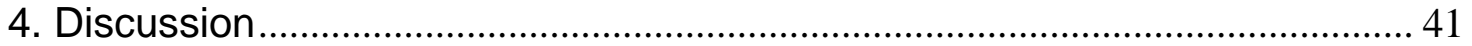

4.1. Isotope biogeochemistry in Lake Superior ........................................................ 41

4.2. Residence times from isotope distributions: steady-state model ....................... 55

4.3. Model characteristic times and model validation............................................... 60

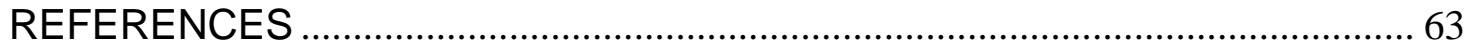


Chapter Three - Particle dynamics in the temporary deposition zone

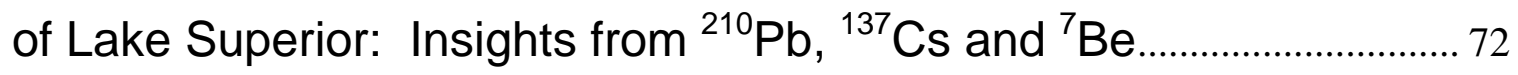

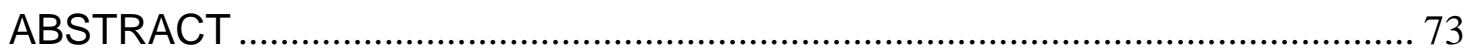

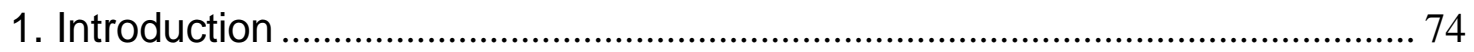

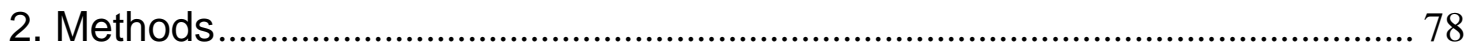

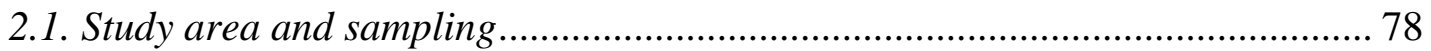

2.2. Sample pretreatment and analysis ................................................................. 82

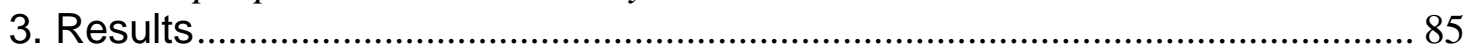

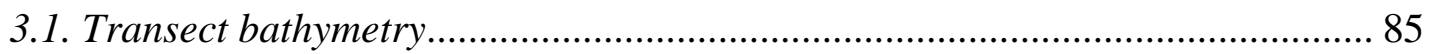

3.2. Sediment characteristics - bulk density and porosity ........................................ 86

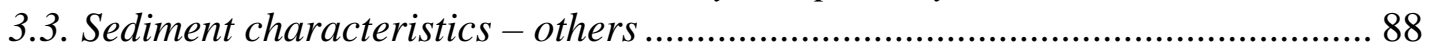

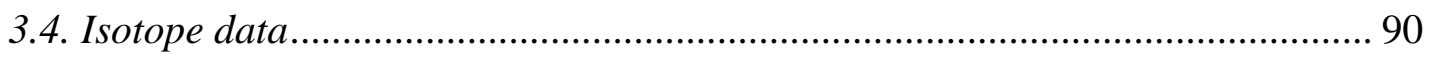

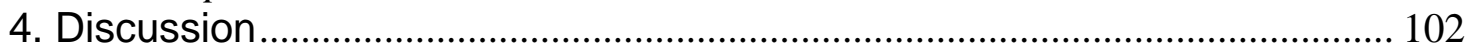

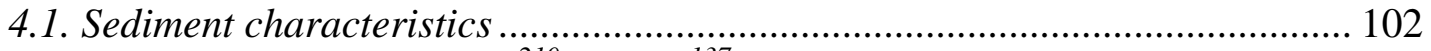

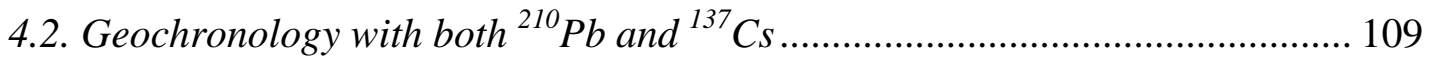

4.3. Nearshore to offshore: quantification of focusing ............................................ 111

4.4. Isotope residence times in temporary depositional zones................................ 114

4.5. Pathways and timescales of sediment transport: a larger view ....................... 131

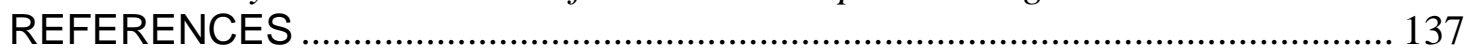

Chapter Four - Naturally occurring radiotracers $\left({ }^{210} \mathrm{Po} /{ }^{210} \mathrm{~Pb}\right)$ in a coupled physical-biological model for Lake Superior: the role of particle scavenging and sediment resuspension ...................................... 143

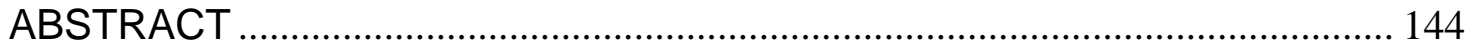

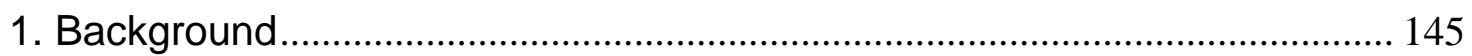

2. Introduction to the original model ........................................................................ 146

2.1. Features of the existing numerical model ...................................................... 146

2.2. Modeling practice with Lake Superior .......................................................... 152

3. Modified model with isotope tracers .................................................................... 160

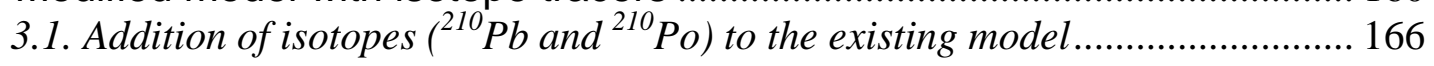

3.2. Addition of particles....................................................................................... 168

3.3. Sediment-related processes........................................................................... 172

4. Numerical experiments with the modified model (model applications) ....... 174

4.1. Effect of particle settling velocity ..................................................................... 174

4.2. Effect of Kd value .......................................................................................... 176

4.3. Sediment resuspension: from a one-box model to a complex hydrodynamic

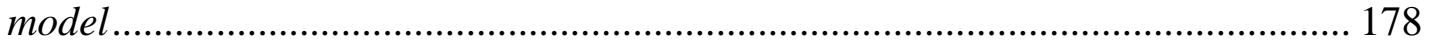

4.4. Improved resuspension and settling process: advantage of complex model ... 183

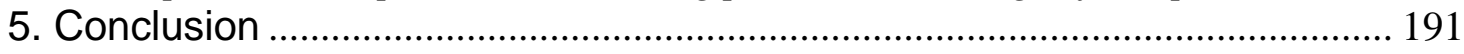

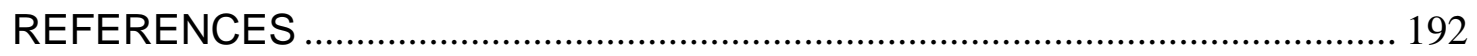

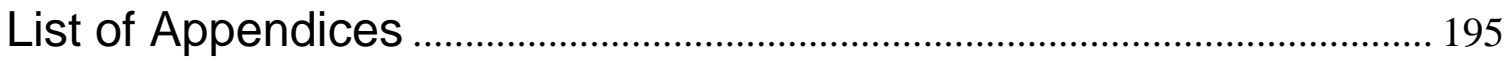


Appendix - 1. Back calculation for isotope activities based on two point

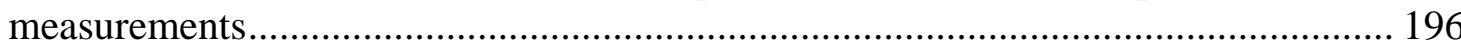

Appendix - 2. Isotope activities (Chapter 2) .................................................... 198

Appendix - 3. Sediment core data: porosity, bulk density and isotope activity (Chapter

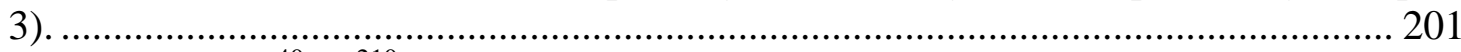

Appendix - 4. ${ }^{40} \mathrm{~K}:{ }^{210} \mathrm{~Pb}$ ratios for all sediment cores (Chapter 3). ......................... 218

Appendix - 5. Geochronologies for sediment cores on each transect ....................... 221

Appendix - 6. Estimated ${ }^{137} \mathrm{Cs}$ (and ${ }^{90} \mathrm{Sr}$ ) atmospheric deposition flux to Lake

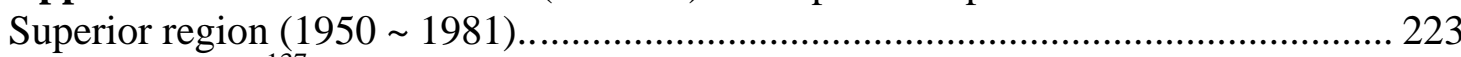

Appendix - 7. ${ }^{137}$ Cs activities and fluxes in 2000 sediment traps .............................. 228

Appendix - 8. Laboratory procedures..................................................................... 229

Appendix - 9. Computer code (in Fortran) of the Niebauer model as modified for isotope modeling. ......................................................................................................... 232 


\section{LIST OF TABLES}

\section{Chapter Two}

Table 1: Distribution of ${ }^{210} \mathrm{Po}$ and ${ }^{210} \mathrm{~Pb}$ between dissolved and particulate phase and associated coefficients $\left(\mathrm{K}_{\mathrm{D}}\right)$. date of collection is April 28, 2001. Errors are based on $1 \sigma$ counting errors

Table 2: Isotope activities and isotope and solids fluxes in sediment trap samples in

Lake Superior .35

Table 3: Sediment trap samples with only ${ }^{210} \mathrm{~Pb}$ measurements .36

\section{Chapter Three}

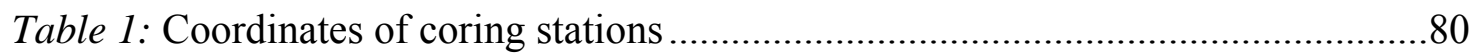

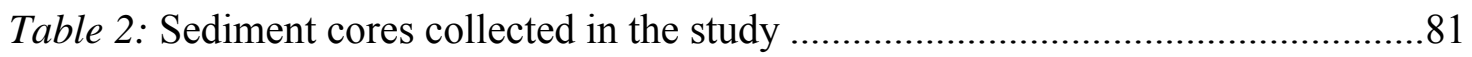

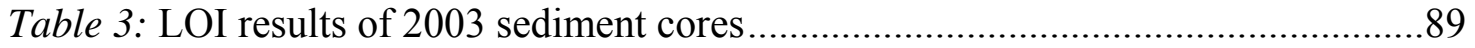

Table 4: ${ }^{210} \mathrm{~Pb}$ (upper) and ${ }^{137} \mathrm{Cs}$ (lower) data of 2001 cores $-\mathrm{HN}$ transect.................94

Table 5: ${ }^{210} \mathrm{~Pb}$ (upper) and ${ }^{137} \mathrm{Cs}$ (lower) data of 2002 cores $-\mathrm{HN}$ transect..................95

Table 6: ${ }^{210} \mathrm{~Pb}$ (previous page) and ${ }^{137} \mathrm{Cs}$ (this page) data from 2003 cores - EH and

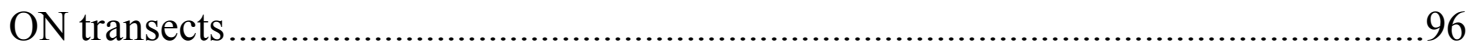

Table 7: Isotope inventory of all the sediment cores taken in three transects.............98

Table 8: Isotope inventories from replicated cores from year 2002, HN transect........99

Table 9: ${ }^{7}$ Be activity and inventory of $2002(\mathrm{HN})$ and 2003 cores ..........................100

Table 10: Sedimentation rates in the deposition zones on three transects..................110

Table 11: ${ }^{210} \mathrm{~Pb}$ residence times and cross-margin transport fluxes from the box-inseries mode.

Table 12: ${ }^{210} \mathrm{~Pb}$ residence times and cross-margin transport fluxes from the nested-box model

Table 13: Offshore sediment transport estimated with isotope cross-margin transport fluxes from the nested-box model.

\section{Chapter Four}




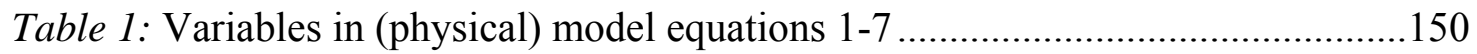

Table 2: Initial input parameters for the model. ....................................................153

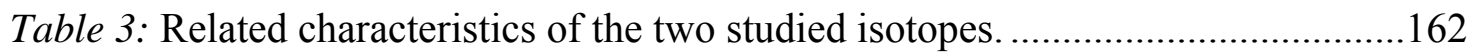




\section{LIST OF FIGURES}

\section{Chapter One}

Figure 1: Particle dynamics in the nearshore region of a lake

\section{Chapter Two}

Figure 1: Keweenaw Peninsula region of Lake Superior.

Figure 2: Model components and processes.

Figure 3: Statistical analysis of isotopes on particulate samples. Error bars represent 95\% C.I.s of the means.

Figure 4: Isotope activities (both ${ }^{210} \mathrm{~Pb}$ and ${ }^{210} \mathrm{Po}$ ) of TSP samples from $\mathrm{HN}$ and $\mathrm{ON}$ transects.

Figure 5: ${ }^{210} \mathrm{~Pb}$ activity on suspended particles. The inverse relationship fits a model of constant partition coefficient and constant activity in the water column

Figure 6: Settling fluxes of particles and ${ }^{210} \mathrm{~Pb}$....

Figure 7: Biogenic element $(\mathrm{C}, \mathrm{N})$ contents vs. isotope activities or ratios for sediment trap samples

Figure 8: Isotope activity ratios $\left({ }^{210} \mathrm{Po}:{ }^{210} \mathrm{~Pb}\right)$ of particles within Lake Superior .53

\section{Chapter Three}

Figure 1: Bathymetry of the three transect with coring sites also shown .85

Figure 2: Sediment properties (left - porosity (\%), right - bulk density $\left(\mathrm{g} / \mathrm{cm}^{3}\right)$ ) of selected cores.

Figure 3: (A) C and N concentrations in surface sediments from HN transect; (B) C:N (molar) ratio in the surface sediment along the HN transect, year 2001

Figure 4: Depth profile of LOI of EH050 core, 2003. The average LOI value of the 8 samples is $3.47 \% \pm 0.09 \%$

Figure 5: Two "typical” isotope profiles of the sites. Top: depth profiles at a netdepositional zone; bottom: depth profiles at a temporary depositional zone.

Figure 6: Mean particle size and sediment grain size distribution from ponar data ...104 
Figure 7: Relationship between organic matter content (LOI) of surface sediments and water depth

Figure 8: LOI of surface sediments vs. isotope inventories for 2003 cores: EH (top)

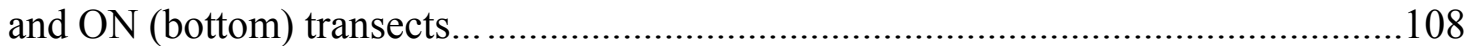

Figure 9: Geochronology for EH070 core.

Figure 10: Focusing factors $\left({ }^{210} \mathrm{~Pb}\right.$-based $)$ of the coring sites, plotted against water depth.

Figure 11: Box-in-series model diagram for the calculation of ${ }^{210} \mathrm{~Pb}$ residence time and cross-margin transport flux...

Figure 12: Diagram for the nested-box model.

Figure 13: Measured ${ }^{210} \mathrm{~Pb}$ inventories in the sediment cores (2001) and water column

Figure 14: Relationship between particle size and fine-particle or isotope residence time as predicted by the box-in-series model..

Figure 15: Comparison of Focusing factors based on two isotopes..........................130

Figure 16: ${ }^{210} \mathrm{~Pb}$ inventories of the three transects..

Figure 17: Comparison of transport pathways of short-lived $\left({ }^{7} \mathrm{Be}\right)$ and longer-lived $\left({ }^{210} \mathrm{~Pb}\right)$ isotopes in the study region of Lake Superior.

Figure 18: The historical pattern of ${ }^{137} \mathrm{Cs}$ deposition to Lake Superior.

Figure 19: ${ }^{137} \mathrm{Cs} /{ }^{210} \mathrm{~Pb}$ sediment inventory ratios of the three transects.

Figure 20: Excess ${ }^{210} \mathrm{~Pb}$ inventory in Lake Superior..

Figure 21: Currents in the Lake Superior: A historical map.

\section{Chapter Four}

Figure 1: Schematic of the cross section model. $\mathrm{x}, \mathrm{y}$ and $\mathrm{z}$ coordinates and grid sizes

are also shown

Figure 2-a: Lake Superior with an inset showing the study area. The dashed line represents the modeled cross section at Eagle Harbor.

Figure 2-b: Near shore bathymetry of the EH transect.. 148

Figure 3-a: Predicted temperature $\left({ }^{\circ} \mathrm{C}\right)$ distributions in the lake cross-section 155

Figure 3-b: Chlorophyll concentrations $\left(\mathrm{mg} \mathrm{Chl} / \mathrm{m}^{3}\right)$ in the lake cross-section 156 
Figure 4: Comparison of modeled and measured depth profiles (5 km from shore) of Temperature and Chlorophyll-a

Figure 5: SPM distribution at day 56 when a hypothesized river input occurs in cell (1, 1)

Figure 6: Particle distributions at day 56 with (top) and without (bottom) atmospheric deposition of particles

Figure 7: Model predictions of particle distributions without (left) and with (right)

resuspension.

Figure 8: Effect of settling velocity on isotope $\left({ }^{210} \mathrm{~Pb}\right)$ distribution.

Figure 9: Comparison between simulated ${ }^{210} \mathrm{~Pb}$ depth profiles with different settling velocities and field measurements. 176 Figure 10: Time series plots of predicted $\mathrm{Po} / \mathrm{Pb}$ ratios with different $\mathrm{K}_{\mathrm{d}}$ values for Po. Top: initial $\mathrm{Po} / \mathrm{Pb}$ ratio of 0.6 ; bottom: initial $\mathrm{Po} / \mathrm{Pb}$ ratio of 0.44 ..

Figure 11: Predicted SPM distribution on day 56 of the model run...

Figure 12: Predicted isotope distributions at day 56 of model simulation. 180

Figure 13: Ratio at the end of model simulation. 181

Figure 14: Time series of predicted isotope inventories and ratios .182

Figure 15: Allocation of resuspension fluxes at different depth of water column .....184 Figure 16: Predicted SPM contours after 56-day model simulation with resuspension allocated among depths. .185

Figure 17: Predicted isotope distributions at the end of 56-d model simulation with exponential allocation of resuspended solids

Figure 18: Predicted isotope ratio (Po: $\mathrm{Pb})$ after 56-d model simulation with resuspended solids distributed exponentially through the water column...

Figure 19: Isotope distribution when two settling velocities are applied.....

Figure 20: Predicted isotope ratio $(\mathrm{Po}: \mathrm{Pb})$ at the end of a 56-d model simulation with two settling velocities.. 


\title{
Chapter one
}

Introduction to the Dissertation

\author{
Yingtao Chai
}




\section{Study of particle movement in the nearshore region of Lake Superior with radioisotope tracers}

\section{General Information}

Coastal zones, the transition regions between land and ocean, are of significant importance to humans. More than half of the U.S. population lives within 50 miles of the shoreline. The increased threat of global warming and the resulting rise in sea level may accelerate erosion problems that are already occurring to the coastal zone [Thornton et al., 2000]. From the perspective of biogeochemistry, understanding coastal processes is increasingly important because of the unique characteristics of this zone. The coastal zone is both a significant source and sink for many atmospheric species; it serves as a medium for the exchange of matter and energy; and strong physical-biological coupling makes it a complex system [Siefert, 2004]. Recent studies of coastal zones have reported important biogeochemical exchanges of almost every major species in biogeochemistry: water, nutrients, salts, carbon (including dissolved organic carbon (DOC)), particulate organic carbon (POC) and carbon dioxide $\left.\left(\mathrm{CO}_{2}\right)\right)$ and both organic and inorganic trace gases [Raymond and Hopkinson, 2003; Walsh et al., 1997; Walsh and Dieterle, 1994].

The Great Lakes of North American have more than 10,000 miles of shoreline. Coastal processes in the Great Lakes are also geologically, chemically and biologically dynamic [Green and Eadie, 2004]. To gain a better understanding of these processes, including cross-margin transport and effects of episodic events, two major projects were supported jointly by NSF and NOAA. The EEGLE project, or Episodic Events - Great Lakes Experiment, focused on the processes occurring in southern Lake Michigan. The 
KITES project, or the Keweenaw Interdisciplinary Transport Experiment in Superior, sought to explore the role of thermal fronts and longshore currents in mediating the transport of biogeochemically important materials across the coastal margin of Lake Superior. A variety of approaches was employed including field work, satellite imaging and numerical modeling. Some significant contributions to science have been achieved as evident by a series of high quality articles (to name a few, [Chen et al., 2001;

Churchill et al., 2003; Churchill et al., 2004; Urban et al., 2004a; Urban et al., 2005; Zhu et al., 2001]).

The research conducted for my Ph.D. was supported by the NSF-funded KITES project and by a grant from the Michigan Great Lakes Protection Fund (MGLPF) to study Diporeia in Lake Superior. As part of the KITES project, my Ph.D. research focused on particle movement in the nearshore region of Lake Superior using naturally occurring and anthropogenic radioisotopes $\left({ }^{210} \mathrm{Po},{ }^{210} \mathrm{~Pb},{ }^{137} \mathrm{Cs}\right.$ and $\left.{ }^{7} \mathrm{Be}\right)$ as tracers. The research included field sampling, laboratory measurements, data interpretation and numerical model simulations. For the MGLPF project, the same tools were utilized to quantify the flux of organic matter to the slope region of the lake. Three chapters are included in this dissertation. Each chapter is in the format of a manuscript. Chapter one has been published in Journal of Geophysical Research - Oceans [Chai and Urban, 2004]. Chapter two and three will be submitted for publication in Limnology and Oceanography and Ecological Modeling, respectively. Parts of my research also were important components of two other KITES publications [Urban et al., 2004b; Urban et al., 2004c], and the results from chapter 3 will be used in another publication to quantify the fluxes of organic carbon available to Diporeia in the shelf, slope and profundal regions of the lake. 


\section{Scientific Details}

\subsection{Background knowledge}

Like other water bodies on earth, Lake Superior is heavily influenced by interactions at the land-water interface such as the supply of nutrients, sediments, toxic contaminants and wastes via tributary streams, rivers and estuaries. Cross margin transport, the focus of the KITES project, is the combination and result of many coastal processes including particle movement in the nearshore region.

Particulate matter (or particles) is an important component in aquatic systems. Particles in natural waters consist mainly of clay minerals (kaolinite, montmorillonite, illite, etc.), metal oxides, and bacteria and algae as well as detritus. The majority of the particle mass is associated with particles between 1 and $100 \mu \mathrm{m}$ in diameter (e.g., [Jeong, 2002]). While chemical structure and surface chemical properties (important for particles as well as the chemical compounds associated with them) may differ among particles according to their origin, the transport and deposition behavior of all particles is similar because of the dominance of electrostatic and van der Waals particle interaction forces [Hahn et al., 1980]. This similarity in behavior enables the study of particles as individual objects (described by the bulk or average particle characteristics) to be used in many analyses and simulation procedures, even though property (e.g., size) distributions of particles are required for some purposes.

As illustrated in the diagram below, particle-related processes are major components of nearshore environments. Particles can serve as both sinks and sources of anthropogenic materials to the lake. Particles can also act as carriers in the cross margin 
transport of nutrients and contaminants because many of those are highly particlereactive and a large proportion may be associated with the particulate phase. Study of the processes shown in the figure is not only essential for the KITES project but is also beneficial for the scientific understanding of coastal biogeochemistry.

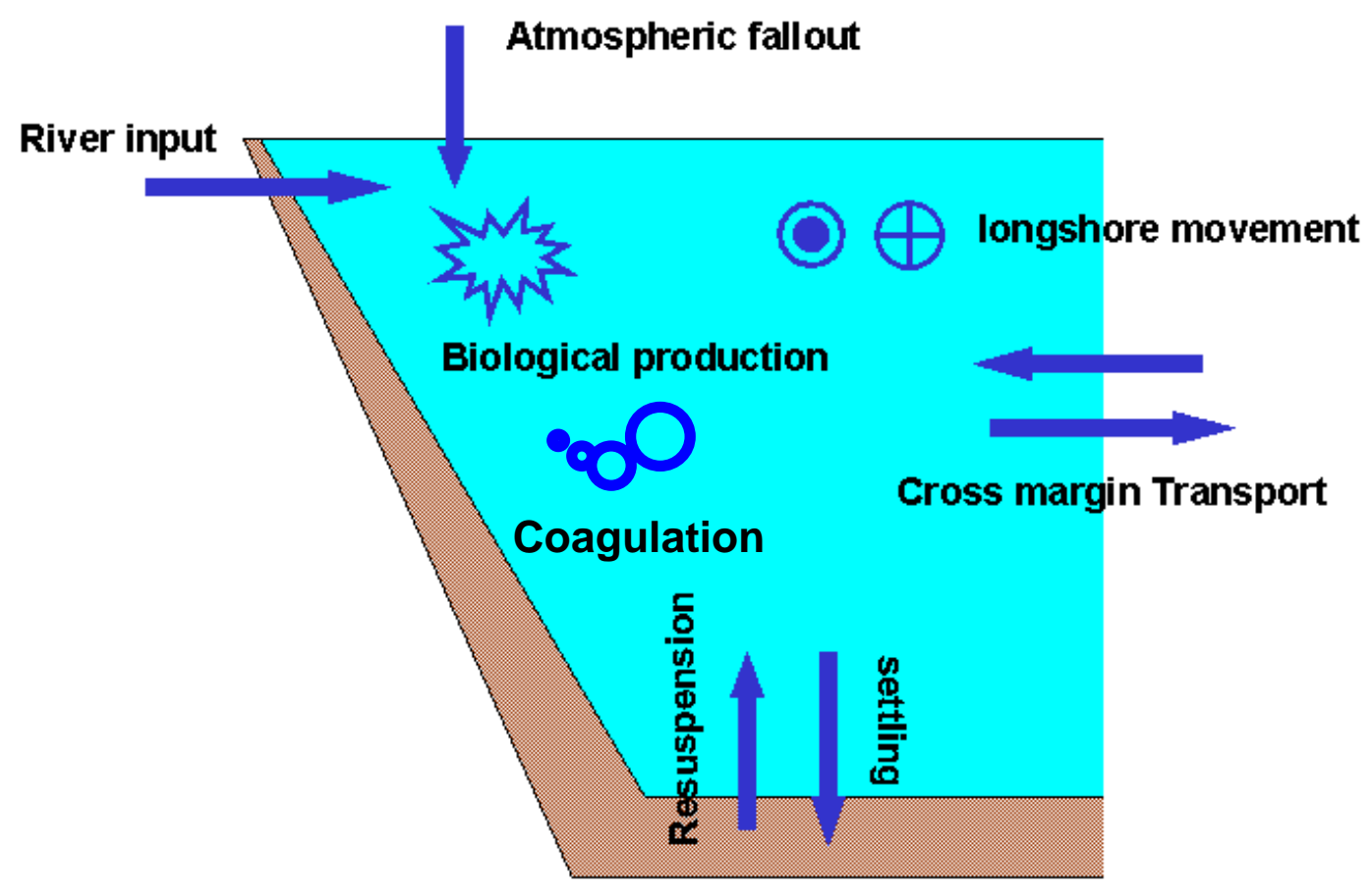

Figure 1. Particle dynamics in the nearshore region of a lake.

Radioisotopes have proven to be powerful tools for the study of particle dynamics [Honeyman and Santschi, 1989; Maier-Reimer and Henderson, 1998; Nozaki et al., 1991; Pempkowiak et al., 2002]. Some examples include determination of POC export fluxes from the upper ocean with ${ }^{234} \mathrm{Th} /{ }^{238} \mathrm{U}$ [Cochran et al., 2000; Santschi et al., 2003] and estimation of sedimentation rates in lakes with ${ }^{210} \mathrm{~Pb}$ and ${ }^{137} \mathrm{Cs}$ geochronology 
[Krishnaswami and Lal, 1978]. Isotope tracers have been successfully applied to study several processes in Figure 1 in different environmental settings [Brunskill and Wilkinson, 1987; Hancock, 2000; Henderson and Maier-Reimer, 2002; Lamborg et al., 2000; Santschi et al., 1999]. It is the physical, chemical and radiometric characteristics of radioisotopes that determine whether they are appropriate tracers of particle-mediated processes. First, the isotopes must be particle reactive (i.e., the majority of the isotope must be bound to the particulate phase) such that they follow the same transport pathways as particles. Second, the isotopes should have easily determined sources to the lake as compared with particles (examples might include the almost constant atmospheric

deposition of ${ }^{210} \mathrm{~Pb}$ and ${ }^{7} \mathrm{Be}$, the pulse input for ${ }^{137} \mathrm{Cs}$ as a byproduct of nuclear weapons testing, groundwater or specific river inflows [Smith et al., 1999]) to facilitate tracking the isotope movement within the system. Third, the radiometric decay provides an absolute timer; for this timer to be useful, the isotope half-life must be of roughly the same magnitude as the characteristic time of the environmental process under study. Finally, the analytical techniques must enable detection of the ultra low levels of isotopes present in the environment [e.g., Eakins and Morrison, 1978; Kim et al., 1999; Waples et al., 2003].

\subsection{Focal Questions of this Dissertation}

In the context of the KITES project, my research focused on three central questions: 1) What are the time-scales of particle-related processes in the coastal region? 2) What is the magnitude of resuspension in the shelf and slope regions of the lake? And 3) What are the relative importance of local deposition and cross-margin transport as a 
function of distance from shore in the KITES study region? To answer these questions, I first had to resolve many smaller issues. Can these questions be addressed with isotope tracers? Which isotopes which are suitable for the tasks? What sampling and modeling approaches are appropriate?

For the MGLPF project, I tried to answer two specific questions: 1) What is the flux of organic matter to the sediments in the shelf, slope and profundal regions of the study area? and 2) What is the residence time of "fresh" organic matter in each of these three zones? Answers to both questions are essential to understanding the ecology of Diporeia in Lake Superior. Diporeia are the dominant benthic organism in Lake Superior and, until recently, in the other Laurentian Great Lakes as well. Because these organisms are experiencing drastic declines in abundance or even vanishing from the other Great Lakes [Dermott, 2001], it is critical to have a complete understanding of this benthic organism, its life history and the interaction between Diporeia and the surrounding environment. In all of the Great Lakes, Diporeia exhibits maximum abundance in the slope region. It remains unknown whether this distribution is a response to predation, food availability, or other environmental factors. My role in this project was to use radioisotopes to determine the spatial pattern and the magnitude of organic matter deposition. Early results indicated that it was important to distinguish between "fresh" and resuspended organic matter; radioisotopes were particularly useful for this fractionation. The rates and pathways of carbon flow, and hence the food supply for Diporeia, are closely related to the KITES issues of the time scale and magnitude of cross margin transport. 


\subsection{Research approach}

The questions posed above are addressed in the three chapters in this dissertation. The first chapter focuses on the biogeochemical cycling of ${ }^{210} \mathrm{~Pb}$ and its decay daughter, ${ }^{210} \mathrm{Po}$, in the water column [Chai and Urban, 2004]. This article represents the first comprehensive study of this pair of isotopes in the Great Lakes. The specific goals of this chapter are to quantify the residence times of the isotopes in the water column and to identify the process(es) controlling the distributions of the isotopes. Isotope activities in water, suspended particles, sediment trap material (settling particles), and sediment samples along three transects are reported. Departures from secular equilibrium (activity ratio of ${ }^{210} \mathrm{Po}:{ }^{210} \mathrm{~Pb}=1$ ) [Olley et al., 1997] were observed for all phases (suspended particles, settling particles, dissolved) in the water column. About $85 \%$ of both ${ }^{210}$ Po and

${ }^{210} \mathrm{~Pb}$ is bound to the particulate phase in the water column; this observation validates the use of this pair of isotopes as particle tracers. The measured isotope distributions were used in a one-box, steady state model (after the commonly used ${ }^{234} \mathrm{Th}-{ }^{238} \mathrm{U}$ model in oceanography [Moran et al., 2003; Waples et al., 2004]) to derive particle settling velocities and residence times in the water column. The model indicated that large fluxes of both isotopes from sediment resuspension were necessary to explain the observed isotope ratios. Residence times for both ${ }^{210} \mathrm{Po}$ and ${ }^{210} \mathrm{~Pb}$ were $55 \sim 75$ days in a $150-\mathrm{m}$ deep water column despite the large difference between the half lives of the two isotopes (22.3-year versus 138-day); this similarity of residence times points to the dominant role of resuspension in regulating the distributions and residence times of both isotopes. One disadvantage of the one-box model is that the spatial variability (nearshore versus offshore and/or different transects) is not addressed adequately. 
Spatial issues are addressed explicitly in the third chapter that focused on the distributions of isotopes in the surface sediments. The isotopes used in this chapter include ${ }^{210} \mathrm{~Pb},{ }^{137} \mathrm{Cs}$ and ${ }^{7} \mathrm{Be}$. The goals of this chapter are to quantify the residence times and cross-margin fluxes of isotopes and particles in the NEAR shore zone. A novel approach was developed that utilizes a 2-dimensional transect model (Fig. 1); the transect could be subdivided into boxes-in-series or nested boxes for increased spatial resolution along the transect. ${ }^{210} \mathrm{~Pb}$ and ${ }^{137} \mathrm{Cs}$, normally used as tools in geochronology [Krishnaswami and Lal, 1978], acted more like transport tracers than age indicators in this non-depositional region. Of the 30 sites from which cores were collected in the study region, only three sites exhibited net sediment deposition and had focusing factors greater than one. For two of these sites, geochronologies (and sedimentation rates) based on ${ }^{210} \mathrm{~Pb}$ and ${ }^{137} \mathrm{Cs}$ were identical. Isotope inventories $\left({ }^{210} \mathrm{~Pb}\right.$ and ${ }^{137} \mathrm{Cs}$ ) and activities (all three isotopes) were used to quantify isotope residence times in the nearshore system (water AND sediment) and the cross-margin flux. Similarities and differences among the three transects yield insights into the relative importance of currents and waves. The short-lived ${ }^{7}$ Be was observed only in surface sediments; high activities found in the offshore (deep water) sediments point to rapid sediment delivery. Sediments in the slope region exhibited longer residence times and thus a local temporary deposition zone that might explain in part the distribution of Diporeia [Kahn, 2002].

Despite the significant findings in the first two chapters, lack of data in both temporal and spatial scales and oversimplification in the box models still might obscure some interactions of transport and biogeochemical processes. Accordingly, an attempt to couple the isotopes into a hydrodynamic model is summarized in chapter three. The goal 
of this chapter is to bridge the gap between the first two chapters and to test some conclusions from these chapters with numerical simulations. A "finer than real” simulation model was developed for the ${ }^{210} \mathrm{~Pb}$ and ${ }^{210} \mathrm{Po}$ isotope pair. The model was modified from an existing 2-D finite difference physical-biological model which has previously been successfully applied in Lake Superior [Niebauer et al., 1977; Niebauer et al., 2004]. Steps necessary to couple the hydrodynamic model with the isotopes included: definition of state variables for isotope species; addition of suspended particulate matter as a state variable; and parameterization of sediment-related processes. Numerical experiments were then performed with the modified model. The effects of environmental variables on isotope behavior were investigated focusing particularly on the partitioning coefficients $\left(\mathrm{K}_{\mathrm{d}}\right)$ and particle settling velocity $\left(\mathrm{v}_{\mathrm{s}}\right)$. The results from chapter one were used as initial conditions in model simulations, but the model output after 56 days showed an unrealistic isotope distribution in the water column. Alterations in parameter values and process descriptions (coding) were used to obtain isotope distributions that more nearly matched the field data. As concluded in chapter 1 , it was essential to include resuspension before the model prediction would approach the observed isotope distributions. At this stage of the model development, unlimited sediment sources (for both particles and isotopes) are assumed, and thus the model does not predict an accurate isotope inventory that might be compared with those reported in chapter two. However, the modeling exercises reveal the potential utility of hydrodynamic models for study of isotopes in the lake.

\subsection{Questions remaining}


In the scientific world, the attempt to solve specific questions always introduces new questions, which is the beauty of science. This research is no exception in this regard. The application of radioisotope tracers in a variety of approaches clarified the time scales and magnitudes of some biogeochemical processes in Lake Superior and demonstrated the importance of sediment resuspension. However, new questions also arose. Where are the NET deposition zones in the lake? What is the time scale for sediment transport to those sites? How close are these deposition regions to the KITES study area? How do the pathways for carbon flow in Lake Superior compare with those in the other Great Lakes? Can this information be used to aid in the recovery of Diporeia in the lower Great Lakes?

\section{REFERENCES}

Brunskill, G.J., and P. Wilkinson, Annual supply of ${ }^{238} \mathrm{U},{ }^{234} \mathrm{U},{ }^{230} \mathrm{Th},{ }^{226} \mathrm{Ra},{ }^{210} \mathrm{~Pb},{ }^{210} \mathrm{Po}$, and ${ }^{232}$ Th to Lake 239 (Experimental Lakes Area, Ontario) from terrestrial and atmospheric sources, Can. J. Fish. Aquat. Sci., 44 (Supplement 1), 215-230, 1987.

Chai, Y., and N.R. Urban, ${ }^{210} \mathrm{Po}$ and ${ }^{210} \mathrm{~Pb}$ distributions and residence times in the nearshore region of Lake Superior, J. Geophys. Res., 109 (C10S07), doi:10.1029/2003JC002081, 2004.

Chen, C., J. Zhu, E. Ralph, S.A. Green, J.W. Budd, and F.Y. Zhang, Prognostic modeling studies of the Keweenaw Current in Lake Superior. Part I: formation and evolution, Journal of Physical Oceanography, 31, 379-395, 2001.

Churchill, J.H., E.A. Ralph, A.M. Cates, J.W. Budd, and N.R. Urban, Observations of a negatively buoyant river plume in a large lake, Limnol. Oceanogr., 48 (2), 884894, 2003.

Churchill, J.H., A.J. Williams, and E.A. Ralph, Bottom stress generation and sediment transport over the shelf and slope off of Lake Superior's Keweenaw peninsula, $J$. Geophys. Res., 109 (C10S04), doi:10.1029/2003JC001997, 2004. 
Cochran, J.K., K.O. Buesseler, M.P. Bacon, H.W. Wang, D.J. Hirschberg, L. Ball, J. Andrews, G. Grossin, and A. Fleer, Short-lived thorium isotope (234Th, 228Th) as indicators of POC export and particle cycling in the Ross Sea, Southern Ocean, Deep-Sea Research II, 47, 3451-3490, 2000.

Dermott, R.M., Sudden disapperance of the amphipod Diporeia from eastern Lake Ontario, 1993-1995, J. Great Lakes Res., 27 (4), 423-433, 2001.

Eakins, J.D., and R.T. Morrison, A new Procedure for the Determination of Lead-210 in Lake and Marine Sediments, International Journal of Applied Radiation and Isotopes, 29, 531-536, 1978.

Green, S.A., and B.J. Eadie, Introduction to special section: Transport and transformation of biogeochemically important materials in coastal waters, J. Geophys. Res., 109 (C10S01), doi:10.1029/2004JC002697, 2004.

Hahn, H.H., F. Kaser, and R. Klute, Modeling particulate transport in impounded rivers,,, 1980.

Hancock, G.J., Identifying resuspended sediment in an estuary using the ${ }^{228}$ th/ $/{ }^{232} \mathrm{Th}$ activity ratio: The fate of lagoon sediment in the Bega River estuary, Australia, Marine and Freshwater Research, 51 (7), 659-667, 2000.

Henderson, G.M., and E. Maier-Reimer, Advection and removal of ${ }^{210} \mathrm{~Pb}$ and stable $\mathrm{Pb}$ isotopes in the oceans: A general circulation model study, Geochimica et Cosmochimica Acta, 66 (2), 257-272, 2002.

Honeyman, B.D., and P.H. Santschi, A Brownian-pumping model for oceanic trace metal scavenging: evidence from Th isotopes, Journal of Marine Research, 47 (4), 951992, 1989.

Jeong, J., Biogeochemical cycling of copper associated with particulate matter in Lake Superior, Michigan Technological University, Houghton, 2002.

Kahn, J.E., The abundance and distribution of benthic invertebrates along the Keweenaw Peninsula, Lake Superior, Michigan Technological University, Houghton, 2002.

Kim, G., N. Hussain, T.M. Church, and H. Yang, A practical and accurate method for the determination of ${ }^{234} \mathrm{Th}$ simultaneously with ${ }^{210} \mathrm{Po}$ and ${ }^{210} \mathrm{~Pb}$ in seawater, Talanta, 49, 851-858, 1999. 
Krishnaswami, S., and D. Lal, Radionuclide Limnochronology, in Lakes: Chemistry, Geology, Physics, edited by A. Lerman, pp. 153-178, Springer-Verlag, New York, 1978.

Lamborg, C.H., W.F. Fitzgerald, W.C. Graustein, and K.K. Turekian, An examination of the atmospheric chemistry of mercury using ${ }^{210} \mathrm{~Pb}$ and ${ }^{7} \mathrm{Be}$, Journal of Atmospheric Chemistry, 36 (3), 325-338, 2000.

Maier-Reimer, E., and G. Henderson, ${ }^{210} \mathrm{~Pb}$ in the ocean: A pilot tracer for modeling particle reactive elements, Proceedings of the Indian Academy of Sciences, Earth and Planetary Sciences, 107 (4), 351-357, 1998.

Moran, S.B., S.E. Weinstein, H.N. Edmonds, J.N. Smith, R.P. Kelly, M.E.Q. Pilson, and W.G. Harrison, Does ${ }^{234} \mathrm{Th} /{ }^{238} \mathrm{U}$ disequilibrium provide an accurate record of the export flux of particulate organic carbon from the upper ocean?, Limnol. Oceanogr., 48 (3), 1018-1029, 2003.

Niebauer, H.J., T. Green, and R.A. Ragotzkie, Coastal upwelling/downwelling cycles in southern Lake Superior, Journal of physical Oceanography, 7 (917-927), 1977.

Niebauer, H.J., N.R. Urban, M.T. Auer, and L.A. Bub, Primary production in Lake Superior: A numerical model of phosphorus cycling, Ecological Modeling, In review, 2004.

Nozaki, Y., H. Tsubota, V. Kasemsupaya, M. Yashima, and N. Ikuta, Residence times of surface water and particle-reactive ${ }^{210} \mathrm{~Pb}$ and ${ }^{210} \mathrm{Po}$ in the East China and Yellow seas, Geochimica et Cosmochimica Acta, 55, 1265-1272, 1991.

Olley, J.M., R.G. Roberts, and A.S. Murray, A novel method for determining residence times of river and lake sediments based on disequilibrium in the thorium decay series, Water Resources Research, 33 (6), 319-326, 1997.

Pempkowiak, J., J. Deldowski, P. K., S. A., T. Leipe, and E. K.-C., The contribution of the fine sediment fraction to the Fluffy Layer Suspended Matter (FLSM), Oceanologia, 44 (4), 513-527, 2002.

Raymond, P.A., and C.S. Hopkinson, Ecosystem Modulation of Dissolved Carbon Age in a Temperate Marsh-Dominated Estuary, Ecosystems, 6 (7), 694-705, 2003. 
Santschi, P.H., S. Cappellino, C. Dobbs, L. McShea, M.A. Allison, S. Asbill, and A.B. Perlet, Sediment transport and Hg recovery in Lavaca Bay, as evaluated from radionuclide and Hg distributions, Environ. Sci. Technol., 33 (3), 378-391, 1999.

Santschi, P.H., C.-C. Hung, G. Schultz, N. Alvarado-Quiroz, L. Guo, J. Pinckney, and I. Walsh, Control of acid polysaccharide production, and ${ }^{234} \mathrm{Th}$ and POC export fluxes by marine organisms, Geophysical Research Letters, 30 (2), 1044, doi:10.1029/2002GL016046, 2003.

Siefert, R., The role of coatal zones in global biogeochemical cycles, in EOS, Transactions, American Geophysical Union, pp. 469, Washington DC, 2004.

Smith, J.T., S.V. Fesenko, B.J. Howard, A.D. Horrill, N.I. Sanzharova, R.M. Alexakhin, D.G. Elder, and C. Naylor, Temporal change in fallout ${ }^{137} \mathrm{Cs}$ in terrestrial and aquatic systems: A whole ecosystem approach, Environ. Sci. Technol., 33 (1), 4954, 1999.

Thornton, E., T. Dalrymple, T. Drake, S. Elgar, E. Gallagher, B. Guza, A. Hay, R. Holman, J. Kaihatu, T. Lippmann, and T. Ozkan-Haller, State of nearshore processes research: II, pp. 38, Naval Postgraduate School, Monterey, CA, 2000.

Urban, N.R., D.S. Apul, and M.T. Auer, Planktonic respiration rates in Lake Superior, J. Great Lakes Res., 30 (Supplement 1), 230-244, 2004a.

Urban, N.R., M.T. Auer, S.A. Green, and X. Lu, Carbon cycling in Lake Superior, J. Geophys. Res., In Press, 2005.

Urban, N.R., Y. Chai, and J. Jeong, The benthic Nepheloid layer (BNL) north of the Keweenaw Peninsula in Lake Superior: composition, dynamics and role in sediment transport, J. Great Lakes Res., 30 (Supplement 1), 133-146, 2004b.

Urban, N.R., L. Xu, Y. Chai, and D.S. Apul, Sediment trap studies in Lake Superior: insight into resuspension, cross-margin transport and carbon cycling, J. Great Lakes Res., 30 (Supplement 1), 147-161, 2004c.

Walsh, J.J., K. Aagaard, A.T. Roach, T.E. Whitledge, D. Stockwell, D.A. Dieterle, and F.E. Muller-Karger, $\mathrm{CO}_{2}$ cycling in the coastal ocean. II. Seasonal organic loading of the Arctic Ocean from source waters in the Bering Sea, Continental Shelf Research, 17 (1), 1-36, 1997. 
Walsh, J.J., and D.A. Dieterle, $\mathrm{CO}_{2}$ cycling in the coastal ocean. I - a numerical analysis of the southeastern Bering Sea with applications to the Chukchi Sea and the northern Gulf of Mexico, Progress in Oceanography, 34 (4), 335-392, 1994.

Waples, J.T., K.A. Orlandini, D.N. Edgington, and J.V. Klump, Seasonal and spatial dynamics of ${ }^{234} \mathrm{Th} /{ }^{238} \mathrm{U}$ disequilibria in southern Lake Michigan, J. Geophys. Res., 109 (C10), doi:10.1029/2003JC002204, 2004.

Waples, J.T., K.A. Orlandini, D.N. Edington, and J.V. Klump, Measuring low concentrations of ${ }^{234}$ Th in water and sediment, Mar. Chem., 80, 265-281, 2003.

Zhu, J., C. Chen, E. Ralph, S.A. Green, J.W. Budd, and F.Y. Zhang, Prognostic modeling studies of the Keweenaw Current in Lake Superior. Part II: simulation, Journal of Physical Oceanography, 31, 396-410, 2001. 


\section{Chapter Two}

\section{${ }^{210} \mathrm{Po}$ and ${ }^{210} \mathrm{~Pb}$ Distributions and Residence Times in the Near- Shore Region of Lake Superior ${ }^{1}$}

': This chapter has been published in Journal of Geophysical Research - Oceans with the same title. The formal citation is:

Chai, Y., and N. R. Urban (2004), ${ }^{210} \mathrm{Po}$ and ${ }^{210} \mathrm{~Pb}$ distributions and residence times in the nearshore region of Lake Superior, J. Geophys. Res., 109, C10S07, doi:10.1029/2003JC002081. (http://www.agu.org/pubs/crossref/2004/2003JC002081.shtml) 


\section{Abstract:}

The naturally occurring radionuclide, ${ }^{210} \mathrm{~Pb}$, and its decay daughter, ${ }^{210} \mathrm{Po}$, were measured in the Keweenaw Peninsula region of Lake Superior. Water, suspended particles, sediment trap material (settling particles), and sediment cores and grab samples were collected along three transects that stretched from 1 to $21 \mathrm{~km}$ from shore. Departures from secular equilibrium (activity ratio of ${ }^{210} \mathrm{Po}:{ }^{210} \mathrm{~Pb}=1$ ) were observed for most samples. ${ }^{210}$ Po-deficiency was observed in both suspended particles (TSP) with a ratio of $0.43 \pm 0.05( \pm 95 \%$ C.I. $)$ and settling particles with a ratio of $0.57 \pm 0.04$; higher ratios in the settling particles resulted from an admixture of resuspended sediments. Ratios in the dissolved phase were $0.45 \pm 0.12$. Approximately $83 \%$ and $85 \%$ of total ${ }^{210} \mathrm{Po}$ and ${ }^{210} \mathrm{~Pb}$ in the water column was in the particulate phase. No evidence of biological uptake of Po was found. Seasonal and spatial variability in activities and ratios was small. Using steady state solutions to the mass balance equations for both isotopes, similar residence times in the water column were calculated for ${ }^{210} \mathrm{Po}$ and ${ }^{210} \mathrm{~Pb}(55 \sim 75$ days in a 150-m deep water column). It was possible to calibrate a 1-box model for the paired isotopes so that the model output closely matched rates of sediment and isotope resuspension estimated from sediment traps. However, this calibration required a fractionation of the isotopes during resuspension. The particle settling velocity was estimated to be $2.3 \mathrm{~m} \mathrm{~d}^{-1}$, which also is in agreement with the estimate $\left(2.4 \pm 2.2 \mathrm{~m} \mathrm{~d}^{-1}\right)$ from sediment traps. These results indicate rapid fluxes of radioisotopes and sediments through the water column largely driven by resuspension of sediments in near-shore areas. 


\section{Introduction:}

The naturally occurring radioisotopes ${ }^{210} \mathrm{~Pb}$ (half-life $=22.3$ years) and ${ }^{210} \mathrm{Po}$ (half-life $=138$ days) have been used as tracers for many environmental processes, including aerosol transport [Marley et al., 2000] and particle scavenging in aquatic environments [Bacon et al., 1976; Boisson et al., 2001; Nozaki et al., 1991]. ${ }^{210} \mathrm{~Pb}$ has long been used as a tracer in limnology and oceanography for sediment deposition and particle transport processes, and well established analytical methods and mathematical models are available for this purpose [Krishnaswami et al., 1971; Masqué et al., 2002; Robbins and Edington, 1975]. ${ }^{210} \mathrm{Po}$ is the decay daughter of ${ }^{210} \mathrm{~Pb}$, and the two will reach secular equilibrium in a closed system given enough time ( 2 yr) [Olley et al., 1997]. Both isotopes have a strong tendency to be associated with particulate matter in the water column through surface adsorption or biological uptake [Bacon et al., 1976; Boisson et al., 2001; Sarin et al., 1994]. Although many researchers have used the ${ }^{210} \mathrm{~Pb}:{ }^{210} \mathrm{Po}$ isotope pair for studying biogeochemical processes [e.g., El-Daoushy, 1989; Kim, 2001; Kim and Church, 2001], relatively few studies [Balistrieri et al., 1995; Benoit, 1995; Benoit and Hemond, 1991; Benoit and Hemond, 1992; Schuler et al., 1991; Wang and Cornett, 1993; Wieland et al., 1991] have looked at the behavior of these isotopes in freshwater systems.

The coastal region of lakes and oceans serves as a buffer zone between the land and deep water. Nutrients and contaminants pass from land to open water through this region [Gustafsson et al., 1997; Olsen et al., 1986; Zuo and Eisma, 1993]. For particlereactive ${ }^{210} \mathrm{Po}$ and ${ }^{210} \mathrm{~Pb}$ in the water column, the distribution between dissolved and particulate phases is affected strongly by the dynamic near-shore environment [Boisson et 
al., 2001; Hong et al., 1999; Zuo and Eisma, 1993]. All major processes related to particle movement (e.g., settling, resuspension) influence isotope distributions.

Therefore, isotopes are useful tools to study these processes. For example, the input of particulate matter and associated isotopes from the Yangtze plume has significant effects on ${ }^{210} \mathrm{Po}$ residence times in surface water in the East China and Yellow seas [Nozaki et al., 1991]. A few studies [Baker and Eisenreich, 1989; Baker et al., 1991; Jeremiason et al., 1998; Schneider et al., 2002] have assessed the material input from bottom sediments (such as PCBs and PAHs) through mechanisms other than dispersion /diffusion such as particle resuspension. This process is particularly important in near-shore regions. Particle-reactive radioisotopes are good tracers for resuspension [Hancock, 2000; Turnewitsch and Springer, 2001].

There are a few studies of the biogeochemical cycling of ${ }^{210} \mathrm{~Pb}$ and ${ }^{210} \mathrm{Po}$ in freshwater lakes [e.g., Balistrieri et al., 1995; Benoit and Hemond, 1987; Schuler et al., 1991; Talbot and Andren, 1984; Wieland et al., 1991], and these are restricted to small lakes. In the previous studies, either large particles (settling particles) [e.g., Balistrieri et al., 1995; Benoit and Hemond, 1987; Talbot and Andren, 1984] or suspended particles [Schuler et al., 1991; Wieland et al., 1991] were omitted. No study has yet examined all relevant phases (dissolved, colloidal, suspended particulate, settling particulate, sediment, pore water) for both ${ }^{210} \mathrm{~Pb}$ and ${ }^{210} \mathrm{Po}$ in a fresh water system. In this paper, we present both ${ }^{210} \mathrm{~Pb}$ and ${ }^{210} \mathrm{Po}$ activities in suspended particles, settling particles, the dissolved phase, and surficial sediments in a near-shore region of Lake Superior. As part of the Keweenaw Interdisciplinary Transport Experiment in Superior (KITES) project, the 
objectives of this study were to determine particle and isotope residence times in nearshore regions, and to determine the factors controlling these residence times.

\section{Methods:}

\subsection{Study area}

Lake Superior is the largest freshwater lake in the world by surface area and second largest by volume, with a surface area of $8.21 \times 10^{10} \mathrm{~m}^{2}$ and a mean depth of 150 $\mathrm{m}$. It accounts for $10 \%$ of the world's fresh surface water. It is also an ultra-oligotrophic lake with a Secchi depth greater than $15 \mathrm{~m}$. Concentrations of suspended particles

(generally $<1 \mathrm{mg} \mathrm{L}^{-1}$, [Jeong, 2002]) are low, and rates of sediment accumulation (0.1-3 $\mathrm{mm} \mathrm{yr}^{-1}$, [Evans et al., 1981]) are correspondingly low.

This study was conducted along approximately 150 kilometers of coastline on the northwest side of the Keweenaw Peninsula in Lake Superior (Fig. 1). Within the study area, sampling was conducted in three main regions primarily along transects oriented perpendicular to the shoreline and extending from 0 to $21 \mathrm{~km}$ offshore (only $0-9 \mathrm{~km}$ for the northern transect). The lake bathymetry changes from a gentle slope (0.007) at the southernmost $(\mathrm{ON})$ transect to a narrow shelf at the middle transect $(\mathrm{HN})$ to a steep slope (0.035) along the northernmost transect (EH). Previous investigations have reported the presence of a strong northeastward coastal current off the Keweenaw Peninsula, commonly referred to as the Keweenaw current [Ragotzkie, 1966; Viekman and Wimbush, 1993]. Numerical modeling by Chen et al. [2001]and Zhu et al. [2001] has indicated that the current is, in part, thermally driven, caused by rapid warming of nearshore (vs. offshore) water. 

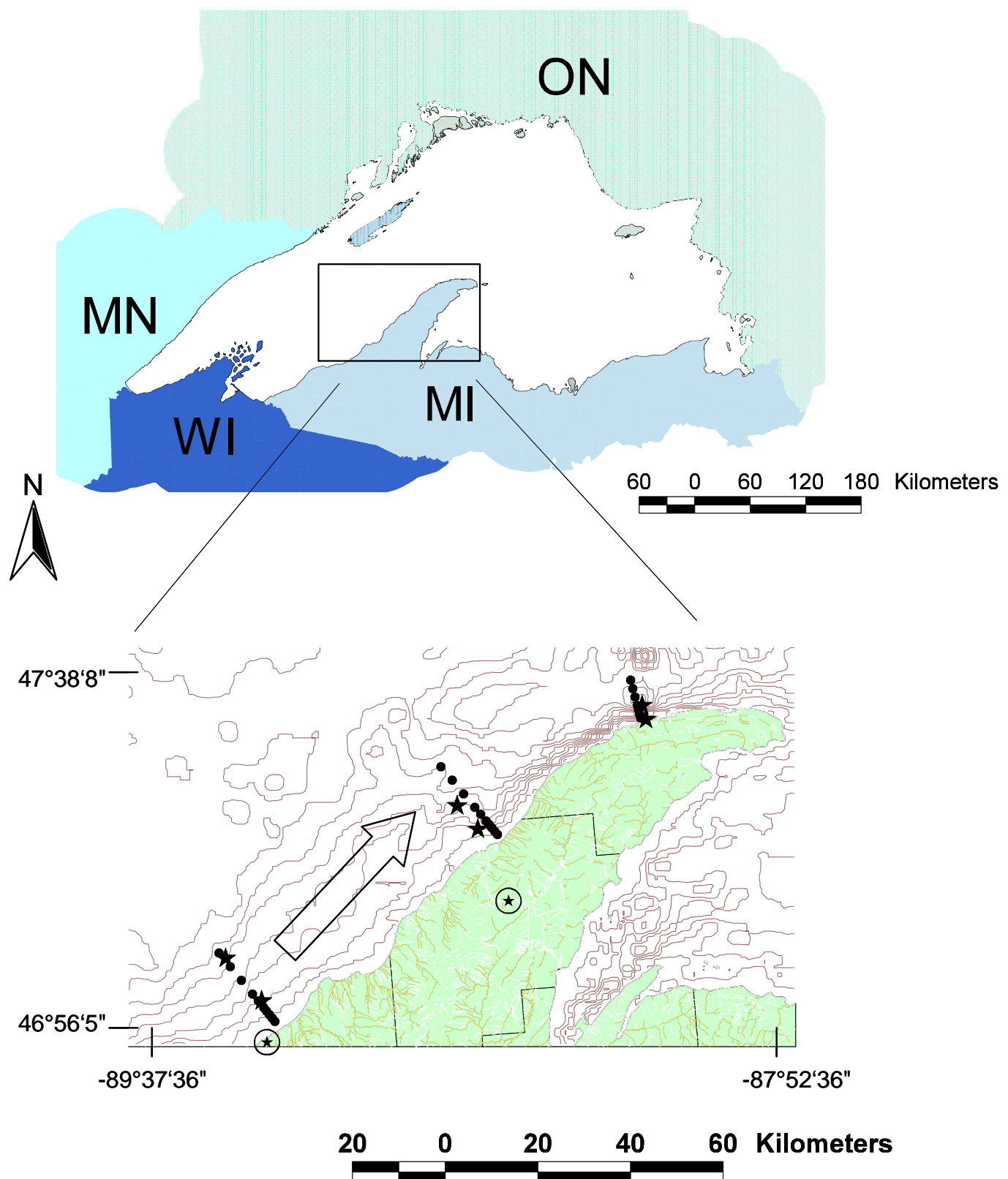

Figure 1. Keweenaw Peninsula region of Lake Superior. Three sampling transects and sampling sites are shown in the lower map. Solid circles represent the water sampling sites and stars represent sites for sediment trap deployment. The contour lines in the lower map show the bathymetry of Lake Superior. The northeast running arrow represents the Keweenaw Current. 


\subsection{Field sampling}

The majority of water and suspended particle samples in this study were collected between early May and late October in year 2000. Sediment traps were deployed over the duration of the KITES project (1998 2000), and surface sediments were collected in 2001. Based on lake thermal stratification (more details discussed later), the sampling period was separated into three seasons: pre-stratification (May - mid-July), stratification (mid-July - August), and late stratification (September and October).

Large volume (50-100 L) water samples were pumped into plastic reservoirs on deck and then pumped through pre-combusted 144-mm $\varnothing \mathrm{GF} / \mathrm{F}$ filters (nominal pore size $0.7 \mu \mathrm{m})$. Small volume $(\sim 10 \mathrm{~L})$ water samples were also collected with niskin bottles at the same site and depth and filtered through 47-mm $\varnothing \mathrm{GF} / \mathrm{F}$ filters. Total suspended particle (TSP) concentrations were determined gravimetrically on small filters [Jeong, 2002], and large filters were used for isotope analyses. The filtered water was kept for measurement of dissolved isotope concentrations.

Sediment traps were deployed in three consecutive years, from April to October each year [Urban et al., 2004d]. In any given sampling season, three sediment trap moorings were deployed at three different stations. On each mooring, three traps were employed at each of three depths. The top traps were placed 35 meters below the surface, right below the summer thermocline, while the two bottom traps were located at 5 meters and 10 meter above the sediments. Traps were serviced at intervals of 30 days, on average. When the traps were serviced, water was decanted and trap materials were transferred completely to $500-\mathrm{ml}$ plastic bottles. The bottles were frozen on board until further analysis. 
A ponar dredge was used to collect surface sediment samples along the three transects. Gravity cores were collected where possible. Depending on sediment characteristics, cores of $10-70 \mathrm{~cm}$ length were collected with $5-\mathrm{cm} \varnothing$ core tubes. Core tubes were sealed with lake water in the headspace and refrigerated on board. A total of 9 cores and 16 ponar samples were collected in year 2001. Additional cores were taken in the following two years and data from those cores are presented in chapter three.

Within the sediment cores, the unconsolidated surface layers (fluff) or easily resuspendable sediment constitutes a critical component. Others have collected this material by mixing surface sediments with ultrafiltered seawater and then filtering the supernatant after settling over night [Guo and Santschi, 2000]. In this study, water was siphoned out of the headspace until only $5 \mathrm{~cm}$ of water remained above the sediments. A diffusion stone was suspended $\sim 1 \mathrm{~cm}$ above the sediments and air was sparged $(15 \mathrm{kPa})$ through the stone to resuspend surficial sediments. The water-sediment mixture was then collected using a syringe. From 0.26 to 1.5 grams of surficial sediments were recovered after oven drying of the slurries.

\subsection{Analysis}

All samples were stored at $4{ }^{\circ} \mathrm{C}$ before treatment. Filter samples and sediment samples were dried at $60^{\circ} \mathrm{C}$ and $105^{\circ} \mathrm{C}$, respectively. Sediment trap samples were freezedried. Large-volume water samples were reduced in volume by heating in a convection oven followed by freeze-drying. Dried and homogenized samples were subjected to isotope analysis. 
Samples of at least $100 \mathrm{mg}$ dry weight (DW) were prepared for the sediment trap samples and at least $1000 \mathrm{mg}$ DW were used for ponar and sediment core samples. Longer counting times were used if these masses were not available. Filter samples were cut into two equal parts. Samples were measured for ${ }^{210} \mathrm{Po}(\alpha)$ activities within $\sim 1$ month after collection. The remainder of the sample was stored for 6 months or longer before determination of ${ }^{210} \mathrm{~Pb}$ by means of ${ }^{210} \mathrm{Po}$ [Eakins and Morrison, 1978]. Secular equilibrium was not assumed; rather, initial activities of both isotopes were calculated according to isotopic decays of both isotopes. The mathematical approach for the back calculation is provided in Appendix 1.

Isotope extraction and plating followed the method of Eakins and Morrison [1978] as modified by Engstrom [1985]. Before digestion, a known activity of ${ }^{209} \mathrm{Po}$ (NIST Standard Reference Material (SRM) 4326) was added to each sample. Plating was to Ag planchettes. Counting times of 12 to 48 hours resulted in uncertainties of 5-10\%. Recovery of ${ }^{209}$ Po ranged from $40-70 \%$. A quality assurance sample (fine ponar sediment) was counted once per 30 samples to verify accuracy and precision. A relative error (standard error/mean) of $1.6 \%$ was observed for this sample $(n=25)$.

The majority of samples were analyzed for several other analytes including organic carbon and nitrogen [Urban et al., 2004b; 2004d]. Organic carbon was measured on dried samples with a Carlo Erba NA 1500 Elemental Analyzer. Precision was better than 5\%, and accuracy was verified with NIST SRM 2704 (Buffalo River Sediments). Because Lake Superior is undersaturated with respect to calcite, total carbon content very nearly equals organic carbon content for suspended and settling particles. 


\subsection{Model framework}

A mathematical model similar to that commonly used in oceanographic studies of ${ }^{234} \mathrm{Th}:{ }^{238} \mathrm{U}$ ratios [Aller et al., 1980; Bhat et al., 1969; Gustafsson et al., 1997] was employed. This model focuses on the isotope distribution of ${ }^{210} \mathrm{Po}$ and ${ }^{210} \mathrm{~Pb}$ in the system and links isotope distributions and disequilibria with particle dynamics. Figure 2 illustrates the framework for this model. The water column of Lake Superior is modeled as completely mixed or as two boxes (epilimnion 0-25 m, hypolimnion $25 \mathrm{~m}$-bottom). Total (i.e., dissolved plus particulate) concentrations/activities of ${ }^{210} \mathrm{~Pb}$ and ${ }^{210} \mathrm{Po}$ are considered within the model. A mass-balance for the two isotopes constitutes the mathematical basis for the model as shown in equations 1 and 2 .

$$
\begin{aligned}
& V \frac{d{ }^{210} P b}{d t}=F_{210} P b \cdot A-\lambda_{P b} \cdot{ }^{210} \mathrm{~Pb} \cdot V-\frac{v_{s}}{H} \cdot f_{s P b} \cdot{ }^{210} \mathrm{~Pb} \cdot V \\
& V \frac{d{ }^{210} \mathrm{Po}}{d t}=F_{210} \cdot A+\lambda_{P o} \cdot{ }^{210} \mathrm{~Pb} \cdot V-\lambda_{P o} \cdot{ }^{210} \mathrm{Po} \cdot V-\frac{v_{s}}{H} \cdot f_{s P o} \cdot{ }^{210} \mathrm{Po} \cdot V \\
& { }^{210} \mathrm{~Pb} /{ }^{210} \mathrm{Po}-{ }^{210} \mathrm{~Pb} /{ }^{210} \mathrm{Po} \text { activity }\left(\mathrm{dpm} \mathrm{m} \mathrm{m}^{-3}\right) \\
& \lambda_{P b} / \lambda_{P_{o}} \text {-decayrate of }{ }^{210} \mathrm{~Pb} /{ }^{210} \mathrm{Po}\left(d^{-1}\right)
\end{aligned}
$$

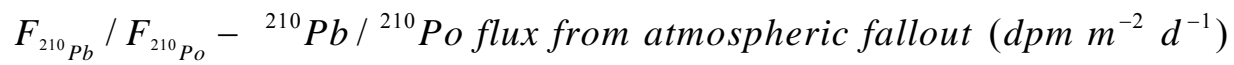

$$
\begin{aligned}
& V \text { - volume of the lake }\left(\mathrm{m}^{3}\right) \\
& \text { A- area of the lake }\left(\mathrm{m}^{2}\right) \\
& H \text { - mean depth of the lake }(m), \frac{V}{A} \\
& v_{s} \text { - average particle settling velocity }\left(m d^{-1}\right) \\
& f_{s}-\text { fraction of }{ }^{210} \mathrm{~Pb} /{ }^{210} \mathrm{Po} \text { in particulate phase (unitless), } \frac{K_{d} C}{1+K_{d} C} \\
& K_{d} \text { - isotope water - particle partitioning coefficient }\left(\mathrm{m}^{3} \mathrm{~kg}^{-1} \text {, or } \mathrm{L} \mathrm{mg}^{-1}\right) \\
& C \text { - particle concentration in the water column }\left(\mathrm{mg} \mathrm{L}^{-1}\right)
\end{aligned}
$$




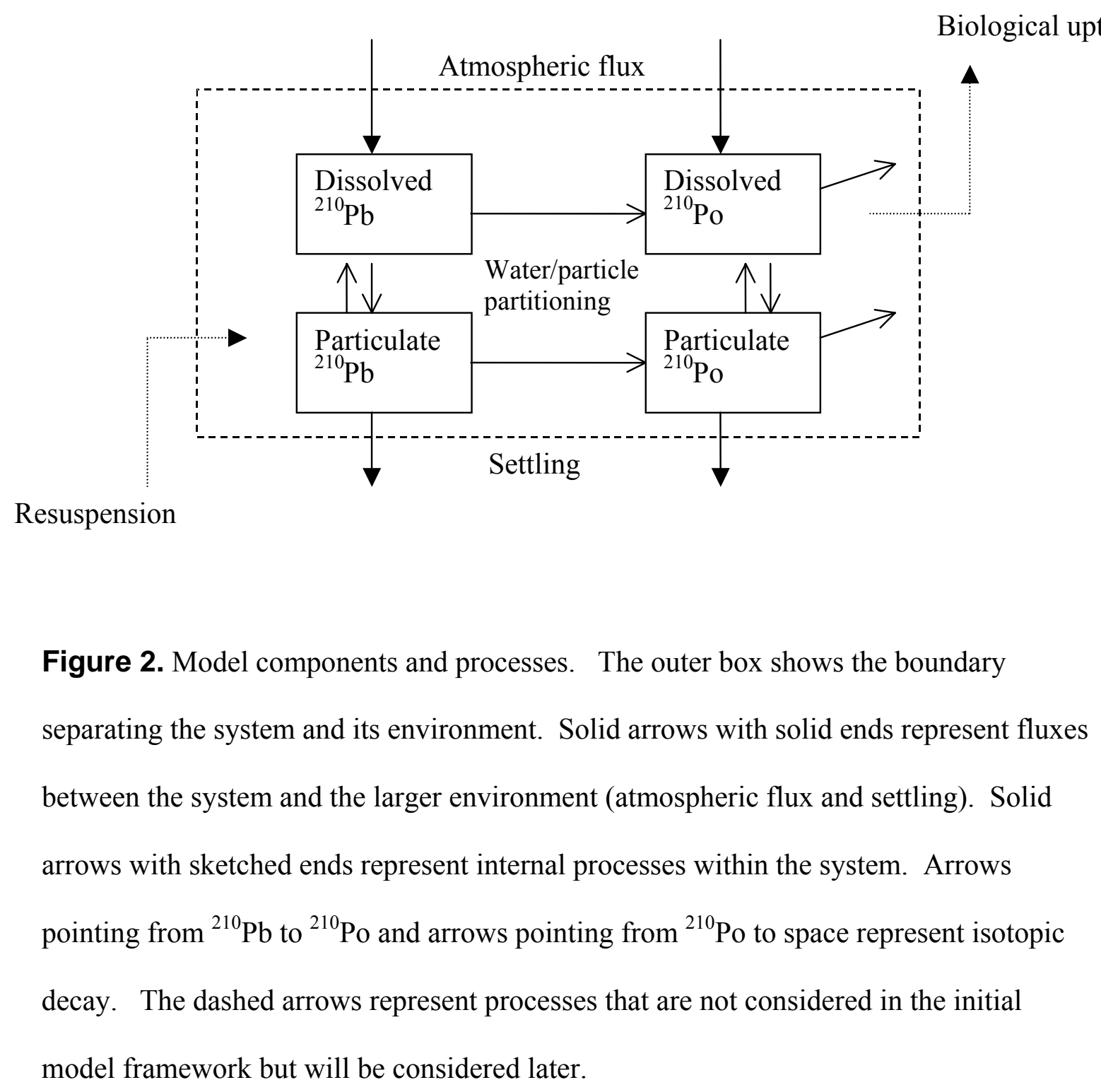

In equation 1 , the change in ${ }^{210} \mathrm{~Pb}$ inventory is determined by the relative magnitudes of the sources (atmospheric input) and sinks (isotopic decay and water column scavenging by particulate matter). For ${ }^{210} \mathrm{Po}$ in equation 2 , similar items are included except that the sources of this isotope include atmospheric deposition and decay 
of ${ }^{210} \mathrm{~Pb}$ in the water column. For the scavenging process, it is assumed that all particles (operationally defined as those collected on a GF/F filter with a nominal pore size of 0.7 $\mu \mathrm{m})$ in the water column sink at a constant settling velocity $\left(v_{s}\right)$, and that the dissolved isotopes are in sorptive equilibrium with all particles. This simple model ignores colloidal particles and "colloidal pumping" of isotopes [Honeyman and Santschi, 1989]. Because nonsettling colloids are ignored, the larger is $f_{s}$, the faster the isotope will be scavenged by particles. Earlier research has shown that both isotopes in this study are particle-reactive [Hong et al., 1999; Nozaki et al., 1991; Sarin et al., 1999] and may be used as particle tracers. The particle settling velocity $\left(v_{s}\right)$ is a key descriptor of the rate of particle scavenging. It has units of meter day $^{-1}$, but has little physical meaning (see discussion); rather it is the quotient of particle flux (sediment trap) and particle concentration (TSP). Particle residence time is calculated from mean depth and the settling velocity using equation 3 :

$$
\tau_{\text {particle }}=\frac{H}{v_{s}}
$$

Model input consists of the physical and geological characteristics of Lake Superior and isotope and/or particle concentrations in the lake. The model can be used either to predict the isotope concentrations given a particle-scavenging rate or to determine the particle settling velocity and residence time in the water column given the isotope patterns in the system. In this paper, both model applications are performed based on field measurements in Lake Superior.

For a one-box model, the characteristic time for a perturbation to decay is defined rigorously in terms of parameters in the differential equation or set of such equations. 
Because all processes related to isotope/particle movement in our model are described as first order reactions, the characteristic time can be determined from the two mass balance equations (equations 1 and 2).

$$
\begin{gathered}
\tau_{1}=\frac{1}{\lambda_{P b}+\frac{v_{s}}{H} f_{S P b}} \\
\tau_{2}=\frac{1}{\lambda_{P o}+\frac{v_{s}}{H} f_{S P o}}
\end{gathered}
$$

$\tau_{1}$ and $\tau_{2}$ are the residence times of ${ }^{210} \mathrm{~Pb}$ and ${ }^{210} \mathrm{Po}$ in the system. When values of settling velocity $\left(v_{s}\right)$ and particulate fractions $\left(f_{s}\right)$ are used, the relative magnitudes of decay

$(\lambda)$ and particle scavenging $\left(\frac{V_{s}}{H} f_{s}\right)$ in the denominator reveal which process is the major sink for isotopes in the system.

\section{Results}

\subsection{System characteristics}

As mentioned before, most data presented in this paper are from samples collected in a region within $20 \mathrm{~km}$ distance from the shore of the Keweenaw Peninsula. Water depths of sampling sites vary from about 10 meters to 230 meters. Total phosphorus concentrations of 1.5-3.5 $\mathrm{mg} \mathrm{P} \mathrm{m}^{-3}$ [Siew, 2003] and chlorophyll-a concentrations of $0.2-1.5 \mathrm{mg} \mathrm{m}^{-3}[\mathrm{Bub}, 2001]$ were observed, clear indications that Lake Superior is ultra-oligotrophic. Total suspended particle (TSP) concentrations in this study ranged from $0.03-1.60 \mathrm{mg} \mathrm{L}^{-1}$ with a mean of $0.45 \mathrm{mg} \mathrm{L}^{-1}$; all higher values occurred in near-shore sites or following storms [Jeong et al., 2003]. The TSP 
concentrations observed in offshore sites are close to those reported previously for open waters of Lake Superior [Baker and Eisenreich, 1989; Jeremiason et al., 1998].

\subsection{Partitioning of isotope between water and particulate matter}

The distribution of $\mathrm{Pb}$ and $\mathrm{Po}$ between the particulate and aqueous phases was examined on a small subset of samples collected in spring of 2001 (Table 1). The fraction of the isotopes in the particulate phase (f) was used to calculate a partition coefficient $\left(K_{d}, \mathrm{~L} \mathrm{~kg}^{-1}\right)$ :

$$
f=\frac{\text { activity } \cdot \text { in } \cdot \text { particulate } \cdot \text { phase }}{\text { total } \cdot \text { activity }}=\frac{K_{d} \cdot C}{1+K_{d} \cdot C}
$$

where $C$ is the suspended solids concentration $\left(\mathrm{mg} \mathrm{L}^{-1}\right)$. The median $( \pm$ S.D. $)$ partition coefficient for ${ }^{210} \mathrm{~Pb}$ was $12 \pm 4.0 \times 10^{6} \mathrm{~L} \mathrm{~kg}^{-1}$. The median value for ${ }^{210} \mathrm{Po}\left(15 \pm 6 \times 10^{6}\right.$ $\mathrm{L} \mathrm{kg}^{-1}$ ) is based on only 4 samples and is biased by one high value. We believe that a more accurate value $\left(11 \times 10^{6} \mathrm{~L} \mathrm{~kg}^{-1}\right)$ may be calculated from the average $(\mathrm{n}=63) \mathrm{Po}: \mathrm{Pb}$ ratios on particles $(0.43)$, the average $(n=4) \mathrm{Po}: \mathrm{Pb}$ ratio in the dissolved phase $(0.46)$, and the average $(n=6) K_{D}$ value for ${ }^{210} \mathrm{~Pb}$. These values are within the range reported for freshwaters for both isotopes [Balistrieri et al., 1995; Benoit and Hemond, 1987; Hong et al., 1999; Wang and Cornett, 1993]. Due to the limited data and shallow water depth, no clear trend of increasing $K_{d}$ with increasing depth was found as reported by Baskaran and Santschi [2002]. More details about $K_{d}$ will be addressed in the discussion. 
Table 1. Distribution of ${ }^{210} \mathrm{Po}$ and ${ }^{210} \mathrm{~Pb}$ between dissolved and particulate phase and associated coefficients $\left(\mathrm{K}_{\mathrm{D}}\right)$. date of collection is April 28, 2001. Errors are based on $1 \sigma$ counting errors.

\begin{tabular}{|c|c|c|c|c|c|c|c|c|}
\hline \multirow[t]{2}{*}{ Site } & \multirow{2}{*}{$\begin{array}{c}\text { Depth } \\
\text { (m) }\end{array}$} & \multirow{2}{*}{$\begin{array}{c}\text { TSP } \\
\text { concentration } \\
(\mathrm{mg} / \mathrm{L})\end{array}$} & \multicolumn{2}{|c|}{$\begin{array}{c}{ }^{210} \text { Po activities } \\
\text { (dpm/100L) }\end{array}$} & \multirow{2}{*}{$\begin{array}{c}{ }^{210} \mathrm{Po} \mathrm{K}{ }_{D} \\
(\mathrm{~L} / \mathrm{mg})\end{array}$} & \multicolumn{2}{|c|}{$\begin{array}{c}{ }^{210} \mathrm{~Pb} \text { activities } \\
(\mathrm{dpm} / 100 \mathrm{~L})\end{array}$} & \multirow{2}{*}{$\begin{array}{c}{ }^{210} \mathrm{~Pb} \mathrm{~K} \\
(\mathrm{~L} / \mathrm{mg})\end{array}$} \\
\hline & & & dissolved & particulate & & dissolved & particulate & \\
\hline HN010 & 0 & 0.41 & 1 & 1 & 1 & $2.10 \pm 0.41$ & $9.06 \pm 0.70$ & 10.5 \\
\hline HN010 & 9 & 0.16 & 1 & 1 & 1 & $5 . \overline{1} 1$ & $8.03 \pm 0.38$ & 9.8 \\
\hline HN210 & 0 & 0.15 & $1.11+0.07$ & $4.30 \pm 0.21$ & 25.8 & $1.74+0.36$ & $3.64 \pm 0.32$ & 13.9 \\
\hline HN210 & 75 & 0.26 & $\overline{2}$ & $0.17 \pm 0.01$ & 1 & $\frac{1}{2}$ & $6.04+0.51$ & 1 \\
\hline HN210 & 125 & 0.15 & $0.61 \pm 0.05$ & $0.97 \pm 0.05$ & 10.6 & $1.45 \pm 0.30$ & $3.38+0.34$ & 15.5 \\
\hline HN210 & 168 & 0.12 & $0.86 \pm 0.05$ & $1.53 \pm 0.08$ & 14.8 & $2.41 \pm 0.54$ & $2.63 \pm 0.29$ & 9.1 \\
\hline EH015 & 100 & 0.12 & $0.81+0.05$ & $2.02+0.11$ & 15.6 & $1.99+0.38$ & $5.27+0.46$ & 16.6 \\
\hline
\end{tabular}

1. Not available

2. Below detection limit 


\subsection{Isotope activities on the TSP samples}

Approximately 70 large-volume water samples were filtered, and the particulate matter was analyzed for both ${ }^{210} \mathrm{~Pb}$ and ${ }^{210} \mathrm{Po}$. Activities ranged from 2.0-9.2 dpm $100 \mathrm{~L}^{-1}$ for ${ }^{210} \mathrm{~Pb}$ and from $0.4-4.3 \mathrm{dpm} 100 \mathrm{~L}^{-1}$ for ${ }^{210} \mathrm{Po}$. This range is similar to but narrower than that reported previously in other lakes [Balistrieri et al., 1995; Benoit and Hemond, 1987; Wang and Cornett, 1993]. Among these samples, the two isotopes behave somewhat differently. Activities of ${ }^{210} \mathrm{~Pb}$ were significantly higher (student's t-test, $\mathrm{P}<$ $0.05)$ in the nearshore region than offshore, but there were no systematic differences in activities with transect, sampling depth, or time of year. For ${ }^{210} \mathrm{Po}$, on the other hand, activities were systematically higher deeper in the water column, closer to shore and in the unstratified season (Fig.3) but did not differ among transects. Despite the different behavior, there is a highly significant correlation between the activities of the two isotopes (Fig.4) such that the ratio of ${ }^{210} \mathrm{Po}:{ }^{210} \mathrm{~Pb}(0.43 \pm 0.05$, mean $\pm 95 \% \mathrm{CI}, \mathrm{n}=63)$ varies relatively little on the suspended particles. 

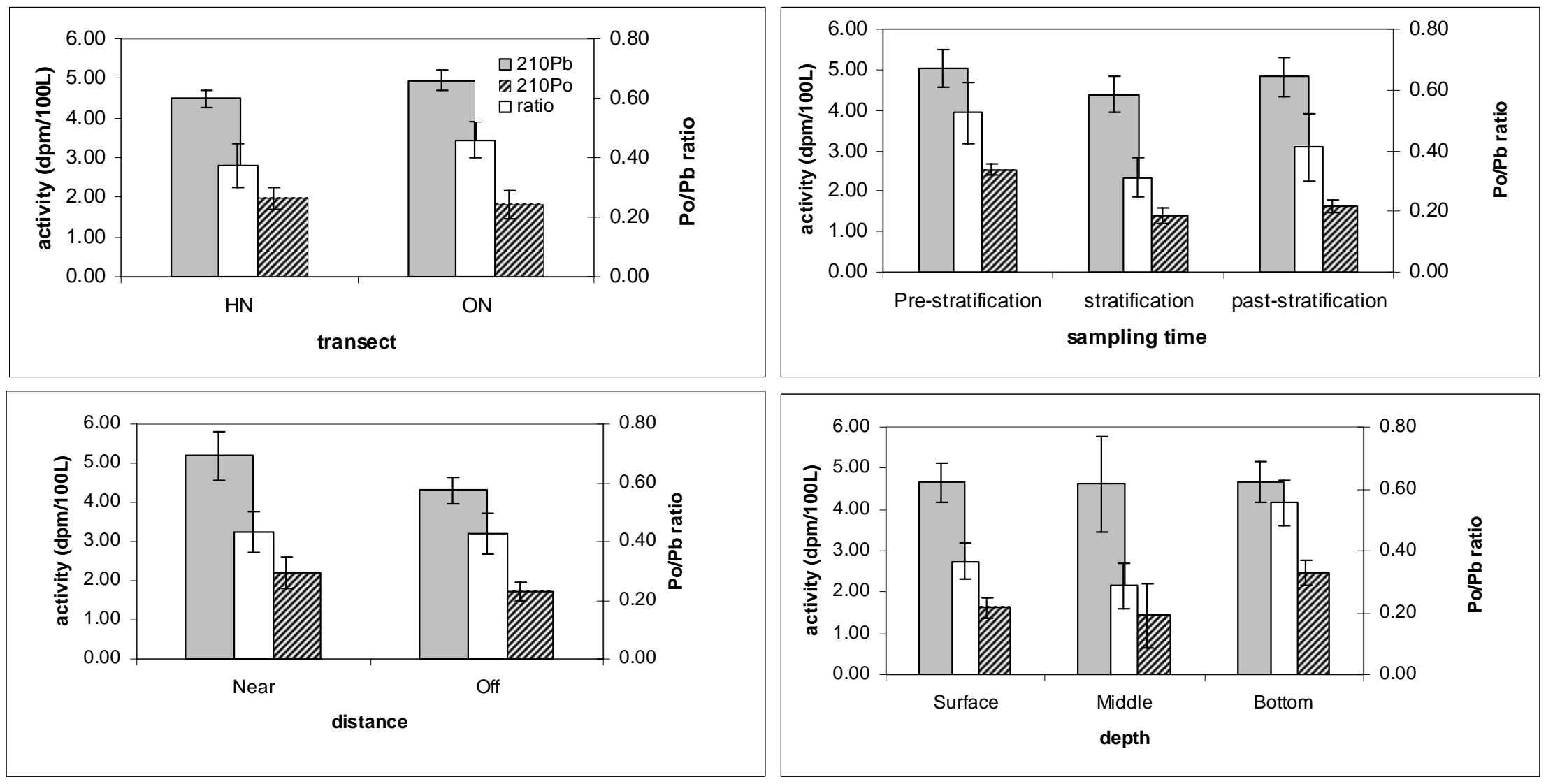

Figure 3. Statistical analysis of isotopes on particulate samples. Error bars represent 95\% C.I.s of the means. 


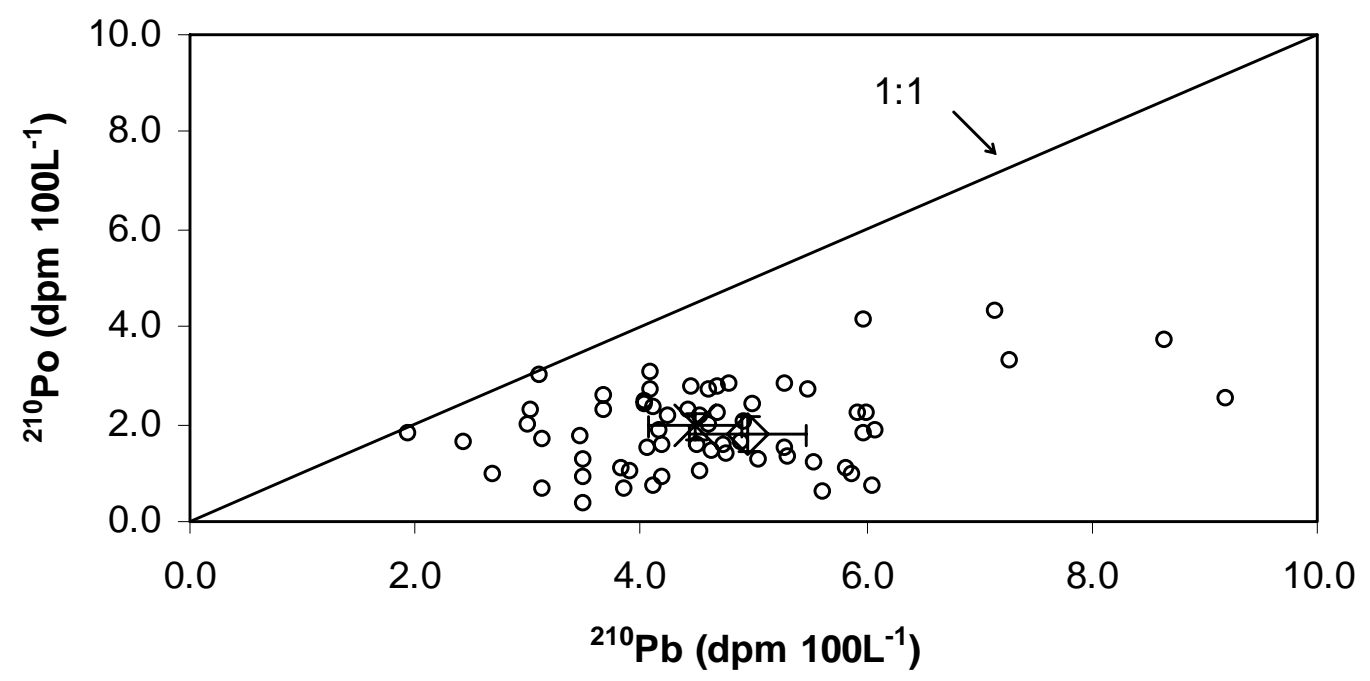

Figure 4. Isotope activities (both ${ }^{210} \mathrm{~Pb}$ and ${ }^{210} \mathrm{Po}$ ) of TSP samples from $\mathrm{HN}$ and $\mathrm{ON}$ transects. Means of $\mathrm{HN}(\times)$ and $\mathrm{ON}(\diamond)$ samples are shown with $95 \%$ C.I. as error bars. There is a significant albeit weak $\left(r^{2}=0.13, n=63, p=0.004\right)$ correlation between the activities of the two isotopes.

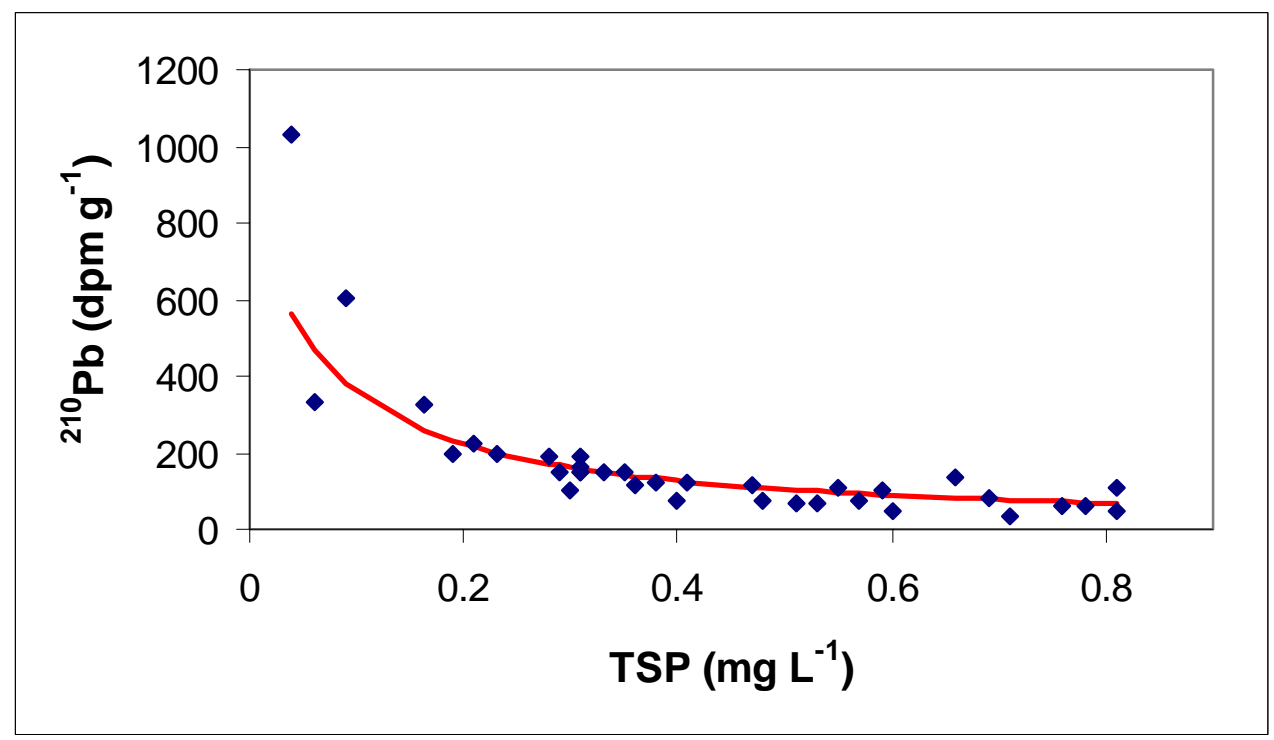

Figure 5. ${ }^{210} \mathrm{~Pb}$ activity on suspended particles. The inverse relationship fits a model (solid line) of constant partition coefficient $\left(15 \times 10^{6} \mathrm{~L} \mathrm{~kg}^{-1}\right)$ and constant activity in the water column $\left(0.045 \mathrm{dpm} \mathrm{L}^{-1}\right)$. 
Isotope activities expressed per gram of suspended matter were inversely proportional to TSP concentrations (Fig. 5). This behavior is expected if the total isotope inventory in the water column remains constant while the inventory of particles varies. Based on the assumption of constant total activity, a partition coefficient for ${ }^{210} \mathrm{~Pb}$ may be calculated by fitting (least squares) all the points in Fig. 5 to equation 6 . The value obtained from this analysis $\left(15 \times 10^{6} \mathrm{~L} \mathrm{~kg}^{-1}\right)$ is within the range of values calculated from simultaneous measurements of particulate and dissolved phases $\left(12 \pm 4.0 \times 10^{6} \mathrm{~L} \mathrm{~kg}^{-1}\right)$. A value at the high end of the observed range is not unexpected; this analysis tends to treat different TSP concentrations equally. However, in reality the majority of TSP concentrations occur around the mean $\left(0.45 \mathrm{mg} \mathrm{L}^{-1}\right)$, and thus the $K_{d}$ based on measurement of both phases is smaller [Honeyman and Santschi, 1989]. 
Table 2. Isotope activities and isotope and solids fluxes in sediment trap samples in Lake Superior.

\begin{tabular}{|c|c|c|c|c|c|c|c|c|c|}
\hline Transect & $\begin{array}{c}\text { Water } \\
\text { depth }(\mathrm{m})\end{array}$ & $\begin{array}{c}\text { Trap } \\
\text { depth (m) }\end{array}$ & $\begin{array}{c}\text { Retrieval } \\
\text { date }\end{array}$ & $\begin{array}{c}{ }^{210} \mathrm{Po} \\
\left(\mathrm{dpm} \mathrm{g} \mathrm{g}^{-1}\right)\end{array}$ & $\begin{array}{c}{ }^{210} \mathrm{~Pb} \\
\left(\mathrm{dpm} \mathrm{g} \mathrm{g}^{-1}\right)\end{array}$ & 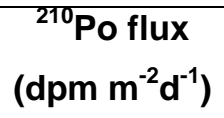 & 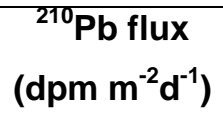 & $\begin{array}{l}\text { Mass flux } \\
\left(g^{-2} d^{-1}\right)\end{array}$ & Po:Pb \\
\hline $\mathrm{EH}$ & 50 & 45 & $5 / 16 / 00$ & 38.2 & 67.4 & 70.0 & 123.6 & 1.83 & 0.57 \\
\hline $\mathrm{EH}$ & 50 & 45 & $6 / 20 / 00$ & 42.5 & 68.1 & 74.9 & 120.0 & 1.76 & 0.62 \\
\hline $\mathrm{EH}$ & 50 & 40 & $5 / 16 / 00$ & 38.0 & 71.8 & 57.1 & 108.1 & 1.51 & 0.53 \\
\hline $\mathrm{EH}$ & 50 & 40 & $6 / 20 / 00$ & 41.3 & 79.3 & 68.8 & 132.2 & 1.67 & 0.52 \\
\hline $\mathrm{EH}$ & 50 & 35 & $5 / 16 / 00$ & 37.0 & 72.6 & 62.6 & 122.8 & 1.69 & 0.51 \\
\hline $\mathrm{EH}$ & 50 & 35 & $6 / 20 / 00$ & 48.5 & 70.3 & 71.3 & 103.3 & 1.47 & 0.69 \\
\hline ON & 120 & 115 & $6 / 19 / 00$ & 59.1 & 95.4 & 77.2 & 124.5 & 1.31 & 0.62 \\
\hline ON & 120 & 110 & $6 / 19 / 00$ & 62.6 & 96.4 & 66.9 & 103.0 & 1.07 & 0.65 \\
\hline ON & 120 & 35 & $6 / 19 / 00$ & 60.0 & 100.2 & 45.1 & 75.3 & 0.75 & 0.60 \\
\hline ON & 50 & 45 & $6 / 10 / 00$ & 37.5 & 62.8 & 94.5 & 158.4 & 2.52 & 0.60 \\
\hline ON & 50 & 45 & $6 / 19 / 00$ & 38.0 & 58.8 & 91.3 & 141.1 & 2.40 & 0.65 \\
\hline ON & 50 & 40 & $6 / 10 / 00$ & 38.1 & 62.1 & 53.8 & 87.6 & 1.41 & 0.61 \\
\hline ON & 50 & 40 & $6 / 19 / 00$ & 31.3 & 68.6 & 53.2 & 116.8 & 1.70 & 0.46 \\
\hline ON & 50 & 35 & $6 / 10 / 00$ & 38.0 & 67.5 & 61.1 & 108.7 & 1.61 & 0.56 \\
\hline ON & 50 & 35 & $6 / 19 / 00$ & 26.1 & 73.7 & 40.2 & 113.5 & 1.54 & 0.35 \\
\hline
\end{tabular}


Table 3. Sediment trap samples with only ${ }^{210} \mathrm{~Pb}$ measurements.

\begin{tabular}{|c|c|c|c|c|c|c|}
\hline Transect & $\begin{array}{c}\text { Water } \\
\text { depth } \\
(\mathrm{m})\end{array}$ & $\begin{array}{c}\text { Trap } \\
\text { depth } \\
(\mathrm{m})\end{array}$ & $\begin{array}{l}\text { Retrieval } \\
\text { date }\end{array}$ & $\begin{array}{c}{ }^{210} \mathrm{~Pb} \\
\left(\mathrm{dpm} \mathrm{g} \mathrm{g}^{-1}\right)\end{array}$ & 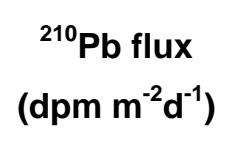 & $\begin{array}{l}\text { Mass flux } \\
\left(g^{-2} d^{-1}\right)\end{array}$ \\
\hline $\mathrm{HN}$ & 50 & 40 & $6 / 9 / 98$ & 85.3 & 60.4 & 0.71 \\
\hline $\mathrm{HN}$ & 50 & 25 & 6/9/98 & 80.0 & 40.9 & 0.51 \\
\hline $\mathrm{HN}$ & 120 & 115 & 6/9/98 & 97.8 & 125.7 & 1.29 \\
\hline $\mathrm{HN}$ & 120 & 25 & 6/9/98 & 103.8 & 36.8 & 0.35 \\
\hline $\mathrm{HN}$ & 50 & 40 & $7 / 22 / 98$ & 100.3 & 41.6 & 0.42 \\
\hline $\mathrm{HN}$ & 50 & 25 & $7 / 22 / 98$ & 108.2 & 31.8 & 0.29 \\
\hline $\mathrm{EH}$ & 50 & 45 & $7 / 24 / 98$ & 54.4 & 166.8 & 3.07 \\
\hline $\mathrm{EH}$ & 50 & 40 & $7 / 24 / 98$ & 54.0 & 158.3 & 2.93 \\
\hline $\mathrm{EH}$ & 50 & 25 & 7/24/98 & 54.2 & 107.7 & 1.99 \\
\hline $\mathrm{EH}$ & 230 & 225 & $7 / 24 / 98$ & 105.1 & 93.0 & 0.88 \\
\hline $\mathrm{EH}$ & 230 & 25 & 7/24/98 & 96.3 & 27.8 & 0.29 \\
\hline $\mathrm{EH}$ & 50 & 45 & 8/19/98 & 45.6 & 133.3 & 2.93 \\
\hline $\mathrm{EH}$ & 50 & 40 & 8/19/98 & 48.1 & 111.8 & 2.32 \\
\hline $\mathrm{EH}$ & 50 & 25 & 8/19/98 & 52.7 & 76.4 & 1.45 \\
\hline $\mathrm{EH}$ & 230 & 225 & 8/19/98 & 107.6 & 62.9 & 0.58 \\
\hline $\mathrm{EH}$ & 230 & 220 & 8/19/98 & 98.2 & 32.8 & 0.33 \\
\hline ON & 50 & 45 & $5 / 30 / 98$ & 39.3 & 110.0 & 2.80 \\
\hline ON & 50 & 40 & 5/30/98 & 42.8 & 85.5 & 2.00 \\
\hline ON & 50 & 25 & $5 / 30 / 98$ & 50.7 & 33.6 & 0.66 \\
\hline ON & 120 & 115 & $5 / 30 / 98$ & 82.9 & 141.7 & 1.71 \\
\hline ON & 120 & 25 & $5 / 30 / 98$ & 68.5 & 59.1 & 0.86 \\
\hline ON & 50 & 45 & 7/28/98 & 69.4 & 81.2 & 1.17 \\
\hline ON & 50 & 40 & $7 / 28 / 98$ & 127.8 & 112.8 & 0.88 \\
\hline ON & 50 & 25 & $7 / 28 / 98$ & 88.4 & 39.1 & 0.44 \\
\hline ON & 50 & 25 & $7 / 28 / 98$ & 90.6 & 35.7 & 0.39 \\
\hline ON & 120 & 115 & 7/28/98 & 100.6 & 82.0 & 0.82 \\
\hline ON & 120 & 110 & $7 / 28 / 98$ & 99.1 & 60.1 & 0.61 \\
\hline ON & 120 & 25 & $7 / 28 / 98$ & 123.7 & 29.3 & 0.24 \\
\hline $\mathrm{HN}$ & 175 & 165 & $5 / 14 / 99$ & 186.9 & 81.8 & 0.44 \\
\hline $\mathrm{HN}$ & 175 & 170 & $5 / 14 / 99$ & 106.8 & 92.9 & 0.87 \\
\hline $\mathrm{HN}$ & 90 & 35 & $5 / 14 / 99$ & 105.8 & 69.1 & 0.65 \\
\hline $\mathrm{HN}$ & 90 & 80 & $5 / 14 / 99$ & 57.9 & 74.8 & 1.29 \\
\hline $\mathrm{HN}$ & 90 & 85 & $5 / 14 / 99$ & 58.0 & 202.6 & 3.49 \\
\hline $\mathrm{HN}$ & 50 & 35 & $5 / 14 / 99$ & 81.9 & 55.2 & 0.67 \\
\hline $\mathrm{HN}$ & 50 & 40 & $5 / 14 / 99$ & 78.6 & 52.4 & 0.67 \\
\hline $\mathrm{HN}$ & 50 & 45 & $5 / 14 / 99$ & 61.0 & 38.5 & 0.63 \\
\hline $\mathrm{HN}$ & 175 & 35 & 7/10/99 & 107.0 & 50.1 & 0.47 \\
\hline $\mathrm{HN}$ & 175 & 165 & $7 / 10 / 99$ & 107.8 & 85.0 & 0.79 \\
\hline $\mathrm{HN}$ & 175 & 170 & 7/10/99 & 102.4 & 87.1 & 0.85 \\
\hline $\mathrm{HN}$ & 50 & 35 & 7/10/99 & 89.9 & 53.1 & 0.59 \\
\hline $\mathrm{HN}$ & 50 & 40 & 7/10/99 & 79.3 & 54.5 & 0.69 \\
\hline $\mathrm{HN}$ & 50 & 45 & 7/10/99 & 74.3 & 61.2 & 0.82 \\
\hline $\mathrm{HN}$ & 175 & 35 & 8/20/99 & 126.8 & 19.9 & 0.16 \\
\hline $\mathrm{HN}$ & 175 & 165 & 8/20/99 & 122.6 & 59.8 & 0.49 \\
\hline $\mathrm{HN}$ & 175 & 165 & 8/20/99 & 126.5 & 53.3 & 0.42 \\
\hline $\mathrm{HN}$ & 175 & 170 & 8/20/99 & 117.4 & 72.2 & 0.61 \\
\hline $\mathrm{HN}$ & 50 & 35 & 8/20/99 & 99.7 & 110.8 & 1.11 \\
\hline $\mathrm{HN}$ & 50 & 40 & 8/20/99 & 101.1 & 127.4 & 1.26 \\
\hline $\mathrm{HN}$ & 50 & 40 & 8/20/99 & 100.8 & 116.5 & 1.16 \\
\hline
\end{tabular}




\begin{tabular}{lcccccc} 
HN & 175 & 165 & $10 / 4 / 99$ & 118.6 & 173.4 & 1.46 \\
HN & 175 & 170 & $10 / 4 / 99$ & 110.3 & 148.5 & 1.35 \\
HN & 90 & 35 & $10 / 4 / 99$ & 72.5 & 399.4 & 5.51 \\
HN & 90 & 80 & $10 / 4 / 99$ & 64.5 & 476.7 & 7.39 \\
HN & 50 & 35 & $10 / 4 / 99$ & 54.4 & 419.9 & 7.72 \\
HN & 50 & 40 & $10 / 4 / 99$ & 54.2 & 469.1 & 8.65 \\
HN & 50 & 45 & $10 / 4 / 99$ & 53.2 & 544.2 & 10.23 \\
EH & 50 & 45 & $5 / 16 / 00$ & 67.2 & 123.1 & 1.83 \\
EH & 50 & 40 & $5 / 16 / 00$ & 71.5 & 119.6 & 1.51 \\
EH & 50 & 35 & $5 / 16 / 00$ & 71.8 & 107.7 & 1.69 \\
ON & 50 & 45 & $6 / 10 / 00$ & 62.2 & 131.8 & 2.52 \\
ON & 50 & 40 & $6 / 10 / 00$ & 61.6 & 121.6 & 1.41 \\
ON & 50 & 35 & $6 / 10 / 00$ & 66.9 & 103.0 & 1.61 \\
ON & 50 & 40 & $6 / 19 / 00$ & 68.4 & 123.6 & 1.70 \\
ON & 50 & 35 & $6 / 19 / 00$ & 73.5 & 102.2 & 1.54 \\
ON & 50 & 45 & $6 / 19 / 00$ & 58.6 & 74.6 & 2.40 \\
ON & 120 & 115 & $6 / 19 / 00$ & 94.7 & 157.0 & 1.31 \\
ON & 120 & 110 & $6 / 19 / 00$ & 95.6 & 140.7 & 1.07 \\
ON & 120 & 35 & $6 / 19 / 00$ & 99.4 & 86.8 & 0.75 \\
EH & 50 & 45 & $6 / 20 / 00$ & 67.9 & 116.4 & 1.76 \\
EH & 50 & 40 & $6 / 20 / 00$ & 79.1 & 107.7 & 1.67 \\
EH & 50 & 35 & $6 / 20 / 00$ & 70.1 & 113.1 & 1.47 \\
ON & 50 & 35 & $7 / 29 / 00$ & 66.2 & 47.7 & 0.72 \\
ON & 50 & 40 & $7 / 29 / 00$ & 75.3 & 64.8 & 0.86 \\
ON & 50 & 45 & $7 / 29 / 00$ & 67.4 & 82.2 & 1.22 \\
ON & 120 & 35 & $6 / 19 / 00$ & 99.4 & 68.6 & 0.69 \\
ON & 120 & 110 & $6 / 19 / 00$ & 95.6 & 100.4 & 1.05 \\
ON & 120 & 115 & $6 / 19 / 00$ & 94.7 & 111.7 & 1.18 \\
ON & 50 & 35 & $9 / 25 / 00$ & 55.0 & 117.2 & 2.13 \\
ON & 50 & 40 & $9 / 25 / 00$ & 47.5 & 104.5 & 2.2 \\
ON & 50 & 45 & $9 / 25 / 00$ & 47.8 & 241.9 & 5.06 \\
ON & 120 & 35 & $9 / 25 / 00$ & 40.9 & 12.7 & 0.31 \\
ON & 120 & 110 & $9 / 25 / 00$ & 87.3 & 137.9 & 1.58 \\
ON & 120 & 115 & $9 / 25 / 00$ & 89.6 & 198.0 & 2.21 \\
EH & 50 & 35 & $9 / 26 / 00$ & 42.4 & 243.4 & 5.74 \\
EH & 50 & 40 & $9 / 26 / 00$ & 43.0 & 284.7 & 6.62 \\
EH & 50 & 45 & $9 / 26 / 00$ & 41.8 & 317.7 & 7.60 \\
\hline & & & & & & \\
\hline
\end{tabular}




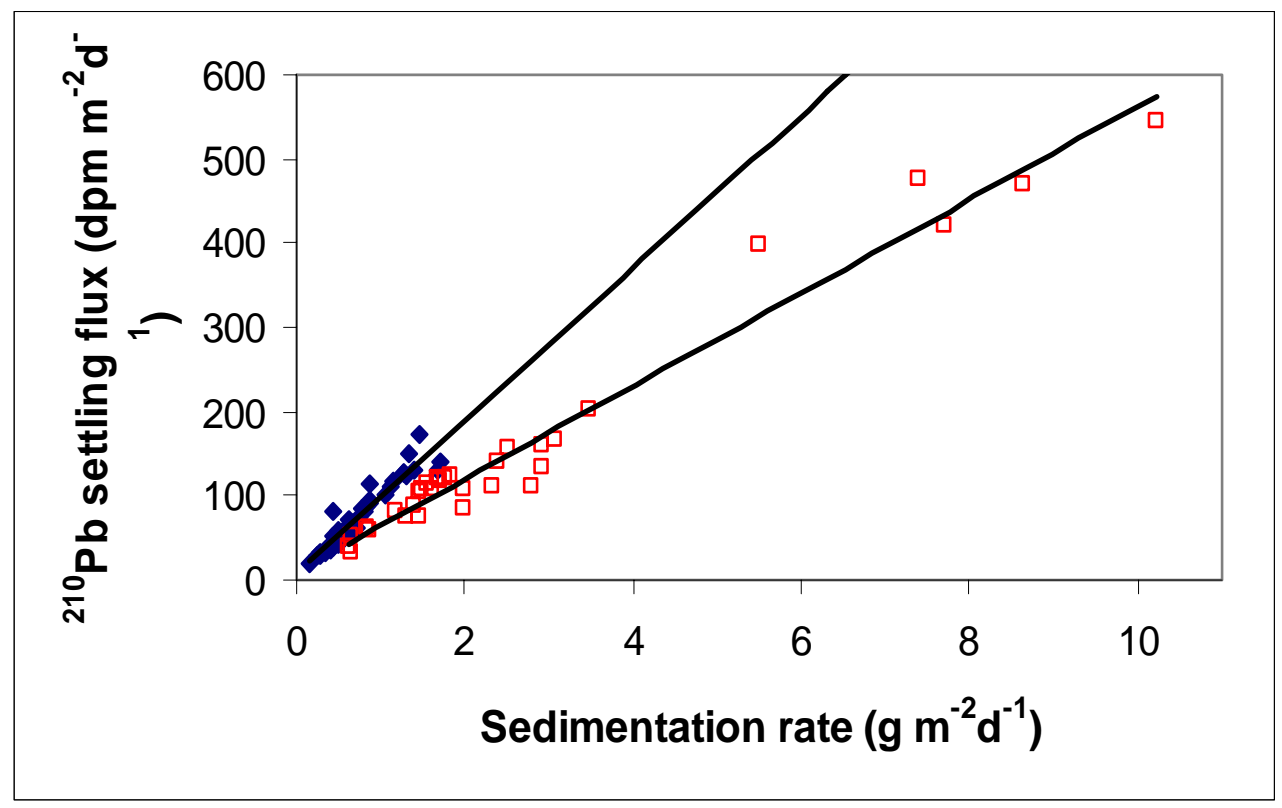

Figure 6. Settling fluxes of particles and ${ }^{210} \mathrm{~Pb}$. The data appear to fall in two groups: those with high ${ }^{210} \mathrm{~Pb}$ activities on particles (hollow square) and those with lower activities (solid square). The two regression equations are: ${ }^{210} \mathrm{~Pb}$ flux $=8( \pm 8)+91( \pm 10) \cdot$ Sed. Rate $\left(\mathrm{n}=40, \mathrm{r}^{2}=0.90, \mathrm{p}<0.001\right)$ and ${ }^{210} \mathrm{~Pb}$ flux $=9( \pm 15)+55( \pm 4) \cdot$ Sed. Rate $\left(\mathrm{n}=32, \mathrm{r}^{2}=\right.$ $0.96, p<0.001$ ) where the errors in slopes and intercepts are $95 \%$ confidence intervals.

\subsection{Isotope activity and fluxes in sediment traps}

The extensive measurements of ${ }^{210} \mathrm{~Pb}$ in sediment traps (Table 3) reveal patterns that are not as clear in the smaller set of ${ }^{210}$ Po measurements (Table 2). Activities of ${ }^{210} \mathrm{~Pb}$ in sedimenting material range from 39 to $187 \mathrm{dpm} \mathrm{g}^{-1}$ with an average of $88 \mathrm{dpm} \mathrm{g}^{-1}$.

These activities are much higher than those measured in either surface sediments (2.7-71.3 $\left.\mathrm{dpm} \mathrm{g}^{-1}\right)$ or easily resuspendable sediments $\left(7.0-84.3 \mathrm{dpm} \mathrm{g}^{-1}\right)$. Sedimentation fluxes of ${ }^{210} \mathrm{~Pb}$ also span a wide range beginning close to the literature value for the average rate of atmospheric deposition $\left(27 \mathrm{dpm} \mathrm{m}^{-2} \mathrm{~d}^{-1}\right)$ and reaching as high as $544 \mathrm{dpm} \mathrm{m} \mathrm{m}^{-2}$.

Although the sedimentation flux of ${ }^{210} \mathrm{~Pb}$ is highly correlated with the mass sedimentation rate $\left(r^{2}=0.94, n=72, p \ll 0.001\right)$, it appears as if the data fall into two groups, each with a 
relatively constant ${ }^{210} \mathrm{~Pb}$ activity (Fig.6). The sediment trap samples with the lower ${ }^{210} \mathrm{~Pb}$ activities (mean activity $=55 \mathrm{dpm} \mathrm{g}^{-1}$ ) include all of the samples from periods with high mass sedimentation rates. Near-shore sediment traps comprise $84 \%$ of this group of lowactivity samples vs. $58 \%$ of the total pool of trap samples. These samples may represent primarily resuspended sediments, although the mean ${ }^{210} \mathrm{~Pb}$ activity in this group of sediment trap samples $\left(55 \mathrm{dpm} \mathrm{g}^{-1}\right)$ is higher than the activities measured in the "easily resuspendable sediments" (discussed below) in the same region. The settling particles with higher activities are captured at times and locations of low mass sedimentation; even among these samples, however, the ${ }^{210} \mathrm{~Pb}$ flux out of the water column is directly dependent on the availability of particles to scavenge the isotope.

Rates of both mass sedimentation and ${ }^{210} \mathrm{~Pb}$ sedimentation also show clear differences between near- and offshore zones. Mass sedimentation rates are higher in the traps moored in $50 \mathrm{~m}$ of water $\left(1.5 \pm 0.7 \mathrm{~g} \mathrm{~m}^{-2} \mathrm{~d}^{-1}\right.$, mean $\left.\pm 95 \% \mathrm{CI}\right)$ than in those moored in 120-230 m of water. [0.4 $\pm 0.07 \mathrm{~g} \mathrm{~m}^{-2} \mathrm{~d}^{-1}$, Urban et al., 2004d]. Although fluxes of ${ }^{210} \mathrm{~Pb}$ also are higher in the near-shore traps $\left(97 \pm 48 \mathrm{dpm} \mathrm{m}^{-2} \mathrm{~d}^{-1}\right)$ than in the offshore traps $\left(79 \pm 16 \mathrm{dpm} \mathrm{m}^{-2} \mathrm{~d}^{-1}\right)$, the difference is not nearly as large as for mass sedimentation rates. Sedimentation in the near-shore region is strongly affected by large particles, while fluxes further offshore are dominated by finer particles that have higher ${ }^{210} \mathrm{~Pb}$ activities $(109 \pm 9$ dpm $\mathrm{g}^{-1}$ offshore vs. $76 \pm 9 \mathrm{dpm} \mathrm{g}^{-1}$ in near-shore traps).

Sedimentation of ${ }^{210} \mathrm{Po}$ appears to follow the same patterns as for ${ }^{210} \mathrm{~Pb}$. Settling particles in near-shore areas have lower ${ }^{210} \mathrm{Po}$ activities $\left(26-49 \mathrm{dpm} \mathrm{g}^{-1}\right)$ than material collected offshore (59-63 dpm g$\left.{ }^{-1}\right)$. The ratio of $\mathrm{Po}: \mathrm{Pb}$ is relatively constant with a mean $( \pm 95 \% \mathrm{CI})$ of $0.57 \pm 0.04$. A similar ratio $(0.6)$ of ${ }^{210} \mathrm{Po}:{ }^{210} \mathrm{~Pb}$ was observed in sediment 
trap material in the coastal NE Taiwan Sea [Hung and Chung, 1998]. The flux of ${ }^{210}$ Po in the sediment traps (mean of $66 \mathrm{dpm} \mathrm{m}^{-2} \mathrm{~d}^{-1}$ ) is, however, much larger relative to the rate of atmospheric deposition (approx. $2.7 \mathrm{dpm} \mathrm{m}^{-2} \mathrm{~d}^{-1}$ ) than is the case for ${ }^{210} \mathrm{~Pb}$.

Three lines of evidence suggest that, in both near- and offshore locations, sediment trap material, even in traps immediately below the thermocline, was dominated by resuspended sediments. First, the ${ }^{210} \mathrm{~Pb}$ fluxes $\left(97 \pm 48 \mathrm{dpm} \mathrm{m} \mathrm{m}^{-2} \mathrm{~d}^{-1}\right.$ near-shore and $79 \pm 16$

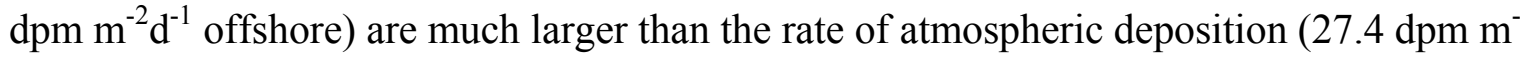
$\left.{ }^{2} \mathrm{~d}^{-1}\right)$. The issue of local resuspension vs. focusing will be addressed later. Second, the ${ }^{210} \mathrm{~Pb}$ activities were similar in traps $5 \mathrm{~m}$ above the sediments $\left(62 \pm 8 \mathrm{dpm} \mathrm{g}^{-1}\right.$ near-shore and $108 \pm 5 \mathrm{dpm} \mathrm{g}^{-1}$ offshore $)$ and in traps $35 \mathrm{~m}$ below the water surface $\left(76 \pm 9 \mathrm{dpm} \mathrm{g}{ }^{-1}\right.$ near-shore and $109 \pm 9 \mathrm{dpm} \mathrm{g}^{-1}$ offshore); evidently the source of particles was similar for traps at both heights in the water column. Finally, the activity of ${ }^{210} \mathrm{~Pb}$ in the sediment trap material is between that in suspended particles $\left(176 \mathrm{dpm} \mathrm{g}^{-1}\right)$ and that in easily resuspendable sediments $\left(23 \pm 12 \mathrm{dpm} \mathrm{g}^{-1}\right.$, see below). A simple mixing ratio calculation would suggest that $70 \%$ of the material in near-shore traps ( $35 \mathrm{~m}$ below water surface) is derived from resuspension and that $44 \%$ in offshore traps (again at $35 \mathrm{~m}$ below water surface) is derived from resuspension. Similar observations were made for organic carbon, nitrogen, and phosphorus in the sediment trap material collected in this study [Urban et al., 2004d].

\subsection{Sediments}

${ }^{210} \mathrm{~Pb}$ activities and inventories in lake and ocean sediments have been studied for several decades mainly for the purpose of geochronology [Edgington et al., 1991; Evans et 
al., 1981; Johnson et al., 1982; Kerfoot and Robbins, 1999; Krishnaswami and Lal, 1978; Krishnaswami et al., 1971; Masqué et al., 2002]. In contrast, few studies have shown ${ }^{210} \mathrm{Po}$ activities in sediments [Pempkowiak et al., 2002; Wang and Cornett, 1993]. The main focus of this study is on the reservoirs of isotopes in the sediments that may move to and from the water column. As discussed below, the major mechanism for exchange with the water column in Lake Superior is via sediment resuspension. Hence, our focus is on the pool of easily resuspendable sediments. Within this pool of easily resuspendable sediments, ${ }^{210} \mathrm{~Pb}$ activities ranged from 7-71 $\mathrm{dpm} \mathrm{g}^{-1}$ with a mean of $23 \mathrm{dpm} \mathrm{g}^{-1}$, while

${ }^{210} \mathrm{Po}$ activities ranged from $5-70 \mathrm{dpm} \mathrm{g}^{-1}$ with a mean of $22 \mathrm{dpm} \mathrm{g}^{-1}$. Secular equilibrium between ${ }^{210} \mathrm{Po}$ and ${ }^{210} \mathrm{~Pb}$, activity ratio of $0.94 \pm 0.07$, was observed in the samples. Activities increased with increasing distance from shore due to both increasing net deposition of isotopes and decreasing abundance of sand-size particles with low activities. Activities reported for surface sediments in the center of the lake typically are in the range of 70-100 dpm g ${ }^{-1}$ [Durham and Joshi, 1981; Evans et al., 1981; Klump et al., 1989]. More details (based on more cores) on the distribution of isotope activities and inventories along the sampling transects will be discussed in the next chapter.

\section{Discussion}

\subsection{Isotope biogeochemistry in Lake Superior}

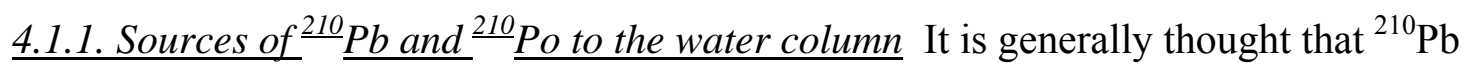
enters a lake via four major pathways: atmospheric deposition, tributaries, catchment runoff, and decay of the parent isotope, ${ }^{226} \mathrm{Ra}$, within the system [Krishnaswami and Lal, 1978]. For lakes in different geographical locations and with variable hydrological 
conditions, the relative importance of input sources may vary. In Bickford Pond (Reservoir) in Massachusetts, a small lake with a short hydraulic residence time of less than 100 days, ${ }^{210} \mathrm{~Pb}$ in stream and ground water were the major sources of this isotope to the lake [Benoit and Hemond, 1987]. Although atmospheric deposition of ${ }^{210} \mathrm{~Pb}$ in Lake Sammamish was only $30 \%$ of that in Bickford Pond, it was still the major source, and fluvial inputs of ${ }^{210} \mathrm{~Pb}$ accounted for only a small fraction $(<28 \%)$ of the total supply [Balistrieri et al., 1995]. Similarly, when inputs of multiple isotopes to Lake 239 (Experimental Lakes Area, Ontario) were studied, it was observed that the major source of ${ }^{210} \mathrm{~Pb}$ to the lake was atmospheric deposition; stream runoff and in situ decay of ${ }^{226} \mathrm{Ra}$ accounted for less than $15 \%$ of the total input to the lake [Brunskill and Wilkinson, 1987]. Compared to ELA Lake 239, Lake Superior has much less tributary input and a much longer hydraulic residence time [Quinn, 1992]. It is therefore expected that the major source of ${ }^{210} \mathrm{~Pb}$ to Lake Superior will be atmospheric deposition. Even within the study region, the water $\left(\right.$ and $\left.{ }^{210} \mathrm{~Pb}\right)$ input from the river is small compared to the flow of lake water. Consequently, even the study site closest to the river shows only modestly higher ${ }^{210} \mathrm{~Pb}$ activity in the water column (Fig 3).

Several studies have estimated the ${ }^{210} \mathrm{~Pb}$ fallout flux within North America, either by direct measurements [i.e., collection of wet and dry deposition, Baskaran et al., 1993; Brunskill and Wilkinson, 1987; Kim et al., 2000b; Olsen et al., 1985] or by estimation from soil or sediment inventories [Christensen and Bhunia, 1986; Olsen et al., 1985; Urban et al., 1990]. A compilation in 1990 gave an average rate for direct deposition measurements of $1.02 \mathrm{dpm} \mathrm{cm}^{-2} \mathrm{yr}^{-1}$ and $0.91 \mathrm{dpm} \mathrm{cm}^{-2} \mathrm{yr}^{-1}$ based on inventories [Urban et al., 1990]. From the eight studies summarized by $\operatorname{Kim}$ [2000b], the average depositional flux of ${ }^{210} \mathrm{~Pb}$ 
in North America within the period from 1977-1996 was $1.0 \pm 0.3 \mathrm{dpm} \mathrm{cm}^{-2} \mathrm{yr}^{-1}$. A value of $0.99 \pm 0.06 \mathrm{dpm} \mathrm{cm}^{-2} \mathrm{yr}^{-1}$ was estimated from 6 sediment cores from northern Lake Michigan [Christensen and Bhunia, 1986], a site close to Lake Superior. For the present study, a value of $1.0 \mathrm{dpm} \mathrm{cm}^{-2} \mathrm{yr}^{-1}\left(27.4 \mathrm{dpm} \mathrm{m}^{-2} \mathrm{~d}^{-1}\right)$ as atmospheric fallout flux of ${ }^{210} \mathrm{~Pb}$ to Lake Superior is used, which is the same value used by Baskaran and Santschi [2002] for calculation of ${ }^{210} \mathrm{~Pb}$ residence times in the Gulf of Mexico.

There is rather limited data with which to test the assumption that atmospheric deposition is the major source of ${ }^{210} \mathrm{~Pb}$ to L. Superior. The ${ }^{210} \mathrm{~Pb}$ activity in the Ontonagon River was measured in two samples and found to be $150 \mathrm{dpm} \mathrm{m}^{-3}$, a value similar to the ${ }^{210} \mathrm{~Pb}$ activity of $100-300 \mathrm{dpm} \mathrm{m}^{-3}$ in the stream to Bickford Pond [Benoit and Hemond, 1987] and 9.2-201 dpm m ${ }^{-3}$ in Lake Sammamish [Balistrieri et al., 1995] but smaller than the $288 \pm 24 \mathrm{dpm} \mathrm{m}^{-3}$ in stream water entering Lake 239 [Brunskill and Wilkinson, 1987]. The total average stream flow to Lake Superior is about $1300 \sim 1400 \mathrm{~m}^{3} \mathrm{~s}^{-1}$ [Matheson and Munawar, 1978; USGS, 2003]. If all tributaries to Lake Superior have a similar ${ }^{210} \mathrm{~Pb}$ activity, then the input flux of ${ }^{210} \mathrm{~Pb}$ would be approximately $0.0075 \mathrm{dpm} \mathrm{cm}^{-2} \mathrm{yr}^{-1}$. Obviously, this flux is negligible relative to atmospheric deposition.

The magnitude of in situ production can be estimated from sediment profiles through a comparison of supported and unsupported ${ }^{210} \mathrm{~Pb}$. Among the nine cores in depositional areas presented by Klump et al. [1989], the ratio of unsupported to supported ${ }^{210} \mathrm{~Pb}$ in surface sediments ranged from 5 to 91 . Similarly, Evans et al. [1981] reported supported ${ }^{210} \mathrm{~Pb}$ activities of $1.5-6 \mathrm{dpm} \mathrm{g}^{-1}$ and unsupported activities of $11-216 \mathrm{dpm} \mathrm{g}^{-1}$ or ratios of excess to supported of 7 to 70 . Among the 29 cores presented in these two studies, on average, supported ${ }^{210} \mathrm{~Pb}$ was only $3 \%$ of unsupported ${ }^{210} \mathrm{~Pb}$ in the surface 
sediments. Clearly, dissolved ${ }^{226} \mathrm{Ra}$ is not a significant source of ${ }^{210} \mathrm{~Pb}$ relative to atmospheric deposition; even the oceanic ${ }^{226} \mathrm{Ra}$ concentration $\left[1.63 \mathrm{~Bq} \mathrm{~m}^{-3}\right.$, Peck and Smith, 2000] would result in a generation of only $6.3 \times 10^{-4} \mathrm{dpm} \mathrm{cm}^{-2} \mathrm{yr}^{-1}$ of ${ }^{210} \mathrm{~Pb}$.

It is more difficult to evaluate the relative importance of all potential sources of ${ }^{210} \mathrm{Po}$. It was observed that the general ratio of $\mathrm{Po}: \mathrm{Pb}$ in atmospheric deposition is $<0.5$ in the boreal zone of Canada [Brunskill and Wilkinson, 1987]. Balistrieri et. al. [1995] observed a ${ }^{210} \mathrm{Po}:{ }^{210} \mathrm{~Pb}$ atmospheric flux ratio of $0.11 \pm 0.09$ in a location along the west coast. Benoit et. al. [1987] used a fallout ratio of 0.04. A recent study reported a ratio of 0.1 for aerosols in the Chicago area [Marley et al., 2000]. Measured ${ }^{210} \mathrm{Po}:{ }^{210} \mathrm{~Pb}$ activity ratios in size fractionated aerosols from the coast of Japan had a mean value of $0.21 \pm 0.13$ [Suzuki et al., 1999]. It is consistently observed that ratios in aerosols are larger than those in atmospheric deposition [Suzuki and Shiono, 1995]. A fallout ratio of 0.1 and a deposition rate of $27.4 \mathrm{dpm} \mathrm{m}^{-2} \mathrm{~d}^{-1}$ for ${ }^{210} \mathrm{~Pb}$ yields a ${ }^{210} \mathrm{Po}$ flux of $2.7 \mathrm{dpm} \mathrm{m}^{-2} \mathrm{~d}^{-1}$; these are the values used in this study. Four bulk deposition samples collected in Houghton, MI had ${ }^{210} \mathrm{Po}$ fluxes of $2.3-2.8 \mathrm{dpm} \mathrm{m}^{-2} \mathrm{~d}^{-1}$, rates similar to that estimated from the literature. Unlike ${ }^{210} \mathrm{~Pb}$, the production of ${ }^{210} \mathrm{Po}$ from decay of its parent isotope $\left({ }^{210} \mathrm{~Pb}\right)$ is significant. From the total ${ }^{210} \mathrm{~Pb}$ activity in the water column of $55 \mathrm{dpm} \mathrm{m}^{-3}$, a generation of $41 \mathrm{dpm} \mathrm{m} \mathrm{m}^{-2} \mathrm{~d}^{-1}$ for ${ }^{210} \mathrm{Po}$ can be calculated. It would appear that, as in other locations [e.g., Nozaki et al., 1991], in L. Superior the major source of ${ }^{210} \mathrm{Po}$ is in situ decay of ${ }^{210} \mathrm{~Pb}$ and atmospheric deposition is much smaller $\left(2.74 \mathrm{dpm} \mathrm{m}^{-2} \mathrm{~d}^{-1}\right)$. The other two sources for ${ }^{210} \mathrm{Po}$, tributaries and sediments, are not as well documented as for ${ }^{210} \mathrm{~Pb}$. However, the same calculations as described above for ${ }^{210} \mathrm{~Pb}$ support the conclusion that the major 
sources of ${ }^{210} \mathrm{Po}$ to Lake Superior are in situ production from decay of ${ }^{210} \mathrm{~Pb}$ and atmospheric fallout.

\subsubsection{Isotope partitioning between water and particulate phases After entering}

the water column by atmospheric deposition or other means, both isotopes partition themselves between dissolved and particulate phases. According to Baskaran and Santschi [1993], this process operates on a timescale of hours to one day. As particle-reactive isotopes [Balistrieri et al., 1995; Boisson et al., 2001; Hong et al., 1999; Nozaki and Tsunogai, 1976; Zuo and Eisma, 1993], both ${ }^{210} \mathrm{~Pb}$ and ${ }^{210} \mathrm{Po}$ are expected to be predominantly in the particulate phase. However, the mass balance model requires the total (particulate and dissolved) activity in the water column. Logistically, it is easier to measure the particulate phase and to calculate the total activity from the relationship shown in equation 7 rather than to extract the dissolved isotopes or eliminate the large volumes of water necessary to measure the isotopes.

$$
C_{\text {total }}=C_{s} f_{s}^{-1}=C_{s}\left(\frac{K_{d} C}{1+K_{d} C}\right)^{-1}
$$

(Here $\mathrm{C}_{\text {total }}$ and $\mathrm{C}_{\mathrm{s}}$ are the total concentration and concentration in the solid phase in dpm $\mathrm{m}^{-3}, \mathrm{f}_{\mathrm{s}}$ is the fraction of the isotope in the solid phase, $K_{d}$ is the partition coefficient $\left(\mathrm{L} \mathrm{kg}^{-}\right.$ ${ }^{1}$ ), and $\mathrm{C}$ is the suspended solids concentration $\left(\mathrm{mg} \mathrm{L}^{-1}\right)$.) Consequently, in this study, in only a few samples were both dissolved and particulate phases measured. For ${ }^{210} \mathrm{Po}$, the estimated partition coefficient, $11 \times 10^{6} \mathrm{~L} \mathrm{~kg}^{-1}$, predicts that, on average, $83 \%$ of total Po is in the particulate phase. For ${ }^{210} \mathrm{~Pb}$, analysis of both particulate and dissolved phases yielded a partition coefficient of $12 \pm 3 \times 10^{6} \mathrm{~L} \mathrm{~kg}^{-1}$. This value is similar to the $10 \times 10^{6} \mathrm{~L}$ 
$\mathrm{kg}^{-1}$ given by Chapra [1997] for ${ }^{210} \mathrm{~Pb}$ in freshwater and to the value of $15 \times 10^{6} \mathrm{~L} \mathrm{~kg}^{-1}$ estimated based on an assumption of constant water column inventories (Fig. 5). This value predicts that approximately $85 \%$ of ${ }^{210} \mathrm{~Pb}$ is in the particulate phase, on average. These calculated fractions ( $\sim 83 \%$ for ${ }^{210} \mathrm{Po}$ and $\left.85 \%{ }^{210} \mathrm{~Pb}\right)$ are similar to or perhaps slightly higher than the measurements of $63 \%$ for ${ }^{210} \mathrm{Po}$ and $78 \%$ for ${ }^{210} \mathrm{~Pb}$ in Lake 239 , the ranges observed in Bickford Pond [Benoit and Hemond, 1987; Brunskill and Wilkinson, 1987], or values observed in Lake Sammamish $\left(61 \pm 12 \%\right.$ for ${ }^{210}$ Po and $76 \pm 14 \%$ for $\left.{ }^{210} \mathrm{~Pb}\right)$ [Balistrieri et al., 1995].

The model used here assumes that equilibrium sorption is the process regulating the distribution of isotopes between particulate and dissolved phases and that the compositions of the dissolved and particulate phases are constant in space and time within the lake. The issue of active uptake of Po into algal cells will be addressed later in this paper. The minor spatial and temporal variations in the abundance of major ions and $\mathrm{pH}$ within $\mathrm{L}$. Superior [Weiler, 1978] would not cause significant deviations from a constant partition coefficient. There are, however, spatial and temporal variations in the composition of the particles [Jeong et al., 2003; Urban et al., 2004a]. There also are temporal and spatial variations in the concentration of suspended particles. The suspended solids concentration (C) enters directly into the equation (6) that defines the fraction of particulate isotope, and it also has a secondary effect on the magnitude of the partition coefficient. Trace metal partition coefficients often are observed to be inversely proportional to the concentration of suspended solids [e.g., Honeyman and Santschi, 1989; Wang and Cornett, 1993] possibly because of the dynamics of colloid formation and aggregation [colloidal pumping, Honeyman and Santschi, 1991]. Data from marine and lake studies clearly show this 
particle-concentration effect (PCE) for both ${ }^{210} \mathrm{~Pb}$ and ${ }^{210} \mathrm{Po}$ [Bacon et al., 1988; Hong et al., 1999; Zuo and Eisma, 1993; Sarin et al., 1999; Peck and Smith, 2000; Benoit, 1995]. Over the range of particle concentrations generally observed in Lake Superior [0.1- $1.6 \mathrm{mg}$ $\mathrm{L}^{-1}$, Jeong et al., 2003], the particle concentration effect might cause the partition coefficients to vary by less than one order of magnitude [Benoit, 1995]. Because high particle concentrations $\left(>0.7 \mathrm{~m} \mathrm{~L}^{-1}\right)$ are observed only in near-shore waters for short periods in response to wind-induced resuspension [Churchill et al., 2003; Jeong et al., 2003], the simplest model for the whole lake would use a constant partition coefficient.

4.1.3. Biological uptake of Po As shown in the model framework in Figure 2, another process not considered in the simple model is biological uptake of either isotope.

Biological uptake of ${ }^{210}$ Po by organisms is important in marine systems [Sarin et al., 1999; Stewart and Fisher, 2003a; Stewart and Fisher, 2003b; Swarzenski et al., 1999]. Biological uptake of Po or upwelling events [Kadko, 1993] can result in an excess of ${ }^{210} \mathrm{Po}$ relative to ${ }^{210} \mathrm{~Pb}$ in the water column. Accumulation of ${ }^{210} \mathrm{Po}$ along the food chain contributes most of the natural nuclide dose to some species in some oceanic regions [Heyraud and Cherry, 1979]. However, this study reveals no evidence of biological uptake of Po. First, the results show an increase in the Po:Pb ratio from small suspended particles (higher organic carbon contents) to larger settling particles (lower organic carbon contents) to bottom sediments (still lower organic carbon contents). If biological uptake of ${ }^{210} \mathrm{Po}$ were occurring, the $\mathrm{Po}: \mathrm{Pb}$ ratio would decrease as the organic carbon content of the solids decreased. Similarly, within each class of particles (i.e., suspended, settling, bottom sediments) there is no significant correlation $(\mathrm{P}>0.05)$ between Po content and organic $\mathrm{C}$ 
content. There are significant correlations between ${ }^{210} \mathrm{~Pb}$ activity and organic $\mathrm{N}$ content in sediment trap material, as well as between $\mathrm{Po} / \mathrm{Pb}$ ratios and organic $\mathrm{N}$ content in suspended particles (Fig. 7). However, the correlation is not significant $(\mathrm{P}>0.05)$ for Po in either suspended or settling particles.
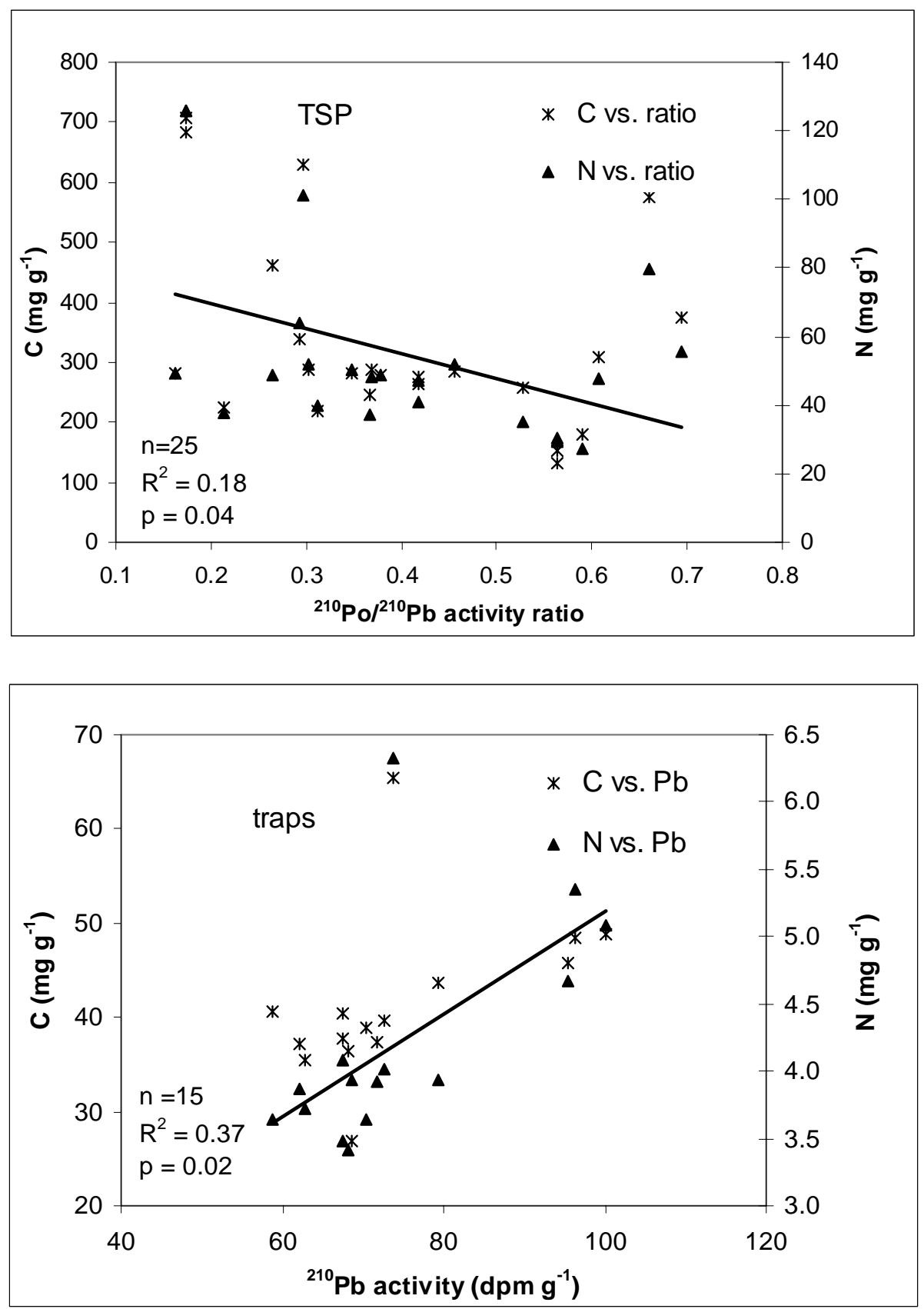
Figure 7. Biogenic element $(\mathrm{C}, \mathrm{N})$ contents vs. isotope activities or ratios for sediment trap samples. A statistically significant correlation exists only between ${ }^{210} \mathrm{~Pb}$ and $\mathrm{N}$ contents, and $\mathrm{Po}: \mathrm{Pb}$ ratios and $\mathrm{N}$ contents as shown in the figures.

Additional evidence that biological uptake of Po is unimportant comes from the distribution of isotopes between particulate and dissolved phases, i.e., the $K_{d}$ value. In marine water, ${ }^{210} \mathrm{Po}$ is more particle-reactive than ${ }^{210} \mathrm{~Pb}$ with a higher $K_{d}$ [Boisson et al., 2001; Hong et al., 1999; Nozaki and Tsunogai, 1976; Zuo and Eisma, 1993]. However in freshwater, the reverse trend is observed. In Lake Sammamish, $K_{d}$ for ${ }^{210} \mathrm{~Pb}$ based on more than 60 water column samples is $6.4 \pm 6.9 \times 10^{6} \mathrm{~L} \mathrm{~kg}^{-1}$ and the $K_{d}$ for ${ }^{210} \mathrm{Po}$ from the same samples is $1.7 \pm 1.2 \times 10^{6} \mathrm{~L} \mathrm{~kg}^{-1}$ [Balistrieri et al., 1995]. Limited data from Lake 239 [Brunskill and Wilkinson, 1987] and Lake Superior (this study, $12 \times 10^{6} \mathrm{~L} \mathrm{~kg}^{-1}$ for ${ }^{210} \mathrm{~Pb}$ and $11 \times 10^{6} \mathrm{~L} \mathrm{~kg}^{-1}$ for ${ }^{210} \mathrm{Po}$ ) also indicate that Po is not more particle-reactive than $\mathrm{Pb}$. The difference in $K_{d}$ between marine and fresh water suggests that different mechanisms may exist for the two systems; i.e., biological uptake of ${ }^{210}$ Po which is common in the oceans may not occur in fresh waters. Given that Po is processed biologically as an analogue of sulfur [Cherrier et al., 1995], biological uptake of Po in marine phytoplankton is closely tied with osmoregulation. In that case, it is logical that uptake of Po by freshwater phytoplankton is negligible even as production of dimethyl sulfide (DMS) by fresh water algae is unimportant [Caron and Kramer, 1994]. Thus the application of ${ }^{210}$ Po as a tracer of nitrogen fixation [Kim, 2001] or DMS air-water exchange [Kim et al., 2000a] may not be appropriate in freshwater systems. In the sediments of Lake Superior, secular equilibrium of ${ }^{210} \mathrm{~Pb}$ and ${ }^{210} \mathrm{Po}$ was observed in 
contrast to other systems where biological uptake leads to an excess of ${ }^{210} \mathrm{Po}$ [Swarzenski et al., 1999] [Pempkowiak et al., 2002].

4.1.4. Seasonal cycling This study covered a sampling period of May through October, and hence it is intermediate between the year-round sampling possible in small lakes [Balistrieri et al., 1995; Benoit and Hemond, 1987] and the oceanographic studies that are confined to short cruises. Seasons in L. Superior are quite different than in small lakes. Holomixis occurs in mid-December, and weak inverse stratification occurs in most winters. A warm near-shore region develops inside a thermal bar in spring, and the lake does not stratify vertically until mid-July. The period of summer stratification is short, persisting only into early September. From September through December, storms progressively erode the thermocline. Hence, this study distinguishes three seasons: prestratification (May - mid-July), stratification (mid-July - August), and late stratification (September - October). The waters of Lake Superior are chemically uniform both vertically and horizontally [e.g., Weiler, 1978; Zarull and Edwards, 1990], and welldefined seasonal cycles (nitrate, silica, $\mathrm{pH}$ and oxygen) exist only in the surface layer [Weiler, 1978]. Thus, dramatic changes of isotope inventories caused by seasonal redox cycling [Balistrieri et al., 1995] are not expected in this lake.

The seasonal variation in isotope distributions is much less than in smaller freshwater lakes [Balistrieri et al., 1995; Benoit and Hemond, 1987] probably because of the lack of seasonal redox cycling in Lake Superior. Isotope activities on suspended particles during stratification $\left(1.40 \mathrm{dpm} 100 \mathrm{~L}^{-1}\right.$ for ${ }^{210} \mathrm{Po}, 0.31 \mathrm{Po}: \mathrm{Pb}$ ratio) are significantly ( $\mathrm{P}<0.05$, student's t-test) lower than those of the pre- and late-stratification 
seasons (Fig. 3-c). Under non-stratified conditions (spring) and as deep waters are being mixed into the epilimnion during fall, higher isotope ratios occur either as a result of resuspension introducing particles with high ratios into the water column or simply due to longer particle residence times in the water column (discussed below). It is also observed that for ${ }^{210} \mathrm{~Pb}$ the summer drop in activity on particles is only $12 \%$ and for ${ }^{210} \mathrm{Po}$ the drop is $45 \%$. Clearly, sampling in winter is needed to complete the seasonal picture, especially for the biogeochemical cycling of ${ }^{210} \mathrm{~Pb}$.

\subsubsection{Suspended particles vs. settling particles Settling particles are larger and denser} than suspended particles and are primarily comprised of fecal pellets, aggregates, and larger algal species [e.g., diatoms,Bloesch and Uehlinger, 1986; Evans et al., 1998]. Settling particles often have lower C:N:P ratios than suspended particles [Urban et al., 2004c] as a result of colonization by bacteria. It would be expected that settling particles would have shorter residence times in the water column than suspended particles, and therefore lower $\mathrm{Po}: \mathrm{Pb}$ ratios (discussed further below). However, in this study, suspended particles had lower $\mathrm{Po}: \mathrm{Pb}$ ratios $(0.43 \pm 0.05)$ than settling particles $(\mathrm{Po}: \mathrm{Pb}$ ratio of $0.57 \pm$ 0.04). The average isotope activities on the suspended particles were $176 \mathrm{dpm} \mathrm{g}^{-1}$ for ${ }^{210} \mathrm{~Pb}$ and $45 \mathrm{dpm} \mathrm{g}{ }^{-1}$ for ${ }^{210} \mathrm{Po}$. The ${ }^{210} \mathrm{~Pb}$ activities in $35-\mathrm{m}$ sediment traps averaged $76 \mathrm{dpm} \mathrm{g}^{-1}$ in near-shore areas and $109 \mathrm{dpm} \mathrm{g}^{-1}$ in offshore areas, and the ${ }^{210} \mathrm{Po}$ activity was $42 \mathrm{dpm} \mathrm{g}^{-}$ ${ }^{1}$ (average of all traps). The higher $\mathrm{Po}: \mathrm{Pb}$ ratios in the settling particles likely result from a mixture of particles with low ratios (suspended particle aggregates, large phytoplankton, fecal pellets) and resuspended sediments with higher ratios. 
4.1.6. Residence times Residence time (or transit time) is defined as the time spent in a reservoir by an individual atom or molecule [Butcher et al., 1992]. For a reservoir in steady state, residence time is equal to the turnover time, which is obtained by dividing the reservoir inventory by the total flux [Bolin and Rodhe, 1973]. As shown in the model description in the methods section, three residence times are calculated in this study: residence times for individual isotopes $\left({ }^{210} \mathrm{~Pb}\right.$ and $\left.{ }^{210} \mathrm{Po}\right)$, and a residence time for particles.

There are several approaches for estimating isotope residence times in the water column [Dominik et al., 1989]. As mentioned above, if atmospheric deposition is the primary source of isotopes to the water column, the residence time may be calculated as the isotope inventory in the water column divided by the flux from the atmosphere. The average activity of ${ }^{210} \mathrm{~Pb}$ on suspended particles $\left(4.7 \mathrm{dpm} 100-\mathrm{L}^{-1}\right)$ together with the estimate that $85 \%$ of the isotope is bound on the particles yields an inventory of ${ }^{210} \mathrm{~Pb}$ in the water column of $6.7 \times 10^{14} \mathrm{dpm}$. Because the ${ }^{210} \mathrm{~Pb}$ activity on the particles increases as the particle concentration decreases (Fig 5), this estimate of a lake-wide inventory would not be seriously biased by the preponderance of near-shore samples in this study if the partition coefficient remained relatively constant as it is expected to do over the narrow range of TSP found in the lake. If $K_{d}$ increased as TSP decreased, the lake-wide inventory might be underestimated. As discussed above, the atmospheric flux is close to $27.4 \mathrm{dpm}$ $\mathrm{m}^{-2} \mathrm{~d}^{-1}$. These estimates of inventory and flux yield a residence time of $\sim 300$ days. Because the flux into the water column neglects sources other than atmospheric deposition, this estimated residence time is an upper limit. Combining this residence time with the average depth of the lake $(150 \mathrm{~m})$ yields a lower limit for the average settling velocity of $0.5 \mathrm{~m} \mathrm{~d}^{-1}$. 


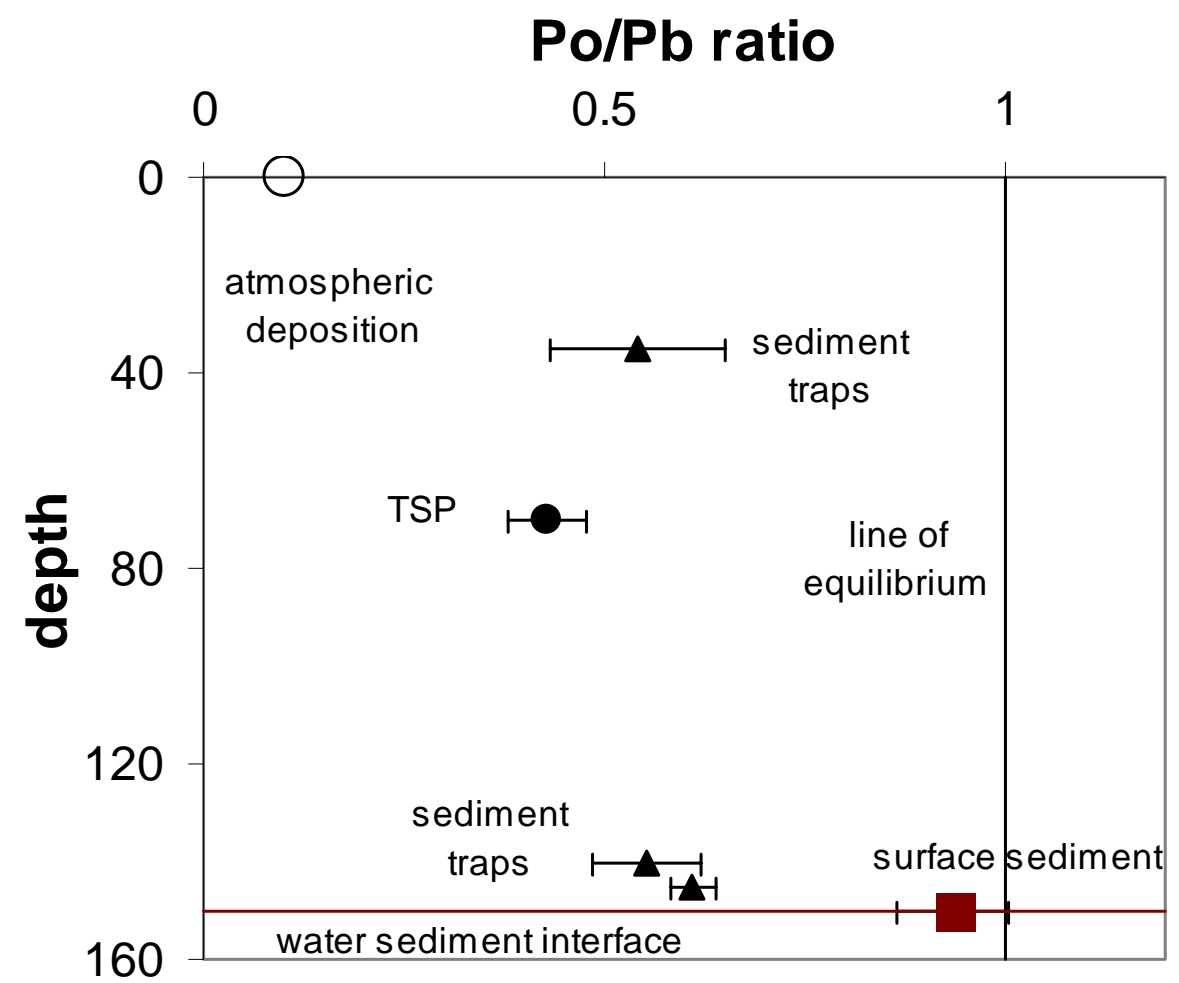

Figure 8. Isotope activity ratios $\left({ }^{210} \mathrm{Po}:{ }^{210} \mathrm{~Pb}\right)$ of particles within Lake Superior. Two artificial lines are secular equilibrium (vertical) and the water-sediment interface. Error bars represent $95 \%$ confidential intervals about the mean.

A second estimate of residence times may be calculated as the inventory divided by the flux out of the water column. Obviously, when integrated over the entire lake, the rate of isotope accumulation in the sediments has to equal the total isotope input less decay and outflow. However, in this study as in many others [Evans et al., 1981; Johnson et al., 1982; Klump et al., 1989] there is a discrepancy between sediment accumulation rates in dated cores $\left(0.1-0.5 \mathrm{~g} \mathrm{~m}^{-2} \mathrm{~d}^{-1}\right)$ and sedimentation rates $\left(1.1 \pm 0.3 \mathrm{~g} \mathrm{~m}^{-2} \mathrm{~d}^{-1}\right)$ as measured with sediment traps. Our estimate of the annual rate of ${ }^{210} \mathrm{~Pb}$ deposition in offshore sediment traps ( $35-\mathrm{m}$ traps) is $79 \pm 16 \mathrm{dpm} \mathrm{m}^{-2} \mathrm{~d}^{-1}$. This output from the water column 
would suggest that the residence time is only 102 days. The discrepancy between sediment accumulation rates and sedimentation rates in sediment traps is due to sediment resuspension and subsequent focusing. Sedimentation rates at 35-m depth measured in this study $\left[0.4 \pm 0.07 \mathrm{~g} \mathrm{~m}^{-2} \mathrm{~d}^{-1}\right.$, Urban et al., 2004d] are slightly higher than those reported in the central lake area $\left[\sim 0.14 \mathrm{~g} \mathrm{~m}^{-2} \mathrm{~d}^{-1}\right.$, Baker et al., 1991] because of higher resuspension rates in near-shore areas; the discrepancy is larger in traps placed $5 \mathrm{~m}$ above the sediments $\left(1.1 \pm 0.3\right.$ vs. $\left.0.14 \sim 1.1 \mathrm{~g} \mathrm{~m}^{-2} \mathrm{~d}^{-1}\right)$. Hence it is more appropriate to estimate a residence time for ${ }^{210} \mathrm{~Pb}$ in the near-shore water column (mean depth $50 \mathrm{~m}$ ) of $\leq 34$ days based on the sediment trap fluxes; this residence time suggests the settling velocity is roughly $1.5 \mathrm{~m} \mathrm{~d}^{-1}$. Regardless of the near-shore bias of our data, this calculation clearly indicates that the actual isotope residence time in the water column is much less than 300 days because of sediment resuspension.

There is a third method to estimate residence times with isotope ratios based on the disequilibrium between parent and daughter isotopes [Olley et al., 1997]. The timescale(s) of environmental process(es) that can be examined by this method depend(s) on the halflives of the isotope pair in question. For the ${ }^{210} \mathrm{Po} /{ }^{210} \mathrm{~Pb}$ pair (half-lives of 138 days and 22.3 yrs, respectively), a system (environmental reservoir) that begins with only the parent isotope present would reach $95 \%$ of secular equilibrium in 4.5 daughter half-lives or 630 days. Thus, 630 days represents an upper limit to the timescale of environmental processes that can be examined with the ${ }^{210} \mathrm{Po} /{ }^{210} \mathrm{~Pb}$ isotope pair. Should the initial ratio of ${ }^{210} \mathrm{Po}:{ }^{210} \mathrm{~Pb}$ be greater than zero, the timescale amenable to study will be shortened.

Before examining the residence time with the ${ }^{210} \mathrm{Po}$ and ${ }^{210} \mathrm{~Pb}$ measurements in $\mathrm{L}$. Superior, it is instructive to consider a hypothetical situation. If a lake were completely 
mixed, and if the only source of these two isotopes were atmospheric deposition in which the ${ }^{210} \mathrm{Po}:{ }^{210} \mathrm{~Pb}$ ratio was less than 0.1 , the isotope ratio in the lake water column (including particulate and dissolved phases) would depend on the isotopes' residence times in the water column. The ${ }^{210} \mathrm{Po}:{ }^{210} \mathrm{~Pb}$ ratio (all phases combined) would be unity if the residence time was greater than or equal to 630 days. Smaller ratios would indicate shorter residence times in the water column. The isotope ratios in individual phases (e.g., dissolved isotope, isotope adsorbed on particle surfaces, isotope inside organisms) would depend on the isotope residence time in the given phase, the fractionation factor for uptake from the water into that phase, and the isotope ratio in the water.

The isotope ratios observed in this study (summarized in Fig. 8) clearly show disequilibrium in the water column. Evidently, the residence time in the water column is less than 630 days. The two estimates above, 300 days estimated from loading and 105 days from sediment traps, both indicated shorter residence times. The discussion below utilizes the mass balances for the isotopes to examine further the isotope residence times.

\subsection{Residence times from isotope distributions: steady-state model}

Estimates of the isotope residence times may be obtained from the mass balance model for the isotopes (eqns 1,2). The idea is to calculate a steady state settling velocity $\left(v_{s}\right)$ based on isotope patterns in the lake. Then according to equations 4 and 5 , isotope residences times can be obtained as well as particle residence times according to equation

3. The steady state solution to equations 1 and 2 yields relationships between isotope activities in the water column and particle settling velocity (eqns 8,9$)$ : 


$$
\begin{aligned}
{ }^{210} \mathrm{~Pb}_{s s}= & \frac{\frac{F_{210} \mathrm{~Pb}}{H}}{\lambda_{P b}+\frac{v_{s}}{H} f_{s P b}} \\
{ }^{210} \mathrm{Po}_{s s}= & \frac{\frac{F_{210} P o}{H}+\lambda_{P o}{ }^{210} \mathrm{~Pb}}{\lambda_{P o}+\frac{v_{s}}{H} f_{s P o}}
\end{aligned}
$$

Under steady-state conditions, the activity of ${ }^{210} \mathrm{~Pb}$ depends on the balance between sources (atmospheric deposition) and sinks (isotope decay, settling). For ${ }^{210}$ Po there is the additional source from decay of the parent isotope, ${ }^{210} \mathrm{~Pb}$. From the isotope field measurements, estimated values of all terms in equations 6 and 7 are available except for the settling velocities.

Given the formulation of the model (eqns 1, 2), the "settling velocities" for both isotopes should be identical because this term represents the rate of particle settling. If the two isotopes are bound to different classes of particles, however, the settling velocities might be different. Use of the average of all measured activities in the water column (i.e., the average activities on suspended particles, 4.7 and $1.9 \mathrm{dpm} 100 \mathrm{~L}^{-1}$ for $\mathrm{Pb}$ and $\mathrm{Po}$, divided by the fraction of isotope on particles, 0.85 for $\mathrm{Pb}$ and 0.83 for $\mathrm{Po}$ ) yields a ${ }^{210} \mathrm{~Pb}$ settling velocity of $0.6 \mathrm{~m} \mathrm{~d}^{-1}$ and a ${ }^{210} \mathrm{Po}$ settling velocity of $1.4 \mathrm{~m} \mathrm{~d}^{-1}$. The value for ${ }^{210} \mathrm{~Pb}$ is similar to that estimated above $\left(0.5 \mathrm{~m} \mathrm{~d}^{-1}\right)$ based on the inventory and atmospheric deposition, and it also is similar to particle settling velocities estimated by Baker and Eisenreich [1989] and Jeremiason et al [1998]. The different value for Po suggests that either the two isotopes are not bound to the same particles, or that some processes have been omitted from the mass balance model. 
Another approach is to compare the steady-state solution with the measured ${ }^{210} \mathrm{~Pb}$ and ${ }^{210} \mathrm{Po}$ activities using measured particle concentrations and a settling velocity estimated from sediment traps as model input. The average TSP concentration reported for the open lake is $0.2 \mathrm{mg} \mathrm{L}^{-1}$ [Jeremiason et al., 1994], and the settling velocity reported for the open lake as well as derived above for ${ }^{210} \mathrm{~Pb}$ is $0.5 \mathrm{~m} \mathrm{~d}^{-1}$. Using these values with the range of partition coefficients determined in this study predicts a wide range of predicted steady state activities for ${ }^{210} \mathrm{~Pb}\left(69-82 \mathrm{dpm} \mathrm{m}^{-3}\right)$ and ${ }^{210} \mathrm{Po}\left(47-59 \mathrm{dpm} \mathrm{m}^{-3}\right)$; for both isotopes this predicted range is well above the measured activities $\left(55 \mathrm{dpm} \mathrm{m}^{-3}\right.$ for ${ }^{210} \mathrm{~Pb}$ and $22 \mathrm{dpm} \mathrm{m}^{-}$ ${ }^{3}$ for ${ }^{210} \mathrm{Po}$ ). This discrepancy would suggest that the model is missing processes that remove the isotopes from the water column. However, when the TSP values (mean of 0.45 $\left.\mathrm{mg} \mathrm{L}^{-1}\right)$ and settling velocities $\left(2.4 \mathrm{~m} \mathrm{~d}^{-1}\right.$ calculated from 3-yr mean sedimentation rate and TSP concentration) specific to the KITES region are used, the predicted steady state concentrations of both isotopes (13-14 $\mathrm{dpm} \mathrm{m}^{-3}$ for ${ }^{210} \mathrm{~Pb}$ and $4.3-4.8 \mathrm{dpm} \mathrm{m}^{-3}$ for ${ }^{210} \mathrm{Po}$ ) are now considerably less than the measured activities. For the KITES region, additional sources of both isotopes are needed in the model. Both approaches for evaluating the simple mass balance model (eqns 1,2) indicate (1) that the two isotopes may be behaving differently (i.e., have different settling velocities), or (2) that the model is missing an important isotope source with a relatively high $\mathrm{Po}: \mathrm{Pb}$ ratio, for instance, the surficial sediment.

Of the two options listed above, we have chosen to investigate the possibility of additional isotope inputs to the water column. Although marine studies indicate that Po may be biologically scavenged and thus behave differently than $\mathrm{Pb}$, as discussed above, there is no evidence of biological scavenging in Lake Superior. Size fractionation of the 
sediments does indicate that different size classes of particles may have different $\mathrm{Po}: \mathrm{Pb}$ ratios, and in marine studies two (or more) size classes of particles have been investigated routinely with both experimental and modeling approaches [Cochran et al., 2000; Santschi et al., 2003]. However, in this study only one size class of particle $(>0.7 \mu \mathrm{m})$ was sampled, and therefore only one size class was modeled. The additional isotope source to the water column that was evaluated was sediment resuspension. In previous mass balance studies of freshwater systems [Bickford Pond and Lake Sammamish, Balistrieri et al., 1995; Benoit and Hemond, 1987], diffusion of ${ }^{210} \mathrm{~Pb}$ and ${ }^{210} \mathrm{Po}$ from sediment/pore water was considered as a major transport mechanism for the isotopes under anoxic bottom conditions [Benoit and Hemond, 1991]. However, in Lake Superior, an oxic and oligotrophic lake with low primary productivity [Thomas and Dell, 1978], such a mechanism is not likely to dominate. Sediment resuspension is the most likely mechanism for isotopes to reenter the lake from the sediments. Another possible source may be lateral particle transport by bottom currents and focusing (i.e., downslope particle migration). However, it is difficult to distinguish these two fluxes (resuspension and lateral transport) with either field measurements or modeling.

Addition of resuspension to the model results in equations 10 and 11. An average sediment resuspension rate $\left(\mathrm{R}_{\text {sed }}\right)$ times the activities of ${ }^{210} \mathrm{~Pb}$ and ${ }^{210} \mathrm{Po}$ in the surface sediment gives the resuspension flux for each isotope $\left(\mathrm{R}_{\mathrm{Po}}, \mathrm{R}_{\mathrm{Pb}}\right)$.

$$
\begin{aligned}
& V \frac{d^{210} \mathrm{~Pb}}{d t}=F_{210_{P b}} \cdot A+R_{P b} \cdot A-\lambda_{P b} \cdot{ }^{210} \mathrm{~Pb} \cdot V-\frac{v_{s}}{H} \cdot f_{s-P b} \cdot{ }^{210} \mathrm{~Pb} \cdot V \\
& V \frac{d^{210} \mathrm{Po}}{d t}=F_{{ }_{210} P_{O}} \cdot A+R_{P o} \cdot A+\lambda_{P o} \cdot{ }^{210} \mathrm{~Pb} \cdot V-\lambda_{P_{o}} \cdot{ }^{210} \mathrm{Po} \cdot V-\frac{v_{s}}{H} \cdot f_{s-P o} \cdot{ }^{210} \mathrm{Po} \cdot V
\end{aligned}
$$


Two assumptions made in modeling resuspension are worth mentioning. First, episodic events (resuspension) are modeled with a constant rate. Second, the isotope activities in the resuspended sediments are assumed to be those measured in particles that were manually resuspended above sediment cores. The steady state solutions to the modified model are shown in equations 12 and 13.

$$
\begin{aligned}
& { }^{210} \mathrm{~Pb} \text { ss }=\frac{\frac{F_{210} \mathrm{~Pb}}{H}+\frac{R_{\text {sed }} \cdot{ }^{210} \mathrm{P} b_{\text {sed }}}{H}}{\lambda_{P b}+\frac{v_{s}}{H} \cdot f_{s-P b}} \\
& { }^{210} \mathrm{Po}_{s s}=\frac{\frac{F_{210} \mathrm{Po}}{H}+\frac{R_{\text {sed }} \cdot{ }^{210} \mathrm{Po} \text { sed }}{H}+\lambda_{P b} \cdot{ }^{210} \mathrm{~Pb}}{\lambda_{P o}+\frac{v_{s}}{H} \cdot f_{s P o}}
\end{aligned}
$$

There are two unknowns, $\mathrm{R}_{\text {sedi }}$ and $\mathrm{v}_{\mathrm{s}}$, in equations 12 and 13. All other parameters are either known constants or can be estimated from measured parameters.

The model is able to reproduce field measurements only when further calibrated. Using the measured parameters, the model predicts a negative resuspension rate and a settling velocity close to zero. Only if the ratio of $\mathrm{Po}: \mathrm{Pb}$ in the sediments is reduced to values below 1 can positive values of resuspension and settling velocity be predicted. A sediment $\mathrm{Po}: \mathrm{Pb}$ ratio of 0.2 predicts a settling velocity of $2.3 \mathrm{~m} \mathrm{~d}^{-1}$ (comparable to the KITES value of $2.4 \mathrm{~m} \mathrm{~d}^{-1}$ ), a solids resuspension flux of $3.5 \mathrm{~g} \mathrm{~m}^{-2} \mathrm{~d}^{-1}, \mathrm{a}^{210} \mathrm{~Pb}$ resuspension flux of $81 \mathrm{dpm} \mathrm{m}^{-2} \mathrm{~d}^{-1}$, and a ${ }^{210}$ Po resuspension flux of $16 \mathrm{dpm} \mathrm{m}^{-2} \mathrm{~d}^{-1}$. Independent estimates of resuspension fluxes can be obtained from the sediment trap fluxes. The average rate of sedimentation in sediment traps $5 \mathrm{~m}$ above the bottom was $1.9 \mathrm{~g} \mathrm{~m}^{-2} \mathrm{~d}^{-1}$ 
[Urban et al., 2004d], somewhat lower than the model prediction. The rate of ${ }^{210} \mathrm{~Pb}$ resuspension (79-137 $\left.\mathrm{dpm} \mathrm{m}^{-2} \mathrm{~d}^{-1}\right)$ may be approximated as the average flux in sediment traps (106-165 $\mathrm{dpm} \mathrm{m}^{-2} \mathrm{~d}^{-1}$ in traps $5 \mathrm{~m}$ above bottom) less the rate of atmospheric deposition $\left(27.4 \mathrm{dpm} \mathrm{m}^{-2} \mathrm{~d}^{-1}\right)$. A rate of ${ }^{210}$ Po resuspension $\left(22 \mathrm{dpm} \mathrm{m}^{-2} \mathrm{~d}^{-1}\right)$ may be roughly estimated as the sedimentation flux $\left(66 \mathrm{dpm} \mathrm{m}^{-2} \mathrm{~d}^{-1}\right)$ less the rate of atmospheric deposition $\left(2.7 \mathrm{dpm} \mathrm{m}^{-2} \mathrm{~d}^{-1}\right)$ and the rate of production in the water column from decay of ${ }^{210} \mathrm{~Pb}\left(41 \mathrm{dpm} \mathrm{m}^{-2} \mathrm{~d}^{-1}\right)$. Thus it is possible to calibrate the model to match several independent measures. The low $\mathrm{Po}: \mathrm{Pb}$ ratio required for this calibration might result from slower desorption kinetics of Po relative to $\mathrm{Pb}$ as has been observed in experimental studies [Ulrich and Degueldre, 1993].

\subsection{Model characteristic times and model validation}

Based on the improved estimate of $\mathrm{v}_{\mathrm{s}}\left(2.3 \mathrm{~m} \mathrm{~d}^{-1}\right)$ characteristic times (isotope residence times) of 75 days for ${ }^{210} \mathrm{~Pb}$ and 55 days for ${ }^{210} \mathrm{Po}$ may be calculated (eqns 4,5 ) for a 150-m water column or 18-25 days for a 50-m water column. These times are much shorter than either of the estimates given above (102 days, 300 days). The residence times for both isotopes are similar although they have different decay rates and different tendencies to partition to particulate matter. The similarity in residence times points to the dominant role played by resuspension in controlling the activities and fluxes of both isotopes.

The analysis above has been based on the assumption of steady state. The time to reach steady state for the isotopes ( $\sim 3$ times the residence time or $\sim 150$ days) is clearly much shorter than the hydraulic residence time in the lake (180 years) [Quinn, 1992]. The 
time to steady state also is shorter than the unstratified period of the lake (Dec. - mid-July), and comparable to the period of stratification (Aug.-Dec). Although it is possible that the epilimnion does not reach steady state, the small differences between epilimnion and hypolimnion discussed above suggest that the steady state approximation for a one-box model is not grossly in error. A two-box model also was evaluated, but it leads to the same conclusions. Even in the epilimnion, an additional source (isotope input from resuspension) is still needed to balance the high settling fluxes, and dispersion through the thermocline is not fast enough to balance the efflux. Of course, resuspension in epilimnetic waters is likely confined to near-shore areas, but the isotope analyses suggest that this material is brought to offshore locations by rapid lateral transport [Chai and Urban, 2004].

This study was conducted in a region extending only $20 \mathrm{~km}$ from shore, and there is a possibility that the estimates of residence times and inventories are biased by nearshore values. Although relatively small spatial variations were observed in this study (Fig. 3), sediment trap studies indicate that the "offshore" fluxes measured in the KITES study [Urban et al., 2004d] are higher than fluxes measured further from shore [Baker et al., 1991]. Particle residence times in the open lake area have been calculated to be about 300 days [Baker et al., 1991] in contrast to the $\sim 60$ days in this study. However, particles and radionuclides show divergent behavior in this regard; ${ }^{210} \mathrm{~Pb}$ born on fine particles is focused to a much larger extent than is bulk sediment mass. Even net depositional fluxes of ${ }^{210} \mathrm{~Pb}$ estimated from sediment cores in the center of the lake [Evans et al., 1981; Klump et al., 1989] are 3-6 times higher than the rate of atmospheric deposition due to focusing of fine particles towards the deep basins of the lake. Hence, ${ }^{210} \mathrm{~Pb}$ residence times in the 
central lake area are going to be three- to six-fold smaller than residence times calculated as the quotient of inventories and atmospheric deposition or particle residence times estimated by sediment trap fluxes (both $\sim 300$ days). There are no measurements with which to estimate the water-column inventories in the center of the lake; the lesser abundance of particles may be offset by higher $\mathrm{K}_{\mathrm{d}}$ values associated with these particles in the center of the lake. Hence, in the absence of data to the contrary, we predict that the isotope residence times in the lake center are similar to those calculated in this study. In both areas, sediment resuspension and focusing play a central role in regulating these residence times. 
Acknowledgments: This work was funded by NSF (OCE9712872) as part of the KITES project. We are grateful to the captains and crews of the $R / V$ Blue Heron and $R / V$ Laurentian for their able assistance on the lake. We would also like to acknowledge the assistance in the field and laboratory from C. Larsen and J. Koehler. We also thank J. Jeong, D. Apul and X. Lu for assistance obtaining and analyzing sediment trap and TSP samples. The insightful reviews of Dr. Kevin Yeager and Dr. Peter Santschi are greatly appreciated.

\section{REFERENCES:}

Aller, R.C., L.K. Benninger, and J.K. Cochran, Tracking particle-associated processes in nearshore environments by use of ${ }^{234} \mathrm{Th} /{ }^{238} \mathrm{U}$ disequilibrium, Earth Planet. Sci. Lett., 47, 161-175, 1980.

Bacon, M.P., R.A. Belastock, M. Tecotzky, K.K. Turekian, and D.W. Spencer, Lead-210 and polonium-210 in ocean water profiles of the continental shelf and slope south of New England, Continental Shelf Research, 8 (5-7), 841-853, 1988.

Bacon, M.P., D.W. Spencer, and P.G. Brewer, ${ }^{210} \mathrm{~Pb} /{ }^{226} \mathrm{Ra}$ and ${ }^{210} \mathrm{Po} /{ }^{210} \mathrm{~Pb}$ disequilibrium in seawater and suspended particulate matter, Earth Planet. Sci. Lett., 32, 277-296, 1976.

Baker, J.E., and S.J. Eisenreich, PCBs and PAHs as tracers of particulate dynamics in large lakes, J. Great Lakes Res., 15 (1), 84-103, 1989.

Baker, J.E., S.J. Eisenreich, and B.J. Eadie, Sediment trap fluxes and benthic recycling of organic carbon, polycyclic aromatic hydrocarbons, and polychlorobiphenyl congeners in Lake Superior, Environ. Sci. Technol., 25, 500-509, 1991.

Balistrieri, L.S., J.W. Murray, and B. Paul, The geochemical cycling of stable $\mathrm{Pb},{ }^{210} \mathrm{~Pb}$, and ${ }^{210}$ Po in seasonally anoxic Lake Sammamish, USA, Geochimica et Cosmochimica Acta, 59 (23), 4845-4861, 1995. 
Baskaran, M., C.H. Coleman, and P.H. Santschi, Atmospheric depositional fluxes of ${ }^{7}$ Be and ${ }^{210} \mathrm{~Pb}$ at Galveston and College Station, Texas, Journal of Geophysical Research, 98 (D11), 20555-20571, 1993.

Baskaran, M., and P.H. Santschi, The role of particles and colloids in the transport of radionuclides in coastal environments of Texas, Marine Chemistry, 43 (1-4), 95$114,1993$.

Baskaran, M., and P.H. Santschi, Particulate and dissolved ${ }^{210} \mathrm{~Pb}$ activities in the shelf and slope regions of the Gulf of Mexico waters, Continental Shelf Research, 22 (10), 1493-1510, 2002.

Benoit, G., Evidence of the particle concentration effect for lead and other metals in fresh waters based on clean technique analyses, Geochimica et Cosmochimica Acta, 59, 2677-2687, 1995.

Benoit, G., and H.F. Hemond, A biogeochemical mass balance of ${ }^{210} \mathrm{Po}$ and ${ }^{210} \mathrm{~Pb}$ in an oligotrophic lake with seasonally anoxic hypolimnion, Geochimica et Cosmochimica Acta, 51, 1445-1456, 1987.

Benoit, G., and H.F. Hemond, Evidence for diffusive redistribution of ${ }^{210} \mathrm{~Pb}$ in lake sediments, Geochimica et Cosmochimica Acta, 55, 1963-1975, 1991.

Benoit, G., and H.F. Hemond, ${ }^{210} \mathrm{Po}$ and ${ }^{210} \mathrm{~Pb}$ remobilization from lake sediments in relation to iron and manganese cycling, Environmental Science \& Technology, 24, 1224-1234, 1992.

Bhat, S.G., S. Krishnaswamy, D. Lal, Rama, and W.S. Moore, ${ }^{234} \mathrm{Th} /{ }^{238} \mathrm{U}$ ratios in the ocean, Earth Planet. Sci. Lett., 5, 483-491, 1969.

Bloesch, J., and U. Uehlinger, Horizontal sedimentation differences in a eutrophic Swiss lake, Limnology and Oceanography, 31 (5), 1094-1109, 1986.

Boisson, F., J.-C. Miquel, O. Cotret, and S.W. Fowler, ${ }^{210} \mathrm{Po}$ and ${ }^{210} \mathrm{~Pb}$ cycling in a hydrothermal vent zone in the coastal Aegean Sea, Science of the Total Environment, 281 (1-3), 111-119, 2001.

Bolin, B., and H. Rodhe, A note on the concepts of age distribution and transit time in natural reservoirs, Tellus, 25, 58-62, 1973.

Brunskill, G.J., and P. Wilkinson, Annual supply of ${ }^{238} \mathrm{U},{ }^{234} \mathrm{U},{ }^{230} \mathrm{Th},{ }^{226} \mathrm{Ra},{ }^{210} \mathrm{~Pb},{ }^{210} \mathrm{Po}$, and ${ }^{232}$ Th to Lake 239 (Experimental Lakes Area, Ontario) from terrestrial and atmospheric sources, Can. J. Fish. Aquat. Sci., 44 (Supplement 1), 215-230, 1987. 
Bub, L.A., Horizontal and temporal structure in phytoplankton dynamics in Lake Superior, Michigan Technological University, Houghton, MI, 2001.

Butcher, S.S., R.J. Charlson, G.H. Orians, and G.V. Wolfe, Global biogeochemical cycles, 379 pp., Academic Press, 1992.

Caron, F., and J.R. Kramer, Formation of volatile sulfides in freshwater environments, Science of the Total Environment, 153 (3), 177-194, 1994.

Chapra, S.C., Surface Water-Quality Modeling, WCB/McGraw-Hill, 1997.

Chen, C., J. Zhu, E. Ralph, S.A. Green, J.W. Budd, and F.Y. Zhang, Prognostic modeling studies of the Keweenaw Current in Lake Superior. Part I: formation and evolution, Journal of Physical Oceanography, 31, 379-395, 2001.

Cherrier, J., W.C. Burnett, and P.A. Larock, Uptake of Polonium and Sulfur by bacteria, Geomicrobiology Journal, 13, 103-115, 1995.

Christensen, E.R., and P.K. Bhunia, Modeling radiotracers in sediments: comparison with observations in Lake Huron and Michigan, Journal of Geophysical Research, 91, 8559-9571, 1986.

Churchill, J.H., A.J. Williams, and E.A. Ralph, Sediment resuspension and transport over the shelf and slope off of Lake Superior's Keweenaw Peninsula, Journal of Geophysical Research, in review, 2003.

Cochran, J.K., K.O. Buesseler, M.P. Bacon, H.W. Wang, D.J. Hirschberg, L. Ball, J. Andrews, G. Grossin, and A. Fleer, Short-lived thorium isotope (234Th, 228Th) as indicators of POC export and particle cycling in the Ross Sea, Southern Ocean, Deep-Sea Research II, 47, 3451-3490, 2000.

Dominik, J., C. Schuler, and P.H. Santschi, Residence time of 234Th and 7Be in Lake Geneva, Earth Planet. Sci. Lett., 93, 345-358, 1989.

Durham, R.W., and S.R. Joshi, Sedimentation rates in western Nipigon Bay, Lake Superior using the ${ }^{210} \mathrm{~Pb}$ method, Science of the Total Environment, 22 (1), 51-59, 1981.

Eakins, J.D., and R.T. Morrison, A new Procedure for the Determination of Lead-210 in Lake and Marine Sediments, International Journal of Applied Radiation and Isotopes, 29, 531-536, 1978.

Edgington, D.N., J.V. Klump, J.A. Robbins, Y.S. Kusner, V.D. Pampura, and I.V. Sandimirov, Sedimentation rates, residence times and radionuclide inventories in Lake Baikal from ${ }^{137} \mathrm{Cs}$ and ${ }^{210} \mathrm{~Pb}$ in sediment cores, Nature, 350 (6319), 601-604, 1991. 
El-Daoushy, F., A summary on the lead-210 cycle in nature and related applications n Scandinavia, Environment International, 14, 305-319, 1989.

Engstrom, D.R., E.B. Swain, and J.C. Kingston, A palaeolimnological record of human disturbance from Harvey's Lake, Vermont: geochemistry, pigments and diatoms, Freshwater Biology, 15 (3), 261-288, 1985.

Evans, J.E., T.C. Johnson, E.C.J. Alexander, R.S. Lively, and S.J. Eisenreich, Sedimentation rates and depisitional processes in Lake Superior from $210 \mathrm{~Pb}$ geochronology, J. Great Lakes Res., 7 (3), 299-310, 1981.

Evans, M.S., B.J. Eadie, and R.M. Glover, Sediment trap studies in southeastern Lake Michigan: fecal pellet express or the more traveled route?, J. Great Lakes Res., 24 (3), 555-568, 1998.

Guo, L., and P.H. Santschi, Sedimentary sources of old high molecular weight dissolved organic carbon from the ocean margin benthic nepheloid layer, Geochimica et Cosmochimica Acta, 64 (4), 651-660, 2000.

Gustafsson, O., P. Gschwend, and K.O. Buesseler, Settling removal rates of PCBs into the northwestern Atlantic derived from ${ }^{238} \mathrm{U}_{-}{ }^{234}$ Th disequilibria, Environ. Sci. Technol., 31, 3544-3550, 1997.

Hancock, G.J., Identifying resuspended sediment in an estuary using the ${ }^{228} \mathrm{th} /{ }^{232} \mathrm{Th}$ activity ratio: The fate of lagoon sediment in the Bega River estuary, Australia, Marine and Freshwater Research, 51 (7), 659-667, 2000.

Heyraud, M., and R.D. Cherry, Polonium-210 and Lead-210 in marine food chains, Marine Biology, 52, 227-236, 1979.

Honeyman, B.D., and P.H. Santschi, A Brownian-pumping model for oceanic trace metal scavenging: evidence from Th isotopes, Journal of Marine Research, 47 (4), 951992, 1989.

Honeyman, B.D., and P.H. Santschi, Coupling adsorption and particle aggregation: laboratory studies of "colloidal pumping' using ${ }^{59}$ Fe-labeled hematite, Environ. Sci. Technol., 25 (2), 1739-1747, 1991.

Hong, G.-H., S.-K. Park, M. Baskaran, S.-H. Kim, C.-S. Chung, and S.-H. Lee, Lead-210 and polonium-210 in the winter well-mixed turbid waters in the mouth of the Yellow Sea, Continental Shelf Research, 19 (8), 1049-1064, 1999. 
Hung, G.W., and Y.-C. Chung, Particulate fluxes, ${ }^{210} \mathrm{~Pb}$ and ${ }^{210} \mathrm{Po}$ measured from sediment trap samples in a canyon off northeastern Taiwan, Continental Shelf Research, 18 (12), 1475-1491, 1998.

Jeong, J., Biogeochemical cycling of copper associated with particulate matter in Lake Superior, Michigan Technological University, Houghton, 2002.

Jeong, J., N.R. Urban, S.A. Green, and J. Budd, Short-term dynamics and distribution of suspended particles in the Keweenaw Peninsula region of Lake Superior, J. Great Lakes Res., In review, 2003.

Jeremiason, J.D., S.J. Eisenreich, J.E. Baker, and B.J. Eadie, PCB decline in settling particles and benthic recycling of PCBs and PAHs in Lake Superior, Environ. Sci. Technol., 32 (21), 3249-3256, 1998.

Jeremiason, J.D., K.C. Hornbuckle, and S.J. Eisenreich, PCBs in Lake Superior, 19781992: decreases in water concentrations reflect loss by volatilization, Environ. Sci. Technol., 28 (5), 903-914, 1994.

Johnson, T.C., J.E. Evans, and S.J. Eisenreich, Total Organic carbon in Lake Superior sediments: Comparisons with hemipelagic and pelagic marine environments, Limnology and Oceanography, 27 (3), 481-491, 1982.

Kadko, D., Excess ${ }^{210}$ Po and nutrient recycling within the California coastal transition zone, Journal of Geophysical Research, 98 (C1), 857-864, 1993.

Kerfoot, W.C., and J.A. Robbins, Nearshore regions of Lake Superior: Multi-element signatures of mining discharges and a test of $\mathrm{Pb}-210$ deposition under conditions of variable sediment mass flux, J. Great Lakes Res., 25 (4), 697-720, 1999.

Kim, G., Large deficiency of polonium in the oligotrophic ocean's interior, Earth Planet. Sci. Lett., 192, 15-21, 2001.

Kim, G., and T.M. Church, Seasonal biogeochemcal fluxes of ${ }^{234} \mathrm{Th}$ and ${ }^{210} \mathrm{~Pb}$ in the upper Sargasso Sea: influence from atmosphric iron deposition, Global Biogeochemical Cycles, 15 (3), 651-661, 2001.

Kim, G., N. Hussain, and T.M. Church, Excess ${ }^{210}$ Po in the coastal atmosphere, Tellus, Series B: Chemical and Physical Meteorology, 52 (1), 74-80, 2000a.

Kim, G., N. Hussain, J.R. Scudlark, and T.M. Church, Factors influencing the atmospheric depositional fluxes of stable $\mathrm{Pb},{ }^{210} \mathrm{~Pb}$, and ${ }^{7} \mathrm{Be}$ into Chesapeake Bay, Journal of Atmospheric Chemistry, 36 (1), 65-79, 2000b. 
Klump, V., M. Boraas, P. Anderson, P. R, C.C. Remsen, and S.A. Fitzgerald, Variations in sediment accumulation rates and the flux of labile organic matter in eastern Lake Superior basins, J. Great Lakes Res., 15 (1), 104-122, 1989.

Krishnaswami, S., and D. Lal, Radionuclide Limnochronology, in Lakes: Chemistry, Geology, Physics, edited by A. Lerman, pp. 153-178, Springer-Verlag, New York, 1978.

Krishnaswami, S., D. Lal, M.J. M., and M. Meybeck, Geochronology of lake sediments, Earth Planet. Sci. Lett., 11, 407-414, 1971.

Marley, N.A., J.S. Gaffney, P.J. Drayton, M.M. Cunningham, K.A. Orlandini, and R. Paode, Measurement of ${ }^{210} \mathrm{~Pb},{ }^{210} \mathrm{Po}$, and ${ }^{210} \mathrm{Bi}$ in size-fractionated atmospheric aerosols, an estimate of fine-aerosol residence times, Aerosol Science and Technology, 32, 569-583, 2000.

Masqué, P., A. Palanques, J.M. Bruach, P. Puig, J. Guillén, E. Isla, and J.A. SanchezCabeza, Sediment accumulation rates and carbon fluxes to bottom sediments at the Western Bransfield Strait (Antarctica), Deep-Sea Research Part II: Topical Studies in Oceanography, 49 (4-5), 921-933, 2002.

Matheson, D.H., and M. Munawar, Lake Superior basin and its development, J. Great Lakes Res., 4 (3-4), 249-263, 1978.

Nozaki, Y., H. Tsubota, V. Kasemsupaya, M. Yashima, and N. Ikuta, Residence times of surface water and particle-reactive ${ }^{210} \mathrm{~Pb}$ and ${ }^{210} \mathrm{Po}$ in the East China and Yellow seas, Geochimica et Cosmochimica Acta, 55, 1265-1272, 1991.

Nozaki, Y., and S. Tsunogai, ${ }^{226} \mathrm{Ra},{ }^{210} \mathrm{~Pb}$ and ${ }^{210} \mathrm{Po}$ disequilibria in the western north Pacific, Earth Planet. Sci. Lett., 32, 313-321, 1976.

Olley, J.M., R.G. Roberts, and A.S. Murray, A novel method for determining residence times of river and lake sediments based on disequilibrium in the thorium decay series, Water Resources Research, 33 (6), 319-326, 1997.

Olsen, C.R., I.L. Larsen, P.D. Lowry, N.H. Cutshall, and M.M. Nichols, Geochemistry and deposition of ${ }^{7} \mathrm{Be}$ in river-estuarine and coastal waters, Journal of Geophysical Research, 91, 896-908, 1986.

Olsen, C.R., I.L. Larsen, P.D. Lowry, N.H. Cutshall, J.F. Todd, G.T.F. Wong, and W.H. Casey, Atmospheric fluxes and marsh-soil inventories of ${ }^{7} \mathrm{Be}$ and ${ }^{210} \mathrm{~Pb}$, Journal of Geophysical Research, 90 (20), 10487-10495, 1985. 
Peck, G.A., and J.D. Smith, Distribution of dissolved and particulate ${ }^{226} \mathrm{Ra},{ }^{210} \mathrm{~Pb}$ and ${ }^{210} \mathrm{Po}$ in the bismarck sea and western equatorial pacific ocean, Mar. Freshwater Res., 51, 647-58, 2000.

Pempkowiak, J., J. Deldowski, P. K., S. A., T. Leipe, and E. K.-C., The contribution of the fine sediment fraction to the Fluffy Layer Suspended Matter (FLSM), Oceanologia, 44 (4), 513-527, 2002.

Quinn, F.H., Hydraulic residence times for the Laurentian Great Lakes, J. Great Lakes Res., 18 (1), 22-28, 1992.

Ragotzkie, R.A., The Keweenaw Current, a regular feature of summer circulation of Lake Superior, pp. 36, Department of Meteorology, University of Wisconsin, Madison, Madison, Wisconsin, 1966.

Robbins, J.A., and D.N. Edington, Determination of recent sedimentation rates in Lake Michigan using Pb-210 and Cs-137, Geochimica et Cosmochimica Acta, 39, 285304, 1975.

Santschi, P.H., C.-C. Hung, G. Schultz, N. Alvarado-Quiroz, L. Guo, J. Pinckney, and I. Walsh, Control of acid polysaccharide production, and ${ }^{234} \mathrm{Th}$ and POC export fluxes by marine organisms, Geophysical Research Letters, 30 (2), 1044, doi:10.1029/2002GL016046, 2003.

Sarin, M.M., G. Kim, and T.M. Church, ${ }^{210} \mathrm{Po}$ and ${ }^{210} \mathrm{~Pb}$ in the South-equatorial Atlantic: distribution and disequilibrium in the upper $500 \mathrm{~m}$, Deep-Sea Research Part II: Topical Studies in Oceanography, 46 (5), 907-917, 1999.

Sarin, M.M., S. Krishnaswami, R. Ramesh, and B.L.K. Somayajulu, ${ }^{238}$ U decay series nuclides in the northeastern Arabian Sea: scavenging rates and cycling processes, Continental Shelf Research, 14 (2/3), 251-265, 1994.

Schneider, A.R., B.J. Eadie, and J.E. Baker, Episodic particle transport events controlling PAH and PCB cycling in Grand Traverse Bay, Lake Michigan, Environ. Sci. Technol., 36, 1181-1190, 2002.

Schuler, C., E. Wieland, P.H. Santschi, M. Sturm, A. Lueck, S. Bollhalder, J. Beer, G. Bonani, H.J. Hofmann, M. Suter, and W. Wolfli, A multitracer study of radionuclides in Lake Zurich, Switzerland: 1. Comparison of atmospheric and sedimentary fluxes of ${ }^{7} \mathrm{Be},{ }^{10} \mathrm{Be},{ }^{210} \mathrm{~Pb},{ }^{210} \mathrm{Po}$, and ${ }^{137} \mathrm{Cs}$, Journal of Geophysical Research, 96 (C9), 17051-17065, 1991. 
Siew, P.-F., The Distribution and Cycling of Phosphorus in Lake Superior, Michigan Technological University, Houghton, MI, 2003.

Stewart, G.M., and N.S. Fisher, Bioaccumulation of Polonium-210 in marine copepods, Limnology and Oceanography, 48 (5), 2011-2019, 2003a.

Stewart, G.M., and N.S. Fisher, Experimental studies on the accumulation of Polonium210 by marine phytoplankton, Limnology and Oceanography, 48 (3), 1193-1201, $2003 b$.

Suzuki, T., and $\mathrm{H}$. Shiono, Comparison of ${ }^{210} \mathrm{Po} /{ }^{210} \mathrm{~Pb}$ activity ratio between aerosol and deposition in the atmospheric boundary layer over the west coast of Japan, Geochemical Journal, 29 (5), 287-291, 1995.

Suzuki, T., K. Yamada, K. Ohta, Y. Maruyama, and N. Nakayama, Measurement of the ${ }^{210} \mathrm{Po} /{ }^{210} \mathrm{~Pb}$ activity ratio in size fractionated aerosols from the coast of the Japan Sea, Atmospheric Environment, 33 (14), 2285-2288, 1999.

Swarzenski, P.W., B.A. McKee, K. Sorensen, and J.F. Todd, ${ }^{210} \mathrm{~Pb}$ and ${ }^{210} \mathrm{Po}$, manganese and iron cycling across the $\mathrm{O}_{2} / \mathrm{H}_{2} \mathrm{~S}$ interface of a permanently anoxic fjord: Framvaren, Norway, Marine Chemistry, 67 (3-4), 199-217, 1999.

Talbot, R.W., and A.W. Andren, Seasonal variations of ${ }^{210} \mathrm{~Pb}$ and ${ }^{210} \mathrm{Po}$ concentrations in an oligotrophic lake, Geochimica et Cosmochimica Acta, 48 (10), 2053-2063, 1984.

Thomas, R.L., and C.I. Dell, Sediments of Lake Superior, J. Great Lakes Res., 4 (3-4), 264-275, 1978.

Turnewitsch, R., and B.M. Springer, Do bottom mixed layers influence ${ }^{234}$ Th dynamics in the abyssal near-bottom water column?, Deep-Sea Research I, 48, (5), 1279-1307, 2001.

Ulrich, H.J., and C. Degueldre, The sorption of Pb-210, Bi-210 and ${ }^{210} \mathrm{Po}$ on Montmorillonite: A study with emphasis on reversibility aspects and on the effect of the radioactive decay of adsorbed nuclides, Radiochim. Acta., 62, 81-90, 1993.

Urban, N.R., D.S. Apul, and M.T. Auer, Planktonic respiration rates in Lake Superior, J. Great Lakes Res., In press, 2004a.

Urban, N.R., M.T. Auer, and S.A. Green, Carbon cycling in Lake Superior, Journal of Geophysical Research, In review, 2004b.

Urban, N.R., S.J. Eisenreich, D.F. Grigal, and K.T. Schurr, Mobility and diagenesis of Pb and ${ }^{210} \mathrm{~Pb}$ in peat, Geochimica et Cosmochimica Acta, 54 (12), 3329-3346, 1990. 
Urban, N.R., R. Gaechter, and J. Bloesch, The significance of C:N ratios in lacustrine particles, Can. J. Fish. Aquat. Sci., In press, 2004c.

Urban, N.R., L. Xu, Y. Chai, and D.S. Apul, Sediment trap studies in Lake Superior: insight into resuspension, cross-margin transport and carbon cycling, J. Great Lakes Res., In press, $2004 \mathrm{~d}$.

USGS, Surface-water data for the nation: calendar year streamflow statistics for the nation, 2003.

Viekman, B.E., and M. Wimbush, Observations of the vertical structure of the Keweenaw current, Lake Superior, J. Great Lakes Res., 19 (2), 470-479, 1993.

Wang, K., and R.J. Cornett, Distribution coefficients of ${ }^{210} \mathrm{~Pb}$ and ${ }^{210} \mathrm{Po}$ in laboratory and natural aquatic systems, Journal of Paleolimnology, 9 (2), 179-188, 1993.

Weiler, R.R., Chemistry of Lake Superior, J. Great Lakes Res., 4 (3-4), 370-385, 1978.

Wieland, E., P.H. Santschi, and J. Beer, A multitracer study of radionuclides in Lake Zurich, Switzerland: 2. Residence times, removal processes, and sediment focusing, Journal of Geophysical Research, 96 (C9), 17067-17080, 1991.

Zarull, M.A., and C.J. Edwards, A review of Lake Superior water quality with emphasis on the 1983 intensive survey. Report to the Surveillance Subcommittee of the Great Lakes Water Quality Board, pp. 220 pp, Windsor, Ontario, 1990.

Zhu, J., C. Chen, E. Ralph, S.A. Green, J.W. Budd, and F.Y. Zhang, Prognostic modeling studies of the Keweenaw Current in Lake Superior. Part II: simulation, Journal of Physical Oceanography, 31, 396-410, 2001.

Zuo, Z., and D. Eisma, ${ }^{210} \mathrm{~Pb}$ and ${ }^{210} \mathrm{Po}$ distributions and disequilibrium in the coastal and shelf waters of the southern North Sea, Continental Shelf Research, 13 (8/9), 999$1022,1993$. 


\title{
Chapter Three
}

\section{Particle dynamics in the temporary deposition zone of Lake}

\section{Superior: Insights from ${ }^{210} \mathrm{~Pb},{ }^{137} \mathrm{Cs}$ and ${ }^{7} \mathrm{Be}^{1}$}

\author{
Yingtao Chai and Noel R. Urban* \\ Department of Civil \& Environmental Engineering, Michigan Technological University, \\ Houghton, MI 49931
}

*Corresponding author: $\quad$ (906)487-3640 (tel), (906)487-2943 (fax) nurban@mtu.edu

1. A manuscript targeting Limnology and Oceanography 


\section{Abstract}

Sediment cores were taken along three transects in the nearshore region of Lake Superior as part of the KITES project. Inventories of excess ${ }^{210} \mathrm{~Pb}$ and ${ }^{137} \mathrm{Cs}$ and focusing factors (based on both isotopes) were calculated for 28 cores. ${ }^{7} \mathrm{Be}$ was only found in the fluff layer of the sediments at most sites, but its presence in deep-water sites attests to the rapidity of sedimentation. Among all the cores, only three sites (one from each transect) have focusing factors $(\mathrm{FF})$ larger than 1 . The ${ }^{210} \mathrm{~Pb}$-derived $\mathrm{FF}$ ranges from 0.04 to 2.3 with mean and median values of 0.36 and 0.15 , respectively. The study region is thus categorized as a temporary deposition zone. A 2-dimensional steady-state box-in-series model was developed and applied to individual transects with the ${ }^{210} \mathrm{~Pb}$ inventories as model input, together with a modified nested box model. The model was used to predict isotope residence times and cross-margin fluxes of sediments and isotopes at different locations along each transect. The time scale for sediment focusing from the nearshore to offshore regions of the transect was on the order of 10 years. The pattern of ${ }^{7} \mathrm{Be}$ focusing was similar to that of ${ }^{210} \mathrm{~Pb}$; evidently, short-term dynamics of particle transport during unstratified conditions are similar to the decadal pattern. High ratios of ${ }^{137} \mathrm{Cs}:{ }^{210} \mathrm{~Pb}$ were interpreted to indicate longshore transport by the Keweenaw Current and the general counter-clockwise circulation in the lake. This circulation entrains older sediments into the nearshore zone where they remain for periods of 10-30 years. 


\section{Introduction}

The five Laurentian Great Lakes of North America form the largest surface fresh water system on earth. They have more than 16,000 kilometers of shoreline. Their waters are heavily influenced by interactions at the land-water interface such as the supply of nutrients and sediments, toxic contaminants and wastes via tributary streams and rivers [e.g., Robertson, 1997], coastal wetlands [Brazner and DeVita, 1998; Keough et al., 1999], and atmospheric transport [e.g., Eisenreich et al., 1977; Eisenreich et al., 1981]. The coastal boundary of the Great Lakes is geologically, chemically and biologically dynamic. The Keweenaw Interdisciplinary Transport Experiment in Superior or KITES project sought to explore the role of thermal fronts and longshore currents in mediating the transport of biogeochemically important materials across the coastal margin of Lake Superior. As part of the KITES project, radioisotope tracers were used to study particle movement within the nearshore region of Lake Superior.

Radioisotopes (both natural and artificial) in lakes or oceans have fates determined by their physical and chemical characteristics [e.g., Coale and Bruland, 1988; Kim and Church, 2001; Wieland and Spieler, 2001]. Residence time is a useful parameter to describe an isotope's fate after its entry into a system. In geochemistry, residence time $(\tau)$ is defined as the inventory divided by the total flux. The residence time is the net effect of all processes related to isotope transport within the system. Thus, examination of isotope residence times reveals information about related processes. For example, residence times of particle-reactive isotopes can be related to particle movements in the system, in this case, sedimentation and/or cross-margin transport of particulate matter [e.g., Dominik et al., 1989; Gustafsson et al., 1997]. 
Particulate matter can act as a carrier in the cross-margin transport of nutrients and contaminants. Particle dynamics in the nearshore region are schematized in Figure 1 of the introduction (page 5). Isotope tracers have been applied frequently to study one or more processes described in the diagram [Chai and Urban, 2004; Eadie et al., 1990; Edgington and Robbins, 1990; Fitzgerald et al., 2001; Heussner et al., 1990; Robbins and Eadie, 1991; Urban et al., 2004; Wieland et al., 1991; Zuo and Eisma, 1993]. In the nearshore region, the final destination of particles (and particle-reactive isotopes) is either deposition and burial in sediments or transport to offshore zones. Cross-margin transport may have the effect that particles (and isotopes) reside longer in the water column and upper sediment before being buried.

In large lakes, cross-margin transport is one component of sediment focusing, or the tendency of fine-grained sediment to move towards the deep portion of the lake [Davis and Ford, 1982]. As a measure of sediment focusing, the focusing factor is defined as the actual ${ }^{210} \mathrm{~Pb}$ inventory divided by the theoretical ${ }^{210} \mathrm{~Pb}$ inventory (from atmospheric fallout) [Kada and Heit, 1992]. Focusing factors make possible comparison of sediment transport processes among different lakes. For large lakes like the Great Lakes, focusing factors can be used to trace the movement of sediments within the lake. Unlike in many small lakes where the deepest spots are net depositional sites and the final destination of sediment focusing [Yohn et al., 2002], in large lakes more than one deposition zone is expected. Lake Michigan has two major depositional basins, and the site to which sediments are focused does not coincide with the deepest location in the southern basin [Edgington and Robbins, 1990]. Lake Superior has multiple depositional basins [Kemp et al., 1978]. The pathways of sediment transport from river inputs and 
coastal erosion to ultimate burial in profundal zones remain unknown for Lake Superior. Previous studies have used metal and mineral contaminants introduced by mining activities to deduce pathways of sediment transport within the lake [Cook, 1975; Kerfoot et al., 1999; Kerfoot and Robbins, 1999; Urban et al., 2004]; this study uses radioisotopes to determine the timeframe as well as pathways of transport.

Significant questions remain about the mechanisms for sediment transport in large lakes. The relative importance of waves [Hawley, 2000], wind-driven and buoyancy currents [e.g., the Keweenaw current, Viekman and Wimbush, 1993; Viekman et al., 1989], density currents [Churchill et al., 2003; Halfman and Johnson, 1989], internal waves [Gloor et al., 1994; Hawley and Muzzi, 2003], thermocline scour [Eadie et al., 1984], and episodic events [Eadie et al., 2002] remain unclear. The three transects studied in this project experience different water currents and have different bathymetries and thus help to clarify the role of these features in sediment transport.

Particle transport is also ecologically important. Diporeia, a major component of the food web of all the Laurentian Great Lakes [Hudson et al., 1995] and the dominant benthic organism in Lake Superior [Auer and Kahn, 2004], is restricted to a narrow band (3-5 km wide) in the nearshore region of the lake with water depths of 75-125 $\mathrm{m}$ [Auer and Kahn, 2004]. Previous studies [Fitzgerald and Gardner, 1993; Lu, 2004] have suggested that diatoms are the major food source for these organisms, but it remains unclear how and why the diatoms are focused into this narrow band. Naturally occurring radioisotopes have long been used as tracers for POC [Bloesch and Uehlinger, 1986; Cochran et al., 2000; Friedrich and van der Loeff, 2002], and in this study are used to determine 1) the source of organic carbon, 2) the flux of "new" or fresh organic carbon, 
and (3) the residence time of organic carbon on the slope to see if it is adequate to allow for consumption by Diporeia.

To answer the questions posed above regarding the time scales and magnitudes of particle movements in the nearshore region of Lake Superior, high-resolution sediment cores were collected along the three KITES transects. Activities of ${ }^{210} \mathrm{~Pb}$, ${ }^{137} \mathrm{Cs}$ and ${ }^{7} \mathrm{Be}$ were measured. The isotope inventories were also calculated for all three isotopes. The ${ }^{210} \mathrm{~Pb}$ data were used in a sequential-box model to determine the isotope residence times in the nearshore region. The ${ }^{7} \mathrm{Be}$ data were used to evaluate the short-term dynamics of the system. The similarity and differences between ${ }^{210} \mathrm{~Pb}$ and ${ }^{137} \mathrm{Cs}$ provide insights into sediment sources and transport pathways. 


\section{Methods}

\subsection{Study area and sampling}

The nearshore region of Lake Superior along the west side of the Keweenaw Peninsula was the focus area of the KITES project. Lake Superior is the largest freshwater lake in the world by surface area and second largest by volume, with a surface area of $8.21 \times 10^{10} \mathrm{~m}^{2}$ and a mean depth of $150 \mathrm{~m}$. It accounts for $10 \%$ of the world's fresh surface water. It is also an ultra-oligotrophic lake with a Secchi depth greater than $15 \mathrm{~m}$. Concentrations of suspended particles (generally $<1 \mathrm{mg} \mathrm{L}^{-1}$, [Jeong, 2002]) are low, and rates of sediment accumulation (0.1-3 $\mathrm{mm} \mathrm{yr}^{-1}$, [Evans et al., 1981]) are correspondingly low.

This study was conducted along approximately 150 kilometers of coastline on the northwest side of the Keweenaw Peninsula in Lake Superior (Figure 1 in chapter two, page 21). Within the study area, sampling was conducted in three main regions primarily along transects oriented perpendicular to the shoreline and extending from 0 to $21 \mathrm{~km}$ offshore (only $0-9 \mathrm{~km}$ for the northern transect). The lake bathymetry changes from a gentle slope $(0.007)$ at the southernmost $(\mathrm{ON})$ transect to a narrow shelf at the middle transect $(\mathrm{HN})$ to a steep slope (0.035) along the northernmost transect $(\mathrm{EH})$. Previous investigations have reported the presence of a strong northeastward coastal current off the Keweenaw Peninsula, commonly referred to as the Keweenaw current [Ragotzkie, 1966; Viekman and Wimbush, 1993]. Numerical modeling by Chen et al. [2001] and Zhu et al. [2001] has indicated that the current is, in part, thermally driven, caused by rapid warming of near-shore (vs. offshore) water. 
As the major purpose of this research is to quantify the deposition and crossmargin transport fluxes in the 'transitional' zones, sediment cores were collected as close to shore as possible. It is the sediment characteristics that determine whether a core can be collected at any site. As shown in Table 1, the closest sites vary from $1 \mathrm{~km}$ on the EH transect to $9 \mathrm{~km}$ from shore on the $\mathrm{ON}$ transect. This, to some extent, already implies different sediment deposition behaviors on the three transects. On the EH transect, fine sediments start to accumulate within $1 \mathrm{~km}$ of shore. In contrast, the sandy bottom of nearshore ON sites (coring was unsuccessfully attempted between 5 and $8 \mathrm{~km}$ from shore) prevents sediment cores from being collected. On the HN transect, sediment cores were collectible first at 4 5 km from shore. The furthest sites from shore on each transect are at $21 \mathrm{~km}$ on the $\mathrm{ON}$ and $\mathrm{HN}$ transects and at $9 \mathrm{~km}$ on the $\mathrm{EH}$ transect. The number of cores obtained along each transect ranged from 5 to 7 (Tables $1 \& 2$ ).

Approximately 10 cores were taken in each year because of limited availability of gamma detectors. Table 2 gives more details about the cores taken in the three sampling years. In year 2001, the project was initiated and trial samples were taken on the HN transect. In year 2002 and 2003, all three transects were visited after promising preliminary results were obtained in the first year. To examine spatial heterogeneity at individual stations, at two stations three replicate cores were collected and at three stations duplicate cores were collected. The stations along the HN transect were visited multiple times to examine seasonal variations in isotope inventories.

The majority of the cores were collected with a gravity corer; for some of the cores collected in 2003 a Jenkin's corer was used. For the gravity corer, a clean 5-cm diameter, 76-cm long lexan core tube was used inside a stainless steel sleeve. In 2003, 
the different bottom conditions along the $\mathrm{ON}$ and $\mathrm{EH}$ transects caused over-penetration (i.e., sediment entered the free space above the core tube) and made it impossible to preserve the water-sediment interface. In those cases, a different coring device, the Jenkin's corer, was applied and cores were taken successfully. The core tube used in the Jenkin's corer is $7.6 \mathrm{~cm}$ in diameter and $30 \mathrm{~cm}$ long; generally, a $\sim 10 \mathrm{~cm}$ core was obtained. The Michigan Tech research vessel, $R / V$ Agassiz, was used on the sampling cruises.

Table 1. Coordinates of coring stations.

\begin{tabular}{lrrr} 
Station & Lat (decimal) & Lon (decimal) & distance $\mathbf{( k m )}$ \\
\hline EH010 & 47.4802 & -88.1352 & 1 \\
EH020 & 47.4891 & -88.1375 & 2 \\
EH030 & 47.4979 & -88.1398 & 3 \\
EH050 & 47.5156 & -88.1445 & 5 \\
EH070 & 47.5333 & -88.1491 & 7 \\
EH090 & 47.5510 & -88.1537 & 9 \\
HN040 & 47.2803 & -88.6087 & 4 \\
HN050 & 47.2876 & -88.6163 & 5 \\
HN060 & 47.2950 & -88.6239 & 6 \\
HN070 & 47.3024 & -88.6315 & 7 \\
HN080 & 47.3098 & -88.6391 & 8 \\
HN090 & 47.3171 & -88.6467 & 9 \\
HN100 & 47.3245 & -88.6543 & 10 \\
HN130 & 47.3466 & -88.6772 & 13 \\
HN170 & 47.3760 & -88.7076 & 17 \\
HN210 & 47.4055 & -88.7381 & 21 \\
ON090 & 46.9705 & -89.3457 & 9 \\
ON110 & 46.9853 & -89.3608 & 11 \\
ON130 & 47.0000 & -89.3759 & 13 \\
ON170 & 47.0294 & -89.4062 & 17 \\
ON210 & 47.0589 & -89.4365 & 21
\end{tabular}


Table 2. Sediment cores collected in the study.

\begin{tabular}{|c|c|c|c|c|c|}
\hline Transect & Station & Sampling date & Distance (km) & Water depth (m) & Core length $(\mathrm{cm})$ \\
\hline \multirow{24}{*}{$\mathrm{HN}$} & unknown $^{1}$ & $6 / 3 / 2003$ & $4 \sim 5$ & 88 & \\
\hline & \multirow[t]{3}{*}{050} & $7 / 20 / 2001$ & 5 & 115 & 18 \\
\hline & & $6 / 12 / 2002$ & & 115 & $15^{6}$ \\
\hline & & $6 / 3 / 2003^{2}$ & & 115 & $15^{6}$ \\
\hline & \multirow[t]{2}{*}{060} & $7 / 20 / 2001$ & 6 & 113 & 33 \\
\hline & & 2002July ${ }^{3}$ & & & $6^{4}$ \\
\hline & \multirow[t]{3}{*}{070} & $7 / 20 / 2001$ & 7 & 127 & 23 \\
\hline & & $6 / 12 / 2002^{2}$ & & 127 & $15 / 6^{5}$ \\
\hline & & $10 / 24 / 2002$ & & & $15^{6}$ \\
\hline & \multirow[t]{2}{*}{080} & $7 / 20 / 2001$ & 8 & 118 & 25 \\
\hline & & $6 / 12 / 2002$ & & 117 & $15^{6}$ \\
\hline & \multirow[t]{3}{*}{090} & $7 / 20 / 2001$ & 9 & 109 & 38 \\
\hline & & $6 / 12 / 2002^{2}$ & & 120 & $15 / 6^{5}$ \\
\hline & & 2002July ${ }^{3}$ & & & $6^{4}$ \\
\hline & \multirow[t]{2}{*}{100} & $7 / 20 / 2001$ & 10 & 111 & 51 \\
\hline & & $6 / 12 / 2002$ & & 113 & $15^{6}$ \\
\hline & \multirow[t]{2}{*}{130} & $7 / 20 / 2001$ & 13 & 147 & 60 \\
\hline & & $6 / 12 / 2002$ & & 147 & $15^{6}$ \\
\hline & \multirow[t]{2}{*}{170} & $7 / 20 / 2001$ & 17 & 180 & 66 \\
\hline & & $6 / 12 / 2002$ & & 179.5 & 10 \\
\hline & \multirow[t]{4}{*}{210} & $7 / 20 / 2001$ & 21 & 170 & 38 \\
\hline & & $6 / 12 / 2002$ & & 161.5 & $15^{6}$ \\
\hline & & $9 / 24 / 2002$ & & & $15^{6}$ \\
\hline & & $6 / 3 / 2003$ & & 164 & $15^{6}$ \\
\hline \multirow{7}{*}{$\mathrm{EH}$} & 010 & $6 / 4 / 2003$ & 1 & 109 & 12 \\
\hline & 020 & $6 / 4 / 2003$ & 2 & 207 & $15^{6}$ \\
\hline & 030 & $6 / 4 / 2003$ & 3 & 255 & 12 \\
\hline & \multirow[t]{2}{*}{050} & $5 / 25 / 2003$ & 5 & 255 & $15^{6}$ \\
\hline & & $6 / 4 / 2003$ & & 254 & \\
\hline & 070 & $6 / 3 / 2003$ & 7 & 257 & $15^{6}$ \\
\hline & 090 & $6 / 3 / 2003$ & 9 & 261 & 10 \\
\hline \multirow{5}{*}{ ON } & 090 & $7 / 16 / 2003$ & 9 & 70.5 & $15^{6}$ \\
\hline & 110 & $7 / 16 / 2003$ & 11 & 74.5 & $15^{6}$ \\
\hline & 130 & $7 / 16 / 2003$ & 13 & 84 & $15^{6}$ \\
\hline & 170 & $7 / 16 / 2003$ & 17 & 105 & 12.5 \\
\hline & 210 & $7 / 16 / 2003$ & 21 & 128 & 10 \\
\hline \multicolumn{6}{|c|}{ 1. Site is between 040 and 050.} \\
\hline \multicolumn{6}{|c|}{ 2: Two replicate cores were taken. } \\
\hline \multicolumn{6}{|c|}{ 3: Three replicate cores were taken at the sites. } \\
\hline \multicolumn{6}{|c|}{ : Only top 6 centimeters of the core were extruded. } \\
\hline \multicolumn{6}{|c|}{ 5: One core was extruded regularly and the other one was only extruded for the top $6 \mathrm{~cm}$. } \\
\hline
\end{tabular}




\subsection{Sample pretreatment and analysis}

Sediment cores were initially refrigerated upon collection and brought back to the laboratory for further processing. Care was taken during the sampling and handling procedures so that the water-sediment interface would be well preserved. In each core, the surficial layer of newly deposited sediments, the "fluff layer", was first removed, and then the underlying sediments were extruded as detailed below.

Upon return to the lab, the first priority was to collect the unconsolidated surface layers (i.e., the 'fluff') or easily resuspendable sediments. Water was siphoned out of the headspace of the core tube until about $10 \mathrm{~cm}$ of water remained above the sediments. A diffusion stone was suspended $\sim 1 \mathrm{~cm}$ above the sediments and air was sparged (15 $\mathrm{kPa}$ ) for more than 5 minutes through the stone to resuspend surficial sediments. The watersediment mixture was then collected using tubing connected to a peristaltic pump. The resultant water-sediment mixture was frozen and then freeze-dried with a LabConco freeze drier.

After removal of the fluff layer, the core was secured on a custom-made hydraulic extruder. Cores were extruded and sliced every $0.5 \mathrm{~cm}$ until $5 \mathrm{~cm}$ depth. After that, $1-$ $\mathrm{cm}$ intervals were used until $15 \mathrm{~cm}$. The remainder of the cores were discarded as results from longer (up to $60-\mathrm{cm}$ ) cores in the first year indicated that ${ }^{137} \mathrm{Cs}$ and excess ${ }^{210} \mathrm{~Pb}$ inventories were confined to the top $15 \mathrm{~cm}$. After each core increment was extruded, the sediment was transferred to a pre-weighed beaker. The beaker with wet sediment was weighed, a subsample (about one fourth) was transferred to a whirl-pak bag and frozen, and the beaker was reweighed. The beaker with the remaining sediment was then put in 
the oven at $105^{\circ} \mathrm{C}$ for at least 24 hours. The dry sediment was weighed and then ground with a mortar and pestle.

Isotope counting: Radiometric measurements were made using low-background gamma counting systems with well-type high purity germanium detectors [Appleby et al., 1988; Schelske et al., 1994]. About 1 2 g dry sediment was packed and sealed (epoxy) in a polypropylene vial and then counted for at least 48 hours. Activities for each radioisotope were calculated from raw counts using energy-specific counting efficiencies, sample mass and counting time. Efficiency calibrations were performed with Baltic Sea Sediments (IAEA) in the same configuration as samples so no geometry correction was applied. Counting efficiency for ${ }^{7} \mathrm{Be}$ was determined by linear interpolation because this isotope is not present in the standard [Robbins and Eadie, 1991]. The 1- $\sigma$ counting error (\% of total counts) was within $5-10 \%$ in most cases. Total ${ }^{210} \mathrm{~Pb}$ activity was obtained from the $46.5 \mathrm{keV}$ photon peak, and ${ }^{7} \mathrm{Be}$ and ${ }^{137} \mathrm{Cs}$ peaks are at $477.6 \mathrm{keV}$ and $661.2 \mathrm{keV}$, respectively. Another naturally occurring gamma-emitting radionuclide, ${ }^{40} \mathrm{~K}$, was also monitored at its $1460.7 \mathrm{keV}$ peak.

C \& N measurements: Carbon and nitrogen were measured on some samples with a Carlo Erba NA 1500 Elemental Analyzer. Precision was better than 5\% for both elements, and accuracy was verified with NIST SRM 2704 (Buffalo River Sediments).

Loss On Ignition: A subsample of the dried sediment samples was transferred into a pre-weighed aluminum pan and placed in a muffle furnace at $550^{\circ} \mathrm{C}$ for 2 hours. After 
cooling, the percentage of the dry weight lost on ignition was calculated. About 1 2 gram of sediment was used although less sample mass was used in some instances due to limited sample amounts. Triplicate measurements for some samples and blank samples (only pans) were made for quality control. 


\section{Results}

\subsection{Transect bathymetry}
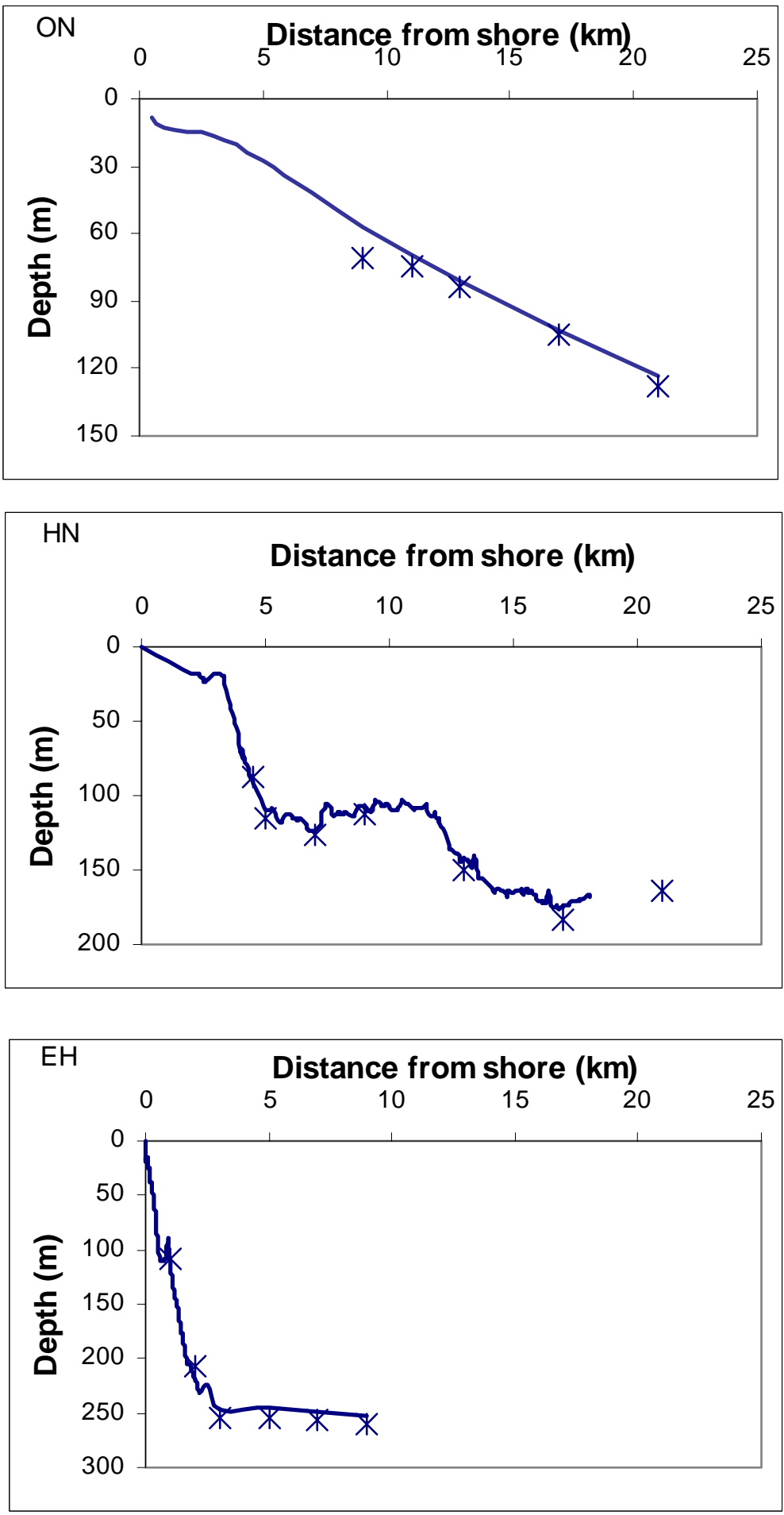

Figure 1. Bathymetry of the three transect with coring sites also shown 
Although the three transects are all located along the northwest coast of the Keweenaw Peninsula and the direct distance from station ON210 to station EH090 is only $115 \mathrm{~km}$, the three transects exhibit markedly different bathymetries (Figure 1). The bathymetric profiles are from the ship-based measurements $(R / V$ Blue Heron $)$ in the first field year in the KITES project. The field-recorded core depths fit the bathymetry generally well as shown by the points in Figure 1 . The ON transect is located about $5 \mathrm{~km}$ northeast of the mouth of the Ontonagon River, the second largest riverine source of phosphorus and sediments along the U.S. shore of the lake [Robertson, 1997]. This transect also experiences markedly lower velocities of the Keweenaw current than does the EH transect (E. Ralph, Univ. Minnesota, unpubl. data).

\subsection{Sediment characteristics - bulk density and porosity}

In Appendix 1, the porosity (water contain in percentage) and bulk density (density of dry sediment in $\mathrm{g} / \mathrm{cm}^{3}$ ) of all the cores listed in Table 2 are tabulated and graphed. Some examples are shown in Figure 2 with sites from the two different zones (temporary deposition zone and net deposition zone) along each transect. 

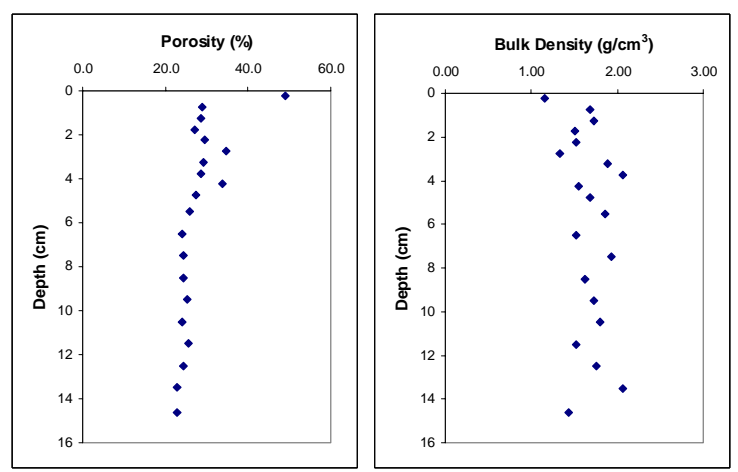

HN050
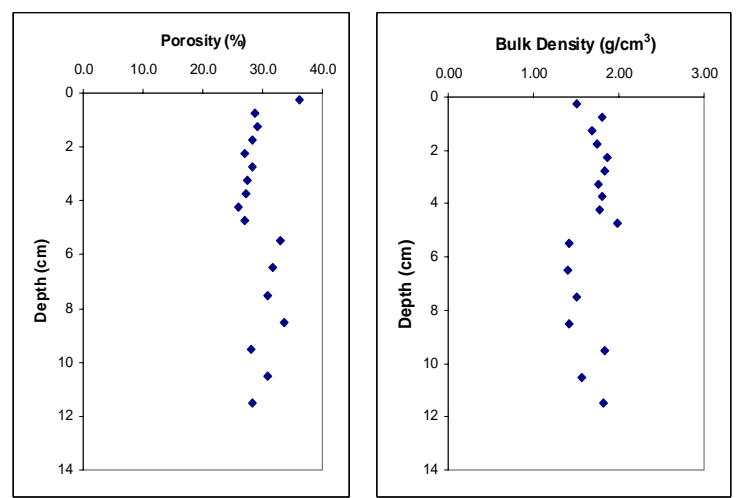

EH010
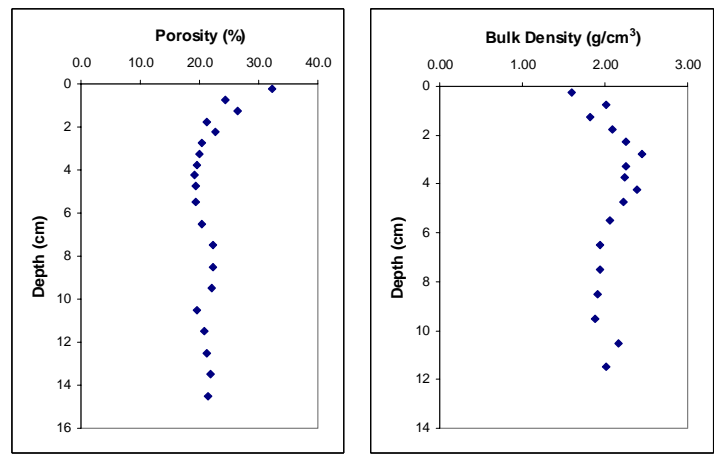

ON090
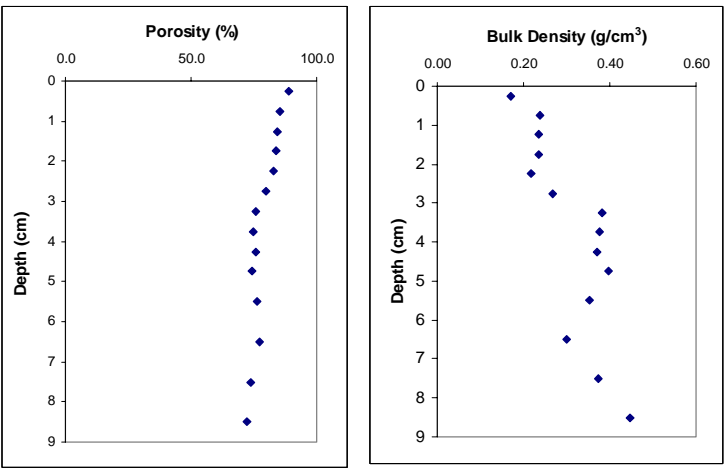

HN170
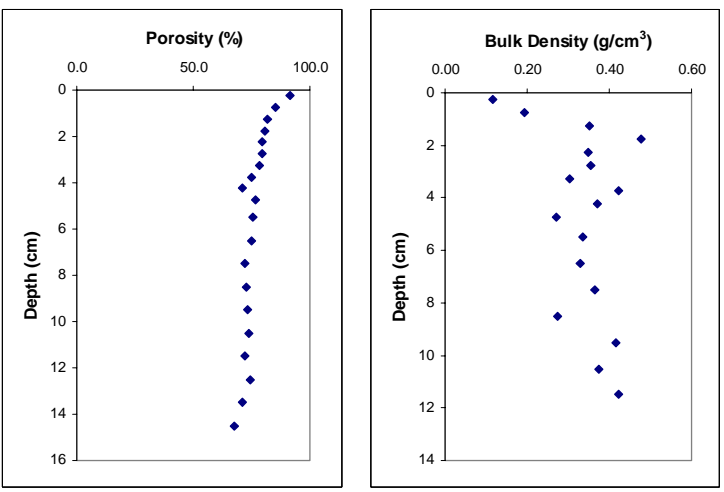

EN070
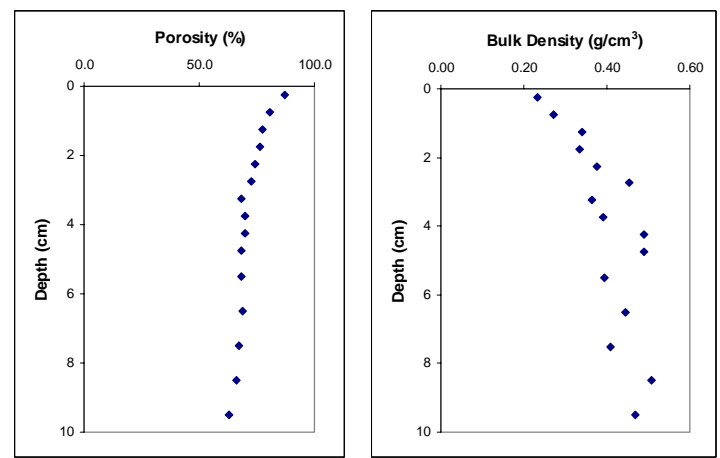

ON210

Figure 2. Sediment properties (left - porosity (\%), right - bulk density $\left(\mathrm{g} / \mathrm{cm}^{3}\right)$ ) of selected cores. 


\subsection{Sediment characteristics - others}

Other sediment characteristics ( $\mathrm{C}$ and $\mathrm{N}$ content, LOI, $\mathrm{C}: \mathrm{N}$ ratio) also are markedly different in the three lake zones. Carbon and nitrogen content are much higher in the profundal zone as compared with the slope region. Ratios of carbon to nitrogen, however, suggest that the lower slope (HN100-HN130) along the HN transect either receives different organic matter or processes the organic matter differently than the upper slope (HN050-HN090). Loss on ignition (LOI), a surrogate for organic carbon content [Davis and Ford, 1982], shows essentially the same pattern. Surface values for LOI as well as depth profiles are summarized in Table 3.

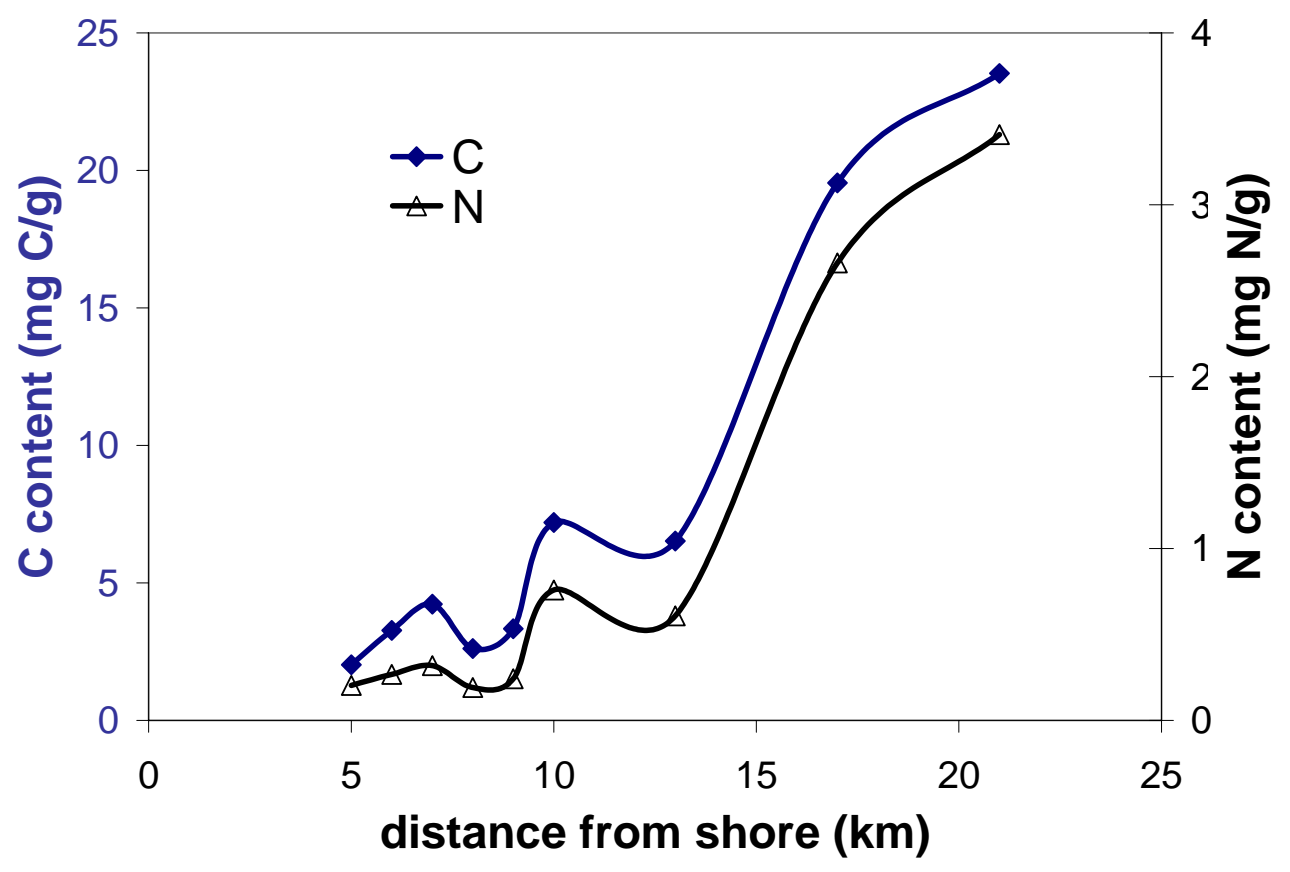




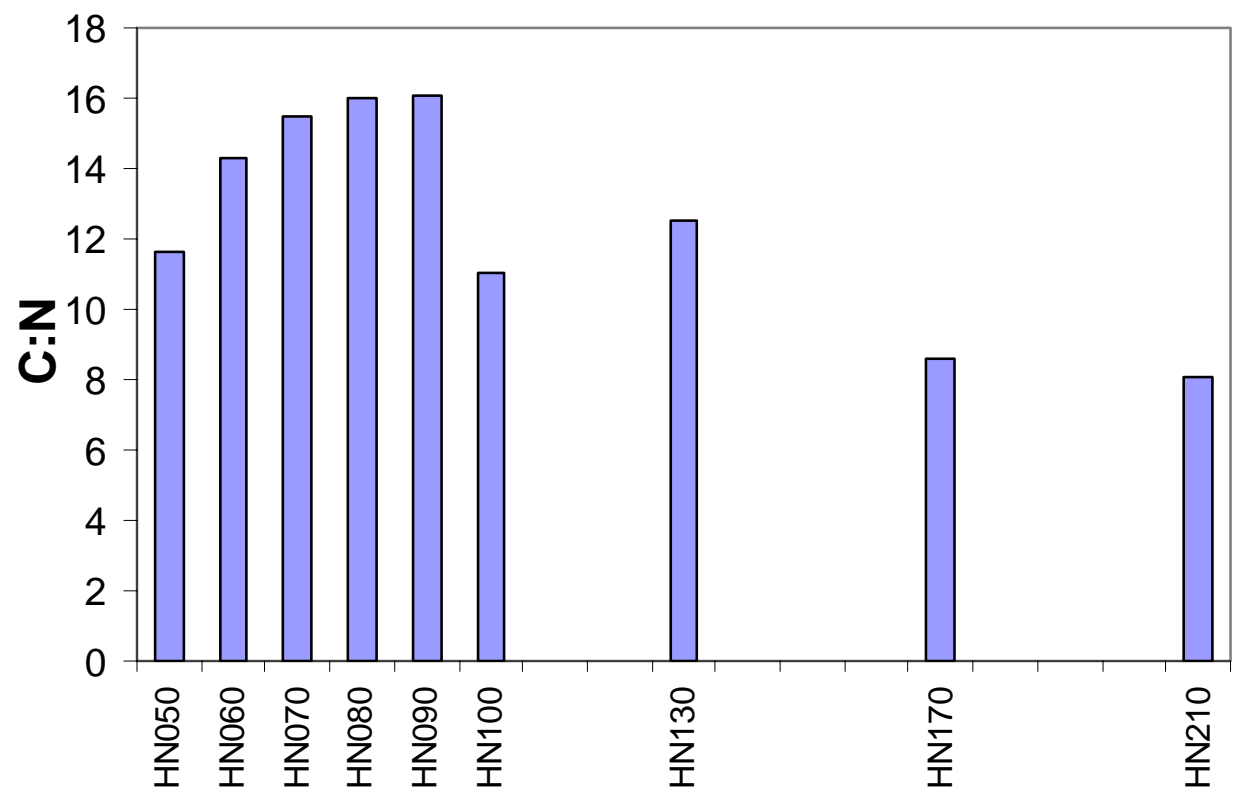

Figure 3. (A) $\mathrm{C}$ and $\mathrm{N}$ concentrations in surface sediments from $\mathrm{HN}$ transect; (B) $\mathrm{C}: \mathrm{N}$ (molar) ratio in the surface sediment along the $\mathrm{HN}$ transect, year 2001.

Table 3. LOI results of 2003 sediment cores.

\begin{tabular}{l|cccccc}
\hline & EH010 & EH020 & EH030 & EH050 & EH070 & EH090 \\
$\mathbf{0 - 0 . 5} \mathbf{~ c m}$ & 1.43 & 2.03 & 5.60 & 3.30 & 9.14 & 6.78 \\
$\mathbf{0 . 5 - 1 . 0 ~ c m ~}$ & 1.18 & & & 3.49 & & -1 \\
$\mathbf{5 - 6} \mathbf{~ c m}$ & 1.90 & & & 3.57 & & 5.44 \\
\hline & ON090 & ON110 & ON130 & ON170 & ON210 & \\
$\mathbf{0 - 0 . 5} \mathbf{~ c m}$ & 1.47 & 1.5 & 2.77 & 6.51 & 8.34 & \\
$\mathbf{0 . 5 - 1 . 0 ~ c m ~}$ & 1.19 & & 2.18 & & 7.59 & \\
$\mathbf{5 - 6} \mathbf{~ c m ~}$ & 0.84 & & $2.02 \pm 0.25^{2}$ & & 5.28 & \\
\hline & HN050 & HN210 & & & & \\
$\mathbf{0 - 0 . 5} \mathbf{~ c m}$ & 1.74 & 4.72 & & & & \\
\hline
\end{tabular}

1: Sample was spilled.

2. Mean and $95 \% \mathrm{Cl}$ was calculated based on three replicated measurements. 


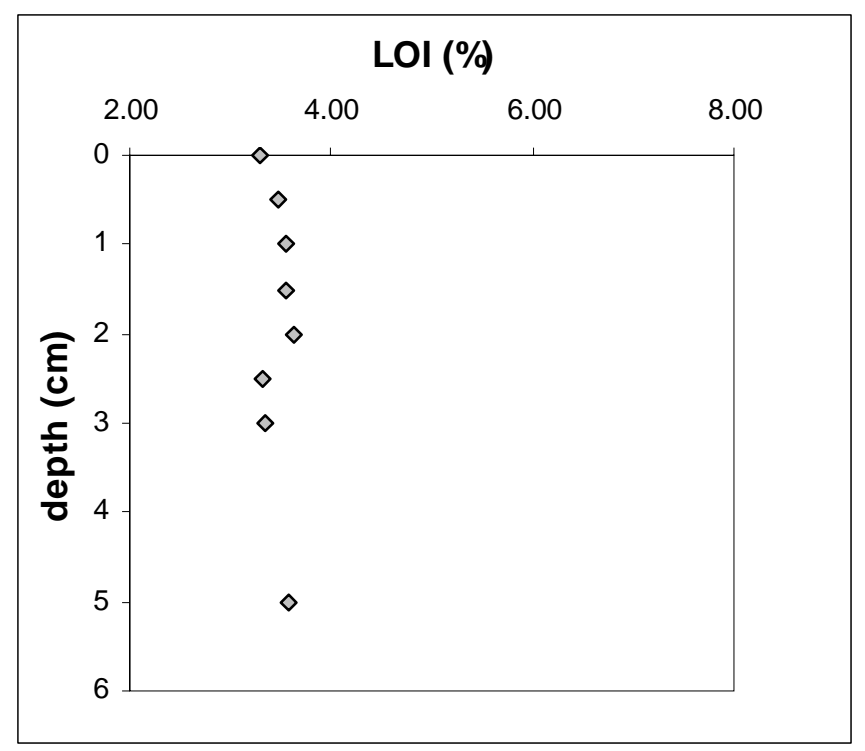

Figure 4. Depth profile of LOI of EH050 core, 2003. The average LOI value of the 8 samples is $3.47 \% \pm 0.09 \%$.

From the limited data shown in Table 3, two general trends in the LOI data can be observed. First, at individual sites, the LOI is generally higher in surface sediment and lower at depth. However, exceptions occur such as EH050 where significant depth-wise variation is not observed (Figure 4). Secondly, along a transect, LOI generally increases with distance from shore (Table 3).

\subsection{Isotope data}

For ${ }^{210} \mathrm{~Pb}$ and ${ }^{137} \mathrm{Cs}$ measured in this project, three categories of data are reported: (1) isotope activities in the easy resuspendable sediments (fluff layer), (2) isotope activity profiles with depth, and (3) calculated isotope inventories for entire cores. For ${ }^{7} \mathrm{Be}$, only activities and inventories in the fluff layer as well as in the top sediment layer, 0-0.5 cm, 
are shown because of the short half-life ( $57 \mathrm{~d}$ ) of this isotope. All results are corrected for isotopic decay to the date of sample collection.
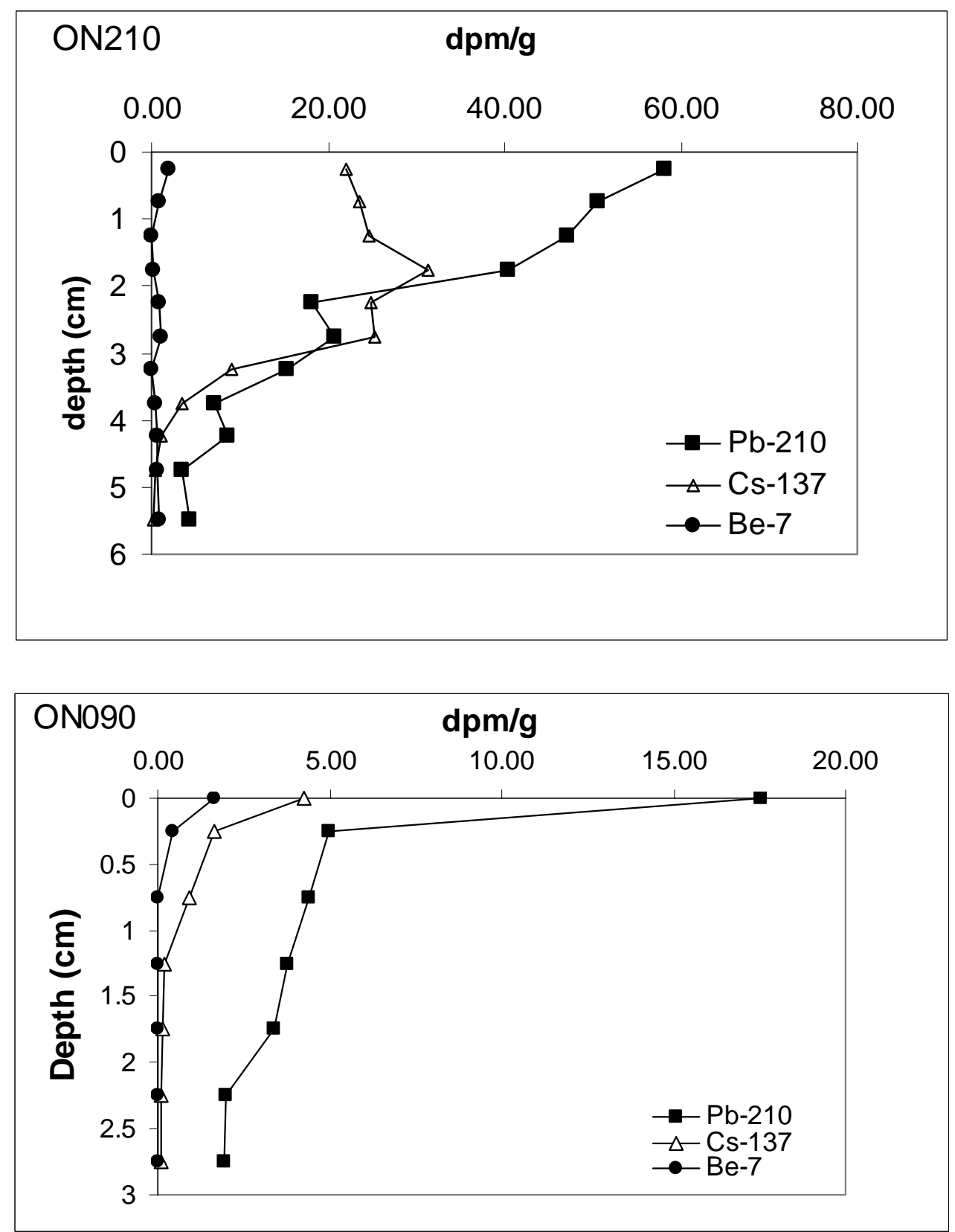

Figure 5. Two "typical" isotope profiles of the sites. Top: depth profiles at a netdepositional zone; bottom: depth profiles at a temporary depositional zone. 
Tables 4 to 6 list total activities of ${ }^{210} \mathrm{~Pb}$ and ${ }^{137} \mathrm{Cs}$ for all core samples. It can be seen that both isotope activity (high vs. low) and shape of depth profiles (depositional vs. non-depositional for both lead and cesium) are very different among cores from different sites. Figure 5 above shows two types of commonly observed profiles. For core ON210, profiles for both ${ }^{210} \mathrm{~Pb}$ and ${ }^{137} \mathrm{Cs}$ accurately show the record of atmospheric deposition, and the activities are comparable with previous studies [Evans et al., 1981; Kerfoot and Robbins, 1999]. However, at other sites such as ON090 the isotope inventories are much lower, and the historical record of deposition is not well preserved. The radioisotopes used here cannot be used to establish geochronologies for these sites, but do provide useful information on particle residence times and cross margin fluxes as discussed later.

${ }^{210} \mathrm{~Pb}$ activities have two components: (1) supported or background ${ }^{210} \mathrm{~Pb}$ generated by decay of ${ }^{226} \mathrm{Ra}$ present in the minerals, and (2) unsupported or excess ${ }^{210} \mathrm{~Pb}$ that is derived from atmospheric deposition. Thus supported ${ }^{210} \mathrm{~Pb}$ is coming from internal sources in the sediment, while unsupported ${ }^{210} \mathrm{~Pb}$ is from external sources, such as atmospheric deposition or groundwater inflows. By definition, supported ${ }^{210} \mathrm{~Pb}$ is in secular equilibrium with sedimentary ${ }^{226} \mathrm{Ra}$ and is equal to total ${ }^{210} \mathrm{~Pb}$ activity at depth where excess ${ }^{210} \mathrm{~Pb}$ activity is not measurable due to decay. This statement provides the rationale for two methods of determining supported ${ }^{210} \mathrm{~Pb}$. The first is to measure the ${ }^{226} \mathrm{Ra}$ activity in a sample; actually either ${ }^{214} \mathrm{Bi}$ or ${ }^{214} \mathrm{~Pb}$ are measured. These gamma emitting, short-lived daughters of ${ }^{226} \mathrm{Ra}$ also are in secular equilibrium with ${ }^{226} \mathrm{Ra}$ (if the samples were sealed for an adequate time (about 5-6 half-lives of ${ }^{222} \mathrm{Rn}$ ) prior to measurement). The second method is to assume that activities of supported ${ }^{210} \mathrm{~Pb}$ are constant throughout the core, and to use measured ${ }^{210} \mathrm{~Pb}$ activity at depth as a direct 
measure of the background concentration. Unfortunately, sealing of sediment in the vial prevents the timely measurement of ${ }^{7} \mathrm{Be}$ in the sediment whose activity may be low and rapidly decaying.

In this project, the second method was applied and each core was examined carefully to determine the supported ${ }^{210} \mathrm{~Pb}$ activities. First, the profiles of ${ }^{210} \mathrm{~Pb}$ were examined to identify the depth at which the activity plateaus. A sample at depths well below the beginning of the plateau, normally $5-6 \mathrm{~cm}$, was counted and this value was subtracted from activities higher in the core. These results were verified with two other isotopes. The first is ${ }^{137} \mathrm{Cs}$, which has a similar half-life as ${ }^{210} \mathrm{~Pb}$ but is an anthropogenic isotope only introduced to the environment in the last century. The ${ }^{137} \mathrm{Cs}$ activities should be zero at depths where excess ${ }^{210} \mathrm{~Pb}$ is absent. Another check is to examine the ratio of ${ }^{210} \mathrm{~Pb}$ to ${ }^{40} \mathrm{~K}$, a long-lived $\left(\tau_{1 / 2}=1600 \mathrm{yr}\right.$ ), naturally-occurring isotope. As long as the mineralogy within a core remains constant with depth, the ratio of ${ }^{226} \mathrm{Ra}$ to ${ }^{40} \mathrm{~K}$, and thus the supported ${ }^{210} \mathrm{~Pb}:{ }^{40} \mathrm{~K}$ ratio, should remain constant. Profiles of these ratios are presented in Appendix 4. Compared with use of the ${ }^{210} \mathrm{~Pb}$ profile alone, use of the ${ }^{40} \mathrm{~K}$ normalized ${ }^{210} \mathrm{~Pb}$ profile more clearly identifies the depth at which background ${ }^{210} \mathrm{~Pb}$ equals total ${ }^{210} \mathrm{~Pb}$; minor changes in sediment characteristics do not affect this ratio. Using these procedures, the background ${ }^{210} \mathrm{~Pb}$ activity for each core was determined as summarized in tables 4-6. The underlined data show the points used to compute the background ${ }^{210} \mathrm{~Pb}$. Excess ${ }^{210} \mathrm{~Pb}$ is calculated as the difference between total ${ }^{210} \mathrm{~Pb}$ activity of that sample and the supported ${ }^{210} \mathrm{~Pb}$ activity for the core. 
Table 4. ${ }^{210} \mathrm{~Pb}$ (upper) and ${ }^{137} \mathrm{Cs}$ (lower) data of 2001 cores - $\mathrm{HN}$ transect. Unit is dpm/g. For ${ }^{210} \mathrm{~Pb}$, underlined values are those on which the background ${ }^{210} \mathrm{~Pb}$ values are based.

\begin{tabular}{|c|c|c|c|c|c|c|c|c|c|}
\hline & 050 & 060 & 070 & 080 & 090 & 100 & 130 & 170 & 210 \\
\hline top layer & 21.85 & - & 31.64 & - & 7.90 & - & 12.32 & 67.50 & 45.28 \\
\hline $0-0.5 \mathrm{~cm}$ & 6.51 & 5.75 & 10.05 & 4.49 & 3.68 & 9.47 & 4.17 & 26.50 & 41.80 \\
\hline $0.5-1.0 \mathrm{~cm}$ & 6.70 & 5.28 & 8.55 & 4.58 & 3.70 & 3.16 & 3.97 & 16.90 & 42.75 \\
\hline $1.0-1.5 \mathrm{~cm}$ & 5.83 & 4.87 & 5.19 & 4.03 & 3.70 & 3.12 & 4.97 & 9.10 & 29.59 \\
\hline $1.5-2.0 \mathrm{~cm}$ & 4.49 & 4.61 & 3.94 & 3.61 & 3.82 & 3.03 & 3.72 & 8.22 & 23.93 \\
\hline $2.0-2.5 \mathrm{~cm}$ & $\overline{4.43}$ & $\overline{5.09}$ & 4.53 & $\overline{4.43}$ & 2.99 & $\overline{3.00}$ & $\overline{3.45}$ & $\overline{8.29}$ & 10.47 \\
\hline $2.5-3.0 \mathrm{~cm}$ & & $\overline{3.22}$ & 4.12 & $\overline{3.78}$ & $\overline{2.77}$ & & & $\overline{7.28}$ & 8.59 \\
\hline $3.0-3.5 \mathrm{~cm}$ & & & & & & & & 8.14 & 7.64 \\
\hline $3.5-4.0 \mathrm{~cm}$ & & & & & & & & 7.54 & $\underline{6.60}$ \\
\hline $4.0-4.5 \mathrm{~cm}$ & & & & & & & & $\overline{8.63}$ & \\
\hline $4.5-5.0 \mathrm{~cm}$ & & & & & & & & 7.38 & \\
\hline $5-6 \mathrm{~cm}$ & $\underline{4.50}$ & 4.12 & 4.35 & $\underline{3.42}$ & 3.68 & 3.68 & 3.36 & $\underline{6.37}$ & $\underline{5.56}$ \\
\hline background & $\overline{4.48}$ & $\overline{4.26}$ & 4.23 & 3.81 & 2.88 & 3.05 & 3.51 & 7.73 & 6.08 \\
\hline
\end{tabular}

\begin{tabular}{|c|c|c|c|c|c|c|c|c|c|}
\hline & 050 & 060 & 070 & 080 & 090 & 100 & 130 & 170 & 210 \\
\hline Top layer & 4.24 & - & 11.54 & - & 1.75 & - & 3.04 & 17.77 & 21.76 \\
\hline $0-0.5 \mathrm{~cm}$ & 2.30 & 1.13 & 7.24 & 0.45 & 0.01 & 3.75 & 0.53 & 12.39 & 22.14 \\
\hline $0.5-1.0 \mathrm{~cm}$ & 4.91 & 0.32 & 5.02 & 0.16 & 0.13 & 0.83 & 0.51 & 1.41 & 22.29 \\
\hline $1.0-1.5 \mathrm{~cm}$ & 4.69 & 0.14 & 1.33 & 0.34 & 0.15 & 0.02 & 0.21 & 0.34 & 18.63 \\
\hline $1.5-2.0 \mathrm{~cm}$ & 0.65 & 0.19 & 1.10 & 0.24 & 0.05 & 0.06 & 0.13 & 0.13 & 11.06 \\
\hline $2.0-2.5 \mathrm{~cm}$ & 0.33 & 0.05 & 0.43 & 0.11 & 0.10 & 0.01 & 0.00 & 0.19 & 4.25 \\
\hline $2.5-3.0 \mathrm{~cm}$ & & 0.13 & & 0.10 & 0.11 & & & 0.05 & 1.56 \\
\hline $3.0-3.5 \mathrm{~cm}$ & & & & & & & & 0.11 & 0.71 \\
\hline $3.5-4.0 \mathrm{~cm}$ & & & & & & & & 0.11 & 0.60 \\
\hline $4.0-4.5 \mathrm{~cm}$ & & & & & & & & 0.09 & \\
\hline $4.5-5.0 \mathrm{~cm}$ & & & & & & & & 0.07 & \\
\hline $5-6 \mathrm{~cm}$ & & & & & & & & 0.10 & \\
\hline
\end{tabular}


Table 5. ${ }^{210} \mathrm{~Pb}$ (upper) and ${ }^{137} \mathrm{Cs}$ (lower) data of 2002 cores - HN transect. Unit is dpm/g. For ${ }^{210} \mathrm{~Pb}$, underlined values are those on which the background ${ }^{210} \mathrm{~Pb}$ values are based.

\begin{tabular}{|c|c|c|c|c|c|c|c|c|c|c|c|}
\hline & 050 & 070 & 070-1 & 070-Cct. & 080 & 090 & 090-1 & 100 & 130 & 170 & 210 \\
\hline top layer & 5.80 & 13.70 & 12.50 & 8.35 & 20.39 & 41.81 & 34.81 & 14.17 & 32.32 & 66.93 & 41.77 \\
\hline $0-0.5 \mathrm{~cm}$ & 3.19 & 9.07 & \multirow{10}{*}{3.69} & 3.71 & 5.54 & 6.08 & \multirow{10}{*}{4.11} & 3.88 & 6.76 & 63.02 & 10.42 \\
\hline $0.5-1.0 \mathrm{~cm}$ & 3.89 & 7.10 & & 2.85 & 3.31 & 4.42 & & 4.40 & 5.15 & 64.44 & 5.87 \\
\hline $1.0-1.5 \mathrm{~cm}$ & 3.61 & 2.00 & & 2.67 & 2.31 & 4.16 & & 3.63 & 4.46 & 71.32 & 2.97 \\
\hline $1.5-2.0 \mathrm{~cm}$ & 3.06 & 2.00 & & 3.22 & & 3.17 & & & & 53.21 & $\underline{3.60}$ \\
\hline $2.0-2.5 \mathrm{~cm}$ & 2.84 & 2.33 & & & & 3.32 & & & & 61.66 & \\
\hline $2.5-3.0 \mathrm{~cm}$ & 3.07 & & & & & & & & & 44.63 & \\
\hline $3.0-3.5 \mathrm{~cm}$ & 3.48 & & & & & & & & & 17.95 & \\
\hline $3.5-4.0 \mathrm{~cm}$ & 1.98 & & & & & & & & & 8.27 & \\
\hline $4.0-4.5 \mathrm{~cm}$ & & & & & & & & & & 6.62 & \\
\hline $4.5-5.0 \mathrm{~cm}$ & & & & & & & & & & 4.50 & \\
\hline $5-6 \mathrm{~cm}$ & 3.91 & & 1.65 & 3.05 & 2.26 & & 2.24 & 5.01 & 4.64 & 4.78 & 4.32 \\
\hline background & 3.13 & \multicolumn{2}{|c|}{2.11} & 2.95 & 2.28 & \multicolumn{2}{|c|}{3.24} & 3.63 & 4.55 & 4.64 & 3.63 \\
\hline
\end{tabular}

\begin{tabular}{|c|c|c|c|c|c|c|c|c|c|c|c|}
\hline & 050 & 070 & 070-1 & 070-Oct. & 080 & 090 & 090-1 & 100 & 130 & 170 & 210 \\
\hline Top layer & 1.63 & 2.38 & 4.07 & 1.30 & 5.34 & 5.24 & 7.15 & 3.82 & 9.31 & 33.91 & 25.77 \\
\hline $0-0.5 \mathrm{~cm}$ & 0.73 & 1.16 & \multirow{10}{*}{0.59} & 0.09 & 3.45 & 2.30 & \multirow{10}{*}{0.75} & 0.63 & 1.53 & 29.17 & 5.57 \\
\hline $0.5-1.0 \mathrm{~cm}$ & 0.92 & 3.27 & & 0.20 & 0.61 & 2.53 & & 0.07 & 0.20 & 27.45 & 0.46 \\
\hline $1.0-1.5 \mathrm{~cm}$ & 1.50 & 0.26 & & 0.04 & 0.09 & 0.16 & & 0.14 & 0.18 & 25.89 & 0.16 \\
\hline $1.5-2.0 \mathrm{~cm}$ & 2.60 & 0.10 & & 0.13 & & 0.15 & & & & 21.19 & 0.15 \\
\hline $2.0-2.5 \mathrm{~cm}$ & 2.54 & 0.18 & & & & & & & & 16.71 & \\
\hline $2.5-3.0 \mathrm{~cm}$ & 1.06 & & & & & & & & & 28.76 & \\
\hline $3.0-3.5 \mathrm{~cm}$ & 0.12 & & & & & & & & & 11.12 & \\
\hline $3.5-4.0 \mathrm{~cm}$ & 0.06 & & & & & & & & & 0.61 & \\
\hline $4.0-4.5 \mathrm{~cm}$ & & & & & & & & & & 0.71 & \\
\hline $4.5-5.0 \mathrm{~cm}$ & & & & & & & & & & 0.19 & \\
\hline $5-6 \mathrm{~cm}$ & 0.08 & & 0.02 & 0.11 & 0.00 & 0.10 & 0.03 & 0.17 & 0.05 & 0.30 & 0.12 \\
\hline
\end{tabular}


Table 6. ${ }^{210} \mathrm{~Pb}$ (this page) and ${ }^{137} \mathrm{Cs}$ (next page) data from 2003 cores - EH and ON transects. Unit is dpm/g. For ${ }^{210} \mathrm{~Pb}$, underlined values are those on which the background ${ }^{210} \mathrm{~Pb}$ values are based.

\begin{tabular}{|c|c|c|c|c|c|c|c|c|c|c|c|}
\hline & EH010 & EH020 & EH030 & EH050 & EH070 & EH090 & ON090 & ON110 & ON130 & ON170 & ON210 \\
\hline Top layer & 13.57 & 76.79 & 15.75 & 76.47 & 61.24 & 13.88 & 17.51 & 5.64 & 30.89 & 62.96 & 23.16 \\
\hline $0-0.5 \mathrm{~cm}$ & 1.83 & 8.07 & 8.85 & 7.88 & 71.66 & 15.25 & 4.97 & 6.94 & 14.85 & 37.74 & 58.10 \\
\hline $0.5-1.0 \mathrm{~cm}$ & 1.37 & 8.67 & 7.49 & 3.68 & 60.63 & 8.69 & 4.38 & 4.99 & 6.92 & 40.09 & 50.52 \\
\hline $1.0-1.5 \mathrm{~cm}$ & 1.19 & 5.19 & 6.67 & 1.84 & 60.43 & 6.80 & 3.75 & 4.51 & 4.69 & \multirow{2}{*}{25.37} & 47.21 \\
\hline $1.5-2.0 \mathrm{~cm}$ & 1.20 & 3.83 & 4.24 & 1.45 & 55.05 & 3.72 & 3.40 & 1.98 & 3.57 & & 40.41 \\
\hline $2.0-2.5 \mathrm{~cm}$ & 1.41 & 3.65 & 5.49 & 2.37 & 49.66 & 2.46 & 1.98 & & & 15.45 & 18.16 \\
\hline $2.5-3.0 \mathrm{~cm}$ & 0.59 & 2.92 & 3.77 & 1.61 & 46.15 & 2.20 & 1.94 & & & 15.35 & 20.83 \\
\hline $3.0-3.5 \mathrm{~cm}$ & 0.97 & 3.08 & $\underline{4.65}$ & & 36.54 & 2.63 & & & & 11.15 & 15.27 \\
\hline $3.5-4.0 \mathrm{~cm}$ & 0.93 & 3.04 & & & 28.98 & & & & & 7.97 & 7.12 \\
\hline $4.0-4.5 \mathrm{~cm}$ & 0.69 & 3.84 & & & 20.20 & & & & & 8.45 & 8.66 \\
\hline $4.5-5.0 \mathrm{~cm}$ & 0.39 & & & & 15.72 & & & & & $\underline{6.60}$ & $\underline{3.51}$ \\
\hline $5-6 \mathrm{~cm}$ & $\underline{0.59}$ & 0.92 & & 1.08 & 15.10 & & 2.40 & 2.01 & 3.19 & 5.28 & 4.25 \\
\hline $6-7 \mathrm{~cm}$ & & & & & 11.53 & & & & & $\underline{5.51}$ & \\
\hline $7-8 \mathrm{~cm}$ & & & & & 10.37 & & & & & & \\
\hline $8-9 \mathrm{~cm}$ & & & & & 6.61 & & & & & & \\
\hline $9-10 \mathrm{~cm}$ & & & & & 6.79 & & & & & & \\
\hline $10-11 \mathrm{~cm}$ & & & & & 3.51 & & & & & & \\
\hline $11-12 \mathrm{~cm}$ & & & & & 4.50 & & & & & & \\
\hline Background & 0.69 & 3.22 & 4.54 & 1.63 & 4.00 & 2.43 & 1.96 & 1.99 & 3.38 & 5.80 & 3.88 \\
\hline
\end{tabular}


Table 6. Continues

\begin{tabular}{|c|c|c|c|c|c|c|c|c|c|c|c|}
\hline & EH010 & EH020 & EH030 & EH050 & EH070 & EH090 & ON090 & ON110 & ON130 & ON170 & ON210 \\
\hline top layer & 4.32 & 19.84 & 5.35 & 17.02 & 18.15 & 21.03 & 4.24 & 3.44 & 11.78 & 20.50 & 14.72 \\
\hline $0-0.5 \mathrm{~cm}$ & 0.96 & 2.50 & 7.29 & 5.09 & 22.49 & 12.00 & 1.64 & 2.17 & 11.16 & 13.47 & 22.11 \\
\hline $0.5-1.0 \mathrm{~cm}$ & 0.88 & 4.21 & 11.06 & 6.82 & 20.25 & 13.75 & 0.94 & 0.90 & 3.86 & 17.50 & 23.49 \\
\hline $1.0-1.5 \mathrm{~cm}$ & 1.14 & 5.89 & 8.54 & 5.00 & 22.18 & 19.46 & 0.20 & 0.18 & 0.27 & \multirow{2}{*}{18.97} & 24.75 \\
\hline $1.5-2.0 \mathrm{~cm}$ & 1.40 & 6.42 & 2.35 & 0.94 & 20.87 & 4.75 & 0.13 & 0.12 & 0.06 & & 31.41 \\
\hline $2.0-2.5 \mathrm{~cm}$ & 1.88 & 2.96 & 0.58 & 0.97 & 21.49 & 0.68 & 0.09 & 0.01 & & 8.29 & 24.78 \\
\hline $2.5-3.0 \mathrm{~cm}$ & 1.87 & 0.63 & 0.10 & 0.11 & 23.04 & 0.47 & 0.08 & 0.10 & & 15.61 & 25.40 \\
\hline $3.0-3.5 \mathrm{~cm}$ & 3.11 & 0.24 & 0.13 & & 25.16 & 0.07 & & & & 4.76 & 9.18 \\
\hline $3.5-4.0 \mathrm{~cm}$ & 3.41 & 0.09 & & & 20.20 & & & & & 0.86 & 3.43 \\
\hline $4.0-4.5 \mathrm{~cm}$ & 1.31 & 0.04 & & & 16.95 & & & & & 0.28 & 1.03 \\
\hline $4.5-5.0 \mathrm{~cm}$ & 0.46 & & 0.23 & & 12.20 & & & & & 0.50 & 0.40 \\
\hline $5-6 \mathrm{~cm}$ & 0.10 & 0.08 & & & 6.98 & & 0.05 & & 0.14 & 0.24 & 0.22 \\
\hline $6-7 \mathrm{~cm}$ & & & & & 2.38 & & & & & & \\
\hline $7-8 \mathrm{~cm}$ & & & & & 0.61 & & & & & & \\
\hline $8-9 \mathrm{~cm}$ & & & & & 0.37 & & & & & & \\
\hline $9-10 \mathrm{~cm}$ & & & & & 0.18 & & & & & & \\
\hline $10-11 \mathrm{~cm}$ & & & & & 0.06 & & & & & & \\
\hline $11-12 \mathrm{~cm}$ & & & & & 0.12 & & & & & & \\
\hline
\end{tabular}


Table 7. Isotope inventory of all the sediment cores taken in three transects.

\begin{tabular}{|c|c|c|c|c|c|}
\hline \multirow{2}{*}{$\begin{array}{c}\text { Sampling } \\
\text { site }\end{array}$} & \multirow[b]{2}{*}{ Year } & \multicolumn{3}{|c|}{ Isotope Inventory ( $\left.\mathrm{dpm} / \mathrm{cm}^{2}\right)$} & \multirow{2}{*}{$\begin{array}{c}\text { Inventory } \\
\text { ratio } \\
\text { (ExPb/Cs) }\end{array}$} \\
\hline & & total ${ }^{210} \mathrm{~Pb}$ & $\mathrm{Ex}{ }^{210} \mathrm{~Pb}$ & $137 \mathrm{Cs}$ & \\
\hline HN050 & 2001 & & 4.30 & 9.36 & 0.46 \\
\hline HN060 & 2001 & & 3.24 & 1.27 & 2.55 \\
\hline HN070 & 2001 & & 5.12 & 6.57 & 0.78 \\
\hline HN080 & 2001 & & 1.57 & 0.97 & 1.61 \\
\hline HN090 & 2001 & & 2.35 & 0.51 & 4.62 \\
\hline HN100 & 2001 & & 1.62 & 1.36 & 1.19 \\
\hline HN130 & 2001 & & 1.49 & 0.58 & 2.56 \\
\hline HN170 & 2001 & & 3.52 & 1.35 & 2.60 \\
\hline HN210 & 2001 & & 23.53 & 15.56 & 1.51 \\
\hline HN050 & 2002 & 10.98 & 1.29 & 7.39 & 0.17 \\
\hline HNO70 & 2002 & 18.25 & 10.28 & 4.19 & 2.45 \\
\hline HN080 & 2002 & 11.02 & 4.72 & 3.59 & 1.31 \\
\hline HN090 & 2002 & 18.22 & 7.83 & 5.90 & 1.33 \\
\hline HN100 & 2002 & 9.84 & 1.41 & 0.97 & 1.45 \\
\hline HN130 & 2002 & 10.67 & 2.68 & 1.53 & 1.76 \\
\hline HN170 & 2002 & 56.03 & 47.23 & 22.94 & 2.06 \\
\hline HN210 & 2002 & 10.37 & 5.22 & 3.52 & 1.48 \\
\hline EH010 & 2003 & 6.04 & 3.05 & 14.77 & 0.21 \\
\hline EH020 & 2003 & 22.71 & 10.22 & 17.83 & 0.57 \\
\hline EH030 & 2003 & 21.23 & 10.11 & 23.38 & 0.43 \\
\hline EH050 & 2003 & 10.06 & 3.84 & 8.64 & 0.44 \\
\hline EH070 & 2003 & 86.98 & 74.40 & 64.74 & 1.15 \\
\hline EH090 & 2003 & 7.58 & 3.64 & 15.80 & 0.23 \\
\hline ON090 & 2003 & 18.65 & 8.94 & 3.03 & 2.95 \\
\hline ON110 & 2003 & 12.34 & 7.84 & 2.53 & 3.10 \\
\hline ON130 & 2003 & 14.77 & 8.01 & 6.29 & 1.27 \\
\hline ON170 & 2003 & 40.95 & 26.36 & 19.66 & 1.34 \\
\hline ON210 & 2003 & 42.88 & 36.56 & 28.39 & 1.29 \\
\hline
\end{tabular}

From the isotope activities and bulk density values for each sample, the cumulative inventories (or total inventories) of both excess ${ }^{210} \mathrm{~Pb}$ and ${ }^{137} \mathrm{Cs}$ were calculated for all cores. For the sake of comparison, total ${ }^{210} \mathrm{~Pb}$ inventories were also computed for some sites, for example, 2002 and 2003 sites. The results are given in Table 7. In 2002, the average supported ${ }^{210} \mathrm{~Pb}$ inventory (total minus excess inventory) at different sites along the $\mathrm{HN}$ transect is $8.26 \pm 1.16 \mathrm{dpm} / \mathrm{cm}^{2}(95 \% \mathrm{CI}, \mathrm{n}=9)$. For 2003 cores from the $\mathrm{EH}$ and $\mathrm{ON}$ transect, the average is $8.0 \pm 2.6 \mathrm{dpm} / \mathrm{cm}^{2}$. 
Table 8. Isotope inventories from replicated cores from year 2002, HN transect.

\begin{tabular}{|c|c|c|c|c|}
\hline \multirow{4}{*}{$\begin{array}{c}\text { Site } \\
\text { HN070 }\end{array}$} & \multirow{3}{*}{ Rep \# } & \multirow{2}{*}{$\begin{array}{l}\text { Sampling } \\
\text { date }\end{array}$} & \multicolumn{2}{|c|}{ Isotope inventory $\left(\mathrm{dpm} / \mathrm{cm}^{2}\right)$} \\
\hline & & & $\mathrm{Ex}-{ }^{210} \mathrm{~Pb}$ & ${ }^{137} \mathrm{Cs}$ \\
\hline & & Jun 02 & 10.28 & 4.19 \\
\hline & 2 & Jun 02 & 11.64 & 4.35 \\
\hline \multirow[t]{2}{*}{ HN090 } & 1 & Jun 02 & 7.83 & 5.90 \\
\hline & 2 & Jun 02 & 7.80 & 5.79 \\
\hline HN210 & & Jun 02 & 5.22 & 3.52 \\
\hline HN210 & & Sept 02 & 4.32 & 3.47 \\
\hline \multirow[t]{3}{*}{ HN060 ${ }^{1}$} & 1 & Jul 02 & 9.24 & 5.40 \\
\hline & 2 & Jul 02 & 15.14 & 7.98 \\
\hline & 3 & Jul 02 & 6.68 & 5.13 \\
\hline \multirow[t]{3}{*}{$\mathrm{HN} 090^{1}$} & 1 & Jul 02 & 1.04 & 2.10 \\
\hline & 2 & Jul 02 & 2.00 & 1.99 \\
\hline & 3 & Jul 02 & 4.49 & 2.54 \\
\hline
\end{tabular}

1: Cores were taken as sub-cores from a box core collected onboard the EPA R/V Lake Guardian.

Spatial and temporal variability of isotope data was examined with cores taken as replicates. For the first half of Table 8, reproducibility was observed for both HN070 and HN090 sites where two cores were taken during the same cruise. Although the two cores were treated differently with one extruded every half $\mathrm{cm}$ and the other treated as one sample $(0-5 \mathrm{~cm})$, isotope inventories for both isotopes are in good agreement. The temporal variation is minimal as observed from the two cores taken at the HN210 site three months apart. The ${ }^{137} \mathrm{Cs}$ inventories were almost identical (3.52 versus 3.47 $\mathrm{dpm} / \mathrm{cm}^{2}$ ). The difference between ${ }^{210} \mathrm{~Pb}$ inventories is probably coming from the difference within the fluff material collected for both cores. In the first core, 1.11 gram of fluff with ${ }^{210} \mathrm{~Pb}$ activity $41.77 \mathrm{dpm} / \mathrm{g}$ was obtained, while for the September core, $0.5 \mathrm{~g}$ of $21.92 \mathrm{dpm} / \mathrm{g}$ fluff was collected. Thus the discrepancy in Table 8 might come from this difference in the fluff. The same explanations may also apply to the HN060 and HN090 cores in the $2^{\text {nd }}$ half of the table. 
Table 9. ${ }^{7}$ Be activity (top two samples) and inventory of $2002(\mathrm{HN})$ and 2003 cores.

\begin{tabular}{|c|c|c|c|c|c|}
\hline Site & $\begin{array}{c}\text { distance } \\
(\mathbf{k m})\end{array}$ & $\begin{array}{l}\text { depth } \\
\text { (m) }\end{array}$ & $\begin{array}{c}\text { Core } \\
\text { fraction }\end{array}$ & $\begin{array}{c}{ }^{7} \text { Be Activity } \\
\text { (dpm/g) }\end{array}$ & $\begin{array}{c}{ }^{7} \text { Be Inventory } \\
\text { (dpm/cm2) }\end{array}$ \\
\hline \multirow[t]{2}{*}{ HN050 } & 5 & 115 & fluff & 0.15 & 0.00 \\
\hline & & & $0-0.5 \mathrm{~cm}$ & 0.00 & \\
\hline \multirow[t]{2}{*}{ HN070 } & 7 & 127 & fluff & 0.46 & 1.20 \\
\hline & & & $0-0.5 \mathrm{~cm}$ & 0.42 & \\
\hline \multirow[t]{2}{*}{ HN080 } & 8 & 117 & fluff & 0.85 & 0.00 \\
\hline & & & $0-0.5 \mathrm{~cm}$ & 0.48 & \\
\hline \multirow[t]{2}{*}{ HN090 } & 9 & 120 & fluff & 7.28 & 0.20 \\
\hline & & & $0-0.5 \mathrm{~cm}$ & 0.13 & \\
\hline \multirow[t]{2}{*}{ HN100 } & 10 & 113 & fluff & 1.88 & 0.08 \\
\hline & & & $0-0.5 \mathrm{~cm}$ & 0.00 & \\
\hline \multirow[t]{2}{*}{ HN130 } & 13 & 147 & fluff & 1.28 & 0.83 \\
\hline & & & $0-0.5 \mathrm{~cm}$ & 1.28 & \\
\hline \multirow[t]{2}{*}{ HN170 } & 17 & 179.5 & fluff & 1.42 & 2.36 \\
\hline & & & $0-0.5 \mathrm{~cm}$ & 1.79 & \\
\hline \multirow[t]{2}{*}{ HN210 } & 21 & 161.5 & fluff & 0.23 & 0.00 \\
\hline & & & $0-0.5 \mathrm{~cm}$ & 0.00 & \\
\hline \multirow[t]{2}{*}{ EH010 } & 1 & 109 & fluff & 10.07 & 0.03 \\
\hline & & & $0-0.5 \mathrm{~cm}$ & 0.26 & \\
\hline \multirow[t]{2}{*}{ EH020 } & 2 & 207 & fluff & 7.09 & 0.45 \\
\hline & & & $0-0.5 \mathrm{~cm}$ & 0.54 & \\
\hline \multirow[t]{2}{*}{ EH030 } & 3 & 255 & fluff & no data & 0.00 \\
\hline & & & $0-0.5 \mathrm{~cm}$ & 0.44 & \\
\hline \multirow[t]{2}{*}{ EH050 } & 5 & 255 & fluff & 16.11 & 0.11 \\
\hline & & & $0-0.5 \mathrm{~cm}$ & 0.13 & \\
\hline \multirow[t]{2}{*}{ EH070 } & 7 & 257 & fluff & 165.92 & 0.66 \\
\hline & & & $0-0.5 \mathrm{~cm}$ & 2.48 & \\
\hline \multirow[t]{2}{*}{ EH090 } & 9 & 261 & fluff & 3.58 & 0.02 \\
\hline & & & $0-0.5 \mathrm{~cm}$ & 0.51 & \\
\hline \multirow[t]{2}{*}{ ON090 } & 9 & 70.5 & fluff & 1.66 & 0.10 \\
\hline & & & $0-0.5 \mathrm{~cm}$ & 0.43 & \\
\hline \multirow[t]{2}{*}{ ON110 } & 11 & 74.5 & fluff & 0.57 & 0.92 \\
\hline & & & $0-0.5 \mathrm{~cm}$ & 1.29 & \\
\hline \multirow[t]{2}{*}{ ON130 } & 13 & 84 & fluff & 1.91 & 0.08 \\
\hline & & & $0-0.5 \mathrm{~cm}$ & 0.54 & \\
\hline \multirow[t]{2}{*}{ ON170 } & 17 & 105 & fluff & 2.70 & 0.73 \\
\hline & & & $0-0.5 \mathrm{~cm}$ & 2.98 & \\
\hline \multirow[t]{2}{*}{ ON210 } & 21 & 128 & fluff & 6.90 & 0.44 \\
\hline & & & $0-0.5 \mathrm{~cm}$ & 1.91 & \\
\hline
\end{tabular}


As shown in Table 9, the ${ }^{7}$ Be activities for most of the cores are confined to the fluff layer. Along the $\mathrm{EH}$ transect, a 95\% decrease in ${ }^{7} \mathrm{Be}$ activity between the fluff layer and the next sediment increment was observed, on average. Similar to ${ }^{210} \mathrm{~Pb}$, the major source of ${ }^{7} \mathrm{Be}$ to the lake is atmospheric fallout [McNeary and Baskaran, 2003; Olsen et al., 1985], and the isotope is also highly particle reactive [Baskaran and Santschi, 1993]. Its fast decay rate (half live of 57 days) makes it a good tracer for short time-scale processes [Fitzgerald et al., 2001]. In southern Lake Michigan, ${ }^{7} \mathrm{Be}$ is not found in the surface sediments when the lake is stratified [Robbins and Eadie, 1991] because of the time required for particles to pass through the thermocline. All cores in which ${ }^{7} \mathrm{Be}$ was measured in this study were collected during unstratified lake conditions. The presence of ${ }^{7} \mathrm{Be}$ in surface sediments of deep sites points to a rapid scavenging from the water column possibly combined with movement from nearshore (shallow water column) to offshore (deep water). 


\section{Discussion}

\subsection{Sediment characteristics}

Sediments are of great importance in the biogeochemical processes occurring in coastal areas. Acting as both sinks and sources, sediments directly affect the biogeochemical cycles of many nutrients and contaminants as well as radioisotopes [Aller et al., 1980; Chai and Urban, 2004; Kerfoot and Robbins, 1999]. Conversely, biogeochemical processes can also alter fundamental sediment qualities, as evidenced by the size-selective sorting of sediments by waves and currents or the systematic changes in sorptive capacity and metal or isotope content of sediments that accompany selective loss of organic matter during early diagenesis. Thus it is desirable to look at the distribution of sediment properties first to gain insights into the physical and biogeochemical processes that are operative.

The sediments of Lake Superior clearly reveal the oligotrophic state of the lake and the oxic conditions of the water column. As discussed below, sedimentation rates are low $(\sim 1 \mathrm{~mm}$ per year) as is the organic matter content of the sediments $(\leq 10 \%$ at the surface, generally $1-4 \%$ below). These traits combined are indicative of an oligotrophic lake [Tartari and Biasci, 1997]. The oxic condition of the water column is revealed both by the low organic matter content of the sediments (organic matter is largely decomposed in the water column), by the abundance of iron oxides in surface sediments [McKee et al., 1989], and by the depth of the band of iron and manganese oxides $(2-10 \mathrm{~cm}$ in the cores of this study).

As in most lakes, the sediments of Lake Superior exhibit a progradation from coarse to fine materials with increasing water depth [Thomas and Dell, 1978]. The size 
distribution of sediments was mapped throughout the entire lake by Thomas and Dell [1978] with a high sampling density (406 samples across the Lake). Our results, confined to a zone within $21 \mathrm{~km}$ of shore, also show this decrease in sediment size with increasing water depth (Figure 6).

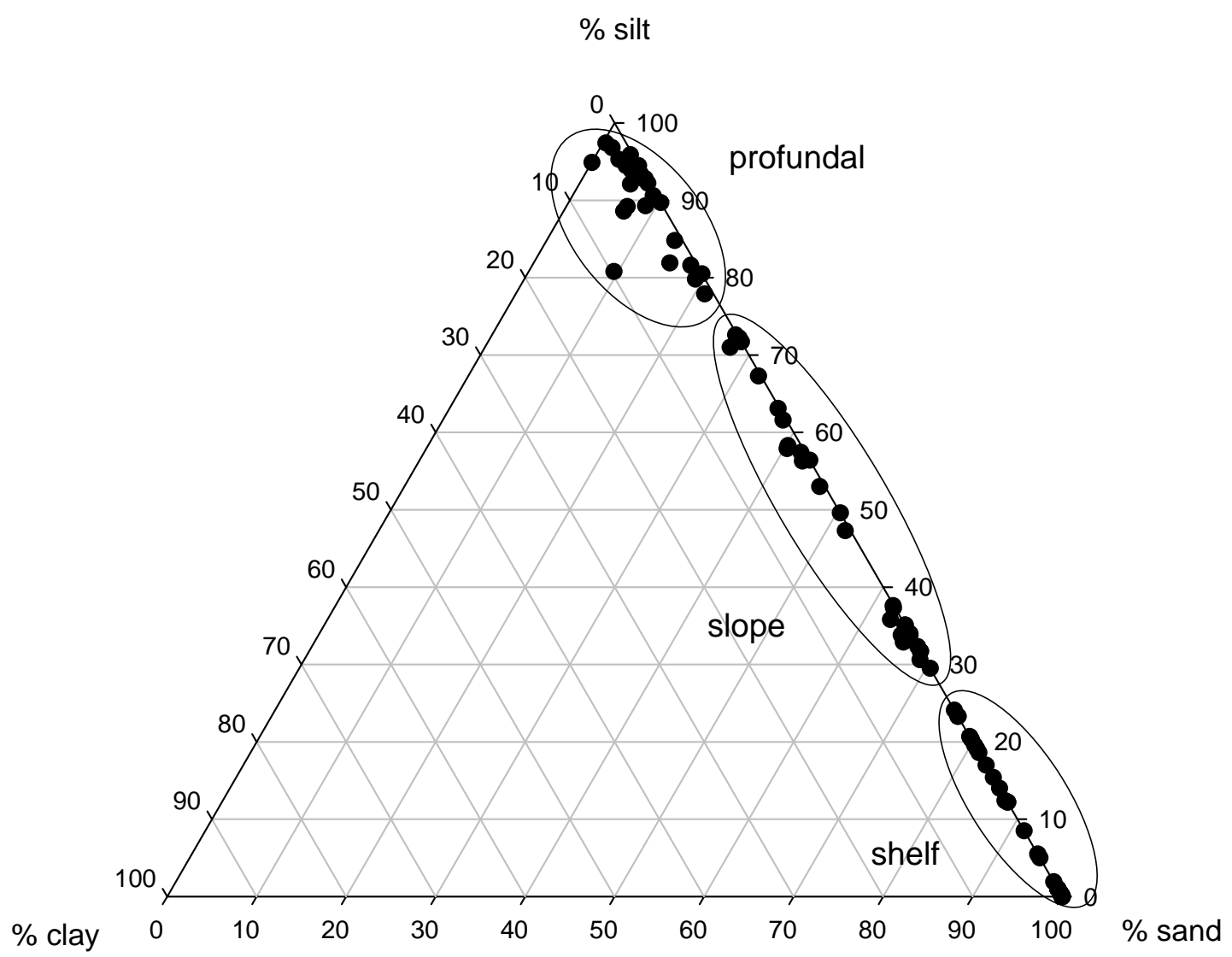




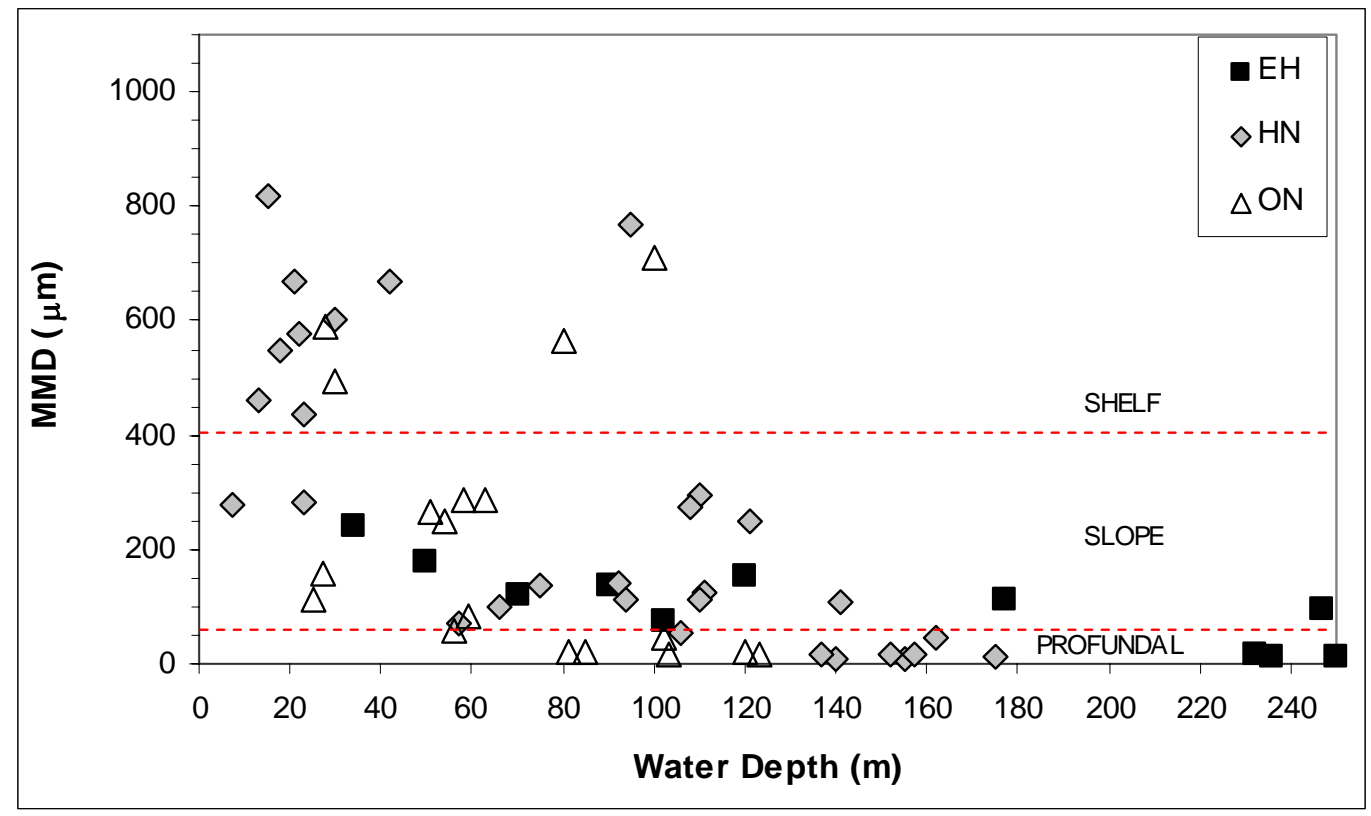

Figure 6. Mean particle size and sediment grain size distribution from ponar data (KITES data). (A) Sediment grain size distribution from multiple transects (B) Mean particle sizes along the three transects. For graph (A), three categories were used for the sediment composition: sand - with mean size of $60 \sim 700 \mu \mathrm{m}$, silt - with size of 2- $60 \mu \mathrm{m}$ and clay $<2 \mu \mathrm{m}$.

Three different zones (shelf, slope, profundal) can be distinguished from the sediment grain size distribution (expressed either as mass median diameter or the $\%$ clay plus silt). Figure 6a depicts data from 114 ponar samples collected in KITES field years of 1999 and 2000 [Jeong, 2002]. The sampling sites include but are not limited to the three transects studied here. Figure $6 \mathrm{~b}$ shows the results from the three transects in terms of the mass median diameter (MMD). The three zones (shelf, slope and profundal) can be distinguished in both figures although the placement of the boundaries between zones 
is arbitrary. The boundaries chosen here were (Figure $6 \mathrm{a}$ ): $>75 \%$ slit + clay corresponds to samples from the profundal region; $25 \sim 75 \%$ silt + clay represents the intermediate slope region; and $<25 \%$ silt + clay represents the shelf region, where no sediment cores could be obtained. The decreasing grain size with increasing water depth reflects the attenuation of turbulent kinetic energy by water depth [Gilbert, 1999]; generally, the orbital velocity of waves is modeled as decreasing with the square root of water depth [Hunt, 1979].

Differences between the grain-size distributions among transects (Figure 7b) reflect the different hydrodynamic conditions along each transect. Along all three transects, particles get smaller as water depth increases because the turbulent kinetic energy transmitted to the lake bottom decreases with increasing water depth. However, along the $\mathrm{ON}$ transect finer particles are found in much shallower water than along the $\mathrm{EH}$ transect; the $\mathrm{HN}$ transect is intermediate between these two. If the profundal zone is defined by hydrodynamic conditions (Figure 6b), it extends to shallower depths along the ON transect (70-80 m) than along either the HN (120-140 m) or EH (180-230 m) transects.

Other important sediment properties covary with particle size and thus vary systematically with position in the lake. In particular, the organic matter content of the sediments (here reported as either carbon content or loss-on-ignition, LOI) increases systematically with water depth (Figure 7, Table 3). There is a particularly sharp increase in the organic matter content of surface sediments in the profundal zone relative to the slope (Figure 7; see also Figure 3a). Cross-margin transport or sediment focusing 
selectively winnows organic-rich, fine particles from nearshore areas and deposits them in offshore, profundal regions.

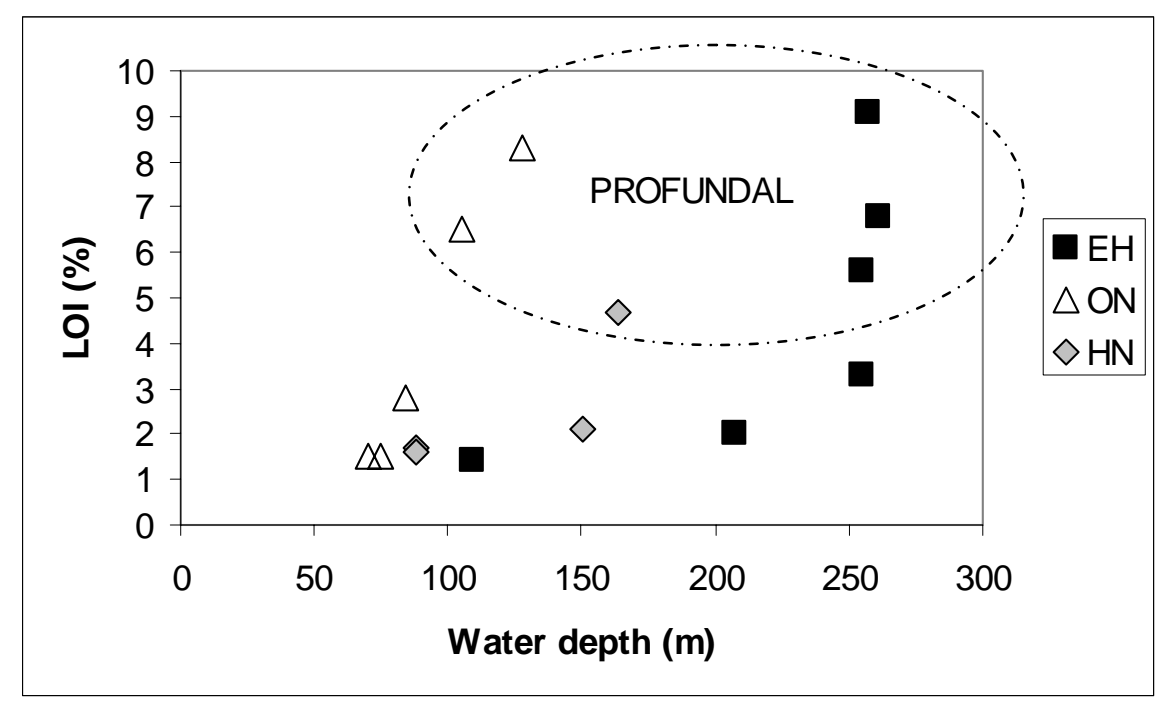

Figure 7. Relationship between organic matter content (LOI) of surface sediments and water depth. Along all three transects there is an abrupt increase in organic matter content once the profundal zone is reached.

There is a very tight linkage between the organic matter content and the activity of radioisotopes in the sediments. This linkage can be seen in the linear relationship between LOI of surface sediments and the isotope inventories at any site as shown in Figure 8. The relationship is particularly linear along the ON transect where the p-values are $<0.001\left({ }^{137} \mathrm{Cs}\right)$ and $<0.01\left({ }^{210} \mathrm{~Pb}\right)$. This correlation implies that ${ }^{137} \mathrm{Cs}$ and ${ }^{210} \mathrm{~Pb}$ are good tracers for the transport of particulate organic matter as suggested in a number of previous studies [e.g., Friedrich and van der Loeff, 2002; Sarin et al., 1999]. There is a marked difference between the strength of the organic matter-isotope correlation along the EH and ON transects (Figure 8). The stronger correlation (higher $\mathrm{r}^{2}$ ) and the lower 
slope of the regression line for the $\mathrm{ON}$ transect suggest that the organic matter and isotopes are following the same transport pathways. Along the EH transect, there is no correlation between LOI and isotope inventories in the slope region (as defined by the LOI-water depth relation in Figure 7), but both jump markedly in the profundal zone. In this region of the lake there may be additional sources of isotopes (longshore sediment transport as discussed later) that are not co-transported with organic matter. No systematic LOI data are available for the $\mathrm{HN}$ transect; however, there is a significant correlation $(\mathrm{p}<0.05, \mathrm{n}=9)$ between the carbon contents and ${ }^{210} \mathrm{~Pb}$ inventories of this transect (2001 data). 

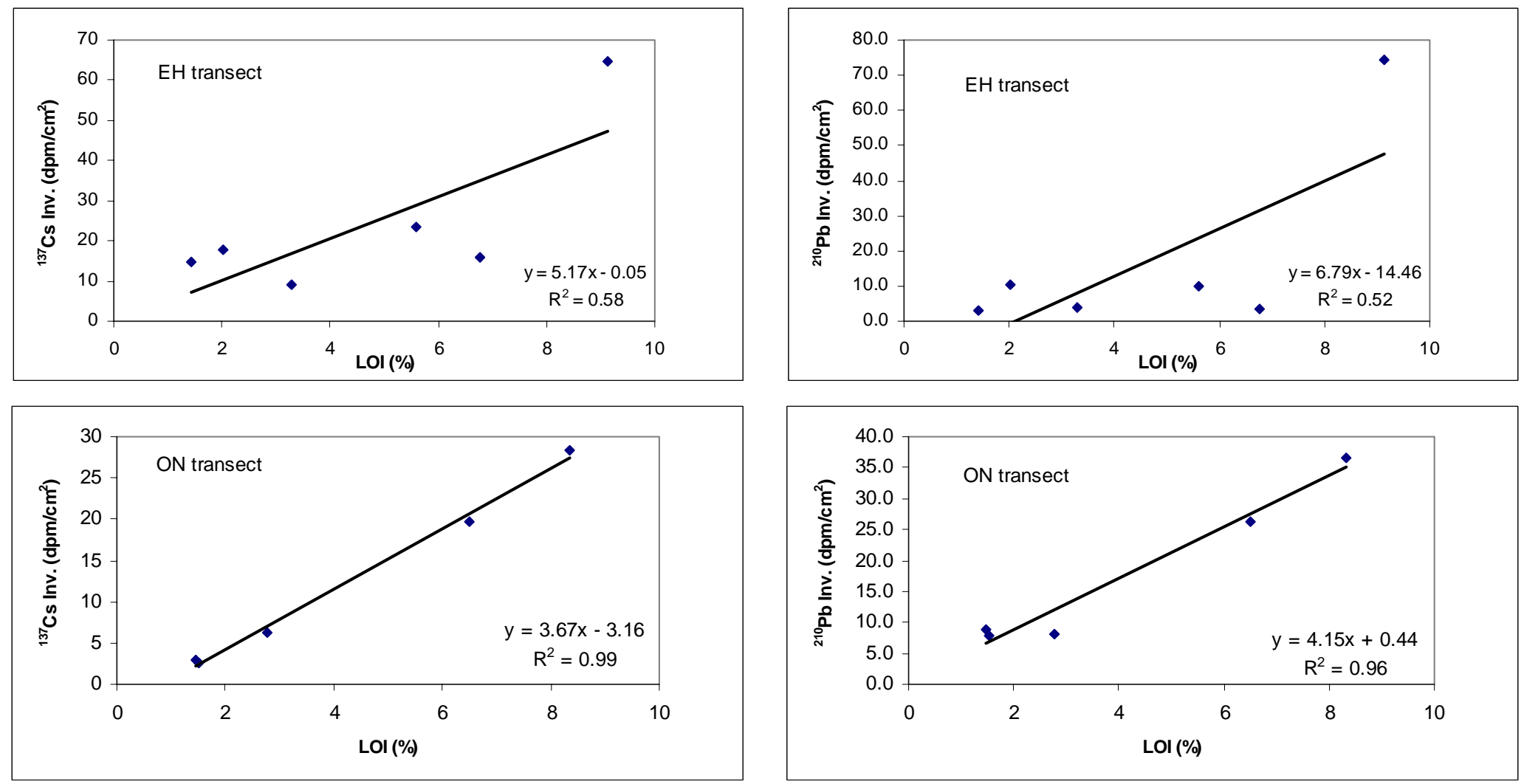

Figure 8. LOI of surface sediments vs. isotope inventories for 2003 cores: EH (top) and ON (bottom) transects. 


\subsection{Geochronology with both ${ }^{210} \mathrm{~Pb}$ and ${ }^{137} \mathrm{Cs}$}

Within the 30-40 years' of application of radioisotopes in limnology and oceanography, the major use for ${ }^{210} \mathrm{~Pb}$ and ${ }^{137} \mathrm{Cs}$ is to establish sediment geochronologies and sediment accumulation rates [Abril, 2003; Appleby et al., 1988; Krishnaswami et al., 1971; Schelske et al., 1994]. Partly due to the good linear correlations shown in Figure 8, we utilize the two isotopes as transport tracers for particles including particulate organic matter. A major assumption of the model that will be employed is that isotope inventories throughout the study region are in a steady state; recurrent or periodic temporal variations in the inventories would seriously compromise the approach to be taken. One approach for examining the constancy of the net fluxes along the transects is to examine the deep-water stations at the ends of the transects to determine if sediment accumulation rates at these sites have been constant.

Accordingly, geochronologies were established with both ${ }^{210} \mathrm{~Pb}$ and ${ }^{137} \mathrm{Cs}$ at three net depositional sites (discussed in detail below) to determine current and historical sedimentation rates at these sites. As in most previous research [e.g., Edgington et al., 1991; Robbins et al., 1978], both ${ }^{210} \mathrm{~Pb}$ and ${ }^{137} \mathrm{Cs}$ dating are utilized. Each provides an independent check on the other method. For ${ }^{210} \mathrm{~Pb}$, both the Constant Initial Concentration, CIC, model [Krishnaswami and Lal, 1978; Robbins, 1978] with constant sedimentation rate and the Constant Rate of Supply, CRS, model [Appleby and Oldfield, 1978; Krishnaswami and Lal, 1978; Sanchez-Cabeza et al., 2000] with time-variable sedimentation rates are evaluated. The dating results are shown in Table 10 and graphed (EH070) in Figure 9. 
Table 10. Sedimentation rates in the deposition zones on three transects.

\begin{tabular}{llll} 
Sites & \multicolumn{2}{l}{$\begin{array}{l}\text { Sedimentation rate } \\
(\mathrm{cm} / \mathrm{yr})\end{array}$} & $\begin{array}{c}\left.{ }^{2} \mathrm{~g} / \mathrm{cm}^{2}-\mathrm{yr}\right) \\
\text { Cs peak year }\end{array}$ \\
\hline EH070 & 0.089 & 0.031 & $1954 \sim 1961$ \\
HN170 & 0.036 & 0.011 & Not available ${ }^{1}$ \\
ON210 & 0.044 & 0.017 & $1962 \sim 1968$
\end{tabular}

${ }^{1}$ : No dating favorable ${ }^{137} \mathrm{Cs}$ profile exists for the HN170 site.

2; Rate based on CIC model

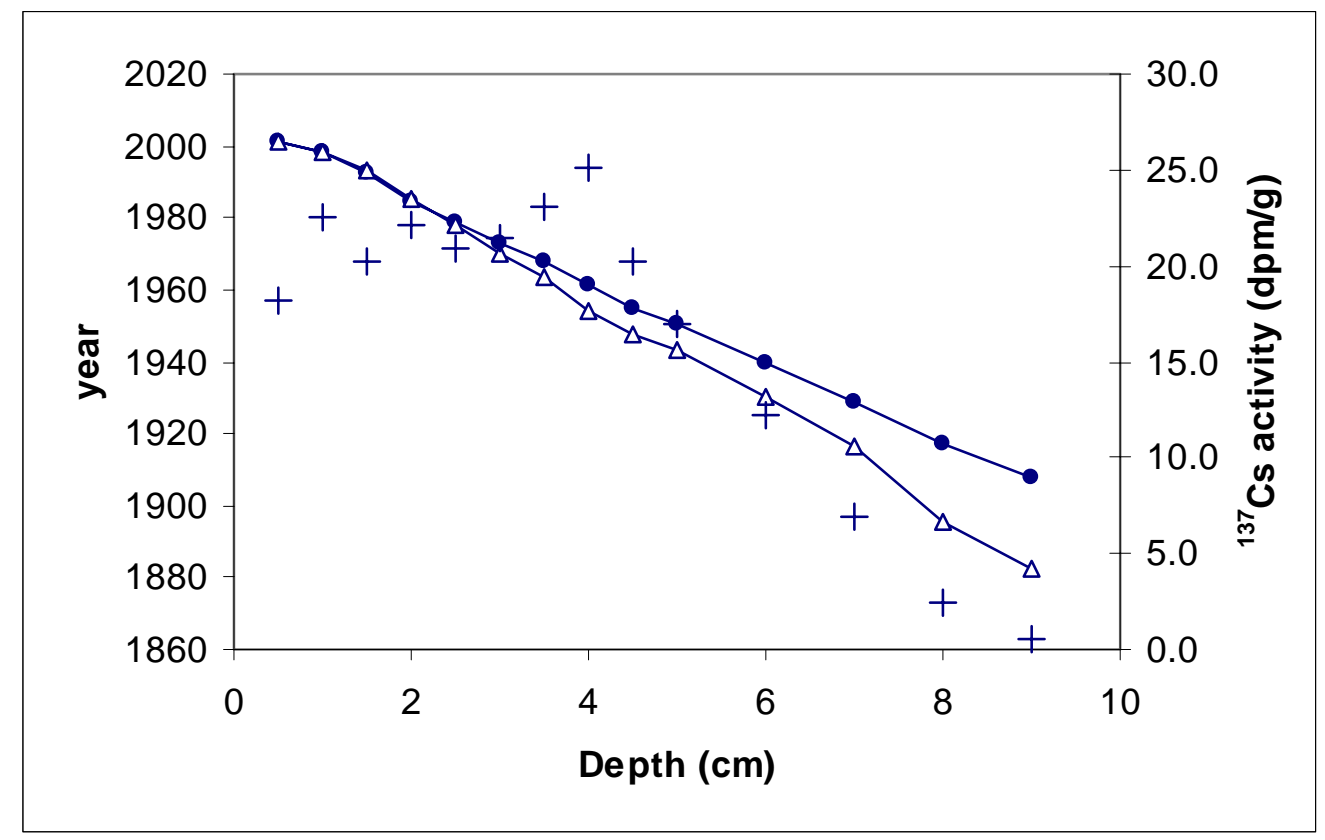

Figure 9. Geochronology for EH070 core. Solid circles represent ages determined with the CIC model that invokes a constant sedimentation rate $\left(0.031 \mathrm{~g} / \mathrm{cm}^{2}-\mathrm{yr}\right.$ as in Table 10$)$. Hollow triangles represent ages based on the CRS model. ${ }^{137} \mathrm{Cs}$ activity is also shown as crosses.

The two ${ }^{210} \mathrm{~Pb}$ models yield almost identical sediment ages for the most recent 30 years as shown in Figure 9 although they diverge in older sediments. This agreement 
indicates that the sediment accumulation rate has remained constant over this time period (30 years). The ${ }^{210} \mathrm{~Pb}$ chronology also agrees well with the ${ }^{137} \mathrm{Cs}$ profile; the peak ${ }^{137} \mathrm{Cs}$ activity occurs at depths corresponding to the early 1960s. The constant sedimentation rate over the past three decades supports the application of the steady-state model that will be discussed below.

Another reason for establishing the geochronologies is to quantify the current sedimentation rates in the deposition zones at the end of each transect. All values shown in Table 10 are extremely low when compared with other freshwater systems [Abril, 2003; Tartari and Biasci, 1997] but are in good agreement with other isotope studies in Lake Superior [Durham and Joshi, 1981; Evans et al., 1981]. The data also show large differences (up to 2-fold) in sedimentation rates at deep sites of different transects. The highest sedimentation rate occurs at EH070, a site where longshore sediment transport has already been implicated by the poor correlation between isotope inventories and organic matter content. The $\mathrm{ON}$ and $\mathrm{HN}$ transects have similar sedimentation rates with a slightly higher value at the $\mathrm{ON}$ site possibly due to the sediment input from the Ontonagon River [Robertson, 1997]. These sediment accumulation rates will be used to evaluate the model of cross-margin transport developed below.

\subsection{Nearshore to offshore: quantification of focusing}

For the majority of the coring stations sediment geochronologies were not calculated because isotope inventories were low. However, the depositional character of each site can be quantified with the "focusing factor". Focusing factors (FF) provide a measure of the net result from many sediment-related processes including resuspension, 
sediment redistribution and lateral transport [Edgington and Robbins, 1990]. Isotope inventories (both ${ }^{210} \mathrm{~Pb}$ and ${ }^{137} \mathrm{Cs}$ ) are used to calculate FF. Most commonly, the FF is calculated from the ${ }^{210} \mathrm{~Pb}$ inventory of sediment cores [Kerfoot et al., 1999; Yohn et al., 2002] according to the following equation:

Focusing factor $=\frac{{ }^{210} \mathrm{~Pb} b_{\text {excess }} \text { Inventory in a core }}{\text { theoretical }{ }^{210} \mathrm{P} b_{\text {excess }} \text { inventory }}$

The theoretical ${ }^{210} \mathrm{~Pb}$ inventory is defined as the steady-state inventory that would result if all atmospherically deposited ${ }^{210} \mathrm{~Pb}$ remained at a site. In other words, the theoretical inventory is the rate of atmospheric deposition $\left(\mathrm{F}_{\mathrm{A}}, \mathrm{dpm} / \mathrm{cm}^{2} \mathrm{yr}\right)$ divided by the decay constant $\left(\mathrm{k}, \mathrm{yr}^{-1}\right)$ for ${ }^{210} \mathrm{~Pb}$. In this study, the ${ }^{210} \mathrm{~Pb}$ atmospheric fallout flux is taken to be $27.4 \mathrm{dpm} / \mathrm{m}^{2}$-day [Chai and Urban, 2004]; this fallout flux results in a steady-state ${ }^{210} \mathrm{~Pb}$ inventory of $32.2 \mathrm{dpm} / \mathrm{cm}^{2}$. Other researchers have used slightly different estimates of the atmospheric deposition rate and corresponding values of the theoretical inventory. E.g., a steady state inventory of $34.4 \mathrm{dpm} / \mathrm{cm}^{2}$ was used in the recent study of organic pollutants in the sediments of Lake Superior [Song et al., 2004]. Focusing factors also may be calculated for ${ }^{137} \mathrm{Cs}$; in this case, the theoretical inventory is the time-integrated deposition (hemisphere and latitude specific) at a site corrected for isotope decay following deposition. For Lake Superior, the decay-corrected, integrated deposition is $16.4 \mathrm{dpm} / \mathrm{cm}^{2}$ [Robbins, 1985].

The ${ }^{210} \mathrm{~Pb}$-FF for the 28 cores collected in this study ranged from 0.04 (two 2002 $\mathrm{HN}$ sites) to 2.31 (EH070). The average and median values are 0.36 and 0.15 , respectively. Only three sites have focusing factors above 1 (Figure 10) and can therefore be categorized as net deposition sites. The sedimentation rates for these three 
sites were discussed already. Along the ON transect, focusing factors increase steadily with increasing water depth (distance from shore). Along the $\mathrm{HN}$ and $\mathrm{EH}$ transects there is an abrupt transition from low focusing factors to values close to one.

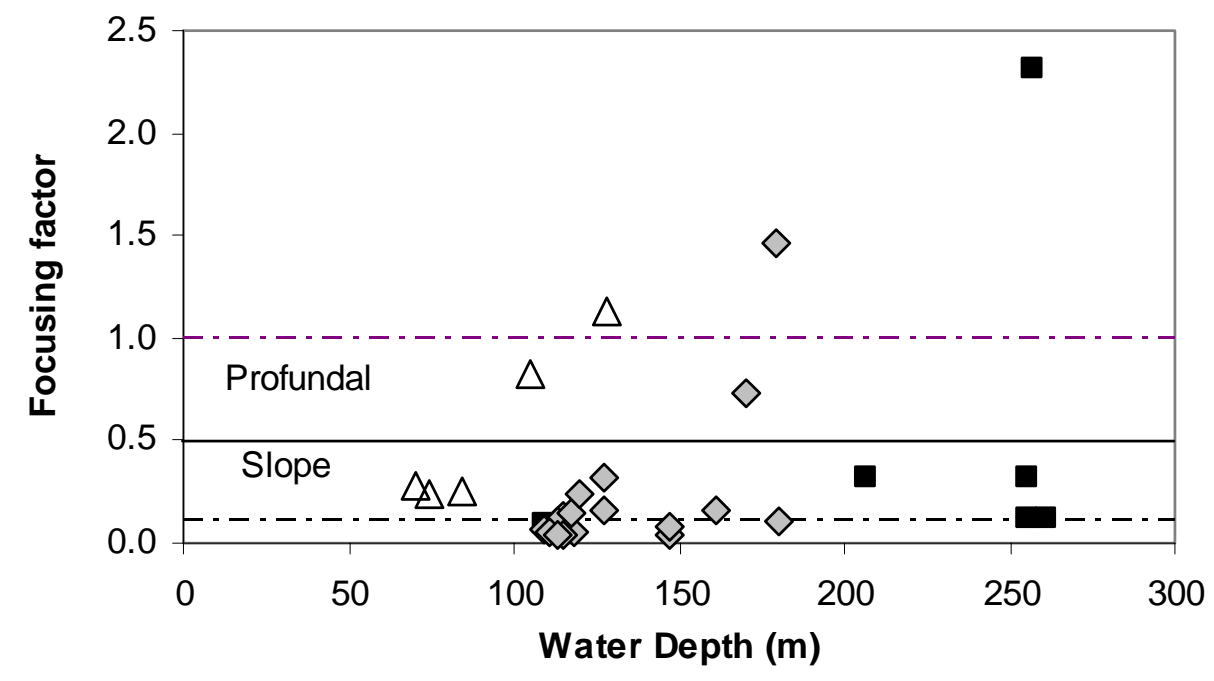

Figure 10. Focusing factors $\left({ }^{210} \mathrm{~Pb}\right.$-based $)$ of the coring sites, plotted against water depth. Diamonds represent data from the HN transect (2001 and 2002). Squares represent cores from the EH transect, and triangles represent sites on the $\mathrm{ON}$ transect (both 2003). The artificial line at 0.5 separates the data into two groups.

The depositional character of sites along the three transects can be categorized based on the focusing factors. Those sites with a focusing factor less than 0.1 can be viewed as non-depositional zones. At these sites, the radioisotopes (and fine sediments) do not accumulate for any appreciable time but are quickly resuspended and carried elsewhere. Three of the 28 sites (one on each transect) are net depositional sites with focusing factors above 1. At these sites, the net flux of ${ }^{210} \mathrm{~Pb}$ to the sediments is greater than or 
equal to the flux at the lake surface; there may still be a flux of sediment (and isotopes) past these sites, but the net flux of ${ }^{210} \mathrm{~Pb}$ to these sites is greater than or equal to the rate at the lake surface. All the other sites fall in the middle range with ratios between 0.1 and 1.0, and are classified as temporary or transient deposition sites. Particles (and isotopes) deposited at these sites are subject to future movement, whether cross-margin or longshore transport, as part of the dynamics of sediment focusing.

The focusing factor changes systematically across the three zones discussed above. No sediment cores could be collected in the shelf region, but focusing factors in this region are presumed to be less than 0.1 . The majority of the coring sites in this study can be categorized as slope sites. Fine sediments and isotopes found in this region exist in a dynamic steady state where the influx of new material is balanced by export (crossmargin or longshore transport). The length of time that particles (and isotopes) reside at these transient deposition sites is quantified in the ensuing section.

\subsection{Isotope residence times in temporary depositional zones}

The entire slope region was characterized as a temporary deposition zone in the discussion above. Particles and isotopes may settle for a time within this zone but are subject to continuous or episodic movement toward a net deposition zone in the profundal region of the lake. In Figure 1 in the Introduction to this thesis, three axes for particle (and isotope) movement were identified as vertical (direction of particle settling), parallel to the coast (direction of longshore transport), and perpendicular to the coast (direction of "cross-margin" transport). Chapter 2 focused primarily on the vertical processes (sedimentation and resuspension) and assumed that the lake was homogenous in the other two directions. In this chapter, we will examine cross-margin transport by 
constructing a 2-dimensional model along transects running perpendicular to shore.

Long-shore transport will be evaluated by comparison of the three transects.

The 2-dimensional model used to examine cross-margin transport was inspired by a similar model framework used by Niebauer to study water column hydrodynamics in this region of the lake [Niebauer et al., 1977]. The Niebauer model used a grid of 2dimensional boxes along a transect oriented perpendicular to shore (EH in his case). The model is based on an assumption that fluxes into any cell on the grid from either direction parallel to shore are balanced by equal fluxes out of the cell in the opposite direction; the probability that this assumption is valid increases as the width of the transect decreases. If gradients in the longshore direction are negligible, the thickness of the transect becomes less important. The transect or cross-section of the Niebauer model is here extended downward to include the upper or active layer of sediments. The active layer is defined as that containing all excess or unsupported ${ }^{210} \mathrm{~Pb}$. The water-column transects of Niebauer extended across the width of the lake such that conservation of mass and energy could be assumed. In the present application of the model, the transect will be terminated at successive distances from shore such that the isotope and particle flux perpendicular to shore (the cross-margin transport) may be quantified. The multi-cell, finite difference model used by Niebauer for simulating hydrodynamics will be replaced with a single-cell model with which a mass balance for isotopes will be performed (Figures 11 and 12). The mass balance for each cell has only three components: the inputs from atmospheric deposition and cross-margin transport from the previous cell (if not the first cell), the inventory within the cell, and outputs via radioactive decay and cross-margin transport to the next cell. 
The two quantities that will be derived from the model are the residence time and the efflux or the cross-margin transport occurring at the open-lake end of the cell. Residence time (for isotopes or particles) can be defined with the following equation:

$$
\tau=\frac{I}{\sum f}\left\{\begin{array}{l}
\tau-\text { residence time } \\
I-\text { inventory } \\
f-\text { flux }
\end{array}\right.
$$

It is easier to apply this mass balance equation/model to isotopes in the lake than to particles. It is difficult to measure every influx and efflux of particles to and from the system. It also is difficult to quantify the inventory of particles susceptible to being moved. For isotopes, this is not the case. For example, ${ }^{210} \mathrm{~Pb}$ has a nearly constant input to the lake from atmospheric deposition that is the main source of this isotope to the lake [e.g., Chai and Urban, 2004]. If the whole-lake inventory and isotope fallout flux (as $\Sigma f$ ) are used in equation 2, then an isotope residence time in the lake can be calculated. By careful selection of particle-reactive radioisotopes with known rates of atmospheric deposition and proper definition of system boundaries, isotope residence times in portions of the lake may be calculated. The steady state assumption used initially will be evaluated below.

Two modeling approaches were developed based on the assumptions above. They are a box-in-series model as illustrated in Figure 11 and a nested-box model as in Figure 12. According to the box-in-series model, the inventory in box number $1, \mathrm{I}_{1}$, can be calculated by adding the ${ }^{210} \mathrm{~Pb}$ inventories in the water column and the sediment. $\mathrm{I}_{1}=$ $\mathrm{I}_{\mathrm{W} 1}+\mathrm{I}_{\mathrm{S} 1}$, where $\mathrm{I}_{\mathrm{W}}=$ water inventory $=\mathrm{I}_{\mathrm{W}}=\int_{0}^{h}\left\{{ }^{210} \mathrm{P} b_{i, h}\right\} d h$ with ${ }^{210} \mathrm{~Pb}_{\mathrm{i}, \mathrm{h}}$ being the activity at depth $\mathrm{h}$ in box $\mathrm{i}$. $\mathrm{I}_{\mathrm{S}}$ is obtained from the measured sediment core inventory. 
Some assumptions have to be made such as the homogeneity within the box for both water column and sediment. The isotope activity in the water column was assumed to be uniform (60 dpm $/ \mathrm{m}^{3}$, [Chai and Urban, 2004]) throughout the water column. Based on equation 2, the residence time in box $1\left(\tau_{1}=\frac{I_{1}}{F_{A 1}}\right)$ can be calculated. The difference between $\mathrm{F}_{\mathrm{A} 1}\left(27.4 \mathrm{dpm} / \mathrm{m}^{2}-\mathrm{d}\right)$ and $\mathrm{F}_{\mathrm{D} 1}$ (decay flux of ${ }^{210} \mathrm{~Pb}$ inventory in box 1$)$, here denoted as $\mathrm{F}_{\mathrm{X} 1}$, is the resultant of a variety of processes. Those processes may include but are not limited to water column advection and dispersion, sediment lateral transport, and focusing. Other processes, such as settling and resuspension, are internal processes when the box includes both water and surface sediment and thus are not included in the calculation. No sediment cores were taken in the non-depositional zones $(0-1 \mathrm{~km}$ for $\mathrm{EH}$, 0-5 km for $\mathrm{HN}$ and $0-9 \mathrm{~km}$ for $\mathrm{ON}$ ), and a sediment ${ }^{210} \mathrm{~Pb}$ inventory of zero was assumed for these zones. With this approach, the residence time $\left(\tau_{1}\right)$ and cross-margin flux $\left(\mathrm{F}_{\mathrm{X} 1}\right)$ for the box closest to the coast can be calculated.

Calculation of residence times and cross-margin fluxes for each successive box involve the results from the previous box. For box 2,

$$
\tau_{2}=\frac{I_{2}}{\sum F_{2}}=\frac{I_{2}}{F_{A 2}+F_{X 1}}
$$

and $\mathrm{F}_{\mathrm{X} 2}=\mathrm{F}_{\mathrm{A} 2}+\mathrm{F}_{\mathrm{X} 1}-\mathrm{F}_{\mathrm{D} 2}$. The calculated $\tau_{2}$ is the residence time of ${ }^{210} \mathrm{~Pb}$ in box 2 and $\mathrm{F}_{\mathrm{X} 2}$ is the isotope flux from box 2 to box 3 . Calculations can be repeated for successive boxes as long as measured sediment inventories are available. 


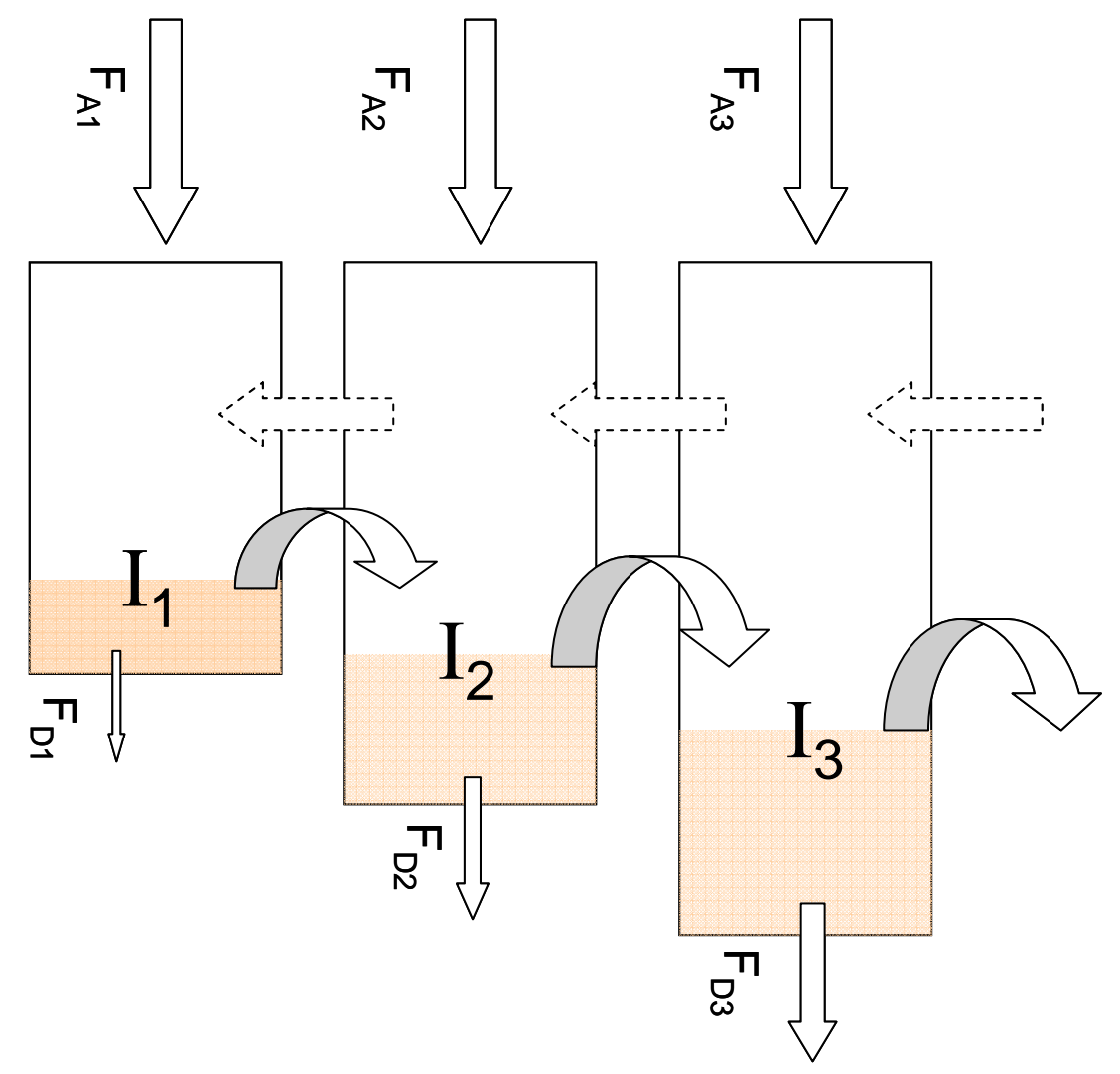

Figure 11. Box-in-series model diagram for the calculation of ${ }^{210} \mathrm{~Pb}$ residence time and cross-margin transport flux. $\mathrm{I}_{\mathrm{i}}(\mathrm{i}=1,2,3 \ldots \mathrm{n})$ represents total ${ }^{210} \mathrm{~Pb}$ inventory in each box, where the first box $\left(\mathrm{I}_{1}\right)$ adjoins the coast. $\mathrm{F}_{\mathrm{Ai}}$ represents the atmospheric fallout flux on the surface of each box. $\mathrm{F}_{\mathrm{Di}}$ is the ${ }^{210} \mathrm{~Pb}$ decay loss within the box. The arrow from box i to $i+1$ represents the cross-margin flux. Dashed arrows represent the possibility of cross-margin transport in the onshore direction.

In contrast to the box-in-series model, all boxes in the nested-box model adjoin the shoreline, and thus there is more variability in the sizes of boxes (Fig. 12). At steady 
state, in any box, the difference between the input from atmospheric deposition $\left(\mathrm{F}_{\mathrm{A}}=\right.$ $\left.27.4 \mathrm{dpm} / \mathrm{m}^{2}-\mathrm{d}\right)$ and isotope decay $\left(\mathrm{F}_{\mathrm{D}}=\mathrm{I}_{\mathrm{i}} \cdot \mathrm{k}\right)$ equals the flux out of the box $\left(\mathrm{F}_{\mathrm{X}}\right)$ or the rate of cross-margin transport at distance $i$ from shore. This flux is the net result of all transport processes including advection and dispersion in the water column, repeated sediment settling and resuspension within the box, and ultimately efflux across the boundary.

The box-in-series model yields residence times of isotopes (and particles) in successive sections of a transect while the nested-box model yields residence times in successively longer transects (all transects beginning from the shoreline). In the nestedbox model, cross-margin transport occurring within a box will be treated as an internal process. Given the year-round presence of the Keweenaw Current, a coastal jet flowing northeastward along the Keweenaw Peninsula [Viekman and Wimbush, 1993], it seems unlikely that all sediment transported off of the model transect (box-in-series) is really transported in an offshore direction. If some sediment is entrained in the current and transported in the longshore direction, then fluxes into successive boxes may be overestimated and residence times underestimated. Alternatively, if sediment and isotopes are transported parallel to shore and result in net inputs to some boxes along a transect, the residence times would be overestimated in the box-in-series model. In this case, the application of the nested-box model may be a useful addition to the box-inseries model. Also, with the nested-box model the cross-margin flux at any site is only related to the atmospheric deposition, $\mathrm{F}_{\mathrm{A}}$, and the radioactive decay within the whole box and does not require the cross-margin flux from the previous box as in the box-in-series 
model; the simpler calculation results in a smaller propagated error (uncertainty) in the cross-margin flux.

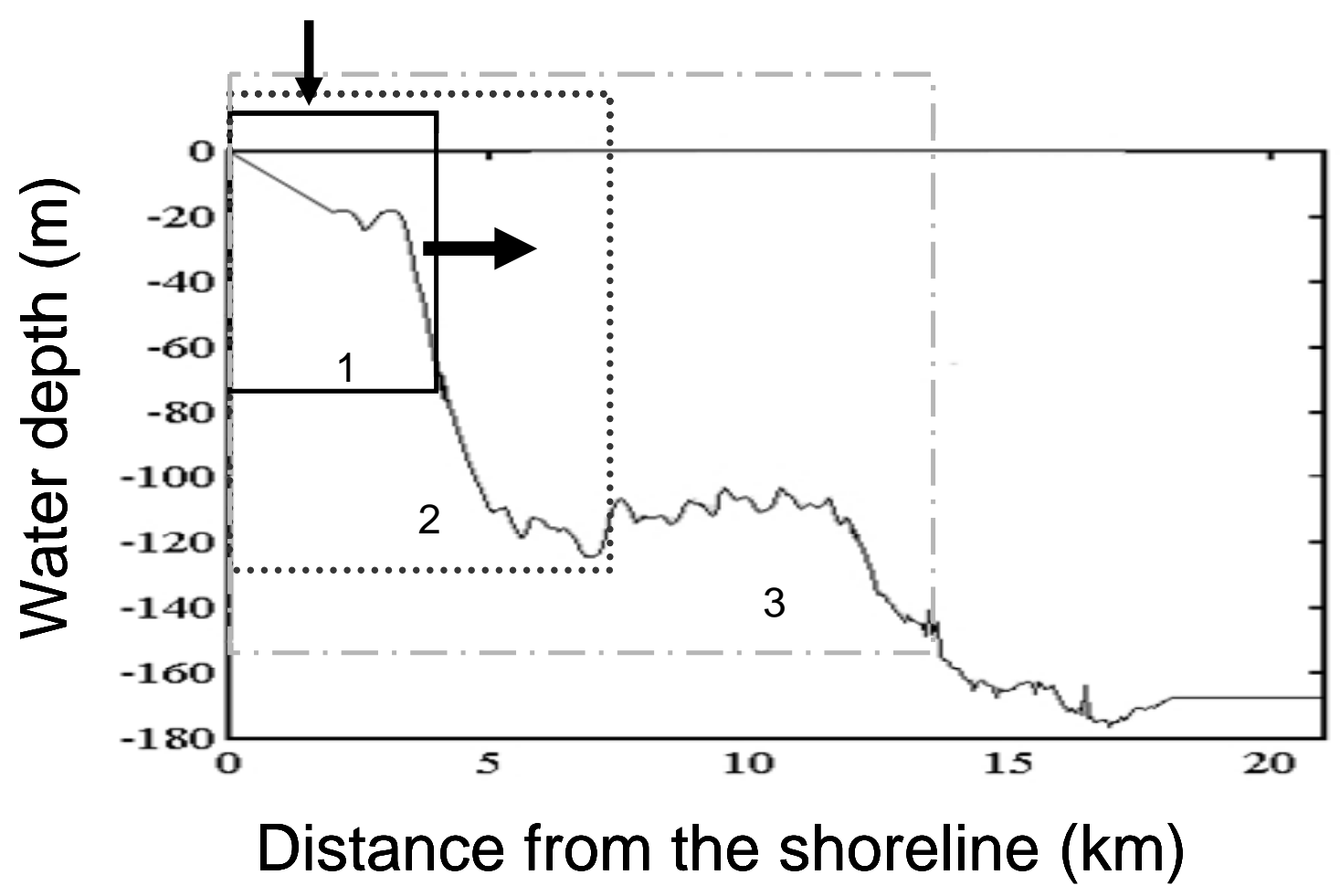

Figure 12. Diagram for the nested-box model. Every box adjoins the coast; a series of boxes with increasing sizes (distance-wise) is considered along a transect. Both water and surface sediments are included in the boxes. The bathymetry of the HN transect is used for illustrative purposes.

Both models were applied to the three transects in this study. Because the vast majority of the isotope inventory for all boxes is in the sediment (Figure 11 and 12), the model predictions are not particularly sensitive to the assumption of a constant isotope 
activity throughout the water column. Also, as can be seen from Figure 13, the sampling frequency (spatially) of water samples is not as intensive as was sediment coring.

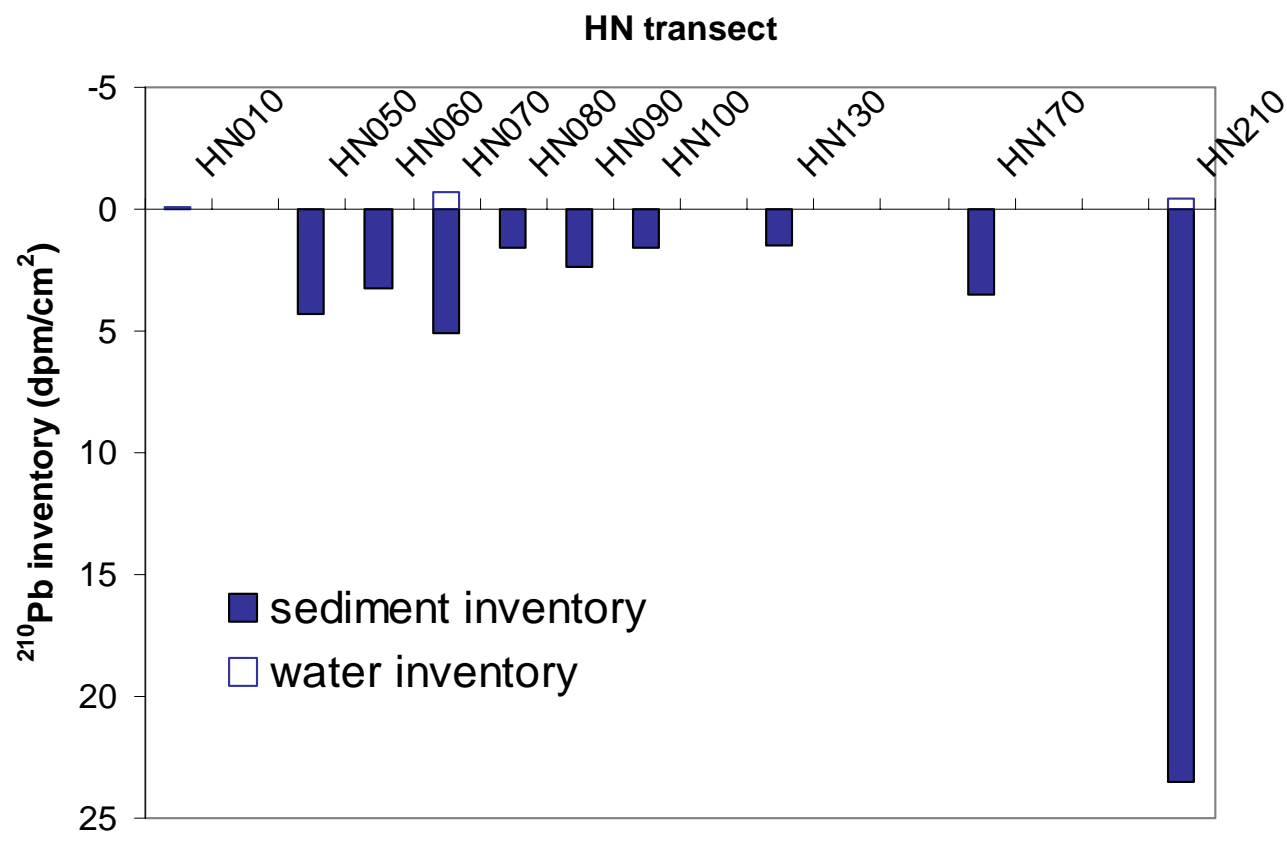

Figure 13. Measured ${ }^{210} \mathrm{~Pb}$ inventories in the sediment cores (2001) and water column. Values for both the water column and sediments apply only to each coring site, not to the box extending from the shore to that site. 
Table 11. ${ }^{210} \mathrm{~Pb}$ residence times and cross-margin transport fluxes from the box-inseries model ${ }^{\mathrm{a}}$.

\begin{tabular}{|c|c|c|c|c|c|c|}
\hline \multirow{2}{*}{ Sites } & \multirow{2}{*}{ Year } & \multirow{2}{*}{$\begin{array}{c}\text { Distance } \\
(\mathrm{km})\end{array}$} & \multirow{2}{*}{$\begin{array}{l}\text { Depth } \\
(\mathrm{m})\end{array}$} & \multicolumn{2}{|c|}{$\tau$} & \multirow{2}{*}{$\begin{array}{c}F_{x} \\
(\mathrm{dpm} / \mathrm{cm} 2-\mathrm{yr})\end{array}$} \\
\hline & & & & $\mathrm{yr}$ & day & \\
\hline HN050 & 2001 & 5 & 115 & 1.00 & 366 & 41.9 \\
\hline HN060 & 2001 & 6 & 113 & 0.76 & 279 & 50.2 \\
\hline HN070 & 2001 & 7 & 127 & 0.74 & 270 & 51.4 \\
\hline HN080 & 2001 & 8 & 118 & 0.54 & 196 & 62.7 \\
\hline HN090 & 2001 & 9 & 109 & 0.31 & 114 & 76.3 \\
\hline HN100 & 2001 & 10 & 111 & 0.28 & 104 & 83.2 \\
\hline HN130 & 2001 & 13 & 147 & 0.60 & 218 & 81.7 \\
\hline HN170 & 2001 & 17 & 180 & 0.90 & 327 & 86.4 \\
\hline HN210 & 2001 & 21 & 170 & 2.97 & 1086 & 104.4 \\
\hline HN050 & 2002 & 5 & 115 & 0.40 & 145 & 42.7 \\
\hline HN070 & 2002 & 7 & 127 & 1.89 & 692 & 51.2 \\
\hline HN080 & 2002 & 8 & 117 & 1.09 & 399 & 61.9 \\
\hline HN090 & 2002 & 9 & 120 & 0.85 & 309 & 66.9 \\
\hline HN100 & 2002 & 10 & 113 & 0.59 & 214 & 78.5 \\
\hline HN130 & 2002 & 13 & 147 & 0.74 & 270 & 78.9 \\
\hline HN170 & 2002 & 17 & 179.5 & 6.68 & 2438 & 68.8 \\
\hline HN210 & 2002 & 21 & 161.5 & 6.65 & 2428 & 80.3 \\
\hline EH010 & 2003 & 1 & 109 & 3.70 & 1351 & 8.1 \\
\hline EH020 & 2003 & 2 & 207 & 4.18 & 1525 & 7.9 \\
\hline EH030 & 2003 & 3 & 255 & 4.43 & 1617 & 8.9 \\
\hline EH050 & 2003 & 5 & 255 & 3.98 & 1452 & 14.7 \\
\hline EH070 & 2003 & 7 & 257 & 14.15 & 5165 & 12.5 \\
\hline EH090 & 2003 & 9 & 261 & 15.55 & 5676 & 10.3 \\
\hline ON090 & 2003 & 9 & 70.5 & 2.09 & 763 & 118.7 \\
\hline ON110 & 2003 & 11 & 74.5 & 1.70 & 622 & 131.8 \\
\hline ON130 & 2003 & 13 & 84 & 1.43 & 521 & 134.5 \\
\hline ON170 & 2003 & 17 & 105 & 4.66 & 1701 & 124.6 \\
\hline ON210 & 2003 & 21 & 128 & 7.55 & 2755 & 132.8 \\
\hline
\end{tabular}

a) Each box stretches from the previous station to the named station (e.g., for HN060 the box extends from HN050 to HN060. For the first box on a transect, the box includes only the $1 \mathrm{~km}$ stretch ending at the named station. 
Table 12. ${ }^{210} \mathrm{~Pb}$ residence times and cross-margin transport fluxes from the nested-box model. Unlike values in Table 11, residence times in this table are for boxes that begin at the shoreline.

\begin{tabular}{|c|c|c|c|c|c|c|}
\hline Sites & Year & $\begin{array}{c}\text { Distance } \\
(\mathrm{km})\end{array}$ & $\begin{array}{l}\text { Depth } \\
(\mathrm{m})\end{array}$ & $\mathrm{yr}$ & day & $\begin{array}{c}F_{X} \\
(\mathrm{dpm} / \mathrm{cm} 2-y r)\end{array}$ \\
\hline HN050 & 2001 & 5 & 115 & 1.8 & 665 & 41.5 \\
\hline HN060 & 2001 & 6 & 113 & 2.3 & 856 & 50.0 \\
\hline HN070 & 2001 & 7 & 127 & 3.1 & 1114 & 50.8 \\
\hline HN080 & 2001 & 8 & 118 & 2.9 & 1067 & 62.8 \\
\hline HN090 & 2001 & 9 & 109 & 2.9 & 1071 & 76.5 \\
\hline HN100 & 2001 & 10 & 111 & 2.9 & 1042 & 83.7 \\
\hline HN130 & 2001 & 13 & 147 & 2.8 & 1022 & 82.4 \\
\hline HN170 & 2001 & 17 & 180 & 3.0 & 1088 & 87.6 \\
\hline HN210 & 2001 & 21 & 170 & 4.9 & 1804 & 107.2 \\
\hline HN050 & 2002 & 5 & 115 & 0.82 & 299 & 42.9 \\
\hline HNO70 & 2002 & 7 & 127 & 3.37 & 1232 & 50.2 \\
\hline HN080 & 2002 & 8 & 117 & 3.78 & 1381 & 61.5 \\
\hline HNO9O & 2002 & 9 & 120 & 4.58 & 1671 & 65.6 \\
\hline HN100 & 2002 & 10 & 113 & 4.22 & 1541 & 78.5 \\
\hline HN130 & 2002 & 13 & 147 & 4.14 & 1511 & 78.7 \\
\hline HN170 & 2002 & 17 & 179.5 & 9.05 & 3302 & 70.0 \\
\hline HN210 & 2002 & 21 & 161.5 & 8.76 & 3198 & 97.4 \\
\hline EH010 & 2003 & 1 & 109 & 3.70 & 1351 & 8.3 \\
\hline EH020 & 2003 & 2 & 207 & 7.58 & 2768 & 7.7 \\
\hline EH030 & 2003 & 3 & 255 & 8.93 & 3261 & 8.9 \\
\hline EH050 & 2003 & 5 & 255 & 8.04 & 2936 & 15.5 \\
\hline EH070 & 2003 & 7 & 257 & 21.62 & 7893 & 10.0 \\
\hline EH090 & 2003 & 9 & 261 & 18.89 & 6894 & 15.7 \\
\hline ON090 & 2003 & 9 & 70.5 & 3.28 & 1197 & 115.8 \\
\hline ON110 & 2003 & 11 & 74.5 & 4.53 & 1653 & 128.4 \\
\hline ON130 & 2003 & 13 & 84 & 5.33 & 1945 & 130.9 \\
\hline ON170 & 2003 & 17 & 105 & 8.94 & 3262 & 119.0 \\
\hline ON210 & 2003 & 21 & 128 & 12.99 & 4742 & 100.2 \\
\hline
\end{tabular}


Residence times and cross-margin fluxes are summarized in Table 11 (box-inseries) and Table 12 (nested-box) for all three transects. In Table 11, residence times for the first station on the transect apply to the transect section from the coastline to the first coring site; subsequent values refer to incremental residence times between coring stations. The fluxes have been normalized to the sediment surface area and thus are not sensitive to the width of the box. Although there is a large range in the estimated residence times with values as low as 104 days at some sites and as high as $\sim 5600$ days (15.6 years) at EH090, some trends are clear. First, the relationship between isotope (and, by inference, fine particle) residence time and sediment size generally is what would be predicted a priori: zones dominated by large particles experience relatively high turbulence and have short residence times while in more quiescent sites fine particles dominate and reside for longer times (Figure 14). The generally inverse relationship shown in Figure 14 lends some support to the validity of the trends if not to the absolute magnitudes of predicted residence times.

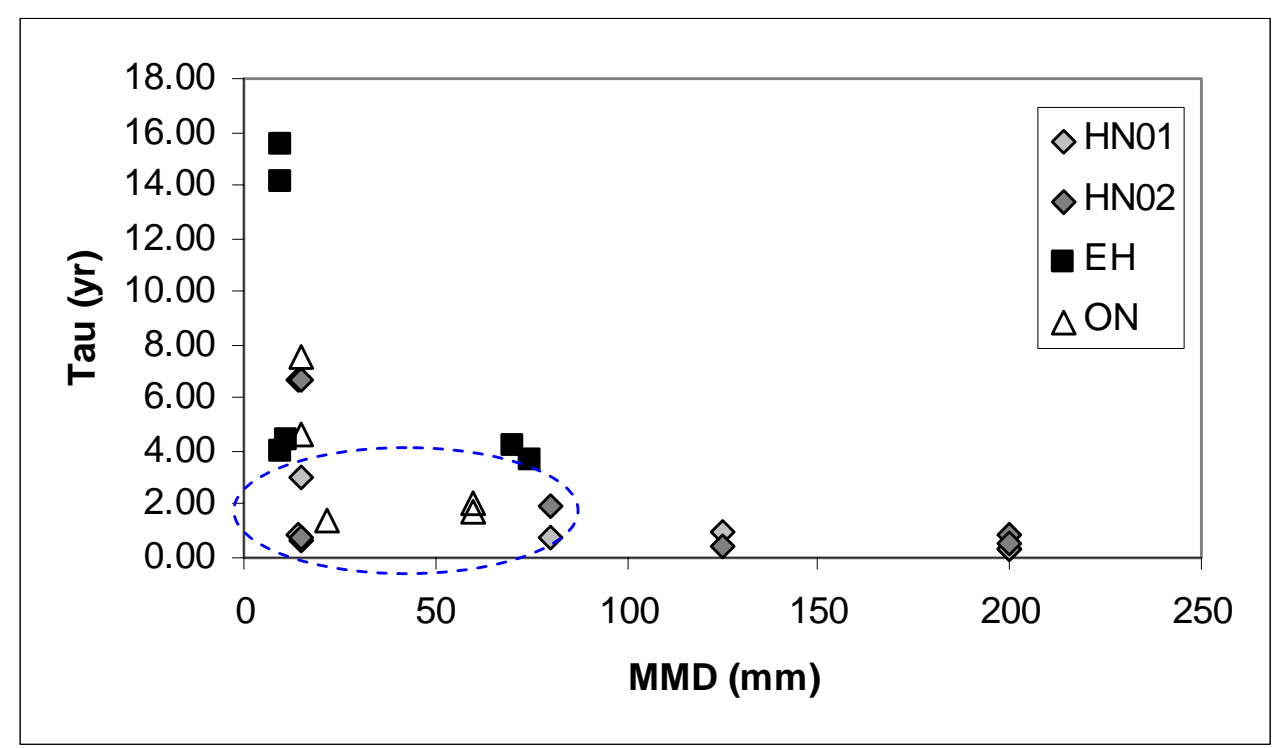


Figure 14. Relationship between particle size and fine-particle or isotope residence time as predicted by the box-in-series model. Values within the dashed circle do not follow the expected inverse relationship.

The ${ }^{210} \mathrm{~Pb}$ residence times do not increase systematically with increasing water depth or distance from shore. Along the $\mathrm{HN}$ transect, for both years, local accumulation is observed in the region between $\mathrm{HN} 050$ and HN070 with a combined residence time of 915 days for 2001 and 837 days for 2002. For both years, the zone from $10 \mathrm{~km}$ to $13 \mathrm{~km}$ (HN100 - HN130) has short residence times implying that isotopes entering this zone are resuspended and transported out of this zone quickly. Similarly, local depositional zones followed by areas with shorter residence times are also found on the other two transects (ON090 and EH010 EH020).

The observed pattern along the HN transect does appear to be related to the bathymetry. The "local deposition zone" at HN050 is at the base of a steep slope. Differences between the two years in calculated residence times for transect sections appear to be related to the actual depth of water where cores were retrieved. In 2001, the HN090 core was taken at a depth of $109 \mathrm{~m}$ and the HN210 core was taken at $170 \mathrm{~m}$, while in 2002, the coring depths were $120 \mathrm{~m}$ and $161.5 \mathrm{~m}$ for HN090 and HN210, respectively. The change in the water depths appears to affect the calculated residence times, where low residence times were observed for the shallower collection depths and higher residence times were obtained when the sampling depth increased by $\sim 10 \mathrm{~m}$. 
Traditionally, ${ }^{210} \mathrm{~Pb}$ has been used as a tracer for particulate organic carbon (POC) [Friedrich and van der Loeff, 2002; Sarin et al., 1999], and the pattern of residence times for ${ }^{210} \mathrm{~Pb}$ may mirror the pattern for residence times of particulate organic matter. A longer residence time for POC in the local deposition zones might explain the observed distribution of Diporeia along all three transects [Auer and Kahn, 2004]. The longer residence times between $\mathrm{HN} 050$ and $\mathrm{HN} 070$ may indicate a temporary accumulation zone for POC where Diporeia experience a greater availability of food. Although POC resides even longer in the deeper water at the open-lake ends of the transects, the organic matter may be more degraded at this point and may not provide as high quality of a food source as at the base of the slope.

Both models suggest that there is greater export of ${ }^{210} \mathrm{~Pb}$ and, by inference, sediments from the $\mathrm{HN}$ and $\mathrm{ON}$ transects than from the $\mathrm{EH}$ transects. The fluxes at the furthest sites along the $\mathrm{HN}$ and $\mathrm{ON}$ transect are almost 6.4 6.8 times (nested-box) to 9.8 12.9 times (box-in-series) higher than that at the furthest site on the EH transect (Tables 11 and 12). This pattern is the opposite of the pattern of sediment accumulation rates (Table 10), which seems reasonable as the total ${ }^{210} \mathrm{~Pb}$ or fine sediment input to a given transect is distributed between the two pathways; on the EH transect it preferentially accumulates while on the other two transects it is preferentially exported.

The cross-margin fluxes of the isotopes may be used to estimate the rates of sediment export from the transects. Two approaches were used for this estimate as summarized in Table 13. As discussed above, the nested-box model yields estimates of cross-margin fluxes with less uncertainty than does the box-in-series model. Cross margin transport of ${ }^{210} \mathrm{~Pb}$ equals the influx from the atmosphere less the amount lost to 
radioactive decay in the region of the box. The radioisotope is carried off of the transect bound to sediments that have been resuspended into the water column. The ratio of the mass of sediments that are exported to the amount of radioisotope that is exported is simply the inverse of the specific activity $(\mathrm{dpm} / \mathrm{g})$ of the isotope in the transported solids. Thus, if the specific activity and the isotope flux are known, the flux of solids may be calculated. Two estimates of the specific ${ }^{210} \mathrm{~Pb}$ activity were used to put bounds on the magnitude of the sediment flux. The upper bound is obtained by using the activity of the isotope in the fluff material at the top of the sediment cores. The lower limit on sediment transport is obtained by using a higher specific activity calculated as the total water column inventory divided by the suspended solids inventory (this is approximately the same as using the activity measured on suspended solids as reported in Chai and Urban [2004]).

Table 13. Offshore sediment transport estimated with isotope cross-margin transport fluxes from the nested-box model. The fluxes have been normalized to the vertical water column surface of each individual transect.

\begin{tabular}{cccrrrr} 
& depth & distance & \multicolumn{2}{c}{ C-M w/ water } & \multicolumn{2}{c}{ C-M w/ sediment } \\
sites & $(\mathrm{m})$ & $(\mathrm{km})$ & $\mathrm{g} / \mathrm{m}^{2}-\mathrm{yr}$ & $\mathrm{mg} / \mathrm{m}^{2}-\mathrm{s}$ & $\mathrm{g} / \mathrm{m}^{2}-\mathrm{yr}$ & $\mathrm{mg} / \mathrm{m}^{2}-\mathrm{s}$ \\
\hline HN210 & 164 & 21 & 7203 & 0.23 & 16644 & 0.53 \\
ON210 & 128 & 21 & 7506 & 0.24 & 15895 & 0.50 \\
EH090 & 261 & 9 & 1164 & 0.04 & 2534 & 0.08
\end{tabular}

As seen in Table 13, the two methods yield different estimates of the sediment transport flux although a similar pattern is observed among the three transects $(\mathrm{HN} \approx \mathrm{ON}$ $>\mathrm{EH})$. The cross margin transport process likely is a combination of both water column 
and sedimentary processes. Thus the two approaches set an upper and lower limit for export of sediments from the study transects.

These model predictions of sediment transport may be compared with estimates based on measurements of currents and suspended solids immediately above the sediments [Churchill et al., 2004]. The average offshore flux calculated from measurements made on three tripods located at water depth $60 \sim 90 \mathrm{~m}$ on the $\mathrm{HN}$ transect was $0.41 \pm 0.36 \mathrm{mg} / \mathrm{m}^{2}$-s $(95 \%$ C.I. and $\mathrm{n}=21)$. The estimate based on ${ }^{210} \mathrm{~Pb}$ export from the end of the $\mathrm{HN}$ transect $\left(0.53 \mathrm{mg} / \mathrm{m}^{2}-\mathrm{s}\right)$ falls within this range.

The tripod measurements, however, point to a potential weakness in the 2dimensional model. In addition to cross-margin (perpendicular to shore) transport, Churchill et al. [2004] also calculated longshore transport that is ignored in both models. The average longshore sediment flux calculated for the same time period at the same tripod location on the $\mathrm{HN}$ transect was $6.1 \pm 2.8 \mathrm{mg} / \mathrm{m}^{2}$-s, a number significantly higher than the cross-margin transport. If all of this material passed from one side of the transect to the other in the long-shore direction, the 2-D model would not be compromised. If, however, any of the longshore flux either originates from the transect or is (even temporarily) deposited on the transect and thereby contributes to the measured isotope inventory, the model may be compromised.

A comparison of ${ }^{210} \mathrm{~Pb}$ and ${ }^{137} \mathrm{Cs}$ measurements on the transects also seems to point to long shore transport. A significant linear correlation between isotope inventories and model-predicted residence times (Figure 15) is expected based on the defining equation (Equation 2). However, the existence of ${ }^{137} \mathrm{Cs}$ in the nearshore sites already indicates that ${ }^{137} \mathrm{Cs}$ must have other sources besides atmospheric deposition; otherwise, it 
should have worked its way out of this temporary deposition zone given the short residence times calculated for ${ }^{210} \mathrm{~Pb}$ as compared with the 40 -year period since the peak deposition of ${ }^{137}$ Cs. Since there currently is no measurable atmospheric deposition of ${ }^{137} \mathrm{Cs}$ [Baskaran, Personal Communication 2004], the measured ${ }^{137} \mathrm{Cs}$ inventory has to come from other sources such as lateral transport.

Under the assumption that ${ }^{210} \mathrm{~Pb}$ and ${ }^{137} \mathrm{Cs}$ are associated with the same particles, the ${ }^{210} \mathrm{~Pb}$ inventory derived from recent atmospheric deposition directly to the transect can be calculated with the following equation;

$$
{ }^{210} \mathrm{~Pb} \text { atmos }\left(\mathrm{dpm} / \mathrm{cm}^{2}\right)={ }^{210} \mathrm{~Pb} \text { total }-\alpha \cdot{ }^{137} \mathrm{Cs}_{\text {total }}
$$

In Equation 3, total inventories are those measured in the cores and the atmospherically derived inventory is the ${ }^{210} \mathrm{~Pb}$ inventory from recent atmospheric deposition to the nearshore zone. The factor $\alpha$ in Equation 3 is the ratio of ${ }^{210} \mathrm{~Pb}$ to ${ }^{137} \mathrm{Cs}$ on the particles that are transported laterally within the lake. The value of $\alpha$ probably varies with location in the lake; a potential value would be about 2 , the ratio of the steady-state inventory of ${ }^{210} \mathrm{~Pb}$ to the decay-corrected inventory of ${ }^{137} \mathrm{Cs}$ in Lake Superior [Robbins, 1985]. Compared with the total ${ }^{210} \mathrm{~Pb}$, the recently atmospherically-derived fraction of ${ }^{210} \mathrm{~Pb}$ (should mainly be found in the water column and very top of the sediments) might provide a better tracer for "fresh" organic matter generated in the upper water column. With this new and smaller inventory of ${ }^{210} \mathrm{~Pb}$ (Eqn 3), even shorter residence times are expected than those presented in Table 11. For example, with an alpha value of 2 , the residence time in the HN local deposition zone (HN050 070) would change from $\sim 1000$ days to about 200 days. 


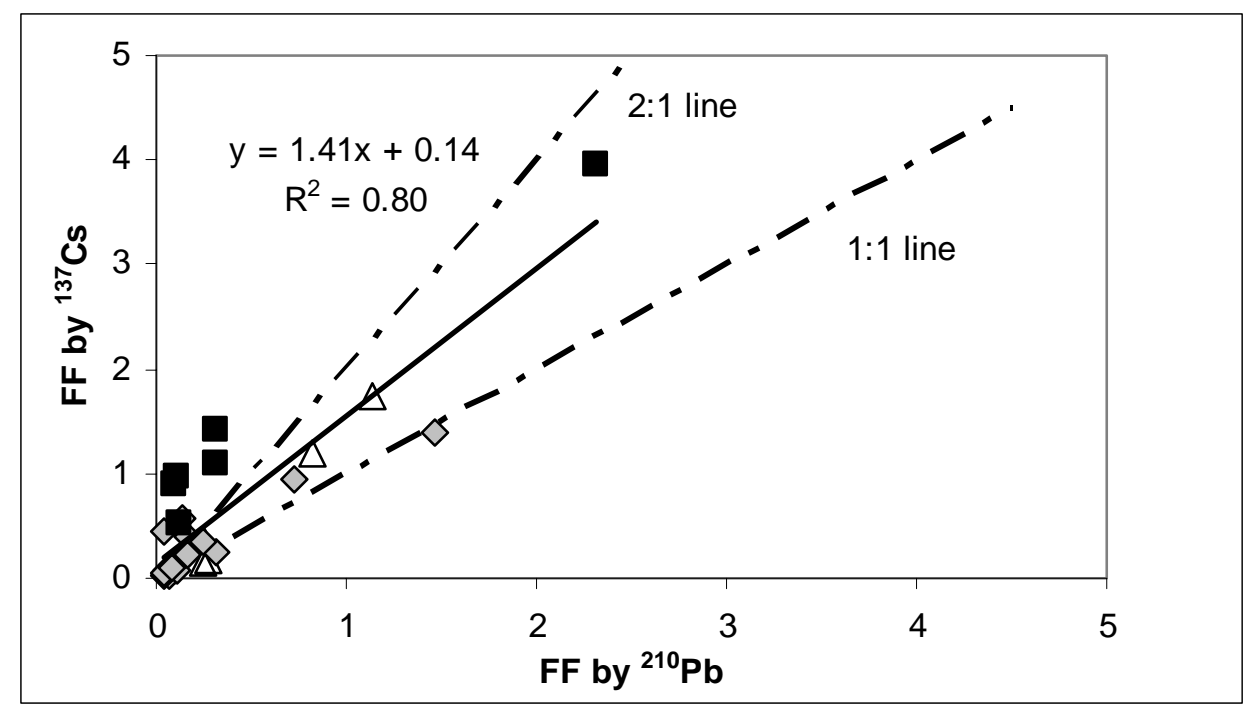

Figure 15. Comparison of Focusing factors based on two isotopes. The diamonds represent cores from the $\mathrm{HN}$ transect, triangles represent the $\mathrm{ON}$ transect, and squares represent the EH transect. A linear regression fitting curve (solid line with equation and $\mathrm{R}^{2}$ ) and two arbitrary lines (ratios of 2:1 and 1:1) are also shown.

The ${ }^{137} \mathrm{Cs}$-based correction to the ${ }^{210} \mathrm{~Pb}$ inventory cannot be performed with an alpha value of 2 at many sites because the ratio of ${ }^{210} \mathrm{~Pb}:{ }^{137} \mathrm{Cs}$ inventories is often less than 2. As seen in Figure 15, eight out of the 28 cores (five in EH and three in $\mathrm{HN}$ ) have ${ }^{137} \mathrm{Cs}$ derived FF's more than two times higher than FF's from ${ }^{210} \mathrm{~Pb}$. Only at sites where the ratio $\mathrm{FF}^{137} \mathrm{Cs} / \mathrm{FF}^{-210} \mathrm{~Pb}$ is less than 1 , or where ${ }^{210} \mathrm{~Pb}:{ }^{137} \mathrm{Cs}$ is greater than 2.0 , is this operation feasible. This confines application of this correction to six sites: four on the EH transect (EH070, 090, 130 and 170) and two on the ON transect (ON090, ON110). The remainder of the cores have higher ${ }^{137} \mathrm{Cs}$ inventories than can be explained with an alpha value of 2. An alternative set of explanations might include that ${ }^{210} \mathrm{~Pb}$ and ${ }^{210} \mathrm{Cs}$ are not bound to the same set of particles and thus ${ }^{137} \mathrm{Cs}$ has more mobility, or that other 
sources of ${ }^{137} \mathrm{Cs}$ such as shoreline erosion [Santschi et al., 1999] lead to values of alpha less than 2 .

\subsection{Pathways and timescales of sediment transport: a larger view}

The isotope data from this study clearly demonstrate the cross-margin (i.e., offshore) transport of sediments along the coast of the Keweenaw Peninsula. The increasing inventories of ${ }^{210} \mathrm{~Pb}$ along all three transects (Figure 16) point to removal of this isotope from the nearshore region and its focusing into deeper waters. The isotope residence times calculated with a simple 2-dimensional model suggest that this transport occurs over a timescale of about a decade.

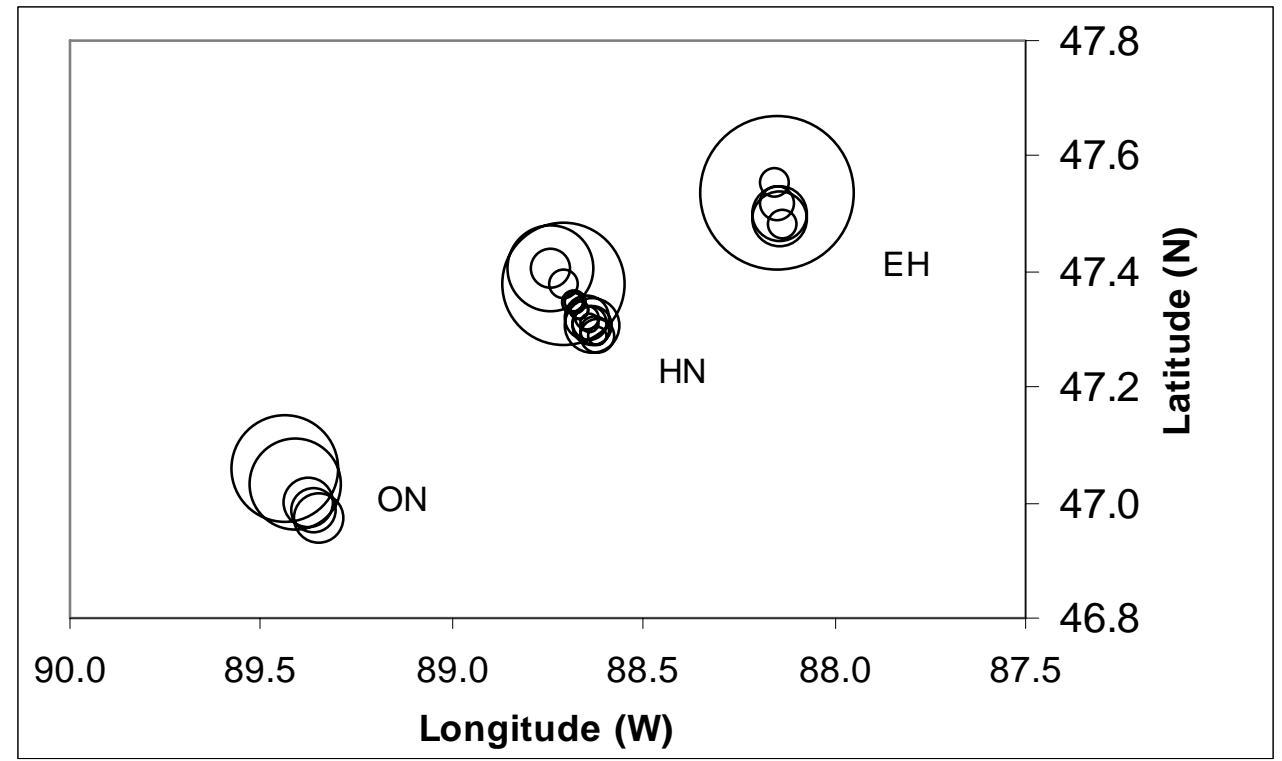

Figure 16. ${ }^{210} \mathrm{~Pb}$ inventories of the three transects. Note the size of bubbles only indicates relative magnitude within the data set plotted although a unit of $\mathrm{dpm} / \mathrm{cm}^{2}$ was used. 
Inventories of the short-lived ${ }^{7} \mathrm{Be}$ isotope indicate that the same pathways of transport are followed over a timescale of days to a few months (Figure 17) at least during the non-stratified period in the lake. Along each of the three transects, inventories of ${ }^{7} \mathrm{Be}$ are proportional to inventories of ${ }^{210} \mathrm{~Pb}$. The rapid radioactive decay of ${ }^{7} \mathrm{Be}$ may prevent the deep-water sites from accumulating this isotope in the same proportion to ${ }^{210} \mathrm{~Pb}$ as occurs in shallower sites. Only two (circled in Figure 17) of 19 sites have anomalously high ${ }^{7} \mathrm{Be}$ inventories that are not explained by a correspondingly high inventory of ${ }^{210} \mathrm{~Pb}$.

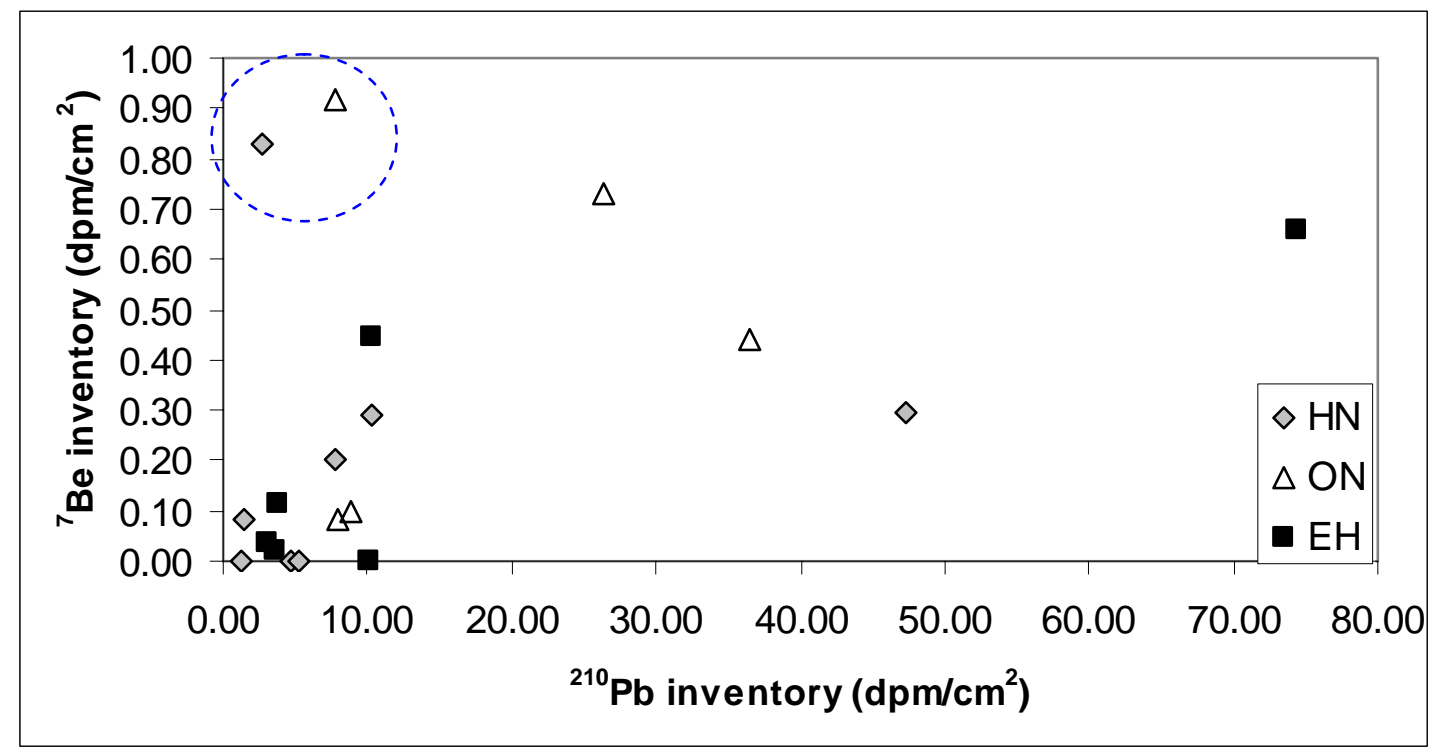

Figure 17. Comparison of transport pathways of short-lived ( $\left.{ }^{7} \mathrm{Be}\right)$ and longer-lived $\left({ }^{210} \mathrm{~Pb}\right)$ isotopes in the study region of Lake Superior. Only the two circled sites do not follow the general pattern of increasing inventories of ${ }^{7} \mathrm{Be}$ corresponding to increasing inventories of ${ }^{210} \mathrm{~Pb}$. 
The third isotope, ${ }^{137} \mathrm{Cs}$, clearly reveals the occurrence of longshore sediment transport that maintains a pool of fine-grained sediments in the near-shore zone for decades. ${ }^{137} \mathrm{Cs}$ is fundamentally different than the other two isotopes in that $>90 \%$ of the isotope present in the lake entered more than 30 years ago (Figure 18). Because there is no current input to the lake, this isotope is a good tracer of sediment reworking and focusing [Edgington and Robbins, 1990]. This study found that ${ }^{137} \mathrm{Cs}$ still is present in significant amounts in the nearshore sediments of Lake Superior despite the input to the lake having been cut-off in the mid-1960s and despite the fact that the half-life is only 30 years. There are only two possible explanations for the existence of ${ }^{137} \mathrm{Cs}$ in the nearshore region: either shoreline erosion is providing an ongoing and significant input of this isotope to the lake [Santschi et al., 1999] or older sediments are being entrained and circulated within the nearshore zone for decades. The strong counterclockwise circulation that persists year-round in Lake Superior [Beletsky et al., 1999] might be one mechanism for both entraining old sediments into the nearshore zone as well as maintaining them in that zone for extended time periods. The distribution of ${ }^{137} \mathrm{Cs}$ in the study region supports the latter hypothesis as explained below. 


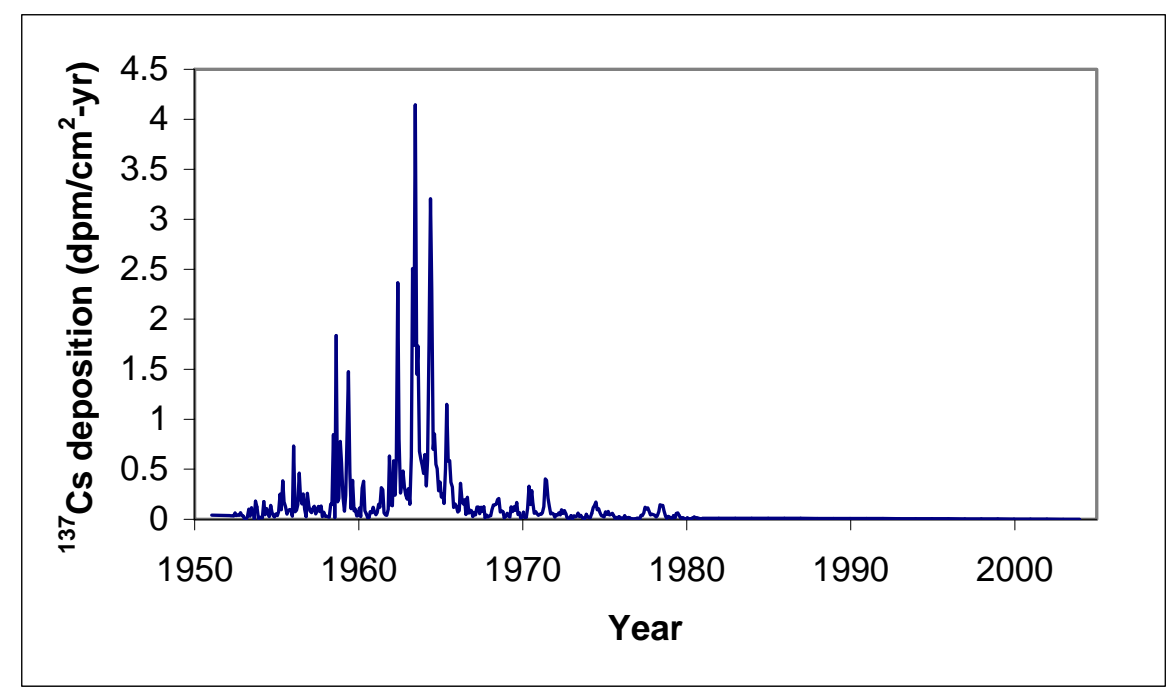

Figure 18. The historical pattern of ${ }^{137} \mathrm{Cs}$ deposition to Lake Superior. Data from Robbins [1985] have been corrected for decay to 2004 .

Once in the nearshore zone, ${ }^{137} \mathrm{Cs}$ is focused offshore in much the same fashion as is ${ }^{210} \mathrm{~Pb}$. The inventories and focusing factors for the two isotopes follow much the same pattern among the coring sites as illustrated in Figure 15. Thus, there is little evidence that the two isotopes are associated with different sizes of particles or that ${ }^{137} \mathrm{Cs}$ is scavenged from the water by different mechanisms than is ${ }^{210} \mathrm{~Pb}$ (e.g., scavenging by littoral sediments as reported by Wieland et al. [1993]).

On the other hand, the ratios of the ${ }^{137} \mathrm{Cs}$ inventory to that of ${ }^{210} \mathrm{~Pb}$ reveal that some sites within the study region are selectively enriched with ${ }^{137} \mathrm{Cs}$ (Figure 19). The large load of clay particles brought into the lake by the Ontonagon River [Robertson, 1997] clearly is not a source of ${ }^{137} \mathrm{Cs}$; the Ontonagon transect has the lowest and most uniform $\mathrm{Cs}: \mathrm{Pb}$ ratios in the study region. To some extent, this observation argues against soil erosion as being the source of ${ }^{137} \mathrm{Cs}$ to the nearshore zone. The sites with the high $\mathrm{Cs}: \mathrm{Pb}$ ratios are the upper slope region of the $\mathrm{HN}$ transect and most of the $\mathrm{EH}$ transect. 
Sediment trap measurements also have shown large gross rates of sediment deposition in these regions [Urban et al., 2004]. These are the regions most directly exposed to the Keweenaw Current [Churchill et al., 2004; Niebauer et al., 1977; Viekman and Wimbush, 1993]. The Keweenaw Current is part of the general counter-clockwise circulation of the lake, and, as mentioned above, it might provide a mechanism for bringing old sediments into the nearshore region of the study area. The relative paucity of ${ }^{137} \mathrm{Cs}$ along the $\mathrm{ON}$ transect may reflect the fact that this region of the lake is largely bypassed by the Keweenaw current [Churchill et al., 2003].

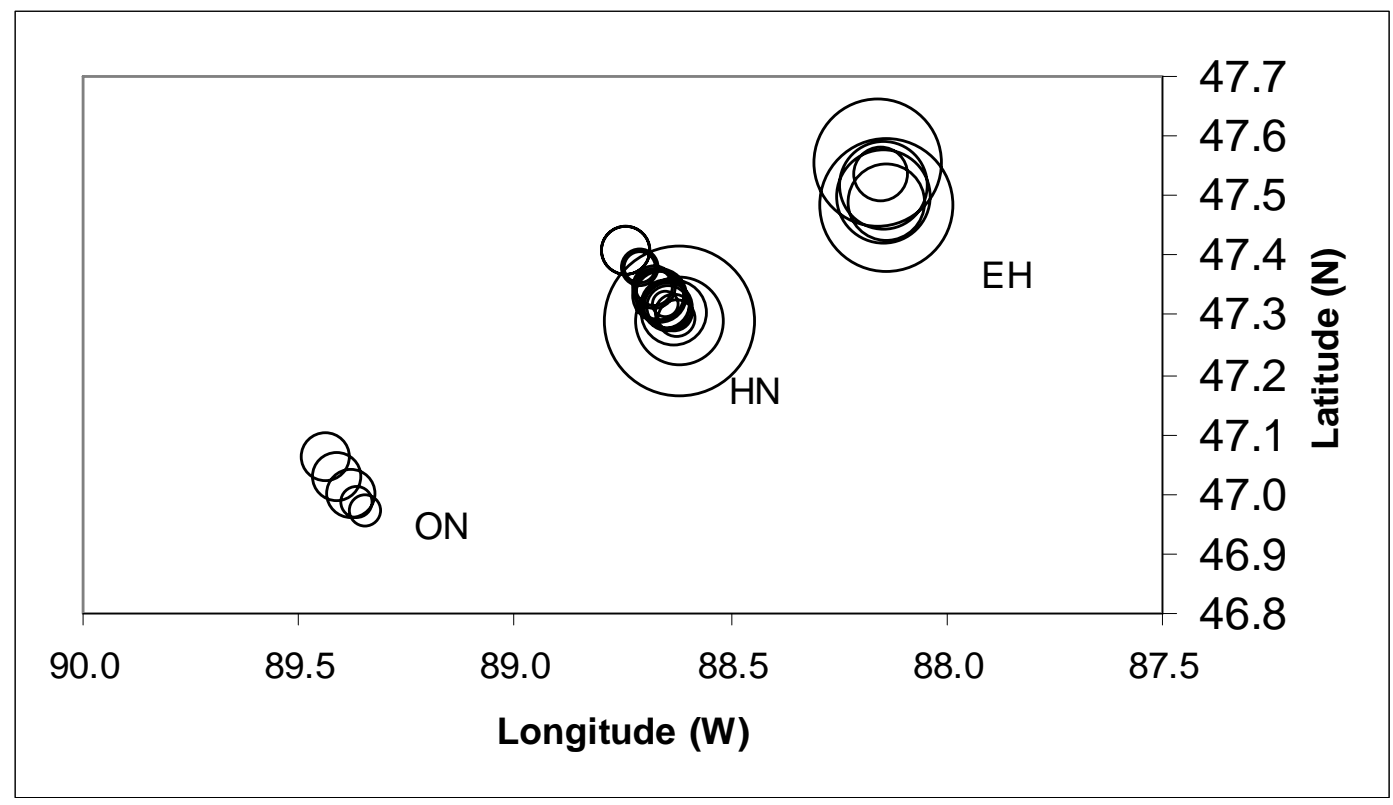

Figure 19. ${ }^{137} \mathrm{Cs} /{ }^{210} \mathrm{~Pb}$ sediment inventory ratios of the three transects. Again the size of bubbles only indicates relative magnitude within the data set. 


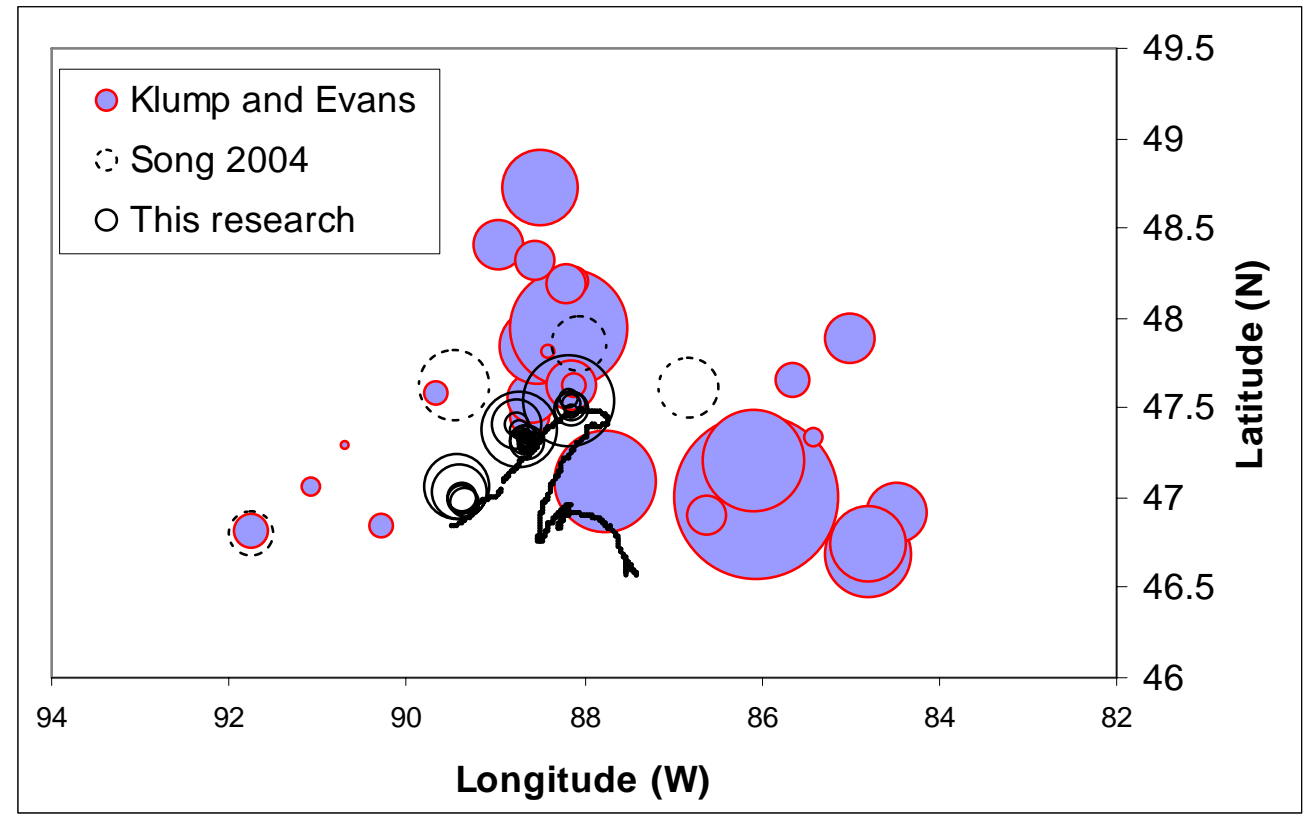

Figure 20. Excess ${ }^{210} \mathrm{~Pb}$ inventory in Lake Superior. Data are from two previous studies ([Evans et al., 1981; Klump et al., 1989]), one recent article [Song et al., 2004], and this research. The shoreline along the study region is also shown.

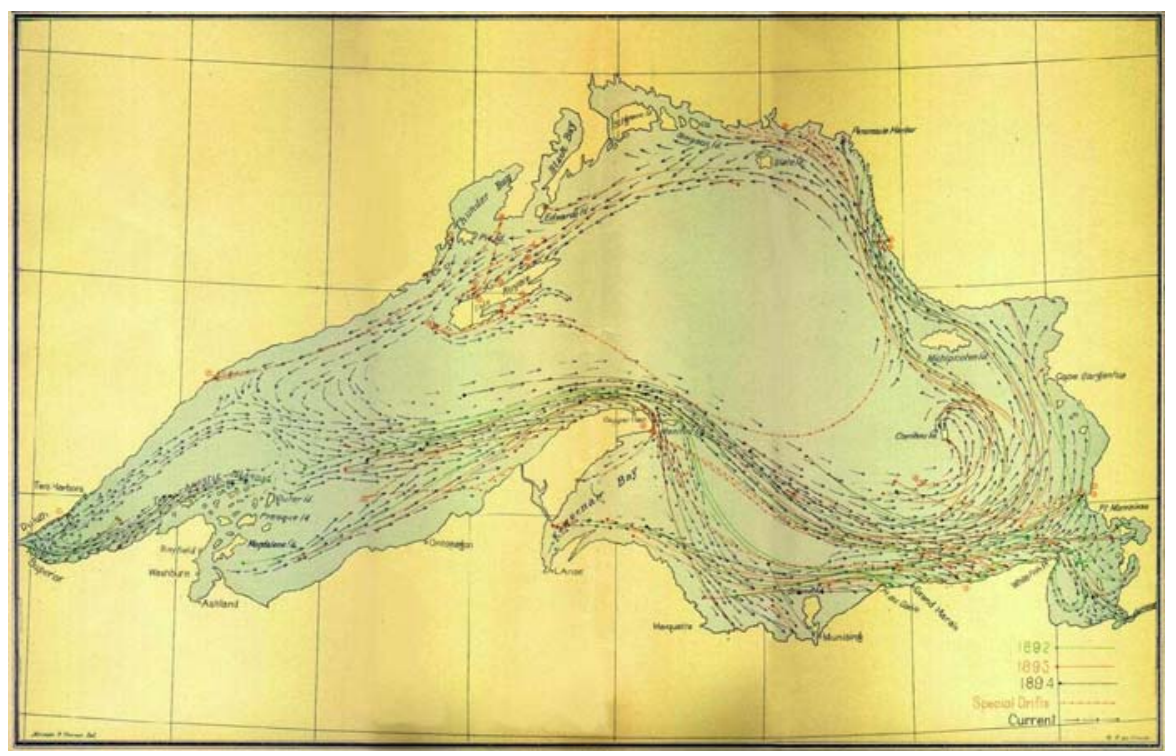


Figure 21. Currents in the Lake Superior: A historical map. Figure taken from: M.W. Harrington, 1895, US Department of Agriculture, Weather Bureau Bulletin

The pathways of sediment transport discussed above and the distribution of ${ }^{210} \mathrm{~Pb}$ inventories in the study region are consistent with previous measurements in the lake (Figure 20). In details, for all studies the distribution of ${ }^{210} \mathrm{~Pb}$ inventories is consistent with both cross-margin focusing into the Chefswet and Isle Royale basins as well as with entrainment of fine sediments into currents circulating around the lake periphery as illustrated in figure 21. These currents would appear to direct the fine sediments into the central lake (Isle Royale basin) off the tip of the Keweenaw Peninsula, a pathway consistent with hydrodynamic modeling of the lake [Chen et al., 2002], as well as into the Keweenaw and Caribou basins in the Keweenaw eddy [Budd, 2004].

\section{REFERENCES:}

Abril, J.M., Difficulties in interpreting fast mixing in the radiometric dating of sediments using ${ }^{210} \mathrm{~Pb}$ and ${ }^{137} \mathrm{Cs}$, J. Paleolimnol., 30 (4), 407-414, 2003.

Aller, R.C., L.K. Benninger, and J.K. Cochran, Tracking particle-associated processes in nearshore environments by use of ${ }^{234} \mathrm{Th} /{ }^{238} \mathrm{U}$ disequilibrium, Earth Planet. Sci. Lett., 47, 161-175, 1980.

Appleby, P.G., S.R. Higgitt, P.J. Nolan, F. Oldfield, and N. Richardson, ${ }^{210} \mathrm{~Pb}$ dating of lake sediments and ombrotrophic peats by Gamma essay, Sci. Total Environ., 69, 157-177, 1988.

Appleby, P.G., and F. Oldfield, The calculation of lead-210 dates assuming a constant rate of supply of unsupported ${ }^{210} \mathrm{~Pb}$ to the sediment, Catena, 5, 1-8, 1978.

Auer, N.A., and J.E. Kahn, Abundance and distribution of benthic invertebrates, with emphasis on Diporeia, along the Keweenaw Peninsula, Lake Superior, J. Great Lakes Res., In Press, 2004.

Baskaran, M., ${ }^{137} \mathrm{Cs}$ atmospheric fallout flux in Detroit, MI area, Personal Communication, edited by Y. Chai, Houghton, MI, 2004. 
Baskaran, M., and P.H. Santschi, The role of particles and colloids in the transport of radionuclides in coastal environments of Texas, Mar. Chem., 43 (1-4), 95-114, 1993.

Beletsky, D., J.H. Saylor, and D.J. Schwab, Mean circulation in the Great Lakes, J. Great Lakes Res., 25 (1), 78-93, 1999.

Bloesch, J., and U. Uehlinger, Horizontal sedimentation differences in a eutrophic Swiss lake, Limnol. Oceanogr., 31 (5), 1094-1109, 1986.

Brazner, J., and W. DeVita, PCBs, DDE, and mercury in young-of-the-year littoral fishes from Green Bay, Lake Michigan, J. Great Lakes Res., 24 (1), 83-92, 1998.

Budd, J.R., Remote sensing of large-scale transport phenomena in Lake Superior: the Keweenaw eddy and Ontonagon plume, J. Great Lakes Res., 30 (Suppl. 1), 2004.

Chai, Y., and N.R. Urban, ${ }^{210} \mathrm{Po}$ and ${ }^{210} \mathrm{~Pb}$ distributions and residence times in the nearshore region of Lake Superior, J. Geophys. Res., 109 (C10S07), doi:10.1029/2003JC002081, 2004.

Chen, C., J. Zhu, K. Kang, H. Liu, E. Ralph, S.A. Green, and J.R. Budd, Cross-frontal transport along the Keweenaw coast in Lake Superior: a Lagrangian model study, Dynamics of Atmospheres and Oceans, 36, 83-102, 2002.

Chen, C., J. Zhu, E. Ralph, S.A. Green, J.W. Budd, and F.Y. Zhang, Prognostic modeling studies of the Keweenaw Current in Lake Superior. Part I: formation and evolution, J. Phys. Oceanogr., 31, 379-395, 2001.

Churchill, J.H., E.A. Ralph, A.M. Cates, J.W. Budd, and N.R. Urban, Observations of a negatively buoyant river plume in a large lake, Limnol. Oceanogr., 48 (2), 884894, 2003.

Churchill, J.H., A.J. Williams, and E.A. Ralph, Bottom stress generation and sediment transport over the shelf and slope off of Lake Superior's Keweenaw peninsula, $J$. Geophys. Res., 109 (C10S04), doi:10.1029/2003JC001997, 2004.

Coale, K.H., and K.W. Bruland, Copper complexation in the Northeast Pacific, Limnol. Oceanogr., 33 (5), 1084-1101, 1988.

Cochran, J.K., K.O. Buesseler, M.P. Bacon, H.W. Wang, D.J. Hirschberg, L. Ball, J. Andrews, G. Grossin, and A. Fleer, Short-lived thorium isotope $\left({ }^{234} \mathrm{Th},{ }^{228} \mathrm{Th}\right)$ as indicators of POC export and particle cycling in the Ross Sea, Southern Ocean, Deep-Sea Research II, 47, 3451-3490, 2000.

Cook, P.M., Semi-quantitative determination of asbestiform amphibole mineral concentrations in Western Lake Superior water samples, in Advances in X-ray analysis, edited by W.L. Pickles, C.S. Barrett, J.B. Newkirk, and C.O. Ruud, pp. 557-567, Plenum Publishing Co., New York, 1975.

Davis, M.B., and M.S. Ford, Sediment focusing in Mirror Lake, New Hampshire, Limnol. Oceanogr., 27 (1), 137-150, 1982.

Dominik, J., C. Schuler, and P.H. Santschi, Residence time of 234Th and 7Be in Lake Geneva, Earth Planet. Sci. Lett., 93, 345-358, 1989.

Durham, R.W., and S.R. Joshi, Sedimentation rates in western Nipigon Bay, Lake Superior using the ${ }^{210} \mathrm{~Pb}$ method, Sci. Total Environ., 22 (1), 51-59, 1981.

Eadie, B.J., R.L. Chambers, W.S. Gardner, and G.L. Bell, Sediment trap studies in Lake Michigan: resuspension and chemical fluxes in the Southern Basin, J. Great Lakes Res., 10 (3), 307-321, 1984. 
Eadie, B.J., G.S. Miller, R.E. Holland, G.A. Leshkevich, M.B. Lansing, N.R. Morehead, J.A. Robbins, N. Hawley, D.N. Edgington, P.L. Van Hoof, D.J. Schwab, T.H. Johengen, and P.J. Lavrentyev, Particle transport, nutrient cycling, and algal community structure associated with a major winter-spring sediment resuspension event in southern Lake Michigan, J. Great Lakes Res., 28 (3), 324-337, 2002.

Eadie, B.J., H.A. Vanderploeg, J.A. Robbins, and G.L. Bell, Significance of sediment resuspension and particle settling, in Large Lakes Ecological Structure and Function, edited by M.M. Tilzer, and C. Serruya, pp. 196-209, Springer-Verlag, New York, 1990.

Edgington, D.N., J.V. Klump, J.A. Robbins, Y.S. Kusner, V.D. Pampura, and I.V. Sandimirov, Sedimentation rates, residence times and radionuclide inventories in Lake Baikal from ${ }^{137} \mathrm{Cs}$ and ${ }^{210} \mathrm{~Pb}$ in sediment cores, Nature, 350 (6319), 601-604, 1991.

Edgington, D.N., and J.A. Robbins, Time scales of sediment focusing in large lakes as revealed by measurement of fallout Cs-137, in Large Lakes Ecological Structure and Function, edited by M.M. Tilzer, and C. Serruya, pp. 210-223, SpringerVerlag, New York, 1990.

Eisenreich, S.J., P.J. Emmling, and A.M. Beeton, Atmospheric loading of phosphorus and other chemicals to Lake Michigan, J. Great Lakes Res., 3 (3-4), 291-304, 1977.

Eisenreich, S.J., B.B. Looney, and J.D. Thornton, Airborne organic contaminants in the Great Lakes ecosystem, Environ. Sci. Tech., 15 (1), 30-38, 1981.

Evans, J.E., T.C. Johnson, E.C.J. Alexander, R.S. Lively, and S.J. Eisenreich, Sedimentation rates and depisitional processes in Lake Superior from $210 \mathrm{~Pb}$ geochronology, J. Great Lakes Res., 7 (3), 299-310, 1981.

Fitzgerald, S.A., and W.S. Gardner, An algal carbon budget for pelagic-benthic coupling in Lake Michigan, Limnol. Oceanogr., 38 (3), 547-560, 1993.

Fitzgerald, S.A., V. Klump, P.W. Swarzenski, R.A. Mackenzie, and K.D. Richards, Beryllium-7 as a tracer of short-term sediment deposition and resuspension in the Fox River, Wisconsin, Environ. Sci. Technol., 35 (2), 300-305, 2001.

Friedrich, J., and M.M.R. van der Loeff, A two-tracer $\left({ }^{210} \mathrm{Po}_{-}{ }^{234} \mathrm{Th}\right)$ approach to distinguish organic carbon and biogenic silica export flux in the Antarctic Circumpolar Current, Deep-Sea Research I, 49 (1), 101-120, 2002.

Gilbert, R., Calculated wave base in relation to the observed patterns of sediment deposition in northeastern Lake Ontario, J. Great Lakes Res., 25 (4), 883-891, 1999.

Gloor, M., A. Wuest, and M. Munnich, Benthic boundary mixing and resuspension induced by internal seiches, Hydrobiologia, 284 (1), 59-68, 1994.

Gustafsson, O., P. Gschwend, and K.O. Buesseler, Settling removal rates of PCBs into the northwestern Atlantic derived from ${ }^{238} \mathrm{U}_{-}{ }^{234}$ Th disequilibria, Environ. Sci. Technol., 31, 3544-3550, 1997.

Halfman, B.M., and T.C. Johnson, Surface and benthic nepheloid layers in the western arm of Lake Superior, 1983, J. Great Lakes Res., 15 (1), 15-25, 1989.

Hawley, N., Sediment resuspension near the Keweenaw peninsula, Lake Superior during the fall and winter 1990-1991, J. Great Lakes Res., 26 (4), 495-505, 2000. 
Hawley, N., and R.W. Muzzi, Observations of nepheloid layers made with an autonomous vertical profiler, J. Great Lakes Res., 29 (1), 124-133, 2003.

Heussner, S., R.D. Cherry, and M. Heyraud, ${ }^{210} \mathrm{Po},{ }^{210} \mathrm{~Pb}$ in sediment trap particles on a Mediterranean continental margin, Cont. Shelf Res., 10 (9-11), 989-1004, 1990.

Hudson, P.L., J.F. Salvino, and C.R. Bronte, Predator-prey relations and competition for food between age-0 lake trout and slimy sculpin in the Apostle Island region of Lake Superior, J. Great Lakes Res., 21, 445-457, 1995.

Hunt, J.N., Direct solution of wave dispersion equation, J. Waterways, Ports, Coastal Ocean Div., ASCE, 105 (WW4), 457-459, 1979.

Jeong, J., Biogeochemical cycling of copper associated with particulate matter in Lake Superior, Michigan Technological University, Houghton, 2002.

Kada, J., and M. Heit, The inventories of anthropogenic Pb, $\mathrm{Zn}, \mathrm{As}, \mathrm{Cd}$, and the radionuclides ${ }^{137} \mathrm{Cs}$ and excess ${ }^{210} \mathrm{~Pb}$ in lake sediments of the Adirondack region, USA, Hydrobiologia, 246 (3), 231-241, 1992.

Kemp, A.L.W., C.I. Dell, and N.S. Harper, Sedimentation rates and a sediment budget for Lake Superior., J. Great Lakes Res., 4 (3-4), 276-287, 1978.

Keough, J.R., T.A. Thompson, G.R. Guntenspergen, and D.A. Wilcox, Hydrogeomorphic factors and ecosystem responses in coastal wetlands of the Great Lakes, Wetlands, 19 (4), 821-834, 1999.

Kerfoot, W.C., S. Harting, R. Rossmann, and J.A. Robbins, Anthropogenic copper inventories and mercury profiles from Lake Superior: evidence for mining impacts, J. Great Lakes Res., 25 (4), 663-682, 1999.

Kerfoot, W.C., and J.A. Robbins, Nearshore regions of Lake Superior: Multi-element signatures of mining discharges and a test of $\mathrm{Pb}-210$ deposition under conditions of variable sediment mass flux, J. Great Lakes Res., 25 (4), 697-720, 1999.

Kim, G., and T.M. Church, Seasonal biogeochemcal fluxes of ${ }^{234} \mathrm{Th}$ and ${ }^{210} \mathrm{~Pb}$ in the upper Sargasso Sea: influence from atmosphric iron deposition, Global Biogeochemical Cycles, 15 (3), 651-661, 2001.

Klump, V., M. Boraas, P. Anderson, P. R, C.C. Remsen, and S.A. Fitzgerald, Variations in sediment accumulation rates and the flux of labile organic matter in eastern Lake Superior basins, J. Great Lakes Res., 15 (1), 104-122, 1989.

Krishnaswami, S., and D. Lal, Radionuclide Limnochronology, in Lakes: Chemistry, Geology, Physics, edited by A. Lerman, pp. 153-178, Springer-Verlag, New York, 1978.

Krishnaswami, S., D. Lal, M.J. M., and M. Meybeck, Geochronology of lake sediments, Earth Planet. Sci. Lett., 11, 407-414, 1971.

$\mathrm{Lu}, \mathrm{X}$., The carbon cycle and food web structure of Lake Superior, Michigan Technological University, Houghton, MI, 2004.

McKee, J.D., T.P. Wilson, D.T. Long, and R.M. Owen, Geochemical partitioning of Pb, $\mathrm{Zn}, \mathrm{Cu}, \mathrm{Fe}$ and $\mathrm{Mn}$ across the sediment-water interface in large lakes, J. Great Lakes Res., 15 (1), 46-58, 1989.

McNeary, D., and M. Baskaran, Depositional characteristics of ${ }^{7} \mathrm{Be}$ and ${ }^{210} \mathrm{~Pb}$ in southeastern Michigan, J. Geophys. Res., 108 (D7), 4210, 2003.

Niebauer, H.J., T. Green, and R.A. Ragotzkie, Coastal upwelling/downwelling cycles in southern Lake Superior, J. Phys. Oceanogr., 7 (917-927), 1977. 
Olsen, C.R., I.L. Larsen, P.D. Lowry, N.H. Cutshall, J.F. Todd, G.T.F. Wong, and W.H. Casey, Atmospheric fluxes and marsh-soil inventories of ${ }^{7} \mathrm{Be}$ and ${ }^{210} \mathrm{~Pb}, J$. Geophys. Res., 90 (20), 10487-10495, 1985.

Ragotzkie, R.A., The Keweenaw Current, a regular feature of summer circulation of Lake Superior, pp. 36, Department of Meteorology, University of Wisconsin, Madison, Madison, Wisconsin, 1966.

Robbins, J.A., Geochemical and geophysical applications of radioactive lead, in The biogeochemistry of lead in the environment, edited by J.O. Nriagu, pp. 285-393, Elsevier/North, Holland, 1978.

Robbins, J.A., Great Lakes regional fallout source functions, pp. 22, NOAA-GLERL, Ann Arbor, MI, 1985.

Robbins, J.A., and B.J. Eadie, Seasonal cycling of race element ${ }^{137} \mathrm{Cs},{ }^{7} \mathrm{Be}$, and ${ }^{239+240} \mathrm{Pu}$ in Lake Michigan, in J. Geophys. Res., pp. 17081-17104, 1991.

Robbins, J.A., D.N. Edgington, and A.L.W. Kemp, Comparative ${ }^{210} \mathrm{~Pb},{ }^{137} \mathrm{Cs}$ and pollen geochronologies of sediments from Lake Ontaria and Erie, Quatern. Res., 10, 256-278, 1978.

Robertson, D.M., Regionalized loads of sediment and phosphorus to Lakes Michigan and Superior - High flow and long-term average, J. Great Lakes Res., 23, 416-439, 1997.

Sanchez-Cabeza, J.A., I. Ani-Ragolta, and P. Masque, Some considerations of the ${ }^{210} \mathrm{~Pb}$ constant rate of supply (CRS) dating model, Limnol. Oceanogr., 45 (4), 990-995, 2000 .

Santschi, P.H., S. Cappellino, C. Dobbs, L. McShea, M.A. Allison, S. Asbill, and A.B. Perlet, Sediment transport and $\mathrm{Hg}$ recovery in Lavaca Bay, as evaluated from radionuclide and Hg distributions, Environ. Sci. Technol., 33 (3), 378-391, 1999.

Sarin, M.M., G. Kim, and T.M. Church, ${ }^{210} \mathrm{Po}$ and ${ }^{210} \mathrm{~Pb}$ in the South-equatorial Atlantic: distribution and disequilibrium in the upper 500 m, Deep-Sea Res. II, 46 (5), 907 917, 1999.

Schelske, C.L., A. Peplow, M. Brenner, and C.N. SPencer, Low background gamma counting: Application for 210Pb dating of sediments, J. Paleolim., 10, 115-128, 1994.

Song, W., J.C. Ford, A. Li, W.J. Mills, D. Buckley, and K.J. Rockne, Polybrominated Diphenyl Ethers in the sediments of the Great Lakes. 1. Lake Superior, Environ. Sci. Tech., 38 (12), 3286-3293, 2004.

Tartari, G., and G. Biasci, Trophic status and lake sedimentation fluxes, Water Air Soil Poll., 99, 523-531, 1997.

Thomas, R.L., and C.I. Dell, Sediments of Lake Superior, J. Great Lakes Res., 4 (3-4), 264-275, 1978.

Urban, N.R., L. Xu, Y. Chai, and D.S. Apul, Sediment trap studies in Lake Superior: insight into resuspension, cross-margin transport and carbon cycling, J. Great Lakes Res., 30 (Supplement 1), 147-161, 2004.

Viekman, B.E., and M. Wimbush, Observations of the vertical structure of the Keweenaw current, Lake Superior, J. Great Lakes Res., 19 (2), 470-479, 1993.

Viekman, B.E., M. Wimbush, and J.C. Van Leer, Secondary circulations in the bottom boundary layer over sedimentary furrows, J. Geophys. Res., 94 (C7), 9721-9730, 1989. 
Wieland, E., P.H. Santschi, and J. Beer, A multitracer study of radionuclides in Lake Zurich, Switzerland: 2. Residence times, removal processes, and sediment focusing, J. Geophys. Res., 96 (C9), 17067-17080, 1991.

Wieland, E., P.H. Santschi, P. Hohener, and M. Sturm, Scavenging of Chernobyl ${ }^{137}$ Cs and natural ${ }^{210} \mathrm{~Pb}$ in Lake Sempach, Switzerland, Geochim. Cosmochim. Acta, 57 (13), 2959-2979, 1993.

Wieland, E., and P. Spieler, Colloids in the mortar backfill of a cementitious repository for radioactive waste, Waste Management, 21 (6), 511-523, 2001.

Yohn, S.S., J.P. Giesy, K. Kannan, D.T. Long, J.D. Fett, and L. Patino, Assessing environmental change through chemical-sediment chronologies from inland lakes, Lakes and Reservoirs: Research and Management, 7 (3), 217-230, 2002.

Zhu, J., C. Chen, E. Ralph, S.A. Green, J.W. Budd, and F.Y. Zhang, Prognostic modeling studies of the Keweenaw Current in Lake Superior. Part II: simulation, J. Phys. Oceanogr., 31, 396-410, 2001.

Zuo, Z., and D. Eisma, ${ }^{210} \mathrm{~Pb}$ and ${ }^{210} \mathrm{Po}$ distributions and disequilibrium in the coastal and shelf waters of the southern North Sea, Cont. Shelf Res., 13 (8/9), 999-1022, 1993. 


\title{
Chapter Four
}

\section{Naturally occurring radiotracers $\left({ }^{210} \mathrm{Po} /{ }^{210} \mathrm{~Pb}\right)$ in a coupled physical-biological model for Lake Superior: the role of particle scavenging and sediment resuspension}

\author{
Yingtao Chai and Noel R. Urban* \\ Department of Civil \& Environmental Engineering, Michigan Technological University, \\ Houghton, MI 49931 \\ Henry J. Niebauer \\ Department of Atmospheric \& Oceanic Sciences, University of Wisconsin - Madison, \\ Madison, Wisconsin 53706 \\ *Corresponding author: $\quad$ (906)487-3640 (tel), (906)487-2943 (fax) \\ nurban@mtu.edu
}




\section{Abstract}

A "finer than real" simulation model was developed for the purpose of studying isotope $\left({ }^{210} \mathrm{~Pb}\right.$ and $\left.{ }^{210} \mathrm{Po}\right)$ behaviors in Lake Superior. The model was modified from an existing 2-D finite difference physical-biological model which has previously been successfully applied to Lake Superior. In contrast to the one-box models, the size of the model cell is $1 \mathrm{~km} \times 5 \mathrm{~m}$. Steps were taken to couple the model with isotopes, including adding isotope species, adding suspended particulate matter, and adding some sediment related processes. Numerical experiments were performed with the modified model. The effects of partitioning coefficient $\left(\mathrm{K}_{\mathrm{d}}\right)$ and particle settling velocity $\left(v_{s}\right)$ values were evaluated and discussed. The field results from previous research [Chai and Urban, 2004] were used as initial conditions in model simulations, and the model output after 56 days showed an unrealistic isotope distribution in the water column. Some model alterations, including changing parameters and coding processes differently, were attempted with an aim of mimicking the isotope distribution in the water column, and reasonable results were achieved. The modeling exercises reveal the potential of using a hydrodynamic model to study radioisotope biogeochemistry in the lake although further refinements are necessary, especially for the sediment-related processes. 


\section{Background}

Field measurements from the KITES project and application of one-box and 2dimensional models (chapter 2 and chapter 3 ) all imply that particle settling, crossmargin transport and sediment resuspension play important roles in the biogeochemical processes within this large lake. However, lack of data from offshore regions and oversimplification in the one-box model might obscure some interactions between transport and biogeochemical processes. Besides the establishment of monitoring stations in both nearshore and offshore regions of Lake Superior which is desirable but also expensive, application of numerical models for the whole lake is another approach to compensate for these shortcomings.

Ideally, a model should be able to simulate particle and isotope movement and distribution within this dynamic, large lake. There are some simulation models available for large lakes (including Lake Superior). Some examples include the various Great Lakes versions of the Princeton Ocean Model (POM) [Lou et al., 2000]. However, there are no isotope components in those models. Models for isotope (for example, ${ }^{210} \mathrm{~Pb}$ ) distributions generally are based on the assumption of steady state, and only spatial variation, not temporal variation, is modeled [Spencer et al., 1981]. Maier-Reimer [1998] and Henderson [2002] have applied ${ }^{210} \mathrm{~Pb}$ as a tracer for particle reactive elements in a general circulation model. In addition to the feasibility of this approach, these papers also proved that $\mathrm{Pb}$ may be a good tracer for ocean circulation. Piliposian et al. [2003] described a model approach to study the effect of stream runoff on the loading of mountain lakes with ${ }^{210} \mathrm{~Pb}$ as a tracer; however, it is mainly a non-steady state solution of a one-box model, similar to the one discussed in Chapter 2. Based on the literature and 
our research goals, it is clear that an isotope model with good physical (even biological) representation is essential.

In this chapter, I apply a 'finer than real' numerical hydrodynamic model coupled with isotope tracers. The general goal is to gain insight into the isotope biogeochemical cycles in the study region. More specific objectives were to verify the estimates of settling velocity and resuspension rate derived in Chapter 2 and to verify the estimated rates of cross margin transport from Chapter 3. To this end, equations for the radioisotope chemistry and transport were added to an existing numerical model. The model parameters were optimized to generate the best fit between model output and field measurements.

\section{Introduction to the original model}

Because physical transport strongly impacts the movements and distributions of isotopes in both dissolved and particulate phases, it is necessary to utilize a model with accurate hydrodynamics. There are a few numerical modeling studies focusing on Lake Superior [Chen et al., 2001; Lam and Halfon, 1978; Niebauer et al., 1977; Zhu et al., 2001]. To study particle-reactive isotopes in the lake, a model with both physical and biological components is desirable. The model developed and improved by Niebauer [2002] was chosen due to its previously successful application on Lake Superior and its availability. The most recent version of the model incorporates hydrodynamics and lower food web interactions with nutrients. In this section, a brief introduction and several numerical experiments based on the original model are showcased.

\subsection{Features of the existing numerical model}


The Niebauer model (called the model from now on) is a cross-sectional, multilayered, time-dependent, finite difference numerical model composed of physical, biological and ice sub-models (Figure 1) [Niebauer, 2002]. As seen in Figures 1 and 2-1, in the version for Lake Superior, a $96 \mathrm{~km}$ (horizontal) by 230 meter (vertical) section across the EH transect is modeled with $\Delta \mathrm{x}$ of $1 \mathrm{~km}$ and $\Delta \mathrm{z}$ of $5 \mathrm{~m}$. The simulations have been set to 56 days with a time step $(\Delta \mathrm{t})$ of $10 \mathrm{~min}$. Figure 2-2 shows the nearshore bathymetry of Lake Superior along this transect; large slopes (up to 0.1 at certain locations) enable the modeling of this cross-section of the lake as a rectangle.

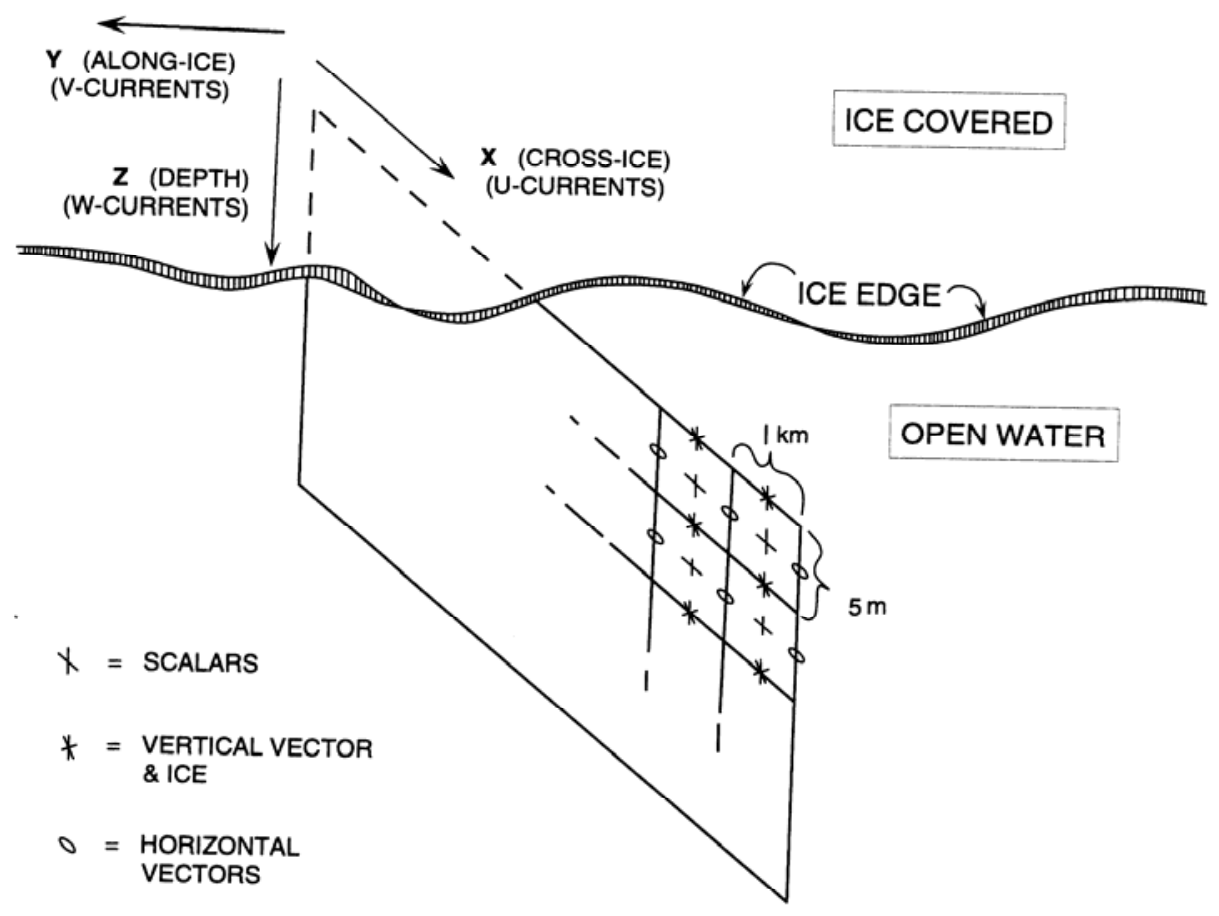

Figure 1. Schematic of the cross section model. $\mathrm{x}, \mathrm{y}$ and $\mathrm{z}$ coordinates and grid sizes are also shown. 


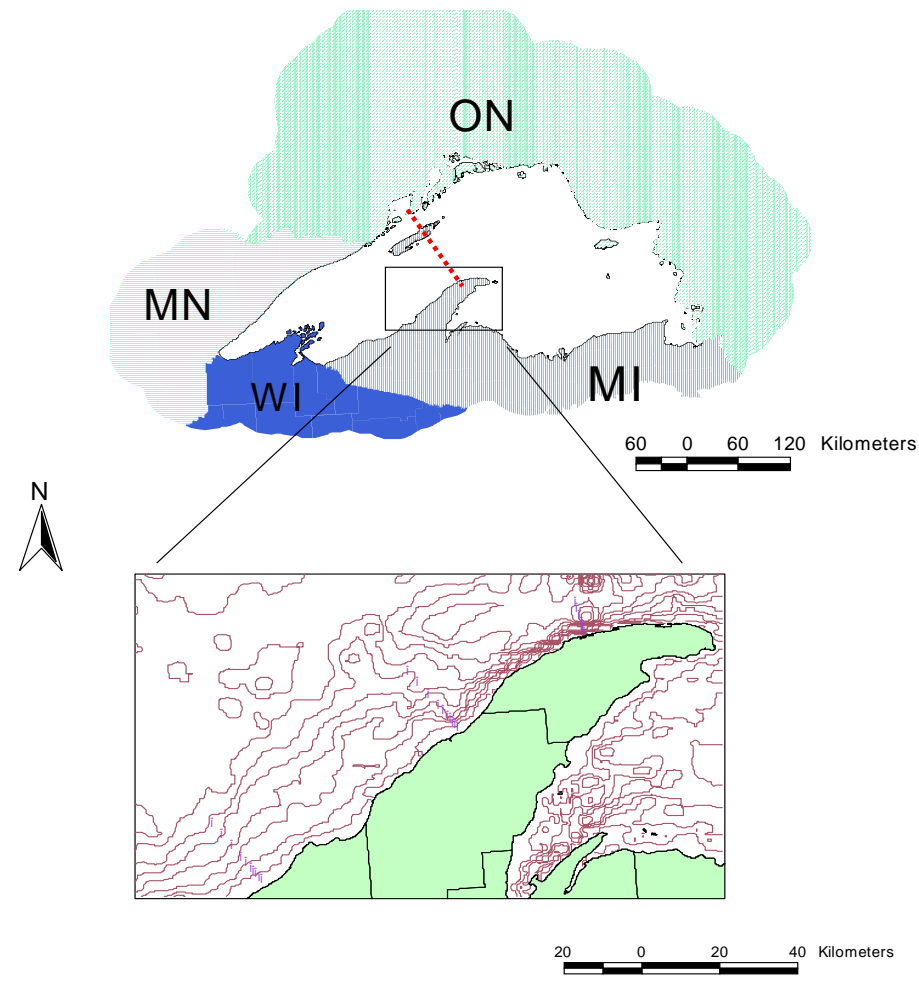

Figure 2-a. Lake Superior with an inset showing the study area. The dashed line represents the modeled cross section at Eagle Harbor.

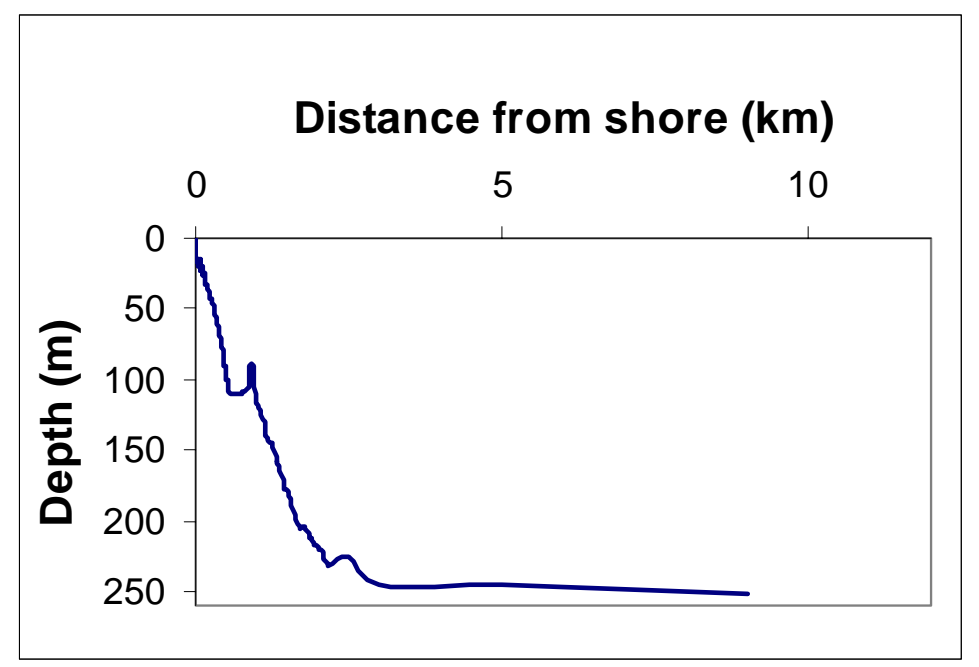

Figure2-b. Near shore bathymetry of the EH transect. The steep slope and flat bottom along this transect make it reasonable to model the transect as a rectangle. 


$$
\begin{aligned}
& \frac{\partial u}{\partial t}+u \frac{\partial u}{\partial x}+w \frac{\partial u}{\partial z}=\frac{-1}{\rho} \frac{\partial p}{\partial x}+\frac{1}{\rho} \frac{\partial \tau_{z x}}{\partial z}+N_{x} \frac{\partial^{2} u}{\partial x^{2}}-f v \\
& \frac{\partial v}{\partial t}+u \frac{\partial v}{\partial x}+w \frac{\partial v}{\partial z}=\frac{-1}{\rho} \frac{\partial p}{\partial y}+\frac{1}{\rho} \frac{\partial \tau_{z y}}{\partial z}+N_{x} \frac{\partial^{2} v}{\partial x^{2}}-f u \\
& \frac{\partial T}{\partial t}+u \frac{\partial T}{\partial x}+w \frac{\partial T}{\partial z}=K_{z T} \frac{\partial^{2} T}{\partial z^{2}}+K_{x T} \frac{\partial^{2} T}{\partial x^{2}} \\
& \frac{\partial S}{\partial t}+u \frac{\partial S}{\partial x}+w \frac{\partial S}{\partial z}=K_{z S} \frac{\partial^{2} S}{\partial z^{2}}+K_{x S} \frac{\partial^{2} S}{\partial x^{2}} \\
& \frac{\partial u}{\partial x}+u \frac{\partial w}{\partial z}=0 \\
& \frac{\partial p}{\partial z}=\rho g \\
& \rho=\rho(S, T, p)
\end{aligned}
$$


Table 1. Variables in (physical) model equations 1-7.

\begin{tabular}{ll}
\hline Variable & Definition \\
\hline$x$ & coordinate normal to coast, across the lake \\
$y$ & coordinate parallel to coast, along the shore \\
$z$ & vertical coordinate \\
$t$ & Time \\
$u(x, y, z)$ & x component of velocity \\
$v(x, y, z)$ & y component of velocity \\
$w(x, y, z)$ & z component of velocity \\
$f$ & Coriolis parameter \\
$g$ & gravitational acceleration \\
$\rho$ & density of water (function of $S, T$ and $p)$ \\
$p$ & Pressure \\
$\tau_{x}(x, y, t)$ & x component of vertical shear stress \\
$\tau_{y}(x, y, t)$ & y component of vertical shear stress \\
$T(x, y, t)$ & Temperature $\left({ }^{\circ} \mathrm{C}\right)$ \\
$S(x, y, t)$ & Salinity $($ psu) \\
$N_{z}(x, z, t)$ & Vertical eddy viscosity $\left(\mathrm{cm}^{2} / \mathrm{s}\right)$ \\
$K_{z}(x, z, t)$ & Vertical eddy diffusivity $\left(\mathrm{cm}^{2} / \mathrm{s}\right)$ \\
$N_{x}$ & Horizontal eddy viscosity $\left(1.5 \mathrm{x} 10^{6} \mathrm{~cm}^{2} / \mathrm{s}\right)$ \\
$K_{x}$ & Horizontal eddy diffusivity of heat and salt $\left(1.5 \times 10^{5} \mathrm{~cm}^{2} / \mathrm{s}\right)$ \\
\hline
\end{tabular}


The model was originally developed in the late 1970s by modifying a hydrodynamic model of Bennett [1974]. The physical, biological and ice sub-models are a series of time- and space-dependent, coupled, non-linear equations of motion that include the effects of wind and heat forcing, ice motion, and vertical and horizontal density gradients and ocean currents. The density is a function of salinity (for Lake Superior salinity is zero), temperature and pressure (equation 7). The physical model is a cross-sectional circulation model; it can be called a 2.5 -dimensional model in space in that current velocities (and scalar properties) can vary in time and space in the vertical and horizontal dimension parallel to the section. However, perpendicular to the section, current can vary only in time but not in space. That is to say that the variation in the dimension perpendicular to the cross section is ignored. Equations 1-6 summarize the modeled physical processes of heat and mass transport mediated by water movement, diffusion and dispersion.

In the biological sub-model, two separate nutrients pools, $\mathrm{N}$ and $\mathrm{P}$, are modeled in the forms of $\mathrm{NH}_{3}$ and $\mathrm{PO}_{4}{ }^{3-}$. Phytoplankton nutrient uptake, zooplankton grazing, nutrient mineralization, as well as biological particle aggregation and settling are the major processes involved. Ten (size) classes of chlorophyll and two (size) classes of zooplankton are invoked in the model. Primary production is modeled as a function of date and latitude as well as physical and nutrient conditions (e.g., depth, temperature, nutrient concentration, etc.).

Because the data available from the KITES project are for early May through late September, the ice routine was disabled. More details about the model framework and its application can be found elsewhere [Niebauer, 2002; Niebauer and Smith, 1989]. 
In short, the model has successfully simulated the ecosystem/sub-ecosystem structure and predicted primary and export production. It has seen numerous applications during the past decade, and has proven to be useful for answering some important questions [Niebauer, 2002; Niebauer and Smith, 1989; Niebauer et al., 2004].

\subsection{Modeling exercises with Lake Superior}

Several numerical experiments (model simulations) were performed to understand better the hydrodynamics of the model and to demonstrate the physical conditions to which isotopes would be exposed. The model was written in FORTRAN and designed to run under a LINUX environment; results are viewable with NCAR Graphics ${ }^{\circledR}$. Some modifications were made in the code to enable it to run within a Windows-based compiler. Output includes both vector (speed and direction of water movement at specified times and locations $(x, z, t))$ and scalar quantities (concentrations of model components including nutrients, chlorophyll, and zooplankton). The model output may

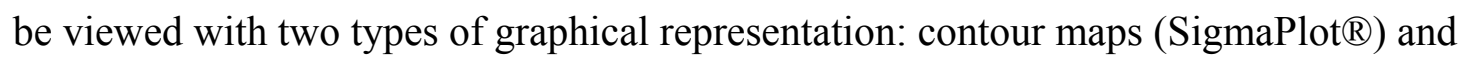
time series plots (MS Excel). The default values are for the model to begin on Julian day 121 (May $1^{\text {st }}$ ) and to run for 56 days (into late June).

\subsubsection{Initial conditions}

For successful simulation, the model should begin with reasonable, albeit hypothetical initial conditions. Table 2 summarizes initial conditions used for the model except for temperature, which will be discussed in more detail later. 
Table 2. Initial input parameters for the model.

\begin{tabular}{lccc}
\hline \multicolumn{1}{c}{ Variables } & Symbols & Values & Units \\
\hline Nutrient - Nitrate & NO3(I, J) & 300 & $\mu \mathrm{g} \mathrm{N} / \mathrm{L}$ \\
Nutrient - phosphorus & PO4(I, J) & 3 & $\mu \mathrm{g} \mathrm{P} / \mathrm{L}$ \\
Salinity & SA(I,J) & 0 & $\mathrm{Psu}$ \\
Chlorophyll & CA(I,J) & 0.20 & $\mathrm{mg} \mathrm{Chl} / \mathrm{m}^{3}$ \\
Zooplankton (large) & ZLA(I,J) & 0.001 & $\mathrm{mg} \mathrm{C} / \mathrm{m}^{3}$ \\
Zooplankton (small) & ZSA(I,J) & 0.001 & $\mathrm{mg} \mathrm{C} / \mathrm{m}^{3}$ \\
\hline
\end{tabular}

The biological sub-model is very sensitive to environmental variables. In the marine environment, those variables include solar radiation, wind conditions, ice thickness, nutrient availability, temperature and salinity. For a freshwater lake like Lake Superior between May and September, salinity and ice may be ignored. Because of the relatively small geological area of the cross-section (compared to oceanic applications), solar radiation does not exhibit much spatial variability. The model does include different wind scenarios to simulate upwelling events driven by changes in wind directions. As shown in Table 2, uniform nutrient concentrations (both $\mathrm{N}$ and $\mathrm{P}$ ) are assumed initially. Consequently, temperature is the variable that most strongly impacts the model simulation. Two different scenarios were utilized for the initial temperature conditions in the lake. The first scenario assumes a uniform temperature $\left(4^{\circ} \mathrm{C}\right)$ throughout the water column; this is similar to the real situation along the EH transect in late winter and early spring. The other scenario invokes some initial warming in nearshore areas; although this is less realistic for the EH transect, it demonstrates how the model handles heat and energy fluxes. The initial temperature conditions can be seen in the first cross-section graph in Figure 3. 


\subsubsection{Model predictions}

This model has already been shown to accurately simulate physical and biological conditions in Lake Superior [Niebauer et al., 1977; Niebauer et al., 2004]. Some of these predictions are shown here for the purpose of demonstration. Two-dimensional distributions of temperature (physical component) and chlorophyll (biological component) at different time steps are summarized in Figure $3 a$ and $3 b$. In Figure 4, the model predictions are compared with measured profiles of temperature and chlorophyll. 


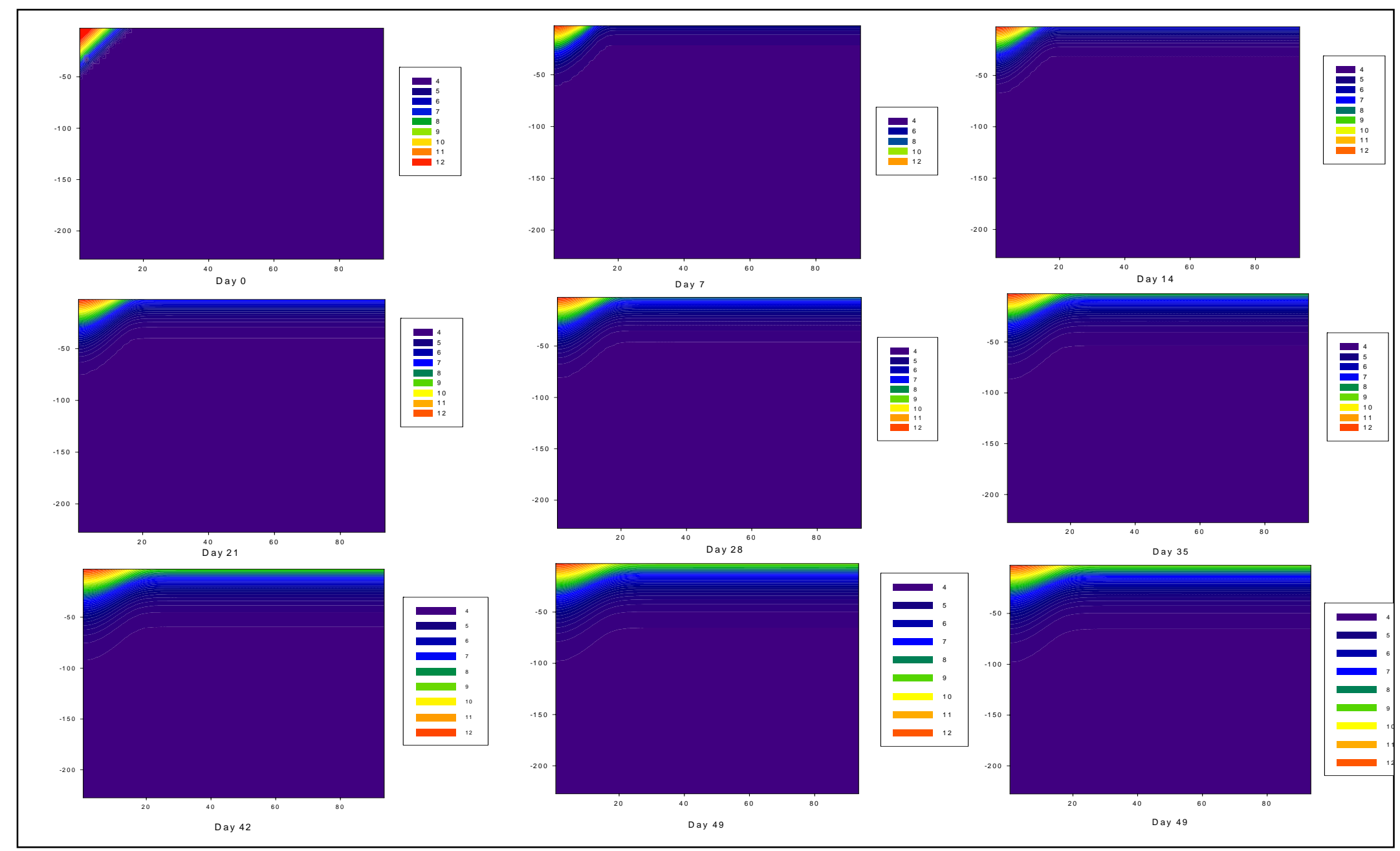

Figure3-a. Predicted temperature $\left({ }^{\circ} \mathrm{C}\right)$ distributions in the lake cross-section. The $\mathrm{x}$-axis is distance from shore $(\mathrm{km})$ and $\mathrm{y}$ is depth (m). 

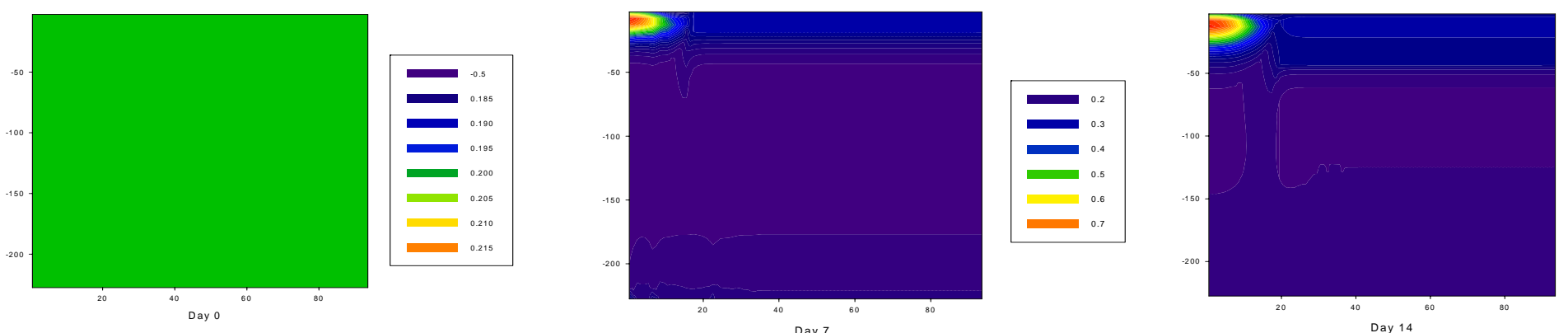

\section{\begin{tabular}{|r|}
\hline 0.2 \\
\hline \\
0.4 \\
0.6 \\
0.0 \\
\hline \\
\end{tabular}}
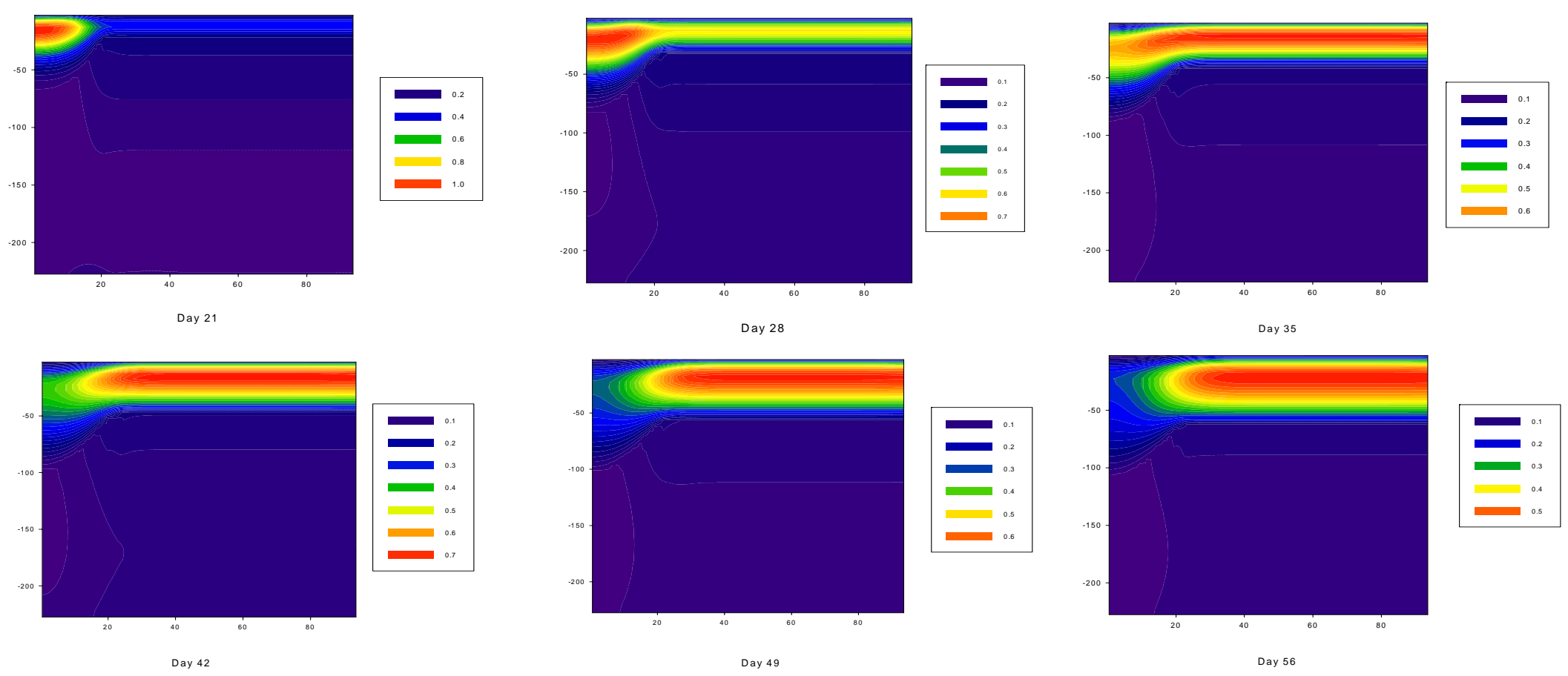

Figure3-b. Chlorophyll concentrations $\left(\mathrm{mg} \mathrm{Chl} / \mathrm{m}^{3}\right)$ in the lake cross-section. Axes are the same as in Figure 3a. 
In any given model run, there are several options available including the two initial temperature distributions (isothermal and pre-warmed nearshore), and the timing of upwelling events. Figures $3 a$ and $3 b$ illustrate model predictions using the pre-warmed nearshore and no wind-driven upwelling events. It can be seen from the figures that the model predictions of heat transfer (temperature) and biological growth (chlorophyll) are reasonable. As time increases, the water column starts to warm from the surface to deeper waters and from nearshore to offshore. Chlorophyll concentrations also change due to water movement as well as to photosynthesis (algal growth) as evidenced by the offshore data.

The model also successfully represents two well known phenomena: the thermal bar and the deep chlorophyll maximum (DCM). Together with the Keweenaw Current, the thermal bar is one of the major features studied in the KITES project that has the potential to regulate cross-margin transport in Lake Superior [Auer and Gatzke, 2004; Gatzke, 2001]. The thermal bar is a vertical temperature front; water in the "bar" has the temperature of maximum density $\left(\mathrm{T} \approx 4{ }^{\circ} \mathrm{C}\right)$ while near-shore water is warmer and offshore water is cooler. There have been numerous theoretical and experimental studies of thermal bars in lakes [e.g., Botte and Kay, 2000; Likhoshway et al., 1996]. It is well established that the presence of a thermal bar can have a profound effect on the distribution of dissolved or suspended matter in a lake. The double-cell circulation and boundary effect between regions of stable and unstable stratification can affect the distribution and movement of plankton and nutrients in the vicinity where the thermal bar is formed. The DCM, which is common in the ocean but less widely recognized in freshwater lakes, refers to the subsurface zone in which chlorophyll is most abundant. 
The DCM was frequently observed in Lake Superior during the KITES project. The mechanism of formation of the DCM is still under investigation [Hodges and Rudnick, 2003; Radenac and Rodier, 1996]. One possibility is that settling organic matter accumulates when it passes through the cooler, denser water below the thermocline. Another hypothesis is that nutrient limitation in the epilimnion favors algal growth at depths where mixing from the hypolimnion can provide additional nutrients; a peak in primary production is often found to be coincident with or just above the DCM [Edwards and Priscu, 1995]. It seems that the model presented here has the necessary hydrodynamic and biological components to study the formation of the DCM in Lake Superior as evidenced by Figure $3 \mathrm{~b}$. However, it is beyond the scope of this research and will not be discussed further here. 
A.
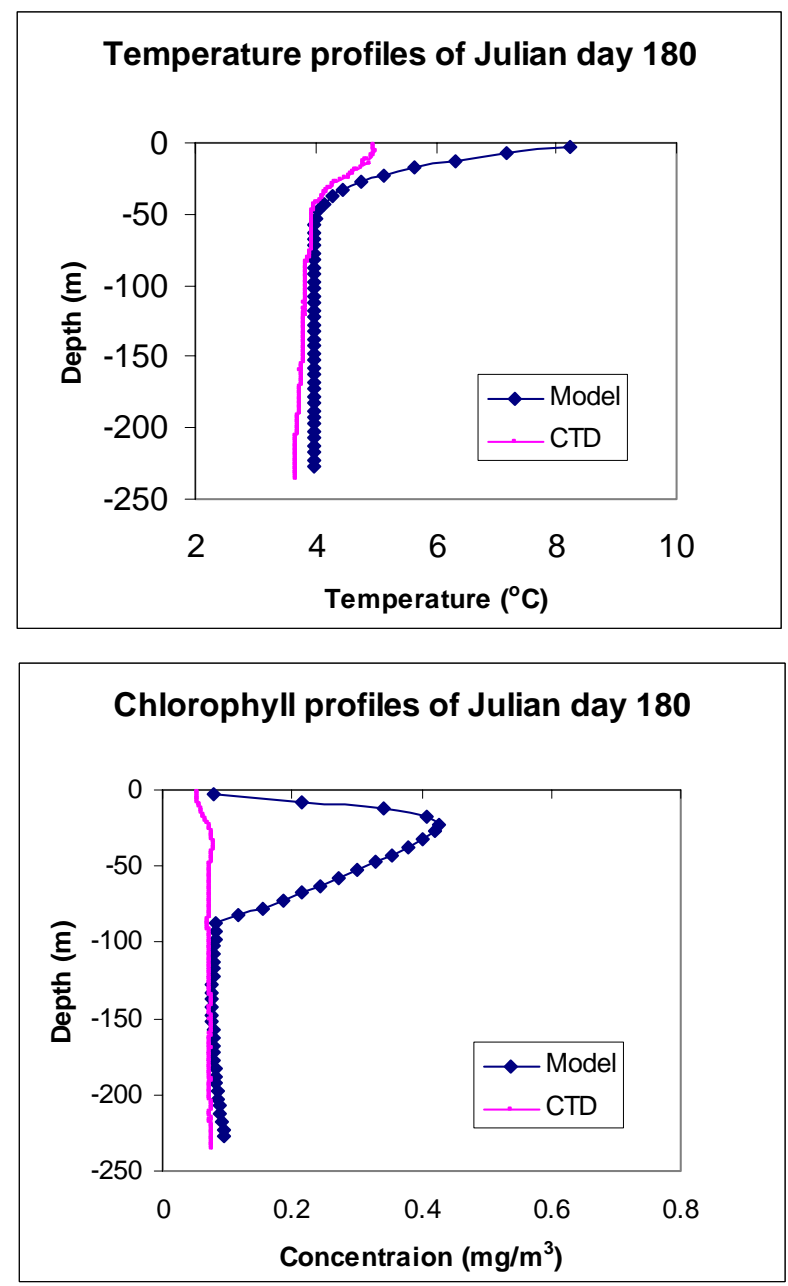

B.
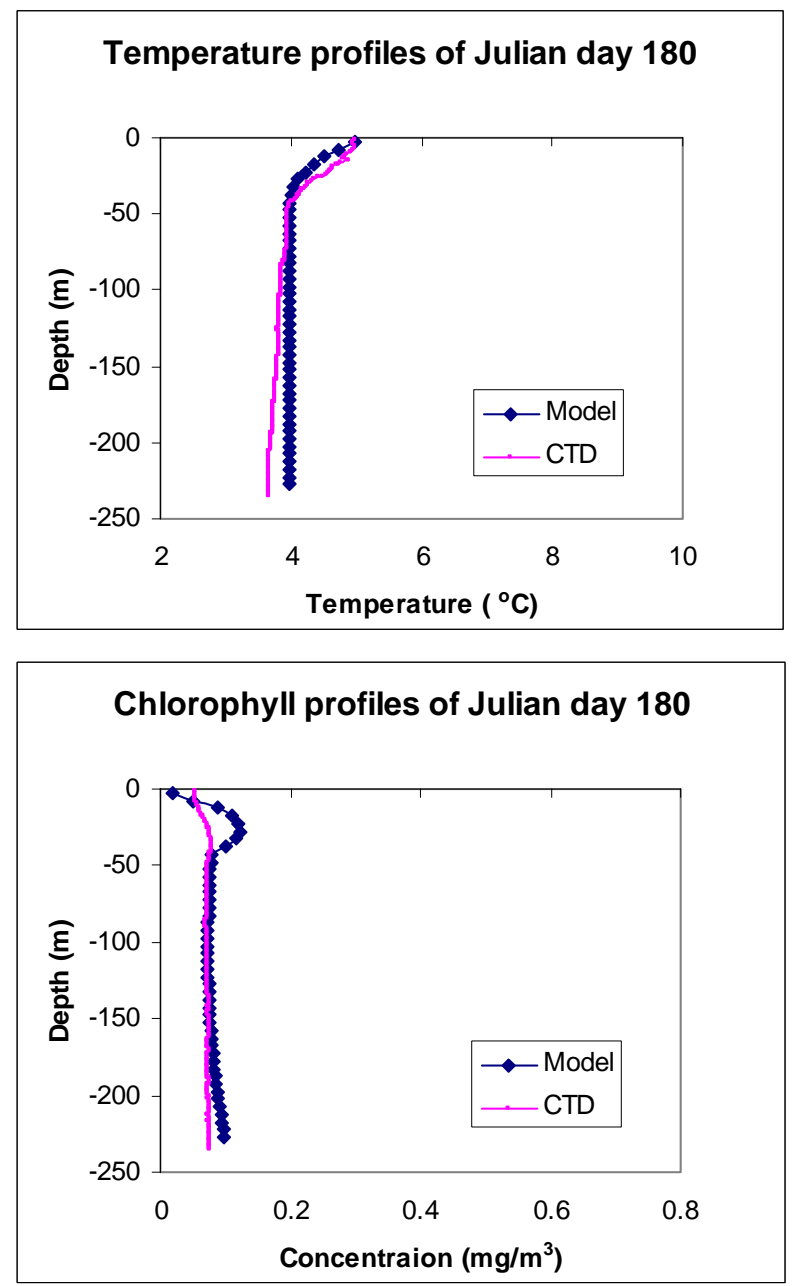

Figure 4. Comparison of modeled and measured depth profiles ( $5 \mathrm{~km}$ from shore) of Temperature and Chlorophyll-a. (A): Results with initially warm nearshore condition; (B): Results with uniform $\left(4^{\circ} \mathrm{C}\right)$ initial temperature condition.

A reference water column, about $5 \mathrm{~km}$ from shore, is selected for comparison between real data and model predictions. The temperature and chlorophyll (Chl-a) measurements from ship-based deployments of the CTD are plotted along with the model 
predictions of $\mathrm{T}$ and Chlorophyll-a concentrations. The CTD recorded measurements at 1-meter intervals while the size of model cells in the $\mathrm{z}$ dimension is 5 meters. However, the CTD data are available only for the nearshore region (within $9 \mathrm{~km}$ for EH transect) on only about 30 days per year. From Figure 4 above, it appears that the model predicts temperature profiles more accurately than chlorophyll profiles for both scenarios. An initially uniform temperature of $4^{\circ} \mathrm{C}$ is closer to the actual temperature condition along the EH transect; consequently, this model scenario gives a better fit with the measured temperature profile than does the initially warm nearshore scenario. The close correspondence between modeled and measured profiles indicates that handling of heat and energy exchange in the model is reasonable. In both scenarios, the model predicts the existence of a significant maximum chlorophyll concentration in the middle of the water column at a depth of about $20 \sim 30$ meters. However, the DCM recorded by the CTD is not as distinct as that predicted by the model. This may imply that biological processes (or other factors affecting chlorophyll) are not simulated as well as temperature-related processes. Since the major processes affecting the isotopes are physical processes, the shortcomings of the biological components of the model may not affect incorporation of isotopes into the model.

\section{Modified model with isotope tracers}

As previously mentioned, ${ }^{210} \mathrm{~Pb}$ has long been used as a geochronology tool for sediment deposition on a time scale of a hundred years. There are few experimental or field studies of this isotope in the water column. There are even fewer modeling studies of the behavior of this isotope in the water column, although there are quite a few chemical transport models dealing with ${ }^{210} \mathrm{~Pb}$ in the atmosphere [Giannakopoulos et al., 
1999; Guelle et al., 1998; Koch et al., 1996]. For ${ }^{210}$ Po, a similar situation exists; most previous studies focused on residence time calculations for the upper ocean water column using the ${ }^{210} \mathrm{Po} /{ }^{210} \mathrm{~Pb}$ pair [Masqué et al., 2002; Nozaki et al., 1991]. Its potential as a tracer of biogenic export is the focus of some recent research ([Friedrich and van der Loeff, 2002; Kim, 2001; Stewart and Fisher, 2003].

According to Maier-Reimer and Henderson [1998], there are four categories of tracers applied in ocean circulation models. With increasing importance for interpretation of data, they are:

1) Dense data of the dynamically active tracers temperature (T) and salinity (S) that determine velocity. These tracers are more valuable in short-term hydrodynamic models than in a GCM.

2) Moderately sparse physical tracer data such as $\mathrm{PO}_{4^{*}},{ }^{14} \mathrm{C}$ from bombs and cosmic rays, CFCs and so on from known sources provide a check on circulation. If the tracer agrees with the model, the model can be used for interpolation in space and time and for computation of inventories.

3) Moderately sparse biogenic tracer data for $\mathrm{PO}_{4}$, alkalinity, $\Sigma \mathrm{CO}_{2}, \mathrm{Si}(\mathrm{OH})_{4}$, and $\mathrm{O}_{2}$ that depend strongly on circulation and weakly on biological parameterizations. Once the physical circulation of the model is accepted, application of these tracers is used to determine the strength of other processes such as biological pumping.

4) Exotic tracers, such as ${ }^{39} \mathrm{Ar},{ }^{3} \mathrm{H}$ from ridge crests, ${ }^{32} \mathrm{Si}$ from cosmic rays, lead isotopes (mainly ${ }^{206} \mathrm{~Pb} /{ }^{207} \mathrm{~Pb}$ ), anthropogenic $\mathrm{CO}_{2}$. In this category, the tracers are characterized either by the sparseness of data or by the lack of knowledge about the sources or by the difficulties of the measurements. In this category of tracers, 
models provide essential tools to interpret the data, either by narrowing the uncertainties of source and sink mechanisms, or even by identifying inconsistencies in data.

In a GCM, ocean circulation, particle fluxes and the distribution of ${ }^{226} \mathrm{Ra}$ (decay parent of ${ }^{210} \mathrm{~Pb}$ ) are complex variables that must be accurately described to model ${ }^{210} \mathrm{~Pb}$. Thus ${ }^{210} \mathrm{~Pb}$ falls in the category of exotic tracers. However, in our study, the ${ }^{210} \mathrm{~Pb}$ isotope falls more nearly in the second category due to a well characterized source and a well developed hydrodynamic model structure. The same is true for ${ }^{210} \mathrm{Po}$, the other isotope of interest which has the potential of behaving as a tracer of biological processes. Its bioavailability is not addressed in this research, but field data suggest that polonium might not be as biologically active in freshwater as in marine environments [Chai and Urban, 2004]. Thus both isotopes can be used to test the accuracy of the hydrodynamic model and the predictions of sediment transport.

Some alterations in the model are needed to include isotopes. Specific steps include: 1) addition of isotope components; 2) addition of suspended particulate matter (SPM); and 3) addition of resuspension and sedimentation.

Table 3. Related characteristics of the two studied isotopes.

\begin{tabular}{l|llll}
\hline Isotope & Half Life & Major sources to L. Superior & $\begin{array}{c}\text { Particle } \\
\text { affinity }\end{array}$ & Bioavailability \\
\hline${ }^{210} \mathrm{~Pb}$ & $22.3 \mathrm{yrs}$ & atmospheric fallout & strong & Unknown \\
${ }^{210} \mathrm{Po}$ & 138 days & $\begin{array}{l}\text { atmospheric fallout, } \\
\text { radioactive decay }\end{array}$ & strong & $\begin{array}{l}\text { yes in marine environment, } \\
\text { unknown in freshwater }\end{array}$ \\
\hline
\end{tabular}


Table 3 shows some common characteristics of the two isotopes that form the basis for the modeling representation of those elements. For example, both isotopes are strongly particle-reactive but still have measurable dissolved fractions; thus consideration must be given when coupling the isotopes. Some basic assumptions that were made regarding the isotopes include:

1) Two phases (particulate, dissolved) were modeled separately even though the outcome of most interest is the total activities (particulate plus dissolved) of the isotopes and the ratio of the total activities of the two isotopes. Dissolved isotopes are modeled analogously to the other dissolved components in the model (such as $\mathrm{NO}_{3}{ }^{-}$and $\mathrm{PO}_{4}{ }^{3-}$ ) and particulate isotopes are modeled in the same fashion as other particulate components (such as chlorophyll).

2) There are two connections between the two isotopic phases, total inventories and water-particle partitioning. Those relationships are defined with the following two equations.

$$
\begin{aligned}
& P b_{\text {total }}=P b_{\text {dis }}+P b_{\text {part }} \\
& K_{d}=\frac{P b_{\text {dis }}}{P b_{\text {part }} \times S P M}
\end{aligned}
$$

3) The unique characteristic of radioisotopes, radioactive decay, is also included in the model. In addition to physical and biological processes, the first-order decay of isotopes is another sink for both ${ }^{210} \mathrm{~Pb}$ and ${ }^{210} \mathrm{Po}$. 
According to Honeyman and Santschi [1989], the time scale for metal (including metal isotopes) partitioning between dissolved and colloidal phases is in the range of seconds to minutes. Thus, it is assumed that after each numerical iteration the isotopes are re-equilibrated between particulate and dissolved phases based on the current conditions, mainly represented by suspended particulate matter (SPM) concentration and the partitioning coefficient $\left(\mathrm{K}_{\mathrm{d}}\right)$. Derived from equations 10 and 11 , equations 12 and 13 were computed after each time step. The calculated new activities are subject to the next modeling time step.

$$
\begin{aligned}
& P b_{\text {part }}=P b_{\text {total }} \times\left(\frac{K_{d} \times S P M}{1+K_{d} \times S P M}\right) \\
& P b_{\text {dis }}=P b_{\text {total }}-P b_{\text {part }}
\end{aligned}
$$

In the four equations above, there are two important parameters, $\mathrm{K}_{\mathrm{d}}$ and SPM. As discussed in the first chapter, $\mathrm{K}_{\mathrm{d}}$ is not likely to vary much in space or time within this specific system; because there is some uncertainty as to the correct value for $\mathrm{K}_{\mathrm{d}}$ the effect of changing the $\mathrm{K}_{\mathrm{d}}$ value (of polonium) on isotope distributions was examined. SPM is critical for the modeling of highly particle-reactive $\mathrm{Pb}$ and Po isotopes. Although it will not affect the total concentration/activities of these isotopes in a closed system when everything is kept in the original state, it does control the distribution and redistribution of isotopes between different phases as well as among different zones. Also when removal of particles and isotopes is included in the model, the process of particle scavenging demands a more accurate modeling representation than simple imposition of a constant SPM concentration $(0.45 \mathrm{mg} / \mathrm{L})$ as was done in the one box model (Chapter 2). 
To model ${ }^{210} \mathrm{~Pb}$ and ${ }^{210} \mathrm{Po}$ in Lake Superior, after adding new variables (SPM and the isotopes $(\mathrm{Pb}$ and $\mathrm{Po}))$ to the model, it is desirable to add a separate 1-D box (physically) underneath the bottom water layer of the existing model that would collect whatever settles from the water column. This reservoir could also provide feedback (recharge) to the upper water column if resuspension is invoked. In the current version of the model, an admittedly unrealistic representation of resuspension (a temporally and spatially constant resuspension rate) is utilized. In the future, it will likely be desirable to add currents, wind waves [e.g., Lou et al., 2000]) and internal waves [Gloor et al., 1994] to calculate the sheer stress above the sediments that induces resuspension. The present representation is also unrealistic in that the sediment box is treated as an unlimited source (pool) of both particles and isotopes. This assumption was also applied by Lou [2000]. This over-simplification may be reasonable for short duration simulations without extreme conditions that might exhaust the actual supply of easily resuspendable sediments.

In summary, the major modifications to the model included addition of isotopes, addition of SPM, addition of a sediment layer, and inclusion of resuspension as well as sedimentation. More details are given below regarding each major change, and some results are shown to demonstrate the successful completion of each modification. 


\subsection{Addition of isotopes $\left({ }^{210} \mathrm{~Pb}\right.$ and $\left.{ }^{210} \mathrm{Po}\right)$ to the existing model}

For isotopes, a complete set of new variables was added to the existing model. In this part, ${ }^{210} \mathrm{~Pb}$ will be use as an example. Polonium is also modeled following the same procedure although the parameters values are different than those for lead. The steps in the procedure can be briefly summarized as: 1) addition of new variables to the code; 2) testing of the isotopic decay equation; 3 ) identification of source and sink terms for the isotope, and 4) modification (and verifying all modifications) of all processes that involve isotopes.

Isotopes were introduced into the model by defining two variables for each isotope: a dissolved phase that would not sink and a particulate phase with a sinking velocity. Linkage between the two phases was accomplished with the partitioning coefficient $\left(\mathrm{K}_{\mathrm{d}}\right)$. The four new variables are coupled with hydrodynamic movements in the model, and particulate phases of both isotopes are subject to settling. Equations 14 and 15 illustrate the processes occurring in all model cells: advection, diffusion, isotopic decay, settling of particulate phase as well as atmospheric fallout flux (top model layer only).

$$
\begin{aligned}
& \frac{\partial\left[{ }^{210} P b\right]_{i j}}{\partial t}=K_{x} \cdot \frac{\partial^{2}\left[{ }^{210} P b\right]_{i j}}{\partial x^{2}}+K_{z} \cdot \frac{\partial^{2}\left[{ }^{210} P b\right]_{i j}}{\partial z^{2}}-u \frac{\partial\left[{ }^{20} P b\right]_{i j}}{\partial x}-v \frac{\partial\left[{ }^{20} P b\right]_{i j}}{\partial z}-\lambda_{p b} \cdot\left[{ }^{210} P b\right]_{i j}-\frac{v_{s}}{H} \cdot f_{s p b} \cdot\left[{ }^{210} P b\right]_{i j}+F_{210 p b} \cdot A(i f i=1)
\end{aligned}
$$

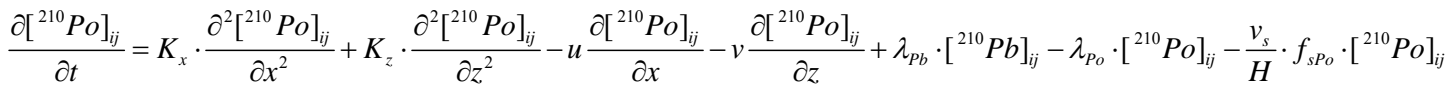

$$
\begin{aligned}
& \text { where: } \\
& f_{s}-\text { fraction of isotope in particulate phase (unitless), } \frac{K_{d} C}{1+K_{d} C}
\end{aligned}
$$


' After the isotopes tracers were added into the model, model performance was evaluated by examining the unique process of isotopic decay. The change in total isotope inventory was examined as a function of time. Theoretically, the isotope concentration should decrease exponentially in a closed system (the case when the settling velocity is set to zero and no inputs are added). Using equation 16, the whole lake inventory of isotope is computed. Because the half-lives of both isotopes are long compared with the 56-day model simulation time, the decrease in inventories is not large. By applying faster decay rates to both lead (30 days) and polonium (10 days), the effect of decay can be seen within the modeled period. Under these conditions, the inventory of ${ }^{210} \mathrm{~Pb}$ followed an exponential decay as expected. When the artificial half-lives were assigned with the same ratio as for the real half-lives (22.3 year vs. 138 day), secular equilibrium was achieved (activities were equal) after a period equal to 4 5 polonium half-lives in accordance with theory. Correct exponential decay of the isotope inventory not only indicates that radioactive decay is coded correctly, but also verifies that transport and reactions for both isotopes have been correctly coupled in all cells.

$$
i n v_{P b}\left(d p m / m^{2}\right)=\frac{\sum P b(i, j) \cdot \Delta x \cdot \Delta z}{X}\left(\frac{d p m / m^{3} \cdot m \cdot m}{m}\right)
$$

The next step was to change from a closed system to an open system with inputs and outputs. For lead, a constant input $\left(1.0 \mathrm{dpm} / \mathrm{cm}^{2}-\mathrm{yr}\right)$ from atmospheric fallout was introduced to the surface layer; this is the major source of ${ }^{210} \mathrm{~Pb}$ to the lake and the single source in the model. For polonium, the major source is radioactive decay of ${ }^{210} \mathrm{~Pb}$ which was already added to the model. However, a fallout flux of ${ }^{210}$ Po was also invoked using 
the commonly observed ratio of ${ }^{210} \mathrm{~Pb}:{ }^{210} \mathrm{Po}$ in atmospheric deposition (10:1, [Marley et al., 2000]).

It should be noted that in the model all equations involving isotopes were based on concentration or mass (atoms) instead of activity such that mass balance could be maintained. However, the inputs and outputs of the model all have units of activity to facilitate comparison between model results and field data. These conversions are handled in the I/O portion of the model.

\subsection{Addition of particles}

The easiest way to incorporate particles in the model is to set artificially a constant concentration in each modeling cell (e.g., $0.45 \mathrm{mg} / \mathrm{L}$ ) that is maintained throughout the entire model simulation. This scenario is too simplistic because hydrodynamic movements should also affect the distribution and movement of suspended particles. A realistic isotope model calls for a realistic treatment of particles. Uniform particle concentrations throughout the water column are, however, a useful initial condition that is then subjected to hydrodynamic movements in the model.

As was done for particulate isotopes and chlorophyll, suspended particles were modeled within the hydrodynamic framework. Biological reactions are not applied to the particles at this stage. A linkage between organic carbon (chlorophyll) and particles (SPM) was not encoded but remains an option for the future. If particle settling was the only process affecting particles, all particles eventually would accumulate in the bottom water layers; isotopes in the upper water column would then no longer be scavenged. Addition of a sediment layer into which particles may settle eliminates the accumulation 
in bottom waters and causes a decrease in total SPM inventory. A source of particles must then be invoked. Two potential source terms were tried, one of riverine particle influx and the other of atmospherically deposited particles. In both approaches, a trialand-error method was used to adjust the particle influx to equal the SPM loss due to settling. The resulting particle fluxes maintain a constant SPM inventory.

Figures 5 and $6 \mathrm{a}$ illustrate the resultant particle distributions when different input fluxes were used. In both cases, particles were allowed to settle into the sediments, and no resuspension was considered. Figure $6 \mathrm{~b}$ is the situation mentioned above when only the sink term was considered. Although both particle sources can maintain a constant SPM inventory in the system, the SPM distribution is very different. The riverine flux generated a nearshore-offshore gradient in SPM concentrations, which is possible when there is a river, but the SPM concentrations were unrealistically high. The second approach seemed to work better in the sense of generating realistic particle distributions illustrated by the almost uniform distribution $(0.45 \mathrm{mg} / \mathrm{L})$ shown in Figure 6a. This distribution still is not entirely realistic because no nearshore-offshore gradients nor gradients with depth are predicted by the model (as Jeong observed [2003]). In spite of this shortcoming, the SPM was modeled using this second approach. It is acknowledged that an ideal particle input would be a combination of the two sources modeled separately above. 


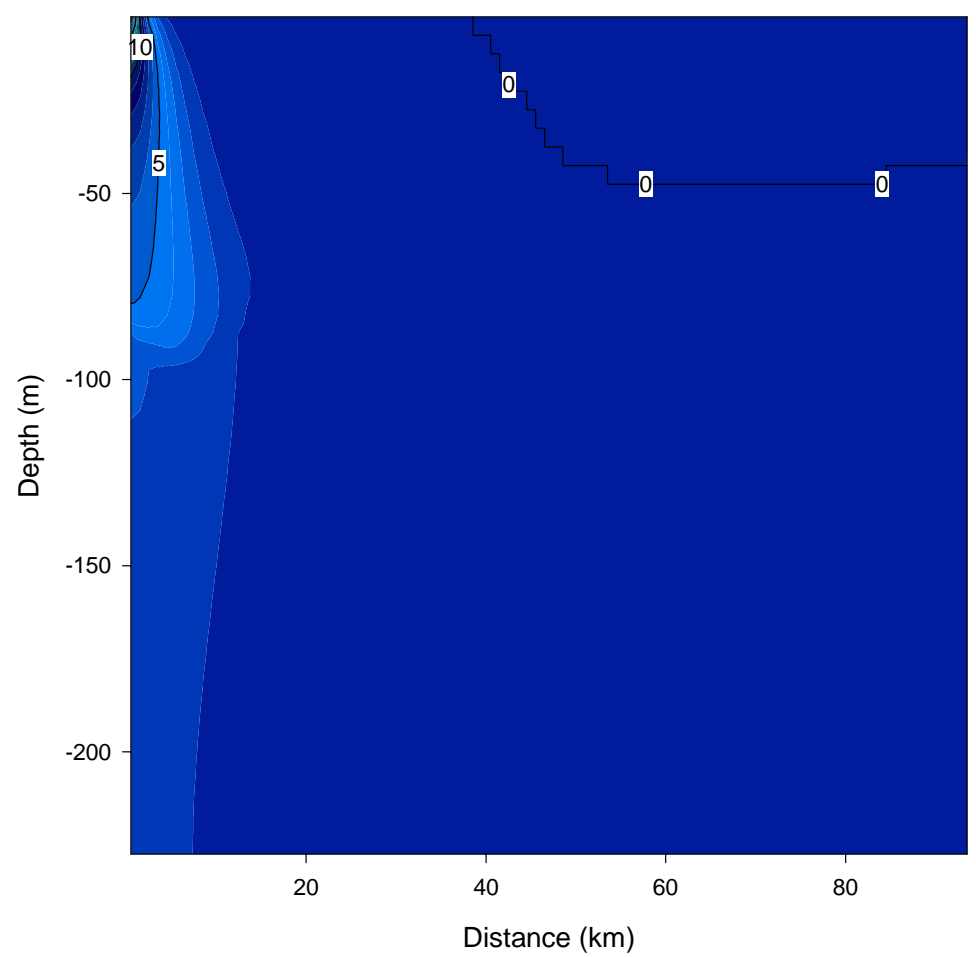

Figure 5. SPM distribution at day 56 when a hypothesized river input occurs in cell (1, $1)$. 

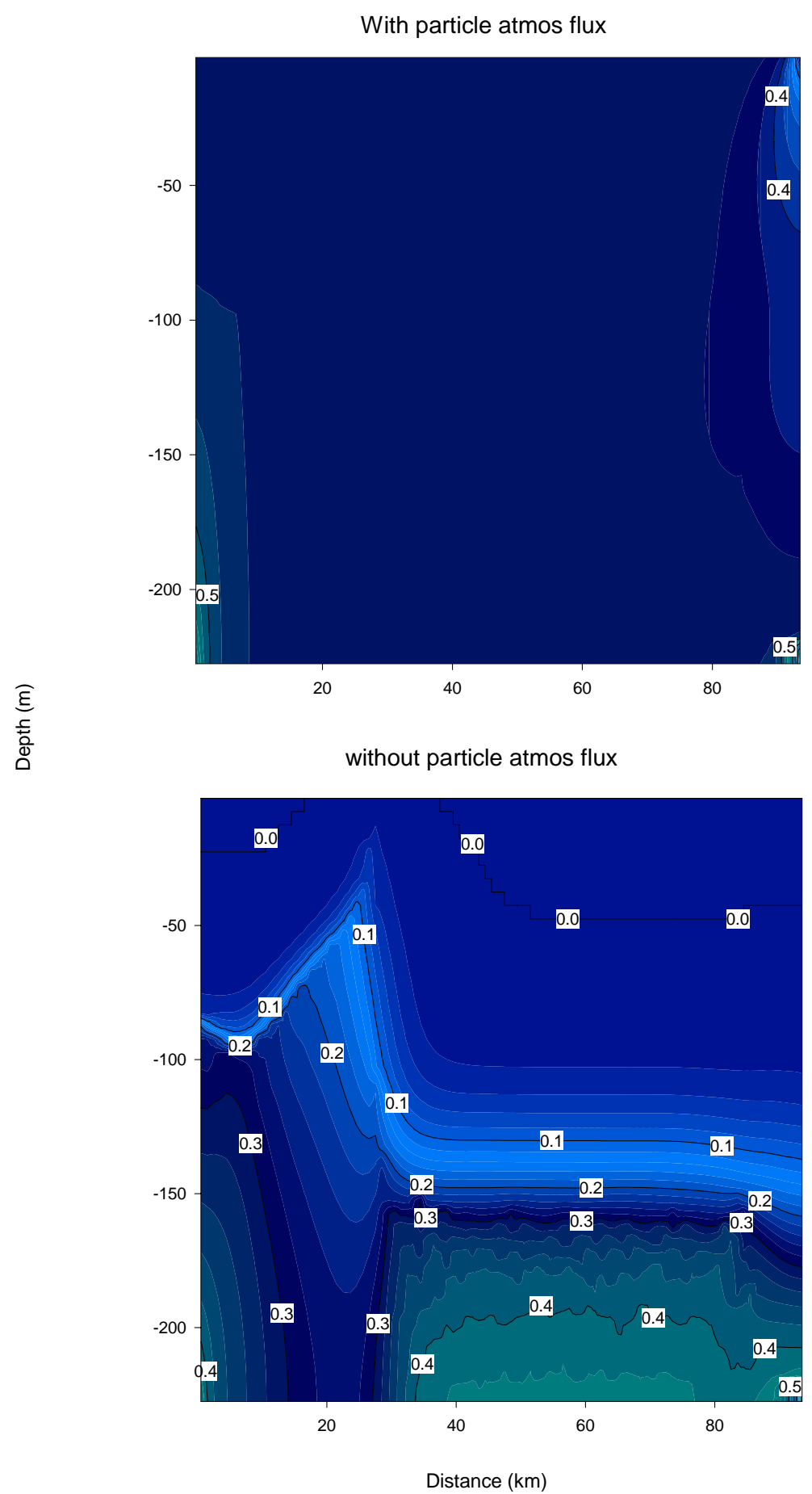

Figure 6. Particle distributions at day 56 with (top) and without (bottom) atmospheric deposition of particles. 


\subsection{Sediment-related processes}

In the original model, the settling velocity of chlorophyll was cut in half at the $2^{\text {nd }}$ bottommost layer and no loss to sediments was allowed. Clearly, when modeling with isotopes and SPM that both have a large potential source in the surficial sediments, modifications are needed. At least two processes have to be considered. First, sedimentation is needed in the model as described for SPM above; secondly, resuspension has been shown to have a major effect on ${ }^{210} \mathrm{~Pb}$ and ${ }^{210} \mathrm{Po}$ distributions in Lake Superior (Chapters 2,3), and thus resuspension of both SPM and isotopes is needed.

1) Particle resuspension. A resuspension rate on the order of $1 \mathrm{~mm} /$ day was found to be too large for the system due to the high bulk density used in the sediment layer, $1.5 \mathrm{~g} / \mathrm{cm}^{3}$, as compared to the average SPM concentration of $\sim 0.45 \mathrm{~g} / \mathrm{m}^{3}$ in the water column. Instead, a constant particle resuspension flux of $1.5 \mathrm{~g} / \mathrm{m}^{2}$-day was added to the bottom layer of the water column. The following figures compare the SPM concentration with and without resuspension. (The rest of the two model runs are identical). 


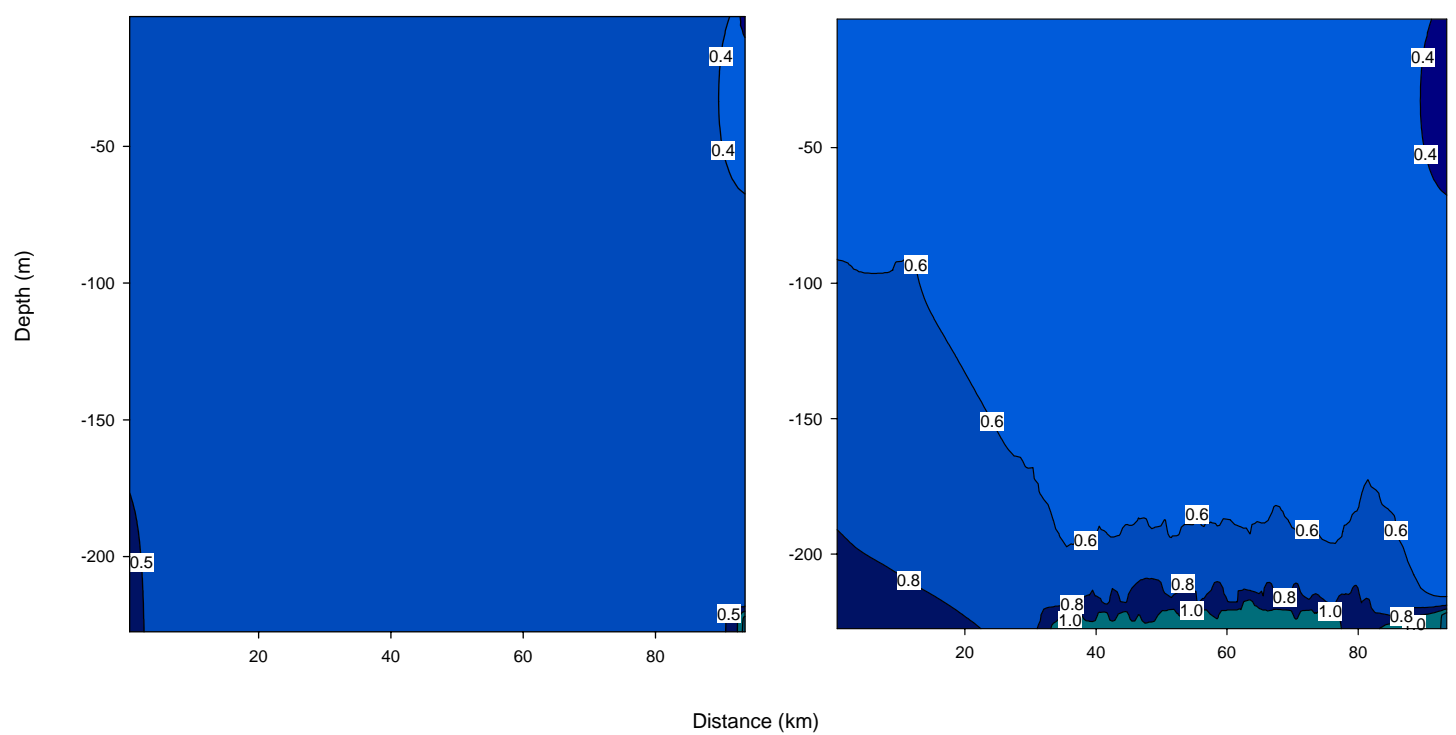

Figure 7. Model predictions of particle distributions without (left) and with (right) resuspension.

As shown in Figure 7, resuspension results in a benthic nepheloid layer (BNL) similar to that observed in the lake. The way resuspension is defined in the model may be different from the real situation where resuspended particles can go higher than 5 meters into the water column. In the model, particles are resuspended into the bottom layer of water and dispersion moves them upward. As a result, a more concentrated BNL is predicted than that observed in the lake.

Given that the model-predicted particle distributions satisfactorily mimic observed distributions, isotope resuspension was encoded by specifying an isotope activity in the sediments. This concentration times the particle resuspension flux $\left(\mathrm{g} / \mathrm{m}^{2}-\right.$ 
d) yields an isotope flux in units of $\mathrm{dpm} / \mathrm{cm}^{2}$-d. As for particles, an unlimited pool of isotope in the sediment was assumed.

\section{Numerical experiments with the modified model (model applications)}

Numerical experiments were conducted with the modified model with the goals of (1) identifying appropriate values for variables that are difficult to measure directly; (2) examining the relative importance of various processes under different environmental conditions. In most cases, model predictions are compared with field measurements of the same parameters.

4.1. Effect of particle settling velocity
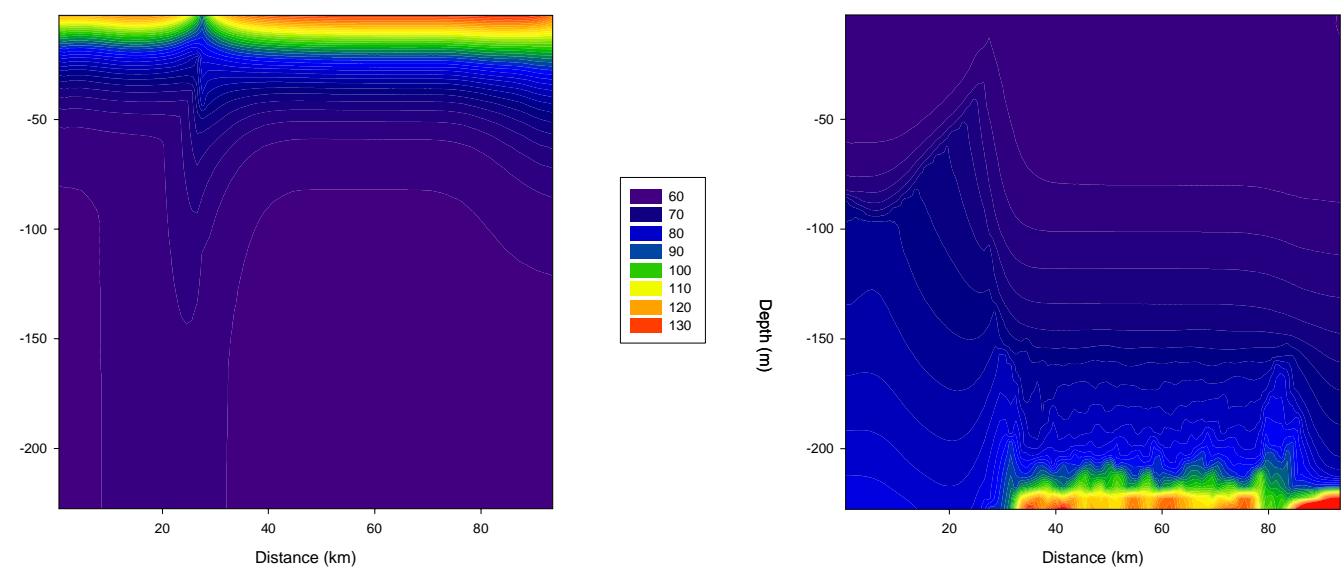

Figure 8. Effect of settling velocity on isotope $\left({ }^{210} \mathrm{~Pb}\right)$ distribution. $\mathrm{A}: \mathrm{v}_{\mathrm{s}}=0 \mathrm{~m} /$ day; $\mathrm{B}$ : $\mathrm{v}_{\mathrm{s}}=5 \mathrm{~m} /$ day. 
The vertical flux of particles in the oceans has long been studied in oceanography [McCave, 1975]. Currently, the POC export flux from the upper ocean is a major focus in global warming studies. Radioisotopes are useful tracers and provide many insights into this process [Friedrich and van der Loeff, 2002; Santschi et al., 2003; Schlüter et al., 2004]. On the other hand, the settling process also has significant effects on the removal of particle-reactive compounds in the water column, such as radioisotopes.

Figure 8 and 9 show the effect of different settling velocities on the distribution of ${ }^{210} \mathrm{~Pb}$ in the lake. In Figure 8, a comparison is made between no settling and a high settling velocity (5m/day) throughout the water column. Without particle settling, hydrodynamic movements are not adequate to move and mix the isotopes from the upper water column into the lower lake waters. In contrast, if the settling velocity is too high, most of the isotopes are scavenged from the water column and accumulate in the bottom waters (note no sediment layer is included in this simulation). Field measurements showed that ${ }^{210} \mathrm{~Pb}$ was uniformly distributed through the water column [Chai and Urban, 2004]. A settling velocity of $0.45 \mathrm{~m} /$ day generated a reasonable fit between model predictions and field measurements. This value is the same as predicted by a steadystate, one-box model when the total ${ }^{210} \mathrm{~Pb}$ inventory in the water column is divided by the atmospheric influx. This coincidence suggests that the model reaches a dynamic steady state after 56 days of model run time. 


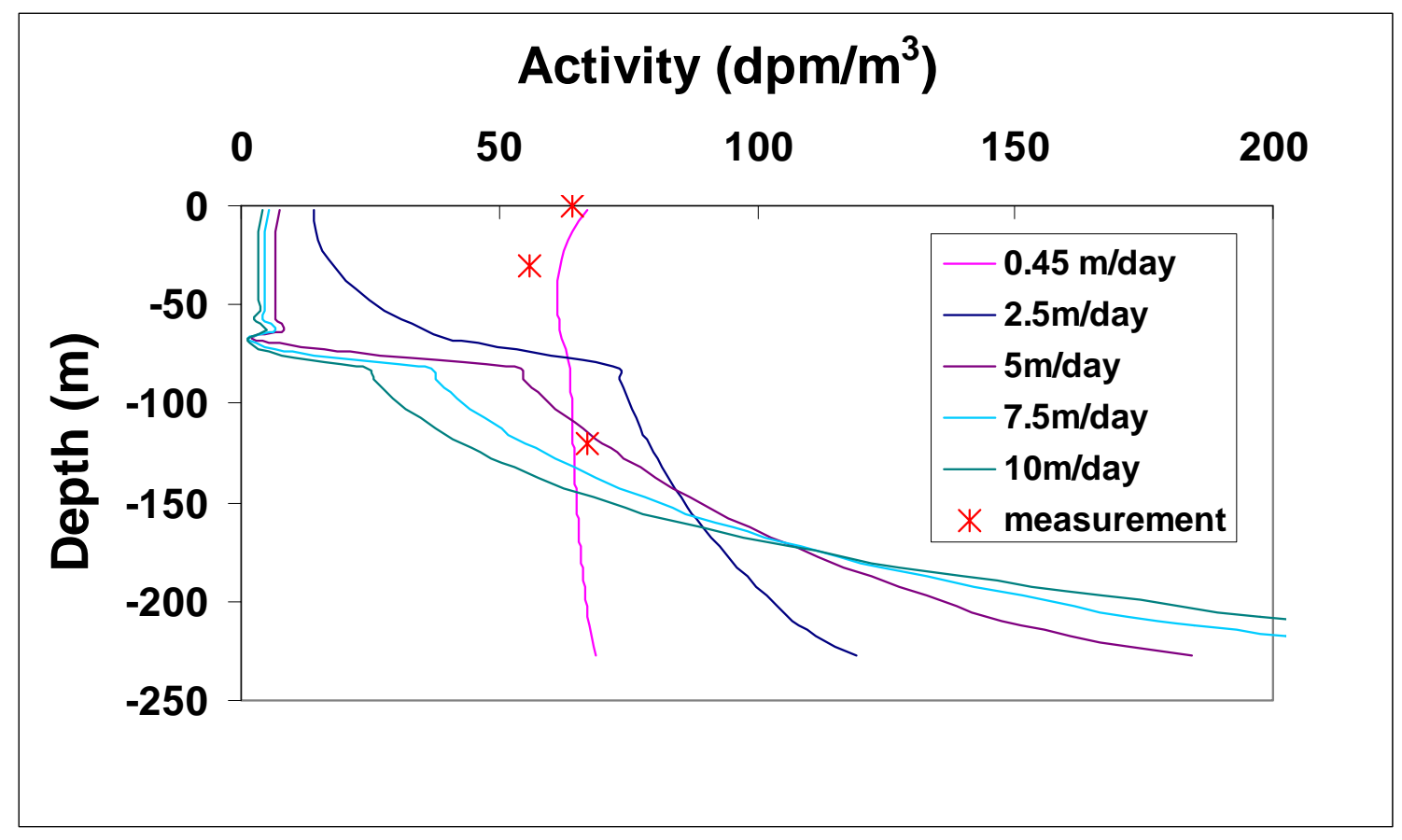

Figure 9. Comparison between simulated ${ }^{210} \mathrm{~Pb}$ depth profiles with different settling velocities and field measurements.

\subsection{Effect of Kd value}

As discussed in previous chapters, the value of $\mathrm{K}_{\mathrm{d}}$ for either of the isotopes is unlikely to vary greatly in space or time given the small variation in other related parameters such as SPM [Benoit, 1995]. However, the limited number of measurements of isotope activities in the dissolved phase results in a large uncertainty in the true value of $\mathrm{K}_{\mathrm{d}}$. This is particularly true for polonium for which there are also few literature data available [Chai and Urban, 2004]. For ${ }^{210} \mathrm{~Pb}$ the measured $\mathrm{K}_{\mathrm{d}}$ value agrees well with a large number of literature values. Thus numerical experiments were performed to examine the influence of the value of $\mathrm{K}_{\mathrm{d}}$ for ${ }^{210} \mathrm{Po}$. In these experiments, $\mathrm{K}_{\mathrm{d}}$ for ${ }^{210} \mathrm{~Pb}$ was held constant at $10 \mathrm{~L} / \mathrm{mg}$. The $\mathrm{K}_{\mathrm{d}}$ values applied are $10 \mathrm{~L} / \mathrm{mg}$ and $4 \mathrm{~L} / \mathrm{mg}$. The initial 
conditions included two different ${ }^{210} \mathrm{Po}:{ }^{210} \mathrm{~Pb}$ inventory ratios, 0.6 and 0.44 , with the latter being the average value from field measurements.
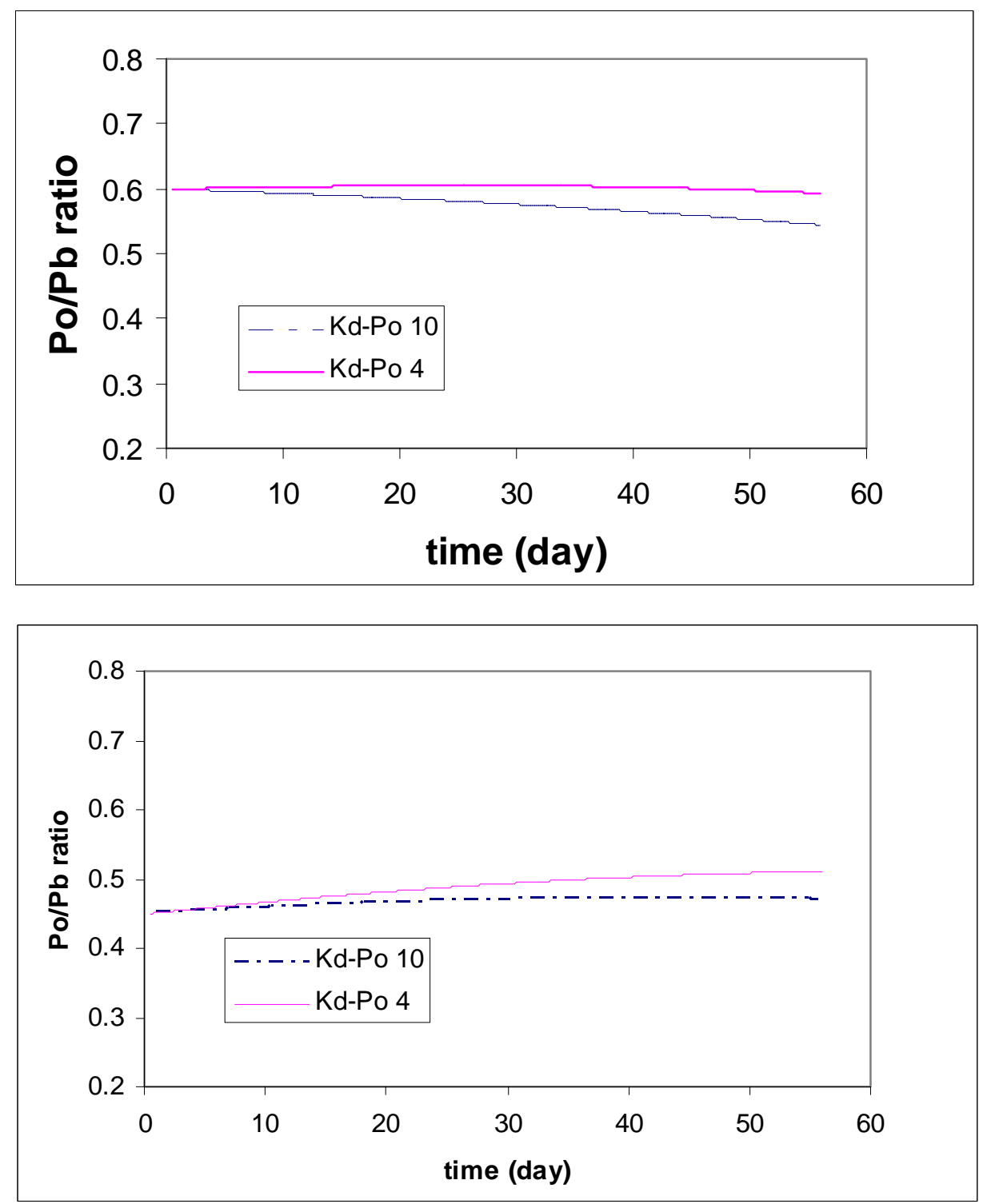

Figure 10. Time series plots of predicted $\mathrm{Po} / \mathrm{Pb}$ ratios with different $\mathrm{K}_{\mathrm{d}}$ values for Po. Top: initial $\mathrm{Po} / \mathrm{Pb}$ ratio of 0.6 ; bottom: initial $\mathrm{Po} / \mathrm{Pb}$ ratio of 0.44 . 
A lower $\mathrm{K}_{d}$ value results in a higher $\mathrm{Po} / \mathrm{Pb}$ ratio. This is reasonable because a lower $\mathrm{K}_{\mathrm{d}}$ results in less scavenging from the water column. The isotope ratio at the end of the model simulation is independent of the initial ratio but does vary with the value of $\mathrm{K}_{\mathrm{d}}$.

\subsection{Sediment resuspension: from a one-box model to a complex hydrodynamic model}

Two of the major conclusions from the one-box model (Chapter 2) were that 1) the particle settling velocity must be high, and 2) resuspension has a large influence on isotope distributions. However, the one-box model is oversimplified and omits some potentially important processes. These conclusions were, therefore, tested with the modified Niebauer hydrodynamic model. The model was run with all the measured parameters and additional parameters predicted by the one-box model [Chai and Urban, 2004]. Input variables were set to the following values: $\mathrm{Po} / \mathrm{Pb}$ ratio -0.4 , settling velocity $-2.3 \mathrm{~m} /$ day, particle resuspension rate $-3.5 \mathrm{~g} / \mathrm{m}^{2}$-day and $\mathrm{Po} / \mathrm{Pb}$ resuspension rates -81 and $16 \mathrm{dpm} / \mathrm{m}^{2}$-day. The following 4 figures summarize the model predictions of SPM concentrations, ${ }^{210} \mathrm{Po}$ and ${ }^{210} \mathrm{~Pb}$ distributions, and $\mathrm{Po} / \mathrm{Pb}$ ratios. The particle inventory increased during the 56-day simulation even with the high settling velocity of $2.3 \mathrm{~m} / \mathrm{d}$. The high settling velocity caused the ${ }^{210} \mathrm{~Pb}$ inventory to drop despite a high resuspension rate. Polonium behaved differently due to a higher decay production rate from $\mathrm{Pb}$. 


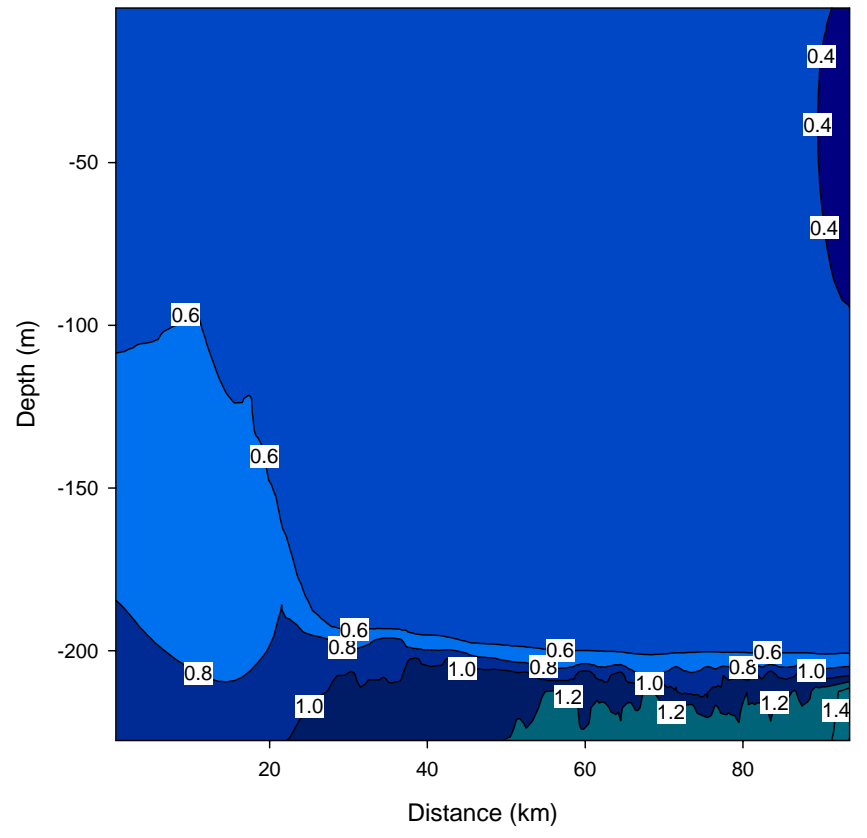

Figure 11. Predicted SPM distribution on day 56 of the model run. 
Pb-210 distribution (dpm/m3)
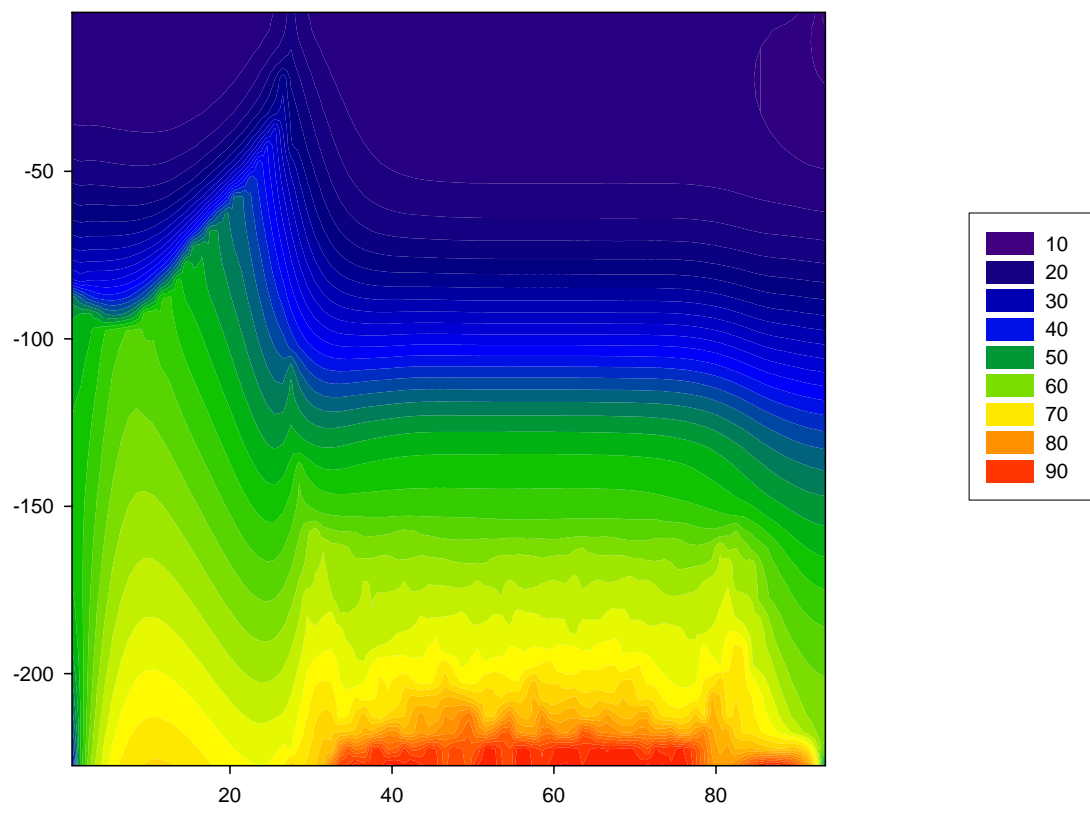

Po-210 distribution

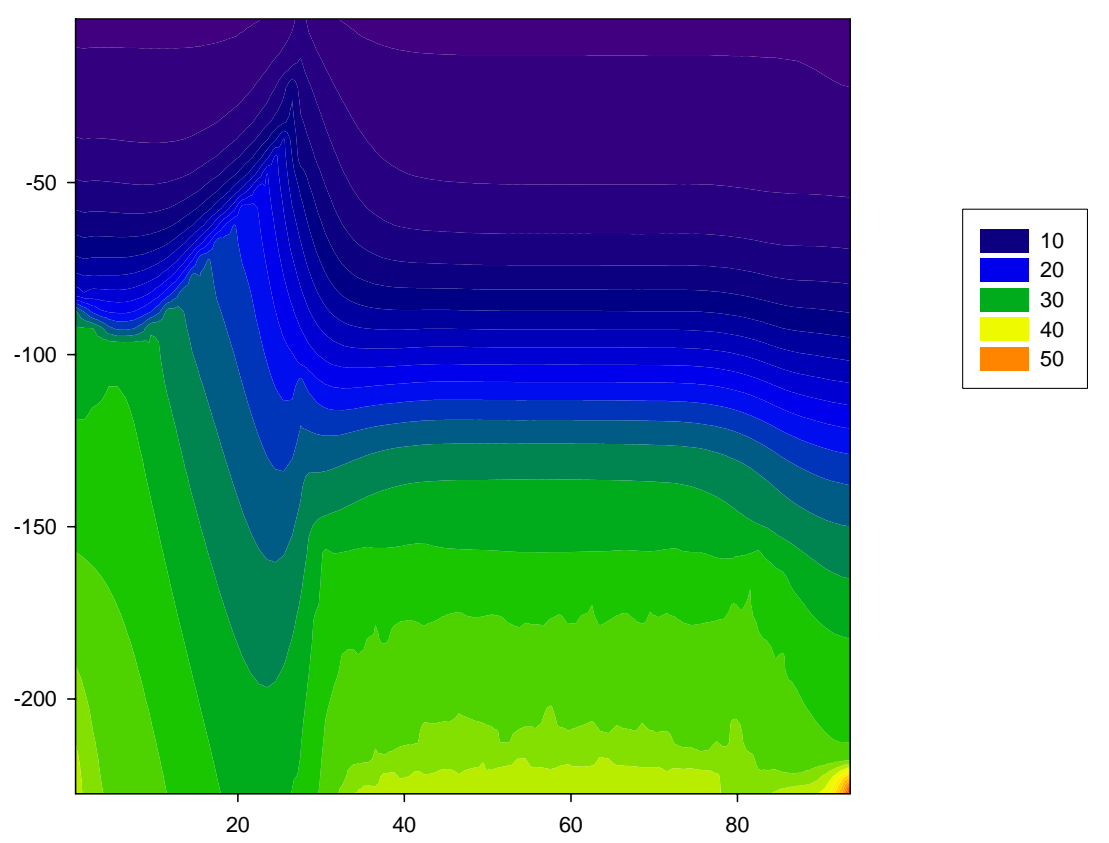

Figure 12. Predicted isotope distributions at day 56 of model simulation. 


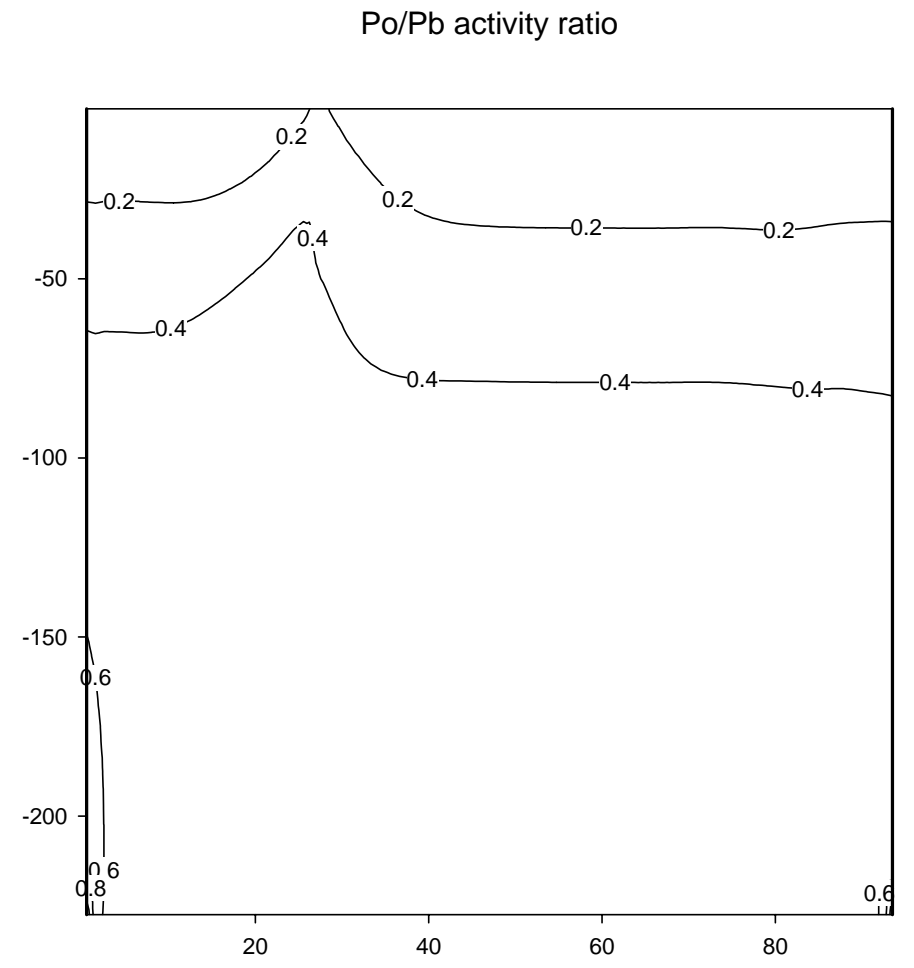

Figure 13. Ratio at the end of model simulation. 


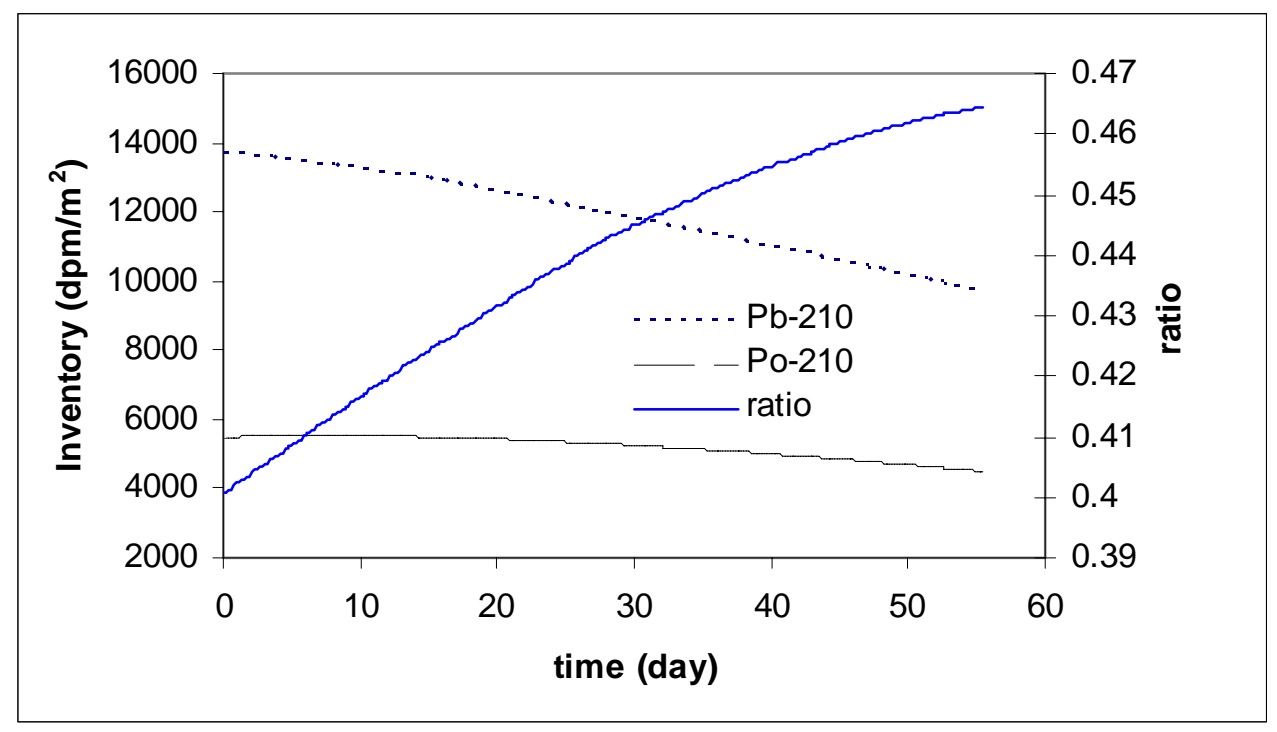

Figure 14. Time series of predicted isotope inventories and ratios.

Generally, both conclusions from the one-box model are supported by the more complex hydrodynamic model. The figures above do reveal some information that can not be obtained from the steady state one-box model. For SPM, the resuspension rate exceeds the settling velocity, and a net increase in SPM inventory is observed. However, it seems that the isotope distributions ( $\mathrm{Po}$ and $\mathrm{Pb}$ ) are more sensitive to settling than to resuspension as evidenced by the accumulation in the bottom waters (Figure 12) and the decrease in inventories during the simulation. The average isotope ratio varies over only a small range (0.4-0.46, Figure 14), but ratios between 0.2 and 0.8 are observed in the water column. In the field, an increase in Po inventory also was observed [Chai and Urban, 2004]. The model predicts much more variation in ${ }^{210} \mathrm{~Pb}$ activities and in the isotope ratio than was observed in the field data. Evidently, model parameters or the modeling approach needs to be improved. 


\subsection{Improved resuspension and settling process: advantage of complex model}

In an effort to predict more realistic isotope distributions in the lake, the model was modified and run again. The effect of confining resuspension to the bottom layer of water was examined by distributing it to more layers. Potential effects of particle aggregation during settling were examined by varying the settling velocity as a function of position in the water column.

\subsubsection{Distribution of resuspension to higher depths}

In the KITES project, resuspended sediments were collected even in sediment traps suspended $30 \mathrm{~m}$ below the water surface and up to $170 \mathrm{~m}$ above the sediments [Urban et al., 2004]. Lacking waves, the hydrodynamic model is unable to simulate the high levels of turbulence that are required to mix resuspended sediments throughout the water column. To get around this problem, resuspended particles and isotopes were distributed in a controlled fashion to water depths above the bottom layer. According to the sediment trap study by Baker et. al. [1991] in Lake Superior, an exponential decay of settling fluxes with depth in the water column is observed. Resuspended sediment fluxes were allocated to different depths in the water column using such an exponential distribution as illustrated in Figure 15. The modeling results are shown with the same set of graphs. 


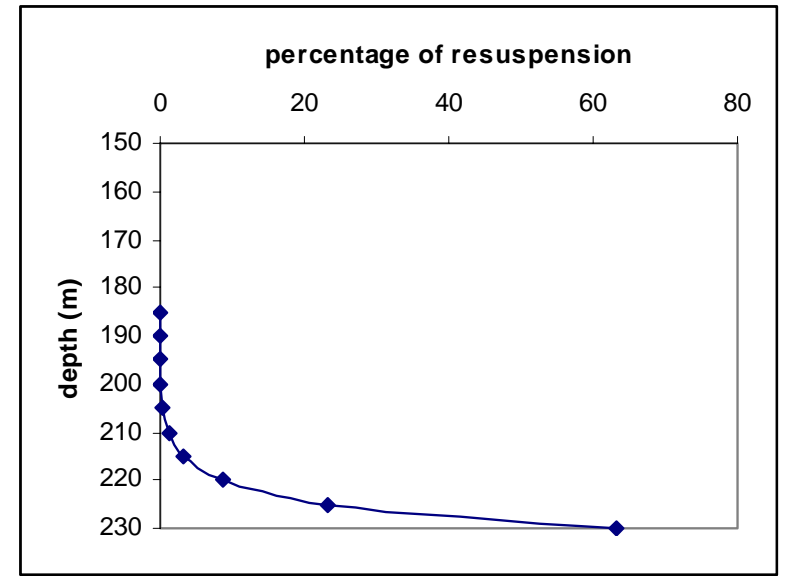

Figure 15. Allocation of resuspension fluxes at different depth of water column. 


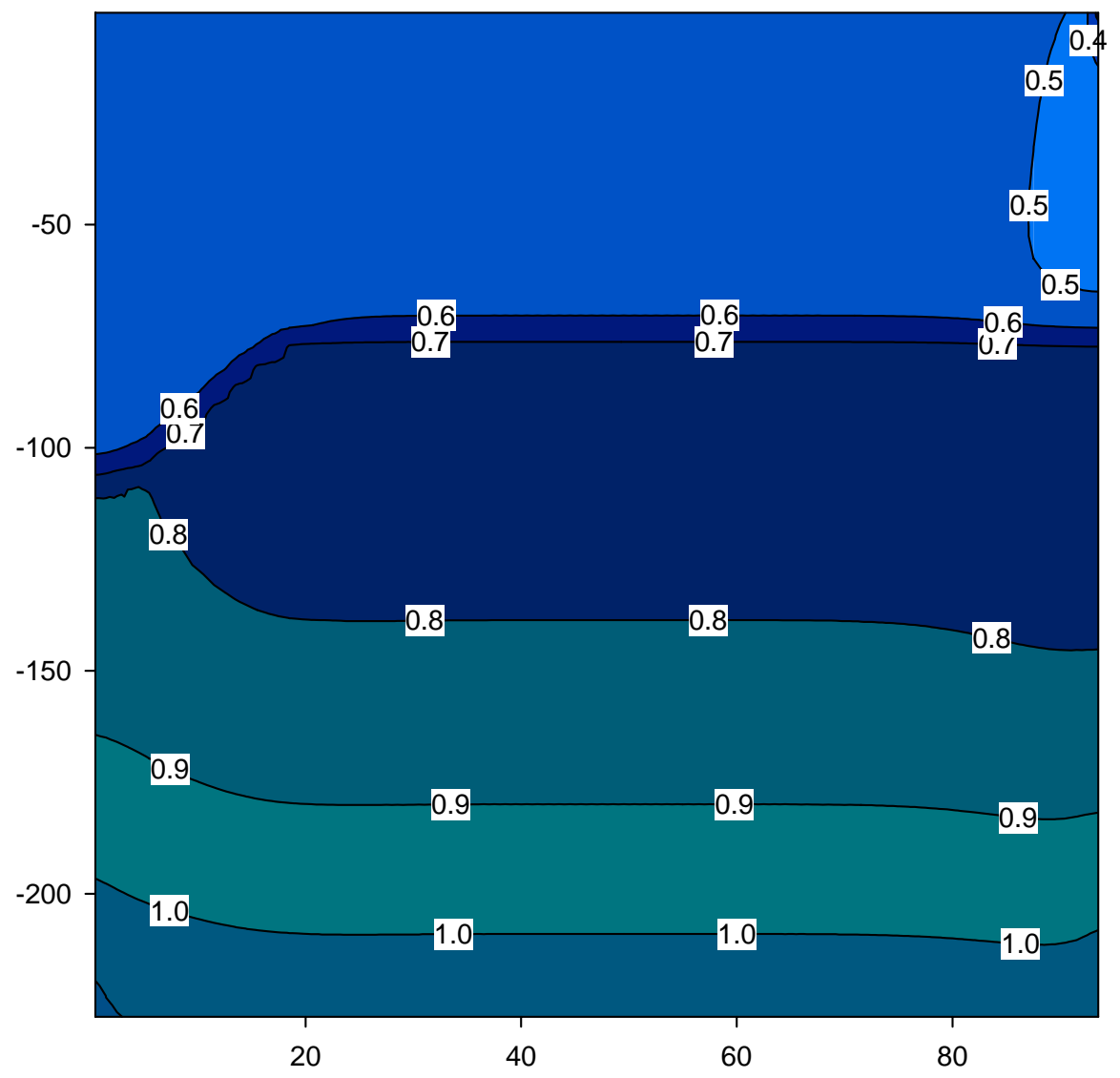

Figure 16. Predicted SPM contours after 56-day model simulation with resuspension allocated among depths. 


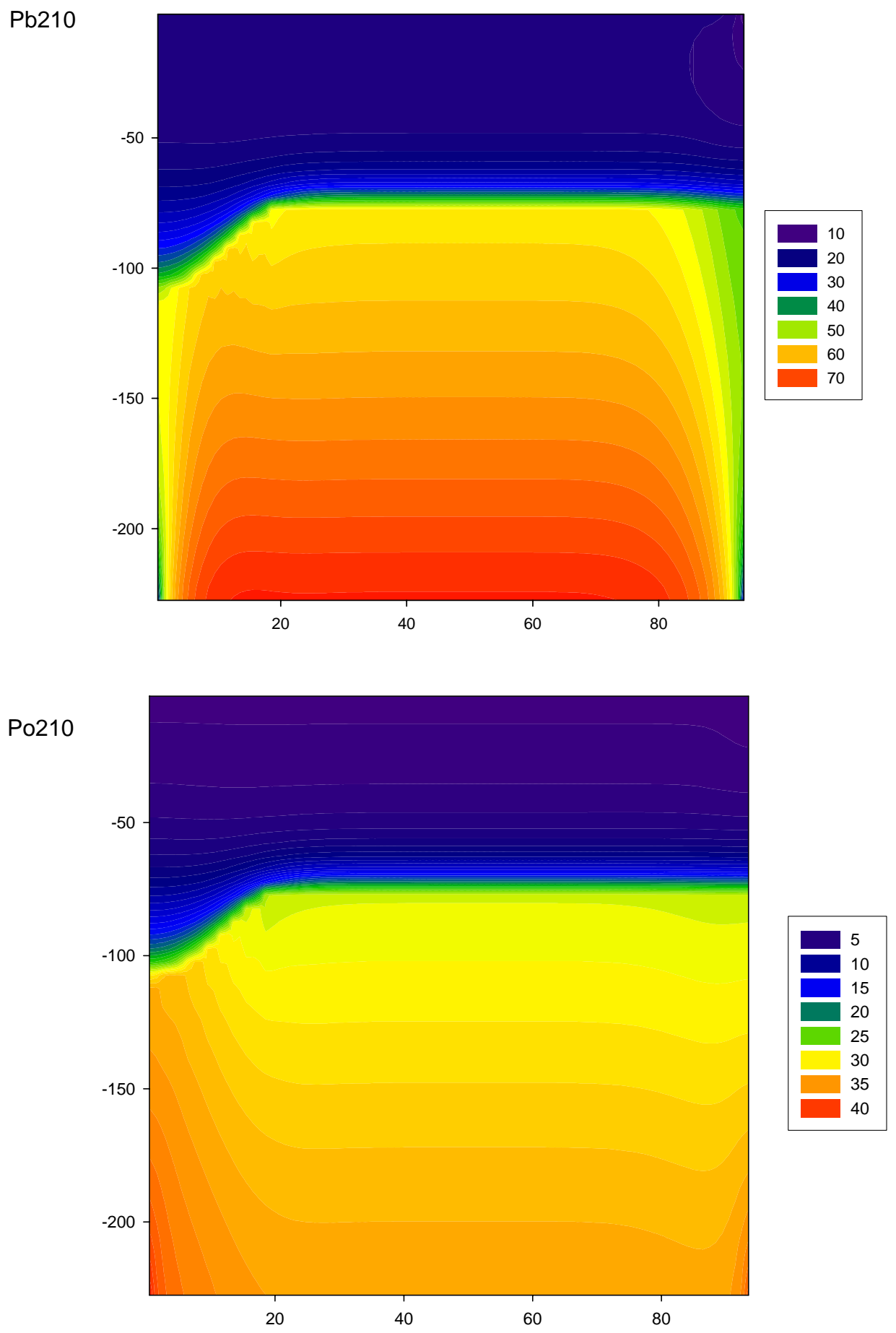

Figure 17. Predicted isotope distributions at the end of 56-d model simulation with exponential allocation of resuspended solids. 


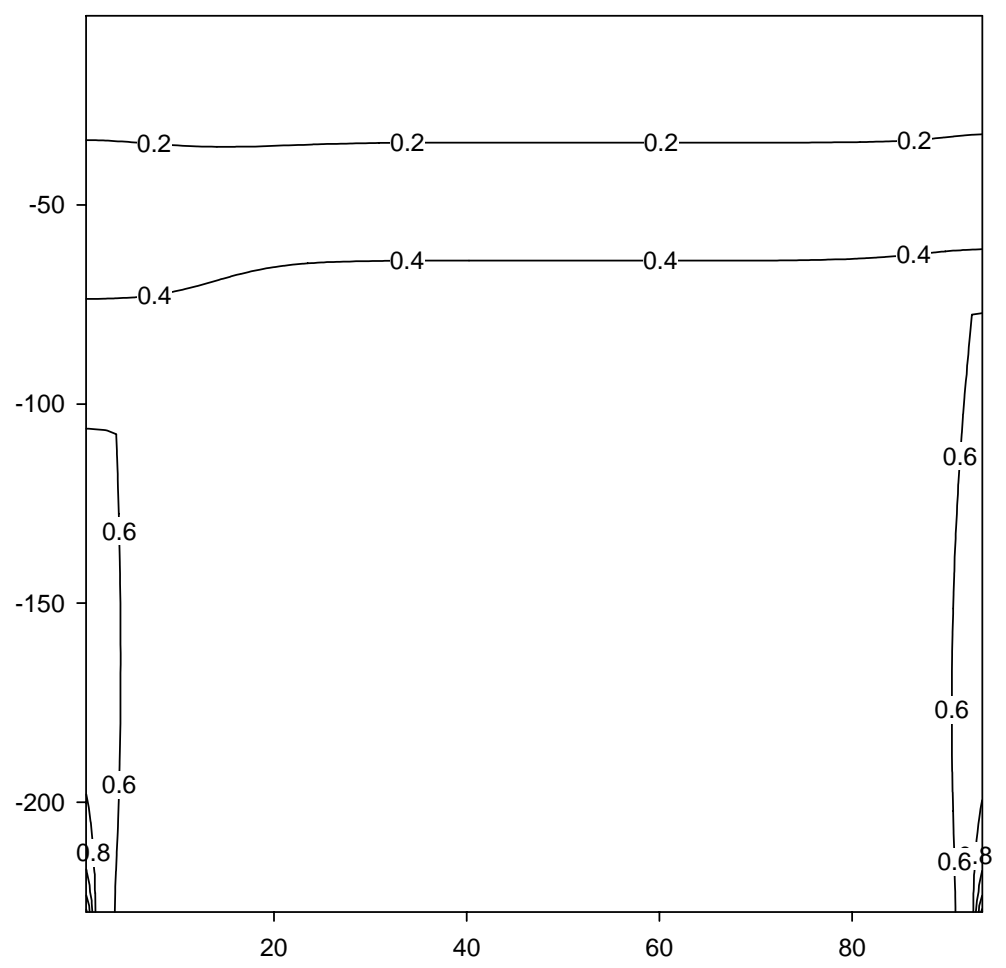

Figure 18. Predicted isotope ratio $(\mathrm{Po}: \mathrm{Pb})$ after $56-\mathrm{d}$ model simulation with resuspended solids distributed exponentially through the water column.

Distributing resuspended solids higher into the water column does improve the fit between model predictions and field measurements. The vertical gradient in both SPM and isotopes are decreased and more closely mimic field measurements. However, activities and isotope ratios in the surface waters are still too low. Although it would be possible to distribute the resuspended solids even higher in the model, the discrepancy 
with field observations might also point to more rapid horizontal mixing of nearshore waters with offshore waters during storm events.

\subsubsection{Variable settling velocity}

In both simulations described above, the $\mathrm{Po} / \mathrm{Pb}$ ratios in the upper water column (epilimnion) remain lower than those measured in the field. Because the rates of supply from fallout are about 10-fold lower for Po as compared with $\mathrm{Pb}$ but the rates of scavenging (from the water by particles) are comparable, it is not surprising to see the ratio drop from 0.4 to 0.2 in two months. In other words, the model predicts that the ratio will approach the input ratio. To maintain a higher isotope ratio in the epilimnion, a longer residence time for Po is required in the upper water column. This result can be achieved by invoking a lower particle settling velocity in the epilimnion than in the hypolimnion. In the model simulation, a settling velocity of $0.5 \mathrm{~m} /$ day was used from 0 $30 \mathrm{~m}$ (the depth of the DCM), and a settling velocity of $2.3 \mathrm{~m} /$ day was applied for the rest of the water column. 
Pb210
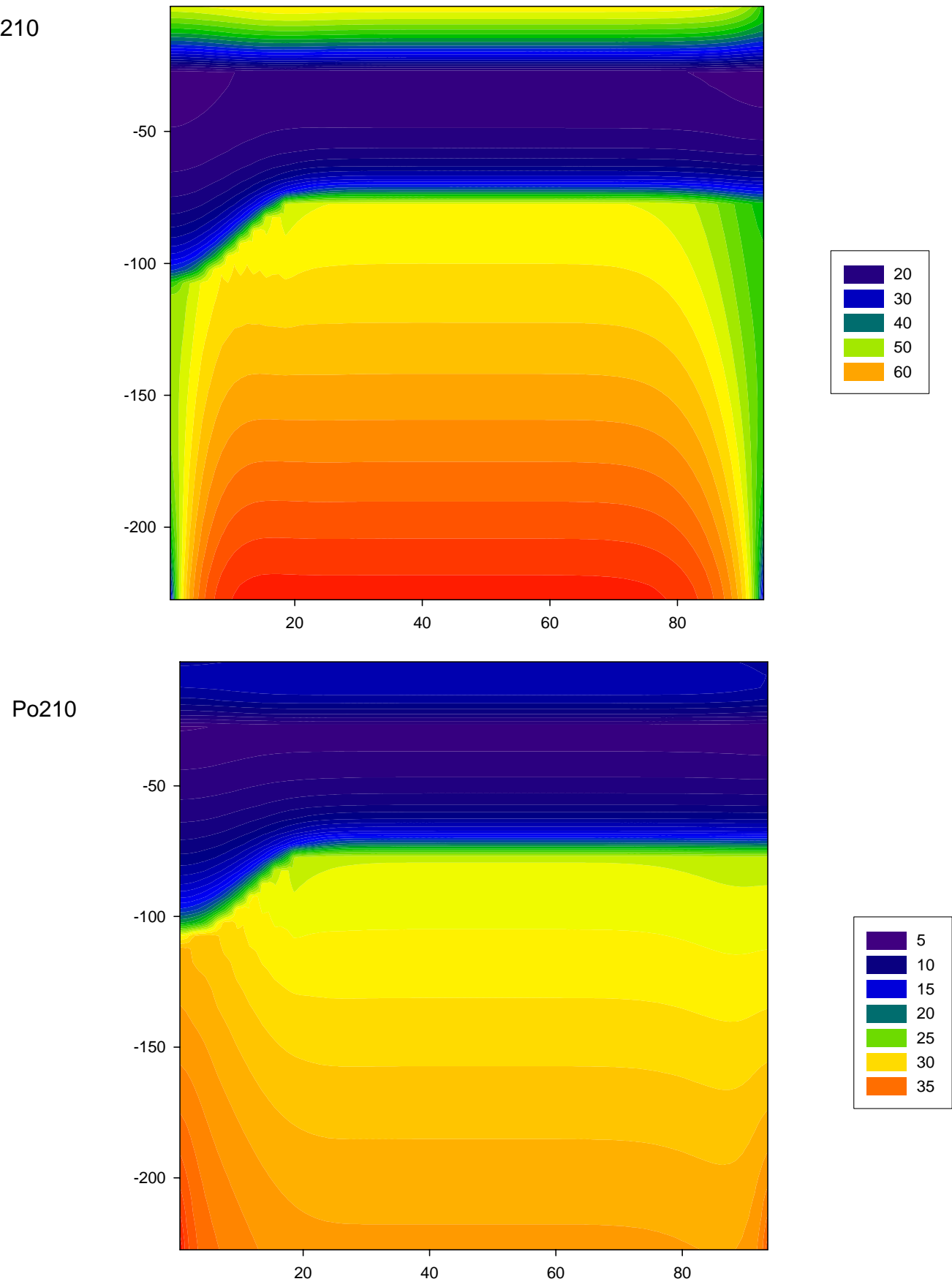

Figure 19. Isotope distribution when two settling velocities are applied. 


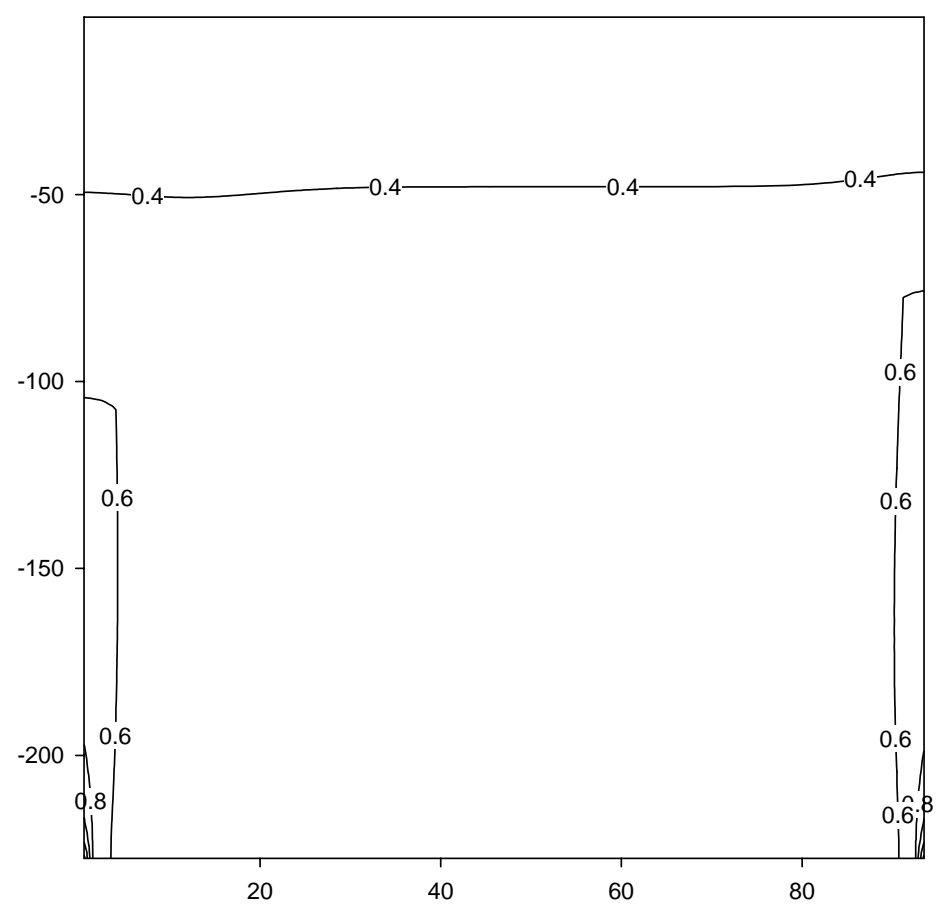

Figure 20. Predicted isotope ratio $(\mathrm{Po}: \mathrm{Pb})$ at the end of a 56-d model simulation with two settling velocities (see text for explanation).

This scenario yields the best agreement with field observations. Isotopes are not excessively depleted in the upper water column, and an isotope ratio of 0.4 is maintained for most of the lake. This scenario suggests that settling is a major control on the isotope distributions, and must be accurately described in the model. The unrealistic mid-water minimum that is predicted by the model for both isotopes is not eliminated even with the simple two-velocity approach. If detailed information about particle size and particle isotope associations could be coupled in the model, better results might be obtained. 


\section{Conclusion}

The modeling efforts achieved several of the goals identified initially. These include:

1) Incorporation of particle-reactive isotopes into a hydrodynamic model. Comparison of measured and predicted isotope distributions allows verification of both the hydrodynamic model and of predictions of particle transport. With this model, patterns of particle transport may be evaluated, and conditions not amenable to field sampling can be simulated.

2) Comparison of the predictions from the simple one-box model with those of a more accurate hydrodynamic model. This comparison indicates that the predictions (settling velocity, resuspension rate) from the one-box model are reasonable, but they cannot explain all features of the observed isotope distributions.

3) Create a tool that may be used to evaluate individual parameters and processes. Model simulations revealed that variable settling velocities and distribution of resuspension through the water column may be important factors that contribute to the observed isotope distributions. Used in an experimental mode, the model should be useful for evaluating theories about the mechanisms for formation of the DCM and BNL. Further refinements in the description of the sediment reservoir are needed to enable quantitative predictions of cross-margin transport and rates of resuspension. 


\section{REFERENCES:}

Auer, M.T., and T. Gatzke, Interaction of the spring runoff event with the Thermal Bar in Lake Superior, J. Great Lakes Res., 30 (Suppl 1), 2004.

Baker, J.E., S.J. Eisenreich, and B.J. Eadie, Sediment trap fluxes and benthic recycling of organic carbon, polycyclic aromatic hydrocarbons, and polychlorobiphenyl congeners in Lake Superior, Environ. Sci. Technol., 25, 500-509, 1991.

Bennett, J.R., On the dynamics of wind-driven lake currents, J. Phys. Oceanogr., 4, 400414, 1974.

Benoit, G., Evidence of the particle concentration effect for lead and other metals in fresh waters based on clean technique analyses, Geochim. Cosmochim. Acta, 59, 26772687, 1995.

Botte, V., and A. Kay, A numerical study of plankton population dynamics in a deep lake during the passage of the Spring thermal bar, J. Mar. Systems, 26 (3-4), 367-386, 2000 .

Chai, Y., and N.R. Urban, ${ }^{210} \mathrm{Po}$ and ${ }^{210} \mathrm{~Pb}$ distributions and residence times in the nearshore region of Lake Superior, J. Geophys. Res., 109 (C10S07), doi:10.1029/2003JC002081, 2004.

Chen, C., J. Zhu, E. Ralph, S.A. Green, J.W. Budd, and F.Y. Zhang, Prognostic modeling studies of the Keweenaw Current in Lake Superior. Part I: formation and evolution, J. Phys. Oceanogr., 31, 379-395, 2001.

Edwards, R.L., and J.C. Priscu, McMurdo LTER: Relationships between vertical nutrient flux and phytoplankton biomass and productivity in lakes of the Taylor Valley, Antarctica, Antarctic J. of the United States, 30 (5 (Review Issue)), 294-295, 1995.

Friedrich, J., and M.M.R. van der Loeff, A two-tracer $\left({ }^{210} \mathrm{Po}-{ }^{234} \mathrm{Th}\right)$ approach to distinguish organic carbon and biogenic silica export flux in the Antarctic Circumpolar Current, Deep-Sea Research I, 49 (1), 101-120, 2002.

Gatzke, T., Spring runoff events, thermal bar formation, and cross-margin transport in Lake Superior, Michigan technological University, Houghton, MI, 2001.

Giannakopoulos, C., M.P. Chipperfield, K.S. Law, and J.A. Pyle, Validation and intercomparison of wet and dry deposition schemes using ${ }^{210} \mathrm{~Pb}$ in a global threedimensional off-line chemical transport model, J. Geophys. Res., 104 (D19), 23,761-23,784, 1999.

Gloor, M., A. Wuest, and M. Munnich, Benthic boundary mixing and resuspension induced by internal seiches, Hydrobiologia, 284 (1), 59-68, 1994.

Guelle, W., P. Monfray, Y.J. Balkanski, M. Schulz, and F. Dulac, Wet deposition in a global size-dependent aerosol transport model. 1. Comparison of a 1 year ${ }^{210} \mathrm{~Pb}$ simulation with ground measurements, J. Geophys. Res., 103 (D10), 11429$11445,1998$.

Henderson, G.M., and E. Maier-Reimer, Advection and removal of ${ }^{210} \mathrm{~Pb}$ and stable $\mathrm{Pb}$ isotopes in the oceans: A general circulation model study, Geochim. Cosmochim. Acta, 66 (2), 257-272, 2002.

Hodges, B.A., and D.L. Rudnick, Simple models of steady deep maxima in chlorophyll and biomass, Eos Trans. AGU, 84 (52), Ocean Sci. Meet. Suppl. Abstract OS22A-09, 2003. 
Honeyman, B.D., and P.H. Santschi, A Brownian-pumping model for oceanic trace metal scavenging: evidence from Th isotopes, Journal of Marine Research, 47 (4), 951992, 1989.

Jeong, J., N.R. Urban, S.A. Green, and J. Budd, Short-term dynamics and distribution of suspended particles in the Keweenaw Peninsula region of Lake Superior, J. Great Lakes Res., In review, 2003.

Kim, G., Large deficiency of polonium in the oligotrophic ocean's interior, Earth Planet. Sci. Lett., 192, 15-21, 2001.

Koch, D.M., D.J. Jacob, and W.C. Graustein, Vertical transport of tropospheric aerosols as indicated by ${ }^{7} \mathrm{Be}$ and ${ }^{210} \mathrm{~Pb}$ in a chemical tracer model, J. Geophys. Res., 101 (D13), 18,651-18,666, 1996.

Lam, D.C.L., and E. Halfon, Model of primary production including circulation influences in Lake Superior, Appl. Math. Model., 2 (1), 30-40, 1978.

Likhoshway, Y.V., M.N. Shimaraev, K.A. Y., T.G. Potyemkina, and V.L. Potyemkin, The distribution of diatoms near a thermal bar in Lake Baikal, J. Great Lakes Res., 22 (1), 5-14, 1996.

Lou, J., D.J. Schwab, D. Beletsky, and N. Hawley, A model of sediment resuspension and transport dynamics in southern Lake Michigan, J. Geophys. Res., 105 (C3), 6591-6610, 2000.

Maier-Reimer, E., and G. Henderson, ${ }^{210} \mathrm{~Pb}$ in the ocean: A pilot tracer for modeling particle reactive elements, Proceedings of the Indian Academy of Sciences, Earth and Planetary Sciences, 107 (4), 351-357, 1998.

Marley, N.A., J.S. Gaffney, P.J. Drayton, M.M. Cunningham, K.A. Orlandini, and R. Paode, Measurement of ${ }^{210} \mathrm{~Pb},{ }^{210} \mathrm{Po}$, and ${ }^{210} \mathrm{Bi}$ in size-fractionated atmospheric aerosols, an estimate of fine-aerosol residence times, Aerosol Sci. Tech., 32, 569583, 2000.

Masqué, P., E. Palacios, M. Canals, J.A. Sanchez-Cabeza, and J.M. Bruach, Balance and residence times of ${ }^{210} \mathrm{~Pb}$ and ${ }^{210} \mathrm{Po}$ in surface waters of the northwestern Mediterranean Sea, Cont. Shelf Res., 22 (15), 2127-2146, 2002.

McCave, I.N., Vertical flux of particles in the ocean, Deep-Sea Res. II, 22, 491-502, 1975.

Niebauer, H.J., Physical-biological numerical modeling on Alaskan Arctic shelves, pp. 84, Institute of Marine Sciences, University of Alaska Fairbanks, Fairbanks, AK, 2002.

Niebauer, H.J., T. Green, and R.A. Ragotzkie, Coastal upwelling/downwelling cycles in southern Lake Superior, J. Phys. Oceanogr., 7 (917-927), 1977.

Niebauer, H.J., and W.O.J. Smith, A numerical model of mesoscale physical-biological interactions in the Fram Strait marginal ice zone, J. Geophys. Res., 94 (C11), 16151-16175, 1989.

Niebauer, H.J., N.R. Urban, M.T. Auer, and L.A. Bub, Primary production in Lake Superior: A numerical model of phosphorus cycling, Ecological Modeling, In preparation, 2005.

Nozaki, Y., H. Tsubota, V. Kasemsupaya, M. Yashima, and N. Ikuta, Residence times of surface water and particle-reactive ${ }^{210} \mathrm{~Pb}$ and ${ }^{210} \mathrm{Po}$ in the East China and Yellow seas, Geochim. Cosmochim. Acta, 55, 1265-1272, 1991. 
Piliposian, G.T., and P.G. Appleby, A model of the impact of winter ice cover on pollutant concentrations and fluxes in mountain lakes, Water, Air and Soil Pollution, 144 (1-4), 101-115, 2003.

Radenac, M.-H., and M. Rodier, Nitrate and chlorophyll distributions in relation to thermohaline and current structures in the western tropical Pacific during 19851989, Deep-Sea Res. II, 43 (4-6), 725-752, 1996.

Santschi, P.H., C.-C. Hung, G. Schultz, N. Alvarado-Quiroz, L. Guo, J. Pinckney, and I. Walsh, Control of acid polysaccharide production, and ${ }^{234} \mathrm{Th}$ and POC export fluxes by marine organisms, Geophysical Research Letters, 30 (2), 1044, doi:10.1029/2002GL016046, 2003.

Schlüter, M., E.J. Sauter, C.E. Andersen, H. Dahlgaard, and P.R. Dando, Spatial distribution and budget for submarine groundwater discharge in Eckernförde Bay (Western Baltic Sea), Limnol. Oceanogr., 49 (1), 157-167, 2004.

Spencer, D.W., M.P. Bacon, and P.G. Brewer, Models of the distribution of ${ }^{210} \mathrm{~Pb}$ in a section across the North Equatorial Atlantic Ocean, J. Mar. Res., 39 (1-4), 1981.

Stewart, G.M., and N.S. Fisher, Experimental studies on the accumulation of Polonium210 by marine phytoplankton, Limnol. Oceanogr., 48 (3), 1193-1201, 2003.

Urban, N.R., L. Xu, Y. Chai, and D.S. Apul, Sediment trap studies in Lake Superior: insight into resuspension, cross-margin transport and carbon cycling, J. Great Lakes Res., 30 (Supplement 1), 147-161, 2004.

Zhu, J., C. Chen, E. Ralph, S.A. Green, J.W. Budd, and F.Y. Zhang, Prognostic modeling studies of the Keweenaw Current in Lake Superior. Part II: simulation, J. Phys. Oceanogr., 31, 396-410, 2001. 


\section{List of Appendices}

I. Back calculation for isotope activities based on two point measurements.

II. Isotope activities (Chapter 2)

III. Sediment core data: porosity, bulk density and isotope activity (Chapter 3).

IV. ${ }^{40} \mathrm{~K}:{ }^{210} \mathrm{~Pb}$ ratios for all sediment cores (Chapter 3 ).

V. Geochronologies for sediment cores on each transect (Chapter 3).

VI. Estimated ${ }^{137} \mathrm{Cs}$ (and ${ }^{90} \mathrm{Sr}$ ) atmospheric deposition flux to Lake Superior (1950 1981).

VII. ${ }^{137}$ Cs activities and fluxes in 2000 sediment traps.

VIII. Laboratory procedures.

IX. Computer code (in Fortran) of the Niebauer model as modified for isotope modeling. 
Appendix - 1. Back calculation for isotope activities based on two point measurements

In this research, secular equilibrium is not assumed; rather the activities of ${ }^{210} \mathrm{Po}$ and ${ }^{210} \mathrm{~Pb}$ at the time of sampling were calculated based on the following equations.

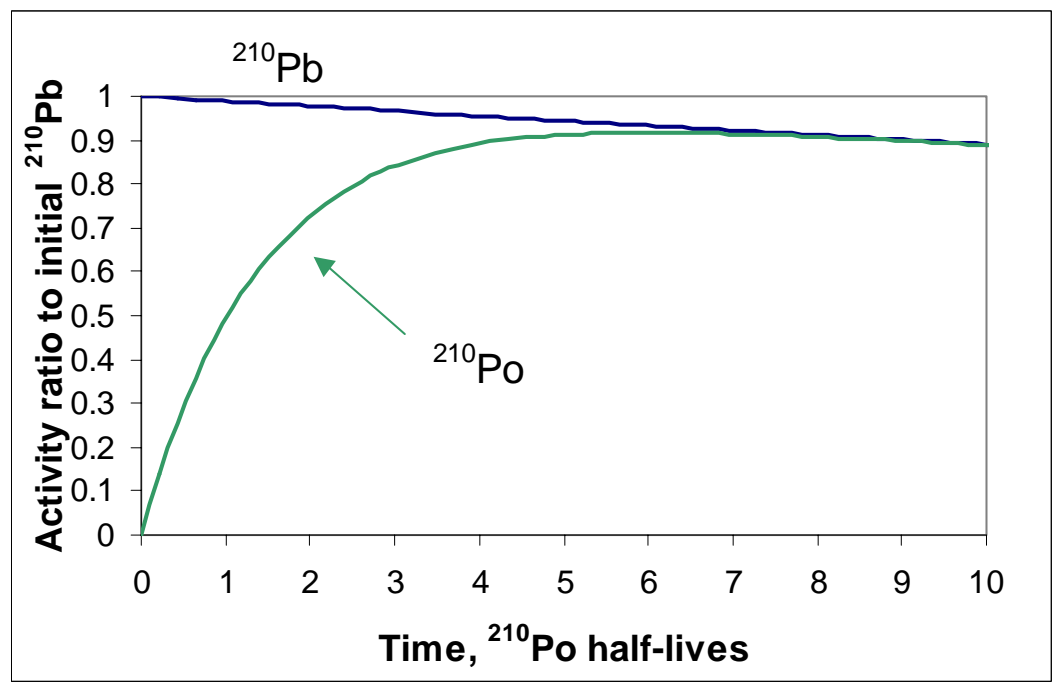

The plot of the approach to secular equilibrium (above) was generated from the equation:

$$
\frac{d[P o]}{d t}=-\lambda_{P_{0}}[P o]+\lambda_{P b}[P b]
$$

If the initial concentration of Po is zero, the analytical solution to equation 1 would be:

$$
\begin{aligned}
& {[P o]_{t}=\frac{\lambda_{P b}}{\lambda_{P b}-\lambda_{P o}} \cdot[P b]_{0}\left[\exp \left(-\lambda_{P b} \cdot t\right)-\exp \left(-\lambda_{P o} \cdot t\right)\right]} \\
& {[P b]_{t}=[P b]_{0} \exp \left(-\lambda_{P b} \cdot t\right)}
\end{aligned}
$$

When the initial concentration of Po is not zero, the solution is then:

$$
\begin{aligned}
& {[P o]_{t}=[P o]_{0} \exp \left(-\lambda_{P_{0}} \cdot t\right)+\frac{\lambda_{P b}}{\lambda_{P o}-\lambda_{P b}} \cdot[P b]_{0}\left[\exp \left(-\lambda_{P b} \cdot t\right)-\exp \left(-\lambda_{P o} \cdot t\right)\right]} \\
& {[P b]_{t}=[P b]_{0} \exp \left(-\lambda_{P b} \cdot t\right)}
\end{aligned}
$$

Equation 4 is the basis for back-calculation based on two measurements ([Po $]_{\mathrm{t} 1}$ and $[\mathrm{Po}]_{\mathrm{t} 2}$ ) at different times. When two sets of data ([Po] and t) are substituted into equation 4 , the results will be: 


$$
\begin{aligned}
& {[P b]_{0}=\left\{[P o]_{t_{2}} \cdot \frac{\lambda_{P o}-\lambda_{P b}}{\lambda_{P b}} \cdot \frac{1}{\exp \left(-\lambda_{P b} \cdot t_{2}\right)-\exp \left(-\lambda_{P o} \cdot t_{2}\right)}-[P o]_{t_{1}} \frac{\exp \left(-\lambda_{P_{0}} t_{2}\right)}{\exp \left(-\lambda_{P o} t_{1}\right)} \frac{\lambda_{P o}-\lambda_{P b}}{\lambda_{P b}} \cdot \frac{1}{\exp \left(-\lambda_{P b} \cdot t_{2}\right)-\exp \left(-\lambda_{P o} \cdot t_{2}\right)}\right\}\left\{1-\frac{\exp \left(-\lambda_{P b} t_{1}\right)-\exp \left(-\lambda_{P o} t_{1}\right)}{\exp \left(-\lambda_{P b} t_{2}\right)-\exp \left(-\lambda_{P o} t_{2}\right)} \cdot \exp \left(-\lambda_{P o} t_{2}\right)\right\}^{-1}} \\
& =\frac{[P o]_{t_{1}}-\frac{\lambda_{P b}}{\lambda_{P o}-\lambda_{P b}} \cdot[P b]_{0}\left(\exp \left(-\lambda_{P b} t_{1}\right)-\exp \left(-\lambda_{P o} t_{1}\right)\right)}{\lambda_{0}} \\
& \exp \left(-\lambda_{P_{0}} t_{1}\right)
\end{aligned}
$$

The calculations above are in terms of concentration (C) instead of activity (A). When activity is calculated from the relationship $A=C \cdot \lambda$, attention has to be paid to the unit conversions. 
Appendix - 2. Isotope activities (Chapter 2)

Table A-1: ${ }^{210} \mathrm{Po}$ and ${ }^{210} \mathrm{~Pb}$ activities for the TSP (total suspended particles) samples.

$\begin{array}{lcccccc}\text { Transect } & \text { Station } & \begin{array}{c}\text { Distance } \\ (\mathbf{k m})\end{array} & \begin{array}{c}\text { Depth } \\ \mathbf{( m )}\end{array} & \begin{array}{c}\text { Date } \\ \text { Activity }\end{array} \text { (dpm/100L) } \\ \text { EH } & 02 & 0.2 & 17.7 & 7 / 31 / 2000 & 1.48 & \text { Pb } \\ \text { EH } & 04 & 0.4 & 17.7 & 7 / 31 / 2000 & 2.38 & 6.14 \\ \text { HN } & 010 & 1 & 0 & 5 / 3 / 2000 & 2.25 & 3.02 \\ \text { HN } & 010 & 1 & 0 & 6 / 9 / 2000 & 2.43 & 4.05 \\ \text { HN } & 010 & 1 & 0 & 7 / 30 / 2000 & 1.50 & 4.06 \\ \text { HN } & 010 & 1 & 0 & 8 / 25 / 2000 & 0.39 & 3.50 \\ \text { HN } & 010 & 1 & 0 & 9 / 24 / 2000 & 2.13 & 4.26 \\ \text { HN } & 010 & 1 & 0 & 10 / 20 / 2000 & 1.20 & 5.55 \\ \text { HN } & 010 & 1 & 10 & 5 / 3 / 2000 & 2.06 & 4.93 \\ \text { HN } & 020 & 2 & 0 & 6 / 20 / 2000 & 2.54 & 9.21 \\ \text { HN } & 030 & 3 & 0 & 5 / 17 / 2000 & 2.37 & 4.04 \\ \text { HN } & 030 & 3 & 16 & 5 / 17 / 2000 & 1.77 & 5.99 \\ \text { HN } & 050 & 5 & 0 & 5 / 17 / 2000 & 2.58 & 3.67 \\ \text { HN } & 050 & 5 & 0 & 6 / 20 / 2000 & 2.20 & 6.01 \\ \text { HN } & 050 & 5 & 109 & 6 / 20 / 2000 & 2.38 & 5.00 \\ \text { HN } & 050 & 5 & 110 & 5 / 17 / 2000 & 2.79 & 5.28 \\ \text { HN } & 050 & 5 & 110 & 6 / 9 / 2000 & 4.15 & 5.98 \\ \text { HN } & 050 & 5 & 110 & 6 / 9 / 2000 & 4.34 & 7.15 \\ \text { HN } & 070 & 7 & 0 & 5 / 3 / 2000 & 2.00 & 3.00 \\ \text { HN } & 070 & 7 & 0 & 5 / 17 / 2000 & 2.29 & 3.67 \\ \text { HN } & 070 & 7 & 0 & 7 / 30 / 2000 & 1.02 & 4.53 \\ \text { HN } & 070 & 7 & 0 & 8 / 25 / 2000 & 0.65 & 3.13 \\ \text { HN } & 070 & 7 & 0 & 9 / 24 / 2000 & 0.96 & 5.89 \\ \text { HN } & 070 & 7 & 0 & 10 / 20 / 2000 & 1.25 & 5.06 \\ \text { HN } & 070 & 7 & 56 & 9 / 24 / 2000 & 1.04 & 3.92 \\ \text { HN } & 070 & 7 & 120 & 5 / 3 / 2000 & 2.68 & 4.08 \\ \text { HN } & 070 & 7 & 120 & 7 / 30 / 2000 & 2.66 & 4.61 \\ \text { HN } & 070 & 7 & 120 & 9 / 24 / 2000 & 3.06 & 4.10 \\ \text { HN } & 070 & 7 & 123 & 10 / 20 / 2000 & 1.74 & 3.47 \\ \text { HN } & 070 & 7 & 124 & 5 / 17 / 2000 & 2.80 & 4.80 \\ \text { HN } & 100 & 10 & 0 & 6 / 20 / 2000 & 2.30 & 4.43 \\ \text { HN } & 170 & 17 & 0 & 6 / 9 / 2000 & 2.21 & 4.68 \\ \text { HN } & 210 & 21 & 0 & 5 / 3 / 2000 & 1.66 & 3.12 \\ \text { HN } & 210 & 21 & 0 & 7 / 30 / 2000 & 1.39 & 4.77 \\ \text { HN } & 210 & 21 & 0 & 8 / 25 / 2000 & 0.95 & 2.70 \\ \text { HN } & 210 & 21 & 0 & 9 / 25 / 2000 & 0.62 & 5.62 \\ \text { HN } & 210 & 21 & 0 & 10 / 20 / 2000 & 1.64 & 4.91 \\ \text { HN } & 210 & 21 & 40 & 9 / 27 / 2000 & 0.68 & 3.87 \\ \text { HN } & 210 & 21 & 145 & 7 / 30 / 2000 & 2.75 & 4.45 \\ \text { HN } & 210 & 21 & 156 & 9 / 27 / 2000 & 1.62 & 2.45 \\ & & & & & & \end{array}$




$\begin{array}{ccccccc}\text { HN } & 210 & 21 & 158 & 5 / 3 / 2000 & 1.96 & 4.61 \\ \text { HN } & 210 & 21 & 158 & 10 / 20 / 2000 & 1.81 & 1.95 \\ \text { ON } & \text { river } & 0 & 0 & 5 / 2 / 2000 & 8.70 & 12.48 \\ \text { ON } & \text { River } & 0 & 0 & 5 / 2 / 2000 & 8.98 & 10.88 \\ \text { ON } & 000 & 0 & 2 & 5 / 2 / 2000 & 3.74 & 8.65 \\ \text { ON } & 005 & 0.5 & 0 & 6 / 19 / 2000 & 1.26 & 3.50 \\ \text { ON } & 010 & 1 & 0 & 7 / 28 / 2000 & 1.07 & 5.82 \\ \text { ON } & 010 & 1 & 0 & 8 / 23 / 2000 & 0.75 & 4.12 \\ \text { ON } & 010 & 1 & 0 & 9 / 25 / 2000 & 1.55 & 4.73 \\ \text { ON } & 010 & 1 & 0 & 10 / 21 / 2000 & 2.16 & 4.54 \\ \text { ON } & 050 & 5 & 18 & 6 / 10 / 2000 & 3.32 & 7.28 \\ \text { ON } & 050 & 5 & 27 & 7 / 28 / 2000 & 1.44 & 4.63 \\ \text { ON } & 050 & 5 & 28 & 6 / 19 / 2000 & 2.77 & 4.70 \\ \text { ON } & 070 & 7 & 0 & 8 / 23 / 2000 & 0.90 & 4.20 \\ \text { ON } & 070 & 7 & 0 & 9 / 25 / 2000 & 1.57 & 4.51 \\ \text { ON } & 070 & 7 & 32 & 8 / 23 / 2000 & 1.09 & 3.84 \\ \text { ON } & 070 & 7 & 32 & 8 / 23 / 2000 & 1.91 & 2.89 \\ \text { ON } & 070 & 7 & 46 & 8 / 23 / 2000 & 2.24 & 5.93 \\ \text { ON } & 070 & 7 & 49 & 9 / 25 / 2000 & 1.84 & 6.09 \\ \text { ON } & 090 & 9 & 0 & 10 / 21 / 2000 & 1.54 & 4.18 \\ \text { ON } & 090 & 9 & 66 & 10 / 21 / 2000 & 2.33 & 4.13 \\ \text { ON } & 210 & 21 & 0 & 7 / 28 / 2000 & 1.32 & 5.32 \\ \text { ON } & 210 & 21 & 0 & 9 / 25 / 2000 & 0.74 & 6.07 \\ \text { ON } & 210 & 21 & 30 & 8 / 23 / 2000 & 0.92 & 3.50 \\ \text { ON } & 210 & 21 & 30 & 9 / 25 / 2000 & 1.51 & 5.29 \\ \text { ON } & 210 & 21 & 136 & 9 / 25 / 2000 & 3.00 & 3.10 \\ \text { ON } & 210 & 21 & 136 & 10 / 21 / 2000 & 1.84 & 4.16 \\ \text { ON } & 210 & 21 & 137 & 8 / 23 / 2000 & 2.69 & 5.50\end{array}$

1: All the activity data (including the values in the table below) is back-calculated to the value at the sampling data according to the approach detailed in appendix -1 . 
Table A-2: ${ }^{210} \mathrm{Po}$ and ${ }^{210} \mathrm{~Pb}$ activities for the 2000 ponar samples.

$\begin{array}{lcccccc}\text { Transect } & \text { Station } & \begin{array}{c}\text { Distance } \\ (\mathbf{k m})\end{array} & \begin{array}{c}\text { Depth } \\ \mathbf{( m )}\end{array} & \text { Date } & \begin{array}{c}\text { Activity } \\ \mathbf{P o}\end{array} & \begin{array}{c}\text { (dpm/100L) } \\ \mathbf{P b}\end{array} \\ \text { HN } & 050 & 5 & 111 & 5 / 7 / 2000 & 8.41 & 8.90 \\ \text { HN } & 060 & 6 & 121 & 5 / 7 / 2000 & 3.53 & 4.13 \\ \text { HN } & 090 & 9 & 110 & 5 / 7 / 2000 & 3.73 & 4.07 \\ \text { HN } & 100 & 10 & 108 & 5 / 3 / 2000 & 2.48 & 2.51 \\ \text { HN } & 210 & 21 & 153 & 7 / 30 / 2000 & 4.96 & 5.19 \\ \text { ON } & 070 & 7 & 51 & 5 / 2 / 2000 & 6.08 & 6.32 \\ \text { ON } & 080 & 8 & 63 & 5 / 2 / 2000 & 2.31 & 3.21 \\ \text { ON } & 090 & 9 & 58 & 5 / 2 / 2000 & 2.22 & 1.97 \\ \text { EH } & 005 & 0.5 & 50 & 5 / 16 / 2000 & 10.61 & 9.68 \\ \text { EH } & 007 & 0.7 & 70 & 5 / 16 / 2000 & 10.01 & 10.87 \\ \text { EH } & 009 & 0.9 & 93 & 5 / 16 / 2000 & 10.21 & 12.72\end{array}$


Appendix - 3. Sediment core data: porosity, bulk density and isotope activity (Chapter 3).

$\begin{array}{rrr}\text { Core: } & \text { HN 050 (2001) } \\ \text { Date extruded: } & 7 / 26 / 2001 & \\ \text { Core diameter: } & 47 \mathrm{~mm}\end{array}$

Increment \# Top depth bottom depth Porosity Bulk Dens. Isotope Activities (dpm/g)

\begin{tabular}{|c|c|c|c|c|c|c|c|}
\hline & $(\mathrm{cm})$ & $(\mathrm{cm})$ & $(\%)$ & $(\mathrm{g} / \mathrm{cm} 3)$ & ${ }^{210} \mathrm{~Pb}$ & ${ }^{137} \mathrm{Cs}$ & ${ }^{40} \mathrm{~K}$ \\
\hline $0^{1}$ & \multicolumn{2}{|l|}{ fluff } & \multicolumn{2}{|c|}{$0.6350 \mathrm{~g}$} & 21.85 & 4.24 & 75.39 \\
\hline 1 & 0 & 0.5 & 32.4 & 1.00 & 6.51 & 2.30 & 35.52 \\
\hline 2 & 0.5 & 1 & 31.3 & 1.28 & 6.70 & 4.91 & 37.82 \\
\hline 3 & 1 & 1.5 & 29.4 & 1.79 & 5.83 & 4.69 & 38.75 \\
\hline 4 & 1.5 & 2 & 30.3 & 1.42 & 4.49 & 0.65 & 30.55 \\
\hline 5 & 2 & 2.5 & 31.9 & 1.55 & 4.43 & 0.33 & 37.75 \\
\hline 6 & 2.5 & 3 & 29.1 & 1.57 & & & \\
\hline 7 & 3 & 3.5 & 30.2 & 1.66 & & & \\
\hline 8 & 3.5 & 4 & 29.0 & 1.71 & & & \\
\hline 9 & 4 & 4.5 & 26.8 & 1.73 & & & \\
\hline 10 & 4.5 & 5 & 23.2 & 1.93 & & & \\
\hline 11 & 5 & 6 & 24.5 & 1.72 & 4.50 & 0.07 & 28.56 \\
\hline 12 & 6 & 7 & 24.0 & 1.66 & & & \\
\hline 13 & 7 & 8 & 26.0 & 1.61 & & & \\
\hline 14 & 8 & 9 & 23.0 & 1.78 & & & \\
\hline 15 & 9 & 10 & 25.4 & 1.68 & & & \\
\hline 16 & 10 & 12 & 21.8 & 1.78 & & & \\
\hline 17 & 12 & 14 & 19.7 & 1.73 & & & \\
\hline 18 & 14 & 15.5 & 18.5 & 1.59 & & & \\
\hline
\end{tabular}

${ }^{1}$ : For the fluff layer, only available data is mass (in $\left.\mathrm{g}\right)$. The accumulated mass $\left(\mathrm{g} / \mathrm{cm}^{2}\right)$ can be calculated based on the surface area of the core. All the cores with fluff fraction collected, this format will be used and will not be additionally footnoted.

Core: HN 060 (2001)

Date extruded: $\quad 11 / 27 / 01$

Core diameter: $\quad 47 \mathrm{~mm}$

\begin{tabular}{rrrrrrrr} 
Increment \# & $\begin{array}{c}\text { Top depth } \\
(\mathrm{cm})\end{array}$ & $\begin{array}{c}\text { bottom depth } \\
(\mathrm{cm})\end{array}$ & \multicolumn{2}{c}{$\begin{array}{c}\text { Porosity } \\
\%\end{array}$} & \multicolumn{2}{c}{$\begin{array}{c}\text { Bulk Den. } \\
\mathrm{g} / \mathrm{cm} 3\end{array}$} & \multicolumn{2}{c}{ Isotope Activities (dpm/g) } \\
& ${ }^{210} \mathrm{~Pb}$ & ${ }^{137} \mathrm{Cs}$ & ${ }^{40} \mathrm{~K}$ \\
\hline 1 & 0 & 0.5 & 41.3 & 1.61 & 5.75 & 1.13 & 32.05 \\
2 & 0.5 & 1 & 35.2 & 1.71 & 5.28 & 0.32 & 36.61 \\
3 & 1 & 1.5 & 30.0 & 2.07 & 4.87 & 0.14 & 29.56 \\
4 & 1.5 & 2 & 30.2 & 2.15 & 4.61 & 0.19 & 38.69 \\
5 & 2 & 2.5 & 28.1 & 2.28 & 5.09 & 0.05 & 38.51 \\
6 & 2.5 & 3 & 25.8 & 2.11 & 3.22 & 0.13 & 30.65 \\
7 & 3 & 3.5 & 25.1 & 2.37 & & & \\
8 & 3.5 & 4 & 24.6 & 2.30 & & & \\
9 & 4 & 4.5 & 22.5 & 2.50 & & &
\end{tabular}




$\begin{array}{rrrrrrrr}10 & 4.5 & 5 & 23.4 & 2.18 & & & \\ 11 & 5 & 6 & 21.8 & 2.29 & 4.12 & 0.03 & 32.14 \\ 12 & 6 & 7 & 20.7 & 2.26 & & & \\ 13 & 7 & 8 & 20.7 & 2.22 & & & \\ 14 & 8 & 9 & 20.9 & 1.97 & & \\ 15 & 9 & 10 & 21.3 & 2.37 & & & \end{array}$

Core: HN 070 (2001)

Date extruded: $\quad 7 / 30 / 01$

Core length: $\quad 23 \mathrm{~cm}$

Core diameter: $\quad 47 \mathrm{~mm}$

Increment \# Top depth bottom depth Porosity Bulk Den. Isotope Activities (dpm/g)

\begin{tabular}{|c|c|c|c|c|c|c|c|}
\hline & $(\mathrm{cm})$ & $(\mathrm{cm})$ & $\%$ & $\mathrm{~g} / \mathrm{cm}^{3}$ & ${ }^{210} \mathrm{~Pb}$ & ${ }^{137} \mathrm{Cs}$ & ${ }^{40} \mathrm{~K}$ \\
\hline 0 & \multicolumn{2}{|l|}{ fluff } & \multicolumn{2}{|c|}{$0.4241 \mathrm{~g}$} & 31.64 & 11.54 & 85.45 \\
\hline 1 & 0 & 0.5 & 37.9 & 0.58 & 10.05 & 7.24 & 35.95 \\
\hline 2 & 0.5 & 1 & 24.4 & 2.37 & 8.55 & 5.02 & 47.77 \\
\hline 3 & 1 & 1.5 & 38.0 & 1.23 & 5.19 & 1.33 & 23.91 \\
\hline 4 & 1.5 & 2 & 34.9 & 1.59 & 3.94 & 1.10 & 34.44 \\
\hline 5 & 2 & 2.5 & 30.9 & 1.59 & 4.53 & 0.43 & 34.77 \\
\hline 6 & 2.5 & 3 & 31.4 & 1.75 & 4.12 & & 32.13 \\
\hline 7 & 3 & 3.5 & 29.6 & 1.81 & & & \\
\hline 8 & 3.5 & 4 & 27.8 & 1.67 & & & \\
\hline 9 & 4 & 4.5 & 25.0 & 1.99 & & & \\
\hline 10 & 4.5 & 5 & 27.1 & 1.72 & & & \\
\hline 11 & 5 & 6 & 26.9 & 1.80 & 4.35 & 0.19 & 30.56 \\
\hline 12 & 6 & 7 & 26.6 & 1.69 & & & \\
\hline 13 & 7 & 8 & 26.9 & 1.75 & & & \\
\hline 14 & 8 & 9 & 24.3 & 2.01 & & & \\
\hline 15 & 9 & 10 & 21.5 & 1.89 & & & \\
\hline 16 & 10 & 11 & 22.0 & 1.86 & & & \\
\hline 17 & 11 & 12 & 18.0 & 2.04 & & & \\
\hline 18 & 12 & 13 & 23.2 & 1.81 & & & \\
\hline 19 & 13 & 14 & 22.6 & 1.99 & & & \\
\hline 20 & 14 & 15 & 23.9 & 1.75 & & & \\
\hline 21 & 15 & 17 & 23.9 & 1.63 & & & \\
\hline
\end{tabular}

Core: $\quad$ HN 080 (2001)

Date extruded: 11/08/01

Core length: $\quad 10 \mathrm{~cm}$

Core diameter: $\quad 47 \mathrm{~mm}$

Increment \# Top depth bottom depth Porosity Bulk Den. Isotope Activities (dpm/g)

\begin{tabular}{rrrrrrrr} 
& $(\mathrm{cm})$ & $(\mathrm{cm})$ & $\%$ & $\mathrm{~g} / \mathrm{cm}^{3}$ & ${ }^{210} \mathrm{~Pb}$ & ${ }^{137} \mathrm{Cs}$ & ${ }^{40} \mathrm{~K}$ \\
\hline 1 & 0 & 0.5 & 53.1 & 1.22 & 4.49 & 0.45 & 25.72 \\
2 & 0.5 & 1 & 40.3 & 1.35 & 4.58 & 0.16 & 28.81 \\
3 & 1 & 1.5 & 37.1 & 1.41 & 4.03 & 0.34 & 21.74
\end{tabular}




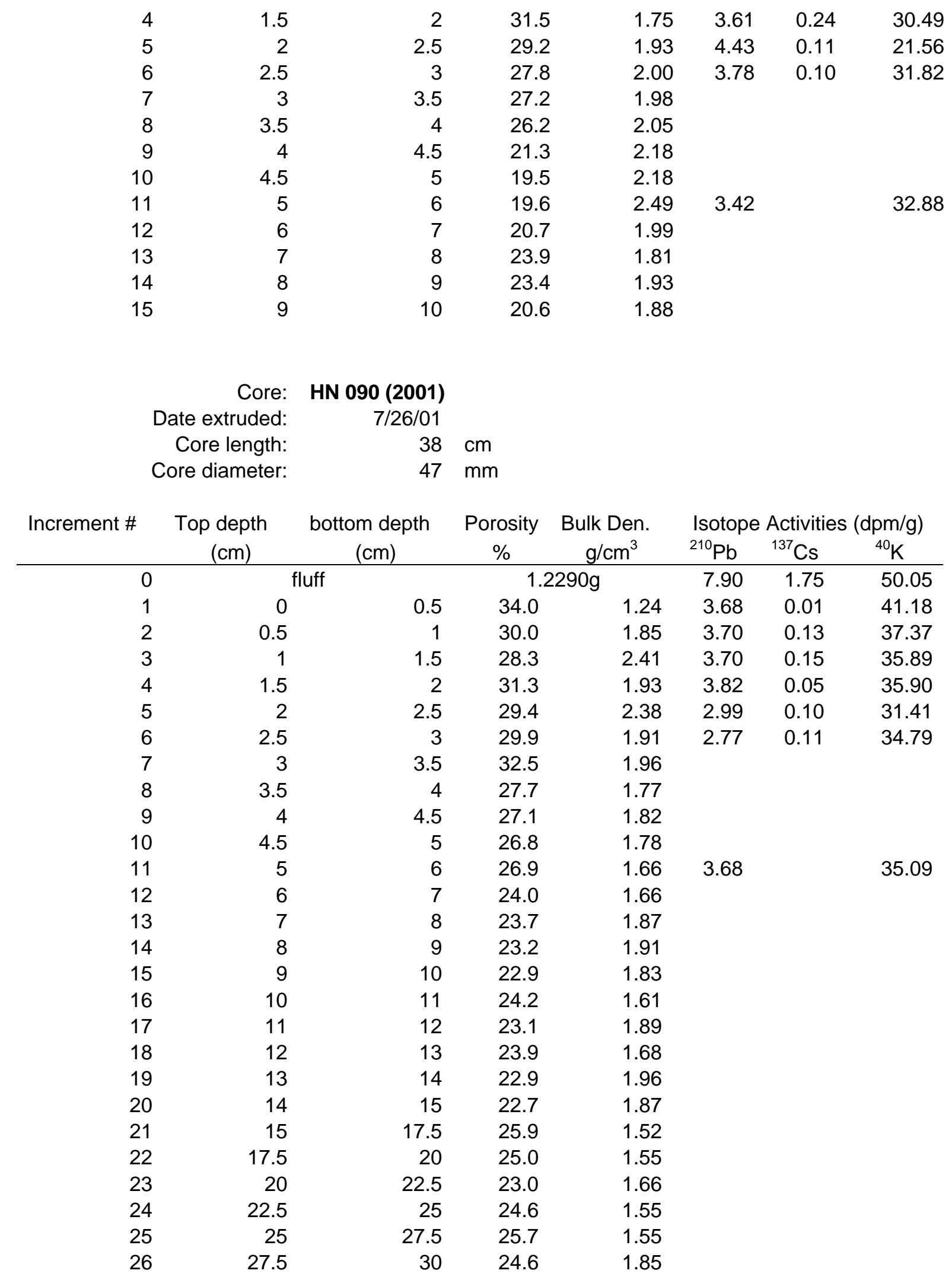




\section{Core: HN 100 (2001)}

$\begin{array}{rrr}\text { Date extruded: } & 11 / 29 / 01 & \\ \text { Core length: } & 51 \mathrm{~cm} \\ \text { Core diameter: } & 47 \mathrm{~mm}\end{array}$

Increment \# Top depth bottom depth Porosity Bulk Den. Isotope Activities (dpm/g)

\begin{tabular}{|c|c|c|c|c|c|c|c|}
\hline & $(\mathrm{cm})$ & $(\mathrm{cm})$ & $\%$ & $\mathrm{~g} / \mathrm{cm}^{3}$ & ${ }^{210} \mathrm{~Pb}$ & ${ }^{137} \mathrm{Cs}$ & ${ }^{40} \mathrm{~K}$ \\
\hline 1 & 0 & 0.5 & 51.5 & 0.95 & 9.47 & 3.75 & 37.61 \\
\hline 2 & 0.5 & 1 & 41.1 & 1.43 & 3.16 & 0.83 & 32.30 \\
\hline 3 & 1 & 1.5 & 37.4 & 1.58 & 3.12 & 0.02 & 34.97 \\
\hline 4 & 1.5 & 2 & 36.0 & 1.75 & 3.03 & 0.06 & 29.53 \\
\hline 5 & 2 & 2.5 & 36.3 & 1.86 & 3.00 & 0.01 & 34.38 \\
\hline 6 & 2.5 & 3 & 37.0 & 1.60 & & & \\
\hline 7 & 3 & 3.5 & 37.0 & 1.64 & & & \\
\hline 8 & 3.5 & 4 & 36.2 & 1.63 & & & \\
\hline 9 & 4 & 4.5 & 35.2 & 1.77 & & & \\
\hline 10 & 4.5 & 5 & 37.5 & 1.81 & & & \\
\hline 11 & 5 & 6 & 34.3 & 1.38 & 3.68 & & 34.68 \\
\hline 12 & 6 & 7 & 31.3 & 1.65 & & & \\
\hline 13 & 7 & 8 & 31.9 & 1.60 & & & \\
\hline 14 & 8 & 9 & 29.4 & 1.62 & & & \\
\hline 15 & 9 & 10 & 28.6 & 1.75 & & & \\
\hline
\end{tabular}

Core: HN 130 (2001)

Date extruded: $\quad 8 / 02 / 01$

Core length: $\quad 60 \mathrm{~cm}$

Core diameter: $\quad 47 \mathrm{~mm}$

Increment \# Top depth bottom depth Porosity Bulk Den. Isotope Activities $(\mathrm{dpm} / \mathrm{g})$

\begin{tabular}{|c|c|c|c|c|c|c|c|}
\hline & $(\mathrm{cm})$ & $(\mathrm{cm})$ & $\%$ & $\mathrm{~g} / \mathrm{cm}^{3}$ & ${ }^{210} \mathrm{~Pb}$ & ${ }^{137} \mathrm{Cs}$ & ${ }^{40} \mathrm{~K}$ \\
\hline 0 & fluff & & 0.5 & & 12.32 & 3.04 & 93.08 \\
\hline 1 & 0 & 0.5 & 42.8 & 1.13 & 4.17 & 0.53 & 40.94 \\
\hline 2 & 0.5 & 1 & 40.8 & 1.53 & 3.97 & 0.51 & 35.41 \\
\hline 3 & 1 & 1.5 & 36.9 & 1.52 & 4.97 & 0.21 & 43.02 \\
\hline 4 & 1.5 & 2 & 32.6 & 1.96 & 3.72 & 0.13 & 34.40 \\
\hline 5 & 2 & 2.5 & 32.6 & 2.07 & 3.45 & 0.00 & 31.09 \\
\hline 6 & 2.5 & 3 & 34.5 & 1.83 & & & \\
\hline 7 & 3 & 3.5 & 40.9 & 1.26 & & & \\
\hline 8 & 3.5 & 4 & 49.6 & 1.13 & & & \\
\hline 9 & 4 & 4.5 & 43.0 & 1.31 & & & \\
\hline 10 & 4.5 & 5 & 43.4 & 1.30 & & & \\
\hline 11 & 5 & 6 & 43.3 & 1.17 & 3.36 & & 40.99 \\
\hline 12 & 6 & 7 & 44.4 & 1.15 & & & \\
\hline 13 & 7 & 8 & 50.8 & 0.87 & & & \\
\hline 14 & 8 & 9 & 52.4 & 0.80 & & & \\
\hline 15 & 9 & 10 & 50.0 & 0.92 & & & \\
\hline 16 & 10 & 11 & 53.1 & 0.80 & & & \\
\hline
\end{tabular}




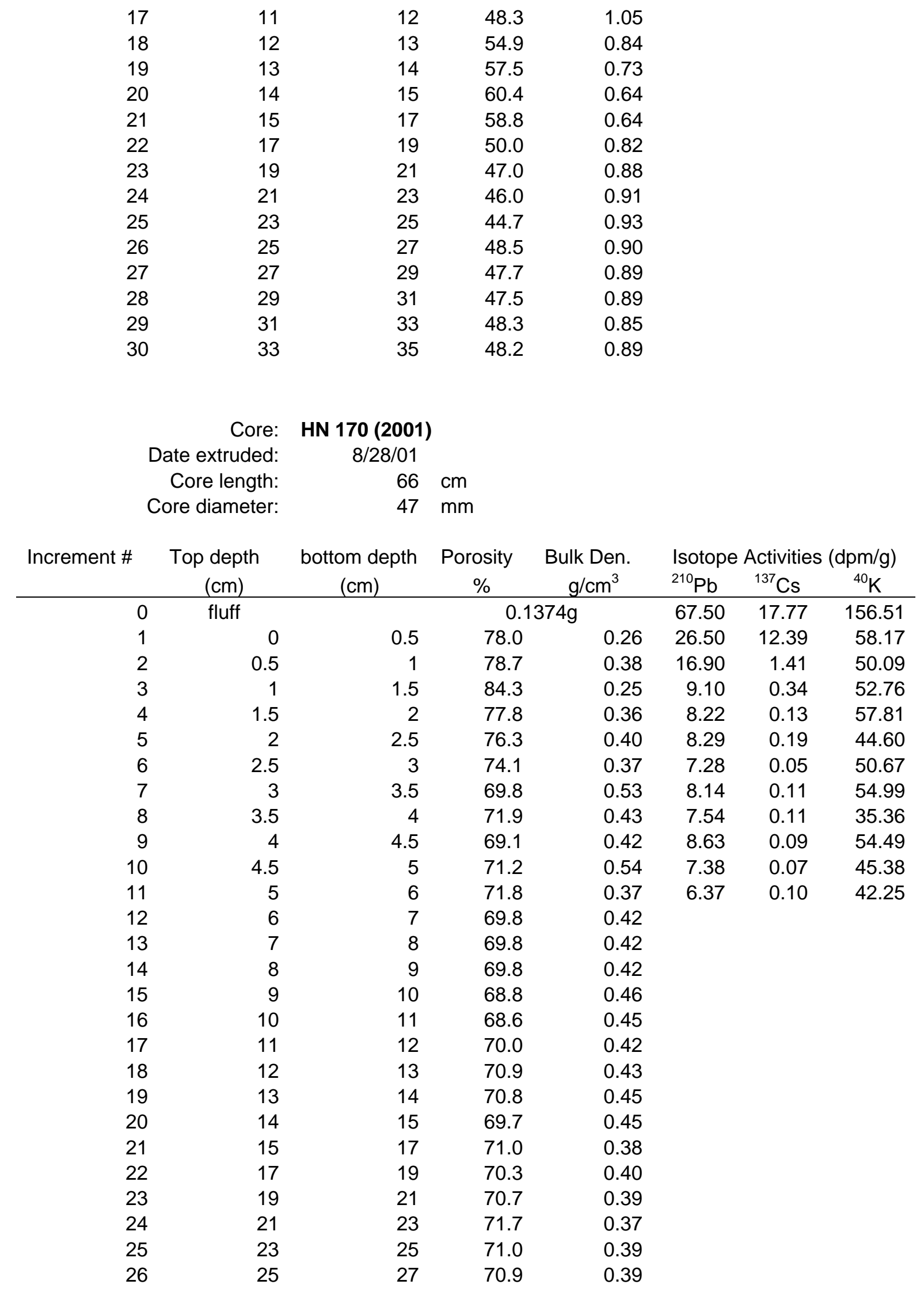




$\begin{array}{lllll}27 & 27 & 29 & 71.5 & 0.37 \\ 28 & 29 & 31 & 70.4 & 0.42 \\ 29 & 31 & 33 & 71.2 & 0.38 \\ 30 & 33 & 35 & 70.8 & 0.40 \\ 31 & 35 & 37 & 69.0 & 0.42 \\ 32 & 37 & 39 & 68.7 & 0.44 \\ 33 & 39 & 41 & 68.6 & 0.44 \\ 34 & 41 & 43 & 69.3 & 0.43 \\ 35 & 43 & 45 & 69.3 & 0.41 \\ 36 & 45 & 47 & 69.1 & 0.43\end{array}$

Core: HN 210 (2001)

Date extruded: $\quad 8 / 08 / 01$

Core length: $\quad 66 \mathrm{~cm}$

Core diameter: $\quad 47 \mathrm{~mm}$

Increment \# Top depth bottom depth Porosity Bulk Den. Isotope Activities (dpm/g)

\begin{tabular}{rrrrrrrr} 
& $(\mathrm{cm})$ & $(\mathrm{cm})$ & \multicolumn{1}{c}{$\%$} & $\mathrm{~g} / \mathrm{cm}^{3}$ & ${ }^{210} \mathrm{~Pb}$ & ${ }^{137} \mathrm{Cs}$ & ${ }^{40} \mathrm{~K}$ \\
\hline 0 & fluff & & $1.6457 \mathrm{~g}$ & & 45.28 & 21.76 & 57.86 \\
1 & 0 & 0.5 & 84.8 & 0.28 & 41.80 & 22.14 & 52.47 \\
2 & 0.5 & 1.1 & 83.8 & 0.23 & 42.75 & 22.29 & 50.40 \\
3 & 1.1 & 1.6 & 79.4 & 0.36 & 29.59 & 18.63 & 49.24 \\
4 & 1.6 & 2.1 & 72.0 & 0.54 & 23.93 & 11.06 & 44.29 \\
5 & 2.1 & 2.6 & 67.4 & 0.66 & 10.47 & 4.25 & 42.54 \\
6 & 2.6 & 3.1 & 62.0 & 0.66 & 8.59 & 1.56 & 43.96 \\
7 & 3.1 & 3.6 & 58.0 & 0.88 & 7.64 & 0.71 & 46.24 \\
8 & 3.6 & 4.1 & 51.8 & 1.05 & 6.60 & 0.60 & 46.79 \\
9 & 4.1 & 4.6 & 51.0 & 1.08 & & & \\
10 & 4.6 & 5.1 & 49.0 & 0.97 & & & \\
11 & 5.1 & 6.1 & 46.6 & 1.04 & 5.56 & 0.40 & 35.69 \\
12 & 6.1 & 7.1 & 49.8 & 0.90 & & & \\
13 & 7.1 & 8.1 & 57.1 & 0.76 & & & \\
14 & 8.1 & 9.1 & 57.5 & 0.72 & & & \\
15 & 9.1 & 10.1 & 55.9 & 0.78 & & & \\
16 & 10.1 & 11.1 & 60.9 & 0.68 & & & \\
17 & 11.1 & 12.1 & 64.0 & 0.57 & & & \\
18 & 12.1 & 13.1 & 62.4 & 0.60 & & & \\
19 & 13.1 & 14.1 & 60.7 & 0.65 & & & \\
20 & 14.1 & 15.1 & 65.0 & 0.60 & & & \\
21 & 15.1 & 17.1 & 67.1 & 0.47 & & & \\
22 & 17.1 & 19.1 & 55.4 & 0.70 & & & \\
23 & 19.1 & 21.1 & 47.0 & 0.91 & & & \\
24 & 21.1 & 23.1 & 50.2 & 0.84 & & & \\
25 & 23.1 & 25.1 & 51.2 & 0.80 & & & \\
26 & 25.1 & 27.4 & 41.0 & 1.06 & & & \\
27 & 27.4 & 29.4 & 53.2 & 0.75 & & &
\end{tabular}




\begin{tabular}{|c|c|c|c|c|c|c|c|}
\hline \multirow[b]{2}{*}{ Increment \# } & $\begin{array}{l}\text { Date extruded: } \\
\text { Core length: } \\
\text { Core diameter: }\end{array}$ & $\begin{array}{r}\text { HN } 050 \text { (2002) } \\
6 / 19 / 02 \\
15 \\
47\end{array}$ & $\begin{array}{l}\mathrm{cm} \\
\mathrm{mm}\end{array}$ & & \multirow{2}{*}{\multicolumn{3}{|c|}{ Isotope Activities (dpm/g) }} \\
\hline & $\begin{array}{l}\text { Top depth } \\
\text { (cm) }\end{array}$ & $\begin{array}{c}\text { bottom depth } \\
(\mathrm{cm})\end{array}$ & $\begin{array}{c}\text { Porosity } \\
\% \\
\end{array}$ & $\begin{array}{c}\text { Bulk Den. } \\
\mathrm{g} / \mathrm{cm}^{3}\end{array}$ & & & \\
\hline 0 & & uff & & $963 g$ & 5.80 & 1.63 & 53.50 \\
\hline 1 & 0 & 0.5 & 49.1 & 1.15 & 3.19 & 0.73 & 33.42 \\
\hline 2 & 0.5 & 1 & 28.9 & 1.68 & 3.89 & 0.92 & 37.61 \\
\hline 3 & 1 & 1.5 & 28.5 & 1.73 & 3.61 & 1.50 & 33.63 \\
\hline 4 & 1.5 & 2 & 27.1 & 1.51 & 3.06 & 2.60 & 33.26 \\
\hline 5 & 2 & 2.5 & 29.5 & 1.52 & 2.84 & 2.54 & 33.22 \\
\hline 6 & 2.5 & 3 & 34.7 & 1.34 & 3.07 & 1.06 & 33.73 \\
\hline 7 & 3 & 3.5 & 29.3 & 1.89 & 3.48 & 0.12 & 31.67 \\
\hline 8 & 3.5 & 4 & 28.6 & 2.06 & 1.98 & 0.06 & 33.33 \\
\hline 9 & 4 & 4.5 & 33.9 & 1.55 & & & \\
\hline 10 & 4.5 & 5 & 27.4 & 1.69 & & & \\
\hline 11 & 5 & 6 & 26.0 & 1.86 & 3.91 & 0.08 & 34.19 \\
\hline 12 & 6 & 7 & 24.0 & 1.52 & & & \\
\hline 13 & 7 & 8 & 24.2 & 1.93 & & & \\
\hline 14 & 8 & 9 & 24.3 & 1.63 & & & \\
\hline 15 & 9 & 10 & 25.1 & 1.72 & & & \\
\hline 16 & 10 & 11 & 24.2 & 1.79 & & & \\
\hline 17 & 11 & 12 & 25.5 & 1.53 & & & \\
\hline 18 & 12 & 13 & 24.3 & 1.76 & & & \\
\hline 19 & 13 & 14 & 22.7 & 2.06 & & & \\
\hline 20 & 14 & 15.2 & 22.9 & 1.44 & & & \\
\hline
\end{tabular}

Core: HN 070 (2002)

Date extruded: $\quad$ 6/13/02

Core length: $\quad 15 \mathrm{~cm}$

Core diameter: $\quad 47 \mathrm{~mm}$

Increment \# Top depth bottom depth Porosity Bulk Den. Isotope Activities (dpm/g)

\begin{tabular}{|c|c|c|c|c|c|c|c|}
\hline \multicolumn{2}{|c|}{$(\mathrm{cm})$} & \multirow[t]{2}{*}{$(\mathrm{cm})$} & \multirow[t]{2}{*}{$\%$} & $\mathrm{~g} / \mathrm{cm}^{3}$ & \multirow{2}{*}{$\frac{{ }^{210} \mathrm{~Pb}}{13.7}$} & \multirow{2}{*}{$\begin{array}{r}{ }^{137} \mathrm{Cs} \\
2.4\end{array}$} & \multirow{2}{*}{$\frac{{ }^{40} \mathrm{~K}}{56.0}$} \\
\hline 0 & fluff & & & & & & \\
\hline 1 & 0 & 0.5 & 35.6 & 1.40 & 9.1 & 1.2 & 30.6 \\
\hline 2 & 0.5 & 1 & 32.1 & 1.71 & 7.1 & 3.3 & 34.3 \\
\hline 3 & 1 & 1.5 & 38.9 & 1.36 & 2.0 & 0.3 & 31.0 \\
\hline 4 & 1.5 & 2 & 27.8 & 1.79 & 2.0 & 0.1 & 34.7 \\
\hline 5 & 2 & 2.5 & 28.7 & 1.30 & 2.3 & 0.2 & 37.8 \\
\hline 6 & 2.5 & 3 & 30.6 & 1.29 & & & \\
\hline 7 & 3 & 3.5 & 27.7 & 1.67 & & & \\
\hline 8 & 3.5 & 4 & 27.6 & 1.61 & & & \\
\hline 9 & 4 & 4.5 & 21.1 & 2.22 & & & \\
\hline 10 & 4.5 & 5 & 20.4 & 2.04 & & & \\
\hline 11 & 5 & 6 & 23.0 & 1.80 & & & \\
\hline 12 & 6 & 7 & 24.5 & 1.71 & & & \\
\hline
\end{tabular}




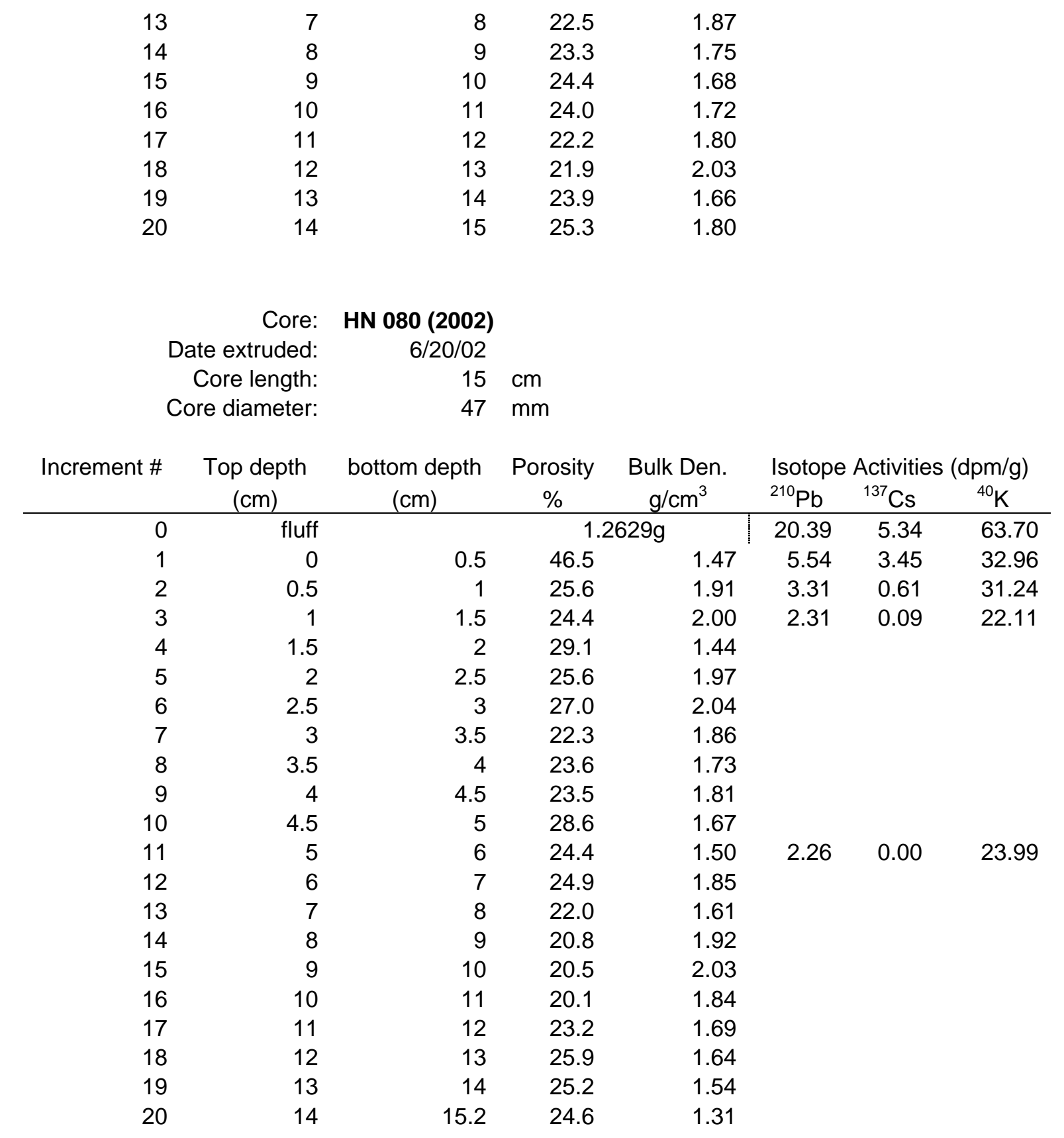

Core: HN 090 (2002)
Date extruded: $\quad 6 / 14 / 02$
Core length: $\quad 15 \mathrm{~cm}$
Core diameter: $\quad 47 \mathrm{~mm}$

Increment \# Top depth bottom depth Porosity Bulk Den. Isotope Activities (dpm/g)

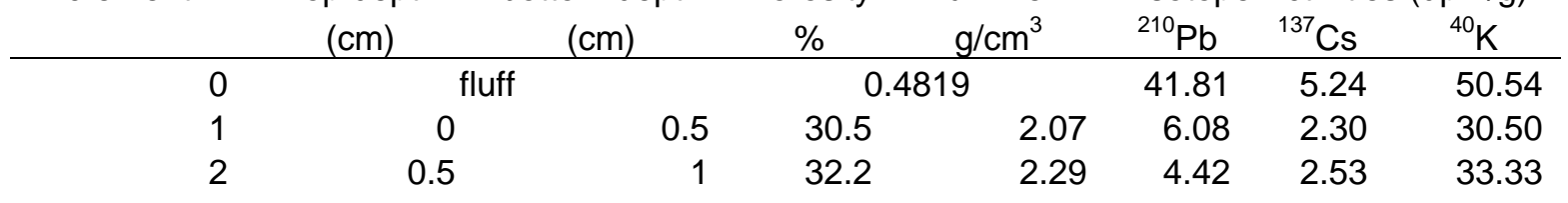




$\begin{array}{rrrrrrrr}3 & 1 & 1.5 & 30.2 & 2.05 & 4.16 & 0.16 & 25.95 \\ 4 & 1.5 & 2 & 24.5 & 2.63 & 3.17 & 0.15 & 32.39 \\ 5 & 2 & 2.5 & 26.0 & 2.47 & 3.32 & 0.10 & 34.09 \\ 6 & 2.5 & 3 & 23.6 & 2.67 & & & \\ 7 & 3 & 3.5 & 24.1 & 2.89 & & & \\ 8 & 3.5 & 4 & 26.3 & 2.62 & & \\ 9 & 4 & 4.5 & 26.7 & 1.95 & & \\ 10 & 4.5 & 5 & 24.2 & 2.31 & & \\ 11 & 5 & 6 & 42.8 & 1.25 & \\ 12 & 6 & 7 & 48.7 & 0.87 & \\ 13 & 7 & 8 & 49.5 & 0.94 & \\ 14 & 8 & 9 & 50.0 & 1.04 & \\ 15 & 9 & 10 & 35.3 & 1.39 & & \\ 16 & 10 & 11 & 25.2 & 1.66 & & \\ 17 & 11 & 12 & 27.3 & 1.60 & & \\ 18 & 12 & 13 & 37.4 & 1.17 & & \\ 19 & 13 & 14 & 41.4 & 1.32 & & \\ 20 & 14 & 15 & 27.3 & 3.14 & & \end{array}$

$\begin{array}{rrl}\text { Core: } & \text { HN } \mathbf{1 0 0} \mathbf{( 2 0 0 2 )} & \\ \text { Date } & & \\ \text { extruded: } & 6 / 21 / 02 & \\ \text { Core length: } & 15 & \mathrm{~cm} \\ \text { Core diameter: } & 47 \mathrm{~mm}\end{array}$

\begin{tabular}{|c|c|c|c|c|c|c|c|}
\hline \multirow[t]{2}{*}{ Increment \# } & \multirow{2}{*}{$\begin{array}{l}\text { Top depth } \\
(\mathrm{cm})\end{array}$} & \multirow{2}{*}{$\begin{array}{l}\text { bottom depth } \\
(\mathrm{cm})\end{array}$} & \multirow{2}{*}{$\begin{array}{c}\text { Porosity } \\
\%\end{array}$} & \multirow{2}{*}{$\begin{array}{l}\text { Bulk Den. } \\
\mathrm{g} / \mathrm{cm}^{3}\end{array}$} & \multicolumn{3}{|c|}{$\begin{array}{l}\text { Isotope Activities } \\
(\mathrm{dpm} / \mathrm{g})\end{array}$} \\
\hline & & & & & ${ }^{210} \mathrm{~Pb}$ & ${ }^{137} \mathrm{Cs}$ & ${ }^{40} \mathrm{~K}$ \\
\hline 0 & & uff & & $42 \mathrm{~g}$ & 14.17 & 3.82 & 63.98 \\
\hline 1 & 0 & 0.5 & 40.2 & 1.97 & 3.88 & 0.63 & 27.52 \\
\hline 2 & 0.5 & 1 & 29.6 & 2.45 & 4.40 & 0.07 & 31.39 \\
\hline 3 & 1 & 1.5 & 36.8 & 1.57 & 3.63 & 0.14 & 30.83 \\
\hline 4 & 1.5 & 2 & 32.3 & 1.71 & & & \\
\hline 5 & 2 & 2.5 & 30.6 & 1.76 & & & \\
\hline 6 & 2.5 & 3 & 42.9 & 1.28 & & & \\
\hline 7 & 3 & 3.5 & 51.9 & 0.94 & & & \\
\hline 8 & 3.5 & 4 & 53.4 & 0.84 & & & \\
\hline 9 & 4 & 4.5 & 51.2 & 0.79 & & & \\
\hline 10 & 4.5 & 5 & 51.2 & 0.93 & & & \\
\hline 11 & 5 & 6 & 51.4 & 0.79 & 5.01 & 0.17 & 55.48 \\
\hline 12 & 6 & 7 & 50.4 & 0.86 & & & \\
\hline 13 & 7 & 8 & 51.1 & 0.73 & & & \\
\hline 14 & 8 & 9 & 52.4 & 0.80 & & & \\
\hline 15 & 9 & 10 & 54.6 & 0.72 & & & \\
\hline 16 & 10 & 11 & 53.9 & 0.66 & & & \\
\hline 17 & 11 & 12 & 54.8 & 0.62 & & & \\
\hline 18 & 12 & 13 & 51.8 & 0.82 & & & \\
\hline 19 & 13 & 14 & 53.1 & 0.69 & & & \\
\hline 20 & 14 & 15 & 54.1 & 0.61 & & & \\
\hline
\end{tabular}




\section{Core: HN 130 (2002)}

Date extruded: $\quad 6 / 26 / 02$

Core length: $\quad 15 \mathrm{~cm}$

Core diameter: $\quad 47 \mathrm{~mm}$

\begin{tabular}{|c|c|c|c|c|c|c|c|}
\hline \multirow[t]{2}{*}{ Increment \# } & Top depth & bottom depth & Porosity & Bulk Den. & \multicolumn{3}{|c|}{ Isotope Activities (dpm/g) } \\
\hline & $(\mathrm{cm})$ & $(\mathrm{cm})$ & $\%$ & $\mathrm{~g} / \mathrm{cm}^{3}$ & ${ }^{210} \mathrm{~Pb}$ & ${ }^{137} \mathrm{Cs}$ & ${ }^{40} \mathrm{~K}$ \\
\hline 0 & \multicolumn{2}{|c|}{ fluff } & \multicolumn{2}{|c|}{$0.6369 \mathrm{~g}$} & 32.32 & 9.31 & 65.93 \\
\hline 1 & 0 & 0.5 & 50.4 & 1.22 & 6.76 & 1.53 & 33.19 \\
\hline 2 & 0.5 & 1 & 41.7 & 1.09 & 5.15 & 0.20 & 34.89 \\
\hline 3 & 1 & 1.5 & 38.0 & 1.15 & 4.46 & 0.18 & 39.79 \\
\hline 4 & 1.5 & 2 & 36.5 & 1.21 & & & \\
\hline 5 & 2 & 2.5 & 41.1 & 1.26 & & & \\
\hline 6 & 2.5 & 3 & 36.1 & 1.17 & & & \\
\hline 7 & 3 & 3.5 & 26.7 & 1.63 & & & \\
\hline 8 & 3.5 & 4 & 34.7 & 1.47 & & & \\
\hline 9 & 4 & 4.5 & 27.5 & 1.41 & & & \\
\hline 10 & 4.5 & 5 & 32.1 & 1.83 & & & \\
\hline 11 & 5 & 6 & 47.8 & 1.00 & 4.64 & 0.05 & 42.07 \\
\hline 12 & 6 & 7 & 49.3 & 0.88 & & & \\
\hline 13 & 7 & 8 & 52.5 & 0.81 & & & \\
\hline 14 & 8 & 9 & 48.0 & 0.96 & & & \\
\hline 15 & 9 & 10 & 48.4 & 1.00 & & & \\
\hline 16 & 10 & 11 & 43.4 & 1.10 & & & \\
\hline 17 & 11 & 12 & 35.4 & 1.53 & & & \\
\hline 18 & 12 & 13 & 33.8 & 1.48 & & & \\
\hline 19 & 13 & 14 & 44.7 & 1.10 & & & \\
\hline 20 & 14 & 15 & 58.3 & 0.59 & & & \\
\hline
\end{tabular}

Core: HN 170 (2002)

Date extruded: $\quad 6 / 26 / 02$

Core length: $\quad 10 \mathrm{~cm}$

Core diameter: $\quad 47 \mathrm{~mm}$

Increment \# Top depth bottom depth Porosity Bulk Den. Isotope Activities (dpm/g)

\begin{tabular}{rrrlrrrr} 
& $(\mathrm{cm})$ & $(\mathrm{cm})$ & $\%$ & $\mathrm{~g} / \mathrm{cm}^{3}$ & ${ }^{210} \mathrm{~Pb}$ & ${ }^{137} \mathrm{Cs}$ & ${ }^{40} \mathrm{~K}$ \\
\hline 0 & fluff & & $1.7351 \mathrm{~g}$ & & 66.93 & 33.91 & 66.25 \\
1 & 0 & 0.5 & 88.7 & 0.17 & 63.02 & 29.17 & 57.27 \\
2 & 0.5 & 1 & 85.3 & 0.24 & 64.44 & 27.45 & 67.94 \\
3 & 1 & 1.5 & 84.3 & 0.24 & 71.32 & 25.89 & 71.49 \\
4 & 1.5 & 2 & 83.6 & 0.24 & 53.21 & 21.19 & 52.71 \\
5 & 2 & 2.5 & 82.7 & 0.22 & 61.66 & 16.71 & 50.32 \\
6 & 2.5 & 3 & 79.6 & 0.27 & 44.63 & 28.76 & 62.86 \\
7 & 3 & 3.5 & 75.8 & 0.38 & 17.95 & 11.12 & 63.35 \\
8 & 3.5 & 4 & 74.9 & 0.38 & 8.27 & 0.61 & 67.99 \\
9 & 4 & 4.5 & 75.6 & 0.37 & 6.62 & 0.71 & 66.22 \\
10 & 4.5 & 5 & 74.1 & 0.40 & 4.50 & 0.19 & 58.14 \\
11 & 5 & 6 & 76.2 & 0.35 & 4.78 & 0.30 & 53.01 \\
12 & 6 & 7 & 77.3 & 0.30 & & &
\end{tabular}




$\begin{array}{lllll}13 & 7 & 8 & 73.9 & 0.37 \\ 14 & 8 & 9 & 72.2 & 0.45\end{array}$

$\begin{array}{rr}\text { Core: } & \text { HN 210 (2002) } \\ \text { Date extruded: } & 6 / 18 / 02 \\ \text { Core length: } & 15 \mathrm{~cm} \\ \text { Core diameter: } & 47 \mathrm{~mm}\end{array}$

Increment \# Top depth bottom depth Porosity Bulk Den. Isotope Activities (dpm/g)

\begin{tabular}{rrrrrrrr} 
& $(\mathrm{cm})$ & $(\mathrm{cm})$ & \multicolumn{1}{c}{$\%$} & $\mathrm{~g} / \mathrm{cm}^{3}$ & ${ }^{210} \mathrm{~Pb}$ & ${ }^{137} \mathrm{Cs}$ & \multicolumn{1}{c}{$\mathrm{K}$} \\
\hline 0 & fluff & & $1.1092 \mathrm{~g}$ & & 41.77 & 25.77 & 38.03 \\
1 & 0 & 0.5 & 70.1 & 0.57 & 10.42 & 5.57 & 45.04 \\
2 & 0.5 & 1 & 55.9 & 0.77 & 5.87 & 0.46 & 37.31 \\
3 & 1 & 1.5 & 56.9 & 0.77 & 2.97 & 0.16 & 45.25 \\
4 & 1.5 & 2 & 53.2 & 0.76 & 3.60 & 0.15 & 40.82 \\
5 & 2 & 2.5 & 56.1 & 0.77 & & & \\
6 & 2.5 & 3 & 51.4 & 0.83 & & & \\
7 & 3 & 3.5 & 50.7 & 0.77 & & & \\
8 & 3.5 & 4 & 49.9 & 0.79 & & & \\
9 & 4 & 4.5 & 60.3 & 0.60 & & & \\
10 & 4.5 & 5 & 60.0 & 0.58 & & & \\
11 & 5 & 6 & 60.0 & 0.60 & 4.32 & 0.12 & 57.69 \\
12 & 6 & 7 & 58.5 & 0.62 & & & \\
13 & 7 & 8 & 58.0 & 0.66 & & & \\
14 & 8 & 9 & 56.9 & 0.64 & & & \\
15 & 9 & 10 & 55.9 & 0.61 & & & \\
16 & 10 & 11 & 55.5 & 0.70 & & & \\
17 & 11 & 12 & 54.5 & 0.72 & & & \\
18 & 12 & 13 & 57.0 & 0.69 & & & \\
19 & 13 & 14 & 56.8 & 0.65 & & & \\
20 & 14 & 15 & 54.3 & 0.59 & & &
\end{tabular}

$\begin{array}{rrr}\text { Core: } & \text { EH010 (2003) } \\ \text { Date extruded: } & 6 / 10 / 03 & \\ \text { Core length: } & 12 \mathrm{~cm} \\ \text { Core diameter: } & 47 \mathrm{~mm}\end{array}$

Increment \# Top depth bottom depth Porosity Bulk Den. Isotope Activities (dpm/g)

\begin{tabular}{rrrrrrrrr} 
& & $(\mathrm{cm})$ & $(\mathrm{cm})$ & \multicolumn{1}{c}{$\%$} & $\mathrm{~g} / \mathrm{cm}^{3}$ & ${ }^{210} \mathrm{~Pb}$ & ${ }^{137} \mathrm{Cs}$ & ${ }^{40} \mathrm{~K}$ \\
\hline 0 & & fluff & & $0.0581 \mathrm{~g}$ & & 13.57 & 4.32 & 221.15 \\
& 1 & 0 & 0.5 & 36.3 & 1.51 & 1.83 & 0.96 & 38.25 \\
& 2 & 0.5 & 1 & 28.6 & 1.81 & 1.37 & 0.88 & 37.13 \\
& 1 & 1.5 & 29.1 & 1.69 & 1.19 & 1.14 & 36.40 \\
& 4 & 1.5 & 2 & 28.2 & 1.75 & 1.20 & 1.40 & 33.81 \\
& 2 & 2.5 & 27.1 & 1.87 & 1.41 & 1.88 & 36.10 \\
& 5 & 2.5 & 3 & 28.3 & 1.83 & 0.59 & 1.87 & 29.79 \\
& 3 & 3 & 3.5 & 27.4 & 1.76 & 0.97 & 3.11 & 32.62 \\
7 & 3.5 & 4 & 27.3 & 1.81 & 0.93 & 3.41 & 25.10 \\
8 & & & & & & &
\end{tabular}




$\begin{array}{rrrrrrrr}9 & 4 & 4.5 & 26.0 & 1.77 & 0.69 & 1.31 & 21.71 \\ 10 & 4.5 & 5 & 27.0 & 1.99 & 0.39 & 0.46 & 25.33 \\ 11 & 5 & 6 & 33.0 & 1.42 & 0.59 & 0.10 & 22.42 \\ 12 & 6 & 7 & 31.6 & 1.40 & & & \\ 13 & 7 & 8 & 30.8 & 1.50 & & & \\ 14 & 8 & 9 & 33.5 & 1.42 & & & \\ 15 & 9 & 10 & 28.1 & 1.84 & & & \\ 16 & 10 & 11 & 30.9 & 1.57 & & & \\ 17 & 11 & 12 & 28.3 & 1.82 & & & \end{array}$

\section{Core: EH020 (2003)}

Date extruded: $\quad 6 / 11 / 03$

Core length: $\quad 15 \mathrm{~cm}$

Core diameter: $\quad 47 \mathrm{~mm}$

Increment \# Top depth bottom depth Porosity Bulk Den. Isotope Activities (dpm/g)

\begin{tabular}{rrrrrrrrr} 
& & $(\mathrm{cm})$ & $(\mathrm{cm})$ & \multicolumn{1}{c}{$\%$} & $\mathrm{~g} / \mathrm{cm}^{3}$ & ${ }^{210} \mathrm{~Pb}$ & ${ }^{137} \mathrm{Cs}$ & \multicolumn{1}{c}{$\mathrm{K}$} \\
\hline 0 & & fluff & & 0.0391 & & 76.79 & 19.84 & 406.79 \\
& 1 & 0 & 0.5 & 37.6 & 1.64 & 8.07 & 2.50 & 37.46 \\
& & 0.5 & 1 & 33.0 & 1.34 & 8.67 & 4.21 & 37.18 \\
3 & 1 & 1.5 & 30.8 & 1.66 & 5.19 & 5.89 & 34.56 \\
& 1.5 & 2 & 30.3 & 1.49 & 3.83 & 6.42 & 28.72 \\
& 2 & 2.5 & 29.1 & 1.63 & 3.65 & 2.96 & 22.57 \\
5 & 2.5 & 3 & 26.3 & 1.80 & 2.92 & 0.63 & 23.34 \\
6 & 3 & 3.5 & 33.3 & 1.53 & 3.08 & 0.24 & 32.37 \\
7 & 3.5 & 4 & 33.4 & 1.63 & 3.04 & 0.09 & 20.05 \\
8 & 4 & 4.5 & 39.0 & 1.43 & 3.84 & 0.04 & 25.36 \\
9 & 4.5 & 5 & 35.5 & 1.32 & & & \\
10 & 5 & 6 & 30.8 & 1.60 & 0.92 & 0.08 & 30.77 \\
11 & 6 & 7 & 30.3 & 1.46 & & & \\
12 & 7 & 8 & 29.4 & 1.65 & & & \\
13 & 8 & 9 & 31.6 & 1.47 & & & \\
14 & 9 & 10 & 27.8 & 1.69 & & & \\
15 & 10 & 11 & 28.4 & 1.84 & & & \\
16 & 11 & 12 & 29.6 & 1.72 & & & \\
17 & 12 & 13 & 28.6 & 1.66 & & & \\
18 & 13 & 14 & 28.3 & 1.78 & & &
\end{tabular}

Core: $\mathrm{EH} 030$ (2003)

$\mathrm{N} \quad 6 / 13 / 03$

Core length: $\quad 15 \mathrm{~cm}$

Core diameter $\quad 47 \mathrm{~mm}$

Increment \# Top depth bottom depth Porosity Bulk Den. Isotope Activities (dpm/g)

\begin{tabular}{rrrrrrrr} 
& $(\mathrm{cm})$ & $(\mathrm{cm})$ & $\%$ & $\mathrm{~g} / \mathrm{cm}^{3}$ & ${ }^{210} \mathrm{~Pb}$ & ${ }^{137} \mathrm{Cs}$ & ${ }^{40} \mathrm{~K}$ \\
\hline 1 & 0 & 0.5 & 58.4 & $\underline{0.59}$ & 15.75 & 5.35 & 36.15 \\
2 & 0.5 & 1 & 42.9 & 1.44 & 8.85 & 7.29 & 32.33
\end{tabular}




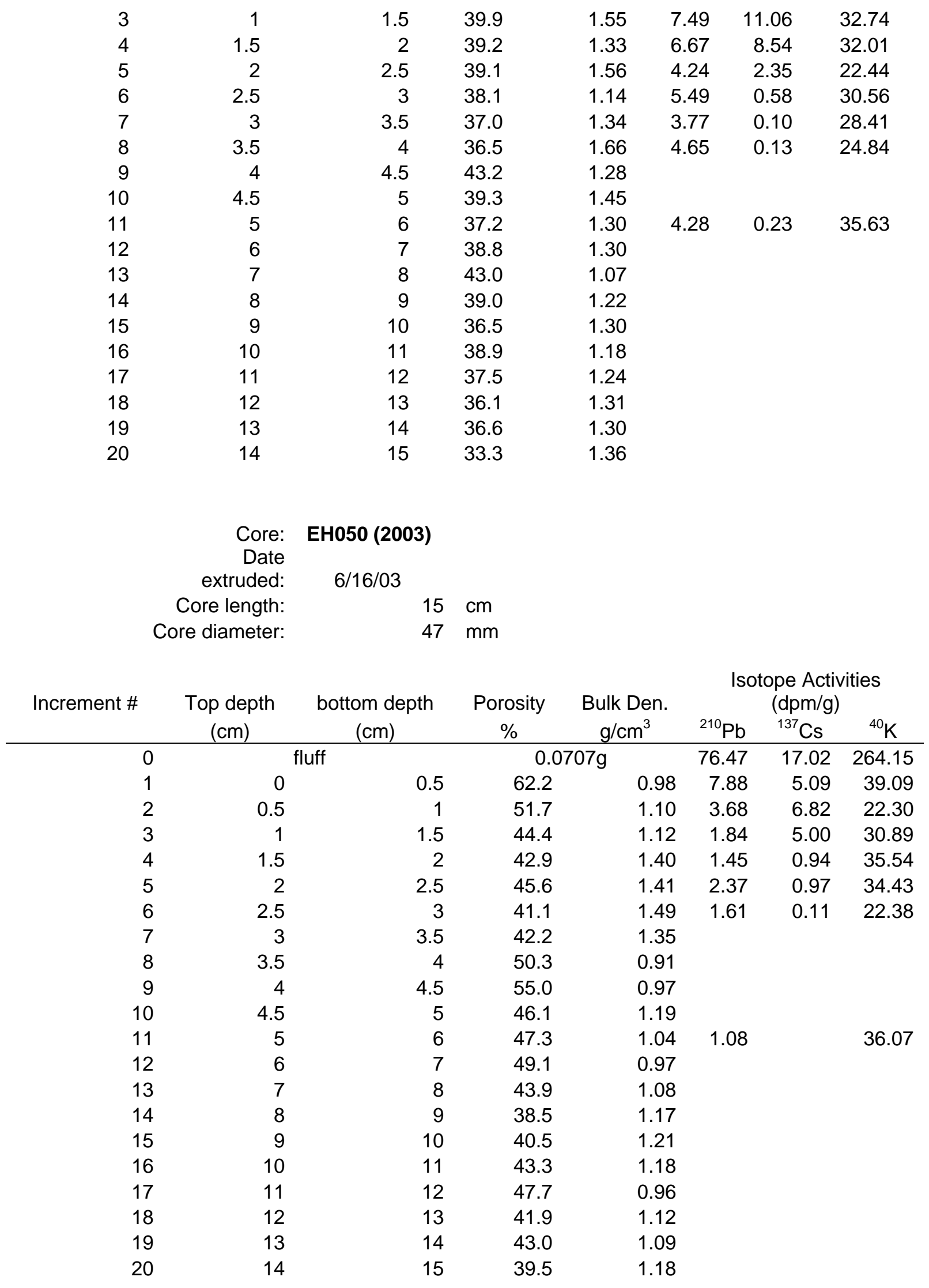




\section{Core: EH070 (2003)}

Date extruded: $\quad 6 / 16 / 03$

Core length: $\quad 15 \mathrm{~cm}$

Core diameter: $\quad 63 \mathrm{~mm}$

\begin{tabular}{|c|c|c|c|c|c|c|c|}
\hline \multirow[t]{2}{*}{ Increment \# } & Top depth & bottom depth & Porosity & Bulk Den. & \multicolumn{3}{|c|}{ Isotope Activities (dpm/g) } \\
\hline & $(\mathrm{cm})$ & $(\mathrm{cm})$ & $\%$ & $\mathrm{~g} / \mathrm{cm}^{3}$ & ${ }^{210} \mathrm{~Pb}$ & ${ }^{137} \mathrm{Cs}$ & ${ }^{40} \mathrm{~K}$ \\
\hline 0 & \multicolumn{2}{|c|}{ fluff } & \multicolumn{2}{|c|}{$0.1235 \mathrm{~g}$} & 61.24 & 18.15 & 140.30 \\
\hline 1 & 0 & 0.5 & 91.5 & 0.12 & 71.66 & 22.49 & 56.15 \\
\hline 2 & 0.5 & 1 & 85.4 & 0.19 & 60.63 & 20.25 & 47.20 \\
\hline 3 & 1 & 1.5 & 81.9 & 0.35 & 60.43 & 22.18 & 48.65 \\
\hline 4 & 1.5 & 2 & 80.7 & 0.48 & 55.05 & 20.87 & 43.06 \\
\hline 5 & 2 & 2.5 & 79.8 & 0.35 & 49.66 & 21.49 & 40.83 \\
\hline 6 & 2.5 & 3 & 79.6 & 0.36 & 46.15 & 23.04 & 45.37 \\
\hline 7 & 3 & 3.5 & 78.6 & 0.30 & 36.54 & 25.16 & 44.68 \\
\hline 8 & 3.5 & 4 & 75.2 & 0.42 & 28.98 & 20.20 & 36.94 \\
\hline 9 & 4 & 4.5 & 71.2 & 0.37 & 20.20 & 16.95 & 36.71 \\
\hline 10 & 4.5 & 5 & 76.8 & 0.27 & 15.72 & 12.20 & 40.92 \\
\hline 11 & 5 & 6 & 75.5 & 0.33 & 15.10 & 6.98 & 43.56 \\
\hline 12 & 6 & 7 & 75.3 & 0.33 & 11.53 & 2.38 & 37.61 \\
\hline 13 & 7 & 8 & 71.9 & 0.36 & 10.37 & 0.61 & 38.78 \\
\hline 14 & 8 & 9 & 72.8 & 0.28 & 6.61 & 0.37 & 39.60 \\
\hline 15 & 9 & 10 & 73.1 & 0.42 & 6.79 & 0.18 & 42.65 \\
\hline 16 & 10 & 11 & 74.0 & 0.37 & 3.51 & 0.06 & 37.63 \\
\hline 17 & 11 & 12 & 71.9 & 0.42 & 4.50 & 0.12 & 37.89 \\
\hline 18 & 12 & 13 & 74.7 & 0.36 & & & \\
\hline 19 & 14 & 14 & 71.1 & 0.35 & & & \\
\hline 20 & 14 & 15 & 67.8 & 0.42 & & & \\
\hline
\end{tabular}

Core: EH090 (2003)

Date extruded: $\quad 6 / 17 / 03$

Core length: $\quad 10 \mathrm{~cm}$

Core diameter: $\quad 63 \mathrm{~mm}$

Increment \# Top depth bottom depth Porosity Bulk Den. Isotope Activities (dpm/g)

\begin{tabular}{|c|c|c|c|c|c|c|c|}
\hline & $(\mathrm{cm})$ & $(\mathrm{cm})$ & $\%$ & $\mathrm{~g} / \mathrm{cm}^{3}$ & ${ }^{210} \mathrm{~Pb}$ & ${ }^{137} \mathrm{Cs}$ & ${ }^{40} \mathrm{~K}$ \\
\hline 0 & fluff & & & & 13.88 & 21.03 & 139.63 \\
\hline 1 & 0 & 0.5 & 85.0 & 0.20 & 15.25 & 12.00 & 39.44 \\
\hline 2 & 0.5 & 1 & 79.1 & 0.38 & 8.69 & 13.75 & 43.70 \\
\hline 3 & 1 & 1.5 & 76.4 & 0.36 & 6.80 & 19.46 & 45.89 \\
\hline 4 & 1.5 & 2 & 74.4 & 0.42 & 3.72 & 4.75 & 33.87 \\
\hline 5 & 2 & 2.5 & 66.8 & 0.72 & 2.46 & 0.68 & 42.52 \\
\hline 6 & 2.5 & 3 & 70.8 & 0.61 & 2.20 & 0.47 & 42.69 \\
\hline 7 & 3 & 3.5 & 69.4 & 0.60 & 2.63 & 0.07 & 42.50 \\
\hline 8 & 3.5 & 4 & 71.6 & 0.40 & & & \\
\hline 9 & 4 & 4.5 & 70.2 & 0.54 & & & \\
\hline 10 & 4.5 & 5 & 68.7 & 0.63 & & & \\
\hline 11 & 5 & 6 & 70.8 & 0.51 & & & \\
\hline 12 & 6 & 6.5 & 72.8 & 0.45 & & & \\
\hline
\end{tabular}




\begin{tabular}{|c|c|c|c|c|c|c|c|}
\hline \multirow[b]{2}{*}{ Increment \# } & $\begin{array}{r}\text { Core: } \\
\text { ate extruded: } \\
\text { Core length: } \\
\text { Core diameter }\end{array}$ & $\begin{array}{r}\text { ON090 (2003) } \\
7 / 18 / 2003 \\
15 \\
47\end{array}$ & \multicolumn{2}{|l|}{$\begin{array}{l}\mathrm{cm} \\
\mathrm{mm}\end{array}$} & \multirow{2}{*}{\multicolumn{3}{|c|}{ Isotope Activities (dpm/g) }} \\
\hline & $\begin{array}{l}\text { Top depth } \\
(\mathrm{cm})\end{array}$ & $\begin{array}{l}\text { bottom depth } \\
(\mathrm{cm})\end{array}$ & $\begin{array}{c}\text { Porosity } \\
\% \\
\end{array}$ & $\begin{array}{c}\text { Bulk Den. } \\
\mathrm{g} / \mathrm{cm}^{3}\end{array}$ & & & \\
\hline 0 & & Iff & & $66 \mathrm{~g}$ & 17.51 & 4.24 & 37.99 \\
\hline 1 & 0 & 0.5 & 32.2 & 1.60 & 4.97 & 1.64 & 28.18 \\
\hline 2 & 0.5 & 1 & 24.4 & 2.02 & 4.38 & 0.94 & 31.85 \\
\hline 3 & 1 & 1.5 & 26.4 & 1.82 & 3.75 & 0.20 & 32.20 \\
\hline 4 & 1.5 & 2 & 21.2 & 2.10 & 3.40 & 0.13 & 29.92 \\
\hline 5 & 2 & 2.5 & 22.7 & 2.25 & 1.98 & 0.09 & 31.22 \\
\hline 6 & 2.5 & 3 & 20.3 & 2.45 & 1.94 & 0.08 & 28.91 \\
\hline 7 & 3 & 3.5 & 20.0 & 2.25 & & & \\
\hline 8 & 3.5 & 4 & 19.6 & 2.24 & & & \\
\hline 9 & 4 & 4.5 & 19.2 & 2.38 & & & \\
\hline 10 & 4.5 & 5 & 19.3 & 2.22 & & & \\
\hline 11 & 5 & 6 & 19.4 & 2.05 & 2.40 & 0.05 & 26.02 \\
\hline 12 & 6 & 7 & 20.4 & 1.94 & & & \\
\hline 13 & 7 & 8 & 22.4 & 1.94 & & & \\
\hline 14 & 8 & 9 & 22.2 & 1.91 & & & \\
\hline 15 & 9 & 10 & 22.1 & 1.89 & & & \\
\hline 16 & 10 & 11 & 19.5 & 2.17 & & & \\
\hline 17 & 11 & 12 & 20.9 & 2.01 & & & \\
\hline 18 & 12 & 13 & 21.3 & 1.95 & & & \\
\hline 19 & 14 & 14 & 21.9 & 2.02 & & & \\
\hline 20 & 14 & 15 & 21.4 & 1.98 & & & \\
\hline
\end{tabular}

$\begin{array}{rrr}\text { Core: } & \text { ON110 (2003) } \\ \text { Date } & & \\ \text { extruded: } & 7 / 18 / 2003 & \\ \text { Core length: } & 15 \mathrm{~cm} \\ \text { Core } & & \\ \text { diameter } & 47 \mathrm{~mm}\end{array}$

Increment \# Top depth bottom depth Porosity Bulk Den. Isotope Activities (dpm/g)

\begin{tabular}{|c|c|c|c|c|c|c|c|}
\hline & $(\mathrm{cm})$ & $(\mathrm{cm})$ & $\% \quad \mathrm{~g} /$ & $\mathrm{cm}^{3}$ & ${ }^{210} \mathrm{~Pb}$ & ${ }^{137} \mathrm{Cs}$ & ${ }^{40} \mathrm{~K}$ \\
\hline 0 & fluff & & $1.2418 \mathrm{~g}$ & & 5.6 & 3.4 & 47.9 \\
\hline 1 & 0 & 0.5 & 37.5 & 1.42 & 6.9 & 2.2 & 35.0 \\
\hline 2 & 0.5 & 1 & 36.9 & 1.51 & 5.0 & 0.9 & 36.2 \\
\hline 3 & 1 & 1.5 & 38.2 & 1.44 & 4.5 & 0.2 & 34.8 \\
\hline 4 & 1.5 & 2 & 36.5 & 1.46 & 2.0 & 0.1 & 26.7 \\
\hline 5 & 2 & 2.5 & 34.3 & 1.36 & & 0.0 & 33.0 \\
\hline 6 & 2.5 & 3 & 33.1 & 1.64 & & 0.1 & 29.9 \\
\hline 7 & 3 & 3.5 & 31.5 & 1.60 & & & \\
\hline 8 & 3.5 & 4 & 35.0 & 1.63 & & & \\
\hline 9 & 4 & 4.5 & 30.9 & 1.74 & & & \\
\hline
\end{tabular}




\begin{tabular}{|c|c|c|c|c|c|c|c|}
\hline 10 & 4.5 & 5 & 31.7 & 1.64 & \multirow{2}{*}{\multicolumn{2}{|c|}{2.0}} & \multirow[b]{2}{*}{26.4} \\
\hline 11 & 5 & 6 & 33.2 & 1.43 & & & \\
\hline 12 & 6 & 7 & 31.1 & 1.39 & & & \\
\hline 13 & 7 & 8 & 33.6 & 1.37 & & & \\
\hline 14 & 8 & 9 & 30.6 & 1.57 & & & \\
\hline 15 & 9 & 10 & 32.1 & 1.54 & & & \\
\hline 16 & 10 & 11 & 31.8 & 1.59 & & & \\
\hline 17 & 11 & 12 & 31.5 & 1.44 & & & \\
\hline 18 & 12 & 13 & 32.4 & 1.61 & & & \\
\hline 19 & 14 & 14 & 28.6 & 1.54 & & & \\
\hline 20 & 14 & 15 & 31.7 & 1.49 & & & \\
\hline \multirow{6}{*}{ Increment \# } & Core: & ON130 (2003) & & & & & \\
\hline & te extruded: & $7 / 20 / 2003$ & & & & & \\
\hline & Core length: & 15 & $\mathrm{~cm}$ & & & & \\
\hline & re diameter: & 47 & $\mathrm{~mm}$ & & & & \\
\hline & Top depth & bottom depth & Porosity & Bulk Den. & \multicolumn{3}{|c|}{ Isotope Activities (dpm/g) } \\
\hline & $(\mathrm{cm})$ & $(\mathrm{cm})$ & $\%$ & $\mathrm{~g} / \mathrm{cm}^{3}$ & ${ }^{210} \mathrm{~Pb}$ & ${ }^{137} \mathrm{Cs}$ & ${ }^{40} \mathrm{~K}$ \\
\hline 0 & \multicolumn{2}{|c|}{ fluff } & \multicolumn{2}{|c|}{$0.7542 \mathrm{~g}$} & 30.9 & 11.8 & 56.8 \\
\hline 1 & 0 & 0.5 & 56.8 & 0.72 & 14.9 & 11.2 & 35.7 \\
\hline 2 & 0.5 & 1 & 42.9 & 1.09 & 6.9 & 3.9 & 36.8 \\
\hline 3 & 1 & 1.5 & 47.9 & 1.01 & 4.7 & 0.3 & 36.2 \\
\hline 4 & 1.5 & 2 & 46.7 & 1.09 & 3.6 & 0.1 & 34.4 \\
\hline 5 & 2 & 2.5 & 49.4 & 1.12 & & & \\
\hline 6 & 2.5 & 3 & 45.9 & 1.20 & & & \\
\hline 7 & 3 & 3.5 & 47.7 & 1.08 & & & \\
\hline 8 & 3.5 & 4 & 45.3 & 1.24 & & & \\
\hline 9 & 4 & 4.5 & 43.4 & 1.35 & & & \\
\hline 10 & 4.5 & 5 & 38.8 & 1.35 & & & \\
\hline 11 & 5 & 6 & 39.5 & 1.26 & 3.2 & 0.1 & 29.3 \\
\hline 12 & 6 & 7 & 37.4 & 1.33 & & & \\
\hline 13 & 7 & 8 & 36.5 & 1.40 & & & \\
\hline 14 & 8 & 9 & 36.1 & 1.35 & & & \\
\hline 15 & 9 & 10 & 36.8 & 1.25 & & & \\
\hline 16 & 10 & 11 & 36.9 & 1.37 & & & \\
\hline 17 & 11 & 12 & 38.6 & 1.32 & & & \\
\hline 18 & 12 & 13 & 34.4 & 1.48 & & & \\
\hline 19 & 14 & 14 & 34.8 & 1.41 & & & \\
\hline 20 & 14 & 15 & 33.2 & 1.42 & & & \\
\hline
\end{tabular}

Core: ON170 (2003)

Date extruded: $\quad 7 / 22 / 2003$

Core length: $\quad 10 \mathrm{~cm}$

Core diameter: $\quad 63 \mathrm{~mm}$

Increment \# Top depth bottom depth Porosity Bulk Den. Isotope Activities (dpm/g)

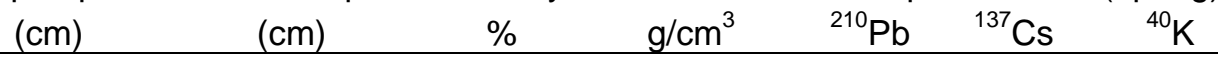




\begin{tabular}{|c|c|c|c|c|c|c|c|}
\hline 0 & \multicolumn{2}{|c|}{ fluff } & \multicolumn{2}{|c|}{$0.1488 \mathrm{~g}$} & 62.96 & 20.50 & 106.28 \\
\hline 1 & 0 & 0.5 & 81.7 & 0.27 & 37.74 & 13.47 & 44.51 \\
\hline 2 & 0.5 & 1 & 75.0 & 0.48 & 40.09 & 17.50 & 47.08 \\
\hline 3 & 1 & 2 & 72.2 & 0.31 & 25.37 & 18.97 & 38.86 \\
\hline 4 & 2 & 2.5 & 70.4 & 0.40 & 15.45 & 8.29 & 37.29 \\
\hline 5 & 2.5 & 3 & 67.7 & 0.55 & 15.35 & 15.61 & 44.67 \\
\hline 6 & 3 & 3.5 & 63.1 & 0.53 & 11.15 & 4.76 & 37.29 \\
\hline 7 & 3.5 & 4 & 60.1 & 0.52 & 7.97 & 0.86 & 35.48 \\
\hline 8 & 4 & 4.5 & 59.5 & 0.58 & 8.45 & 0.28 & 37.06 \\
\hline 9 & 4.5 & 5 & 62.9 & 0.54 & 6.60 & 0.50 & 33.47 \\
\hline 10 & 5 & 5.5 & 60.7 & 0.59 & 5.28 & 0.24 & 45.00 \\
\hline 11 & 5.5 & 6 & 54.1 & 0.75 & 5.51 & & 38.39 \\
\hline 12 & 6 & 6.5 & 53.7 & 0.80 & & & \\
\hline 13 & 6.5 & 7 & 54.0 & 0.48 & & & \\
\hline 14 & 7 & 7.5 & 53.9 & 0.81 & & & \\
\hline 15 & 7.5 & 8 & 53.1 & 0.86 & & & \\
\hline 16 & 8 & 8.5 & 50.9 & 0.84 & & & \\
\hline 17 & 8.5 & 9 & 46.8 & 0.83 & & & \\
\hline
\end{tabular}

Core: ON210 (2003)

Date extruded: $\quad 7 / 22 / 2003$

Core length: $\quad 10 \mathrm{~cm}$

Core diameter: $\quad 63 \mathrm{~mm}$

\begin{tabular}{rrrrrrrr} 
Increment \# & $\begin{array}{c}\text { Top depth } \\
(\mathrm{cm})\end{array}$ & $\begin{array}{r}\text { bottom depth } \\
(\mathrm{cm})\end{array}$ & $\begin{array}{c}\text { Porosity } \\
\%\end{array}$ & \multicolumn{2}{c}{$\begin{array}{c}\text { Bulk Den. } \\
\mathrm{g} / \mathrm{cm}^{3}\end{array}$} & \multicolumn{3}{c}{ Isotope Activities (dpm/g) } \\
& \multicolumn{2}{c}{$\mathrm{Pb}$} & ${ }^{137} \mathrm{Cs}$ & \multicolumn{1}{c}{$\mathrm{K} \mathrm{K}$} \\
\hline 0 & fluff & 0.1149 & & 23.16 & 14.72 & 180.74 \\
1 & 0 & 0.5 & 87.0 & 0.23 & 58.10 & 22.11 & 43.36 \\
2 & 0.5 & 1 & 80.9 & 0.27 & 50.52 & 23.49 & 40.84 \\
3 & 1 & 1.5 & 77.6 & 0.34 & 47.21 & 24.75 & 42.89 \\
4 & 1.5 & 2 & 76.4 & 0.33 & 40.41 & 31.41 & 45.92 \\
5 & 2 & 2.5 & 74.4 & 0.38 & 18.16 & 24.78 & 45.58 \\
6 & 2.5 & 3 & 72.5 & 0.45 & 20.83 & 25.40 & 45.03 \\
7 & 3 & 3.5 & 68.4 & 0.36 & 15.27 & 9.18 & 40.54 \\
8 & 3.5 & 4 & 69.7 & 0.39 & 7.12 & 3.43 & 49.97 \\
9 & 4 & 4.5 & 70.1 & 0.49 & 8.66 & 1.03 & 45.49 \\
10 & 4.5 & 5 & 68.5 & 0.49 & 3.51 & 0.40 & 43.93 \\
11 & 5 & 6 & 68.0 & 0.39 & 4.25 & 0.22 & 41.31 \\
12 & 6 & 7 & 68.6 & 0.45 & & & \\
13 & 7 & 8 & 67.4 & 0.41 & & & \\
14 & 8 & 9 & 66.1 & 0.51 & & & \\
15 & 9 & 10 & 63.1 & 0.47 & & &
\end{tabular}


Appendix - 4. ${ }^{40} \mathrm{~K}:{ }^{210} \mathrm{~Pb}$ ratios for all sediment cores (Chapter 3).

As mentioned in chapter 3, the application of ${ }^{40} \mathrm{~K} /{ }^{210} \mathrm{~Pb}$ ratios helps to distinguish between background (supported) and unsupported ${ }^{210} \mathrm{~Pb}$. Taking the HN170 2002 core as an example, when looking at ${ }^{210} \mathrm{~Pb}$ activity only, it is possible to say that background activities are reached at $3.5-4 \mathrm{~cm}$ and below. However, the $\mathrm{K} / \mathrm{Pb}$ ratio suggests that the background activity does not begin until a depth of $4.5 \mathrm{~cm}$. Also as observed from the following figure, the in-core variability (of isotope activities) is reduced as evidenced by the smooth line of ratios from top to $2.5 \mathrm{~cm}$.

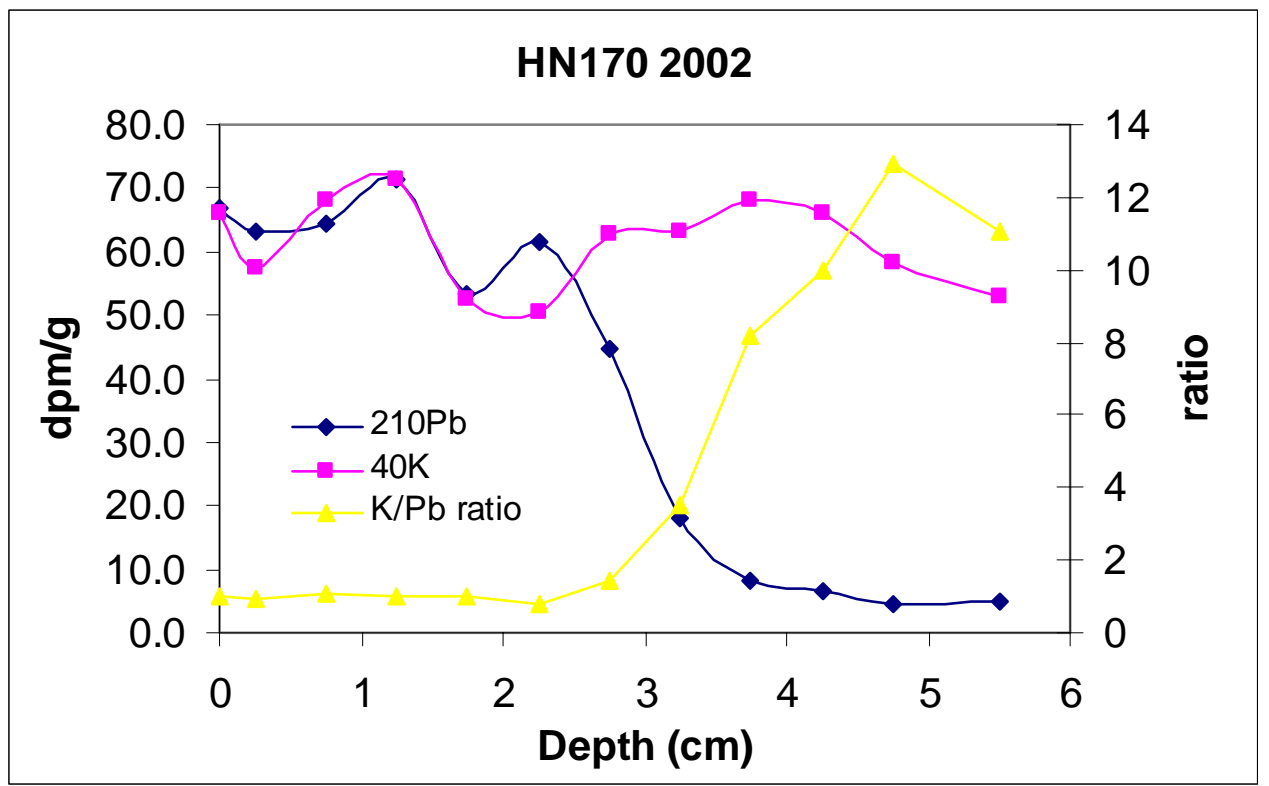

2001 cores $(\mathrm{HN})$

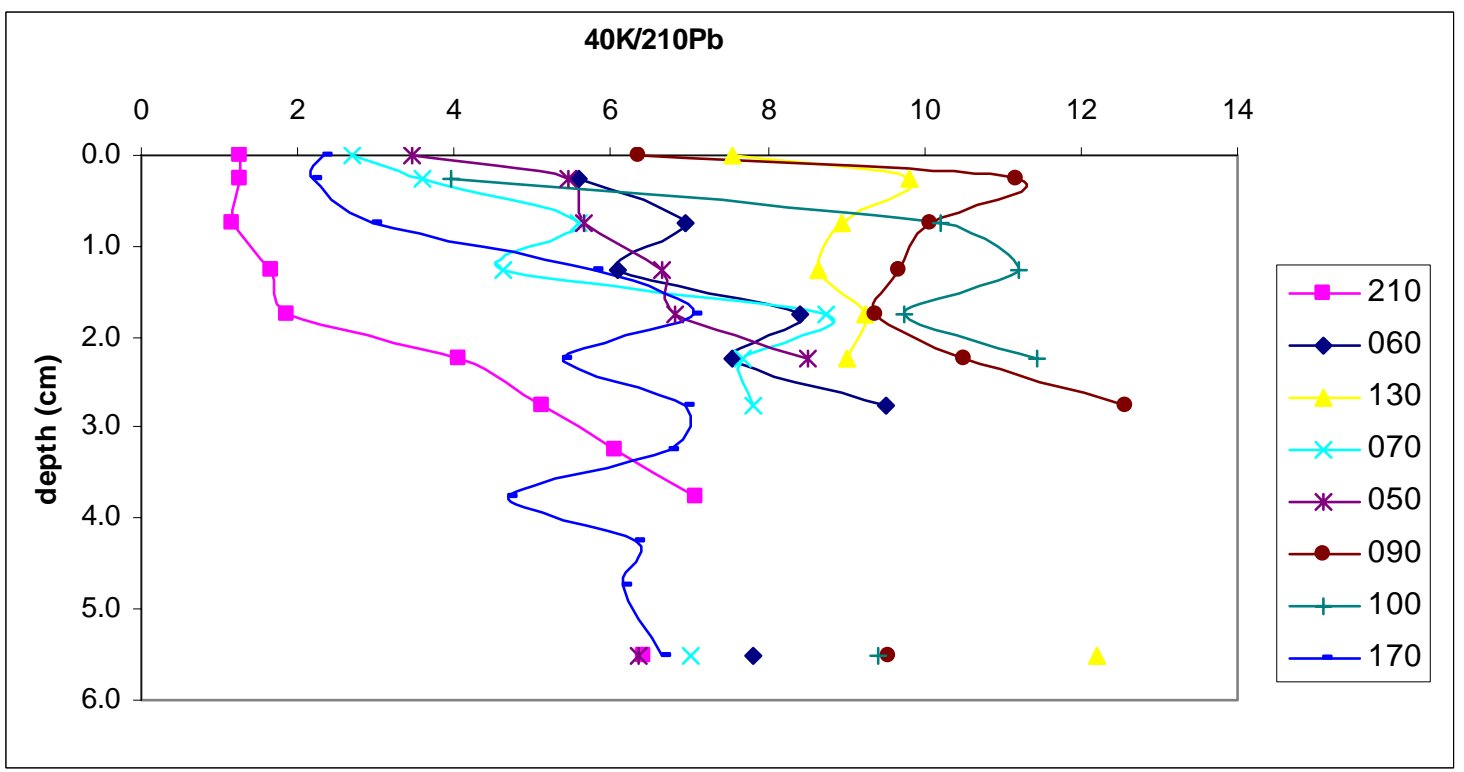


> 2002 cores (HN)

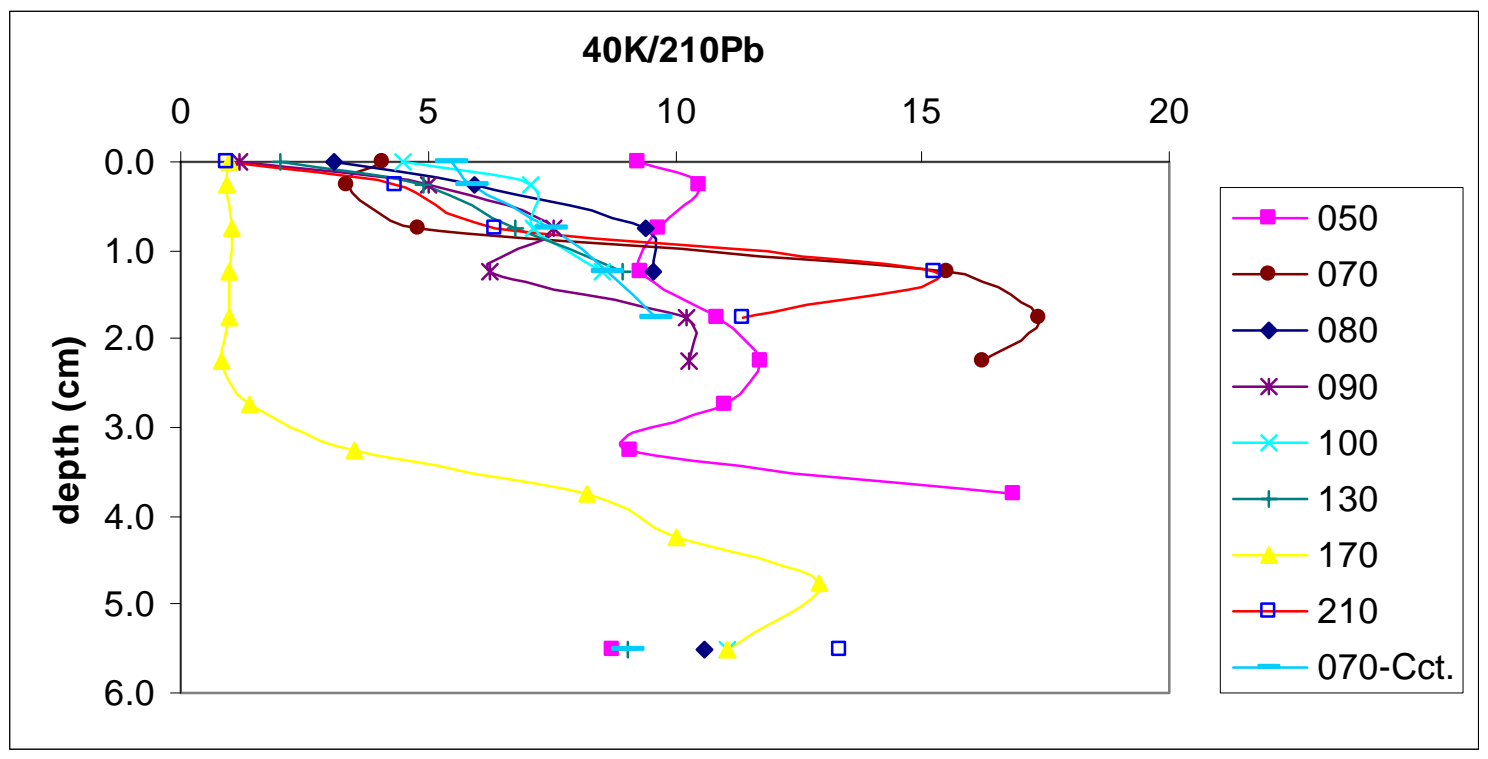


2003 cores (EH and ON)
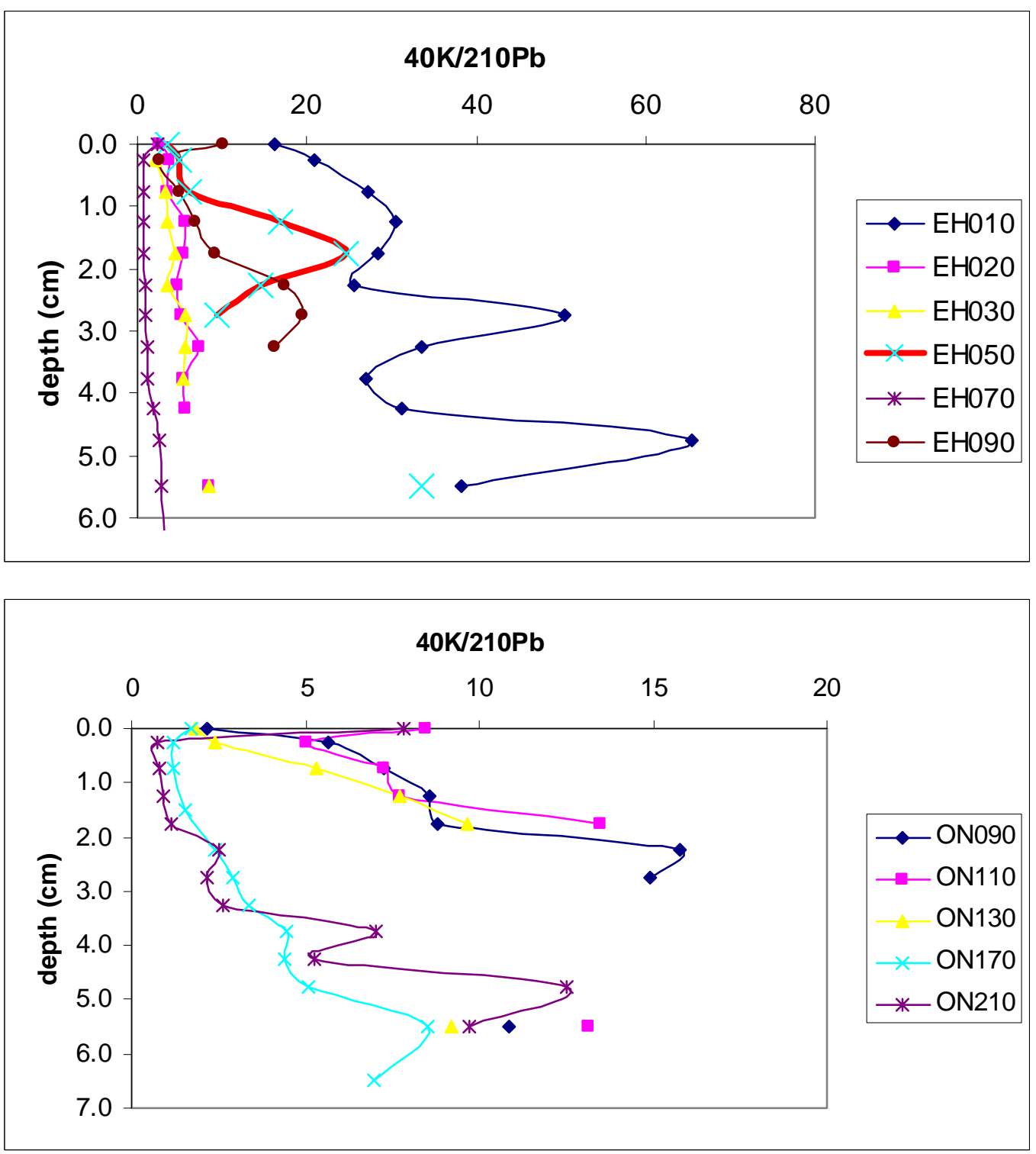
Appendix - 5. Geochronologies for sediment cores on each transect

As discussed in chapter 3 , only three out of about 30 cores in this research are used for isotope dating, i.e. geochronology. In figure 3-9, the geochronology for core EH070 was presented. In the appendix, dating results from three cores at the end of each transect are included.
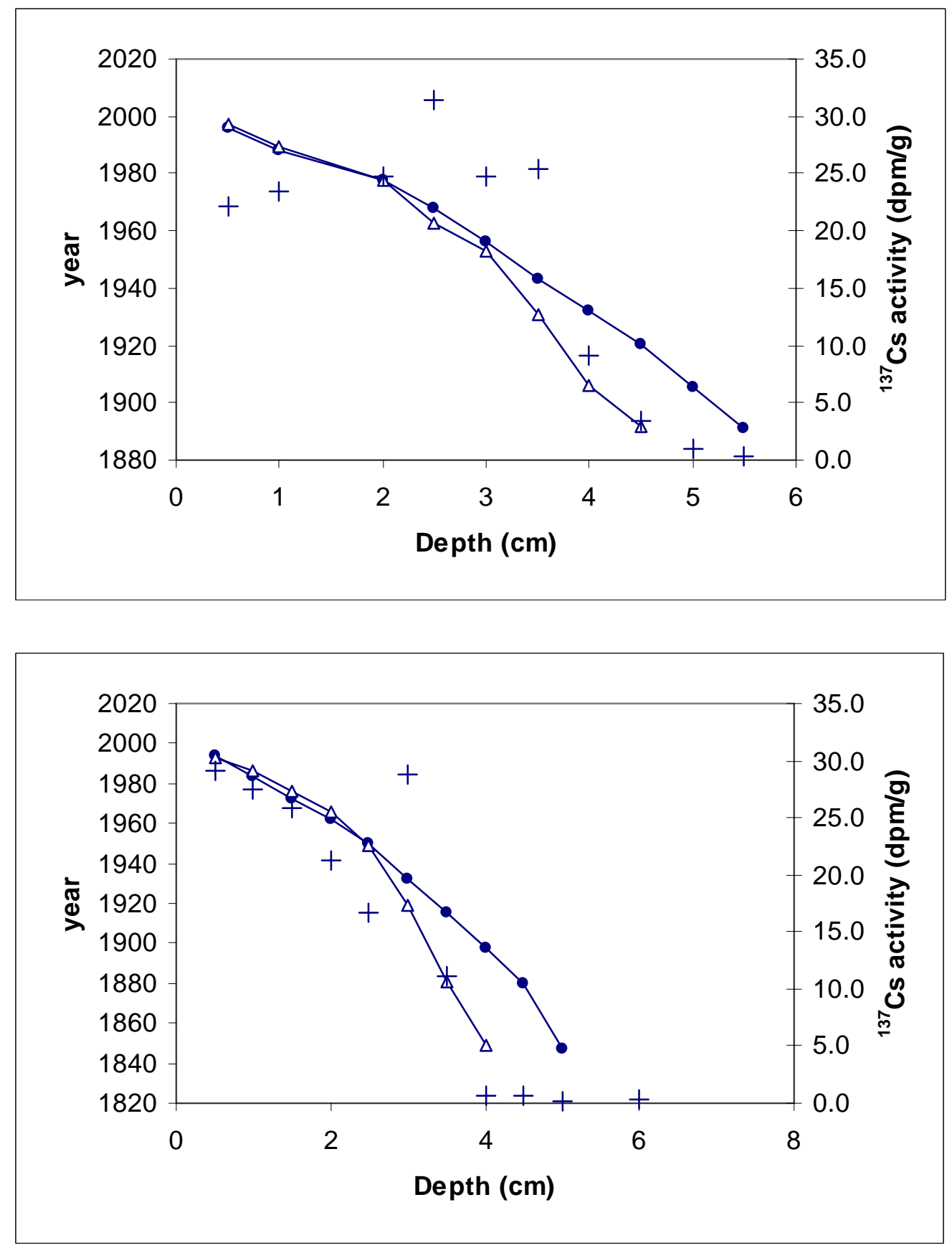


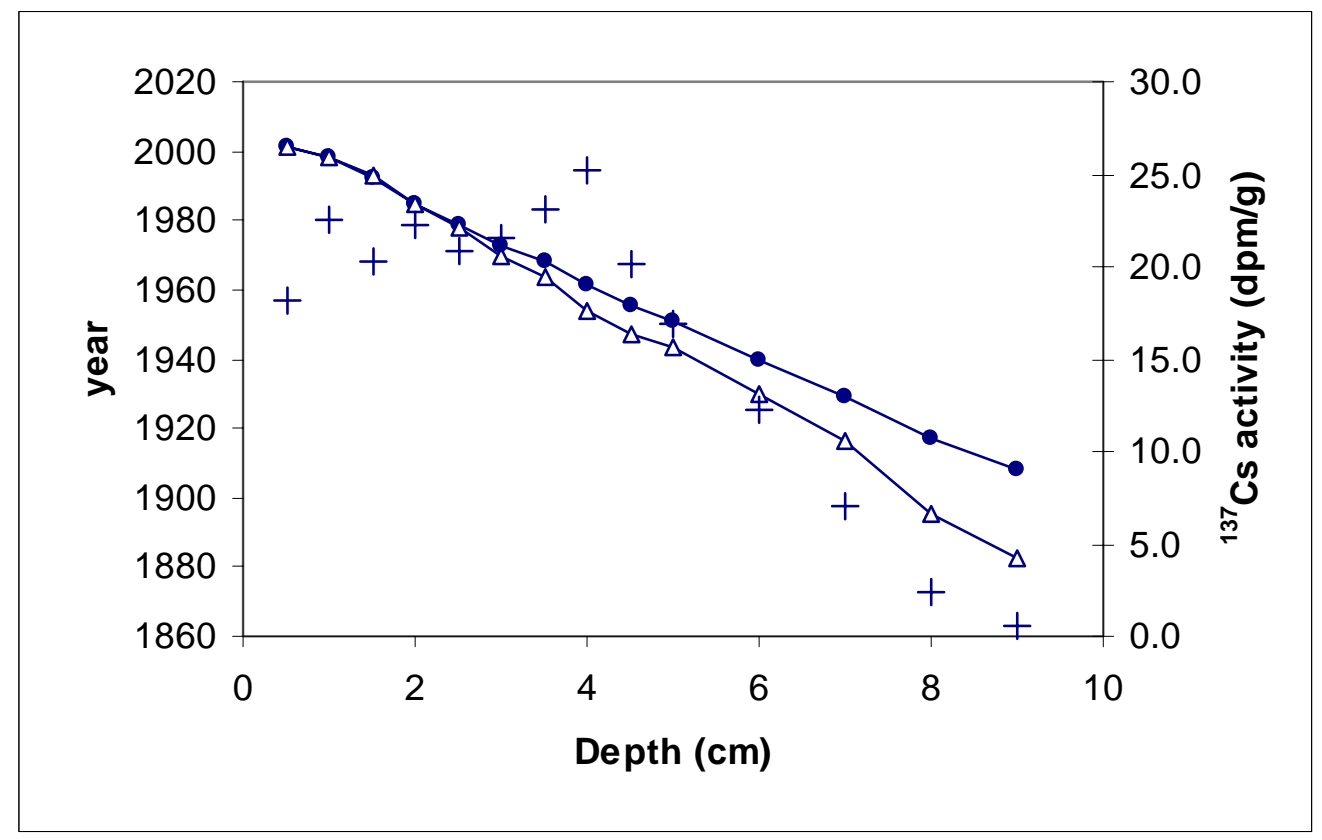

Figure A-x. Geochronology results from ON210 $\left(1^{\text {st }}\right)$, HN170 $\left(2^{\text {nd }}\right)$ and EH070 $\left(3^{\text {rd }}\right)$ core. Solid circles represent ages determined with the CIC model that invokes a constant sedimentation rate (as in Table 3-10). Hollow triangles represent ages based on the CRS model. 137Cs activity is also shown as crosses. 
Appendix - 6. Estimated ${ }^{137} \mathrm{Cs}$ (and ${ }^{90} \mathrm{Sr}$ ) atmospheric deposition flux to Lake Superior region (1950 1981). Data from J. A. Robbins, Great Lakes Regional Source Functions, NOAA Technical Memo ERL GLERL-56.

All five basins of the Great Lakes were covered in the above reference and only data for Lake Superior was retrieved and listed here. In the table, SRDL represents monthly depositional rate of ${ }^{90} \mathrm{Sr}$ isotope and CSDL represents monthly depositional rate of ${ }^{137} \mathrm{Cs}$.

Several assumptions were made Robbins's calculation:

1) A PWW model was applied to link the atmospheric concentrations and deposition rates of fallout isotopes to get a basin wise estimate.

2) A constant ratio of ${ }^{137} \mathrm{Cs}:{ }^{90} \mathrm{Sr}$ was assumed through out because of the higher data availability of ${ }^{90} \mathrm{Sr}$ over ${ }^{137} \mathrm{Cs}$.

3) Dry deposition was also considered based on the soil core inventory.

Summarized from the listed data, a cumulative deposition for ${ }^{137} \mathrm{Cs}$ can be calculated as $35.92 \mathrm{dpm} / \mathrm{cm}^{2}$. Considering the radioactive decay of the isotope and the fact that most of the ${ }^{137} \mathrm{Cs}$ deposition ceased in the late 70 's, a ${ }^{137} \mathrm{Cs}$ theorical inventory for Lake Superior is calculated as $21.63 \mathrm{dpm} / \mathrm{cm}^{2}$ in the year of 2003 . 


\begin{tabular}{|c|c|c|c|c|c|c|c|c|}
\hline YEAR & $\begin{array}{c}\text { SRDL } \\
\left(\mathrm{mCi} / \mathrm{km}^{2}-\mathrm{yr}\right)\end{array}$ & $\begin{array}{c}\text { CSDL } \\
\left(\mathrm{dpm} / \mathrm{cm}^{2}-\mathrm{yr}\right)\end{array}$ & YEAR & $\begin{array}{c}\text { SRDL } \\
\left.\mathrm{mCi} / \mathrm{km}^{2}-\mathrm{yr}\right)\end{array}$ & $\begin{array}{l}\text { CSDL } \\
\left.\mathrm{m} / \mathrm{cm}^{2}-\mathrm{yr}\right)\end{array}$ & YEAR & $\begin{array}{c}\text { SRDL } \\
\left(\mathrm{mCi} / \mathrm{km}^{2}-\mathrm{yr}\right)\end{array}$ & $\begin{array}{c}\text { CSDL } \\
\left(\mathrm{dpm} / \mathrm{cm}^{2}-\mathrm{yr}\right)\end{array}$ \\
\hline 1950.04 & 0 & 0 & 1952.96 & 0.0464 & 0.2583 & 1955.88 & 0.1187 & 0.6609 \\
\hline 1950.13 & 0 & 0 & 1953.04 & 0.0025 & 0.0139 & 1955.96 & 0.0422 & 0.235 \\
\hline 1950.21 & 0 & 0 & 1953.13 & 0.0042 & 0.0234 & 1956.04 & 0.9676 & 5.3874 \\
\hline 1950.29 & 0 & 0 & 1953.21 & 0.0339 & 0.1887 & 1956.13 & 0.099 & 0.5512 \\
\hline 1950.38 & 0 & 0 & 1953.29 & 0.1441 & 0.8023 & 1956.21 & 0.1213 & 0.6754 \\
\hline 1950.46 & 0 & 0 & 1953.38 & 0.0436 & 0.2428 & 1956.29 & 0.1933 & 1.0762 \\
\hline 1950.54 & 0 & 0 & 1953.46 & 0.1645 & 0.9159 & 1956.38 & 0.6048 & 3.3674 \\
\hline 1950.63 & 0 & 0 & 1953.54 & 0.1208 & 0.6726 & 1956.46 & 0.2893 & 1.6108 \\
\hline 1950.71 & 0 & 0 & 1953.63 & 0.0118 & 0.0657 & 1956.54 & 0.2008 & 1.118 \\
\hline 1950.79 & 0 & 0 & 1953.71 & 0.2528 & 1.4075 & 1956.63 & 0.3317 & 1.8468 \\
\hline 1950.88 & 0 & 0 & 1953.79 & 0.1713 & 0.9538 & 1956.71 & 0.1316 & 0.7327 \\
\hline 1950.96 & 0 & 0 & 1953.88 & 0.0151 & 0.0841 & 1956.79 & 0.0338 & 0.1882 \\
\hline 1951.04 & 0 & 0 & 1953.96 & 0.0296 & 0.1648 & 1956.88 & 0.3371 & 1.8769 \\
\hline 1951.13 & 0 & 0 & 1954.04 & 0.0229 & 0.1275 & 1956.96 & 0.1734 & 0.9654 \\
\hline 1951.21 & 0 & 0 & 1954.13 & 0.0227 & 0.1264 & 1957.04 & 0.1073 & 0.5974 \\
\hline 1951.29 & 0 & 0 & 1954.21 & 0.244 & 1.3585 & 1957.13 & 0.0871 & 0.485 \\
\hline 1951.38 & 0 & 0 & 1954.29 & 0.0638 & 0.3552 & 1957.21 & 0.1357 & 0.7555 \\
\hline 1951.46 & 0 & 0 & 1954.38 & 0.1503 & 0.8368 & 1957.29 & 0.1697 & 0.9448 \\
\hline 1951.54 & 0 & 0 & 1954.46 & 0.0789 & 0.4393 & 1957.38 & 0.0685 & 0.3814 \\
\hline 1951.63 & 0 & 0 & 1954.54 & 0.036 & 0.2004 & 1957.46 & 0.1183 & 0.6587 \\
\hline 1951.71 & 0 & 0 & 1954.63 & 0.1903 & 1.0595 & 1957.54 & 0.1654 & 0.9209 \\
\hline 1951.79 & 0 & 0 & 1954.71 & 0.0971 & 0.5406 & 1957.63 & 0.0987 & 0.5495 \\
\hline 1951.88 & 0 & 0 & 1954.79 & 0.0523 & 0.2912 & 1957.71 & 0.1699 & 0.946 \\
\hline 1951.96 & 0 & 0 & 1954.88 & 0.031 & 0.1726 & 1957.79 & 0.0346 & 0.1926 \\
\hline 1952.04 & 0.0628 & 0.3497 & 1954.96 & 0.0737 & 0.4103 & 1957.88 & 0.0907 & 0.505 \\
\hline 1952.13 & 0.0549 & 0.3057 & 1955.04 & 0.0511 & 0.2845 & 1957.96 & 0.0377 & 0.2099 \\
\hline 1952.21 & 0.0508 & 0.2828 & 1955.13 & 0.1041 & 0.5796 & 1958.04 & 0.0399 & 0.2222 \\
\hline 1952.29 & 0.0497 & 0.2767 & 1955.21 & 0.3411 & 1.8992 & 1958.13 & 0.0309 & 0.172 \\
\hline 1952.38 & 0.0472 & 0.2628 & 1955.29 & 0.1287 & 0.7166 & 1958.21 & 0.0265 & 0.1475 \\
\hline 1952.46 & 0.0921 & 0.5128 & 1955.38 & 0.5153 & 2.8691 & 1958.29 & 0.1922 & 1.0701 \\
\hline 1952.54 & 0.0552 & 0.3073 & 1955.46 & 0.234 & 1.3029 & 1958.38 & 0.1858 & 1.0345 \\
\hline 1952.63 & 0.0628 & 0.3497 & 1955.54 & 0.1708 & 0.951 & 1958.46 & 1.0578 & 5.8896 \\
\hline 1952.71 & 0.0567 & 0.3157 & 1955.63 & 0.0684 & 0.3808 & 1958.54 & 0.0225 & 0.1253 \\
\hline 1952.79 & 0.0965 & 0.5373 & 1955.71 & 2240.118 & 0.657 & 1958.63 & 2.2894 & 12.7468 \\
\hline 1952.88 & 0.0521 & 0.2901 & 1955.79 & 0.1302 & 0.7249 & 1958.71 & 0.2174 & 1.2104 \\
\hline
\end{tabular}




\begin{tabular}{|c|c|c|c|c|c|c|c|c|}
\hline \multicolumn{9}{|l|}{ Continue } \\
\hline 1958.79 & 0.2595 & 1.4448 & 1961.79 & 0.1151 & 0.6408 & 1964.79 & 0.545 & 3.0344 \\
\hline 1958.88 & 0.963 & 5.3618 & 1961.88 & 0.7306 & 4.0678 & 1964.88 & 0.305 & 1.6982 \\
\hline 1958.96 & 0.6971 & 3.8813 & 1961.96 & 0.1667 & 0.9281 & 1964.96 & 0.4008 & 2.2316 \\
\hline 1959.04 & 0.2746 & 1.5289 & 1962.04 & 0.1558 & 0.8675 & 1965.04 & 0.2403 & 1.3379 \\
\hline 1959.13 & 0.1001 & 0.5573 & 1962.13 & 0.6726 & 3.7449 & 1965.13 & 0.2698 & 1.5022 \\
\hline 1959.21 & 0.294 & 1.6369 & 1962.21 & 0.2765 & 1.5395 & 1965.21 & 0.1694 & 0.9432 \\
\hline 1959.29 & 1.0878 & 6.0566 & 1962.29 & 0.688 & 3.8306 & 1965.29 & 0.5369 & 2.9893 \\
\hline 1959.38 & 1.8101 & 10.0782 & 1962.38 & 2.7039 & 15.0547 & 1965.38 & 1.2258 & 6.825 \\
\hline 1959.46 & 0.5691 & 3.1686 & 1962.46 & 0.9165 & 5.1029 & 1965.46 & 0.6168 & 3.4342 \\
\hline 1959.54 & 0.1302 & 0.7249 & 1962.54 & 0.2995 & 1.6675 & 1965.54 & 0.6232 & 3.4698 \\
\hline 1959.63 & 0.4714 & 2.6246 & 1962.63 & 0.4164 & 2.3184 & 1965.63 & 0.3922 & 2.1837 \\
\hline 1959.71 & 0.104 & 0.579 & 1962.71 & 0.5469 & 3.045 & 1965.71 & 0.341 & 1.8986 \\
\hline 1959.79 & 0.125 & 0.696 & 1962.79 & 0.3606 & 2.0077 & 1965.79 & 0.1263 & 0.7032 \\
\hline 1959.88 & 0.0403 & 0.2244 & 1962.88 & 0.2754 & 1.5334 & 1965.88 & 0.162 & 0.902 \\
\hline 1959.96 & 0.0463 & 0.2578 & 1962.96 & 0.2276 & 1.2672 & 1965.96 & 0.1384 & 0.7706 \\
\hline 1960.04 & 0.1368 & 0.7617 & 1963.04 & 0.3426 & 1.9075 & 1966.04 & 0.0769 & 0.4282 \\
\hline 1960.13 & 0.0336 & 0.1871 & 1963.13 & 0.1694 & 0.9432 & 1966.13 & 0.0908 & 0.5056 \\
\hline 1960.21 & 0.3737 & 2.0807 & 1963.21 & 0.6992 & 3.893 & 1966.21 & 0.3758 & 2.0924 \\
\hline 1960.29 & 0.4556 & 2.5367 & 1963.29 & 2.8055 & 15.6204 & 1966.29 & 0.2065 & 1.1497 \\
\hline 1960.38 & 0.1027 & 0.5718 & 1963.38 & 1.9424 & 10.8148 & 1966.38 & 0.1608 & 0.8953 \\
\hline 1960.46 & 0.0651 & 0.3625 & 1963.46 & 4.6203 & 25.7247 & 1966.46 & 0.2037 & 1.1342 \\
\hline 1960.54 & 0.0223 & 0.1242 & 1963.54 & 1.6163 & 8.9992 & 1966.54 & 0.0504 & 0.2806 \\
\hline 1960.63 & 0.0228 & 0.1269 & 1963.63 & 1.9258 & 10.7224 & 1966.63 & 0.229 & 1.275 \\
\hline 1960.71 & 0.0885 & 0.4927 & 1963.71 & 0.7505 & 4.1786 & 1966.71 & 0.0643 & 0.358 \\
\hline 1960.79 & 0.0757 & 0.4215 & 1963.79 & 0.6602 & 3.6758 & 1966.79 & 0.0951 & 0.5295 \\
\hline 1960.88 & 0.1442 & 0.8029 & 1963.88 & 0.5955 & 3.3156 & 1966.88 & 0.0871 & 0.485 \\
\hline 1960.96 & 0.0862 & 0.4799 & 1963.96 & 0.503 & 2.8006 & 1966.96 & 0.0282 & 0.157 \\
\hline 1961.04 & 0.0553 & 0.3079 & 1964.04 & 0.7105 & 3.9559 & 1967.04 & 0.0697 & 0.3881 \\
\hline 1961.13 & 0.078 & 0.4343 & 1964.13 & 0.3639 & 2.0261 & 1967.13 & 0.0452 & 0.2517 \\
\hline 1961.21 & 0.1765 & 0.9827 & 1964.21 & 0.6467 & 3.6007 & 1967.21 & 0.1251 & 0.6965 \\
\hline 1961.29 & 0.1424 & 0.7928 & 1964.29 & 1.9367 & 10.7831 & 1967.29 & 0.1259 & 0.701 \\
\hline 1961.38 & 0.3694 & 2.0567 & 1964.38 & 3.4985 & 19.4788 & 1967.38 & 0.0577 & 0.3213 \\
\hline 1961.46 & 0.3429 & 1.9092 & 1964.46 & 2.5009 & 13.9244 & 1967.46 & 0.1238 & 0.6893 \\
\hline 1961.54 & 0.0745 & 0.4148 & 1964.54 & 0.7592 & 4.227 & 1967.54 & 0.0806 & 0.4488 \\
\hline 1961.63 & 0.0508 & 0.2828 & 1964.63 & 0.9254 & 5.1524 & 1967.63 & 0.1274 & 0.7093 \\
\hline 1961.71 & 0.0472 & 0.2628 & 1964.71 & 0.5938 & 3.3061 & 1967.71 & 0.0179 & 0.0997 \\
\hline
\end{tabular}




\begin{tabular}{|c|c|c|c|c|c|c|c|c|}
\hline \multicolumn{9}{|l|}{ Continue } \\
\hline 1967.79 & 0.0422 & 0.235 & 1970.79 & 0.0728 & 0.4053 & 1973.79 & 0.0082 & 0.0457 \\
\hline 1967.88 & 0.0236 & 0.1314 & 1970.88 & 0.0521 & 0.2901 & 1973.88 & 0.0436 & 0.2428 \\
\hline 1967.96 & 0.0331 & 0.1843 & 1970.96 & 0.0369 & 0.2055 & 1973.96 & 0.0232 & 0.1292 \\
\hline 1968.04 & 0.035 & 0.1949 & 1971.04 & 0.0482 & 0.2684 & 1974.04 & 0.0149 & 0.083 \\
\hline 1968.13 & 0.0959 & 0.5339 & 1971.13 & 0.0467 & 0.26 & 1974.13 & 0.017 & 0.0947 \\
\hline 1968.21 & 0.1432 & 0.7973 & 1971.21 & 0.0607 & 0.338 & 1974.21 & 0.0506 & 0.2817 \\
\hline 1968.29 & 0.1428 & 0.7951 & 1971.29 & 0.1175 & 0.6542 & 1974.29 & 0.1021 & 0.5685 \\
\hline 1968.38 & 0.1491 & 0.8302 & 1971.38 & 0.3734 & 2.079 & 1974.38 & 0.1197 & 0.6665 \\
\hline 1968.46 & 0.1977 & 1.1007 & 1971.46 & 0.3601 & 2.005 & 1974.46 & 0.1489 & 0.829 \\
\hline 1968.54 & 0.2077 & 1.1564 & 1971.54 & 0.1972 & 1.098 & 1974.54 & 0.0819 & 0.456 \\
\hline 1968.63 & 0.0725 & 0.4037 & 1971.63 & 0.1248 & 0.6949 & 1974.63 & 0.0917 & 0.5106 \\
\hline 1968.71 & 0.0836 & 0.4655 & 1971.71 & 0.0494 & 0.275 & 1974.71 & 0.0584 & 0.3252 \\
\hline 1968.79 & 0.0735 & 0.4092 & 1971.79 & 0.0575 & 0.3201 & 1974.79 & 0.0317 & 0.1765 \\
\hline 1968.88 & 0.0156 & 0.0869 & 1971.88 & 0.0503 & 0.2801 & 1974.88 & 0.0265 & 0.1475 \\
\hline 1968.96 & 0.0286 & 0.1592 & 1971.96 & 0.0187 & 0.1041 & 1974.96 & 0.019 & 0.1058 \\
\hline 1969.04 & 0.0597 & 0.3324 & 1972.04 & 0.0444 & 0.2472 & 1975.04 & 0.0633 & 0.3524 \\
\hline 1969.13 & 0.0322 & 0.1793 & 1972.13 & 0.0389 & 0.2166 & 1975.13 & 0.041 & 0.2283 \\
\hline 1969.21 & 0.0231 & 0.1286 & 1972.21 & 0.0595 & 0.3313 & 1975.21 & 0.0675 & 0.3758 \\
\hline 1969.29 & 0.1225 & 0.6821 & 1972.29 & 0.0406 & 0.2261 & 1975.29 & 0.037 & 0.206 \\
\hline 1969.38 & 0.0748 & 0.4165 & 1972.38 & 0.0866 & 0.4822 & 1975.38 & 0.0411 & 0.2288 \\
\hline 1969.46 & 0.122 & 0.6793 & 1972.46 & 0.0538 & 0.2995 & 1975.46 & 0.0512 & 0.2851 \\
\hline 1969.54 & 0.0873 & 0.4861 & 1972.54 & 0.0797 & 0.4438 & 1975.54 & 0.0312 & 0.1737 \\
\hline 1969.63 & 0.1641 & 0.9137 & 1972.63 & 0.0521 & 0.2901 & 1975.63 & 0.0097 & 0.054 \\
\hline 1969.71 & 0.0458 & 0.255 & 1972.71 & 0.0159 & 0.0885 & 1975.71 & 0.0162 & 0.0902 \\
\hline 1969.79 & 0.0628 & 0.3497 & 1972.79 & 0.0087 & 0.0484 & 1975.79 & 0.0107 & 0.0596 \\
\hline 1969.88 & 0.0152 & 0.0846 & 1972.88 & 0.0128 & 0.0713 & 1975.88 & 0.0231 & 0.1286 \\
\hline 1969.96 & 0.0191 & 0.1063 & 1972.96 & 0.0332 & 0.1848 & 1975.96 & 0.0089 & 0.0496 \\
\hline 1970.04 & 0.0674 & 0.3753 & 1973.04 & 0.0096 & 0.0535 & 1976.04 & 0.011 & 0.0612 \\
\hline 1970.13 & 0.0172 & 0.0958 & 1973.13 & 0.0304 & 0.1693 & 1976.13 & 0.007 & 0.039 \\
\hline 1970.21 & 0.0189 & 0.1052 & 1973.21 & 0.023 & 0.1281 & 1976.21 & 0.0298 & 0.1659 \\
\hline 1970.29 & 0.1039 & 0.5785 & 1973.29 & 0.0272 & 0.1514 & 1976.29 & 0.0128 & 0.0713 \\
\hline 1970.38 & 0.3123 & 1.7388 & 1973.38 & 0.056 & 0.3118 & 1976.38 & 0.0114 & 0.0635 \\
\hline 1970.46 & 0.1396 & 0.7773 & 1973.46 & 0.0238 & 0.1325 & 1976.46 & 0.015 & 0.0835 \\
\hline 1970.54 & 0.2695 & 1.5005 & 1973.54 & 0.0351 & 0.1954 & 1976.54 & 0.0108 & 0.0601 \\
\hline 1970.63 & 0.1602 & 0.892 & 1973.63 & 0.0165 & 0.0919 & 1976.63 & 0.0035 & 0.0195 \\
\hline 1970.71 & 0.0566 & 0.3151 & 1973.71 & 0.01 & 0.0557 & 1976.71 & 0.0036 & 0.02 \\
\hline
\end{tabular}




\begin{tabular}{|c|c|c|c|c|c|}
\hline \multicolumn{6}{|l|}{ Continue } \\
\hline 1976.79 & 0.0025 & 0.0139 & 1979.79 & 0.0116 & 0.0646 \\
\hline 1976.88 & 0.0052 & 0.029 & 1979.88 & 0.0036 & 0.02 \\
\hline 1976.96 & 0.0081 & 0.0451 & 1979.96 & 0.0037 & 0.0206 \\
\hline 1977.04 & 0.0085 & 0.0473 & 1980.04 & 0.0104 & 0.0579 \\
\hline 1977.13 & 0.0059 & 0.0328 & 1980.13 & 0.0038 & 0.0212 \\
\hline 1977.21 & 0.0321 & 0.1787 & 1980.21 & 0.0039 & 0.0217 \\
\hline 1977.29 & 0.0303 & 0.1687 & 1980.29 & 0.0064 & 0.0356 \\
\hline 1977.38 & 0.0529 & 0.2945 & 1980.38 & 0.0103 & 0.0573 \\
\hline 1977.46 & 0.0975 & 0.5429 & 1980.46 & 0.0173 & 0.0963 \\
\hline 1977.54 & 0.0823 & 0.4582 & 1980.54 & 0.0133 & 0.0741 \\
\hline 1977.63 & 0.093 & 0.5178 & 1980.63 & 0.0116 & 0.0646 \\
\hline 1977.71 & 0.0623 & 0.3469 & 1980.71 & 0.0082 & 0.0457 \\
\hline 1977.79 & 0.0355 & 0.1977 & 1980.79 & 0.0055 & 0.0306 \\
\hline 1977.88 & 0.0421 & 0.2344 & 1980.88 & 0.0024 & 0.0134 \\
\hline 1977.96 & 0.0366 & 0.2038 & 1980.96 & 0.0065 & 0.0362 \\
\hline 1978.04 & 0.033 & 0.1837 & & & \\
\hline 1978.13 & 0.0179 & 0.0997 & & & \\
\hline 1978.21 & 0.0298 & 0.1659 & & & \\
\hline 1978.29 & 0.0609 & 0.3391 & & & \\
\hline 1978.38 & 0.1155 & 0.6431 & & & \\
\hline 1978.46 & 0.1092 & 0.608 & & & \\
\hline 1978.54 & 0.1094 & 0.6091 & & & \\
\hline 1978.63 & 0.0657 & 0.3658 & & & \\
\hline 1978.71 & 0.0256 & 0.1425 & & & \\
\hline 1978.79 & 0.0098 & 0.0546 & & & \\
\hline 1978.88 & 0.0227 & 0.1264 & & & \\
\hline 1978.96 & 0.0163 & 0.0908 & & & \\
\hline 1979.04 & 0.0125 & 0.0696 & & & \\
\hline 1979.13 & 0.0113 & 0.0629 & & & \\
\hline 1979.21 & 0.0294 & 0.1637 & & & \\
\hline 1979.29 & 0.0127 & 0.0707 & & & \\
\hline 1979.38 & 0.0447 & 0.2489 & & & \\
\hline 1979.46 & 0.0502 & 0.2795 & & & \\
\hline 1979.54 & 0.0306 & 0.1704 & & & \\
\hline 1979.63 & 0.0133 & 0.0741 & & & \\
\hline 1979.71 & 0.0106 & 0.059 & & & \\
\hline
\end{tabular}


Appendix - 7. ${ }^{137} \mathrm{Cs}$ activities and fluxes in 2000 sediment traps

\begin{tabular}{|c|c|c|c|c|c|c|}
\hline Transect & $\begin{array}{l}\text { Water depth } \\
(\mathrm{m})\end{array}$ & $\begin{array}{l}\text { Trap depth } \\
\text { (m) }\end{array}$ & $\begin{array}{l}\text { Retrieval } \\
\text { Date }\end{array}$ & $\begin{array}{l}\text { Mass Flux } \\
\left(\mathrm{g} / \mathrm{m}^{2}-\mathrm{d}\right)\end{array}$ & $\begin{array}{c}{ }^{137} \mathrm{Cs} \\
(\mathrm{dpm} / \mathrm{g})\end{array}$ & $\begin{array}{l}{ }^{137} \text { Cs flux } \\
\left(\mathrm{dpm} / \mathrm{m}^{2} \mathrm{~d}\right)\end{array}$ \\
\hline $\mathrm{EH}$ & 50 & 35 & 16-May-00 & 1.61 & 13.41 & 21.59 \\
\hline $\mathrm{EH}$ & 50 & 40 & 16-May-00 & 1.59 & 12.24 & 19.41 \\
\hline $\mathrm{EH}$ & 50 & 45 & 16-May-00 & 1.96 & 10.99 & 21.59 \\
\hline ON & 50 & 35 & 10-Jun-00 & 1.34 & 14.05 & 18.84 \\
\hline ON & 50 & 40 & 10-Jun-00 & 1.78 & 14.00 & 24.86 \\
\hline ON & 50 & 45 & 10-Jun-00 & 2.43 & 10.41 & 25.31 \\
\hline ON & 50 & 35 & 19-Jun-00 & 1.46 & 12.89 & 18.75 \\
\hline ON & 120 & 35 & 19-Jun-00 & 0.63 & 21.92 & 13.83 \\
\hline ON & 120 & 110 & 19-Jun-00 & 1.04 & 18.35 & 19.10 \\
\hline ON & 120 & 115 & 19-Jun-00 & 1.06 & 20.21 & 21.49 \\
\hline $\mathrm{EH}$ & 50 & 35 & 20-Jun-00 & 1.47 & 14.52 & 21.34 \\
\hline $\mathrm{EH}$ & 50 & 40 & 20-Jun-00 & 1.67 & 12.90 & 21.49 \\
\hline $\mathrm{EH}$ & 50 & 45 & 20-Jun-00 & 1.76 & 7.39 & 13.02 \\
\hline ON & 50 & 40 & 29-Jul-00 & 0.90 & 9.87 & 8.84 \\
\hline ON & 120 & 110 & 29-Jul-00 & 0.71 & 17.66 & 12.51 \\
\hline ON & 50 & 40 & 24-Aug-00 & 0.47 & 13.27 & 6.17 \\
\hline ON & 120 & 35 & 25-Sep-00 & 0.31 & 12.96 & 4.02 \\
\hline ON & 120 & 110 & 25-Sep-00 & 1.58 & 20.63 & 32.62 \\
\hline ON & 120 & 115 & 25-Sep-00 & 2.21 & 22.22 & 49.17 \\
\hline $\mathrm{EH}$ & 50 & 35 & 26-Sep-00 & 5.74 & 8.84 & 50.74 \\
\hline $\mathrm{EH}$ & 50 & 40 & 26-Sep-00 & 6.62 & 6.19 & 40.94 \\
\hline $\mathrm{EH}$ & 50 & 45 & 26-Sep-00 & 7.60 & 5.90 & 44.87 \\
\hline
\end{tabular}


Appendix - 8. Laboratory procedures

1) Sediment core extrusion procedure

\section{General procedure}

Cores will be extruded in increments of $0.5-\mathrm{cm}(0-5 \mathrm{~cm}), 1-\mathrm{cm}(6-15 \mathrm{~cm})$, and $2.5-\mathrm{cm}$ (remainder) thickness. Total wet weight will be determined immediately after the complete core has been extruded. Core increments will be distributed among the following containers:

1. Pre-weighed beaker (50-mL) - to be oven dried, (reweighed), ground (mortar \& pestle), and packaged (plastic vials) for analysis of LOI, C, N, Fe, Mn, $\mathrm{TP},{ }^{210} \mathrm{~Pb}$, inorg. C., archival

2. Small whirlpak bags - freeze for later analysis (e.g., grain size).

\section{STEPWISE INSTRUCTIONS}

1. Measure height of sediments and weigh and label the appropriate numbers of beakers and bags;

2. As each core increment is extruded, transfer the entire amount to a pre-weighed beaker;

3. After the core is entirely extruded, weigh the beakers plus wet sediments and record weights.

4. Transfer $1 / 4$ of sediment from beaker to a whirl-pak bag to be frozen;

6. Weigh and record wt. of beaker and remaining sediment;

7. Dry the sediment in the beaker at $100^{\circ} \mathrm{C}$ for at least $24 \mathrm{hr}$;

8. Weigh the dry sediment plus beaker and record wt.

9. Scrape sediment from beaker into mortar and grind with the pestle, then transfer to plastic scintillation vial; label the vial.

\section{Procedure for Loss on Ignition (LOI)}

Ideally, sediments should be freshly dried in the oven or desiccator.

1. Label aluminum pans by scratching with a pencil

2. Weigh empty aluminum pans

3. With pan on balance, add between 0.5 and 1.0 g sediment, record weight;

4. Place pans in muffle furnace ( $\mathrm{Rm} 833$ ), turn it on at $550^{\circ} \mathrm{F}$, leave overnight

5. Turn off muffle furnace, open lower door to allow to cool;

6. When pans are cool, remove them to a desiccator;

7. After another 15-30 minutes, weigh the pans. 


\title{
2) Radiochemical procedures for alpha $\left({ }^{210} \mathrm{Po}\right)$ measurements.
}

\author{
Lead-210 Dating by the 210Po Method
}

Modified from Eakins \& Morrison (1978) and Blake and Norton (unpub.)

by D.R. Engstrom (6/85)

\section{Sediment Preparation}

This section is most efficient if 16 or 24 samples are processed at one time.

(1) Dry sediment in polypropylene beaker for $24 \mathrm{hr}$ at $100^{\circ} \mathrm{C}$ using sufficient wet material to yield $0.5-3 \mathrm{~g}$ dry. Grind to a fine powder in mortar and pestle, return to beaker and cover.

(2) Place a 1-3 g aliquot of dried sediment at the bottom of a labeled $25 \times 150 \mathrm{~mm}$ borosilicate test tube. Draw a line around the test tube 2.5 inches from the bottom with a black marking pen. To insure that no sediment adheres to the walls of the tube, first place the sediment in a 2-dram glass vial. Weigh the vial (with sediment) on an analytical balance, place the vial (using forceps) on the end of the "vial extractor" (a wooden dowel with double-sided tape on one end), and cover with a test tube. Invert, shake the sediment from the vial and lift out with extractor. Obtain the tare weight of the vial taking care not to lose any of the adhering fine sediment.

(3) With a Pasteur pipette, add one volume of conc. $\mathrm{HCl}$ (two volumes if carbonate is abundant) to the sediment and stir with a glass rod. Take care that carbonate sediments do not bubble out of the test tube; use a fine spray of methanol to control severe effervescence. Using as little distilled water as possible, rinse the stirring rod and lower walls of the tube so that no sediment adheres above the mark.

(4) Add ${ }^{209}$ Po tracer solution of known activity (about $4 \mathrm{pCi} / \mathrm{g}$ ) to the test tube with an volumetric pipette; avoid touching the walls of the test tube with the pipette tip. The tracer weight should be determined simultaneously on an analytical balance. Thoroughly mix the contents of the test tube by gentle swirling (stir with a glass rod if sediment slurry is thick).

- Cover the work area where the ${ }^{209} \mathrm{Po}$ is dispensed with an absorbent bench pad.

- Wear rubber gloves when handling ${ }^{209}$ Po tracer.

- Discard the pipette tip in a container for radioactive wastes.

(5) Heat the test tube for $48 \mathrm{hr}$. in an upright position at $100^{\circ} \mathrm{C}$, using a block heater in a wellventilated hood. The contents should be completely dry before proceeding. Cover the tubes with foil and store.

\section{Glassware Cleaning}

All laboratory-ware in contact with Polonium solutions should be thoroughly cleaned to prevent carry-over between samples. Glass items (beakers, watch-glasses, thermometers, stirring rods) should be rinsed under tap water and placed in a detergent solution for initial cleaning. Planchet holders should be cleaned of rubber cement before the detergent bath, and magnetic stir bars should be soaked in a small beaker of methanol separate from the other glassware. The glassware should be scrubbed with a brush and rinsed under tap water. A brown organic film will typically remain around the insides of the beakers, on thermometers, stir-bars, and the stem of the planchet holders - this should be removed by scrubbing with a lab wipe soaked in methanol. After the initial cleaning, glassware should be soaked (preferably overnight) in a 0.5 
$M \mathrm{HCl}$ acid bath, rinsed with distilled water, and left to air dry. Forceps should be cleaned periodically with methanol to remove any organic film. Rubber gloves should be worn when cleaning glassware.

\section{Extraction}

Proceed with eight samples at a time.

(1) Push a 3-cm plug of pyrex wool (saturated with distilled water and expressed to remove all excess moisture) into the upper end of the test tube. The plug should fit snugly (but uncompacted) and not extend below the top $5 \mathrm{~cm}$ of the tube; no water should drip from it.

(2) Insert the closed end of the test tube into a horizontal tube-furnace that has been pre-heated to $575 \pm 25^{\circ} \mathrm{C}$. Make sure that the tube below the mark is heated but not the wetted plug. Heat for 30-40 minutes.

(3) Preheat $50 \mathrm{ml}$ of $0.5 \mathrm{~N} \mathrm{HCl}$ in a labeled $200-\mathrm{ml}$ tall-form beaker to $100^{\circ} \mathrm{C}$; the beaker should be covered with a watch glass to prevent evaporation of the acid.

(4) Prepare a silver planchet for plating. Clean one side (the front) with methanol and coat the back side with rubber cement. Push the end of a planchet holder into the wet cement and allow a few minutes for drying. Clean any excess cement from the front face of the planchet with a cotton swab and methanol.

(5) Remove a test tube from the furnace and place on its side. While it is still hot put a few drops of distilled water on the mark to crack the glass. Tap the test tube on a sharp edge and separate the tube into two halves; discard the lower end in a sharps container for radioactive wastes.

(6) Place the upper end of the tube in a correspondingly labeled beaker and push the glass wool from the tube with a glass rod. Replace the watch-glass cover and reflux the wool and tube for 30 minutes at boiling.

(7) Remove the tube and glass wool with a plastic forceps and wash with a stream of distilled water into the beaker. Be sure that the wool is well rinsed. Discard the wool and tube in a sharps container for radioactive wastes. The final volume should be about $60 \mathrm{ml}$.

\section{Plating}

3. Measure the $\mathrm{pH}$, adjust to between 0.5 and 1.0, use $\mathrm{HCl}$ or $\mathrm{NaOH}$.

4. Add 0.1 to $0.2 \mathrm{gms}$ of Ascorbic acid to each sample and dissolve. The ascorbic acid is added to form a complex with ferric irọn, thereby preventing its possible interference with the Po-210 plating.

5. Transfer the sample to a $125 \mathrm{~mL}$ plastic bottle, rinse the flask 3 times.

6. Polish the preveously labeled disk with polishing , rub it off with a Kimwipe.

7. Add the disk to the sample in the plastic bottle, make sure the polished side is up. cap the bottle.

8. Place the bottle in a $95^{\circ} \mathrm{C}$ oven. Heat over night.

9. Remove the samples from the oven., to remove the copper disk, tighten the cap on the bottle and turn it upside down, the copper disk should be in the cap. Slowly tum the bottle over, the disk should remain in the cap.

10. Remove the disk, rinse with type 1 water then with ethanol, pat dry( do not rub), place in a plastic zip lock bag. The bag should be labeled with the sample ID, date digested and the date plated. 
Appendix - 9. Computer code (in Fortran) of the Niebauer model as modified for isotope modeling.

The model is comprised of two parts, one is the original code from Niebauer and the other one is the isotope related part added just for this research. Although the two are joined seamlessly, it is still possible to disable all the isotope-related parts and run the original Niebauer model.

As mentioned in chapter four, some scenarios can be modeled according to the brief instructions below.

1) Upwelling events. Search for "Up-welling", to find a subroutine named Wind_stress(); Change the wind direction from $T Y(\mathrm{~J})=0$ to $T Y(\mathrm{~J})=1$ at desired times (events); a single (or a series of) upwelling event(s) can be achieved.

2) Various air-sea heat exchanges. Search for heat flux to water to change the solar energy input into the top layer of water column. The default value is $1.34 \mathrm{cal} / \mathrm{cm}^{2}$-min, which is the solar constant at the earth's surface. Similarly to the upwelling events mentioned above, the change in air-sea heating exchanges can also be modeled as discrete events. The events may include but are not limited to changing of cloud covering and forming and melting of ice cover.

More details above the theory and application for the original model can be found in the reference: Niebauer, H.J., Physical-biological numerical modeling on Alaskan Arctic shelves, pp. 84, Institute of Marine Sciences, University of Alaska Fairbanks, Fairbanks, AK, 2002. 
2-D Lake Superior Hydro-Dynamic Model

$$
\text { orignal code: 'Flip-Flat' }
$$

LAKE SUPERIOR TO FLAT ...VERSION OF 5/20/03

THIS VERSION USES DENSITY=D(T, $S, p)$
THIS VERSION IS ALSO TURNED OVER TO AGGREGATION

integrates over, say, $30 \mathrm{~km}$ for $\mathrm{kg} \mathrm{C}$ at $27 \%$

(7) USE EDIT TO GO FIND THESE:

CHECK 1 is where vertfx is calculated for the depth of CHECK sumfCz. Depth where flux is captured

is where you set depth for particle flux spectra

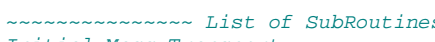

transport $\quad$....... Sets initial mass transport

Initial Ice

Initial Nutrient

...... Sets initial ice cover

Initial Physics $\quad$......... Initial velocity, temp

Density

Richardson

. Calculate density

........Calculate light/extinction

Ice Flux

Calculate a Richardson \#

........set wind conditions

Primary Production

...... Calculate heat flux from ice

.........check kinetic energy for valid solution

white $x$-Sections Divergence

Write Time series $\quad . . . .$. ...

Fluxes $\quad$............

Agg

........ Finite diffuxes for finite dif

Isotope

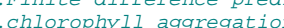

\section{IMPLICIT REAL* $8(A-H, O-Z)$}

!PARAMETER ( $N=94, N M=93, N P=92, M=46, M M=45, M P=44)$

INCUDE ' $C$ IdFIl

!DIMENSION PP $(M, N)$, SUMFCZ $(M, N)$

ALAT $=48 * 0.0174593$

for Superior

$F=0.000145444 * \operatorname{SIN}($ ALAT)

* OPEN(UNIT=2, FILE='TIMEFile.txt', STATUS=' unknown')

!Reads time

Read $\left(2,{ }^{*}\right)$ Duration, AJUL, FREQ

Close (UNIT=2)

Duration $=56$

runing time, start date and sampling fred

AJUL $=121$

AJUL $=151$

\section{$\mathrm{NT}=144^{*}$ Duration}

NTP $=144^{*}$ Freq

$\mathrm{DT}=600$.

(10 minutes)
$\mathrm{H}=23000$

$H=23000$.
$W L=9400000$.

!Time Step

$! \mathrm{cm}$

$\mathrm{DX}=\mathrm{WL} / \mathrm{N}$
$\mathrm{DZ}=\mathrm{H} / \mathrm{M}$

$\mathrm{DD}=\left(2,{ }^{*} \mathrm{DT}\right) / \mathrm{DZ}$

$\mathrm{DC}$
$\mathrm{DC}=\left(2,{ }^{*} \mathrm{DT}\right) / \mathrm{DX}$

$\mathrm{DH}=\mathrm{DZ} /(\mathrm{DX} * 2$.

$\mathrm{DI}=\left(\mathrm{DZ}^{*} \mathrm{DT}\right) /\left(\mathrm{DX}^{*} 2\right.$. $)$

reference depth coordinate $(k s * d t)$

set a

eed $\mathrm{k} 77=$

!may not

$!$ as time

luck $=2$

\section{$K R=N T P / 2$}

$\underset{\mathrm{K}=\mathrm{M}-1}{\cos }$ to file

!\# of days

$\mathrm{NTT}=\mathrm{NT} / 2$

steps forward and backward

DO 5 I $=1$, NTT

$\mathrm{TI}(\mathrm{I}+1)=\mathrm{TI}(\mathrm{I})+\left(2 .{ }^{*} \mathrm{DT}\right) / 3600$

! time

! Uunit in

5 CONTINUE

PBDECY $M=\operatorname{LOG}(2.0) / 22.3 / 365 / 24 / 60$

$! 210 P b$

decay rate in min-1
PODECY_M = LOG(2.0)/138./24/60

PBDECY_M $=\operatorname{LOG}(2.0) / 22.3 / 365 / 24 / 60^{*}(22.3 * 365 / 20)$

0) $/ 138.124 / 60 *(22.3 * 365 / 20)$

Call to Initialization Routines

Call Mass_Transport_Initial()

Call Geometry()

Call Physics_Initial()

call Isotope initial()

call Light()

Call Density()

Call Richardson() 
Main Loop Iterations

Do 2 IT $=1$, NTT

Call Wind_Stress()

call PP_Integrate(

WRITE $(*, *) \operatorname{IT}, C 1 A(2,1$

$77, \operatorname{TTX}(5), C W I$

CALL FLUXES(UB, VB, TB, SB, ZN03B, ZNH4B, C1B, C2B, C3B, C4B,

$\$ C 5 B, C 6 B, C 7 B, C 8 B, C 9 B, C 10 B, Z L B, Z S B, U A, V A, T A$, SA, ZNO3A,

\$ZNHA, C1A, C2A, C3A, C $4 A, C 5 A, C 6 A, C 7 A, C B A, C 9 A, C 1$ CA, ZLA, ZSA

CUA VA, TA, SA, PBPABA, PBDISA, POPARA, PODISA)

CALL SPM_FLUX(UB, VB, TB, SB, SPMB, UA, VA, TA, SA, SPMA)

WRITE $(*, *) \operatorname{IT}, \operatorname{CIA}(2,1), K 77, \operatorname{TTX}(5), \operatorname{CWI}$

CALL PREDIC(UA, VA, TA, SA, ZNO3A, ZNH4A, C1A, C2A, C3A, C4A,

$\$ C 5 A, C 6 A, C 7 A, C 8 A, C 9 A, C 10 A, Z L A, Z S A, U B, V B, T B, S B, Z N 03 B$,

列

\$PODISA, POPARB, PODISB)

CALL SPM PREDIC (SPMA, SPMB)

CALL FLUXES(UA, VA, TA, SA, ZNO3A, ZNH4A, C1A, C2A, C3A, C4A,

$\$ C 5 A, C 6 A, C 7 A, C 8 A, C 9 A, C 1 O A, Z L A, Z S A, \cup B, V B$, TB, SB, ZNO3B,

CZNHAB, C1B, $2 B, C 3 B, C 4 B, C 5 B, C 6 B, C 7 B, C B B, C D B, C 10 B, Z L B, Z S B$ )

\$UB, VB, TB, SB, PBPARB, PBDISB, POPARB, PODISB)
CALL SPM FLUX(UA, VA, TA, SA, SPMA, UB, VB, TB, SB, SPMB)

CALL PREDIC (UB, VB, TB, SB, ZN03B, ZNH4B, C1B, C2B, C3B, C4B,

$\$ C 5 B, C 6 B, C 7 B, C 8 B, C 9 B, C 10 B, Z L B, Z S B, U A, V A$, TA, SA, ZNO3A,

\$ZNH4A, C1A, C2A, C3A, C4A, C5A, C6A, C7A, C8A, C9A, C10A, ZLA, ZSA

CALL SPM PREDIC (SPMB, SPMA)

CALL PARTATION(PBDISA, PBPARA, SPMA, PODISA, POPARA)

Call Kinetic_Energy()

Call FD_Diverge()

CALL RESUSPENSION(
CALL SEDIMENT()

TIME $=2 .{ }^{*} \mathrm{DT}^{*} \mathrm{IT}$

TIME2 $=$ TIME/3600.

TPLT $=\left(\operatorname{TIME}-\left(2,{ }^{*} \mathrm{DT}\right)\right) / 86400$

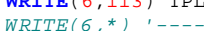

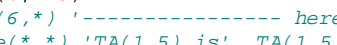

Write $\left(*^{*}{ }^{*}\right)$ 'TA(1,5) is', TA(1,5)
113 FORMAT $\left(\left(1 x_{1}, 17 F 6.2\right)\right)$

Call Write_X_Section( )

2 Continue

Call Write_Time_Series()

STOP

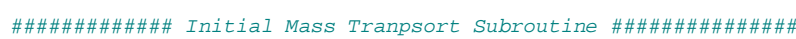
Subroutine Mass_Transport_Initial(

IMPLICIT REAL*8(A-H, O-Z)

PARAMETER ( $N=94, N M=93, N P=92, M=46, M M=45, M P=44)$

INCLUDE 'Gridfile. F'
Initial verical and horizontal diffusivity coeff.

Can be changed AKZ=1.

$A X=16000$

AXS $=100000$

$\mathrm{ANH} 4 \mathrm{X}=1$
$\mathrm{ANH} 4 \mathrm{Z}=1$

$A C 1 X=100000$

$A C 1 Z=1$

IAmmonia Coeff.

Chlorophyll

different

! Large

Small

AZton coeff

calc for

finite diff routine

$D F S=A X S / D X$
$D A=A K Z / D Z$

$D A=A K Z / D Z$

DNO3X=ANO3X/DX

DNH4Z=ANH4Z/DZ

$D C 1 X=A C 1 X / D X$

$\mathrm{DC} 1 Z=A C 1 Z / D Z$
$\mathrm{DC} 2 \mathrm{X}=\mathrm{AC} 2 \mathrm{X} / \mathrm{DX}$

$\mathrm{DC} 2 \mathrm{Z}=\mathrm{AC} 2 \mathrm{Z} / \mathrm{DZ}$

$\mathrm{DC} 3 \mathrm{X}=\mathrm{AC} 3 \mathrm{X} / \mathrm{DX}$

$D C 3 Z=A C 3 Z / D Z$

$\mathrm{DC} 4 \mathrm{X}=\mathrm{AC} 4 \mathrm{X} / \mathrm{DX}$

$D C 4 Z=A C 4 Z / D Z$

DCSX $=A C 5 X D X$
$D C 5 Z=A C 5 / D Z$

$\mathrm{DC} 6 \mathrm{X}=\mathrm{AC} 6 \mathrm{X} / \mathrm{DX}$

$\mathrm{DC} 6 \mathrm{Z}=\mathrm{AC} 6 \mathrm{Z} / \mathrm{DZ}$

$\mathrm{DC} 7 \mathrm{X}=\mathrm{AC7X} / \mathrm{DX}$
$\mathrm{DC} 7 \mathrm{Z}=\mathrm{AC} 7 \mathrm{Z} / \mathrm{DZ}$ 


\section{$\mathrm{DC} 8 \mathrm{X}=\mathrm{AC} 8 \mathrm{X} / \mathrm{DX}$ \\ $\mathrm{DC} 8 \mathrm{Z}=\mathrm{AC} 8 \mathrm{Z} / \mathrm{DZ}$ \\ DC9Z=AC9Z/DZ \\ DC10X $=A C 10 X / D X$
DC10Z=AC10Z/DZ \\ $D Z L X=A Z L X / D X$ \\ $D Z L Z=A Z L Z / D Z$
$D Z S X=A Z S X / D X$ \\ DZSZ $=A Z S Z / D Z$ \\ isotope part. \\ APBDX $=100000$ \\ APBDZ $=1$.
APBPX $=100000$ \\ coeff. \\ $A P B P Z=1$ \\ $\mathrm{DPBDX}=\mathrm{APBDX} / \mathrm{DX}$ \\ DPBDZ=APBDZ/DZ \\ DPBPX $=A P B P X / D X$
DPBPZ=APBPZ/DZ \\ APODX $=100000$ \\ P0210 Coeff
AfDZ \\ AfDZ $=1$.
APOPX $=100000$. \\ P0210 Coeff. \\ APOPZ $=1$.
DPODX $=A P O D X / D X$ \\ $D P O D Z=A P O D Z / D Z$ \\ $D P O P X=A P O P X / D X$ \\ ASPMX $=100000$. \\ ASPMZ $=1$. \\ DSPMX $=$ ASPMX/DX
DSPMZ $=$ ASPMZ/DZ \\ Retur}

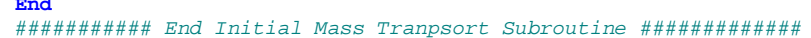

!Disolved

!Particulate

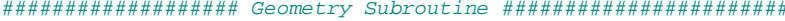
Subroutine Geometry ( )
IMPLICIT REAL*8(A-H, $0-2)$

!PARAMETER $(N=94, N M=93, N P=92, M=46, M M=45, M P=44)$

INCLUDE 'GridFile.f'

$\operatorname{DEPTH}(1)=(\mathrm{DZ} / 2) /$.

Do $10 \mathrm{I}=2, \mathrm{M}$

!Set cell

10 DEPTH(I) $=$ DEPTH $(\mathrm{I}-1)+(\mathrm{DZ} / 100$. DO $11 \mathrm{~J}=2, \mathrm{~N}$

$\operatorname{DIST}(\mathrm{J})=\operatorname{DIST}(\mathrm{J}-1)+(\mathrm{DX} / 1000000$.
CONTINUE

*

$$
\text { Do } 12 \mathrm{~J}=1 \text {, }
$$

depth dimension for flat bottom

12 CONTINUE

!Disolved

Particulate depth dimension for triangular botton

$$
\begin{aligned}
& K=M-1 \\
& D O J=1, K \\
& N K(J)=J \\
& N K(N+1-J)=J \\
& E N D D O
\end{aligned}
$$

Do $83 \mathrm{~J}=2$, NM

$3 N$ NVGP=NVGP+NK ( J ) -

!\# of velocity gridpoints

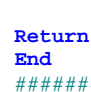

End

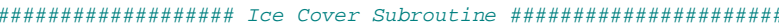

Subroutine Ice Cover ()

! PARAMETER $(N=94, N M=93, N P=92, M=46, M M=45, M P=44)$

INCLUDE 'Gri

INCLUDE 'comblk-r25.f'

anything less than or equal to iedge is ice-fre

IEDGE $=100$
ROICE $=0.917$

water DICE $=100$.

thickness (cm)

!SPM

CWI $=0.086$

coefficients for ice
ESTAN=ROICE*DICE

$A=$ CWI/ESTAN

$\underset{*}{E^{*} D I C E}=1 / S E C$

DO $79 \quad J=1, N$
E(J)=ESTAN

IF (J.LE. IEDGE) E (J) $=0$.

$\operatorname{IF}(\operatorname{PICE}(\mathrm{J})$ LE.

$\operatorname{CE}(1, \mathrm{~J})=\operatorname{PICE}(\mathrm{J})$

$\operatorname{PIUVEL}(1, J)=0$.
$\operatorname{PIVVEL}(1, \mathrm{~J})=0$.

$\operatorname{ZZICE}(\mathrm{J})=\mathrm{E}(\mathrm{J}) / \mathrm{ROICE}$

printing sturu

distance to

for fresh

background ice

!A=ROWWATER*CWI/ROWIC

!ice stuff

ice thickness

!may be

\section{Return}

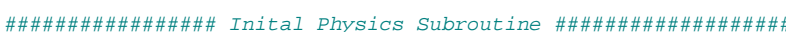

! PARAMETER ( $N=94, N M=93, N P=92, M=46, M M=45, M P=44)$

INCLUDE 'GridFile.f' Subroutine Physics_Initial () 


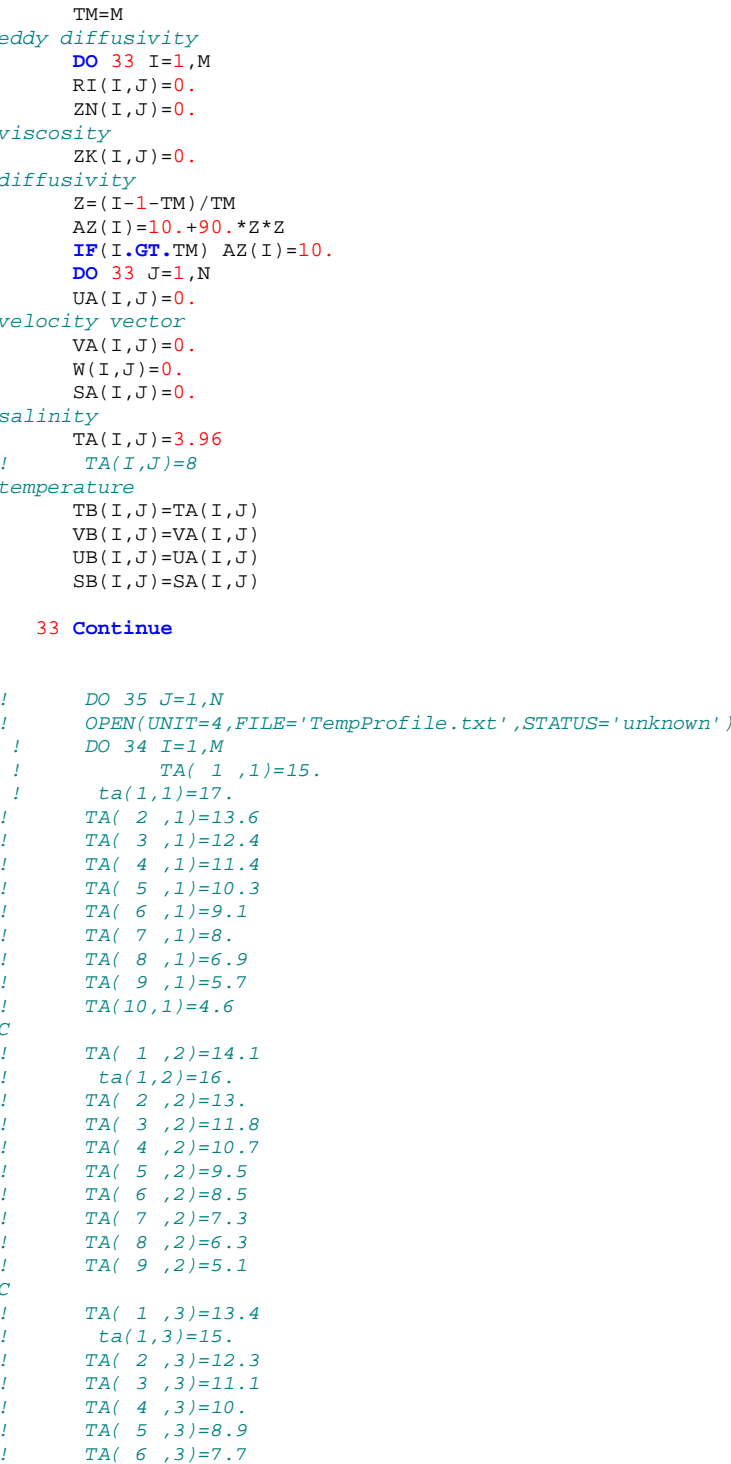

\section{$\operatorname{Bi}(I, J)=V A(I, J)$}

$\mathrm{UB}(I, J)=\mathrm{UA}(\mathrm{I}, J)$
$\mathrm{SB}(\mathrm{I}, \mathrm{J})=\mathrm{SA}(\mathrm{I}, \mathrm{J})$

33 Continue

Do $35 \mathrm{~J}=1, \mathrm{~N}$

FILE= 'TempProfile. txt', STATUS= 'unknown' DO $34 \mathrm{I}=1, M$

$\operatorname{ta}(1,1)=17$.

$\operatorname{TA}(2,1)=13.6$
$\operatorname{TA}(3,1)=12.4$

$\operatorname{TA}(4,1)=11.4$

TAA $(6,1)=9.1$

$\operatorname{TA}(7,1)=8$.

$\operatorname{TA}(8,1)=6.9$

$\operatorname{TA}(9,1)=5.7$
$\operatorname{TA}(10,1)=4.6$

$\operatorname{TA}(1,2)=14.1$

$\operatorname{TA}(2,2)=13$

$\operatorname{TA}(3,2)=11.8$

$\begin{array}{ll}\operatorname{TA} & 3,2)=11.8 \\ \operatorname{TA}(4,2)=10.7\end{array}$

TA $(5,2)=9.5$
TA $(6,2)=8.5$

$\operatorname{TA}(7,2)=7.3$

$\operatorname{TA}(8,2)=6.3$
$\operatorname{TA}(9,2)=5.1$

$\operatorname{TA}(1,3)=13.4$

$\operatorname{ta}(1,3)=15$

$\operatorname{TA}(3,3)=11.1$

$\operatorname{TA}(4,3)=10$.

$\operatorname{TA}(5,3)=8.9$
$\operatorname{TA}(6,3)=7.7$

!initialize

!Richardson \# vertical

!vertical

!don't need?
!don't need?

!intialize

initial

!initial
$T A(8,3)=5.6$

$\operatorname{TA}(1,4)=12.6$

$\operatorname{ta}(1,4)=14$.

$\operatorname{TA}(2,4)=11.6$
$\operatorname{TA}(3,4)=10.4$

TA $(4,4)=9.3$

$T A(5,4)=8.2$
$T A(6,4)=7.1$

$\operatorname{TA}(7,4)=6$.

$\operatorname{TA}(8,4)=4$.

$\operatorname{TA}(1,5)=12$

$\operatorname{TA}(2,5)=10.9$

$\operatorname{TA}(3,5)=9.7$

$\operatorname{TA}(4,5)=8.6$

$\operatorname{TA}(5,5)=7.5$
$\operatorname{TA}(6,5)=6.4$

TA $(7,5)=5.3$

$\operatorname{TA}(1,6)=11.4$

$\operatorname{ta}(1,6)=12$.

$\operatorname{TA}(2,6)=10.2$
$\operatorname{TA}(3,6)=9.1$

TA $(4,6)=7.9$

$T A(5,6)=6.8$

$\operatorname{TA}(6,6)=5.7$
$\operatorname{TA}(7,6)=4.7$

$\operatorname{TA}(1,7)=10.6$

$\operatorname{TA}(2,7)=9.5$

$\operatorname{TA}(3,7)=8.4$

TA $(4,7)=7.3$

TA 5,7$)=6.2$
TA 6,7$)=5$.

$\operatorname{TA}(1,8)=9.9$

$\operatorname{TA}(2,8)=8.8$

TA $\quad 3,8)=7.7$

TA 5,8$)=5.5$

$\operatorname{TA}(6,8)=4.5$

$\operatorname{TA}(1,9)=9.3$

$\operatorname{TA}(2,9)=8.2$

TA 3,9$)=7$.

TA 4,9$)=5.9$

$\operatorname{TA}(1,10)=8.6$

TA $(2,10)=7.5$

$\operatorname{TA}(3,10)=6.4$

$\operatorname{TA}(1,11)=7.9$

TA $(2,11)=6.8$

TA
$\operatorname{TA}(4,11)=4.4$ 

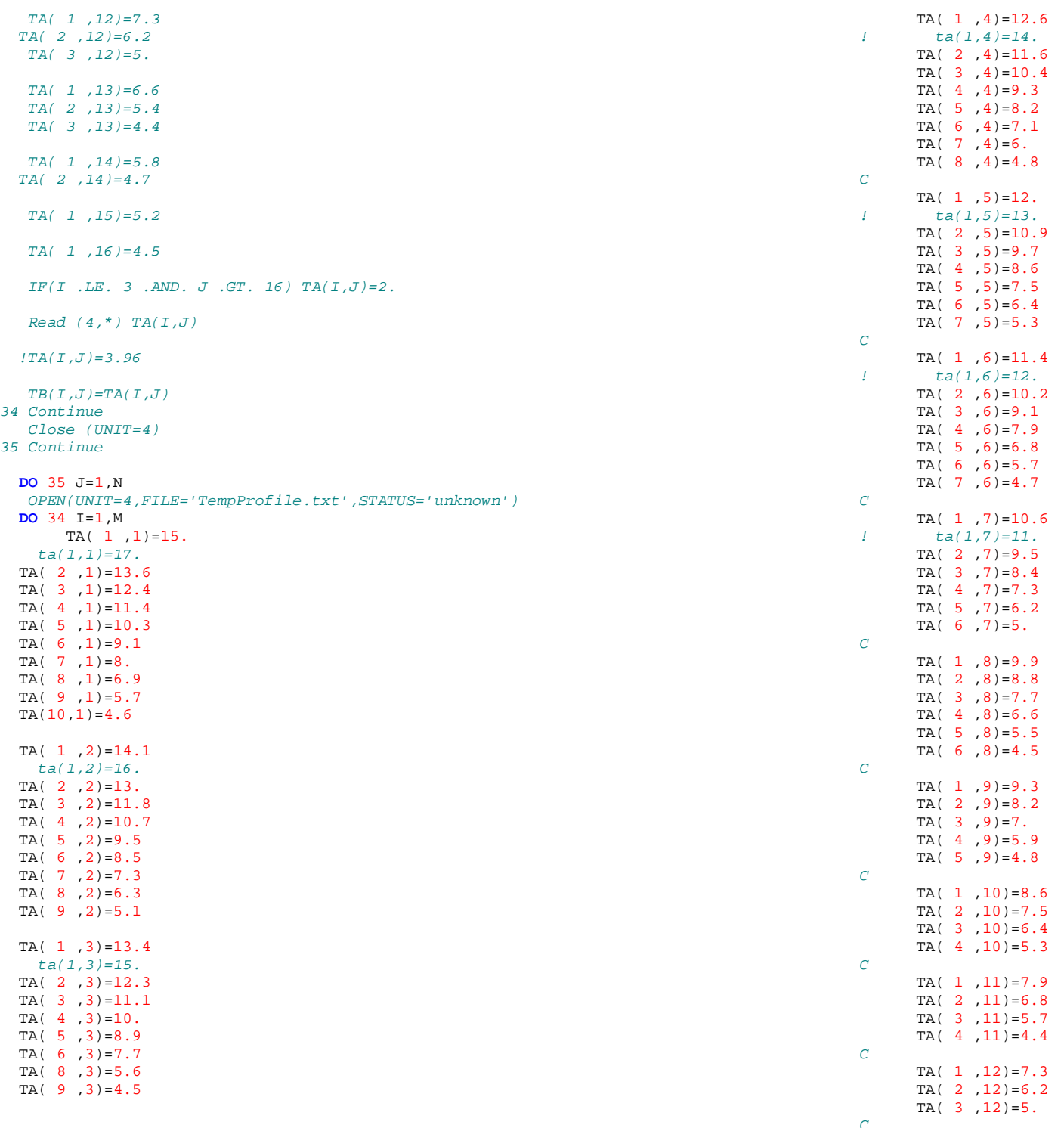


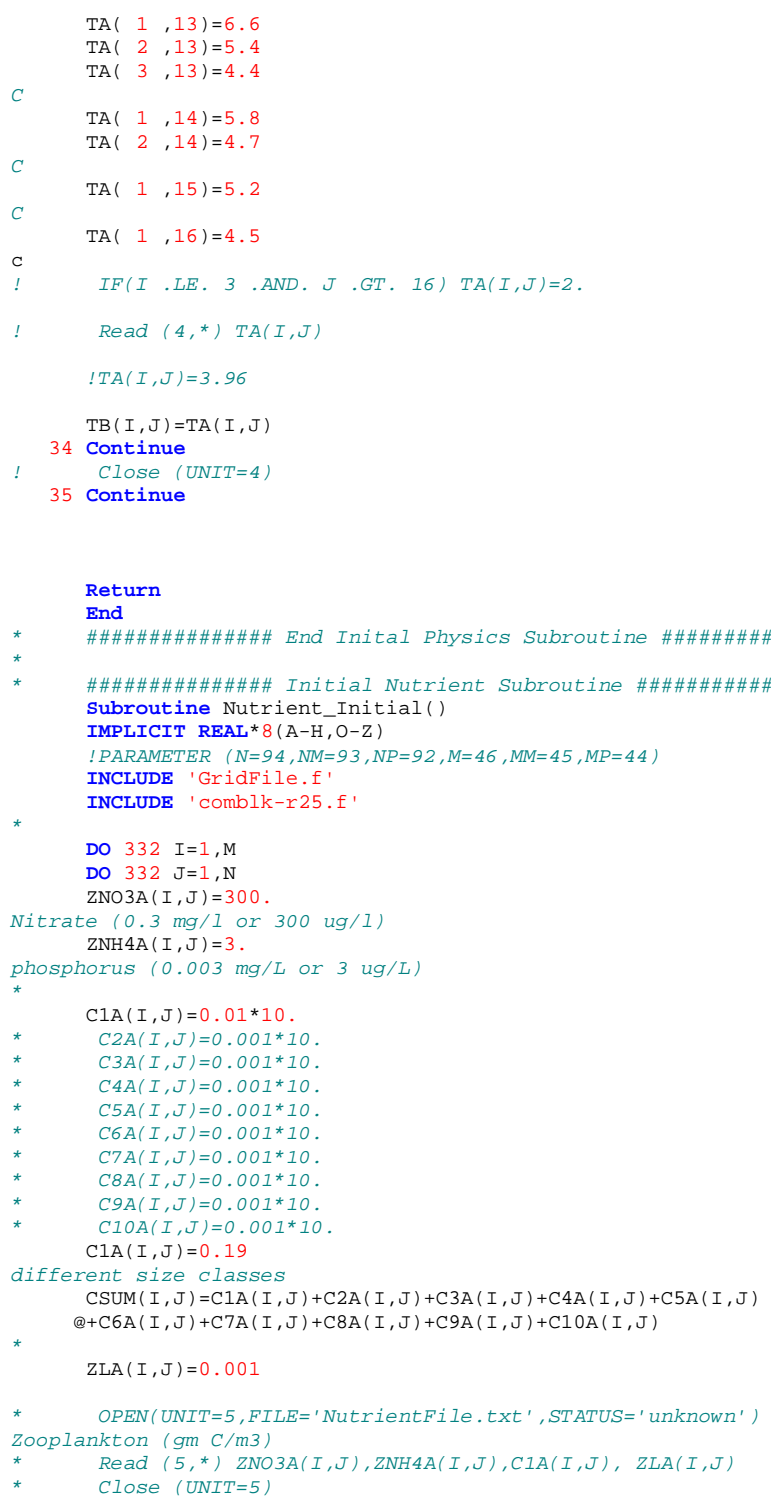

$\operatorname{CIA}(I, J)=0.19$
$\mathrm{ZNO} O A(I, J)=300$

$\mathrm{ZNOBA}(\mathrm{I}, \mathrm{J})=30$
$\mathrm{ZNH} 4 \mathrm{~A}(\mathrm{I}, \mathrm{J})=3$.

$\mathrm{C} 1 \mathrm{~A}(\mathrm{I}, \mathrm{J})=0.2$

$\operatorname{ZLA}(\mathrm{I}, \mathrm{J})=0.001$

Zooplankton ( $g \mathrm{~m} \mathrm{C/m3)}$

$\operatorname{ZSA}(\mathrm{I}, \mathrm{J})=\mathrm{ZLA}(\mathrm{I}, \mathrm{J}) / 1$.

zooplankton $(\mathrm{gm} \mathrm{C} / \mathrm{m} 3)$

$\mathrm{DB}(\mathrm{I})=\mathrm{AZ}(\mathrm{I}) / \mathrm{DZ}$

!not needed

$\mathrm{ZNO3B}(\mathrm{I}, \mathrm{J})=\mathrm{ZNO} 03 \mathrm{~A}(\mathrm{I}, \mathrm{J}) \quad$ !B is for

after $t$

$\mathrm{NNH} 4 \mathrm{~B}(\mathrm{I}, \mathrm{J})=\mathrm{ZNH} 4 \mathrm{~A}(\mathrm{I}, \mathrm{J}$

$\operatorname{CAB}(\mathrm{I}, \mathrm{J})=\mathrm{C} 1 \mathrm{~A}(\mathrm{I}, \mathrm{J})$

$\operatorname{ZSB}(I, J)=\operatorname{ZSA}(I, J)$

332 CONTINUE

\section{Return}

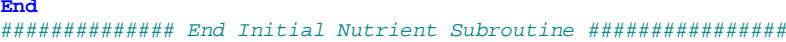

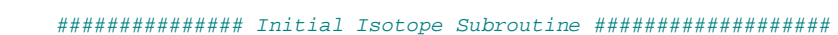
Subroutine Isotope_Initial()

IMPLICIT REAL*8(A-H, O-Z)

PARAMETER (N=94, NM=93, NP=92, M=46, MM=45, MP=44)

INCLUDE 'GridFile.f',

\section{$\begin{array}{lll}\text { Do } & 10 & I=1, M \\ \text { Do } 10 & \mathrm{~J}=1, \mathrm{~N}\end{array}$}

$\operatorname{PBPARA}(\mathrm{I}, \mathrm{J})=0 . / \mathrm{PBDECY} M \mathrm{M} / 6.02 \mathrm{E} 23$

PBDISA $(I, J)=60$

PBISA $(I, J)=60 . /$ PBDECY M/6. 02E23

$\operatorname{PBDISB}(\mathrm{I}, \mathrm{J})=\operatorname{PBDISA}(\mathrm{I}, \mathrm{J})$

after time step $\operatorname{PBPARB}(\mathrm{I}, \mathrm{J})=\operatorname{PBPARA}(\mathrm{I}, \mathrm{J})$

$\operatorname{POPARA}(I, J)=0 . /$ PODECY_M/6. 62 E23

ties, mole/m3
PODISA (I, J) $=60 * 0.45 /$ PODECY M/6. 02 E 23

$\operatorname{PODISB}(I, J)=\operatorname{PODISA}(I, J)$

$\operatorname{PimARB}(\mathrm{I}, \mathrm{J})=\operatorname{POPARA}(\mathrm{I}, \mathrm{J})$

!chlorophyl1

$\operatorname{SPMA}(\mathrm{I}, \mathrm{J})=0.45$

$m g / L \underset{\operatorname{SPMB}(I, J)}{\operatorname{or} g / m 3}=\operatorname{SPMA}(\mathrm{I}, \mathrm{J}$

10 CONTINUE

Thension day) and unlimited is assumed. So isotopre resuspension rate will be particle

suspension flux times

the sediment isotope concentration. $(\mathrm{g} / \mathrm{m} 2$-day $* d p m / g=d p m / m 2$-day $)$. 


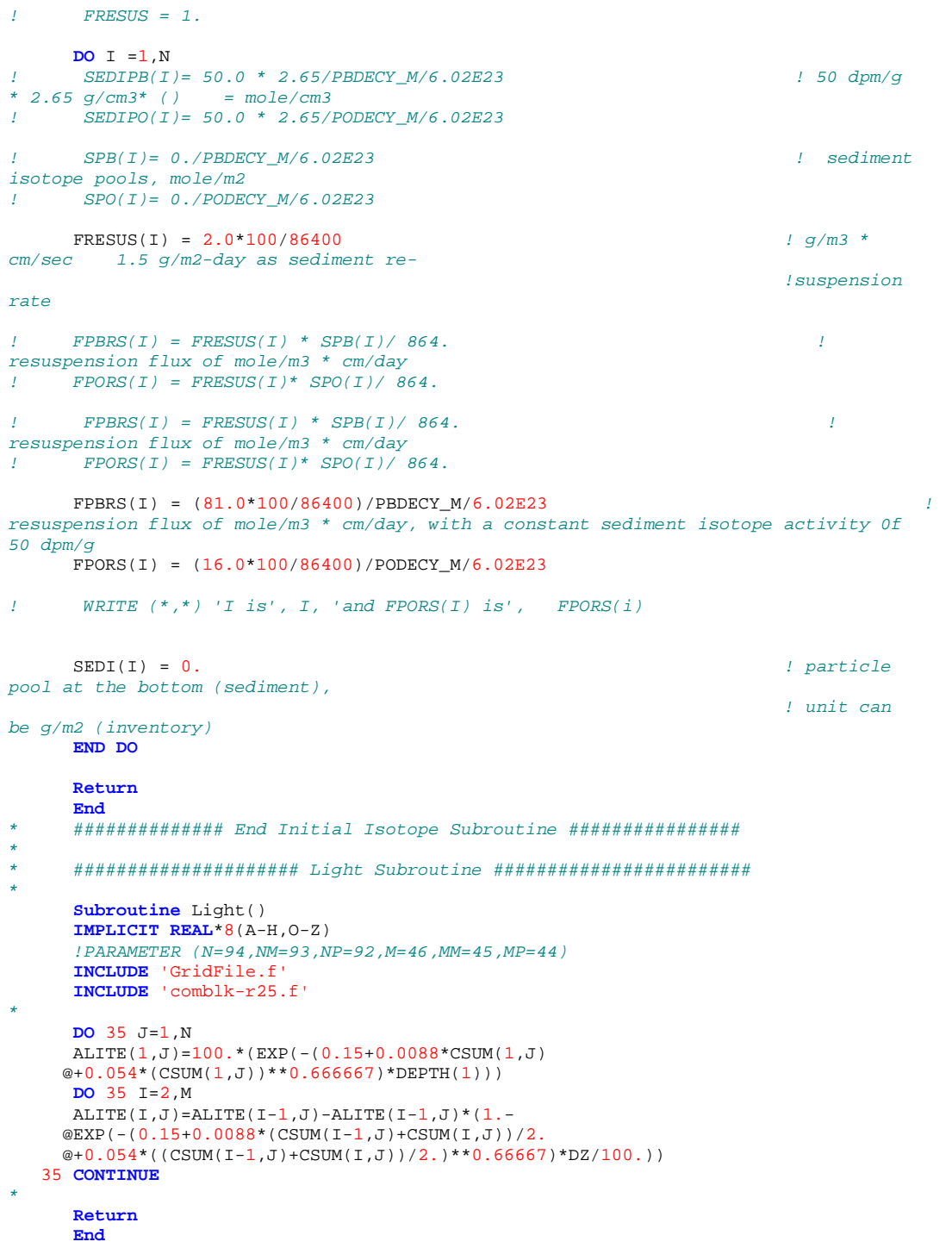

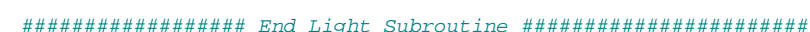

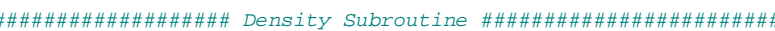

\section{Subroutine Density ()}

MPLICIT REAL*8(A-H, O-Z)

$M P=92, M=46, M M=45, M P=44)$

INCLUDE 'Gridfile.f'

\section{Do $20 \mathrm{I}=1, \mathrm{M}$
DO $20 \mathrm{~J}=1, \mathrm{~N}$ \\ $\operatorname{T} 10=T A(I, J)$}

S10 $\operatorname{SA}(\mathrm{I}, \mathrm{J})$

CALL SIGP(T10, S10, D10, SGSTP)

$\operatorname{Br}(\mathrm{I}, \mathrm{J})=\operatorname{SIGMAT}(\mathrm{I}, \mathrm{J}) * 0.98 \mathrm{D} 0$

Retur

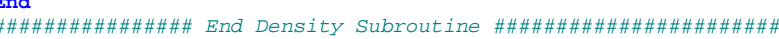

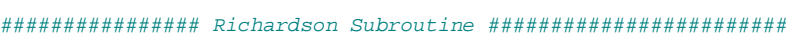

Subroutine Richardson( )

PARAMETER $(N=94, N M=93, N P=92, M=46, M M=45, M P=44)$

INCLUDE 'GridFile.

INCLUDE 'Comb]k-r25.f'

DO $8888 \mathrm{~J}=1, \mathrm{~N}$

DELSIG $=1000$. * $(\operatorname{SIGMAT}(\mathrm{I}-1, \mathrm{~J})$-SIGMAT $(\mathrm{I}, \mathrm{J})) / \mathrm{DZ}$

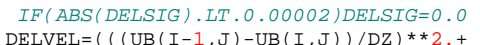

DELVEL $=(((\mathrm{UB}(\mathrm{I}-1, \mathrm{~J})-\mathrm{UB}(\mathrm{I}, \mathrm{J})) / \mathrm{DZ})$
$\left.\mathrm{Q}((\mathrm{VB}(\mathrm{I}-1, \mathrm{~J})-\mathrm{VB}(\mathrm{I}, \mathrm{J})) / \mathrm{DZ})^{* *} 2.\right)$

RI $(\mathrm{I}, \mathrm{J})=(-980 . / 1)$.$* DELSIG/(DELVEL+0.000000000001)$

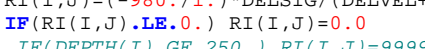

${ }^{*}(1,+10, * R I(I, J))^{* *}(-, 5)$

$\mathrm{ZN}(\mathrm{I}, \mathrm{J})=5 .+50 \cdot{ }^{*}(1 .+10 . * \mathrm{RI}(\mathrm{I}, \mathrm{J}))^{* *}(-.5)$
$\operatorname{ZK}(\mathrm{I}, \mathrm{J})=1,+50 \cdot{ }^{*}\left(1 .+3.33^{*} \mathrm{RI}(\mathrm{I}, \mathrm{J})\right)^{* *}(-1.5)$
$\operatorname{IF}(\mathrm{RI}(\mathrm{I}, \mathrm{J}) . \mathrm{GT} .99999.) \operatorname{RI}(\mathrm{I}, \mathrm{J})=99999$.

C 8888 CONTINUE

Cos8 CONTINUE

Return

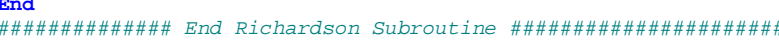

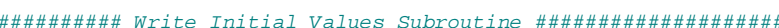

\section{Subroutine Write_Initial(}

PARAMETER ( $N=94, N M=93, N P=92, M=46, M M=45, M P=44)$

INCLUDE 'Gridrile.f',

C OPEN(UNIT=3, FILE= ' TempInitial. txt ' , STATUS= ' unknown '

DO $I X=1, N$
DO $\mathrm{JY}=1, \mathrm{M}$

DIST2=DIST $(\mathrm{IX})+((\mathrm{DX} / 100000) /$.2 . 
WRITE $(3,117) \operatorname{DIST2,}(-1 .)^{*} \operatorname{DEPTH}(J Y), \quad \mathrm{TB}(\mathrm{JY}, \mathrm{IX}), \mathrm{SB}(\mathrm{JY}, \mathrm{IX}), \quad$ !T, SaI

IGMAT (JY, IX)

ENDDO

Close (UNIT=3)

OPEN(UNIT=16, FILE=' NutrientInitial . txt' ', STATUS= ' unknown' $)$

$\begin{array}{ll}\text { Do } & \mathrm{IX}=1, \mathrm{~N} \\ \text { DO } \mathrm{JY}=1, \mathrm{M} & \end{array}$

$\operatorname{DIST2} 2=\operatorname{DIST}(\mathrm{IX})+((\mathrm{DX} / 100000)) / 2$.
$\operatorname{WRITE}(16,763) \operatorname{DIST2},(-1 .)^{*} \operatorname{DEPTH}(\mathrm{JY}), \mathrm{ZNO} 3 \mathrm{~A}(\mathrm{JY}, \mathrm{IX}), \mathrm{ZNH} 4 \mathrm{AA}(\mathrm{JY}, \mathrm{IX}) !$ Nitrate, SRP HutrientInitial. DIXT

\section{ENDDO}

Close (UNIT=16)

C OPEN(UNIT=18, FILE= ' ChloroInitial. txt ' ', STATUS= ' unknown ' )

DO $I X=1, N$

DIST2 $=$ DIST (IX) $+(($ DX/100000 $) / 2$.

$\operatorname{DIST} 2=\operatorname{DIST}(\mathrm{IX})+((\mathrm{DX} / 100000) / 2$.
$\operatorname{WRTTE}(18,763) \operatorname{DIST2},(-1). * \operatorname{DEPTH}(\mathrm{JY}), \operatorname{CSUM}(\mathrm{JY}, \mathrm{IX})$

ChloroInitial. TXT
$@ \mathrm{C} 10 \mathrm{~A}(\mathrm{JY}, \mathrm{IX}), \mathrm{C} 1 \mathrm{~A}(\mathrm{JY}, \mathrm{IX})$

ENDDO

ENDDO (UNIT=18)

OPEN (UNIT=20, FILE= ' ZoopInitial. txt ' , STATUS= ' unknown ' )

Do $I X=1, N$
DO $\mathrm{JY}=1, \mathrm{M}$

$\operatorname{DIST} 2=\operatorname{DIST}(\operatorname{IX})+((\mathrm{DX} / 100000) /$,2 .)
$\operatorname{WRITE}(20,763) \operatorname{DIST2}(-1.){ }^{*} \operatorname{DEPTH}(\mathrm{JY}), \quad \mathrm{ZLA}(\mathrm{JY}, \mathrm{IX}), \mathrm{ZSA}(\mathrm{JY}, \mathrm{IX}) \quad$ ! Zoop to

ZoopInitial.

\section{ENDDO}

Close (UNIT=20)

OPEN (UNIT=1, FILE= ' IceInitial. txt ' , STATUS= ' unknown' )

DO J5ITE $(1,120) \operatorname{DIST}(J 5),(\operatorname{ZZICE}(J 5) / 11.111), \operatorname{ZZICE}(J 5)$

surface to IceInitial. DAT

ENDDO (UNIT=1)

OPEN (UNIT=7, FILE= ' DiffusInitial. txt ' , STATUS= ' unknown ' )

Do $\mathrm{IX}=1, \mathrm{~N}$
DO $\mathrm{JY}=1, \mathrm{M}$

$\operatorname{DIST2}=\operatorname{DIST}(\mathrm{IX})+((\mathrm{DX} / 100000) / 2$.
$\operatorname{WRTTE}(7,763) \operatorname{DIST2},(-1). * \operatorname{DEPTH}(\mathrm{JY}), \mathrm{ZN}(\mathrm{JY}, \mathrm{IX}), \mathrm{ZK}(\mathrm{JY}, \mathrm{IX}) \quad$ !vertical

diffusivity to DiffusInitial.DAT (N=visc, $K=d i f f)$

@, RI (JY, IX)
ENDDO

ENDDO

close (UNIT=7)

OPEN (UNIT=32, FILE= ' IsotopeInitial. txt' ', STATUS= ' unknown ' )

Do $I X=1, N$
DO $\mathrm{JY}=1, \mathrm{M}$

DIST2=DIST ( IX $)+((\mathrm{DX} / 100000) /$,2 . $)$

WRITE $(32,120)$ DIST2, (-1. * ${ }^{*} \operatorname{DEPTH}(J Y)$

\$PBPARA(JY, IX ${ }^{*}$ PBDECY_M*6. $22 E 23$, PBDISA (JY, IX)*PBDECY_M*6. 02E23,

\$POPARA (JY, IX) ${ }^{*}$ PODECY_ $M^{*} 6.02 E 23$, PODISA (JY, IX)*PODECY_ $M^{*} 6.02 E 23$
! ChI to

!ice depth at

! Isotope act. to IsdtopeInitial.DAT

\section{ENDDO}

Close (UNIT=32)

$117 \operatorname{FORMAT}((1 \mathrm{X}, 15 \mathrm{~F} 10.4))$
$120 \operatorname{FORAT}((1 \mathrm{X}, 12 \mathrm{~F} 8.2))$
763 FORMAT $((1 \mathrm{X}, 10 \mathrm{~F} 12.6))$

\section{Return}

\#nd

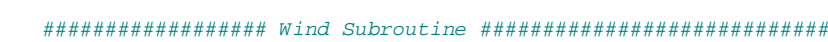

Subroutine Wind_Stress()

IMPLICIT REAL* $*(\mathrm{~A}-\mathrm{H}, \mathrm{O}-\mathrm{Z})$
! PARAMETER $(\mathrm{N}=94, \mathrm{NM}=93, \mathrm{NP}=92, M=46, M M=45, M P=44)$

INCLUDE 'GridFile.f'

c

!DO $1 \mathrm{~J}=1, N$

$\operatorname{tTX}(\mathrm{J})=0$.
$! \operatorname{TY}(\mathrm{J})=0$.

! TY CONTINUE

C DO $651 \mathrm{~J}=1, \mathrm{~N}$

$\operatorname{TY}(\mathrm{J})=0$

direction
$! \quad \operatorname{IF}(I T \cdot G T .936)$
1

$\operatorname{IF}(I T . G T .936) \operatorname{TY}(J)=1$.
$\operatorname{IF}(I T \cdot G T .1008) \operatorname{TY}(J)=0$.
$\operatorname{IF}(I T \cdot G T .1944) \operatorname{TY}(J)=1$

$\operatorname{IF}(I T . G T .2016) \operatorname{TY}(J)=0$.

!TX $(J)=-1$
51 CONTINUE

\section{Return}

End

\#\#\# End Wind Sroutine \#\#\#\#\#-

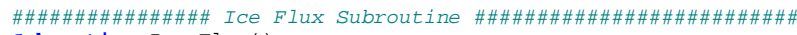

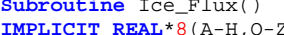

IPARAMETER ( $N=94, N M=93, N P=92, M=46, M M=45, M P=44)$

INCLUDE 'Gridfile.f' THICK $=10$.

\section{Do $7 \mathrm{I}=1, \mathrm{~N}$}

NOTE THAT ICE IS ALWAYS MODELED AS THE SAME THICKNESS--ICE REDUCTION IS A CHANGE IN \% ICE COVER

1.34 CAL/CM2/MIN IS THE SOLAR CONSTANT AT THE EARTH'S SURFACE THIS IS EQUAL TO 0.02233 CAL/CM2/SEC 1360 WATTS M-2 IS THE SOLAR CONSTANT $=2$ SO 911 WATTS $\mathrm{m}-2=0.02233 \mathrm{CAL} / \mathrm{cm} 2 / \mathrm{sec}$

$80 \mathrm{CAL} / \mathrm{CM}^{* *} 3$ IS THE HEAT OF FUSION FOR PURE WATER AT O C 
$80 * 9,17=\sim 73 \mathrm{CAL} / \mathrm{CM}^{*} * 3$

THICK $=E(I)$

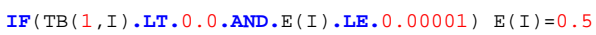

IF(THICK.GT.1.) THICK=1.

$\operatorname{IF}(\operatorname{TB}(1, \mathrm{I}) . \mathrm{LT}, \odot, 0)$ THICK $=0.05$ ice melting (cal/cm2

IF (E(I).LT. 0.00001) G0 TO 25

$\operatorname{IF}(\operatorname{TB}(1, \mathrm{I})$. LT. $\mathrm{Q} . \Theta)$ FICE $(\mathrm{I})=\left(4.86 \mathrm{E}-3^{*}(\mathrm{~TB}(1, \mathrm{I})-(0.0)) / \mathrm{THICK}\right)$ ice fomring 25 conTINUE

C CHECK THE 73 BELOW FOR CORRECT LATENT HEAT OF MELTING

$\operatorname{DELHI}(\mathrm{I})=2 .{ }^{*} \mathrm{DT}{ }^{*} \mathrm{FICE}(\mathrm{I}) / 73$.

thickness $=E(I)-D E L H I(I) *$ ROICE

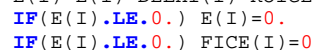

${ }_{C}^{C} Q=0.01 \mathrm{CAL} / \mathrm{CM} / \mathrm{SEC}=408$ watts $/ \mathrm{m} 2$ from walker and ??book, $\sim 250 \mathrm{~W} / \mathrm{m} 2=Q=$

CHIM $=0.00123 * 2$.

flux to water

* neg cools, pos heats up

* ${ }^{*} \operatorname{If}\left(\right.$ I.EQ.16) CHIM $=0.00123^{*} 1 . *(1440 .-I T) / 1440$.

$432=6$ DAYS

IF(I.EQ.17) CHIM=0.00123*1.*(1440. - IT $) / 1440$.

IF(I.EQ.18) CHIM $=0.00123 * 1 . *(1440 .-I T) / 1440$.

IF(I.EQ.19) CHIM $=0.00123^{*} 1 * *(1440 .-I T) / 1440$.

IF(I.EQ 21) CHIM=0.00123*1 * *(1440. IT $/ 1440$.

IF (I.EQ.22) CHIM=0.00123*1. *(1440. - IT $) / 1440$.

IF(I.EQ.23) CHIM $=0.00123 * 1 . *(1440 .-$ IT $) / 1440$.

IF(I.EQ.24) CHIM=0.00123*1. *(1440, - IT $) / 1440$.

$Q(\mathrm{I})=-(\operatorname{FICE}(\mathrm{I}) * \operatorname{PICE}(\mathrm{I}) / 100)+.\left(\mathrm{CHIM}^{*}(1 .-(\operatorname{PICE}(\mathrm{I}) / 100)).\right)$

ice melting

$\operatorname{IF}(\operatorname{TB}(1, \mathrm{I}) \cdot \mathrm{LT} .0 .0) Q(\mathrm{I})=-(\operatorname{FICE}(\mathrm{I}) *(\operatorname{PICE}(\mathrm{I}) / 100)$.

ice forming ${ }^{*}+\left(\operatorname{CHIM}^{*}(1 .-(\operatorname{PICE}(\mathrm{I}) / 100)).\right)$

$\operatorname{SZ}(\mathrm{I})=(-.91) *(\mathrm{SB}(1, \mathrm{I})-00.0) *((\mathrm{FICE}(\mathrm{I}) *(\operatorname{PICE}(\mathrm{I}) / 100)) / 73$.

is sal in ppm)

DELHI ( I ) $=$ DELHI (I)
hickness $(\mathrm{cm} /$ day)

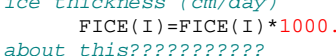

* about this???????????

ice from wind $2 .{ }^{*} \mathrm{TX}(\mathrm{I})$

$\operatorname{TAIY}(\mathrm{I})=2 \cdot{ }^{*} \mathrm{TY}(\mathrm{I})$
$\mathrm{BI}(\mathrm{I})=\mathrm{TAIX}(\mathrm{I}) / \mathrm{TSTAN}$

$\mathrm{BI}(\mathrm{I})=\operatorname{TAIX}(\mathrm{I}) / \mathrm{ESTAN}$
$\mathrm{C}(\mathrm{I})=\operatorname{TAIY}(\mathrm{I}) / \mathrm{ESTAN}$ !heat

!thick has to >

!heat flux of

!heat flux from

change in ice

Ichange heat

! I $T=72=1 D A Y$, SO

!heat from

!heat from

salt flux

!change in

!not sure

Istress on

$\operatorname{UICE}(I)=\left(A^{*}\left(B I(I)+A^{*} \operatorname{UA}(1, I)\right)-(-F) *\left(C(I)+A^{*} V A(1, I)\right)\right) /\left(A^{* *} 2+F^{* *} 2\right)$ ! ice movement $\operatorname{VICE}(I)=\left(A^{*}\left(C(I)+A^{*} \operatorname{VA}(1, I)\right)-(F) *\left(B I(I)+A^{*} U A(1, I)\right)\right) /\left(A^{* *} 2+F^{* *}\right)$

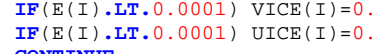

DO $9 \quad I=2$ NM

FLXICE $(I)=((E(I-1) * \operatorname{UICE}(I-1))+(E(I+1) * \operatorname{UICE}(I+1))) / 2$

!flux of ice

$\operatorname{FLXICE}(1)=F \operatorname{LICE}(2)$

conditions
FLXICE (N) $=$ FLXICE (NM)

DO $8 \mathrm{I}=2$, NM

$\mathrm{XICE}(\mathrm{I}+1))^{*} \mathrm{DC} / 1$

$\operatorname{IF}(E(I)$.LT.๑.) $E(I)=0$

CONTINUE

conditions

C DO $838 \mathrm{I}=1$,

DO $838 \mathrm{I}=1, \mathrm{~N}$
$\operatorname{ZZICE}(\mathrm{I})=\mathrm{E}(\mathrm{I}) / \mathrm{ROICE}$

PICE(I) $=E(I) * 100$. /ESTAN

PICRICE $=$ PICE (I)

!percent of ice

IF (PERICE . GT . 100. ) PERICE $=100$.

$\operatorname{WIND}=\left((\operatorname{TY}(I) * * 2)+\left(\operatorname{TX}(\mathrm{I}){ }^{* *} 2\right)\right) * * \bullet .5$

!friction from

$\operatorname{IF}(A B S($ WIND). LT $\cdot 0.01) \operatorname{VICE}(\mathrm{I})=\mathrm{VICE}(\mathrm{I}) * 0.9$

$\operatorname{TTX}(\mathrm{I})=\left((100 .-\operatorname{PERICE}) * \operatorname{TX}(\mathrm{I})+\mathrm{CWI}{ }^{*}(-\mathrm{UA}(1, \mathrm{I})+\mathrm{UICE}(\mathrm{I})) * \operatorname{PICE}(\mathrm{I})\right) / 100 . \quad$ ! stress on

$\operatorname{TTY}(\mathrm{I})=\left((100 .-\mathrm{PERICE}) * \operatorname{TY}(\mathrm{I})+\mathrm{CWI}{ }^{*}(-\mathrm{VA}(1, \mathrm{I})+\mathrm{VICE}(\mathrm{I})) * \operatorname{PICE}(\mathrm{I})\right) / 100$

IF(IT.EQ.1)GO TO 7776

$\mathrm{INP}=(\mathrm{IT} / 12) * 12$
$3=1$ HOUR $12=4$ HOUR

$! 6=2$ HOURS

HOUR, $12=4$ HOUR
IF(INP.LT. IT) GO TO 7777

7776 CONTINUE

$\mathrm{K} 77=\mathrm{K} 77+1$

$\operatorname{PICE}(1)=\operatorname{PICE}(2)$

7777 CONTINUE

\section{Return}

End

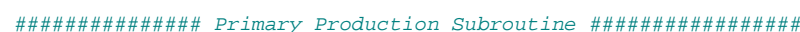
Subroutine PP-Integrate ()
IMPLICIT REAL ${ }^{\star} 8(\mathrm{~A}-\mathrm{H}, 0-\mathrm{Z})$

IPARAMETER ( $N=94, N M=93, N P=92, M=46, M M=45, M P=44)$

INCLUDE Griflle. 
!DIMENSION PP $(M, N), \operatorname{SUMFCZ}(M, N)$

IF(IT.EQ.1)GO TO 7778

$\mathrm{INP}=(\mathrm{IT} / 12) * 12$
OUR, $12=4$ HOUR

IF(INP.LT.IT) GO TO 956

7778 CONTINUE

PPN $=0$.
production from nitrate (may be SRP?)

prodution from sum of phytos

C Integration over a specified area

DO $1373 \mathrm{~J}=1, \mathrm{~N}$, 10 ) 1373

IF (J.LT.1.OR.J.GT.10) G0 TO

vertical section for integration $(\theta-40)$

$\mathrm{PPN}=\mathrm{PPN}+\mathrm{GROL} 3(\mathrm{I}, \mathrm{J}) *(\mathrm{DZ} / 100.){ }^{*} \operatorname{CSUM}(\mathrm{I}, \mathrm{J}) *(40 . / 1000$.

of primary production
PPPLUS $=\operatorname{PPPLUS}+(\operatorname{GROL} 4(\mathrm{I}, \mathrm{J}) * \operatorname{CSUM}(\mathrm{I}, \mathrm{J}) *(\mathrm{DZ} / 100) *.(40 . / 1000)$.

1374 CONTINUE

c This is integrated over the \# of cells specified (total) $\mathrm{NNN}=10$

integrated over

(km) $\mathrm{PPN}=\left(\mathrm{PPN}^{*} \mathrm{NNN}^{*} \operatorname{deltax}{ }^{*} 1000 . / 1000.\right) / \mathrm{NNN}$

units to $k g-C /$ day
PPPLUS=(PPPLUS*NNN*deltax*1000./1000.)/NNN

C VERTFX $=0$.

carbon flux at different depths (mg-ChI/day)

$F 2=100 \mathrm{~m}, F 3=200 \mathrm{~m}$

VERTF $3=0$.

VFXPB1 $=0$.

TFXPB1
VFXPB2 $=0$.

VFXPB2 $=0$.

VFXPO1 $=0$.

flux of isotope

VFXPO2 $=0$.
VFXP02 $=0$.

Do $955 \mathrm{~J}=1, \mathrm{~N}$

$C \quad \operatorname{PPICE}(K 77, \mathrm{~J})=\operatorname{PICE}(\mathrm{J})$

lotting $\operatorname{PIUVEL}(K 77, \mathrm{~J})=\operatorname{UICE}(\mathrm{J})$

$\operatorname{PIVVEL}(K 77, J)=\operatorname{VICE}(\mathrm{J})$

$\operatorname{U2VEL}(K 77, \mathrm{~J})=\operatorname{UB}(1, \mathrm{~J})$

$\operatorname{V2VEL}(K 77, J)=\operatorname{VB}(1, \mathrm{~J})$
$\mathrm{W} 2 \operatorname{VEL}(\mathrm{K} 77, \mathrm{~J})=\mathrm{W}(3, \mathrm{~J})$
IF(J.LT.1.OR.J.GT.10) G0 TO 955

depends on integration sections

! 6=2 HOURS，

primary

!primary

!define

!define

integration

VERTFX $=\operatorname{VERTFX} *(40 . / 1000) *.(1 . / 1000$.
conversion to carbon (by C2ChI ratio - YC) conversion to carbon $($ by C2Chl ratio-YC)
VERTF2 $2=\operatorname{VERTF2} 2^{*}(40, / 1000) *.(1 . / 1000$.

VERTF2 $=\operatorname{VERTF2} 2(40 . / 1000) *.(1 . / 1000$.
VERTF3 $=\operatorname{VERTF3} 3(40 . / 1000) *.(1 . / 1000$.

$\operatorname{VAR}(K 77,1)=0$.

!\# of cells

!deltax $=D X$

Arrays

$\operatorname{VAR}(K 77,2)=0$.

$\operatorname{VAR}(K 77,3)=0$.

$\operatorname{VAR}(K 77,5)=0$.

$\operatorname{VAR}(\mathrm{K} 77,7)=0$.

$\operatorname{VAR}(K 77,8)=0$.

$\operatorname{VAR}(K 77,9)=0$.

$\operatorname{VAR}(K 77,10)=0$.
$\operatorname{VAR}(K 77,11)=0$.

$\operatorname{VAR}(K 77,12)=0$.

$\operatorname{VAR}(K 77,13)=0$.

$\operatorname{VAR}(K 77,14)=0$

$\operatorname{VAR}(K 77,15)=0$.

$\operatorname{VAR}(K 77,16)=0$

$\operatorname{VAR}(K 77,18)=0$

$\operatorname{VAR}(K 77,19)=0$.

$\operatorname{VAR}(K 77,20)=0$

for isotope

$\operatorname{VAR}(K 77,21)=0$

$\operatorname{VAR}(K 77,22)=0$.

$\operatorname{PBINV}(K 77)=0$.

$\operatorname{POINV}(K 77)=0$.

TEST1 $(K 77)=0$.

TEST2 (K77) $=0$.

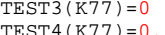

$\begin{aligned} \text { TEST } & \text { TK K } 77)=0 . \\ \text { TEST5 } & \text { K }\end{aligned}$

$\operatorname{TEST6}(K 77)=0$.

C1INV (K77) $=0$.

$\operatorname{SPMINV}(K 77)=0$. !this also 
$\operatorname{SEDIINV}(K 77)=0$

SPBINV $(K 77)=0$.
SPOINV $(K 77)=0$

Do $957 \mathrm{I}=1$, NK( LUCK)

column (user defined)

C TG11 $(\mathrm{I}, \mathrm{K} 77)=(\operatorname{grol4}(\mathrm{i}$, luck $) * \operatorname{CSUM}(\mathrm{I}, \mathrm{LUCK}) * 0.04 * 1000 . / 1000$. G33 $(\mathrm{I}, \mathrm{K} 77)=\operatorname{SUMFCZ}(\mathrm{I}, \mathrm{LUCK})$

vertical chloro flux

\section{$\operatorname{TLI}(\mathrm{I}, \mathrm{K} 77)=\mathrm{ZNO} 03 \mathrm{~B}(\mathrm{I}, \mathrm{LUCK})$}

TGRO $3(\mathrm{I}, \mathrm{K} 77)=$ CSUM $(I, L U C K)$

$\operatorname{TGROL} 4(\mathrm{I}, \mathrm{K} 77)=\mathrm{C} 1 \mathrm{OB}(\mathrm{I}, \mathrm{LUCK})$

TGROS3 $(1, K 77)=Z L B\left(I_{1}\right.$

TGROS4 $(\mathrm{I}, \mathrm{K} 77)=\mathrm{ZSB}(\mathrm{I}, \mathrm{LUCK})$

$\operatorname{TSPBD}(\mathrm{I}, \mathrm{K} 77)=\operatorname{PBDISB}(\mathrm{I}, \operatorname{LUCK})$

${ }^{P b-210} \operatorname{TSPBP}(I, K 77)=\operatorname{PBPARB}(\mathrm{I}$, LUCK)

culate $P b-210$

SMFPBZ(I, LUCK)

Pb210 flux (sum of all)

$\operatorname{TSPOD}(I, K 77)=\operatorname{PODISB}(\mathrm{I}$, LUCK $)$

${ }^{\operatorname{PSPOP}}(\mathrm{I}, \mathrm{K} 77)=\operatorname{POPARB}(\mathrm{I}, \mathrm{LUCK})$

culate PO-210

TSPOFZ( $($, K77) $=\operatorname{SMFPOZ}(\mathrm{I}$, LUCK)
P0210 flux (sum of all)

C THESE ARE TO WRITE GRO TO PLOT TIME SERIES, GRO IS USED TO CALCULATE WHEN TO SHIFT THE STICKYNESS IN THE AGG SUBROUTINE.

THESE ARE WRITTEN TO THE ZOOP FILES WHEN ACTIVATED.

$\operatorname{TSAL}(I, K 77)=S B(I, L U C K)$

TSIG $(I, K 77)=$ SIGMAT $(I, L U C K)$

$\operatorname{VAR}(K 77,11)=\operatorname{SUN}(10)$

$\operatorname{IF}(\mathrm{DEPTH}$ (I).GT.40.) GO TO 957

over specified depth

$\operatorname{VAR}(K 77,1)=\operatorname{VAR}(K 77,1)+\mathrm{ZNO} 03 \mathrm{~A}(\mathrm{I}, \mathrm{LUCK}){ }^{*} \mathrm{DZ} / 100$

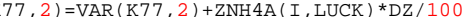

VAR $(K 77,4)=\operatorname{VAR}(\mathrm{K} 77,4)+\mathrm{C} 10 \mathrm{OA}(\mathrm{I}, \mathrm{LUCK}) * \mathrm{DZ} / 100$

$\operatorname{VAR}(K 77,6)=\operatorname{VAR}(K 77,6)+$ GROL3 $(\mathrm{I}$, LUCK $){ }^{*} \mathrm{DZ} / 100 .{ }^{*}$ ( CSUM $(\mathrm{I}$, LUCK $)$ * 40 .

$\operatorname{VAR}(K 77,5)=\operatorname{VAR}(K 77,5)+\mathrm{CSUM}(\mathrm{I}$, LUCK $) * \mathrm{DZ} / 100$

$\operatorname{VAR}(K 77,7)=\operatorname{VAR}(K 77,7)+\left(\right.$ GROL $4($ I LUCK $){ }^{*} \operatorname{CSUM}(I$, LUCK $) * D Z / 100$

C/m2/day)

$\operatorname{VAR}(K 77,8)=\operatorname{VAR}(K 77,8)+Z L A(I, L U C K) * D Z / 100$

VAR $(K 77,9)=V A R(K 77,9)+Z$ ZA $(1$, IUCK $) \times D Z / 100$.

isotope part $/ \mathrm{Pb}$-only

$\operatorname{VAR}(K 77,21)=V A R(K 77,21)+P B D I S A(I, L U C K) * D Z / 100$

unit: mole/m2 Pb210-dis

$\operatorname{VAR}(K 77,22)=\operatorname{VAR}(K 77,21)+\operatorname{PBPARA}(\mathrm{I}$, LUCK $){ }^{*} \mathrm{DZ} / 100$ !reference

!Total

!initial

!Nitrate

!SRP

! Isumall phyto

large zoo

dissolved

vertical

dissolved

vertical

! integrated

inventory,

$\operatorname{VAR}(K 77,21)=\operatorname{VAR}(K 77,21)+\mathrm{PBTTL}(\mathrm{I}$, LUCK $) * \mathrm{DZ} / 100$

\section{CONTINUE}

Horizontal Integrations (long shore and cross shore)

$\operatorname{VAR}(*, 17$ AND *,19) WATER MASS TRANSPORTS (m3/day)

$\mathrm{cm} / \mathrm{sec}$ * $(1 \mathrm{~m} / 100 \mathrm{~cm}) *(86400 \mathrm{sec} /$ day $)=\mathrm{m} / \mathrm{day}$

$X:{ }^{*}(D Z / 100) *(D Y)$ (which is unity for the $X$ dir

(DX/100)

SO $=$ MASS TRANSPORTS $=\mathrm{m} 3 /$ day

$\operatorname{VAR}(*, 18$ AND *,20) CARBON TRANSPORTS.

$\mathrm{cm} / \mathrm{sec}^{*} \mathrm{mg} \mathrm{Chlo} / \mathrm{m3} *(1 \mathrm{~m} / 100 \mathrm{~cm} * 40 \mathrm{mg} \mathrm{C} / \mathrm{mg} \mathrm{chl} * 1 \mathrm{gm} / 1000 \mathrm{mg}$ $x: \quad * \quad 86400$ sec/day $)=g m \quad C / m 2 / d a y$

$X: \quad{ }^{*} D Z * D Y * k g / 1000 \mathrm{gm}$
$Y: \quad * D Z * D X * \mathrm{~kg} / 1000 \mathrm{gm}$

GIVES kg C/day over some depth and distance.

$$
\text { "U" FIRST }
$$

Do $974 \mathrm{~J}=1$, NM

IF (J.NE.2) GO TO 973

IF(DEPTH(I).GT.5.) GO TO 973

$\operatorname{VAR}(K 77,17)=\operatorname{VAR}(K 77,17)+\left(0.5^{*}(\mathrm{UB}(\mathrm{I}, \mathrm{J})+\mathrm{UB}(\mathrm{I}, \mathrm{J}+1))\right)$

@ * ${ }^{*}(1 . / 1100 .)^{*} 1 . \quad{ }^{*}(\mathrm{DZ} / 100$.

[0 *34.56*(DZ/100.)*(1, 11000.$)(\mathrm{I}, \mathrm{J})+\mathrm{UB}(\mathrm{I}, \mathrm{J}+1)))^{*} \operatorname{CsUm}(\mathrm{I}, \mathrm{J})$

973 CONTINUE

$$
\text { "Y" SECOND }
$$

Do $975 \mathrm{I}=1$, NK( J)

IF( J.LT. ०. OR. J.GT.6) GO TO 976

dimensions are set to compare directly to obs.

$\operatorname{VAR}(K 77,19)=\operatorname{VAR}(K 77,19)+\left(0.5^{*}(\operatorname{VB}(\mathrm{I}, \mathrm{J})+\operatorname{VB}(\mathrm{I}, \mathrm{J}+1))\right)$

$\$ *(1 . / 100) * .1 . *(D Z / 100) *.(D X / 100$.

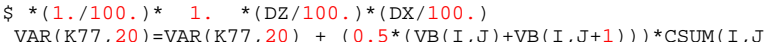

$\$ * 34.56 *(\mathrm{DZ} / 100) *.(\mathrm{DX} / 100) *.(1 . / 1000$.

\section{CONTINUE}

g7t controle lake inventory

write $\left({ }^{*},{ }^{*}\right)$ 'PBTTL $(5,5)$ is ', $\operatorname{PBTTL}(5,5)^{*}{ }^{*} \operatorname{PBDECY} \mathrm{M}^{*} 6.02 \mathrm{E} 23$

write $\left(* *^{*}{ }^{*}\right)$ 'and PBDECYM is ', PBDECY M, PODECYM
write $\left(*,{ }^{*}\right)$ 'POTTL $(5,5)$ is ', POTTL $(5,5){ }^{*}$ PODECY $M^{*} 6.02 E 23$ 
Do $1000 \mathrm{~J}=1, \mathrm{NM}$
Do $1000 \mathrm{I}=1, \mathrm{NK}(\mathrm{J})$

$\operatorname{PBINV}(K 77)=\operatorname{PBINV}(K 77)+\operatorname{PBTTL}(I, J) *(D Z / 100) *.(D X / 100.) /(W L / 100.) \quad ! d p m / m 2$ $\operatorname{PBINV}(K 77)=\operatorname{PBINV}(K 77)+\operatorname{PBTTL}(I, J) *(D Z / 100$. ole $/ m 2$

$\operatorname{POINV}(K 77)=\operatorname{POINV}(K 77)+\operatorname{POTTL}(I, J) *(D Z / 100$. $\mathrm{pm} / \mathrm{m} 2$

(DXINV

$=\operatorname{SPMINV}(\mathrm{K} 77)+\operatorname{SPMA}(\mathrm{I}, \mathrm{J}) *(\mathrm{DZ} / 100$.

$\operatorname{C1INV}(K 77)=\operatorname{C1INV}(K 77)+C 1 A(I, J) *(D Z / 100$.

$\mathrm{dpm} / \mathrm{m}$

1000 CONTINUE

Do $\mathrm{J}=1$, NM

$\operatorname{SEDIINV}(K 77)=\operatorname{SEDIINV}(K 77)+\operatorname{SEDI}(J) *(D X / 100) /$.

! particle inventory

$\operatorname{SPBINV}(K 77)=\operatorname{SPBINV}(K 77)+\operatorname{SPB}(J) *(D X / 100) /$.

inventory in the sediment phase
SPOINV(K77) $=$ SPOINV $(K 77)+\operatorname{SPO}(\mathrm{J}) *(D X / 100) / 94000$.

ENDDO

write * *) 'K77=1, K77, 'and Pb-Inv=1, PBINV(K77)*PBDECY M*6, $02 E 23$,

$\$$ 'and PO-Inv $=1$, POINV(K77)*PODECY_M*6.02E23, ' and SPM-inv $=1$,

SPMINV (K77)

write $\left({ }^{\prime}, *\right)$ 'TA $(1,5)$ is', TA(1,5)

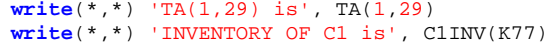

$\operatorname{TEST1}(\mathrm{K} 77)=$

ECY $M^{*} 6.02 E 23$

Pb210 act at cell $(5,5)$

TEST2 $(K 77)=$ PBPARA $(5,5){ }^{*}$ PBDECY_M*6. 02 E23 TEST3 3 K77) $=$ TA $(5,1)$

PODISA $(5,5) *$ PODECY

6.02

$\operatorname{TEST5}(\mathrm{K} 77)=\operatorname{POPARA}(5,5)^{*} \mathrm{PODECY} M^{*} 6.02 \mathrm{E} 23$

TEST6 $(K 77)=((\operatorname{PODISA}(5,5)+\operatorname{POPARA}(5,5)) *$ PODECY_M*6. O2E23)

$\$\left((\operatorname{PBDISA}(5,5)+\operatorname{PBPARA}(5,5)) * \operatorname{PBDECY} M^{*} 6.02 \mathrm{E} 23\right)$

\section{CONTINUE}

$\operatorname{VAR}(K 77,10)=\operatorname{SUMFCZ}(3$, LUCK $)$

VAR (K77, 12) $=$ SUMFCZ $(11$, LUCK $)$

VAR $(K 77,10)=$ ZZice $(L U C K)$

$\operatorname{VAR}(K 77,11)=P$ PN

$\operatorname{VAR}(K 77,13)=\operatorname{VERTFX}$

lux ( $k g$-C/day) over $X$-section
! check the

! check the

!10 m deep

!100 m deep

vertical c
$\operatorname{VAR}(K 77,14)=\operatorname{VERTF} 2$

$\operatorname{AR}(K 77,15)=V E R T F 3$

\section{Return}

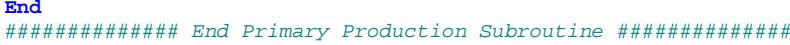

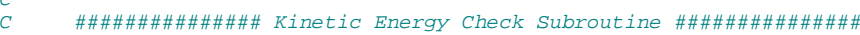
Subroutine Kinetic_Energy
IMPLICIT REAL*8(A-H, $0-Z)$

IPARAMETER ( $N=94, N M=93, N P=92, M=46, M M=45, M P=44)$

INCLUDE GridFile.f

EK2 $=0$

DO $34 \quad \mathrm{I}=1, \mathrm{M}$

DO $34 \mathrm{~J}=1, \mathrm{~N}$

$\mathrm{EKV}=\mathrm{KKU}+.5^{*}(\mathrm{UB}(\mathrm{I}, \mathrm{J}) * * 2$
$\mathrm{EKVV}+.5^{*}(\mathrm{VB}(\mathrm{I}, \mathrm{J}) * * 2$

\section{Retur}

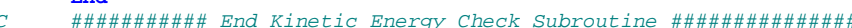

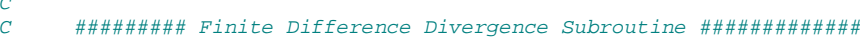
Subroutine FD_Diverge ()
IMPLICIT REAL* $8(\mathrm{~A}-\mathrm{H}, \mathrm{O}-\mathrm{Z})$

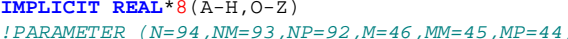

INCLUDE 'GridFile.f'

INCLUDE 'Comblk-r25. f'

!DIMENSION PP( $M, N), \operatorname{SUMFCZ}(M, N)$

$\mathrm{INP}=(\mathrm{IT} / 25) * 25$

To 32

DO $30 \mathrm{~J}=1, \mathrm{~N}$
DO $30 \mathrm{I}=1, \mathrm{M}$

$T A(I, J)=(T A(I, J)+T B(I, J)) / 2$

$\operatorname{TB}(\mathrm{I}, \mathrm{J})=\operatorname{TA}(\mathrm{I}, \mathrm{J})$

$V A(I, J)=(V A(I, J)+V B(I, J)) /$

$\forall A(I, J)=(U A(I, J)+U B(I, J)) / 2$

$\mathrm{UB}(\mathrm{I}, \mathrm{J})=\mathrm{UA}(\mathrm{I}, \mathrm{J})$
$\mathrm{SA}(\mathrm{I}, \mathrm{J})=(\mathrm{SA}(\mathrm{I}, \mathrm{J})+\mathrm{SB}(\mathrm{I}, \mathrm{J})) / 2$

$\mathrm{SB}(\mathrm{I}, \mathrm{J})=\mathrm{SA}(\mathrm{I}, \mathrm{J})$

$\mathrm{ZNO3A}(I, J)=(Z N O 3 A(I, J)+Z N O 3 B(I, J)) / 2$

$\mathrm{ZNO} 3 \mathrm{~B}(\mathrm{I}, \mathrm{J})=\mathrm{ZNO} 3 \mathrm{~A}(\mathrm{I}, \mathrm{J})$

Z $+\mathrm{NHH} 4 \mathrm{~B}(\mathrm{I}, \mathrm{J})) / 2$

$\operatorname{C1A}(I, J)=(\operatorname{C1A}(I, J)+\operatorname{C1B}(I, J)) / 2$.

$\operatorname{C1B}(I, J)=\operatorname{C1A}(I, J)$

$\operatorname{ZLA}(I, J)=(Z \operatorname{LA}(I, J)+Z \operatorname{LB}(I, J)) / 2$.

$\operatorname{ZLB}(I, J)=Z \operatorname{ZLA}(1, J)+Z L B(I, J)) / 2$.

ZSA $(I, J)=(Z A A(I, J)+Z S B(I, J)) / 2$

$\operatorname{PBDISA}(I, J)=(\operatorname{PBDISA}(I, J)+\operatorname{PBDISB}(I, J)) / 2$.

Pb210 - dis and part

$\operatorname{PBDISB}(\mathrm{I}, \mathrm{J})=\operatorname{PBdiSA}(\mathrm{I}, \mathrm{J})$
$\operatorname{PBPARA}(\mathrm{I}, \mathrm{J})=(\operatorname{PBPARA}(\mathrm{I}, \mathrm{J})+\operatorname{PBPARB}(\mathrm{I}, \mathrm{J})) / 2$. 
$\operatorname{PBPARB}(I, J)=\operatorname{PBPARA}(I, J)$

$\operatorname{PBTTL}(\mathrm{I}, \mathrm{J})=\operatorname{PBDISA}(\mathrm{I}, \mathrm{J})+\operatorname{PBPARA}(\mathrm{I}, \mathrm{J})$

$\mathrm{mg} / \mathrm{m} 2 /$ day

is $\mathrm{dpm} / \mathrm{m} 2 / \mathrm{day}$

is $d p m / m 2 / d a y$

30 CONTINUE

32 ContInUe

C Retur

$\operatorname{PODISA}(I, J)=(\operatorname{PODISA}(I, J)+\operatorname{PODISB}(I, J)) / 2$

P0210 - dis and part
$\operatorname{PODISB}(\mathrm{I}, \mathrm{J})=\operatorname{PODISA}(\mathrm{I}, \mathrm{J})$

PODISB $(1, J)=$ PODISA $(I, J)$

$\operatorname{POPARB}(I, J)=\operatorname{POPARA}(I, J)=\operatorname{PaPB}(I, J)) / 2$.

$\operatorname{POTTL}(I, J)=\operatorname{PODISA}(I, J)+\operatorname{POPARA}(I, J)$

$\operatorname{SPMA}(I, J)=(\operatorname{SPMA}(I, J)+\operatorname{SPMB}(I, J)) / 2$

$\operatorname{CSUM}(I, J)=\operatorname{C1A}(I, J)+\operatorname{C} 2 A(I, J)+\operatorname{CBA}(I, J)+\operatorname{CAA}(I, J)+\operatorname{C5A}(I, J)$

\$+C6A $(I, J)+C 7 A(I, J)+C B A(I, J)+C 9 A(I, J)+C 10 A(I, J)$

$\operatorname{SuMFCZ}(I, J)=F C 1 Z(I, J)+F C 2 Z(I, J)+F C 3 Z(I, J)+F C 4 Z(I, J)+F C 5 Z(I, J)$

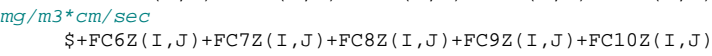
$\$+F C 6 Z(I, J)+F C Z Z(I, J)+F C 8 Z(I, J)+1$
$\operatorname{SuMFCZ}(I, J)=\operatorname{SUMFCZ}(I, J) * 864$

isotope part

$\operatorname{SMFPBZ}(I, J)=\operatorname{FPBDZ}(I, J)+\operatorname{FPBPZ}(I, J)$

for $P b 210(d i s+p a r t), d p m / m 3 * \mathrm{~cm} / \mathrm{sec}$

$\operatorname{SMFPBZ}(I, J)=\operatorname{FPBDZ}(I, J)$

$\operatorname{SMFPOZ}(\mathrm{I}, \mathrm{J})=\mathrm{FPODZ}(\mathrm{I}, \mathrm{J})+\operatorname{FPOPZ}(\mathrm{I}, \mathrm{J})$

for P0210(dis + part $), d p m / m 3 * c m / s e c$

$\operatorname{SMFPOZ}(I, J)=F P O D Z(I, J)$

Call Density()

recalculate after correcting the variables

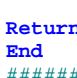

\#\#\#\#\#\#\#\# End Fintite Difference Divergence subroutine \#\#\#\#\#\#

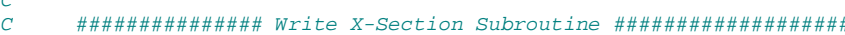
Subroutine Write_X_Section()

IMPLICIT REAL ${ }^{*} 8(\mathrm{~A}-\mathrm{H}, 0-\mathrm{Z})$
!PARAMETER $(N=94, N M=93, N P=92, M=46, M M=45, M P=44)$

G INCLUDE 'GridFile f'

INCLUDE 'comblk-r25, f'

Character*3 Date

!DIMENSION PP $(M, N), \operatorname{SUMFCZ}(M, N)$

C Y You haVe to tURN ONE OF THE THREE LOGICS ON TO GET X-SECTIONS $\mathrm{INQ}=(\mathrm{IT} / \mathrm{KR}){ }^{*} \mathrm{KR}$

print over a certain period
IF(INQ.LT.IT) Go To 41

! F.D. FOR

units $=$

convert to

vertica

! now unit

vertical

now unit

Write (Date, 144) INQ/72
WRITE (* *) Date

144 Format (I3)

C $\quad \sim \sim \sim \sim \sim \sim \sim \sim m$ File Declaration Block

OPEN (UNIT=1, FILE= ' Ice '//Date// ' '. txt ' ', STATUS= ' unknown ' )

OPEN (UNIT $=16$, FILE= 'Nutrient $1 / /$ Date $/ /$ ' ' txt ' STATUS $=$ ' unknown' )

OPEN (UNIT=18, FILE= 'Chloro' //Date//' ' txt' ', STATUS=' unknown')

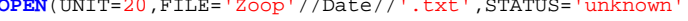

OPEN(UNIT=7, FILE='Diffus'

OPEN (UNTT=4, FILE $=$ 'TAU3. DAT ', STATUS= ' Unknown'

OPEN(UNIT=2, FILE=' STG DAT', STATUS='

OPEN (UNIT $=8$, FILE=' TAU2. DAT' ', STATUS= ' unknown' $)$

OPEN $($ UNIT $=10$, FILE $=$ ' UVWAT. DAT', STATUS= ' unknown' $)$

OPEN (UNIT=11, FILE='PICE. DAT', STATUS=' 'unknown' )

OPEN (UNIT $=13$, FILE=' DELVEL. DAT', STATUS= ' unknown'

OPEN (UNIT $=22$, FILE $=$ ' LIT2, DAT' STATUS $=$ ' Unknown')

OPEN (UNIT $=23$, FILE $=$ 'TS1, DAT ', STATUS $=$ ' unknown' $)$

OPEN (UNIT $=25$, FILE $=$ 'TS3. DAT', 'STATUS= ' unknown')

OPEN (UNIT=28, FILE= ' SINK' //Date///' . txt' ', STATUS= ' unknown ' )

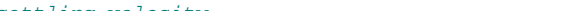

OPEN (UNIT=30, FILE= ' 210PbPo ' //Date//' ' txt ' , STATUS= ' unknown ' )

! output for

! output for OPEN (UNIT=31, FILE= 'TS PBPO. DAT ', STATUS=' 'unknown' ) ! output for

OPEN (UNIT=32, FILE= ' TS_PB_PO_INV . DAT ' , STATUS= ' unknown '

$210 \mathrm{~Pb}$ and $210 \mathrm{PO}-\mathrm{TS}$ - Whole lake inventory

OPEN (UNIT=34,FILE='S

OPEN(UNIT=35, FILE=' SEDIMENT. DAT' ', STATUS=' unknown' )

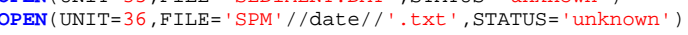

(a)

OPEN (UNIT=38, FILE= ' TS_ISO_INV_ALL-PHASE. DAT' , STATUS= ' unknown ' )

DDEP $=9$.

\section{DO $\mathrm{J} 5=1, \mathrm{~N}$}

DO J5 $=1, \mathrm{~N}$
WRITE (1,120) DIST(J5), (ZZICE (J5)/11.111), ZZICE (J5) surface to SAL.DAT

Do $\mathrm{IX}=1, \mathrm{~N}$
Do $\mathrm{JY}=1, \mathrm{M}$

DIST2 $=$ DIST (IX $)+(($ DX/100000. $) / 2$. $)$

WRTT $(7,763)$ DIST2 $(-1,)^{*}$ DEPTH (JY), ZN(JY, IX), ZK(JY, IX) diffusivity to VISC.DAT (N=visC, K=diff)

ENDDO

Close (UNIT $=7$ )

Do $I X=1, N$
Do $\mathrm{JY}=1, \mathrm{M}$

WRITE $(3,117) \operatorname{DIST2},(-1 .)^{*} \operatorname{DEPTH}(J Y), \operatorname{TB}(J Y, I X), \mathrm{SB}(J Y, I X)$,

! $T$, Sal, 
$\$ \operatorname{SigMAT}(J Y, I X)$

ENDDO

close (UNIT $=3$ )

Do $\mathrm{IX}=1, \mathrm{~N}$

DIST2 $=$ DIST (IX $)+((D X / 100000) /$.2 . $)$

WRITE $(28,117)$ DIST2, (-1.)*DEPTH (JY), SKRT1 (JY, IX),

Iwrite

\$SKRT10(JY, IX)
ENDTO

ENDDO

close (UNIT $=28$ )

! isotope part
Do $\mathrm{IX}=1, \mathrm{~N}$

sotope act.(dis + part) and vert flux X-section to file.
Do $\mathrm{JY}=1, \mathbf{M}$

Do $\mathrm{JY}=1, \mathrm{M}$

DIST2=DIST (IX) $+(($ DX/100000. $) / 2$.)

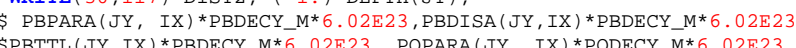
SPODISA (JY, IX) "PODECY_M*6.0223, POPARA (JY, IX) "PODECY_M*6.02E23, \$SMFPBZ (JY, IX) *PBDECY $M^{*} 6.02 E 23$, SMFP0Z (JY, IX)*PODECY_M*6. O2E23, SRATIO ( JY, IX)

\section{ENDDO}

Close (UNIT=30)

iment part

Do $\mathrm{IX}=1, \mathrm{~N}$
DO $\mathrm{JY}=1, \mathrm{M}$

$\operatorname{DIST2} 2=\operatorname{DIST}(\operatorname{IX})+((\mathrm{DX} / 100000) / 2$.
$\operatorname{WRITE}(36,117) \operatorname{DIST2},(-1.){ }^{*} \operatorname{DEPTH}(\mathrm{JY}), \operatorname{SPMA}(\mathrm{JY}, \mathrm{IX})$

ENDDO

ENDDO

close (UNIT $=36)$

Do IX $=1, \mathrm{~N}$

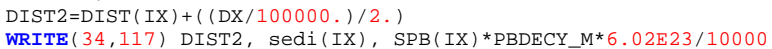

inv unit will be

\$SPO (IX)*PODECY_M*6. 02E23/10000

close (UNIT $=33$ )

USCALE $=0.2$

for vector arrows

WSCALE $=0.0002$

aspect=uscale/wscale

FF22 $=($ ATAN2 ( ( VSCALE*aspect $)$, USCALE) $) *(180, / 3.14159)$
GG22 $=$ SQRT $(($ USCALE**2) $+(($ VSCALE*aspect $) * * 2))$

WRITE $(5,117) \operatorname{DIST}(65),(-1). * \operatorname{DEPTH}(42)$, USCALE,

WRITE $(5,117)$ DIST $(65),(-1). * \operatorname{DEPTH}(42)$, USCALE,

WRITE $(5,117)$ DIST $(65),(-1.){ }^{*} \operatorname{DEPTH}(42)$, USCALE,

\$VSCALE, VSCALE, FF22, GG22

FF22 $=\left(\operatorname{ATAN2}\left(\left(\right.\right.\right.$ WSCALE$^{\star}$ aspect $\left.\left.), \operatorname{VSCALE}\right)\right) *(180 . / 3.14159)$

(degrees) GG22 $^{2}=\operatorname{SQRT}\left(\left(\right.\right.$ VSCALE $\left.^{* *} 2\right)+(($ WSCALE*aspect $\left.) * * 2)\right)$

(horizontal)
$\operatorname{WRITE}(5,117) \operatorname{DIST}(60),(-1). * \operatorname{DEPTH}(37), \operatorname{VSCALE}$,

SVSCALE, WSCALE, FF22, GG22 ( DEPTH(37), VSCALE,

WRITE $(5,117)$ DIST $(60),(-1). * \operatorname{DEPTH}(37), \operatorname{VSCALE}$

\$VSCALE, WSCALE, FF22, GG22 2 WRITE ${ }^{*}$ DEPTH (37), VSCALE,

WRITE $(5,117) \operatorname{DIST}(60),(-1$,
\$VSCALE, WSCALE, FF22, GG22

Do $\mathrm{IX}=1, \mathrm{~N}$
DO $\mathrm{JY}=1, \mathrm{M}$

\section{$\mathrm{EE} 22=(\mathrm{W}(\mathrm{JY}, \mathrm{IX})+0.00001) *$ aspect}

$\mathrm{CC} 22=\mathrm{UB}(\mathrm{JY}, \mathrm{IX})+0.00001$

(180./3.14159)

IF (dist (ix) gt 100 and dist (ix)

$\$ 200$. and depth(jy) . 1t. 280.) 60 T0 5423 . and .depth(jy) .gt .

WRITE $(5,117) \operatorname{DIST}(\mathrm{IX}),(-1.){ }^{*} \operatorname{DEPTH}(\mathrm{JY})$

$\$(U B(J Y, I X)+0.00001), V B(J Y, I X)$,

5423 continue

\section{ENDDO}

ENDDO

close (UNIT=5)

c Do IX $=1, N$

Do $\mathrm{JY}=1, \mathrm{M}$

DIST2=DIST(IX) $+(($ DX/1000000. $) / 2$. $)$

(JY), ZNO3A(JY, IX),

SRP to NO3.DAT (now Nutrient/date/.txt)

ENDDO

Close (UNIT=16)

C DO IX $=1, \mathrm{~N}$

$\operatorname{DIST2}=\operatorname{DIST}(\operatorname{IX})+((\mathrm{DX} / 100000) / 2$.
WRITE $(18,763) \operatorname{DIST2},(-1). * \operatorname{DEPTH}(\mathrm{JY}), \operatorname{CSUM}(\mathrm{JY}, \mathrm{IX})$,

CSUM. DAT ( now Chloro //Date/) . txt)

$\$ C 10 A(J Y, I X), C 1 A(J Y, I X)$

ENDO

close (UNIT=18)

Do $\mathrm{IX}=1, \mathrm{~N}$
DO $\mathrm{JY}=1, \mathrm{M}$

(.) $/ 2$.

), ZLA(JY, IX),

$\$$ ZSA $(J Y, I X)$

Close (UNIT=20) !direction

!magnitude

! Nitrate, 
Do $7999 \quad \mathrm{~J}=1, \mathrm{~N}$
Do $7999 \mathrm{I}=1, \mathrm{M}$

$\operatorname{PP}(I, J)=(\operatorname{GROL} 3(I, J)+\operatorname{grol} 4(i, j))$

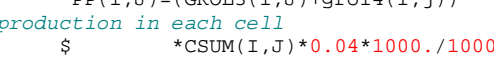

primary

NTINUE

Do $\mathrm{IX}=1, \mathrm{~N}$
DO $\mathrm{JY}=1, \mathrm{M}$

WRITE $(22,763)$ DIST2, $(-1 .)^{*} \operatorname{DEPTH}(J Y), \operatorname{PP}(\mathrm{JY}, \mathrm{IX})$,

IPP, chl

Iux to LIT2.DAT

ENDDO

Close (UNIT $=22$ )

4 continue

13 FORMAT $(1 X, 2(2 F 5.1, F 4.1, F 5.2, F 4.2, F 5.2, F 6.3))$

112 FORMAT $((1 X, 18 F 6.1))$

113 FORMAT $((1 X, 17 F 6.2))$

FORMAT $((1 X, 15 F 5.1))$

6 FORMAT $((1 x, 2014))$

FORMAT $((1 X, 15 \mathrm{~F} 10.4))$

FORMAT $((1 X, 17 F 6.3))$

FORMAT $((1 \mathrm{X}, 12 \mathrm{~F} 8.2))$

FORMAT (1H1)

FORMAT $(/ /$, ' TEMPERATURE', $/)$

FORMAT $(/$, , V-VELOCITY',

FORMAT $(/ /$, , W-VELOCITY',

$\begin{array}{lll} & \operatorname{FORMAT}(/ /, & \text { SALINITY', }\end{array}$

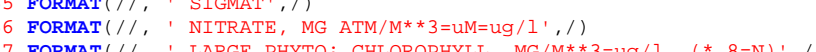

FORMAT $(/ /$, ' LARGE ZOOPLANKTON, ug N/1', $/$ )

$\operatorname{FORMAT}(/ /$, ' \% LIGHT', $/)$

FORMAT $((1 X, 6 \mathrm{~F} 10.3))$
FORMAT $((1 X, 32 \mathrm{~F} 4.0))$

163 FORMAT $(/ /$, , GROWTH, LARGE/NO3, 1/DAY', /)

4 FORMAT $(/ /$, , SINKING RATE, CM/DAY', $/)$

FORMAT $/ /$, , AMMONIUM MG ATM $/ \mathrm{M}^{* *} 3=u M=U \mathrm{~g} / 1$ ',

FORMAT $(/ /$, SMALL PHYTO; CHLOROPHYLL, MG/M**3=ug/1', $/$ )

\begin{tabular}{lll} 
FORMAT $(/ /$, & SMALL ZOOPLANKTON (FLAGELLATES), ug \\
\hline & FORMAT $(/ /$, & DISSOLVED ORGANIC NITROGEN, uM!,$/)$
\end{tabular}

FORMAT $/ \%$, DISSOLVED ORGAN

8 FORMAT $(/ /$, , ' LIGHT DUE TO INHIBITION, , $/)$

$\operatorname{FORMAT}((1 \mathrm{X}, 21 \mathrm{~F} 6.1))$

998 FORMAT $((1 X, 18 \mathrm{~F} 7.1))$

20 FORMAT $(/ /$, ' GROWTH, LARGE/NH4, 1/DAY', /

(OSO FORMAT $(1$, , GROWTH, SMALLNO3, I/DAY',

50 FORMAT $((1 X, / /))$,

8891 FORMAT (1X, ' VERTICAL EDDY VISCOSITY',

(

FORMAT $((1 X, 10 F 12,6))$
TTTTTE $(6,9999)$ IT, TTTTTT

THAT WAS ITERATION NUMBER ', 14, 1,1 TIME SINCE START $=$ ', F10.0, 'HOURS', 1 )

* $\begin{gathered}\text { pause } \\ 41 \text { conTINUE }\end{gathered}$

Return

End

C

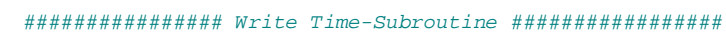

Subroutine Write_Time_Series()

IMPLICIT REAL* $8(\bar{A}-\mathrm{H}, 0-\mathrm{Z})$

作

INCLUDE 'GridFile.f'

DDEP $=0$.
WRITE $(2,120)$
DDEP+2. $),($ DDEP+35. $),($ DDEP+100. $)$

DO I $=1,127$

! time in

WRITE $(2,117) \operatorname{PLTT},(\operatorname{VAR}(\mathrm{I}, 10) / 11.111), \operatorname{VAR}(\mathrm{I}, 10)$

ENDDO

DO $958 \quad \mathrm{I}=1, \mathrm{~K} 77$

DIST2 $=\operatorname{RIST}(\mathrm{K})+((\mathrm{DX} / 100000) / 2$.
$\operatorname{PLTT}=(\operatorname{REAL}(\mathrm{I}))^{*}(1 . / 6)-.(1 . / 6$.

WRITE $(11,117)$ PLTT, DIST2, PPICE $(I, K), \operatorname{PIUVEL}(I, K)$

movement to PICE. DAT
\$PIVVEL $(\mathrm{I}, \mathrm{K})$, W2VEL $(\mathrm{I}, \mathrm{K})$

\$PIVVEL ( $($,
958 CONTINUE

Do $1010 \quad \mathrm{I}=1, \mathrm{~K} 77$

Do $1010 \mathrm{~K}=1, \mathrm{M}$

WRITE $(23,763)$ PLTT, $(-1). * \operatorname{DEPTH}(K), \operatorname{TLI}(K, \mathrm{I}), \operatorname{TLI} 2(K, \mathrm{I})$

1010 CONTINUE

\section{Do $1012 \mathrm{I}=1, \mathrm{~K} 77$}

DO $1012 \mathrm{~K}=1, \mathrm{M}$

PLTT=(REAL(I))*(1./6.)-(1./6.)

WRITE $(25,763)$ PLTT, $(-1$. $) * \operatorname{DEPTH}(K), \operatorname{TGROL} 3(\mathrm{~K}, \mathrm{I}), \operatorname{TGROL} 4(\mathrm{~K}, \mathrm{I})$ 1012 CONTINUE

c Do $1014 \mathrm{I}=1, \mathrm{~K} 77$

Do $1014 \mathrm{I}=1, \mathrm{~K} 77$

PLTT $=(\operatorname{REAL}(\mathrm{I})) *(1,16)-,(1 . / 6$,

WRITE $(27,763)$ PLTT $(-1)$.$* DEPTH (K), T G R O S 3(K, I), T G R O S 4(K, I)$
isotope part
Do $1016 \mathrm{I=1}, \mathrm{K} 77$ 
Do $1016 \quad K=1, M$

PLTT $=(\operatorname{REAL}(\mathrm{I})) *(1 . / 6)-.(1 . / 6$.

$\$ \operatorname{TSPBD}(K, I){ }^{*} \operatorname{PBDECY} M^{*} 6.02 E 23, \operatorname{TSPBP}(K, I){ }^{*}$ PBDECY_M* $6.02 E 23$,

(dis, part \& ver F) to TS_PB.DAT
\$TSPBFZ $(K, I)^{*}$ PBDECY_M*6.02E23, TSPOD $(K, I){ }^{*}$ PODECY_M*6. O2E23, STSPOP $(K, I)^{*}$ PODECY $M^{*} 6.02 E 23$, TSPOFZ $\$ \operatorname{RATIO}(K, J)$

1016 CONTINUE

Do $1022 \quad \mathrm{I}=1, \mathrm{~K} 77$
Do $1022 \mathrm{~K}=1, \mathrm{M}$

$\operatorname{PLTT}=(\operatorname{REAL}(\mathrm{I}))^{*}(1 . / 6)-,(1.16$.

政

WRITE $(33,763) \operatorname{PLTT},(-1). * \operatorname{DEPTH}(K), \operatorname{TSRATI}(K, I)$

1022 CONTINUE SEDIMENT PART

\section{Do $\mathrm{I}=1, \mathrm{~K} 77$}

WRITE $(32,120)$ PLTT, ' - PBINV(I)*PDDECY_M*6. O2E23,

\$'- POIN (I) PODECYM $6.02 E 23$, TESTI(I), TEST2(I),

Pb-210 (WHOLE LAKE INENTORY) To TS_PBINV.DAT
$!$

(I)

\$' - ', POINV(I)*PODECY_M*6. O2E23, TEST2(I),

(WHOLE LAKE INVENTORY) to TS PB INV. DAT

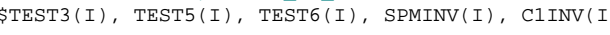

ENDDO

\section{Do $\mathrm{I}=1, \mathrm{~K} 77$}

* (1./6.) $-(1 . / 6$

WRITE $(37,120)$ PLTT, $\operatorname{SPMINV}(\mathrm{I}), \operatorname{SEditnv}(\mathrm{I})$

Do $\mathrm{I}=1, \mathrm{~K} 77$

(I) $) *(1 . / 6)-.(1 . / 6$.

120) PLTT, $1-1, \operatorname{PBINV}(\mathrm{I})^{*} \mathrm{PbDECY} \mathrm{M}^{*} 6.02 \mathrm{E} 23$

作

ENDDO

Do $1018 \quad \mathrm{I}=1, \mathrm{~K} 77$

$\operatorname{PLTT}=(\operatorname{REAL}(\mathrm{I})) *(1 . / 6)-.(1 . / 6$

WRITE $(13,117) \operatorname{PLTT},(-1 .)^{*} \operatorname{DEPTH}(K), \operatorname{TTEMP}(K, \mathrm{I}), \operatorname{TSAL}(K, \mathrm{I})$

, sal, density to DELVEL.DAT

\$, TSIG $(K, I)$

WRITE PPRODS AND VERT CHL FLUX

TG11=PRIMARY PRODS, TG33=VERT CHL FLUX

Do $2005 \mathrm{I}=1, \mathrm{~K} 77$

$\operatorname{PLTT}=(\operatorname{REAL}(\mathrm{I})) *(1, / 6)-.(1 . / 6$.

WRITE $(10,763)$ PLTT, $(-1). * \operatorname{DEPTH}(K), \operatorname{TG11}(K, \mathrm{I}), \mathrm{TG} 33(\mathrm{~K}, \mathrm{I})$

! $P b-210$

$P O / P b$

2005 CONTINUE

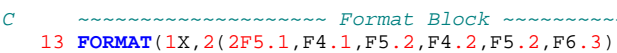

112 FORMAT $((1 \mathrm{X}, 18 \mathrm{~F} 6.1))$

113 FORMAT $((1 \mathrm{X}, 17 \mathrm{~F} 6.2))$

114 FORMAT $((1 X, 11 F 7.4))$

115 FORMAT $((1 X, 15 F 5.1))$

117 FORMAT $((1 X, 15 F 10,4))$

$118 \operatorname{FORMAT}((1 \mathrm{X}, 17 \mathrm{~F} 6.3))$

$119 \operatorname{FORMAT}((1 \mathrm{X}, 17 \mathrm{~F} 6.1))$

120 FORMAT $((1 X, 12$

139 FORMAT $(1 \mathrm{H1})$

( TEMPERATURE', 1 )

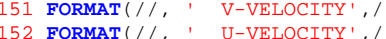

$153 \operatorname{FORMAT}(/ /$, ' W-VELOCITY',

154 FORMAT $(/ /, '$ ' SALINITY', $/)$

155 FORMAT $(/ /$, , SIGMAT', $/)$

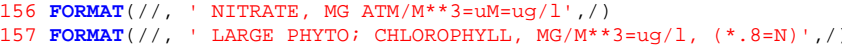

158 FORMAT $(1 /$, , LARGE ZOOPLANKTON, Ug $N / 1,1)$

$159 \operatorname{FORMAT}(/ /, 1 \%$ LIGHT', /)

160 FORMAT $((1 \mathrm{X}, 6 \mathrm{~F} 10.3))$

1 FORMAT $((1 X, 32 \mathrm{~F} 4.0))$

163 FORMAT ( $/ /$, GROWTH, LARGE/NO3, 1/DAY', $/$ )

164 FORMAT $(/ /$,
253 FORMAT $(/ /$,

254 FORMAT $(/ /$, ' SMALL PHYTO; CHLOROPHYLL, MG/M**3=ug/ $/ 1,1)$

255 FORMAT $(/ /$, ' SMALL ZOOPLANKTON (FLAGELLATES), ug N/1', $/$ )

(256 FORMAT( $/ /$, ' DISSOLVED ORGANIC NITROGEN, UM', $/$ )

(257 FORMAT $(/ /$, , 'BACTERIA , $/)$

TO INHIBITION', /)

962 FORMAT $((1 \mathrm{X}, 21 \mathrm{~F} 6,1))$

998 FORMAT $((1 X, 18 F 7.1))$

FORMAT $((1 \mathrm{X}, 18 \mathrm{~F} 6,4))$

1020 FORMAT $(/ /$, GROWTH, LARGE/NH4, 1/DAY',

(O30 FORMAT $(/$, , GROWTH, SMALL/NO3, I/DAY',

AT $(1 X$, , RICHARDSON \#', /

891 FORMAT $(1 X$, ' VERTICAL EDDY VISCOSITY' 1$)$
893 FORMAT $\left(1 X^{\prime}\right.$, VERTICAL EDDY DIFFUSIVITY',

763 FORMAT $((1 X, 10 \mathrm{~F} 12.6))$

\section{Return}

END

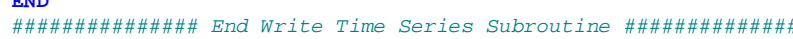

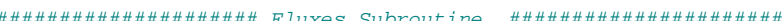

SUBROUTINE FLUXES( $U, V, T, S, Z N 3, Z N 4, C 11, C 22, C 33, C 44, C 55, C 66$, $\$ \mathrm{C} 77, \mathrm{C} 88, \mathrm{C} 99, \mathrm{C} 1010, \mathrm{ZLL}, \mathrm{ZSS}, \mathrm{UU}, \mathrm{VW}, \mathrm{TT}, \mathrm{SS}, \mathrm{ZN3} 3, \mathrm{ZN} 44, \mathrm{C} 112, \mathrm{C222}$,
IMPLICIT REAL*8(A-H, O-Z)
$M P=92, M=46, M M=45, M P=44$

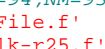

DIMENSTON U(M, $), V(M, N), T(M, N), U U(M, N), V V(M, N), T T(M, N), S(M, N)$, $\$ S S(M, N), Z N 3(M, N), Z N 33(M, N), Z N 4(M, N), Z N 44(M, N), Z L L(M, N), Z L L 2(M, N)$, 
$\$ \mathrm{ZSS}(\mathrm{M}, \mathrm{N}), \mathrm{ZSS} 2(\mathrm{M}, \mathrm{N})$

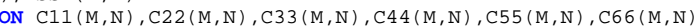
$\$ C 77(M, N), \operatorname{Cr8}(M, N), \operatorname{Cg9}(M, N), \operatorname{C1010}(M, N), \operatorname{C112}(M, N), \operatorname{C222}(M, N)$, $\$ C 332(M, N), C 442(M, N), C$
$\$ C \operatorname{Cog}(M, N), C 10102(M, N)$

Call Richardson()

Do 5
K=NK $\mathrm{J}=1, \mathrm{JM}$

DO 5 I I = $1, K$

c $\quad F U X(I, J)=((U(I, J)+U(I, J+1)) / 2$. $) * * 2-D F^{*}(U U(I, J+1)-U U(I, J))$ $\operatorname{FUX}(I, J)=\quad-D F *(U U(I, J+1)-U U(I, J))$

$\$-D F *(V V(I, J+1)-V V(I, J))$ 5 CONTINUE

\section{DO $6 \quad J=1, N$ \\ $K=N K(J)$
DO 6 II $=1, K$}

$\operatorname{FSX}(\mathrm{I}, \mathrm{J})=0.25^{*}(\mathrm{U}(\mathrm{I}, \mathrm{J})+\mathrm{U}(\mathrm{I}, \mathrm{J}+1))^{*}(\mathrm{~S}(\mathrm{I}, \mathrm{J})+\mathrm{S}(\mathrm{I}, \mathrm{J}+1))$

fluxes $\$$-DFS $($ SS $(I, J+1)-S S(I, J))$

$\operatorname{FTX}(I, J)=0.25 *(U(I, J)+U(I, J+1)) *(T(I, J)+T(I, J+1))$

FNO3X $(I, J)=0.25^{*}(U(I, J)+U(I, J+1)) *(Z N 3(I, J)+Z N 3(I, J+1)$

$\$-\mathrm{DNO} 03 \mathrm{X}^{*}(\mathrm{ZN} 33(\mathrm{I}, \mathrm{J}+1)-\mathrm{ZN} 33(\mathrm{I}, \mathrm{J}))$

FNH4X(I, J $)=0.25^{*}(U(I, J)+U(I, J+1)) *(Z N 4(I, J)+Z N 4(I, J+1))$

$\$-D N H 4 X^{*}(Z N 44(I, J+1)-Z N 44(I, J))$
$\quad F C 1 X(I, J)=0.25^{*}(U(I, J)+U(I, J+1)) *(C 11(I, J)+C 11(I, J+1))$

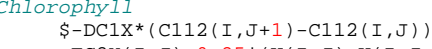

FC2X (I, J $)=0.25^{*}(U(I, J)+U(I, J+1))^{*}(C 22(I, J)+C 22(I, J+1))$

$\$-\mathrm{DC} 2 \mathrm{X}^{\star}(\mathrm{C} 222(\mathrm{I}, \mathrm{J}+1)-\mathrm{C} 222(\mathrm{I}, \mathrm{J}))$

$\operatorname{FC3X}(I, J)=0.25 *(U(I, J)+U(I, J+1)) *(C 33(I, J)+C 33(I, J+1))$

$\$-D C 3 X^{*}(\operatorname{Cr3} 32(\mathrm{I}, \mathrm{J}+1)-\mathrm{C} 332(\mathrm{I}, \mathrm{J}))$

$F C 4 X(I, J)=0.25^{*}(U(I, J)+U(I, J+1)) *(C 44(I, J)+C 44(I, J+1))$

(I, J $\$-D C 5 X^{*}(\operatorname{C55} 52(\mathrm{I}, \mathrm{J}+1)-\operatorname{C5} 52(\mathrm{I}, \mathrm{J}))$
$\operatorname{FCCX}(\mathrm{I}, \mathrm{J})=0.25^{*}(\mathrm{U}(\mathrm{I}, \mathrm{J})+\mathrm{U}(\mathrm{I}, \mathrm{J}+1)) *(\operatorname{C66}(\mathrm{I}, \mathrm{J})+\mathrm{C} 66(\mathrm{I}, \mathrm{J}+1))$

( C66 (I, J $)+C 66(I, J+1))$

$\operatorname{FC7X}(I, J)=0.25^{*}(U(I, J)+U(I, J+1)) *(C 77(I, J)+C 77(I, J+1))$ S-DC7X*(C772(I,J+1)-C772(I,J))

$\mathrm{FC8XX}(\mathrm{I}, \mathrm{J})=0.25^{*}(\mathrm{U}(\mathrm{I}, \mathrm{J})+\mathrm{U}(\mathrm{I}, \mathrm{J}+1)) *(\mathrm{C} 88(\mathrm{I}, \mathrm{J})+\mathrm{C} 88(\mathrm{I}, \mathrm{J}+1))$ $\$-D^{2} 8 X^{*}(C 882(I, J+1)-C 882(I, J))$

$\operatorname{FCgX}(\mathrm{I}, \mathrm{J})=0.25^{*}(\mathrm{U}(\mathrm{I}, \mathrm{J})+\mathrm{U}(\mathrm{I}, \mathrm{J}+1)) *(\operatorname{Cg9}(\mathrm{I}, \mathrm{J})+\operatorname{Cg9}(\mathrm{I}, \mathrm{J}+1))$ $\$$-DC9X*(C992 (I, J+1)-C992 (I, J))

$\mathrm{FC} 10 X(\mathrm{I}, \mathrm{J})=0.25^{*}(\mathrm{U}(\mathrm{I}, \mathrm{J})+\mathrm{U}(\mathrm{I}, \mathrm{J}+1)) *(\mathrm{C} 1010(\mathrm{I}, \mathrm{J})+\mathrm{C} 1010(\mathrm{I}, \mathrm{J}+1)$ FZLX(I,J)=0.25*(U(I,J)+U(I,J更)

\$-DZLX* $(Z L L 2(I, J+1)-Z L L 2(I, J))$

$\operatorname{FZSX}(\mathrm{I}, \mathrm{J})=0.25^{*}(\mathrm{U}(\mathrm{I}, \mathrm{J})+\mathrm{U}(\mathrm{I}, \mathrm{J}+1))^{*}(\mathrm{ZSS}(\mathrm{I}, \mathrm{J})+\mathrm{ZSS}(\mathrm{I}, \mathrm{J}+1))$

$\$-\operatorname{DZSX}^{\star}(Z \operatorname{ZS} 2(I, J+1)-\operatorname{ZSS} 2(I, J))$

\section{CONTINUE}

Do $19 \quad \mathrm{~J}=2$, NM

$\mathrm{K}=\mathrm{NK}(\mathrm{J})$
$\mathrm{KM}=\mathrm{K}-1$
$\mathrm{X}=(\mathrm{UU}(\mathrm{KM}, \mathrm{J}) * * 2+\mathrm{VV}(\mathrm{KM}, \mathrm{J}) * * 2) * * .5$

Vertical vector fluxes
D0 $8 \quad \mathrm{I}=2, \mathrm{KM}$

C $\operatorname{FUZ}(I, J)=$

$(Z N(I, J) / D Z)^{*}$

$\operatorname{FUZ}(\mathrm{I}, \mathrm{J})=0.5^{*} \mathrm{~W}(\mathrm{I}, \mathrm{J}) *(\mathrm{U}(\mathrm{I}, \mathrm{J})+\mathrm{U}(\mathrm{I}-1, \mathrm{~J}))$

$\$-(Z N(I, J) / D Z * *(U U(I-1, J)-U U(I, J))$
$\quad F V Z(I, J)=0.5 * W(I, J)^{*}(V(I, J)+V(I-1, J))$

$\$-(Z N(I, J) / D Z)^{*}(V V(I-1, J)-V V(I, J))$

8 CONTINUE

$\operatorname{FUZ}(K, J)=0.5^{*} W(K, J) *(U(K, J)+U(K M, J))$

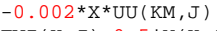

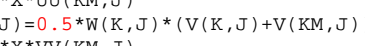

linear

CONTINUE

Do $9 \mathrm{~J}=2$, NM

$\operatorname{FUZ}(1, \mathrm{~J})=-\operatorname{TTX}(\mathrm{J})$
$\operatorname{FVZ}(1, \mathrm{~J})=-\operatorname{TTY}(\mathrm{J})$

9 CONTINUE

! scalar

VERTICAL SCALAR FLUX (IE, TEMP, SALT)

DO $10 \mathrm{~J}=1, \mathrm{~N}$

$\mathrm{K}=\mathrm{NK}(\mathrm{J})$

$\operatorname{FSZ}(\mathrm{I}, \mathrm{J})=.5^{*} \mathrm{~W}(\mathrm{I}, \mathrm{J}) *(\mathrm{~S}(\mathrm{I}-1, \mathrm{~J})+\mathrm{S}(\mathrm{I}, \mathrm{J}))$

! Nitrate

! Phosphorus

fluxes

\$- $(Z K(I, J) / D Z) *(S S(I-1, J)-S S(I, J))$
$\quad \operatorname{FTZ}(I, J)=.5^{*} W(I, J) *(T(I-1, J)+T(I, J))$

$\$-(Z K(I, J) / D Z)^{*}(T T(I-1, J)-T T(I, J))$

F

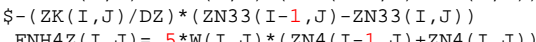

\$- $(\mathrm{ZK}(\mathrm{I}, \mathrm{J}) / \mathrm{DZ})^{*}(\mathrm{ZN} 44(\mathrm{I}-1, \mathrm{~J})-\mathrm{ZN} 44(\mathrm{I}, \mathrm{J}))$

SINKING; $0.0011575 \mathrm{CM} / \mathrm{SEC}=1 \mathrm{M} / \mathrm{DAY}, 0.00038585=1 / 3 \mathrm{M} / D A Y$

inking of phytoplankton

SINKPL $=-0.0011575$

SINKPL=SINKPL/2

$\operatorname{IF}(Z N 3(I, J) . G T .1$.$) GO TO 777$

IF (ALITE I, J). GT.15.) SINKPL=SINKPL/1.

$\operatorname{SI}(I, J)=-S I N K P L{ }^{*} 86400$

SINKPS $=-0.00038585$

$\operatorname{IF}(Z N 3(I, J) \cdot G T .1 . \operatorname{AND} \cdot \operatorname{ALITE}(I, J) \cdot G T .1.) \operatorname{SINKPS}=S I N K P S / 2$

IF (I.EQ.K)SINKPS $=$ SINKPS $/ 2$

probably go in AGG subroutine

if you change DIA or AGGS, then look in the AGGS subroutine.

DIA $=10$.

indv cells (um)

in smallest agg

$\operatorname{DIAM}=\operatorname{DIA}^{*}\left(\left(1 .{ }^{*} \mathrm{AGGS}\right){ }^{* *} 0.44\right)$

agg (um) may be user input
SINK $=(2.29 \mathrm{E}-7) *\left(\right.$ DIAM $\left.^{*} 1.17\right) * 100 . *(-1$.

as fnct of size (cm/sec) !this can

! scalar

! Nitrate

! Phosphorus

! set

!Diameter of

! \# of cells

IDiameter of

sinking rate 
1 pause

$\operatorname{sink}=(-1) * 2.3 * 100 /$.

SKRT1 $(T, J)=S T M K * 3000 * 24 / 100$

$\operatorname{SKRT1}(\mathrm{I}, \mathrm{J})=\mathrm{SINN}^{*} 3600^{*} 24 / 100$
settling velocity $(\mathrm{m} /$ day $)$ for $\mathrm{C} 1$ into an array

$\operatorname{FC1Z}(\mathrm{I}, \mathrm{J})=.5^{*}(\mathrm{~W}(\mathrm{I}, \mathrm{J})+\mathrm{SINK}) *(\mathrm{C} 11(\mathrm{I}-1, \mathrm{~J})+\mathrm{C} 11(\mathrm{I}, \mathrm{J}))$

DIAM $=\operatorname{DIA}^{*}\left(\left(2,{ }^{*}\right.\right.$ AGGS $\left.) * * 0.44\right)$

SINK $=(2.29 E-7) *\left(\right.$ DIAM $^{* * 1.17) * 100 . *} \cdot(-1)$.

Sink $=(-1$.$) (I)$

$F C 2 Z(I, J)=.5^{*}(W(I, J)+\operatorname{SINK}) *(C 22(I-1, J)+C 22(I, J))$

$\$-(Z K(I, J) / D Z) *(C 222(I-1, J)-C 222(I, J))$

$\operatorname{DIAM}=\operatorname{DIA}^{*}\left(\left(3,{ }^{*} \mathrm{AGGS}\right){ }^{* *} \oplus, 44\right)$

sink $(2.20(-1) * 2 * 3 * 100 / 8017) * .100 . *(-1$.

IF (I.EQ.K) SINK=SINK/2.

$F C 3 Z(I, J)=.5 *(W(I, J)+\operatorname{SINK}) *(C 33(I-1, J)+C 33(I, J))$

$\$-(\mathrm{ZK}(\mathrm{I}, \mathrm{J}) / \mathrm{DZ}) *(\mathrm{C} 332(\mathrm{I}-1, \mathrm{~J})-\mathrm{C} 332(\mathrm{I}, \mathrm{J}))$

DIAM $=\operatorname{DIA}^{*}\left(\left(4,{ }^{*} \mathrm{AGGS}\right) * * 0,44\right)$

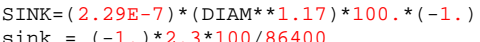

Sink $=(-1) * 2.3 * 100 /$.8640
$\operatorname{IF}(\mathrm{I} . \mathrm{EQ} . \mathrm{K})$ SINK $=\operatorname{SINK} / 2$.

$\mathrm{FC4Z}(\mathrm{I}, \mathrm{J})=.5^{*}(\mathrm{~W}(\mathrm{I}, \mathrm{J})+\mathrm{SINK}) *(\mathrm{C} 44(\mathrm{I}-1, \mathrm{~J})+\mathrm{C} 44(\mathrm{I}, \mathrm{J}))$

DIAM $=\operatorname{DIA}^{*}\left(\left(5,{ }^{*} \mathrm{AGGS}\right){ }^{* *} * 0.44\right)$

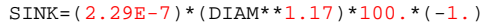

sink $=(-1 .)^{*} 2.3 * 100 / 86400$
$\operatorname{IF}(I . E Q . K)$

FC5Z $(I, J)=5^{*}(W(I, J)+\operatorname{SINK}) *(C 55(I-1, J)+C 55(I, J))$

$\$-(\mathrm{ZK}(\mathrm{I}, \mathrm{J}) / \mathrm{DZ})^{*}(\mathrm{C} 552(\mathrm{I}-1, \mathrm{~J})-\mathrm{C} 552(\mathrm{I}, \mathrm{J}))$

DIAM $=\operatorname{DIA}^{*}\left(\left(6,{ }^{*}\right.\right.$ AGGS $\left.) * * 0.44\right)$

$\operatorname{SINK}=(2.29 \mathrm{E}-7) *\left(\operatorname{DIAM}^{* * 1.17}\right) * 100 . *(-1$.

IF (I. EQ K) SINK=SINK/2.

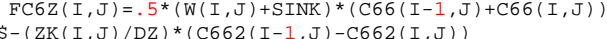

DIAM $=\operatorname{DIA}^{*}\left(\left(7,{ }^{*} \text { AGGS }\right)^{* *} * 0.44\right)$

sink $\left.=(-1,)^{* 2}, 3^{*} 100 / 8640\right) * 100, *(-1$.

IF (I.EQ.K) SINK=SINK $/ 2$,

$F C 7 Z(I, J)=.5^{*}(W(I, J)+S I N K) *(C 77(I-1, J)+C 77(I, J))$

$\$-(Z K(I, J) / D Z) *(C 772(I-1, J)-C 772(I, J)$

DIAM $=\operatorname{DIA}^{*}\left(\left(8,{ }^{*} \mathrm{AGGS}\right){ }^{* *} \mathrm{*}, 44\right)$

SINK $=(2.29 \mathrm{E}-7)^{*}\left(\mathrm{DIAM}^{* * 1} 1.17\right) * 100 . *(-1$.

sink $=(-1). * 2.3^{*} 100 / 86400$
$\operatorname{IF}($ I.EQ.K $)$ SINK $=S I N K / 2$.
$\operatorname{FC8Z}(\mathrm{I}, \mathrm{J})=.5^{*}(\mathrm{~W}(\mathrm{I}, \mathrm{J})+\mathrm{SINK}) *(\operatorname{CB8}(\mathrm{I}-1, \mathrm{~J})+\mathrm{C} 88(\mathrm{I}, \mathrm{J}))$

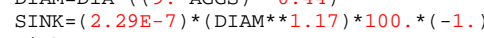

sink $=(-1). * 2.3^{*} 100 / 86400$

$\operatorname{FCgZ}(I, J)=5^{*}(W(I, J)+\operatorname{SINK}) *(\operatorname{Cg9}(I-1, J)+\operatorname{Cg9}(I, J))$

\$- $(\mathrm{ZK}(\mathrm{I}, \mathrm{J}) / \mathrm{DZ}) *(\operatorname{Cg92}(\mathrm{I}-1, \mathrm{~J})-\operatorname{C992}(\mathrm{I}, \mathrm{J}))$

DIAM $=\operatorname{DIA}^{*}\left(\left(10,{ }^{*} \mathrm{AGGS}\right){ }^{* *} 0.44\right)$

SINK $=(2.29 E-7) *\left(\operatorname{DIAM}^{* *} 1.17\right) * 100 * *(-1$.

IF (I.EO.K) SINK $=$ SINK/2

SKRT10 $(\mathrm{I}, \mathrm{J})=\mathrm{SINK} * 3600 * 24 / 100$
settling velocity $(\mathrm{m} /$ day $)$ for C10 into an array

$\mathrm{FC1OZ}(\mathrm{I}, \mathrm{J})=.5^{*}(\mathrm{~W}(\mathrm{I}, \mathrm{J})+\mathrm{SINK}) *(\mathrm{C} 1010(\mathrm{I}-1, \mathrm{~J})+\mathrm{C} 1010(\mathrm{I}, \mathrm{J}))$

$\mathrm{FZLZ}(\mathrm{I}, \mathrm{J})=.5^{*} \mathrm{~W}(\mathrm{I}, \mathrm{J})^{*}(\mathrm{ZLL}(\mathrm{I}-1, \mathrm{~J})+\mathrm{ZLL}(\mathrm{I}, \mathrm{J}))$
$\$-(\mathrm{ZK}(\mathrm{I}, \mathrm{J}) / \mathrm{DZZ})^{*}(\mathrm{ZLL2}(\mathrm{I}-1, \mathrm{~J})-\mathrm{ZLL2}(\mathrm{I}, \mathrm{J}))$

C $\quad$ sink $=(-1) * 2.3 * 100 /$.

SINKZ $=-0.00038585$

zooplankton $(\mathrm{cm} / \mathrm{sec})$

SINKZ $=0$.

$\operatorname{FZSZ}(\mathrm{I}, \mathrm{J})=.5^{*}(\mathrm{~W}(\mathrm{I}, \mathrm{J})+\operatorname{SINKZ}) *(\mathrm{ZSS}(\mathrm{I}-1, \mathrm{~J})+\mathrm{ZSS}(\mathrm{I}, \mathrm{J}))$

$\$-(Z K(I, J) / D Z) *(Z S S 2(I-1, J)-Z S S 2(I, J))$

10 CONTINUE

Do $11 \mathrm{~J}=1, \mathrm{NM}$
$\operatorname{FSZ}(1, \mathrm{~J})=-\mathrm{SZ}(\mathrm{J})$

lux (surface)

$\operatorname{FTZ}(1, \mathrm{~J})=-Q(\mathrm{~J})$

flux (surface)

write $\left(*,{ }^{*}\right)$ 'surface heat flux is', $Q(j)$

if (j.eq.94) pause

Q(J) IS IN CAL/ CM2/ SEC

$c m / \sec ^{*} T(C)$ where $T(C)=c a I^{*} \mathrm{~cm}$

so flux $=\mathrm{cal} / \mathrm{cm} 2 / \mathrm{sec}$

LOADING OF NO3: FOR SUPERIOR: $95.3-21.9$ (St. Marys) $=73.4 \mathrm{Ggm} \mathrm{N} / \mathrm{yr}$.

Now, divide by $82100 \mathrm{KM2}$ and divided by $1016 \mathrm{m2} / \mathrm{km} 2 * 1019 \mathrm{gm} / \mathrm{Ggm}=$

get $2.449 \mathrm{mg} \mathrm{N} / \mathrm{m} 2 /$ day. Then divide by $86400 \mathrm{sec} /$ day to get $2.84 \wedge-5 \mathrm{mg} \mathrm{N} / \mathrm{m} 2 / \mathrm{sec}$.

In subroutine PREDICT this will be * (DT/DZ), or sec/cm

or $(1200 \mathrm{sec} / 500 \mathrm{~cm})$, to give units of $\mathrm{mg} / \mathrm{m3}$. To do this, have

$(m g ~ N / m 2) *(1 / \mathrm{sec}) *(100 \mathrm{~cm} / \mathrm{m})$ * (DT/DZ) in $(1200 \mathrm{sec} / 500 \mathrm{~cm})$ $=6.8^{\wedge-3} \mathrm{mg} \mathrm{N} / \mathrm{m3}$ (increase per time step). 
c Note: For Nitrate, $60 \%$ VIA ATMOSPHERE AND $40 \%$ VIA EDGE

Note: For Nitrate, $60 \%$ VIA

$\operatorname{FNO3Z}(1, \mathrm{~J})=(-2.45 / 86400) *$.100 .

nitrate loads (via atm)

To check this out, *72(steps/day) * 365 days $/ y r=179 \mathrm{mg} \mathrm{P} / \mathrm{m3}$ increase distributed over upper DZ $10 \wedge \mathrm{gm} / \mathrm{Ggm}=14.7 \mathrm{Ggm} \mathrm{N}$ (distributed over the upper $\mathrm{DZ}(5 \mathrm{~m})$.
Multiply by $5 \mathrm{~m}=73.5 \mathrm{Ggm} \mathrm{N}$ per year, which is the same as line 1 above.

LOADING Phosphorous: From Matheson and Munawar, P loading is - $0.05 \mathrm{gm} \mathrm{TP} / \mathrm{m} 2 / \mathrm{yr}, \quad 0.05^{*} .4$, or $0.02 \mathrm{gm} \mathrm{SRP/m2/yr}$ (assuming SRP is $2 / 5$ of TP). This is $=20 \mathrm{mg} S R P / \mathrm{m} 2 / \mathrm{yr}=0.055 \mathrm{mg} P / \mathrm{m} 2 / \mathrm{d}$.
(Recall, initial condition $\mathrm{PO4}=\sim 0.003 \mathrm{mg} / \mathrm{l}=3 \mathrm{ug} / \mathrm{l}=3 \mathrm{mg} / \mathrm{m}$ )

Therefore, annual loading is $0.05 \mathrm{gm} \mathrm{TP} / \mathrm{m} 2 / \mathrm{yr} * 82,100 \mathrm{~km} 2$ * $1,000,000 \mathrm{~m} 2 / \mathrm{km} 2$ divided by $1019 \mathrm{gm} / \mathrm{Ggm}=4.105 \mathrm{giga} \mathrm{gm} / \mathrm{yr}$

Now subtract St. Mary's River $=0.4 \mathrm{giga} \mathrm{gm} / \mathrm{yr}$ results in $\sim 3.75$ giga gm TP $/ y r$.

Said another way: LOADING OF Soluable Reactive Phosphrous (SRP): FOR SUPERIOR: 4.1-0.4 (minus the contribution form St. Marys River) Ggm Total Phosphrous/yr. DIVIDED BY $82100 \mathrm{KM2} / 10 \wedge 6 \mathrm{~m} / \mathrm{km} 2$
$10 \wedge \mathrm{g} / \mathrm{gm} / \mathrm{Ggm}=0.0458 \mathrm{gm} \mathrm{TP} / \mathrm{m} 2 / \mathrm{yr}$. Multiply by 0.4 to change $0.05 \mathrm{mg} \mathrm{P} / \mathrm{m} 2 /$ day. Then divide by $86400 \mathrm{sec} /$ day to get $5.791-7 \mathrm{mg} \mathrm{P} / \mathrm{m} 2 / \mathrm{sec}$. Th subroutine PREDICT this will be (DT/DZ), or sec/cm (1200 sec/s00 to give units of $\mathrm{mg} / \mathrm{m} 3$. To do this, have
FLUXES by $100 \mathrm{~cm} / \mathrm{meter}$ so that in PREDICT:

$(m g P / m 2) *(1 / \mathrm{sec}) *(100 \mathrm{~cm} / \mathrm{m}) \quad *(D T / D Z)$ in $(1200 \mathrm{sec} / 500 \mathrm{~cm})$ $=1.372^{\wedge}-4 \mathrm{mg} P / \mathrm{m} 3$ (increase per time step).

Note that loading 20\% VIA ATMOSPHERE AND $80 \%$ VIA EDGE.

$\mathrm{FNH4Z}(1, \mathrm{~J})=(-0.05 / 86400) *$.

!surface

phos loads (via atm)

To check this out, *72(steps/day) * 365 days $/ y r=3.6 \mathrm{mg} \mathrm{P} / \mathrm{m3}$ increase distributed over upper $D Z(5 \mathrm{~m})$ in one year assuming Now * $82100 \mathrm{~km} 2$ * $1016 \mathrm{~m} 2 / \mathrm{km} 271000 \mathrm{mg} / \mathrm{gm} / \mathrm{c}$ Divide by $0.4 \mathrm{TP} / \mathrm{GRP}$ * SRP (distributed over the upper DZ $(5 \mathrm{~m})$. the same as "line 9 " above.

$\mathrm{FC} 1 Z(1, \mathrm{~J})=0$.

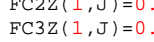

$F C 4 Z(1, J)=0$.

$\operatorname{FC} 5 Z(1, J)=0$.
$\operatorname{FC} 6 Z(1, J)=0$.

FC6Z $(1, j)=0$.

$\operatorname{FCBZ}(1, \mathrm{~J})=0$.

$\operatorname{FCgZ}(1, \mathrm{~J})=0$

$\operatorname{FC} 10 Z(1, J)=0$

$\operatorname{FZLZ}(1, J)=0$

!surface

\section{CONTINUE}

RETU

\#HA

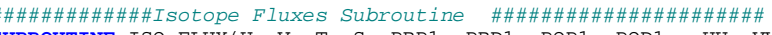
SUBROUTINE ISO_FLUX( $U, V, T, S$, PBP1, PBD1, POP1, POD1, UU, VV , $\$ T T$, SS, PBP2, PBD2, POP2, POD2)

IMPLICIT REAL*8(A-H, O-Z)

PARAMETER $(N=94, N M=93, N P=92, M=46, M M=45, M P=44)$

include 'comblk-r25, f'

DIMENSION $U(M, N), V(M, N), T(M, N), S(M, N), U U(M, N), V V(M, N)$,

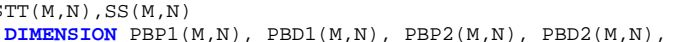

DIMENSION PBP1 $(M, N), \operatorname{PBD} 1(M, N), \operatorname{PBP} 2(M, N)$,
$\$ P O P 1(M, N), \operatorname{POD1}(M, N), \operatorname{POP}(M, N), \operatorname{POD}(M, N)$

Call Richardson()

$\operatorname{SINKPB}=2.3 / 864 \cdot{ }^{*}(-1$.
velocity $(\mathrm{cm} / \mathrm{sec})$ for $210 \mathrm{~Pb}, \mathrm{~m} / \mathrm{day}^{*}(100 \mathrm{~cm} / \mathrm{m}) /(1$ day $/ 86400 \mathrm{sec})$ SINKPO $=2.3 / 864 . *(-1$.

DO $5 \mathrm{~J}=1, \mathrm{NM}$

Do $5 \mathrm{I}=1$,

$\operatorname{FPBDX}(\mathrm{I}, \mathrm{J})=0.25 *(\mathrm{U}(\mathrm{I}, \mathrm{J})+\mathrm{U}(\mathrm{I}, \mathrm{J}+1)) *(\operatorname{PBD} 1(\mathrm{I}, \mathrm{J})+\operatorname{PBD} 1(\mathrm{I}, \mathrm{J}+1))$

$\begin{aligned} & \text { Pb210 } x \text {-deriction } \\ & \text { \$-DPBDX* }(\operatorname{PBD} 2(\mathrm{I}, \mathrm{J}+1)-\operatorname{PBD} 2(\mathrm{I}, \mathrm{J}))\end{aligned}$

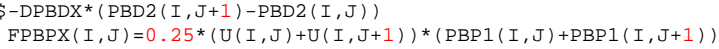

iculate Pb210 X-deriction

* $\operatorname{FPODX}(\mathrm{I}, \mathrm{J})=0.25^{*}(\mathrm{U}(\mathrm{I}, \mathrm{J})+\mathrm{U}(\mathrm{I}, \mathrm{J}+1)) *(\operatorname{POD} 1(\mathrm{I}, \mathrm{J})+\operatorname{POD} 1(\mathrm{I}, \mathrm{J}+1)$

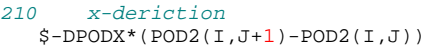

$\operatorname{FPOPX}(\mathrm{I}, \mathrm{J})=0.25^{*}(\mathrm{U}(\mathrm{I}, \mathrm{J})+\mathrm{U}(\mathrm{I}, \mathrm{J}+1)) *(\operatorname{POP} 1(\mathrm{I}, \mathrm{J})+\operatorname{POP} 1(\mathrm{I}, \mathrm{J}+1))$

$\$-D_{P O P X}{ }^{*}(\operatorname{POP} 2(I, J+1)-\operatorname{POP} 2(I, J))$

\section{CONTINUE}

* Vertical scalar flux

Do $10 \mathrm{~J}=1, \mathrm{~N}$

$\mathrm{K}=\mathrm{NK}(\mathrm{J})$

$\operatorname{FPBDZ}(\mathrm{I}, \mathrm{J})=.5^{*} \mathrm{~W}(\mathrm{I}, \mathrm{J}) *(\operatorname{PBD} 1(\mathrm{I}-1, \mathrm{~J})+\operatorname{PBD} 1(\mathrm{I}, \mathrm{J}))$

Dissolved Pb210 Z-deriction
$\$-(\mathrm{ZK}(\mathrm{I}, \mathrm{J}) / \mathrm{DZ})^{*}(\operatorname{PBD} 2(\mathrm{I}-1, \mathrm{~J})-\operatorname{PBD} 2(\mathrm{I}, \mathrm{J}))$

* IF (I.EQ,K) SINK $=S I N K / 2$

$\operatorname{FPBPZ}(\mathrm{I}, \mathrm{J})=.5^{*}(\mathrm{~W}(\mathrm{I}, \mathrm{J})+\operatorname{SINKPB}) *(\operatorname{PBP} 1(\mathrm{I}-1, \mathrm{~J})+\operatorname{PBP} 1(\mathrm{I}, \mathrm{J}))$

particulate
$\$-(Z K(I, J) / D Z) *(\operatorname{PBP} 2(\mathrm{I}-1, \mathrm{~J})-\operatorname{PBP} 2(\mathrm{I}, \mathrm{J}))$

* $\quad F P B P Z(I, J)=.5^{*}(W(I, J)+S I N K) *(P B P 1(I-1, J)+P B P 1(I, J))$

! $\$-(Z K(I, J) / D Z) *(P B P 2(I-1, J)-P B P 2(I, J))$

$\operatorname{FPODZ}(I, J)=.5^{*} W(I, J) *(\operatorname{POD} 1(\mathrm{I}-1, \mathrm{~J})+\operatorname{POD} 1(\mathrm{I}, \mathrm{J}))$ !settling

! Dissolved

Dissolved 
Dissolved P0210 Z-deriction

$\$-(\mathrm{ZK}(\mathrm{I}, \mathrm{J}) / \mathrm{DZ})^{*}(\operatorname{POD} 2(\mathrm{I}-1, \mathrm{~J})-\operatorname{POD} 2(\mathrm{I}, \mathrm{J}))$

* IF(I.EQ.K) SINK=SINK/2

$\operatorname{FPOPZ}(\mathrm{I}, \mathrm{J})=.5^{*}(\mathrm{~W}(\mathrm{I}, \mathrm{J})+\mathrm{SINKPO}) *(\operatorname{POP} 1(\mathrm{I}-1, \mathrm{~J})+\operatorname{POP} 1(\mathrm{I}, \mathrm{J})$

$\$-(Z K(I, J) / D Z * *(P O P 2(I-1, J)-P O P 2(I, J))$

$Z$-deriction
$\$-(Z K(I, J) / D Z) *(P O P 2(I-1, J)-P O P 2(I, J))$

\section{CONTINUE}

DO $15 \mathrm{~J}=1$, NM

$\operatorname{FPBPZ}(1, J)=(-$
$27.4 / 86400.)^{* 100 .} *{ }^{*} .7 / \mathrm{PBDECY}-\mathrm{M} / 6.02 \mathrm{E} 23$

$\operatorname{FPBDZ}(1, \mathrm{~J})=(-27.4 / 86400) * .100 . * 1 . /$ PBDECY_M/6. 02 E23

$\operatorname{FPBPZ}(1, \mathrm{~J})=0 . /$ PBDECY_M $/ 6.02 \mathrm{E} 23$

$\operatorname{FPOPZ}(1, \mathrm{~J})=0 . / \mathrm{PODECY} M / 6.02 \mathrm{E} 23$

* Refer from the fluxes subroutine for how to handle atmospheric flux of N03 and

* $27.4 \mathrm{dpm} / \mathrm{m} 2$-day for 210Pb and $2.74 \mathrm{dpm} / \mathrm{m} 2$-day for 210Po are common used value. Then the final

unit for isotope fluxes will be $\mathrm{dpm}^{*} \mathrm{Cm} / \mathrm{m} 3-\mathrm{sec}$, then times (DT/DZ) (in 1200

get $\mathrm{dpm} / \mathrm{m} 3$ - increase per time step.

Asumption is made that atmos fallout flux contribute only to diss activities.

\section{CONTINUE}

RETUR

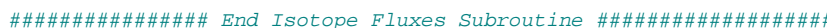

SUBROUTINE SPM_FLUX (U, V, T, S, SPM1, UU, VV, TT, SS, SPM2)

IMPLICIT REAL* $8(A-H, O-Z)$

(

INCLUDE 'Gridfile. $\mathrm{FI}^{\prime}$

DIMENSION $U(M, N), V(M, N), T(M, N), S(M, N), U U(M, N), V V(M, N)$

$\operatorname{STT}(M, N), S S(M, N)$

!atmos fallut

政

call Richardson( )

$\operatorname{SINKPB}=2.5 / 864 . *(-1$.

Sy $(\mathrm{cm} / \mathrm{sec})$ for $210 \mathrm{~Pb}, \mathrm{~m} / \mathrm{day}^{*}(100 \mathrm{~cm} / \mathrm{m}) /(1$ day/86400 sec $)$

write $\left(*^{*}\right)$, here 11111

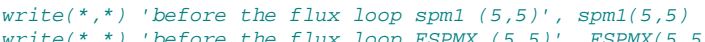

write $(*, *)$ 'before the flux loop $\operatorname{FSPMX}(5,5)$ ', $\operatorname{FSPMX}(5,5)$
write $(*, *)$ 'before the prediction loop $\operatorname{FSPMX}(5,5)$ ', $\operatorname{FSPMX}(5,5)$
Do $5 \mathrm{~J}=1, \mathrm{NM}$

$\mathrm{K}=\mathrm{NK}(\mathrm{J})$
DO $5 \mathrm{I}=1, \mathrm{~N}$

$\operatorname{FSPMX}(\mathrm{I}, \mathrm{J})=0.25^{*}(\mathrm{U}(\mathrm{I}, \mathrm{J})+\mathrm{U}(\mathrm{I}, \mathrm{J}+1)) *(\operatorname{SPM} 1(\mathrm{I}, \mathrm{J})+\operatorname{SPM} 1(\mathrm{I}, \mathrm{J}+1)$

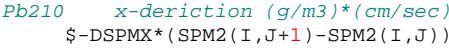

* Vertical scalar fluX

1 write $\left({ }^{*}, *\right)$ 'before the flux loop $\operatorname{fSPMZ}(5,5)$ ', $\operatorname{FSPMZ}(5,5)$

ISINK $=0.0011575 / 2$.

rate for SPM: $0.5 \mathrm{~m} /$ day

!set sink

write $\left({ }^{*},{ }^{*}\right) \operatorname{sink}{ }^{*} 86400 / 100$

pause

Do $10 \mathrm{~J}=1, \mathrm{~N}$

$\mathrm{K}=\mathrm{NK}(\mathrm{J})$
Do $10 \mathrm{I}=2, \mathrm{~K}$

FSPMZ $(I, J)=.5^{*}(W(I, J)+\operatorname{SINK}) *(\operatorname{SPM} 1(I-1, J)+\operatorname{SPM} 1(I, J))$

Pb210 Z-deriction

FSPMZ $(I, J)=.5^{*} W(I, J) *(\operatorname{SPM1}(I-1, J)+\operatorname{SPM1}(I, J)$

particulate Pb210 Z-deriction NO Sink
$! \quad \$-(Z K(I, J) / D Z)^{*}(\operatorname{SPM} 2(I-1, J)-\operatorname{SPM}(I, J))$

$$
\begin{aligned}
& \text { if (it.eq.10) then } \\
& \text { write }\left(*^{*}\right) \text { sink }
\end{aligned}
$$

pause

\section{CONTINUE}

write $(*, *)$ 'after the flux loop $\operatorname{FSPMZ}(5,5)$ ', $\operatorname{FSPMZ}(5,5)$

Do $\mathrm{J}=1$, NM

* $\quad \operatorname{fspmz}(1, J)=0$

$\mathrm{g} / \mathrm{m} 3{ }^{*} \mathrm{~cm} / \mathrm{s}$

ENDDO

RETUR

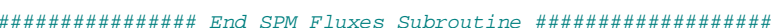

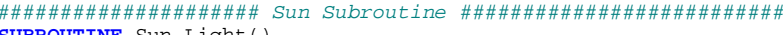
SUBROUTINE SUn_Light ()

I PARAMETER ( $N=94, N M=93, N P=92, M=46, M M=45, M P=44)$

INCLUDE 'Gridfile.f'

include 'comblk-r25. f'

$\mathrm{T} 77=2^{*} \mathrm{DT}{ }^{*} \mathrm{IT} /\left(60 *{ }^{*} 60 . * 24.\right)$
$\mathrm{T} 78=\mathrm{A} J U L+\mathrm{T} 77$ 
$\mathrm{DEC}=0.017453293^{*}(-23.45) * \operatorname{Cos}\left(2 .{ }^{*} 3.14159^{*}(\mathrm{AJUL}+10 .+\mathrm{T} 77) / 365.\right)$ SINELA $=\operatorname{SIN}(A L A T){ }^{*} \operatorname{SIN}(D E C)+\operatorname{Cos}($ ALAT $){ }^{*} \operatorname{COS}(D E C){ }^{*} \operatorname{COS}(15$ *

$\$ 0.017453293^{*} T 77^{*} 24$. )

IF (SINELA.LE.๑.)SINELA $=0.0000000001$

ASINEL=ASIN(SINEL) 180.13 .14

RAML $=1$. $/$ SIN

IF (RAML.GT.27.) RAML $=27$.

CSEC $=0.128-0.054^{*}$ LOG10 (RAML)

$\operatorname{DRC}=0.44 * \operatorname{EXP}\left(-.22^{*} \operatorname{ASIN}(\operatorname{SINELA}) * 180 . / 3.14159\right)$

DO $1 \mathrm{~J}=1, \mathrm{~N}$

0.66 IS AN ESTIMATED ATM EXTINCTION COEFF, 0.3 IS CLOUDS

FROM NIXON, 0.7 IS A MAX, 0.17 IS A MIN, .43 IS AN

AVERAGE FOR NARAGANSETTE BAY.

NOTE THAT THERE ARE NO CLOUDS ANYMORE-- JUST THE REDUCTION RE NEUMANN AND PIERSON

$\operatorname{SUN}(\mathrm{J})=1 .{ }^{*}\left(0.5^{*} 1.923^{*} \operatorname{EXP}\left(-\mathrm{ATF}^{*} \mathrm{CSEC}{ }^{*} \mathrm{RAML}\right){ }^{*} \operatorname{SINELA+DRC}\right)$

AIN $=3.14159 / 2 .-$ ASIN ( SINELA)

$\operatorname{AREFR}=\operatorname{ASIN}(0.75 * \operatorname{SIN}($ AIN $))$

* $*$ * $2 /$ TAN (ATN+AREFR $* * 2$

OCIN (AIN-AREFR)**2/SIN (AIN +AREFR $\left.{ }^{* *} 2\right)$

$\operatorname{SUN}(\mathrm{J})=\operatorname{SUN}(\mathrm{J}) *(1 .-\operatorname{REF}(\mathrm{J}))$
$\operatorname{IF}(\operatorname{ASINEL} . \mathrm{LE} .0001) \operatorname{SUN}(\mathrm{J})=0$

1\% OF THE LIGHT IS ALLOWED THROUGH THE ICE BUT $=F(\%$ ICE COVER $)$ THIS ALLOWS THE RIGHT DISTRIBUTIO THE RTOHT LIGHT LEVEL, SEE BELOW FOR THE LTGHT DISTRTBUTION

FACTOR=ZZICE ( J)/DICE

IF (FACTOR. GT.1.) FACTOR $=1$
IF(FACTOR.LT.. .) FACTOR $=0$

IF(FACTOR.LT. ${ }^{*}$, ', sunlight level w/o ice', $\operatorname{Sun}(j)$

if (J.eq.30) ${ }^{*}$ pause

Here we make FACTOR $=0$ so that the ice stops no light

FACTOR $=0$.

$\operatorname{SUN}(J)=(1 .-\operatorname{FACTOR}) * \operatorname{SUN}(J)+($ FACTOR $* .01) * \operatorname{SUN}(J)$

\section{CONTINUE}

Return

c $\# \# \# \# \# \# \# \# \# \# \# \# \# \# \# \# \#$ End Sun Subroutine $\# \# \# \# \# \# \# \# \# \# \# \# \# \# \# \# \# \# \# \# \# \# \#$

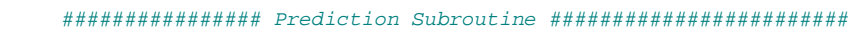
SUBROUTINE PREDIC ( U, V, T, S, ZN3 $, Z N 4, C 11, C 22, C 33, C 44, C 55, C 66$, \$C77, C88, C99, C1010, ZLL, ZSS, UU, WN TT, SS, ZN33, ZN44, C112, C222, $\$ C 332$, C442, C552, C662, C772, C882, C992, C10102, ZLL2, ZSS2)

!PARAMETER ( $N=94, N M=93, N P=92, M=46, M M=45, M P=44)$

INCLUDE 'GridFile.f'

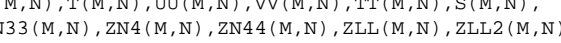
$\$ Z \operatorname{ZSS}(M, N), Z \operatorname{ZSS} 2(M, N), \operatorname{UBAR}(N), \operatorname{BACNIT}(M, N)$
DIMENSTON C11 $(M, N), C 22(M, N), C 33(M, N), C 44(M, N), C 55(M, N), C 66(M, N)$, $\$ C 77(M, N), C 88(M, N), C 99(M, N), C 1010(M, N), \operatorname{C11}(M, N), C 222(M, N)$, $\$ C 332(M, N), C 442(M, N), C 552(M, N), C 662(M, N), \operatorname{C772}(M, N), \operatorname{C8} 2(M, N)$, $\$ C \cos (M, N), C 10102(M, N)$

\section{Call Sun_Light (}

$\mathrm{INQ}=(\mathrm{IT} / 6) * 6$

$\begin{array}{ll}\text { Do } & 775 \mathrm{I}=1, \mathrm{M} \\ \text { Do } & 775 \mathrm{~J}=1, \mathrm{~N}\end{array}$

$\mathrm{C} 1=\mathrm{C} 11(\mathrm{I}, \mathrm{J})$

$\operatorname{UMAX}=\left(10, * *\left(\left(0.0275^{*} T(\mathrm{I}, \mathrm{J})\right)-\odot .23\right)\right)$

G33 $=$ GROL3 $(I, J) /$ UMAX

on Umax

!Production

G44=GROL4 $(I, J) / U M A X$

I CALL AGG(C1, C2, C3, C4, C5, C6, C7, C8, C9, C10, G33, G44)

$\mathrm{INP}=(\mathrm{IT} / 12) * 12$

$3=1$ HOUR, $9=3$ HOURS, $12=4$ HOURS

IF(INP. LT.IT) GO TO 104

size classes

$=2$ HOURS,

!printing

$$
\begin{aligned}
& \text { I. eq. } 2=7.5 \mathrm{~m} \\
& \text { I.eq. } 11=52.5 \mathrm{~m} \\
& \text { I.eq. } 21=102.5 \mathrm{~m} \\
& \text { I.eq. } 49=247.5 \mathrm{~m} \\
& \text { I. eq. } 31=152.5 \mathrm{~m} \\
& \text { I. eq. } 41=202.5 \mathrm{~m}
\end{aligned}
$$

$\mathrm{mcol}=8$

$\mathrm{mcol}=16$
$\mathrm{mCol}=2$

IF (I.EQ.11.AND.J.EQ.mCOI)

政 101 FORMAT (1X, I5, I5, 10F10.5)

102 CONTINUE

IF (I.EQ.21.AND.J.EQ.mCol)

C2 $\mathrm{C}, \mathrm{C} 4, \mathrm{C} 5, \mathrm{C} 6, \mathrm{C} 7, \mathrm{C} 8, \mathrm{C9}, \mathrm{C} 1 \mathrm{O}$ to TAU2. DAT
103 CONTINUE

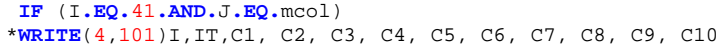
to TAU3 DAT

104 CONTINUE

\section{$\mathrm{C} 11(\mathrm{I}, \mathrm{J})=\mathrm{C} 1$}

\section{CONTINUe}

START OF THE CENTRAL DOMATN

THESE LOOPS CALCULATE THE SCALERS

DO $12 \mathrm{~J}=2$, NM

$\mathrm{K}=\mathrm{NK}(\mathrm{J})-1$ 
PHYTOPLANKTON GROWTH VIA TEMPERATURE

DIVIDING UMAX BY $0.69=$ DOUBLINGS PER DAY

$\operatorname{UMAX}=\left(10, * *\left(\left(.0275^{*} T(I, J)\right)-.23\right)\right)$

SURFACE LIGHT INHIBITION

(1360 W/M2=2 CAL/CM2/MIN)

THE 1.0000 IS FROM P84 OF PARSONS ET AL. THEY HAVE PMAX 1-16, AVE=4 BUT OLIGOTROHIC LAKES $=0.1$ TO 1 (MG C/MG CHL/HR)

$$
\sim \sim \sim \sim \text { LIGHT }
$$

THIS IS THE NEW EFFECT OF LIGHT FROM STEELE (1962)

LIGHT $=($ LIGHT/OPTIMAL LIGHT) * EXP (1- [ LIGHT/OPTIMAL LIGHT ] $)$ LIGHT IN LY/MIN
SOPTL $=$ OPTIMAL

SOPTL $=0.2$

$\operatorname{SLITE}=((\operatorname{ALITE}(\mathrm{I}, \mathrm{J}) / 100). * \operatorname{SUN}(\mathrm{J})) / \mathrm{SOPTL}$

ALITE2 (I, N) SALITE2 (I, N-1)

1\% OF THE LIGHT IS ALLOWED THROUGH THE ICE BUT $=F(\%$ ICE COVER $)$ THIS GETS THE RIGHT LIGHT LEVEL UNDER THE ICE

\section{FACTOR=ZZICE ( J)/DICE}

IF (FACTOR.GT.1.)FACTOR $=1$.
IF(FACTOR.LT. O.)FACTOR $=0$.

$\operatorname{ALITE} 2(\mathrm{I}, \mathrm{J})=(1 .-\mathrm{FACTOR})^{*} \operatorname{ALITE} 2(\mathrm{I}, \mathrm{J})+\left(\mathrm{FACTOR}^{*} .01\right)^{*} \operatorname{ALITE} 2(\mathrm{I}, \mathrm{J})$

$\operatorname{ALITE} 2(\mathrm{I}, \mathrm{N})=\operatorname{ALITE} 2(\mathrm{I}, \mathrm{N}-1)$

CONVERSION RATIOS

C2CHL $=40 \mathrm{mg} \mathrm{C}: 1 \mathrm{mg} \mathrm{Chl}$, OR $0.04 \mathrm{gm} \mathrm{C}: \mathrm{mg} \mathrm{Ch}$

$P 2 \mathrm{CH}=1.0 \mathrm{mg} P: 1.0 \mathrm{mg}$ Chlorophyll

$C 2 P=40 \mathrm{mg} C: 1 \mathrm{mg} P$

$C 2 \mathrm{~N}=40 \mathrm{mg} C \mathrm{cos}$

P2N $=P / N=(1.0 / 7.2)$ CHAPRA; OR (1/15) PARSONS

$\mathrm{C} 2 \mathrm{CHL}=0.04$

$\mathrm{C} 2 \mathrm{~N}=5.5 / 1000$

$\mathrm{P} 2 \mathrm{CH}=1 . / 1$

$\mathrm{C} 2 \mathrm{P}=0.04$

$\mathrm{P} 2 \mathrm{~N}=1.17 .2$

EAT $=5$

on phyto (m3/gm-C/day)

HYDROLYSIS

FIRST--RESPIRATION:
DOC TO P (PHYTO AND ZOOP RESPIRATION) $=7.5 \% / D A Y$

DHYDRO $=0.075$ DOC TO AMMONIA TO N (PHYTO AND ZOOP RESP)

$=7.5 \% / D A Y$ (DOC TO AMMONIA) * 10\%/DAY (AMMONIA TO N) $D H Y D R 2=0.075^{*} 0.1$

SECOND--SLOPPY EATING:

P POC TO DOC TO P (SLOPPY EATING TO DOC TO P) $=10 \% /$ DAY (POC TO
DOC) * 7.5\%/DAY (DOC TO P) DHYDR $3=0.1 * 0.075$

$N$ POC TO DOC TO AMMONIA TO N (SLOPPY EATING TO DOC TO AMMONIA TO N) $\begin{aligned}= & 10 \% / D A Y \text { (POC TO DOC) * 7.5\%/DAY (DOC TO AMMONIA) * } \\ & 10 \% / D A Y \text { (AMMONIA TO N) }\end{aligned}$

DHYDR $4=0.1 * 0.075 * 01.1$

$\sim \sim ~$ END OF HYDROLYSIS

GROWTH AND PARTICULATE NITROGEN GENERATION

FOR LARGE AND SMALL PHYTO FOR NO3 AND PO4

$\operatorname{IF}(Z N 3(I, J) . L T . \Theta$.
$\operatorname{ZN} 3(I, J)=0$
$\operatorname{IF}(Z N 4(I, J) . L T . \Theta$.
$Z N 4(I, J)=0$

$L=L A R G E, S=S M A L L, 3=N O 3,4=P O 4$

LOOKS LIKE THESE HALF SAT CONSTANTS COULD BE $\sim 1 / 2$ the initial nut concentration in $\mathrm{mg} / \mathrm{m} 3$ )

$\operatorname{GROL3}(\mathrm{I}, \mathrm{J})=\mathrm{UMAX} * \operatorname{ALITE} 2(\mathrm{I}, \mathrm{J}) *(\mathrm{ZN} 3(\mathrm{I}, \mathrm{J}) /(10,+\mathrm{ZN} 3(\mathrm{I}, \mathrm{J})))$

THIS IS THE POINT WHERE WE PICK THE MIN RATE OF N AND P AND SET BOTH TO THE MIN RATE. (CHAPRA BOOK, P 608)

\section{$\operatorname{IF}(G R O L 3(\mathrm{I}, \mathrm{J})$.LE.GROL4 $(\mathrm{I}, \mathrm{J}))$ THEN}

!Nutrient

\section{$\operatorname{GROL4}(\mathrm{I}, \mathrm{J})=\operatorname{GROL3}(\mathrm{I}, \mathrm{J})$}

$\operatorname{ELSEL} 3(I, J)=\operatorname{GROL} 4(I, J)$

END IF

HERE IS WHERE WE CALCULATE THE ACTUAL CHLORO INCREASE

AS GROL4 (1/DAY) * CHLORO (MG/M3) * TIME ( 0.00023 DAY)

$\operatorname{C1INC}=G R O L 4(\mathrm{I}, \mathrm{J}) * \operatorname{C11}(\mathrm{I}, \mathrm{J}) *\left(2 .{ }^{*} \mathrm{DT} / 86400.\right)$

$P N G=P A R T$ NITROGEN GENERATION

NOTE-NOW PN3 AND PN4 ARE THE NO3 AND NH4 PARTICULATE NITROGEN

BUT........NOW NO3 IS RETAINED AS PN3, AND NH4 IS NOW PO4

AN2CH IS THE NITROGEN TO CHLOROPHYLL RATIO

$\mathrm{AN} 2 \mathrm{CH}=7.2 / 1$.

PN3C1 $=$ C1INC * AN2CH

nitrogen increase

C P PCH IS THE PHOSPHORUS TO CHLOROPHLYLL RATIO 
THESE ARE THE NH4 (NOW PO4)

MULTIPLY BY P/N OF (1.0/7.2) CHAPRA; OR (1/15) PARSONS

$\mathrm{p} 2 \mathrm{n}=1 . / 15$.

PHYTOPLANKTON RESPIRATION

(UMAX INCLUDES SOME RESPIRATION BUT NEED MORE)

PHYTO RESP + EXCRETION + SOME DEATH BUT NOT GRAZING

FIRST NUMBER $=$ RESP RATE $(1 /$ DAY $)($ RANGE $=0.01-0.5 \mathrm{WITH}$

RESP $=0.15 *(1.08 * *(T(I, J)-20)) *.(2 * D T / 86400$.

!may speed up

$\sim$ BACTERIA MEDIATED NITRIFICATION

BACNIT = SOMETHING * $(1.08 * * T(I, J)-20)) *.\left(2 .{ }^{*} D T / 86400.\right)$ (PAGE 426 IN C, WHERE SOMETHING $=k$ ko $($ organic to ammonia
$=0.25$ per day) * kai (ammonia to nitrite $=0.25 /$ day) * kin (nitrite to nitrate $=0.75 /$ day) $=0.045 /$ day

Then * this by some sort of dead organic stuff like zoops piss but zoop piss is already ammonia so maybe something = kaitkin $\operatorname{BACNIT}(I, J)=Z N 3(I, J) *\left(1 .-\operatorname{EXP}\left(-0.068^{*}\left(1.188^{* *}(T(I, J)-20).\right) *\right.\right.$ @(2. $\left.\left.\left.{ }^{*} D T / 86400.\right)\right)\right)$

SO NOW BACNIT $=$ NOM-DIM 10\% (OF ANYTHING) PER DAY

$\operatorname{BACNIT}(I, J)=0.1 *\left(1.08^{* *}(T(I, J)-20).\right) *\left(2 .{ }^{*} D T / 86400\right)$

〜 ZOOPS GRAZING ON PHYTOPLANKTON

GRAZING IS A FUNCTION OF TEMPERATURE

NOTE: THE 1. IN THE EQUATION=GRAZING RATE IN $\mathrm{m} 3 / \mathrm{gmC} /$ day.

(RANGE=0.5-5.0 WITH TYPICAL 0.1-0.2) CHAPRA PAGE 629

HALF SATURATION $=\sim 2-25 \mathrm{mg} \mathrm{Chl} / \mathrm{m} 3$ with most $=5-15 \mathrm{mg} \mathrm{chl} / \mathrm{m} 3$

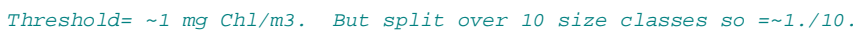

mg Chl/m3.

GLZC* HAVE NO UNITS,

$\operatorname{IF}(C 11(I, J) . G T \cdot \odot .01)$ THEN

function GLZC1=EAT * ZLL $(I, J) *$

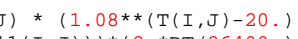

GLZC1=0
END IF

!may want
GRAZING OF LARGE ZOOPS ON SMALL ZOOPS

GRAZING IS A FUNCTION OF TEMP

THE 1.5 IN THE EQUATION = GRAZING RATE IN $\mathrm{m3} / \mathrm{gmC} /$ day (RANGE=0.5-5.0 WITH TYPICAL 0.1-0.2) Chapra page 620.

HALF SAT FOR ZOOPS $=0.4 \mathrm{gmC} / \mathrm{m3}$ (FOR ONTARIO, PAGE 639 IN C). How about $0.04 \mathrm{gm} \mathrm{C/m3}$ for Superior?

Threshold $=\sim 0.0005 / 3 . \mathrm{gm} \mathrm{C/m3}$ (initial conditions

NO UNITS

$\operatorname{IF}(Z S S(I, J) \cdot G T .(0.0005 / 3)$.$) THEN$

GZLZSZ $=1.5 *$ ZLL $(I, J) * *\left(1.08^{* *}(T(I, J)-20)\right.$.

GZLZSZ $=0$.

END IF

TRAZING OF SMALL ZOOPS ON SMALL PHYTO

THIS GRAZING IS ONLY ON ONE SIZE CLASS (FOR NOW) GRAZING IS A FUNCTION OF TEMP

THE 1. IN THE EQUATION=GRAZING RATE IN m3/gmC/day.
(RANGE=0.5-5.0 WITH TYPICAL $0.1-0.2$ ) Chapra page 629

Half saturation $=\sim 2-25 \mathrm{mg} \mathrm{Chl} / \mathrm{m} 3$ with most $=$

Threshold $=\sim 1 \mathrm{mg}$ Chl/m3. But split over

10 size classes so $=\sim 1 . / 10 . \mathrm{mg} \mathrm{Chl} / \mathrm{m3}$.

THIS GRAZING IS ONLY ON ONE SIZE CLASS (FOR NOW)

O UNITS

$\operatorname{IF}\left(\mathrm{C} 11(\mathrm{I}, \mathrm{J}) \cdot \mathrm{GT} \cdot\left(1, / 100^{\prime}\right)\right)$ THEN

GZSZSP $=1 . *$ ZSS $(I, J) *(1.08 * *(T(I, J)-20)$.

$\$$

ERDSZSP $=0$

ZOOPLANKTON RESPIRATION

ZOOP RESPZ + EXCRETION + SOME DEATH, BUT NOT GRAZING

FIRST NUMBER IN RESPZ = RESP RATE (1/DAY) (RANGE = 0.001-0.1 WITH MOST IN $0.01-0.05$ )

DIMLESS
RESPZ $=0.025 *\left(1.08^{* *}(T(I, J)-20).\right) *\left(2^{*}\right.$ DT/86400. $)$

$\sim \sim \sim$ CARNIVORS MUNCHING ON ZOOPS

ZOOP DEATH RATE DUE TO GRAZING BY CARNIVORS IS O.04 1/DAY. GZCLZ = GRAZING OF CARNIVORS ON LARGE ZOOPS

(dimensionless again as above). 
$G Z C L Z=0.040 *(1.08 * *(T(I, J)-20)) *,(2 * D T / 86400$.

$\sim \sim \sim P R E D I C T$ PHOSPHORUS

EPSILON IS THE FEEDING EFFICIENCY (FEEDE) OF ZOOPS, - (0.4-0.8), SO THE AMOUNT OF particulate CARBON AVAILABLE FOR REMINERALIZATION ORGANTC CARTON (POC, ORGANIC CARBON (DOC) AT $O .1$ 1/DAY (10\% PER DAY). THIS IS CHAPRA PAGE 637-639. THEN DOC HYDROLYZIS INTO P AT RATE OF - . . 075/DAY (7.5\% PER DAY). AS THERE ARE NO POOLS OF POC OR DOC, WE JUST APPLY $0.1 * 0.075=0.0075$ (CALLED

IN THE CODE) DHYDR3

RESULTING FROM SLOPPY EATING (IE, 1-EPSILON).

ALSO, I GUESS WE ASSUME THAT ALL THE THE CHLOROPHYLL AND ZOOP RESPIRATION IS COMPELETELY REMINERALIZED INTO P? NO!

DHYDRO

THIS RESP SHOULD PROBABLY ZOOP RESPTRATION INTO

P. HOWEVER, THIS RESP SHOULD PROBABLY GO INTO A POOL OF DOC TO

FEEDE $=0.7$

DHYDRO $=0.075^{*}\left(1.08^{* *}(T(\mathrm{I}, \mathrm{J})-20).\right) *\left(2^{*} \mathrm{DT} / 86400.\right)$

!may not need

\section{DHYDR3=DHYDRO}

CARBON: PHOSPHORUS $=C 2 P=0.04 \mathrm{gm} \mathrm{C}$ TO $1 \mathrm{mg} P$

$\mathrm{C} 2 \mathrm{P}=0 ., 4$

P04 = PO4 - VERTICAL AND HORIZONTAL FLUX- UPTAKE BY PHYTOPLANKTON + PHYTOPLANKTON RESPIRATION + ZOOPLANKTON (BOTH LARGE AND SMALL) RESPIRATION + THAT PORTION (1-() OF ZOOPLANKTON AND

CARNIVOR GRAZING DUE TO SLOPPY EATING

$\mathrm{ZN} 4(\mathrm{I}, \mathrm{J})=\mathrm{ZN} 4(\mathrm{I}, \mathrm{J})-\mathrm{DD}^{*}(\mathrm{FNH} 4 \mathrm{Z}(\mathrm{I}, \mathrm{J})-\mathrm{FNH} 4 \mathrm{Z}(\mathrm{I}+1, \mathrm{~J})$

作 \$-PN4C6-PN4C7-PN4C8-PN4C9-PN4C10

$Z \mathrm{~N} 4(\mathrm{I}, \mathrm{J})=\mathrm{ZN} 4(\mathrm{I}, \mathrm{J})+((\mathrm{GLZC1}+\mathrm{GLZC2}+\mathrm{GLZC} 3+\mathrm{GLZC} 4+\mathrm{GLZC5}+\mathrm{GLZC}$

酒

$\$^{*}$ DHYDR3+((GZCLZ*ZLL(I, J) )+(GZLZSZ*ZSS $\left.\left.(\mathrm{I}, \mathrm{J})\right)\right)^{*}(1 . / \mathrm{C} 2 \mathrm{P})$

$\$^{*}(1-\text { FEEDE })^{*}$ DHYDR3

$\operatorname{IF}(\mathrm{ZN} 4(\mathrm{I}, \mathrm{J}) \cdot \mathrm{LT}$.๑.) $\mathrm{ZN} 4(\mathrm{I}, \mathrm{J})=0$

$\sim \sim \sim \sim P R E D I C T$ NITRATE $\sim$

EPSILON IS THE FEEDING EFFICIENCY (FEEDE) OF ZOOPS, $\sim(0.4-0.8)$, SO THE AMOUNT OF CARBON AVAILABLE FOR REMINERALIZATION TO $N=$ (POC, GRAZING * (1-EPSILON) DISASSOCIATES TO DISSOLVED ORGANIC CARBON (DOC)AT O.1 1/DAY (10\% PER DAY). THIS IS CHAPRA PAGE 637-639. THEN DOC HYDROLYZIS INTO AMMONIUM AT RATE OF 0.075 1/DAY (7.5\% PER DAY). THEN, AMMONIUM IS NITRIFIED TO NITRATE-N AT THE RATE
OF $\sim 0.11 /$ DAY (10\% PER DAY). AS THERE ARE NO POOLS OF POC, DOC OR
AMMONIUM, WE JUST APPLY $0.1 * 0.075 * 0.1=0.00075$ (CALLED DHYD2 IN THE CODE) TO THE DOC RESULTING FROM SLOPPY EATING (IE, 1-EPSILON).

CONTRARY TO P, WE ASSUME THAT ALL THE THE CHLOROPHYLL AND ZOOP RESPIRATION IS HYDROLYZED TO AMMONIUM AT RATE OF $~-0.075$ 1/DAY (7.5\% PER DAY). THEN, AMMONIUM IS NITRIFIED TO NITRATE-N AT THE AMTE OTUM O. IJAY (1O\% PER DAY). AS THERE ARE NO POOLS OF DOC OR THE CODE) TO THE 3 RESPIRATION TERMS.

PREDICT NO3 $=+/$ - PHYSICAL FLUX - PHYTOPLANKTON UPTAKE +

NITRIFICATION OF PHYTO AND ZOOPLANKTON RESPIRATION + NITRIFICATION CANIVORS AND LARGE SMALL ZOOPS.

DHYDR $2=0.075^{*} 0.1 *\left(1.08^{* *}(T(I, J)-20).\right) *(2 * D T / 86400$.

C DHYDR $4=0.1^{*} 0.075^{*} 0.1^{*}\left(1.08^{* *}(T(I, J)-20).\right) *(2 * D T / 86400$.

\section{DHYDR2=DHYDRO}

C2N=5.5/1000.

AN2CH=7.2/1.

(DEFINED ABOVE)

$\mathrm{ZN} 3(\mathrm{I}, \mathrm{J})=\mathrm{ZN} 3(\mathrm{I}, \mathrm{J})-\mathrm{DD}^{*}(\mathrm{FNO3Z}(\mathrm{I}, \mathrm{J})-\mathrm{FNO3Z}(\mathrm{I}+1, \mathrm{~J}))$ S-DC* $($ NO3X (I, J)-FNO3X(I, J-1))-PN3C1-PN3C2-PN3C3-PN3C4-PN3C5 \$-PN3C6-PN3C7-PN3C8-PN3C9-PN3C10+(RESP* ${ }^{*}$ CSUM $(I, J){ }^{*}$ AN2CH)

\$*DHYDR2

$Z N 3(I, J)=Z N 3(I, J)+((G L Z C 1+G L Z C 2+G L Z C 3+G L Z C 4+G L Z C 5+G L Z C$

$\$+G L Z C 7+G L Z C 8+G L Z C 9+G L Z C 10) * A N 2 C H * C S U M(I, J) *(1$. - FEEDE $)$

\$*DHYDR4+((GZCLZ*ZLL(I, J ) )+(GZLZSZ*ZSS $(I, J)))^{*}(1 . / C 2 N)$

$\$+\left(G Z S Z S P{ }^{*} C 11(I, J)\right)^{*} A N 2 C H^{*}(1-$ FEEDE $) *$ DHYDR4

$\operatorname{IF}(\mathrm{ZN} 3(\mathrm{I}, \mathrm{J})$.LT. ๑. $) \quad Z \mathrm{ZN} 3(\mathrm{I}, \mathrm{J})=0$.

PREDICT PHYTOPLANKTON

PREDICT PHYTO IN EACH SIZE CLASS - PHYSICAL FLUX + GROWTH DUE TO INOB OR POU G GRAZING BY BIG AND LITTLE

INCLUDE RESPIRATION DURING LIGHT)

LITTLE ZOOPS IN THIS FIRST C11

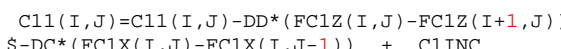

$\$-((G L Z C 1+G Z S Z S P) * C 11(I, J))-\left(\operatorname{RESP}{ }^{*} C 11(I, J)\right.$

$\operatorname{IF}(\operatorname{Cl1}(\mathrm{I}, \mathrm{J})$. LT, 0.001$) \operatorname{C11}(\mathrm{I}, \mathrm{J})=0.001$

PREDICT LARGE ZOOPLANKTON

RULES OF THUMB (*30\% GRAZING FOR GROWTH) - 5\%^DAY MORT \& PRED HERE, EPSILON IS THE FEEDING EFFICIENCY (FEEDE) OF ZOOPS. THEY BIT ACTUALLY GOES IN. THEN THEY LOSE BY RESPIRATION AND BEING GRAZED BY CARNIVORS.

C2CHL $=0.04 \quad$ (DEFINED ABOVE) 

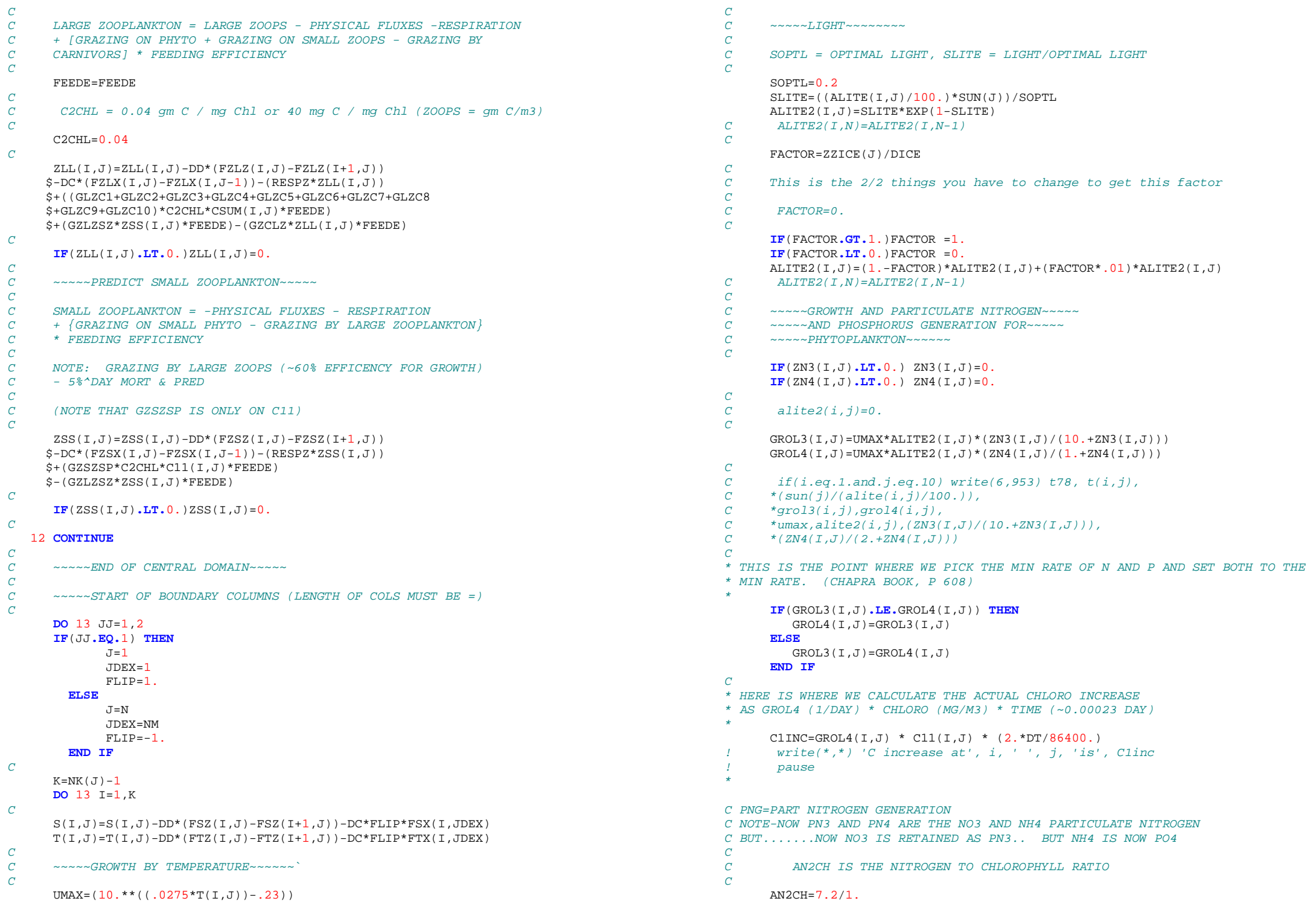


\section{PN3C1 $=$ C1INC * AN2CH}

C P2CH IS THE PHOSPHORUS TO CHLOROPHLYLL RATIO

$\mathrm{P} 2 \mathrm{CH}=1 . / 1$.

PN4C1 $=$ C1INC $*$ P2CH

C THESE ARE THE NH4 (NOW PO4)

C MULTIPLY BY P/N OF (1.0/7.2) CHAPRA; OR (1/15) PARSONS

$\mathrm{P} 2 \mathrm{~N}=1.17 .2$

$\mathrm{p} 2 \mathrm{n}=1 . / 15$

C PHYTOPLANKTON RESPIRATION

RESP $=0.15 *\left(1.08^{* *}(T(\mathrm{I}, \mathrm{J})-20).\right) *(2 * \mathrm{DT} / 86400$.

resp=0.

if(i.eq.1.and.j.eq.10) write(6,953) t78, $t(i, j), R E S P{ }^{*} 100000$.

$\sim \sim \sim B A C T E R I A$ MEDIATED NITRIFICATION

BACNIT $=$ SOMETHING * $(1.08 * * T(I, \mathrm{~J})-20)) *.\left(2 .{ }^{*} D T / 86400.\right)$

(PAGE 426 IN C, WHERE SOMETHING = koa (organic to ammoni

kin (nitrite to nitrate $=0.75 /$ day $)=0.045 /$ day

Then * this by some sort of dead organic stuff like zoops piss but zoop piss is already ammia so maybe something = kai*kin $=0.2$

$\operatorname{BACNIT}(I, J)=Z N 3(I, J) *\left(1 .-\operatorname{EXP}\left(-0.068^{*}\left(1.188^{* *}(T(I, J)-20).\right) *\right.\right.$ @(2. $\left.\left.\left.{ }^{*} D T / 86400.\right)\right)\right)$

SO NOW BACNIT $=$ NOM-DIM $10 \%$ (OF ANYTHING) PER DAY

$\operatorname{BACNIT}(I, J)=0.1 *\left(1.08^{* *}(T(I, J)-20).\right) *\left(2 .{ }^{*} D T / 86400\right)$

GRAZING OF ZOOPS ON PHYTOPLANKTON

$\operatorname{IF}(C 11(\mathrm{I}, \mathrm{J}) \cdot \mathrm{GT} \cdot 0.01)$ THEN

$\mathrm{GLZC1}=\mathrm{EAT} * \mathrm{ZLL}(\mathrm{I}, \mathrm{J}) *(1.08 * *(T(\mathrm{I}, \mathrm{J})-20)$.
$*(\mathrm{C} 11(\mathrm{I}, \mathrm{J}) /(1 .+\mathrm{C} 11(\mathrm{I}, \mathrm{J})))^{*}\left(2 *{ }^{*} \mathrm{DT} / 86400.\right)$

END IF

IF(I.EQ.1.AND.J.EQ.10) WRITE(6,953) T78, $\operatorname{CSUM}(I, J), \operatorname{C11}(I, J)$, ${ }^{*} G L Z C 1 * 10000, Z L L(I, J) * 10000, T(I, J),(C 11(I, J) /((0 . / 10)+.C 11(I, J)))$

ح GRAZING OF LARGE ZOOPS ON SMALL ZOOPS

$\operatorname{IF}(Z S S(I, J) . G T \cdot(0.00005 / 3)$,$) THEN$

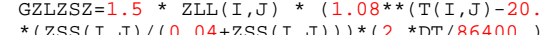

ELSE GZLZSZ $=0$
TRAZING OF SMALL ZOOPS ON SMALL PHYTO

THIS GRAZING IS ONLY ON ONE SIZE CLASS (FOR NOW)

$\operatorname{IF}(C 11(I, J) . G T \cdot(1 . / 100)$,$) THEN$

$*(\operatorname{Cl1}(I, J) /(1+C 11(I, J)))^{*}(2 * \operatorname{DT} /(1, J)-20$. $)$

ELSE

END IF

ZOOPLANKTON RESPIRATION

RESPZ $=0.025 *\left(1.08^{* *}(T(\mathrm{I}, \mathrm{J})-20).\right) *(2 * \mathrm{DT} / 86400$.

$\sim \sim \sim$ CARNIVORS MUNCHING ON ZOOPS

GZCLZ $=0.040 *\left(1.08^{* *}(T(\mathrm{I}, \mathrm{J})-20).\right) *(2 * \mathrm{DT} / 86400$.

$\sim \sim \sim P R E D I C T$ PHOSPHORUS

FEEDE $=0.7$

DHYDRO $=0.075^{*}\left(1.08^{* *}(\mathrm{~T}(\mathrm{I}, \mathrm{J})-20).\right) *\left(2^{*} \mathrm{DT} / 86400.\right)$

DHYDR3 $=0.1^{*} 0.075^{*}\left(1.08^{* *}(\mathrm{~T}(\mathrm{I}, \mathrm{J})-20 .)\right)^{*}\left(2^{*} \mathrm{DT} / 86400.\right)$

\section{DHYDR3=DHYDRO}

CARBON:PHOSPHORUS $=C 2 P=0.04 \mathrm{gm} \mathrm{C}$ tO $1 \mathrm{mg} P$

$\mathrm{C} 2 \mathrm{P}=0.04$

$\mathrm{ZN} 4(\mathrm{I}, \mathrm{J})=\mathrm{ZN} 4(\mathrm{I}, \mathrm{J})-\mathrm{DD}^{*}(\mathrm{FNH} 4 \mathrm{Z}(\mathrm{I}, \mathrm{J})-\mathrm{FNH} 4 \mathrm{Z}(\mathrm{I}+1, \mathrm{~J}))$

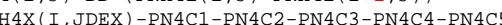
\$-PN4C6-PN4C7-PN4C8-PN4C9-PN4C10

$\$+(\text { RESP*CSUM }(I, J) \text { P2CH })^{*}$ DHYDRO

C.

$Z N 4(I, J)=Z N 4(I, J)+(($ GLZC1 $+G L Z C 2+G L Z C 3+G L Z C 4+G L Z C 5+G L Z C 6$

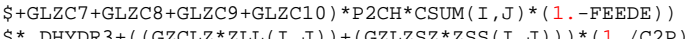

$\$^{*}(1-\mathrm{FEEDE}) *$ DHYDR3+(GZSZSP*C11 $\left.(\mathrm{I}, \mathrm{J})\right)^{*} \mathrm{P} 2 \mathrm{CH}$

$\$ *(1-\text { FEEDE })^{*}$ DHYDR3

$\operatorname{IF}(\mathrm{ZN} 4(\mathrm{I}, \mathrm{J})$.LT. . . $) \quad Z N 4(\mathrm{I}, \mathrm{J})=0$.

PREDICT NITRATE

CARBON (40) TO NITROGEN (7.2) \& (DIVIDE BY 1000 TO TURN TO gm C:mg N

$\mathrm{C} 2 \mathrm{~N}=5.5 / 1000$.

. $075^{*} 0.1^{*}\left(1.08^{* *}(\mathrm{~T}(\mathrm{I}, \mathrm{J})-20).\right) *(2 * \mathrm{DT} / 86400$.

DHYDR2=DHYDRO

$=$ DHYDRO

$\mathrm{ZN3}(\mathrm{I}, \mathrm{J})=\mathrm{ZN} 3(\mathrm{I}, \mathrm{J})-\mathrm{DD}^{*}(\mathrm{FNO3Z}(\mathrm{I}, \mathrm{J})-\mathrm{FNO3Z}(\mathrm{I}+1, \mathrm{~J})$ $\$^{*} \operatorname{DHYDR2}+\left(\operatorname{RESPZ}{ }^{*}(\mathrm{ZLL}(\mathrm{I}, \mathrm{J})+\mathrm{ZSS}(\mathrm{I}, \mathrm{J}))^{*}(1 . / \mathrm{C} 2 \mathrm{~N})\right)^{*} \operatorname{DHYDR2}$

$Z N 3(I, J)=Z N 3(I, J)+((G L Z C 1+G L Z C 2+G L Z C 3+G L Z C 4+G L Z C 5+G L Z C 6$ 
$\$+G L Z C 7+G L Z C 8+G L Z C 9+G L Z C 10 *)^{*}$ AN2CH*CSUM $(I, J) *(1$. -FEEDE $\left.)\right)$ $\$^{*}$ DHYDR4 $+((\operatorname{GZCLZ} \text { ZZLL }(\mathrm{I}, \mathrm{J}))+(\operatorname{GZLZSZ} \text { ZSS }(\mathrm{I}, \mathrm{J})))^{*}(1 . / \mathrm{C} 2 \mathrm{~N})$ $\$+\left(\text { GZSZSP }{ }^{*} \mathrm{C} 11(\mathrm{I}, \mathrm{J})\right)^{*} \mathrm{AN}^{*} \mathrm{CH}^{*}(1-$ FEEDE $) *$ DHYDR4

$\operatorname{IF}(\mathrm{ZN} 3(\mathrm{I}, \mathrm{J}) . \mathrm{LT}$.๑. $) \quad \mathrm{ZN} 3(\mathrm{I}, \mathrm{J})=0$.

PREDICT PHYTOPLANKTON

LITTLE ZOOPS IN THIS FIRST C11

$\operatorname{C11}(\mathrm{I}, \mathrm{J})=\mathrm{C} 11(\mathrm{I}, \mathrm{J})-\mathrm{DD}^{*}(\mathrm{FC} 1 \mathrm{Z}(\mathrm{I}, \mathrm{J})-\mathrm{FC} 1 \mathrm{Z}(\mathrm{I}+1, \mathrm{~J}))$

$\begin{array}{ll} & \\ & \end{array}$

(IF

if(i.eq.1.and.j.eq.10) write(6,953) t78, umax

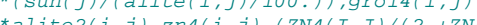

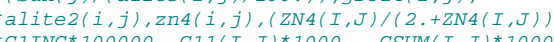

if(i.eq.1.and.j.eq.10) write(6,953) t78, umax

grol4 $(i, j)$, alite2 $(i, j), z n 4(i, j), 053$

$(Z N 4(I, J))(2 .+Z N 4(I, J)))$, CIINC*100000.

$\sim \sim \sim P R E D I C T$ LARGE ZOOPS

\section{FEEDE=FEEDE}

C2CHL $=0.04 \mathrm{gm} \mathrm{C} / \mathrm{mg} \mathrm{ChI}$ or $40 \mathrm{mg} \mathrm{C} / \mathrm{mg} \mathrm{ChI}($ ZOOPS $=\mathrm{gm} \mathrm{C} / \mathrm{m} 3)$

$\mathrm{C} 2 \mathrm{CHL}=0.04$

$\mathrm{ZLL}(\mathrm{I}, \mathrm{J})=\mathrm{ZLL}(\mathrm{I}, \mathrm{J})-\mathrm{DD}^{*}(\mathrm{FZLZ}(\mathrm{I}, \mathrm{J})-\mathrm{FZLZ}(\mathrm{I}+1, \mathrm{~J}))$

\$-DC*FLIP*FZLX(I, JDEX) - (RESPZ*ZLLL I, J J)

$\$+(($ GLZC1+GLZC2+GLZC3+GLZC4+GLZC5+GLZC6+GLZC7+GLZC8

$\$+\left(G Z L Z S Z^{*} Z S S(I, J){ }^{*}\right.$ FEEDE $)-\left(\right.$ GZCLZ*ZLLL $(I, J){ }^{*}$ FEEDE $)$

$\operatorname{IF}(Z L L(I, J) \cdot L T$. O. $) Z L L(I, J)=0$.

T T PREDTCT SMALL ZOOPQ

(NOTE THAT GZSZSP IS ONLY ON C11)

$\mathrm{ZSS}(\mathrm{I}, \mathrm{J})=\mathrm{ZSS}(\mathrm{I}, \mathrm{J})-\mathrm{DD}^{*}(\mathrm{FZSZ}(\mathrm{I}, \mathrm{J})-\operatorname{FZSZ}(\mathrm{I}+1, \mathrm{~J}))$

$\$$ S-DC*FLIP*FZSX (I, JDEX) - (RESPZ*ZSS $(I, J))$

$\$+\left(\right.$ GZSZSP*C2CHL* $\left.\mathrm{C} 11(\mathrm{I}, \mathrm{J}){ }^{*} \mathrm{FEEDE}\right)$

$\operatorname{IF}(\operatorname{ZSS}(I, J)$. LT . ๑ . $) Z \operatorname{ZSS}(I, J)=0$

\section{CONTINU}

END OF COLUMNS

START OF BOUNDARY CORNERS (DEPTH OF CORNERS MUST BE =)

$$
\begin{aligned}
& \text { DO } 54 \text { JJJ=1, } 2 \\
& \text { IF (JJ.EQ.1) } \\
& \text { J=1 }
\end{aligned}
$$

JDEX $=1$

ELSE

$J=N$
$J D E X=N M$

$\mathrm{I}=\mathrm{NK}(\mathrm{J})$

$\quad S(I, J)=S(I, J)-D D^{*} F S Z(I, J)-D C^{*} F L I P^{*} F S X(I, J D E X)$

$\operatorname{T}(I, J)=T(I, J)-D^{*} F T Z(I, J)-D C^{*} F L I P^{*} F T X(I, J D E X)$

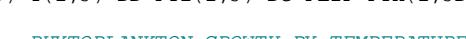

UMAX $=\left(10{ }^{* *}\left(\left(.0275^{*} T(\mathrm{I}, \mathrm{J})\right)-.23\right)\right)$

W SUREACE LIGHT INHIBITION

(1360 $W / M 2=2 \quad C A L / C M 2 / M I N$ )

THE 1.0000 IS FROM P84 OF PARSONS ET AL. THEY HAVE PMAX 1-16, AVE=4 BUT OLIGOTROHIC LAKES $=0.1$ TO 1 (MG C/MG CHL/HR)

SOPTL = OPTIMAL LIGHT, SLITE = LIGHT/OPTIMAL LIGHT

\section{SOPTL $=0.2$}

SLITE $=\left(\left(\operatorname{ALITE}(\mathrm{I}, \mathrm{J}) / 100_{0}\right) * \operatorname{SUN}(\mathrm{J})\right) / \mathrm{SOPTL}$

ALITE2 $(\mathrm{I}, \mathrm{J})=\operatorname{SLITE} \mathrm{EXXP}^{*}(1-\mathrm{SLITE})$

$\operatorname{ALITE} 2(I, N)=\operatorname{ALITE} 2(I, N-1)$

$\operatorname{IF}(I . E Q .3 . A N D . J . E Q .10)$ WRITE(6,953) T78, $\operatorname{ALITE2}(I, J), \operatorname{ALITE}(I, J)$

$*$, sun $(j),(\operatorname{alite}(i, j) * \operatorname{sun}(j) / 100$.

C $1 \%$ OF THE LIGHT IS ALLOWED THROUGH THE ICE BUT $=F(\%$ ICE COVER $)$

C THIS GETS THE RIGHT LIGHT LEVEL UNDER THE IC

FACTOR=ZZICE $(J) / D I C E$

This is the $2 / 2$ things you have to change to get this factor

FACTOR $=0$

IF (FACTOR. GT.1.) FACTOR $=1$

FACTIT $2(\mathrm{I}, \mathrm{J})+\left(\text { FACTOR }^{*}, 01\right)^{*} \operatorname{ALITE} 2(\mathrm{I}, \mathrm{J})$

$\operatorname{ALITE} 2(I, N)=\operatorname{ALITE} 2(I, N-1)$

$\sim$ GROWTH AND PARTICULATE NITROGEN

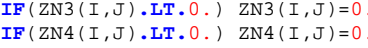

$\operatorname{alite} 2(i, j)=0$

$\operatorname{GROL3}(\mathrm{I}, \mathrm{J})=\operatorname{UMAX}{ }^{*} \operatorname{ALITE} 2(\mathrm{I}, \mathrm{J}) *(\mathrm{ZN} 3(\mathrm{I}, \mathrm{J}) /(10 .+\mathrm{ZN} 3(\mathrm{I}, \mathrm{J}))$
$\operatorname{GROL} 4(\mathrm{I}, \mathrm{J})=\operatorname{UMAX} \mathrm{UMLITE}^{*}(\mathrm{I}, \mathrm{J}) *(\mathrm{ZN} 4(\mathrm{I}, \mathrm{J}) /(1 .+\mathrm{ZN} 4(\mathrm{I}, \mathrm{J})))$

if (i.eq.1.and.j.eq.10) write $(6,953) t 78, t(i, j)$,

$*(\operatorname{sun}(j) /(\operatorname{alite}(i, j) / 100)$.$) ,$ 
${ }^{*} \operatorname{grol3}(i, j), \operatorname{grol4}(i, j)$,

*umax, alite $2(i, j),(Z N)(I, J) /(10 .+Z N 3(I, J)))$,
$*(Z N 4(I, J) /(2,+Z N 4(I, J)))$

THIS IS THE POINT WHERE WE PICK THE MIN RATE OF N AND P AND SET BOTH TO THE

MIN RATE. (CHAPRA BOOK, P 608)

$\operatorname{IF}(\operatorname{GROL} 3(\mathrm{I}, \mathrm{J})$. LE. GROL4 $(\mathrm{I}, \mathrm{J}))$ THEN

$\operatorname{GROL} 4(\mathrm{I}, \mathrm{J})=\mathrm{GROL} 3(\mathrm{I}, \mathrm{J})$

$\operatorname{GROL3}(I, J)=G R O L 4(I, J)$

\section{END IF}

HERE IS WHERE WE CALCULATE THE ACTUAL CHLORO INCREASE

AS GROL4 (1/DAY) * CHLORO (MG/M3) * TIME ( O.00023 DAY)

$\operatorname{C1INC}=G R O L 4(\mathrm{I}, \mathrm{J}) *$ C11 $(\mathrm{I}, \mathrm{J}) *\left(2 .{ }^{*} \mathrm{DT} / 86400.\right)$

PNG-PART NITROGEN GENERATION

N03 AND NH4 PARTICULATE NITROGEN

BUT NH4 IS NOW PO4

AN2CH IS THE NITROGEN TO CHLOROPHYLL RATIO

AN2CH $=7.2 / 1$.

$\mathrm{PN} 3 \mathrm{C} 1=\mathrm{C} 1 \mathrm{INC} * \mathrm{AN} 2 \mathrm{CH}$

C P2CH IS THE PHOSPHORUS TO CHLOROPHLYLL RATIO

$\mathrm{P} 2 \mathrm{CH}=1 . / 1$.

$\mathrm{PN} 4 \mathrm{C} 1=\mathrm{C} 1 \mathrm{INC} * \mathrm{P} 2 \mathrm{CH}$

C MULTIPLY BY P/N OF (1.0/7.2) CHAPRA; OR (1/15) PARSONS

$\mathrm{P} 2 \mathrm{~N}=1 . / 7.2$

$\mathrm{p} 2 \mathrm{n}=1 . / 15$.

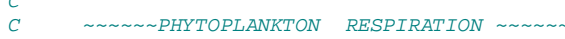

RESP $=0.15^{*}\left(1.08^{* *}(T(\mathrm{I}, \mathrm{J})-20).\right) *(2 * \mathrm{DT} / 86400$.

resp $=0$.

if(i.eq.1.and.j.eq.10) write(6,953) t78, $t(i, j), R E S P^{*} 100000$.

BACTERIA MEDIATED NITRIFICATION

BACNIT = SOMETHING * $(1.08 * * T(I, J)-20)) *.\left(2 .{ }^{*} D T / 86400.\right)$

(PAGE 426 IN C, WHERE SOMETHING = kOa (organiC to ammoni

$=0.25$ per day) * $\mathrm{kai}$ (ammonia to nitrite $=0.25 /$ day)

Then * this by some sort of dead organic stuff like zoops piss but zoop piss is already ammonia so maybe something $=k a i^{*} k i n=$ $=0.2$

$\operatorname{BACNIT}(I, J)=Z N 3(I, J) *\left(1 .-\operatorname{EXP}\left(-0.068^{*}\left(1.188^{* *}(T(I, J)-20).\right) *\right.\right.$ $\left.\left.@\left(2,{ }^{*} D T / 86400.\right)\right)\right)$

SO NOW BACNIT $=$ NOM-DIM $10 \%$ (OF ANYTHING) PER DAY
AS MODIFIED BY T(C) SO $2 \%$ AT OC AND $\sim 4.6 \%$ AT $10 \mathrm{C}$

$\operatorname{BACNIT}(I, J)=0.1 *\left(1.08^{* *}(T(I, J)-20).\right) *\left(2 .{ }^{*} D T / 86400\right)$
- GRAZING OF ZOOPS ON PHYTOPLANKTON

GLZC* HAVE NO UNITS,

$\operatorname{IF}(C 11(I, J) . G T \cdot 0.01)$ THEN

GLZC1=EAT * ZLL(I, J)* * $(1.08 * *(T(I, J)-20)$.

GLZC1=0.

END IF

$\operatorname{IF}(I . E Q .1 . A N D . J . E Q .10) \operatorname{WRITE}(6,953) \operatorname{T78}, \operatorname{CSUM}(I, J), \operatorname{C11}(I, J)$,

10.)+C11(I, J)))

$\sim \sim$ GRAZING OF LARGE ZOOPS ON SMALL ZOOPS

$\operatorname{IF}(Z S S(I, J) . G T .(0.0005 / 3)$.$) THEN$

GZLZSZ $=1.5 * \operatorname{ZLL}(\mathrm{I}, \mathrm{J}) *\left(1.08^{* *}(\mathrm{~T}(\mathrm{I}, \mathrm{J})-20)\right.$.

$\$$ ELSE

GZLZSZ $=0$.

END IF

GRAZING OF SMALL ZOOPS ON SMALL PHYTO

THIS GRAZING IS ONLY ON ONE SIZE CLASS (FOR NOW)

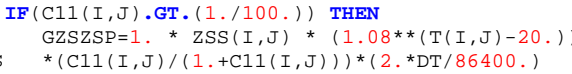

GZSZSP $=0$.

\section{END IF}

$\sim \sim$ ZOOP RESPIRATION

RESPZ $=0.025 *\left(1.08^{* *}(T(\mathrm{I}, \mathrm{J})-20).\right) *(2 * \mathrm{DT} / 86400$.

$\sim \sim \sim$ CARNIVORS EATING ZOOPS

GZCLZ $=0.040 *\left(1.08^{* *}(T(\mathrm{I}, \mathrm{J})-20).\right) *(2 * \mathrm{DT} / 86400$.

C PREDICT PHOSPHORUS

FEEDE $=0.7$

DHYDRO $=0.075^{*}(1.08 * *(T(I, J)-20)) *.(2 * D T / 86400$.

DHYDR3 $=0.1^{*} 0.075^{*}\left(1.08^{* *}(T(\mathrm{I}, \mathrm{J})-20).\right) *\left(2^{*} \mathrm{DT} / 86400.\right)$

\section{DHYDR3=DHYDRO}

CARBON:PHOSPHORUS $=C 2 P=0.04 \mathrm{gm} C$ to $1 \mathrm{mg} P$

$\mathrm{C} 2 \mathrm{P}=0.04$

$\mathrm{ZN} 4(\mathrm{I}, \mathrm{J})=\mathrm{ZN} 4(\mathrm{I}, \mathrm{J})-\mathrm{DD}^{\star} \mathrm{FNH} 4 \mathrm{Z}(\mathrm{I}, \mathrm{J})$

$\$$-DC

$\$+\left(\text { RESP*CSUM }(I, J)^{*} \text { P2CH }\right)^{*}$ HYYDRO

$\$+(\operatorname{RESPZ} *(\mathrm{ZLL}(\mathrm{I}, \mathrm{J})+\mathrm{ZSS}(\mathrm{I}, \mathrm{J})) *(1 . / \mathrm{C} 2 \mathrm{P})))^{*} \mathrm{DHYDRO}$

$Z N 4(I, J)=Z N 4(I, J)+((G L Z C 1+G L Z C 2+G L Z C 3+G L Z C 4+G L Z C 5+G L Z C 6$ $\$+G L Z C 7+G L Z C 8+G L Z C 9+G L Z C 10) * P 2 C H * C S U M(I, J) *(1$. - FEEDE $))$ 
\$*DHYDR3 $+((G Z C L Z * Z L L(I, J))+(G Z L Z S Z * Z S S(I, J))) *(1, / C 2 P)$

$\$ \$^{*}(1-\text { FEEDE })^{*}$ DHYDR3 $+(\text { GZSZSP*C11 }(\mathrm{I}, \mathrm{J}))^{*} \mathrm{P} 2 \mathrm{CH}$

$\$ *(1-F F E D E) * D H Y D R 3$

$\operatorname{IF}(\mathrm{ZN} 4(\mathrm{I}, \mathrm{J}) . \mathrm{LT} . \odot.) \quad \mathrm{ZN} 4(\mathrm{I}, \mathrm{J})=0$

$\sim \sim \sim \sim P R E D I C T$ NITRATE

CARBON (40) TO NITROGEN (7.2) \& (DIVIDE BY 1000 TO TURN TO gm C:mg N.

$\mathrm{C} 2 \mathrm{~N}=5.5 / 1000$

DHYDR2 $=$ DHYDRO
DHYDR4 $=$ DHYDRO

$\mathrm{ZN3}(\mathrm{I}, \mathrm{J})=\mathrm{ZN} 3(\mathrm{I}, \mathrm{J})-\mathrm{DD}^{*} \mathrm{FNO3Z}(\mathrm{I}, \mathrm{J})$

\$-DC* FLP "FNO3X (I, JDEX)-PN3C1-PN3C2-PN3C3-PN3C4-PN3C5 \$-PN3C6-PN3C7-PNic

$Z \mathrm{ZN} 3(\mathrm{I}, \mathrm{J})=Z \mathrm{ZN} 3(\mathrm{I}, \mathrm{J})+((\mathrm{GLZC1}+\mathrm{GLZC2}+\mathrm{GLZC} 3+\mathrm{GLZC} 4+\mathrm{GLZC5}+\mathrm{GLZC} 6$ $\$+G L Z C 7+G L Z C 8+G L Z C 9+G L Z C 10) * A N 2 C H * C S U M(I, J) *(1$. - FEEDE $))$ $\$^{*}$ DHYDR4+((GZCLZ*ZLL(I, J ) )+(GZLZSZ*ZSS $\left.\left.(I, J)\right)\right)^{*}(1 . / C 2 N)$ S* (19ZSZSP*C11(I,

$\operatorname{IF}(\mathrm{ZN} 3(\mathrm{I}, \mathrm{J}) . \mathrm{LT} . \Theta) \quad Z N .3(\mathrm{I}, \mathrm{J})=0$

$\sim \sim \sim P$ PREDICT PHYTOPLANKTON

LITTLE ZOOPS IN THIS FIRST C11

$\mathrm{C} 11(\mathrm{I}, \mathrm{J})=\mathrm{C} 11(\mathrm{I}, \mathrm{J})-\mathrm{DD}{ }^{*} \mathrm{FC} 1 \mathrm{C}(\mathrm{I}, \mathrm{J})$
\$-DC*FLIP*FC1X(I, JDEX + C

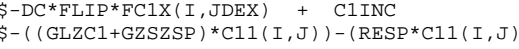

IF $(C 11(I, J) \cdot L T$. 0,001$) C 11(I, J)=0.001$

if (i.eq.1.and.j.eq.10) write(6,953) t78, umax ${ }^{*}(\operatorname{sun}(j) /(\operatorname{alite}(i, j) / 100)),. \operatorname{grol} 4(i, j)$, *alite $2(i, j), z n 4(1, j),(Z N 4(I, J) /(2,+Z N 4(I, J)))$, ${ }^{*}{ }^{*} 1 I_{N C}{ }^{*} 100000 ., \operatorname{C11}(I, J) * 1000 ., \operatorname{CSUM}(I, J) * 1000$.

if(i.eq.1.and.j.eq.10) write $(6,953)$ t78, umax,

${ }^{*} \operatorname{grol} 14(i, j)$, alite2 $(i, j), z n 4(i, j)$,
${ }^{*}(Z N 4(I, J)$
$\left.{ }^{*} C(2 .+Z N 4(I, J))\right), C 1 I N C{ }^{*} 100000$.

${ }^{*} \mathrm{C} 11(\mathrm{I}, \mathrm{J}){ }^{*} 1000 .$, resp

PREDICT LARGE ZOOPS

FEEDE=FEEDE

C C2CHL $=0.04 \mathrm{gm} \mathrm{C} / \mathrm{mg} \mathrm{ChI}$ or $40 \mathrm{mg} \mathrm{C} / \mathrm{mg} \mathrm{ChI} \mathrm{(ZOOPS}=\mathrm{gm} \mathrm{C} / \mathrm{m} 3)$ $\mathrm{C} 2 \mathrm{CHL}=0.04$

$\mathrm{ZLL}(\mathrm{I}, \mathrm{J})=\mathrm{ZLL}(\mathrm{I}, \mathrm{J})-\mathrm{DD}^{*} \mathrm{FZLZ}(\mathrm{I}, \mathrm{J})$

\$-DC*FLIP*FZLX (I, JDEX) - (RESPZ*ZLL I, J J)

$\$+((G L Z C 1+G L Z C 2+G L Z C 3+G L Z C 4+G L Z C 5+G L Z C 6+G L Z C 7+G L Z C 8$

$\$+G L Z C 9+G L Z Z 10)$ C2CHL CSUM $(I, J)$ FEEDE)

$\$+(G Z L Z S Z * Z S S(I, J) *$ FEEDE $)-\left(\operatorname{GZCLZ*ZLL}(I, J){ }^{*}\right.$ FEEDE $)$
$\operatorname{IF}(\mathrm{ZLL}(\mathrm{I}, \mathrm{J})$.LT . ๑. ) ZLL (I, J)=0.

C PREDICT SMALL ZOOPS

$\operatorname{ZSS}(I, J)=Z \operatorname{ZSS}(I, J)-D^{*} \operatorname{FZSZ}(I, J)$

$\$-(G Z I Z Z * Z S S(I, J) *$ FEEDE)

$\operatorname{IF}(Z S S(I, J) . L T . \Theta) Z S S.(I, J)=0$.

54 Continue

START OF BOTTOM BOUNDARY

THE DO 23 LOOP IS TO PREDICT SCALARS AT THE BOTTOM BOUNDARIES

DO $23 \mathrm{~J}=2$, NM

$\mathrm{S}(\mathrm{K}, \mathrm{J})=S(K, J)-\mathrm{DD}^{*} \mathrm{FSZ}(\mathrm{K}, \mathrm{J})-\mathrm{DC}^{*}(\mathrm{FSX}(\mathrm{K}, \mathrm{J})-\mathrm{FSX}(\mathrm{K}, \mathrm{J}-1))$
$\mathrm{T}(\mathrm{K}, \mathrm{J})=\mathrm{T}(\mathrm{K}, \mathrm{J})-\mathrm{DD}^{*} \mathrm{FTZ}(\mathrm{K}, \mathrm{J})-\mathrm{DC}^{*}(\mathrm{FTX}(\mathrm{K}, \mathrm{J})-\mathrm{FTX}(\mathrm{K}, \mathrm{J}-1))$

C PHYTOPLANKTON GROWTH

UMAX $=\left(10 . * *\left(\left(.0275^{*} T(K, \mathrm{~J})\right)-.23\right)\right)$

$\sim \sim \sim \sim$ SURFACE LIGHT INHIBITION

SOPTL = OPTIMAL LIGHT, SLITE $=$ LIGHT/OPTIMAL LIGHT

SOPTL $=0.2$

$\operatorname{SLITE}=((\operatorname{ALITE}(K, J) / 100). * \operatorname{SUN}(J)) /$ SOPTL

$\operatorname{ALITE} 2(K, J)=\operatorname{SLITE} *^{\star} \operatorname{EXP}(1-\operatorname{SLITE})$

$\operatorname{ALITE} 2(K, N)=\operatorname{ALITE} 2(K, N-1)$

$\sim \sim \sim$ GROWTH AND PARTICULATE

THOTROGEN AND PHOSPHOSRUS GENERATION

$\operatorname{IF}(Z N 3(K, J) . L T . \odot$.) $Z N 3(K, J)=\Theta$.

$\operatorname{IF}(Z N 3(K, J) . L T . \Theta$.
$\operatorname{IF}(Z N 4(K, J) . L T . \Theta$.
$Z N 4(K, J)=\Theta$.

$\operatorname{GROL} 3(K, J)=U M A X^{*} \operatorname{ALITE} 2(K, J) *(Z N 3(K, J) /(10 .+Z N 3(K, J)))$
GROL4 $4(K, J)=U M A X^{*} \operatorname{ALITE} 2(K, J) *(Z N 4(K, J) /(1,+Z N 4(K, J)))$

THIS IS THE POINT WHERE WE PICK THE MIN RATE OF N AND P AND SET BOTH TO THE MIN RATE. (CHAPRA BOOK, P 608)

$\operatorname{IF}(\operatorname{GROL} 3(K, J) \cdot$ LE. GROL4 $(K, J))$ THEN

$\operatorname{GROL} 4(K, J)=G R O L 3(K, J)$

$\operatorname{GROL} 3(K, J)=G R O L 4(K, J)$

END IF

HERE IS WHERE WE CALCULATE THE ACTURAL CHLORO INCREASE

AS GROL4 (1/DAY) * CHLORO (MG/M3) * TIME ( ०.,00023 DAY)

C1INC $=G R O L 4(K, J) * \operatorname{C11}(K, J) *\left(2 .{ }^{*}\right.$ DT/86400. $)$

PNG=PART NITROGEN GENERATION 
NOTE-NOW PN3 AND PN4 ARE THE NO3 AND NH4 PARTICULATE NITROGEN BUT ...... NOW NO3 IS RETAINED AS PN3.. BUT NH4 IS NOW PO4

AN2CH IS THE NITROGEN TO CHLOROPHYLL RATIO

AN2CH=7.2/1.

PN3C1 $=$ C1INC * AN2CH

P2CH IS THE PHOSPHORUS TO CHLOROPHLYLL RATIO

$\mathrm{P} 2 \mathrm{CH}=1 . / 1$

PN4C1 $=$ C1INC $*$ P2CH

$\sim \sim \sim \sim P H Y T O P L A N K T O N$ RESPIRATION

RESP $=0.15 *\left(1.08^{* *}(T(K, J)-20).\right) *(2 * D T / 86400$.

= BACTERTA MEDTATED NITRIFICATION

$\operatorname{BACNIT}(K, \mathrm{~J})=Z N 3(K, \mathrm{~J}) *\left(1,-\operatorname{EXP}\left(-0.068^{*}\left(1.188^{* *}(T(K, \mathrm{~J})-20).\right) *\right.\right.$ @(2. $\left.\left.\left.{ }^{*} D T / 86400.\right)\right)\right)$

$\operatorname{BACNIT}(K, J)=0.1 *\left(1.08^{* *}(T(K, J)-20).\right) *\left(2 .{ }^{*} D T / 86400.\right)$

ZOOPS GRAZING ON PHYTOPLANKTON

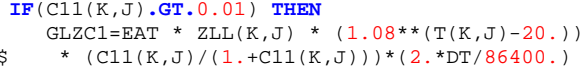

ELSE

GLZC1 $=0$

END I

-GRAZING OF LARGE ZOOPS ON SMALL ZOOPS

$\operatorname{IF}(Z S S(K, J) \cdot G T \cdot(0.0005 / 3)$,$) THEN$

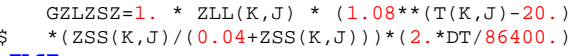

ELSE

GZLZSZ=0

GRAZING OF SMALL ZOOPS ON SMALL PHYTO

THIS GRAZING IS ONLY ON ONE SIZE CLASS (FOR NOW)

$\operatorname{IF}\left(\mathrm{C} 11(\mathrm{~K}, \mathrm{~J}) \cdot \mathbf{G T} \cdot\left(1, / 100^{\prime}\right)\right)$ THEN

* $\left.(C 11(K, J) /(1+C 11(K, J)))^{*}\left(2 * D^{*} /(1, J)-20.\right)\right)$

GZSZSP $=0$.

END IF

TOT2 ZOOPLANKTON RESPTRATION

RESPZ $=0.025 *(1.08 * *(T(K, J)-20)) *.(2 * D T / 86400$.

$\sim \sim \sim$ CARNIVORS MUNCHING ON ZOOPS

GZCLZ $=0.040 *\left(1.08^{* *}(T(K, J)-20).\right) *(2 *$ DT/86400. $)$

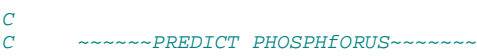

$\mathrm{C} 2 \mathrm{P}=0.04$

FEEDE $=0.7$

RO $=0.075^{*}\left(1.08^{* *}(T(K, J)-20).\right) *(2 * D T / 86400$.

DHYDR3 $=0.1^{*} 0.075^{*}\left(1.08^{* *}(T(K, J)-20).\right) *\left(2^{*}\right.$ DT $\left./ 86400.\right)$

DHYDR3=DHYDRO

PREDICT PO4 \& REDUCE IT BY LARGE AND SMALL PHYTO UPTAKE

$\mathrm{ZN} 4(\mathrm{~K}, \mathrm{~J})=Z \mathrm{ZN} 4(\mathrm{~K}, \mathrm{~J})-\mathrm{DD}^{*}(\mathrm{FNH} 4 \mathrm{Z}(\mathrm{K}, \mathrm{J}))$

\$-PN4C5-PN4C6-PN4C7-PN4C8-PN4C9-PN4C10

$\$+\left(\operatorname{RESP}{ }^{*} \operatorname{CSUM}(K, J){ }^{*} \mathrm{P} 2 \mathrm{CH} H{ }^{*} \mathrm{DHYDRO}\right.$
$\$+\left(\operatorname{RESPZ}^{*}(\mathrm{ZLL}(\mathrm{K}, \mathrm{J})+\mathrm{ZSS}(\mathrm{K}, \mathrm{J}))^{*}(1 . / \mathrm{C} 2 \mathrm{P})\right)^{*} \mathrm{DHYDRO}$

$Z N 4(K, J)=Z N 4(K, J)+((G L Z C 1+G L Z C 2+G L Z C 3+G L Z C 4+G L Z C 5+G L Z C 6$ +GLZC7+GLZC8+GLZC9+GLZC10)*P2CH*CSUM $(K, J)^{*}(1$, - FEEDE $\left.)\right)$

$\$+\left(\operatorname{GZSZSP}{ }^{*} \mathrm{C} 11(\mathrm{~K}, \mathrm{~J})\right)^{*} \mathrm{P}_{2} \mathrm{CH}^{*}(1-\mathrm{FEEDE}){ }^{*} \mathrm{DHYDR} 3$

$\operatorname{IF}(Z N 4(K, J) \cdot L T .0) \quad Z N .4(K, J)=0$.

C PREDICT NITRATE

$\mathrm{C} 2 \mathrm{~N}=5.5 / 1000$.

(

DHYDR $=0.1^{*} 0.075^{*} \cdot 1^{*}\left(1.08^{* *}(T(K, J)-20).\right) *\left(2^{*} \mathrm{DT} / 86400.\right)$

DHYDR2=DHYDRO

DHYDR4=DHYDRO

C2N=5.5/1000.

$\mathrm{ZN} 3(\mathrm{~K}, \mathrm{~J})=\mathrm{ZN} 3(\mathrm{~K}, \mathrm{~J})-\mathrm{DD}^{*}(\mathrm{FNO3Z}(\mathrm{K}, \mathrm{J}))$

S-DC* $(F N 03 X(K, J)-F N 03 X(K, J-1))-P N 3 C 1-P N 3 C 2-P N 3 C 3-P N 3 C 4$ \$-PN3C5 - PN3C6-PN3C7-PN3C8-PN3C9-PN3C10+(RESP*CSUM $\left.(K, J){ }^{*} A N 2 C H\right)$ \$*DHYDR2+ $\left(\operatorname{RESPZ}^{*}(\mathrm{ZLL}(\mathrm{K}, \mathrm{J})+Z \mathrm{ZSS}(\mathrm{K}, \mathrm{J}))^{*}(1 . / \mathrm{C} 2 \mathrm{~N})\right)^{*} \mathrm{DHYDR}^{*}$ $Z N 3(K, J)=Z N 3(K, J)+((G L Z C 1+G L Z C 2+G L Z C 3+G L Z C 4+G L Z C 5+G L Z C 6$ $\$+\left(\left(G Z C L Z^{*} Z L L(K, J)\right)+\left(G Z L Z S Z^{*} Z S S(K, J)\right)\right)^{*}(1 . / C 2 N) *(1-F E E D E)$ $\$ \$^{*}$ DHYDR4

$\$+\left(\operatorname{GZSZSP}{ }^{*} \mathrm{C} 11(\mathrm{~K}, \mathrm{~J})\right)^{*} \mathrm{AN} \mathrm{CH}^{*}(1-\mathrm{FEEDE}){ }^{*}$ DHYDR4

$\operatorname{IF}(Z N 3(K, J) \cdot L T$. ๑. $) \quad Z N 3(K, J)=0$

PREDICT PHYTOPL

SMALL ZOOPS IN THIS FIRST C11

$\mathrm{C} 11(\mathrm{~K}, \mathrm{~J})=\mathrm{C} 11(\mathrm{~K}, \mathrm{~J})-\mathrm{DD}^{*}(\mathrm{FC} 1 \mathrm{Z}(\mathrm{K}, \mathrm{J}))$

S- ((GLCIX $(K, J)-F C 1 X(K, J-1))$,

作

$\operatorname{IF}(C 11(K, J)$. LT . ๑. 001)C11(K, J)=0.001 
$\mathrm{C} 2 \mathrm{CHL}=0.04$

\section{FEEDE=FEEDE}

$Z L L(K, J)=Z L L(K, J)-D D^{*}(F Z L Z(K, J))$

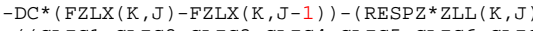

\$)

$\$+\left(\right.$ GZLZSZ*ZSS $(K, J){ }^{*}$ FEEDE $)-\left(\right.$ GZCLZ*ZLL $(K, J)^{*}$ FEEDE $)$

$\operatorname{IF}(Z L L(K, J) . L T . \Theta) Z L L.(K, J)=0$

if (j.eq.10) write $(6,953)$ t78, ZLL (K,J)

$\sim \sim \sim P R E D I C T$ SMALL ZOOPS

$\operatorname{ZSS}(K, J)=Z \operatorname{ZSS}(K, J)-D^{*} \mathrm{FZSZ}(\mathrm{K}, \mathrm{J})$

$\$-D C^{\star}($ FZSX $(K, J)-F Z S X(K, J-1))-($ RESPZ*ZSS $(K, J))$

$\begin{array}{ll} & \\ & \end{array}$

$\operatorname{IF}(Z \operatorname{ZSS}(K, J) \cdot$ LT. . $) \operatorname{ZSS}(K, J)=0$.

\section{CONTINUE}

END OF BOTTOM, END OF SCALERS

PREDICT THE VECTORS

VBAR $=0.0$

DO $14 \mathrm{~J}=2$, NM
$\operatorname{UBAR}(\mathrm{J})=0$.

$\mathrm{P}=0$.
.

$\mathrm{K}=\mathrm{NK}(\mathrm{J})-1$
DO $14 \quad \mathrm{I}=1, \mathrm{~K}$

$U(I, J)=U(I, J)-D^{*}(F U Z(I, J)-F U Z(I+1, J))+P-D C^{*}(F U X(I, J)-F U X(I, J-1))$

$1+D E^{*} V V(I, J)$

UBAR $(J)=\operatorname{UBAR}(J)+U(I, J)$

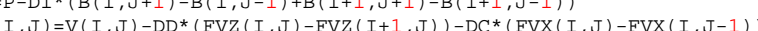

$1-D E^{*} U U(I, J)$

VBAR $=V B A R+V(I, J)$

14 CONTINUE

$c$

DO $15 \mathrm{~J}=2$, NM

$\operatorname{UBAR}(\mathrm{J})=\operatorname{UBAR}(\mathrm{J}) /(\operatorname{NK}(\mathrm{J})-1)$

!conservation of mass

DO $15 \quad I=1, K$
$U(I, J)=U(I, J)-U B A R(J)$

$V(I, J)=V(I, J)-V B A R$

15 CONTINUE

THIS IS A HORIZONTAL RADIATIVE BOUNDARY CONDITION

\section{Do $21 \mathrm{I}=1, \mathrm{M}$}

C these are to copy the last scalar col for contouring.
$T(I, n)=T(I, n-1)$

\section{CONTINUE}

C COMPUTE W

DO $17 \quad I=2, M M$

$W(I, 1)=D H^{*} U(I-1,2)+W(I-1,1)$

$W(I, N)=-D H^{*} U(I-1, N M)+W(I-1, N)$

DO $17 \mathrm{~J}=2, \mathrm{NM}$
$\mathrm{W}(\mathrm{I}, \mathrm{J})=\mathrm{DH}$
(
C $(\mathrm{I}-1, \mathrm{~J}+1)-\mathrm{U}(\mathrm{I}-1, \mathrm{~J}-1))+\mathrm{W}(\mathrm{I}-1, \mathrm{~J})$

C RECALCULATE DENSITY \& LIGHT

Do $16 \mathrm{~J}=1, \mathrm{~N}$

$\mathrm{K}=\mathrm{NK}(\mathrm{J})$

DO $16 \quad I=1, K$

$\operatorname{T} 10=\operatorname{TA}(I, J)$
S10

CALL SIGP(T10, S10, D10, SGSTP

$\operatorname{SIGMAT}(I, J)=S G S T$

$B(I, J)=\operatorname{SIGMAT}(I, J) * 0.98 D 0$

\section{CSUM AGAIN}

$\operatorname{CsUM}(I, J)=\operatorname{C1A}(I, J)+\operatorname{C2A}(I, J)+C 3 A(I, J)+C 4 A(I, J)+C 5 A(I, J)$

16 CONTINUE

C THE LIGHT EQUATION

DO $35 \mathrm{~J}=1, \mathrm{~N}$

$\operatorname{ALITE}(1, \mathrm{~J})=100 .{ }^{*}\left(\operatorname{EXP}\left(-\left(0.15+0.0088^{*} \operatorname{CsUM}(1, \mathrm{~J})\right.\right.\right.$

$\left.\left.\left.\$+0.054^{*}(\operatorname{CSUM}(1, \mathrm{~J}))^{* *} 0.666667\right) * \operatorname{DEPTH}(1)\right)\right)$
DO $35 \mathrm{I}=2, \mathrm{M}$

$\operatorname{ALITE}(\mathrm{I}, \mathrm{J})=\operatorname{ALITE}(\mathrm{I}-1, \mathrm{~J})-\operatorname{ALITE}(\mathrm{I}-1, \mathrm{~J}) *(1,-$

$\$ \operatorname{EXP}\left(-\left(\cdot .15+0.0088^{*}(\operatorname{CSUM}(\mathrm{I}-1, \mathrm{~J})+\operatorname{CSUM}(\mathrm{I}, \mathrm{J})) / 2\right.\right.$.
$\left.\left.\left.\$+0.054^{*}((\operatorname{CSUMM}(\mathrm{I}-1, \mathrm{~J})+\operatorname{CSUM}(\mathrm{I}, \mathrm{J})) / 2 .)^{* *} 0.66667\right) * \mathrm{DZ} / 100.\right)\right)$

\section{RETURN}

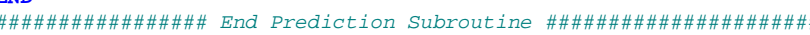

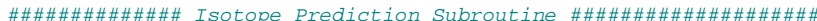
SUBROUTINE ISO_PREDIC(PBP1, PBD1, PBP2, PBD2, POP1, POD1, IMPLICIT REAL*8(A-H, O-Z)

! PARAMETER ( $N=94, N M=93, N P=92, M=46, M M=45, M P=44)$

INCLUDE 'GridFile. F'

DIMENSION PBP1 $(M, N), \operatorname{PBD} 1(M, N), \operatorname{PBP} 2(M, N), \operatorname{PBD} 2(M, N)$

$\$ P O P 1(M, N), \operatorname{POD} 1(M, N), \operatorname{POP} 2(M, N), \operatorname{POD} 2(M, N)$

$\operatorname{PBDECY}=\operatorname{LOG}(2.0) / 22.3 / 365 / 24 / 3600$ 
rate in sec-1

PODECY $=\operatorname{LOG}(2,0) / 138 / 24 / 3600$

rate in sec-1

* $\quad P B D E C Y=\operatorname{LOG}(2.0) / 22.3 / 365 / 24 / 3600^{*}\left(22.3^{*} 365 / 20\right)$

hypothesised fast decay rate
PODECY $=\operatorname{LOG}(2.0) / 138 / 24 / 3600^{*}\left(22.3^{*} 365 / 20\right)$

$P B D E C Y=\operatorname{LOG}(2.0) / 20 / 24 / 3600$

purpose, halr live was set to 20 day.

TIME STEP: $\left.\left.-P B D E C Y * D T^{*}[]\right)\right)$

Call Sun_Light()

$I N Q=(I T / 6) * 6$

START OF THE CENTRAL DOMAIN

DO $120 \mathrm{~J}=2$, NM

$\mathrm{K}=\mathrm{NK}(\mathrm{J})-1$
DO $120 \mathrm{I}=1, \mathrm{~K}$

CONVERSION RATIOS

PB2CHL $=d p m / m 3: g$ chlor $/ \mathrm{m} 3$

PB2CHL = 1 .

ONLY PHYSICAL CONDITIONS HERE, MORE MAYBE NEEDED LATER

$\operatorname{DPBP}=-1 . \quad{ }^{*} \operatorname{PBP} 1(\mathrm{I}, \mathrm{J}) * \operatorname{PBDECY} *\left(2,{ }^{*} \mathrm{DT}\right)$

DPBD $=-1 . \quad$ PBDI $(1, J) * P B D E C Y * *(2, * D T)$

if (i.eq.5.and.j.eq.5) the

write (* *) 'Pb decay is', Pb decay

endif

$\operatorname{PBP} 1(\mathrm{I}, \mathrm{J})=\operatorname{PBP} 1(\mathrm{I}, \mathrm{J})-\mathrm{DD}^{*}(\operatorname{FPBPZ}(\mathrm{I}, \mathrm{J})-\operatorname{FPBPZ}(\mathrm{I}+1, \mathrm{~J}))$

$P$ in the next time step

\section{if (I.eq. 7) then}

resuspension to a higher depth

write $\left(*,{ }^{*}\right)$ 'resuspension here at cell number ....', I

$\operatorname{PBD} 1(\mathrm{I}, \mathrm{J})=\operatorname{PBD} 1(\mathrm{I}, \mathrm{J})-\mathrm{DD}^{*}(\operatorname{FPBDZ}(\mathrm{I}, \mathrm{J})-\operatorname{FPBDZ}(\mathrm{I}+1, \mathrm{~J}))$

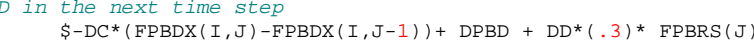

$\operatorname{PBD1}(I, J)=\operatorname{PBD} 1(I, J)-D^{*}(\operatorname{FPBDZ}(I, J)-\operatorname{FPBDZ}(I+1, J))$

$D$ in the next time step

S-DCA $(F P B D X(I, J)-F P B D X(I, J-1))+D P B D$

$\operatorname{IF}\left(\operatorname{PBP} 1(\mathrm{I}, \mathrm{J}) . \mathrm{LT} . \Theta^{\circ}\right) \operatorname{PBP} 1(\mathrm{I}, \mathrm{J})=0$

$\operatorname{IF}(\operatorname{PBD} 1(\mathrm{I}, \mathrm{J}) . \mathrm{LT} . \Theta.) \operatorname{PBD1}(\mathrm{I}, \mathrm{J})=0$

$\operatorname{DPOP}=\operatorname{PBP} 1(\mathrm{I}, \mathrm{J}){ }^{*} \mathrm{PBDECY} *\left(2 .{ }^{*} \mathrm{DT}\right)-\operatorname{POP} 1(\mathrm{I}, \mathrm{J}){ }^{*} \mathrm{PODECY} *\left(2,{ }^{*} \mathrm{DT}\right)$ $\mathrm{DPOD}=\operatorname{PBD} 1(\mathrm{I}, \mathrm{J}){ }^{*} \mathrm{PBDECY} *\left(2{ }^{*} \mathrm{DT}\right)-\operatorname{POD} 1(\mathrm{I}, \mathrm{J}){ }^{*} \mathrm{PODECY}$ *

$\left(2,{ }^{*} \mathrm{DT}\right)$

if(i.eq.5. and.j.eq.5) then

Po_decay $=$ dpop+dpod$$
\text { ! Po_decay }=\text { dpop+dpod }
$$

write $(*, *)$
endif

$\operatorname{POP} 1(\mathrm{I}, \mathrm{J})=\operatorname{POP} 1(\mathrm{I}, \mathrm{J})-\mathrm{DD}^{*}(\operatorname{FPOPZ}(\mathrm{I}, \mathrm{J})-\operatorname{FPOPZ}(\mathrm{I}+1, \mathrm{~J}))$

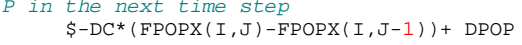

$\operatorname{POD1}(\mathrm{I}, \mathrm{J})=\operatorname{POD1}(\mathrm{I}, \mathrm{J})-\mathrm{DD}^{*}(\operatorname{FPODZ}(\mathrm{I}, \mathrm{J})-\operatorname{FPODZ}(\mathrm{I}+1, \mathrm{~J}))$

!predict Po-

in the next time step

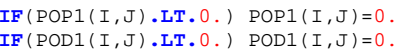

120 CONTINUE

$\sim \sim \sim$ NND OF CENTRAL DOMAIN

START OF BOUNDARY COLUMNS (LENGTH OF COLS MUST BE $=$ )

DO 130 JJ $=1,2$
IF ( JJ.EQ.1) THEN

$$
\begin{aligned}
& \text { JDEX=1 } \\
& F L I P=1 . \\
& J=N \\
& \text { JDEX=NM }
\end{aligned}
$$

ELSE

FLIP $=-1$.

$\mathrm{K}=\mathrm{NK}(\mathrm{J})-1$
DO $130 \quad \mathrm{I}=1, \mathrm{~K}$

$\operatorname{DPBP}=-1 . \quad{ }^{*} \operatorname{PBP} 1(\mathrm{I}, \mathrm{J}){ }^{*} \mathrm{PBDECY} *(2, * \mathrm{DT})$

的

$\operatorname{PBP} 1(\mathrm{I}, \mathrm{J})=\operatorname{PBP} 1(\mathrm{I}, \mathrm{J})-\mathrm{DD}^{*}(\operatorname{FPBPZ}(\mathrm{I}, \mathrm{J})-\operatorname{FPBPZ}(\mathrm{I}+1, \mathrm{~J}))$

$\$-D C^{\star} F L I P{ }^{*} F P B P X(I, J D E X)+D P B P$

$\operatorname{PBD1}(\mathrm{I}, \mathrm{J})=\operatorname{PBD} 1(\mathrm{I}, \mathrm{J})-\mathrm{DD}^{*}(\operatorname{FPBDZ}(\mathrm{I}, \mathrm{J})-\operatorname{FPBDZ}(\mathrm{I}+1, \mathrm{~J}))$

$\$-D C * F L I P * P E$

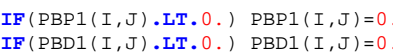

$\operatorname{DPOP}=\operatorname{PBP} 1(\mathrm{I}, \mathrm{J}){ }^{*} \mathrm{PBDECY} *\left(2 .{ }^{*} \mathrm{DT}\right)-\operatorname{POP} 1(\mathrm{I}, \mathrm{J}){ }^{*} \mathrm{PODECY} *\left(2 .{ }^{*} \mathrm{DT}\right)$

change from decay. (gain from Po and lost by self-decay)
$\operatorname{DPOD}=\operatorname{PBD1}(\mathrm{I}, \mathrm{J}){ }^{*} \mathrm{PBDECY} *\left(2 .{ }^{*} \mathrm{DT}\right)-\operatorname{POD} 1(\mathrm{I}, \mathrm{J}){ }^{*} \mathrm{PODECY} *\left(2 .{ }^{*} \mathrm{DT}\right)$

J) $-\operatorname{FPOPZ}(I+1, J))$

$\operatorname{POD1}(\mathrm{I}, \mathrm{J})=\operatorname{POD1}(\mathrm{I}, \mathrm{J})-\mathrm{DD}^{*}(\operatorname{FPODZ}(\mathrm{I}, \mathrm{J})-\operatorname{FPODZ}(\mathrm{I}+1, \mathrm{~J}))$

\$-DC FLIP FPODX (I, JDEX)+DPOD

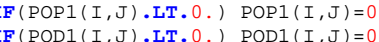

130 CONTINUE 


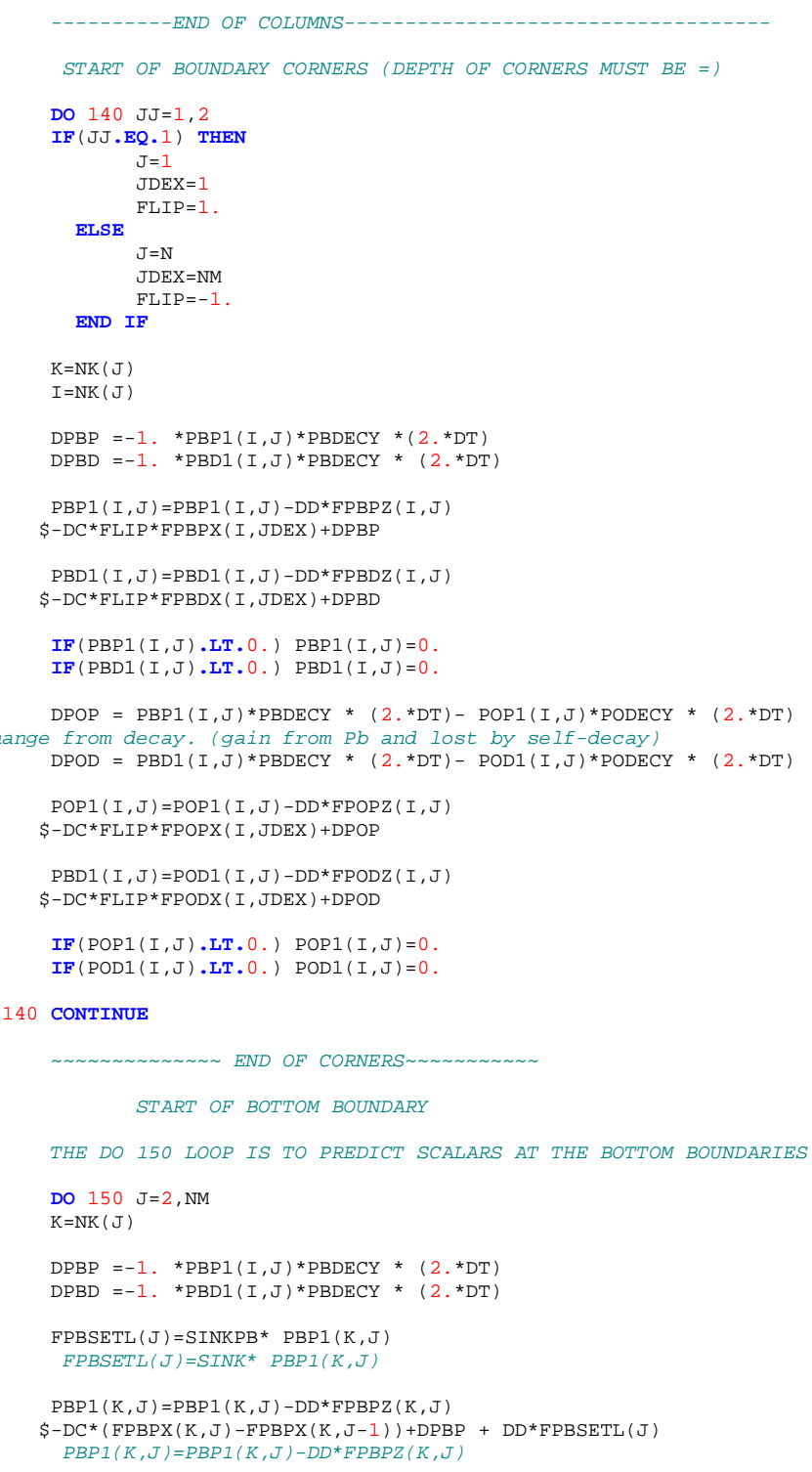

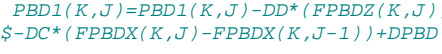

$\operatorname{PBD} 1(K, J)=\operatorname{PBD} 1(K, J)-D^{*}(F P B D Z(K, J))$

$\$-D C^{*}(\operatorname{FPBDX}(K, J)-\operatorname{FPBDX}(K, J-1))+D P B D+D^{*} F \operatorname{PBRS}(J)^{*}, 7$

DPOP $=\operatorname{PBP} 1(\mathrm{I}, \mathrm{J}){ }^{*} \mathrm{PBDECY} *\left(2 .{ }^{*} \mathrm{DT}\right)-\operatorname{POP} 1(\mathrm{I}, \mathrm{J}){ }^{*} \mathrm{PODECY} *\left(2 .{ }^{*} \mathrm{DT}\right) \quad$ 'Activity change from decay. (gain from $\mathrm{Pb}$ and lost by self-decay)
$\operatorname{PPOD}=\operatorname{PBD} 1(\mathrm{I}, \mathrm{J}){ }^{*} \mathrm{PBDECY} *\left(2 .{ }^{*} \mathrm{DT}\right)-\operatorname{POD} 1(\mathrm{I}, \mathrm{J}){ }^{*} \mathrm{PODECY} *\left(2 .{ }^{*} \mathrm{DT}\right)$

$\operatorname{FPOSETL}(\mathrm{J})=\operatorname{SINKPO*} \operatorname{POP} 1(\mathrm{~K}, \mathrm{~J})$
$\operatorname{FPOSETL}(\mathrm{J})=S I N K^{*} \operatorname{POP} 1(K, \mathrm{~J})$

$\operatorname{POP} 1(K, J)=P O P 1(K, J)-D D^{*} F P O P Z(K, J)$

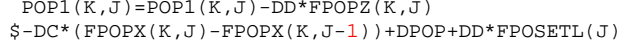

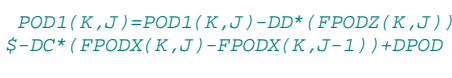

WRITE $(*, *)$ ' 'FPORS (J) is', FPORS (J)

$\$-D C^{*}(F P O D X(K, J)-F P O D X(K, J-1))+D P O D+D^{*} F P O R S(J)$

$\operatorname{IF}(\operatorname{POP} 1(\mathrm{I}, \mathrm{J}) . \mathrm{LT} .0.) \operatorname{POP} 1(\mathrm{I}, \mathrm{J})=0$

$\operatorname{IF}(\operatorname{POD} 1(\mathrm{I}, \mathrm{J}) . \mathrm{LT} .0.) \operatorname{POD} 1(\mathrm{I}, \mathrm{J})=0$

150 CONTINUE

$\sim \sim$ END OF BOTTOM, END OF SCALERS

\section{RETURN}

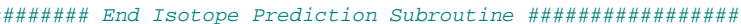

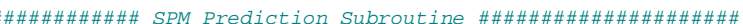
SUBROUTINE SPM_PREDIC (SPM1, SPM2)

REAL ${ }^{\star} 8(A-H, O-Z)$

PARAMETER ( $N=94, N M=93, N P=92, M=46, M M=45, M P=44)$

INCLUDE 'GridFile.f'

DIMENSION SPM1 $(M, N), \operatorname{SPM} 2(M, N)$

write $(*, *)$ 'before the prediction $100 p \operatorname{spm} 1(5,5), \operatorname{spm1}(5,5)$

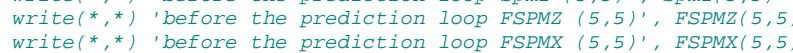

Do $120 \mathrm{~J}=2$, NM

$\mathrm{K}=\mathrm{NK}(\mathrm{J})-1$

if (I.eq. 7) then

resuspension to a higher depth 
write $(*, *)$ 'resuspension here at cell number ....', I

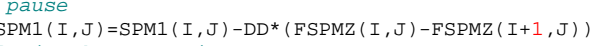
particle in the next time step
$\$-D^{*}(\operatorname{FSPMX}(\mathrm{I}, \mathrm{J})-\operatorname{FSPMX}(\mathrm{I}, \mathrm{J}-1))+\mathrm{DD}^{*}(.3)^{*} \operatorname{FRESUS}(\mathrm{J})$ else $\operatorname{SPM1}(I, J)=\operatorname{SPM} 1(I, J)-D^{*}(\operatorname{FSPMZ}(I, J)-\operatorname{FSPMZ}(I+1, J))$ particle in the next time step
$\$$ - DC $^{*}(\operatorname{FSPMX}(\mathrm{I}, \mathrm{J})-\operatorname{FSPMX}(\mathrm{I}, \mathrm{J}-1))$

end if

$\operatorname{IF}(\operatorname{SPM1}(\mathrm{I}, \mathrm{J})$. LT. .. $) \operatorname{SPM1}(\mathrm{I}, \mathrm{J})=0$.

120 CONTINUE *) 'AFTER the prediction loop spm1 $(5,5)$ ' $\operatorname{spm1}(5,5)$ END OF CENTRAL DOMAIN

$\sim \sim$ START OF BOUNDARY COLUMNS (LENGTH OF COLS MUST BE =) Do $130 \mathrm{JJ}=1,2$

$$
\text { ELSE } \begin{aligned}
& \mathrm{FLIP}=1 . \\
& \mathrm{J}=\mathrm{N} \\
& \mathrm{J}=\mathrm{N} \\
& \mathrm{JDEX}=\mathrm{NM}
\end{aligned}
$$$$
\text { FLIP }=-1
$$

$\mathrm{K}=\mathrm{NK}(\mathrm{J})-1$
DO $130 \quad \mathrm{I}=1, \mathrm{~K}$

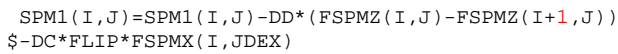

$\operatorname{IF}(\operatorname{SPM} 1(\mathrm{I}, \mathrm{J}) . \mathrm{LT} . \odot.) \operatorname{SPM1}(\mathrm{I}, \mathrm{J})=0$.

130 CONTINUE

-...... END OF COLUMNS-

START OF BOUNDARY CORNERS (DEPTH OF CORNERS MUST BE =) Do 140 JJ $=1,2$
IF (JJ.EO.1) THE

$\operatorname{IF}(\mathrm{JJ} . \mathrm{EQ} .1$. 1 ) TH

$$
\begin{aligned}
& \text { JDEX=1 } \\
& \text { FLIP=1. }
\end{aligned}
$$

ELSE

$$
\begin{aligned}
& J=N \\
& \text { JDEX=NM }
\end{aligned}
$$$$
\begin{aligned}
\text { FLIP }=-1 . & \text {. } \\
\text { END IF } & \text {. }
\end{aligned}
$$

$\mathrm{K}=\mathrm{NK}(\mathrm{J})$
$\mathrm{I}=\mathrm{NK}(\mathrm{J})$

$\operatorname{SPM1}(\mathrm{I}, \mathrm{J})=\operatorname{SPM} 1(\mathrm{I}, \mathrm{J})-\operatorname{DD} * \operatorname{FSPMZ}(\mathrm{I}, \mathrm{J})$

$\$-D C^{*}$ FLIP*FSPMX (I, JDEX)
$\operatorname{IF}(\operatorname{SPM1}(I, J) \cdot$ LT . ๑. $) \operatorname{SPM1}(I, J)=0$

140 CONTINUE

〜 END OF CORNERS

START OF BOTTOM BOUNDARY

THE DO 150 LOOP IS TO PREDICT SCALARS AT THE BOTTOM BOUNDARIES

DO $150 \mathrm{~J}=2$, NM

$\mathrm{K}=\mathrm{NK}(\mathrm{J})$

$\operatorname{FSETL}(\mathrm{J})=\operatorname{SINK} * \operatorname{SPM} 1(\mathrm{~K}, \mathrm{~J})$

$F C 6 Z(I, J)=.5^{*}(W(I, J)+\operatorname{SINK}) *(C 66(I-1, J)+C 66(I, J))$

! reference

$\operatorname{SPM1}(K, J)=\operatorname{SPM1}(K, J)-D^{*} \operatorname{FSPMZ}(K, J)$
$\$-D C^{*}(\operatorname{FSPMX}(K, J)-\operatorname{SSPMX}(K, J-1))+\operatorname{DD} D^{*}\left(\operatorname{FSETL}(\mathrm{J})+(.7)^{*} \operatorname{FRESUS}(\mathrm{J})\right)$

2. $6 E-4$

$\operatorname{IF}(\operatorname{SPM1}(I, J) . L T .0.) \operatorname{SPM} 1(I, J)=0$

150 CONTINUE

$\operatorname{WRITE}\left(6,{ }^{*}\right)$ ' $-\ldots . . . \ldots-\ldots$ here'

$\sim \sim$ END OF BOTTOM, END OF SCALERS

\section{RETUR}

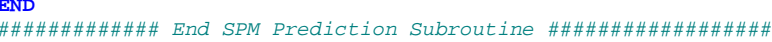

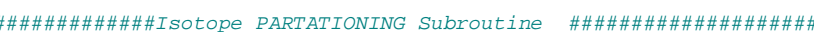
SUBROUTINE PARTATION(PBD1，PBP1，SPM1，POD1，POP1)

IMPLICIT REAL $* 8(A-H, O-Z)$
!PARAMETER $(N=94, N M=93, N P=92, M=46, M M=45, M P=44)$

INCLUDE 'GridFile. $F$,

DIMENSION $U(M, N), V(M, N), T(M, N), S(M, N), U U(M, N), V V(M, N)$,

$\$ T T(M, N), S S(M, N)$

DIMENSION PBP1 $(M, N), \operatorname{PBD} 1(M, N), \operatorname{PBT}(M, N), \operatorname{SPM1}(M, N)$
$\$ \operatorname{POP} 1(M, N), \operatorname{POD}(M, N), \operatorname{POT}(M, N)$

$\mathrm{KD}=10$.

$\begin{aligned} & P b 210, 10 \mathrm{~L} / \mathrm{mg} \\ & \mathrm{KDPO}=10\end{aligned}$

$\begin{array}{ll}\text { Po210, } & 4 \text { L/mg } \\ \text { SPM }=0.45\end{array}$

solid conc of $0.45 \mathrm{mg} / \mathrm{L}$ throughout.

\section{DO $\mathrm{J}=1, \mathrm{~N}$}

$\mathrm{K}=\mathrm{NK}(\mathrm{J})$
DO $\mathrm{I}=1, \mathrm{~K}$

$\operatorname{PBT}(\mathrm{I}, \mathrm{J})=\operatorname{PBD} 1(\mathrm{I}, \mathrm{J})+\operatorname{PBP} 1(\mathrm{I}, \mathrm{J})$

$\operatorname{PBP} 1(I, J)=\operatorname{PBT}(I, J) *(K D * \operatorname{CSUM} 1(I, J) / 1.33) /$

$\$(1,+K D * \operatorname{CSUMM} 1(I, J)(1,33)$

* particulate fraction of $210 P b$ is $f=K D^{*} C /\left(1+K D^{*} C\right)$. Then Pb_total ${ }^{*} f$ will be part Pb210 
(from average

ut SPM conc conc of $0.6 \mathrm{mg} / \mathrm{m3}$ and average SPM ratio of $0.45 \mathrm{mg} / \mathrm{L}$ ) was used to find * in each individual grid.

$\operatorname{PBP} 1(\mathrm{I}, \mathrm{J})=\operatorname{PBT}(\mathrm{I}, \mathrm{J})^{*}\left(\mathrm{KD}^{*} \mathrm{SPM} 1(\mathrm{I}, \mathrm{J}) /\right.$

* $\quad \$(1 .+\mathrm{KD} * \operatorname{SPM} 1(\mathrm{I}, \mathrm{J}))$ )

constant TSP concentration is used throughout the water column.

$\operatorname{PBD} 1(\mathrm{I}, \mathrm{J})=\operatorname{PBT}(\mathrm{I}, \mathrm{J})-\operatorname{PBP} 1(\mathrm{I}, \mathrm{J})$

Po-210 below

$\operatorname{POT}(\mathrm{I}, \mathrm{J})=\operatorname{POD} 1(\mathrm{I}, \mathrm{J})+\operatorname{POP} 1(\mathrm{I}, \mathrm{J})$

$\operatorname{POP} 1(I, J)=\operatorname{POT}(I, J) *\left(\operatorname{KDPO}{ }^{*} \operatorname{CSUM} 1(I, J) / 1.33\right)$

$\$ 1(1,+K D P O * C S U M 1$
$\operatorname{POP} 1(\mathrm{I}, \mathrm{J})=\operatorname{POT}(\mathrm{I}, \mathrm{J}) *\left(\mathrm{KDPO}^{*} \operatorname{SPM} 1(\mathrm{I}, \mathrm{J}) /\right.$

$\$(1 .+\operatorname{KDPO} * \operatorname{SPM} 1(\mathrm{I}, \mathrm{J})))$

$\left.\$\left(1,+\operatorname{KDPO} \operatorname{SPM}^{-}(\mathrm{I}, \mathrm{J})\right)\right)$
$\operatorname{POD} 1(\mathrm{I}, \mathrm{J})=\operatorname{POT}(\mathrm{I}, \mathrm{J})-\operatorname{POP} 1(\mathrm{I}, \mathrm{J})$

$\begin{aligned} \operatorname{RATIO}(\mathrm{I}, \mathrm{J}) & = \\ \left(\mathrm{POT}(\mathrm{I}, \mathrm{J}) * \mathrm{PODECY} \_\mathrm{M}\right) /\left(\mathrm{PBT}(\mathrm{I}, \mathrm{J}) * \mathrm{PBDECY} \_M\right) & \end{aligned}$

activity ratio

\section{ENDDO}

\section{RETURI}

END

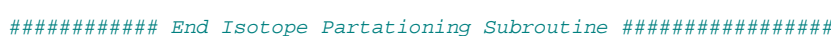

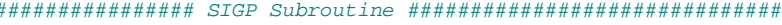

SUBROUTINE SIGP (T, S, DEPTH, SGSTP)

IMPLICIT REAL*8(A-H, O-Z)

OM GIVEN T AND $S$

THEN CALCULATES DENSITY AND SIGMA-T AS A FUNCTION OF $T$, $S$ AND $P$

INITIALIZE COEFFICIENTS

$\mathrm{AW}=999.842594$

AW1 $=6.793952 \mathrm{E}-02$

$A W 2=-9.09529 \mathrm{E}-03$

AW3 $=1.001685 \mathrm{E}-04$

AW4 $=-1.120083 \mathrm{E}-06$

$\mathrm{BO}=.824493$

$\mathrm{B} 1=-.0040899$

$\mathrm{B} 2=7.6438 \mathrm{E}-05$

$\mathrm{B} 3=-8.2467 \mathrm{E}-07$

B4 $=5.3875 \mathrm{E}-09$

$\mathrm{C} 1=1.0227 \mathrm{E}-04$

$\mathrm{D} \Theta=4.8314 \mathrm{E}-04$

C CHANGE DEPTH (M) TO PRESSURE IN BARS
$P=$ DEPTH / 10

$P=\Theta$ MAKES DENSITY NOT A FUNCTION OF PRESSURE

$\mathrm{p}=0$.

COMPUTE POWERS OF $T$

$\mathrm{T} 2=\mathrm{T} * \mathrm{~T}$
$\mathrm{~T} 3=\mathrm{T} 2 * \mathrm{~T}$
$\mathrm{~T} 4=\mathrm{T} 3 * \mathrm{~T}$

$\mathrm{T} 4=\mathrm{T} 3 * \mathrm{~T}$

COMPUTE POWERS OF

\section{$\mathrm{P} 2=\mathrm{P} * \mathrm{P}$}

COMPUTE PURE WATER REFERENCE FROM FIRST 6 FACTORS OF 15 IE, TEMP EFFECTS, FW = FRESH WATER)

$F W=A W 1 * T+A W 2 * T 2+A W 3 * T 3+A W 4 * T 4+A W 5 * T 5$

$T E M P=A W+F W$

COMPUTE TEMPERATURE SALINITY EFFECTS FROM NEXT 5 OUT OF 15 TERMS $\mathrm{S} 32=\mathrm{S} * \operatorname{SQRT}(\mathrm{S})$

TS1 $=B 0^{*} S+B 1^{*} T^{*} S+B 2^{*} T 2^{*} S+B 3^{*} T 3^{*} S+B 4^{*} T 4^{*} S$

COMPUTE TEMPERATURE SALINITY EFFECTS FROM NEXT 3 OF 15 TERMS

$\mathrm{TS} 2=\mathrm{C} 0 * \mathrm{~S} 32+\mathrm{C} 1 * \mathrm{~T} * \mathrm{~S} 32+\mathrm{C} 2 * \mathrm{~T} 2 * \mathrm{~S} 32$

COMPUTE PURE SALINITY CONTRIBUTION FROM LAST 1 OF 15 TERMS

$\mathrm{S} 1=\mathrm{D} \Theta * \mathrm{~S} 2$

COMPUTE DENSITY (D) AND SIGMA- $t$ (SG)

$\mathrm{D}=\mathrm{TEMP}+\mathrm{TS} 1+\mathrm{TS} 2+\mathrm{S} 1$
$\mathrm{SG}=((\mathrm{D} / 1000)-1) * 1000$

NOW COMPUTE THE SECANT BULK MODULUS (IES 80)

CONSTANTS (ALL 26 OF THEM)

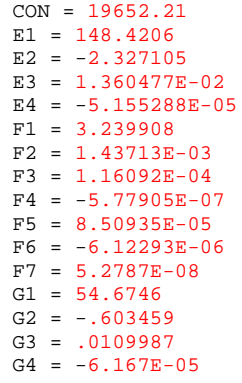

$E 2=-2.327105$

$E 4=-5.155288 \mathrm{E}-05$

$F_{1}=3.239908$

$\mathrm{F} 3=1.16092 \mathrm{E}-04$

$F 5=8.50935 \mathrm{E}-05$

$7=5.2787 \mathrm{E}-08$

$\mathrm{G} 2=-.60345$

$G 4=-6.167 \mathrm{E}-05$ 
$G 5=.07944$

$\mathrm{G} 7=-5.3009 \mathrm{E}-\mathrm{OA}$

$\mathrm{H} 1=.0022838$

$\mathrm{H} 2=-1.0981 \mathrm{E}-05$

$\begin{array}{ll}H 3 & =-1.6078 \mathrm{E}-06 \\ H 4 & =1.91075 \mathrm{E}-04\end{array}$

$\begin{aligned} H 4 & =1.91075 E-64 \\ H 5 & =-9.9348 \mathrm{E}-07\end{aligned}$

$\mathrm{H} 6=2.0816 \mathrm{E}-08$

$\mathrm{H} 7=9.1697 \mathrm{E}-10$

C CAlCulate dUe to temp alone (FIRST 5/26 TERMS)

$E T=C O N+E 1 * T+E 2 * T 2+E 3 * T 3+E 4 * T 4$

CALCULATE DUE TO TEMP AND PRESSURE (NEXT 7/26 TERMS)

$F T P=F 1^{*} P+F 2^{*} T^{*} P+F 3^{*} T 2^{*} P+F 4^{*} T 3^{* P}+F 5 * P 2$
$F T P=F T P+F 6 * T * P 2+F 7 * T 2 * P 2$

CALCULATE dUE TO TEMP AND SAL (NEXT 7/26 TERMS)

$\mathrm{GTS}=\mathrm{G} 1^{*} \mathrm{~S}+\mathrm{G} 2^{*} \mathrm{~T}^{*} \mathrm{~S}+\mathrm{G} 3^{*} \mathrm{~T} 2^{*} \mathrm{~S}+\mathrm{G} 4^{*} \mathrm{~T} 3 * \mathrm{~S}+\mathrm{GS} * \mathrm{~S} 32$
$\mathrm{GTS}=\mathrm{GTS}+\mathrm{G6} * \mathrm{~T} * \mathrm{~S} 32+\mathrm{G} 7 * \mathrm{~T}^{*} * \mathrm{~S} 32$

CALCULATE DUE TO T, S AND P (LAST 7/26 TERMS)

HTSP $=\mathrm{H}^{*} \mathrm{P}^{*} \mathrm{~S}+\mathrm{H}^{*} \mathrm{~T}^{*} \mathrm{P} \mathrm{P}^{*} \mathrm{~S}+\mathrm{H}^{*} \mathrm{~T} \mathrm{~T}^{*} \mathrm{P} * \mathrm{~S}+\mathrm{H} 4 * \mathrm{P} * \mathrm{~S} 32$
$\mathrm{HTSP}=\mathrm{HTSP}+\mathrm{H} 5^{*} \mathrm{P} 2^{*} \mathrm{~S}+\mathrm{H}^{*} \mathrm{~T}^{*} \mathrm{P} 2 * \mathrm{~S}+\mathrm{H} 7 * \mathrm{~T}^{*}{ }^{*} \mathrm{P} 2 * \mathrm{~S}$

CALCULATE K(STP) AND DENSITY (DSPT) AND SIGMA (SGSTP) AS A FUNCTION OF $T, S$, $P$

\section{$\mathrm{SBM}=\mathrm{ET}+\mathrm{FTP}+\mathrm{GTS}+\mathrm{HTSP}$}

SGSTP $=$ DSPT-1000.

C PRINT RESULTS

2 FORMAT $(1 X, 4 F 12.5)$

return
END

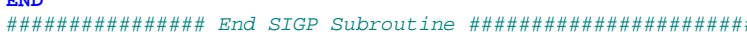

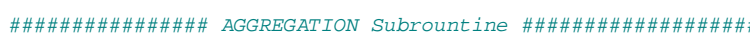

SUBROUTINE AGG (C1, C2, C3, C4, C5, C6, C7, C8, C9, C10, G33, G44) IMPLICIT REAL*8(A-H, $\mathrm{O}-\mathrm{Z})$

SUBROUTINE TO AGGREGATE PARTICLES

THE IDEA IS TO BRING IN CHLOROPHYLL IN, IN $\mathrm{mg} / \mathrm{m} 3$, CHANGE IT

TO CELLS/M3, FORM AGGREGATES, CHANGE IT BACK INTO $\mathrm{mg} / \mathrm{m} 3$

AND SHIP IT BACK OUT AFTER MAKING SURE
AMT COMING IN = TOTAL AMT GOING OUT.

DIMENSION $D(10), \operatorname{CER}(10,10), \operatorname{ECP}(10,10), W(10)$

ASSUMPTION: $10 \wedge 5$ CELLS/M3 $=0.01 \mathrm{MG} \mathrm{CHLORO/M3;10 \wedge 8} \mathrm{CELLS/M3}=$

$10 \mathrm{MG} C H L O R O / M 3$.
$C 1=0.01 \mathrm{mg} \mathrm{CHL} / \mathrm{m} 3=5 \times 10^{\wedge} 3$ PARTICLES OR AGGS $/ \mathrm{MB} 3$
TF=TRANSLATION FACTOR IN CELLS/M3 / MG CHLORO/M3=CELLS/MG CH

this should have a factor for magnitude of $c$

$$
\mathrm{TF}=10 * * 5 / .01
$$

C1-C1O ARE THE CONCENTRATIONS OF AGGREGATIONS

OF NUMBER OF CELLS/AGG OF $20,40 \ldots . .200$ FROM INITIAL CHLORO

$\mathrm{c}=30$.

$\mathrm{C} 1=(\mathrm{C} 1 * \mathrm{TF}) / \mathrm{C}$

NOW WE NEED AN INITIAL CELL SIZE, DI=10 UM, IN ORDER TO CALCULATE THE DIAMETERS OF AGGREGATES OF CELL \# 20, 40 ETC. IE, D(I). W(I)=SINKING OF AGGS BUT USE D(I) IN Um.
ALSO, THE 1 ST SIZE AGGREGATE IS 20 CELLS, IE, C=2O AS ABOVE $\mathrm{DI}=10$.

Do $1 \mathrm{I}=1,10$

$\mathrm{D}(\mathrm{I})=\mathrm{DI} *((\mathrm{I} * \mathrm{C}) * * 0.44)$
$\mathrm{W}(\mathrm{I})=(2.29 \mathrm{E}-07) * \mathrm{D})=\mathrm{D}(\mathrm{I})^{* * 1.17}$
$\mathrm{D}(\mathrm{I})=\mathrm{D}(\mathrm{I}) * 10 \mathrm{E}-6$

$\begin{array}{lll}\text { Do } & 20 & \mathrm{I}=1,10 \\ \text { Do } & 20 & \mathrm{~J}=1,10\end{array}$

$E C P=$ CONTACT EFFICIENCY

(SMALL DIAM) $=D S$ MUST BE < DL=(LARGER DIAM $)$

$\mathrm{DS}=\mathrm{D}(\mathrm{I})$

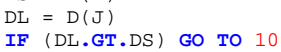

$D S=D(J)$

$100 \operatorname{DL}=\mathrm{ECP}(\mathrm{I}, \mathrm{J})=1.105 * \operatorname{EXP}(-.1 /(\mathrm{DS} / \mathrm{DL}))$

$B D=$ BETA SUb DIFFERENTIAL SETTLING

WE CALCULATE 10X10 CER BUT ONLY USE CER(1,1) TO CER $(4,9)$

$B S(I, J)=.136^{*}((D(I)+D(J)) * * 3) * \operatorname{ECP}(I, J)$
$\operatorname{BD}(I, J)=(3.1415 / 4)^{*}\left((D(I)+D(J))^{* *} 2\right)^{*}(A B S(W(I)-W(J)))^{*} \operatorname{ECP}(I, J)$

"STKY" IS STICKYNESS AND RANGES ENTRE 0.001 AND 0.9 BUT NOMINAL = $0.05-0.1$

STICKY $=0.04$ IS A SORT OF STANDARD CONSTANT STICKYNESS

THIS SAYS THAT IF THE SPECIFIC GROWTH ( $u^{*}$ NUTS ${ }^{*}$ SUN; NOT PP)/UMAX (SO NOW IT IS RELATIVE GROWTH)

IS GT 1/10 A DOUBLING PER DAY THERE IS LITTLE AGGREGATION. ONCE SG THEN STICKY IS SMALL SO THAT THERE IS LITTLE AGGREGATION. ONCE SG
DROPS BELOW $1 / 10$ D/D, THEN STICKY GOES TO O.1 AND THINGS AGGREATE IN A HURRY.

THIS IS AN OLD 'IF' FOR STICKYNESS

IF ((G33+G44).GT.Q.1) THEN 
ELSE $\begin{aligned} & \text { STKY=0.01 } \\ & \text { STKY=0.01 } \\ & \text { END IF }\end{aligned}$

$\operatorname{STKY}=(G 33+G 44) *(-0.667)+0.167$

IF $((G 33+G 44) \cdot G T \cdot 0.22)$ STKY=0.02

$0.04,0.1,0.01,1,0,2,0,0.001$

STKY $=0.02$

IF $((G 33+G 44), L T, \quad 0.15) \quad S T K Y=0.1$

$\operatorname{CER}(I, J)=(B S(I, J)+B D(I, J)) * S T K Y$

LPRINT "FOR I \& J="; I; J; "CONTACT EFFICIENCY = "; ECP(I, J) LPRINT "BS \& $B D=" ; B S(I, J) ; B D(I, J) ; "$ \& COL KERNAL = "; CER $(I, J)$

THIS NEXT LOOP CALCULATES THE $d C / d T$ (DC1-DC10) FOR EACH C1-C10. TIME OF INTEGRATION IS TIME.

TIME $=10 .{ }^{*} 60$.

Do $30 \mathrm{~S}=1,1$

$\mathrm{DC} 1=0$.

PRINT THE PARTICLE OR AGGREGATION CONCENTRATIONS

WRITE $(6,12)$

WORMA (1X,///, "AGGREGATE CONCENTRATIONS BEFORE AGGREGATIONS =")

$\mathrm{C}_{2}, \mathrm{C} 3, \mathrm{C4}, \mathrm{C5}, \mathrm{C6}, \mathrm{C7}, \mathrm{CB}, \mathrm{C9}, \mathrm{C1O}$

ADD UP ALL THE CELLS/M3

ST $1=\left(\mathrm{C} 1^{*} \mathrm{C}\right)+\left(\mathrm{C} 2^{*}\left(2^{*} \mathrm{C}\right)\right)+\left(\mathrm{C} 3^{*}\left(3^{*} \mathrm{C}\right)\right)+\left(\mathrm{C} 4^{*}\left(4^{*} \mathrm{C}\right)\right)+\left(\mathrm{C} 5^{*}\left(5^{*} \mathrm{C}\right)\right)+\left(\mathrm{C} 6^{*}\left(6^{*} \mathrm{C}\right)\right)$ ST1 $=$ ST $1+\left(C 7^{*}\left(7^{*} \mathrm{C}\right)\right)+\left(C 8^{*}\left(8^{*} \mathrm{C}\right)\right)+\left(\mathrm{C} 9^{*}\left(9^{*} \mathrm{C}\right)\right)+\left(\mathrm{C} 10^{*}\left(10^{*} \mathrm{C}\right)\right)$

WRITE $(6,14)$ ST1, st7
14 FORMAT (1X, "TOTAL CELL CONCENTRATION BEFORE AGGREGATION = ", F20.1)

FIRST THE LOSSES

DC1 $=D C 1-\left(C E R(1,1)^{*} C 1^{*} C 1\right)-\left(\operatorname{CER}(1,2)^{*} C 1^{*} C 2\right)-\left(\operatorname{CER}(1,3)^{*} C 1^{*} \mathrm{C} 3\right)$

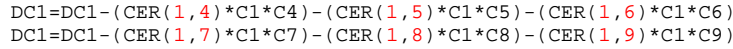

\section{THEN THE GAINS}

HERE WE INTEGRATE THE $d C / d t$ AND ADD THEM TO THE CONCENTRATIONS

$$
\begin{aligned}
& \text { C1 }=\text { C1 }+\left(\mathrm{DC} 1 *{ }^{*} \mathrm{TIME}\right) \\
& \text { IF }(\mathrm{C} 1 . \mathrm{LT} \text {. } \odot .) \mathrm{C} 1=0 .
\end{aligned}
$$

WRITE $(6,15)$

c 15 FORMAT (1X, "AGGREGATION CONCENTRATIONS AFTER AGGREGATION "BUT BEFORE ADJ =") c $\operatorname{WRITE}(6,13) C 1, C 2, C 3, C 4, C 5, C 6, C 7, C 8, C 9, C 10$ C ADD UP ALL THE CELLS/M3 AGAIN

$\mathrm{STT}=\left(\mathrm{C} 1^{*} \mathrm{C}\right)+\left(\mathrm{C} 2^{*}\left(2^{*} \mathrm{C}\right)\right)+\left(\mathrm{C} 3^{*}\left(3^{*} \mathrm{C}\right)\right)+\left(\mathrm{C} 4^{*}\left(4^{*} \mathrm{C}\right)\right)+\left(\mathrm{C} 5^{*}\left(5^{*} \mathrm{C}\right)\right)+\left(\mathrm{C} 6^{*}\left(6^{*} \mathrm{C}\right)\right.$

STT $=\mathrm{STT}+\left(\mathrm{C} 7^{*}\left(7^{*} \mathrm{C}\right)\right)+\left(\mathrm{C} 8^{*}\left(8^{*} \mathrm{C}\right)\right)+\left(\mathrm{C9^{* }}\left(9^{*} \mathrm{C}\right)\right)+\left(\mathrm{C} 10^{*}\left(10^{*} \mathrm{C}\right)\right)$

WRITE $(6,16)$ STT
FORMAT (1X, "TOTAL CELL CON AFTER AGG BUT BEFORE ADJ = ", F20.1)

C THIS IS THE ADJUSTER THAT MAKES SURE THAT THE \# CELLS COMING IN

$c=$ NUMBER OF CELLS (NOT AGGREGATES) GOING OUT AFTER AGGREGATION

\section{st1=st7}

$\mathrm{C} 1=\mathrm{C} 1+\left(\left(\left(\mathrm{C} 1{ }^{*} \mathrm{C}\right) / \mathrm{ST} 1\right) *(\mathrm{ST} 1-\mathrm{STT})\right) / \mathrm{C}$

WRITE $(6,116)$

116 FORMAT (1X "\# OF AGGREGATIONS IN EACH BIN AFTER AGG AND ADJ =")

WRITE $(6,13) C 1, C 2, C 3, C 4, C 5, C 6, C 7, C 8, C 9, C 10$

C ADD UP ALL THE CELLS/M3 AGAIN

$\mathrm{ST}=\left(\mathrm{C} 1^{*} \mathrm{C}\right)+\left(\mathrm{C} 2^{*}\left(2^{*} \mathrm{C}\right)\right)+\left(\mathrm{C} 3^{*}\left(3^{*} \mathrm{C}\right)\right)+\left(\mathrm{C} 4^{*}\left(4^{*} \mathrm{C}\right)\right)+\left(\mathrm{C} 5^{*}\left(5^{*} \mathrm{C}\right)\right)+\left(\mathrm{C} 6^{*}\left(6^{*} \mathrm{C}\right)\right)$ $\mathrm{ST}=\mathrm{ST}+\left(\mathrm{C} 7^{*}\left(7^{*} \mathrm{C}\right)\right)+\left(\mathrm{C} 8^{*}\left(8^{*} \mathrm{C}\right)\right)+\left(\mathrm{C} 9^{*}\left(9^{*} \mathrm{C}\right)\right)+\left(\mathrm{C} 10^{*}\left(10^{*} \mathrm{C}\right)\right)$

17 FORMAT(1X, "TOTAL CELL CON AFTER AGG \& ADJ= ", F20.1)

30 CONTINUE

$\mathrm{C} 1=(\mathrm{C} 1 / \mathrm{TF}) * \mathrm{C}$

\section{RETURN}

\section{END}

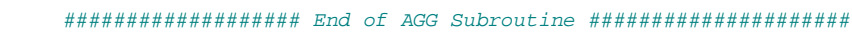

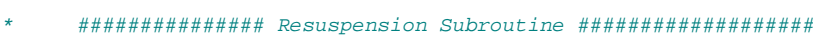

\section{Subroutine RESUSPENSION()}

IPARAMETER $(N=94, N M=93, N P=92, M=46, M M=45, M P=44)$

INCLUDE 'Gridfile.f'

INCLUDE 'comblk-r25.f'

$\operatorname{SMFPBZ}(I, J)=F P B D Z(I, J)+\operatorname{FPBPZ}(I, J)$

for $P b 210($ dis + part $), d p m / m 3 * \mathrm{~cm} / \mathrm{sec}$

is $d p m / m 2 / d a y$ $\operatorname{SMFPBZ}(I, J)=\operatorname{SMFPBZ}(I, J) * 864$.

S_DEN $=2.65$

$2.65 \mathrm{~g} / \mathrm{cm} 3$

$$
\text { Do } 5 \mathrm{~J}=1, \mathrm{~N}
$$

! $\operatorname{SEDIPB}(J){ }^{*} D X^{*} D Y^{*} 1 C m=\operatorname{SEDIPB}(J){ }^{*} D X^{*} D Y^{*} 1 C m+F P B P Z(94, J) * D T^{*} D X^{*} D Y$

$\operatorname{DPO}=\operatorname{SEDIPB}(\mathrm{J}){ }^{*} \operatorname{PBDECY} *\left(2 .{ }^{*} \mathrm{DT}\right)-\operatorname{SEDIPO}(\mathrm{J}){ }^{*} \operatorname{PODECY} *\left(2 .{ }^{*} \mathrm{DT}\right) \quad$ !Activity $\mathrm{DPO}=\operatorname{SEDIPB}(\mathrm{J}){ }^{*} \mathrm{PBDECY} *\left(2,{ }^{*} \mathrm{DT}\right)-\mathrm{SEDIPO}(\mathrm{J}){ }^{*} \mathrm{PODECY}$
change from decay. (gain from $\mathrm{Pb}$ and lost by self-decay $)$
$\mathrm{DPB}=-1 .{ }^{*} \operatorname{SEDIPB}(\mathrm{J}){ }^{*} \mathrm{PBDECY} *\left(2,{ }^{*} \mathrm{DT}\right)$

$\operatorname{SEDIPB}(\mathrm{J})=\operatorname{SEDIPB}(\mathrm{J})+(-1 .)^{*} \operatorname{FPBPZ}(46, \mathrm{~J}){ }^{*} \mathrm{DD}+\operatorname{DPB}$ sediment $P b$ activity should have unit of $\mathrm{dpm} / \mathrm{cm} 3$. 
$\operatorname{SEDIPO}(J)=\operatorname{SEDTPO}(J)+(-1,)^{*} \operatorname{FPOPZ}(46, J) * D D+\operatorname{DPO}$

5 CONTINUE

End

End

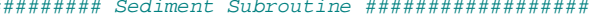

Subroutine SEDIMENT ()

IMPLICIT REAL* $8(\mathrm{~A}-\mathrm{H}, \mathrm{O}-\mathrm{Z})$

PARAMETER ( $N=94, N M=93, N P=92, M=46, M M=45, M P=44$ )

INCLUDE 'GridFile.f'

$\operatorname{SMFPBZ}(I, \mathrm{~J})=F P B D Z(I, J)+\operatorname{FPBPZ}(I, \mathrm{~J})$

for $P b 210($ dis + part $), d p m / m 3 * \mathrm{~cm} / \mathrm{sec}$

$S M F P B Z(I, J)=F P B D Z(I, J)$

is $\mathrm{dpm} / \mathrm{m} 2 / \mathrm{day}$.

BLKDSTY $=1.5$
density $1.5 \mathrm{~g} / \mathrm{cm}$

! sediment

Do $5 \mathrm{~J}=1, \mathrm{~N}$

$\operatorname{SEDIPB}(J){ }^{*} D X^{*} D Y^{*} 1 C m=\operatorname{SEDIPB}(J){ }^{*} D X^{*} D Y^{*} 1 C m+F P B P Z(94, J){ }^{*} D T^{*} D X^{*} D Y$

resuspension

$\operatorname{RESUS}(\mathrm{J})=1.0 / 10 / 86400$

rususpension rate of $1.0 \mathrm{~mm} /$ day $/(10 \mathrm{~mm} / \mathrm{cm}) /(86400 \mathrm{sec} /$ day)

I FRESUS $(J)=$ BLKDSTY * RESUS $(\mathrm{J})$

! Cm/SeC $\operatorname{FRESUS}(J)=1.5 * 100 / 86400$

$! \mathrm{g} / \mathrm{cm} 3$

$\mathrm{cm} / \mathrm{sec} \quad 1.5 \mathrm{~g} / \mathrm{m} 2$-day

$\operatorname{SEDI}(J)=\operatorname{SEDI}(J)+(-1.){ }^{*} \operatorname{FSETL}(J) *\left(2,{ }^{*} D T\right) / 100$.

edi $(j)$, sediment SPM inventory, unit of $g / m 2$

$\operatorname{SEDI}(\mathrm{J})=\operatorname{SEDI}(\mathrm{J})$

$\$^{*}\left(2 .{ }^{*} \mathrm{DT}\right) / 100$

DPOS $=\operatorname{SPB}(\mathrm{J}){ }^{*} \mathrm{PBDECY} *\left(2,{ }^{*} \mathrm{DT}\right)-\mathrm{SPO}(\mathrm{J}){ }^{*} \mathrm{PODECY} *\left(2,{ }^{*} \mathrm{DT}\right)$

change from decay. (gain from $P b$ and lost by self-decay)
$\operatorname{DPBS}=-1 . * \operatorname{*} \operatorname{SPB}(\mathrm{J}) * \operatorname{PBDECY} *\left(2,{ }^{*} \mathrm{DT}\right)$

$\operatorname{SPB}(J)=\operatorname{SPB}(\mathrm{J})+(-1 \cdot)^{*} \mathrm{PBPSETL}(\mathrm{J}) *\left(2,{ }^{*} \mathrm{DT}\right) / 100 .+\mathrm{DPBS}$

\section{CONTINUE}

End

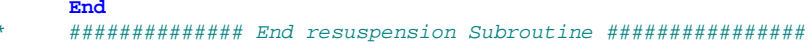

